\title{
STRUCTURAL VULNERABILITY OF ANCIENT DRY MASONRY TOWERS UNDER LATERAL LOADING
}

\author{
A Thesis Submitted to \\ the Graduate School of Engineering and Sciences of \\ İzmir Institute of Technology \\ in Partial Fulfillment of the Requirements for the Degree of \\ DOCTOR OF PHILOSOPHY \\ in Architectural Restoration \\ by \\ Funda GENÇER
}

APRIL 2019

İMIR 
We approve the thesis of Funda GENÇER

Examining Committee Members:

Assoc. Prof. Dr. Mine TURAN

Department of Architectural Restoration, İzmir Institute of Technology

Assoc. Prof. Dr. Engin AKTAŞ

Department of Civil Engineering, İzmir Institute of Technology

Prof. Dr. Hasan BÖKE

Department of Architectural Restoration, İzmir Institute of Technology

Assoc. Prof. Dr. Abdullah SÖNMEZ

Department of Architecture, Dokuz Eylül University

Assist. Prof. Dr. Tuba AKAR

Department of Architecture, Mersin University

5 April 2019

Assoc. Prof. Dr. Mine TURAN

Supervisor, Department of Architectural Restoration

İzmir Institute of Technology

Prof. Dr. Başak İPEKOĞLU

Head of the Department of

Architectural Restoration
Prof. Dr. Aysun SOFUOĞLU

Dean of the Graduate School of Engineering and Sciences 


\section{ACKNOWLEDGMENTS}

First, I would like to express my special gratitude to my supervisor, Assoc. Prof. Dr. Mine Hamamcıoğlu Turan for her scientific support, guidance and incredible patience throughout my thesis. Special thanks go to Assoc. Prof. Dr. Engin Aktaş for his scientific support and guidance during my thesis. He supported the thesis like a supervisor. This thesis could not be completed without moral and technical support of my supervisor; Assoc. Prof. Dr. Mine Hamamcıoğlu Turan and Assoc. Prof. Dr. Engin Aktaş.

I would like to express my thanks to the jury members; Prof. Dr. Hasan Böke, Assoc. Prof. Dr. Abdullah Sönmez and Assist. Prof. Dr. Tuba Akar for kindly attending my thesis defense exam and important contributions they provided. Special thanks go to Assoc. Prof. Dr. Engin Duran for his scientific support and guidance for statistical studies in the thesis. I am also grateful to Prof. Dr. Alper Baba for his technical support for the characterization of stone types and Spec. Dr. Kerem Şerifaki for her technical support during the laboratory analysis. I thank Prof. Dr. Başak İpekoğlu, head of the Department of Architectural Restoration, for her support and tolerance.

My special thanks go to my dear friend Zişan Kaplan for her friendship and support. She never left me alone at the site surveys in spite of all bad conditions.

Finally, I must express my very profound gratitude to my parents; Hasan and Gülhan Uygun; İskender and Nihal Gençer and to my husband Gökçe Mehmet Gençer for providing me with unfailing support and continuous encouragement throughout my years of study and for their endless love, support and patience. This thesis is dedicated to them. 


\section{ABSTRACT \\ STRUCTURAL VULNERABILITY OF ANCIENT DRY MASONRY TOWERS UNDER LATERAL LOADING}

In the Antiquity, masters constructed dry masonry towers that were resistant to earthquake potential of their sites. Determination of the authentic characteristics, that play role on structural behavior, developed in antiquity should be the first step of conservation planning. This study aims to identify the structural behavior of dry masonry towers under lateral loading in relation with their characteristics so that decision making phase regarding their restoration projects can be supported. Dry masonry towers in ancient Caria, Pamphylia and Cilicia, which have different ground accelerations, are examined.

Methodology of the study consists of documentation of six case studies with traditional methods, design of hypothetical towers, impact analysis of towers with quasistatic tilt technique, examination of results in terms of collapse angle and failure mechanisms, discussion with the help of the statistical approach, and proposal of a framework for vulnerability rankings and possible failure mechanisms.

As a result, parameters effecting structural resistance in the order of high impact to low are staggering ratio, stone depth, ratio between block length and height, proportional relationship between height and length, opening area, number and position and even distribution of header stones. These parameters have impact on each other; so, sustaining of the qualities regarding all of them should be undertaken in their conservation. Furthermore, it is seen that there was awareness of the necessity for usage of different anti-seismic parameters in different earthquake regions. However, appropriate combination of parameters with each other were not always undertaken possibly because of limitations of local materials, budget, time or masters. 


\section{ÖZET}

\section{ANTIKK KURU YIĞMA KULELERIN YANAL YÜK ALTINDA YAPISAL HASAR GÖREBİLIRLİĞI}

Antikçağ'da, ustalar bulundukları yörenin deprem riskini dikkate alarak dayanıklı kuru yığma kuleler inşa etmeye çalışmışlardır. Yapı davranışında rol oynayan, antik dönemde geliştirilmiş özgün özelliklerin belirlenmesi koruma çalışmalarının planlanmasında ilk adım olmalıdır. Bu çalışma, yapı özellikleri bağlamında kuru yığma kulelerin yanal yük altında yapı davranışını özümseyerek, restorasyon projeleri ile ilgili karar alma aşamalarını desteklemeyi amaçlamaktadır. Bu nedenle, farklı zemin ivmelerine sahip antik Karya, Pamfilya ve Kilikya bölgelerinde bulunan kuru yı̆̆ma kuleler incelenmiştir.

Çalışmanın yöntemi, geleneksel yöntemlerle kulelerin belgelenmesi, hipotetik kulelerin tasarlanması, quasi-statik eğme yöntemi ile kulelerin etki analizinin yapılması, analiz sonuçlarının yıkılma açıları ve hasar mekanizmaları açısından incelenmesi, istatiksel yaklaşım ile tartışma ve kulelerin olası hasar görebilirlik derecelerinin ve hasar mekanizmalarının belirlenebilmesi için taslak önerisinden oluşmaktadır.

Sonuç olarak, yapısal dayanımı etkileyen parametreler; basamaklanma katsayısı, taş derinliği, taş blokların uzunluk ve yüksekliği arasındaki oransal ilişki, yapının yükseklik ve uzunluğu arasındaki oransal ilişki, boşluk alanı, sayısı ve konumu ve atkı taşlarının dağılımı olarak etkinliklerine göre sıralanmaktadır. Ancak, parametreler birbirlerini etkilemektedir, bu yüzden koruma çalışmalarında yapı özelliklerine ilişkin tüm niteliklerin sürdürülmesine dikkat edilmelidir. Ayrıca, çalışma sonucunda farklı deprem bölgelerinde farklı sismik parametrelerin kullanılmasının gerekliliği konusunda farkındalık olduğu görülmüştür. Fakat, yerel malzemelerin, bütçenin, zamanın ya da ustaların sınırlamaları nedeniyle, parametrelerin her zaman birbirleriyle uygun şekilde ilişkilendirilemediği tespit edilmiştir. 


\section{TABLE OF CONTENTS}

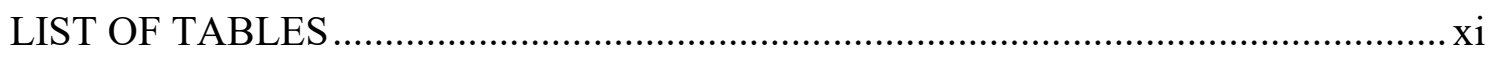

LIST OF FIGURES .........................................................................................

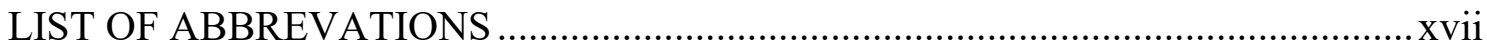

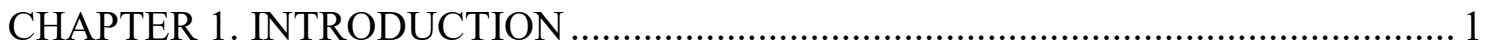

1.1. Ancient dry masonry towers ....................................................... 1

1.1.1. Earthquake threat for dry masonry towers .................................. 5

1.1.1.1. Earthquakes in Caria Region ............................................ 6

1.1.1.2. Earthquakes in Pamphylia Region...................................... 9

1.1.1.3. Earthquakes in Cilicia Region ........................................... 9

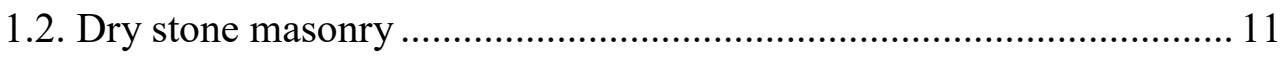

1.2.1. Precautions for sustainability of structural strength in

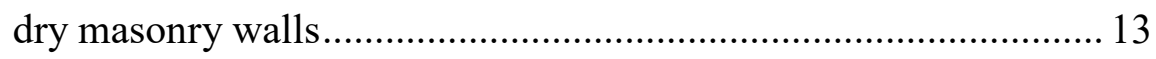

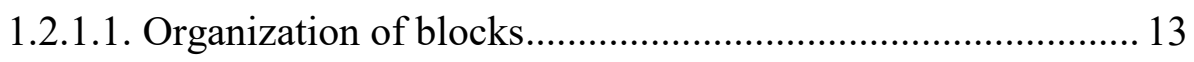

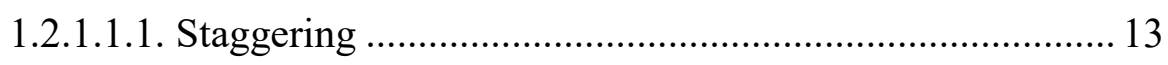

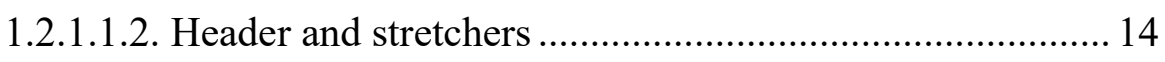

1.2.1.2. External structural elements (clamps and dowels) ............... 16

1.3. Structural vulnerability of masonry structures................................... 16

1.3.1.1. Failure mechanisms of masonry structures under lateral loading related to their characteristics................................. 18

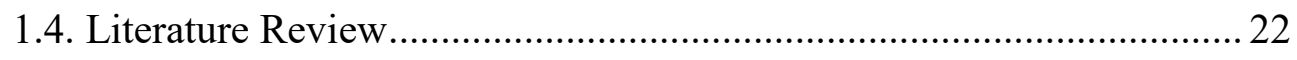

1.4.1. Studies on structural resistance and behavior of dry masonry....... 23

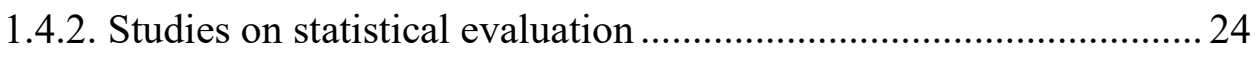

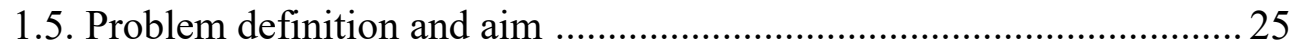

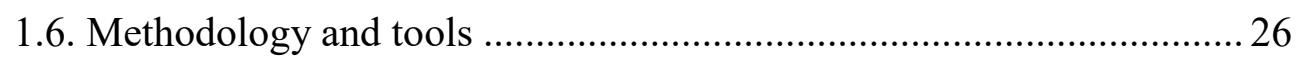




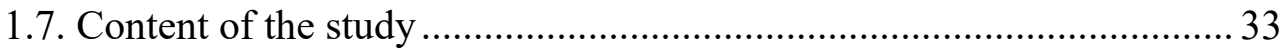

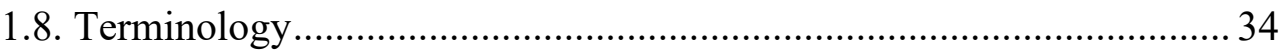

CHAPTER 2. CHARACTERISTICS OF CASE STUDY TOWERS........................... 36

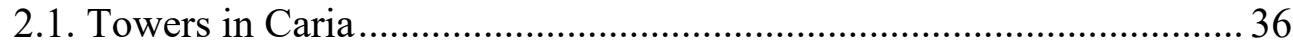

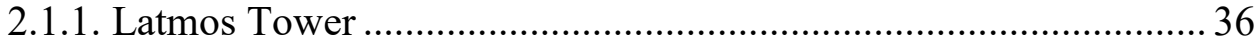

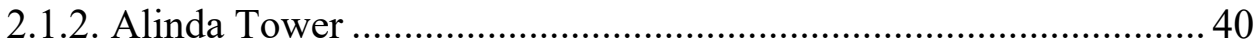

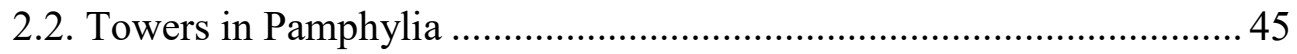

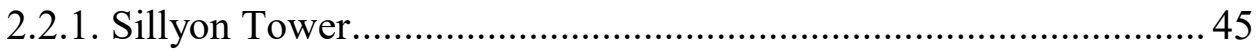

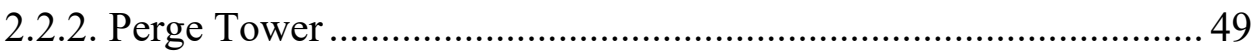

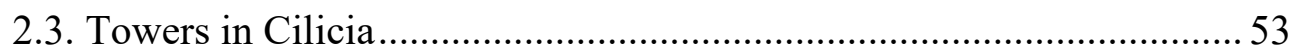

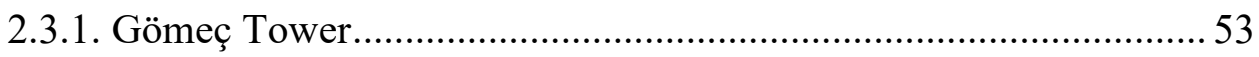

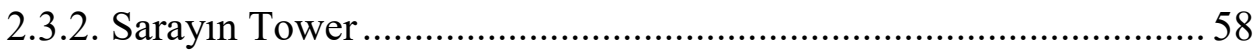

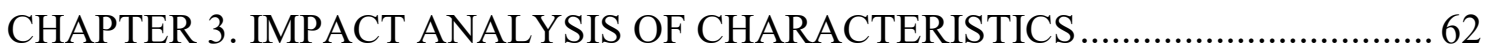

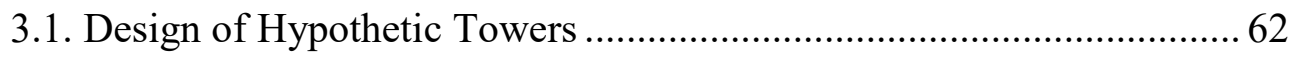

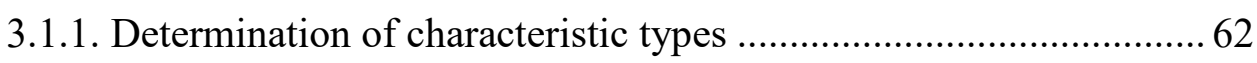

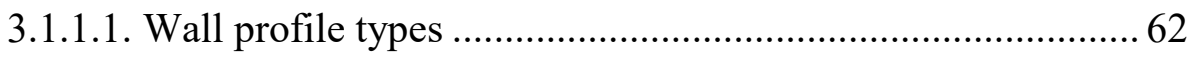

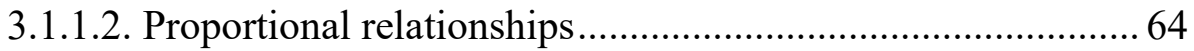

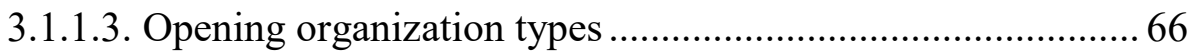

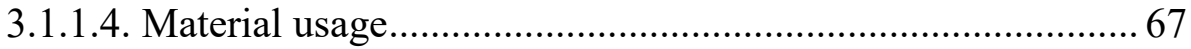

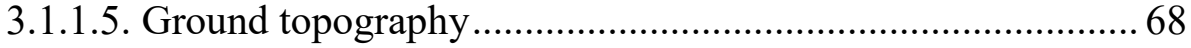

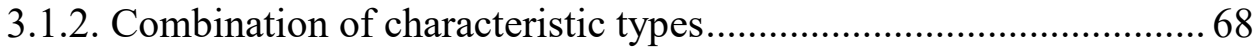

3.2. Validation of Analysis Method ...................................................... 70

3.2.1. Comparison with experimental results of Restrepo-Vélez,

Magenes, and Griffith (2014) ..................................................... 71

3.2.2. Comparison with experimental results....................................... 72

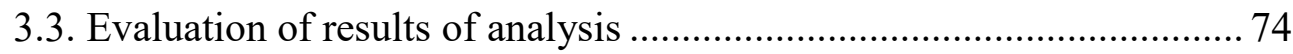




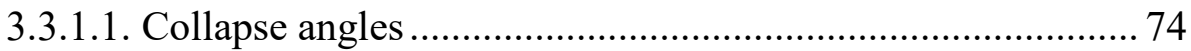

3.3.1.1.1. Wall profile and opening type relation........................... 74

3.3.1.1.2. Wall profile and ratio between height and length

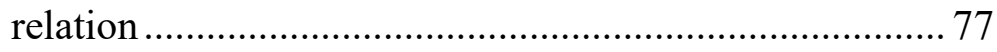

3.3.1.1.3. Wall profile and ground topography relation................... 78

3.3.1.1.4. Wall profile and material usage relation ......................... 78

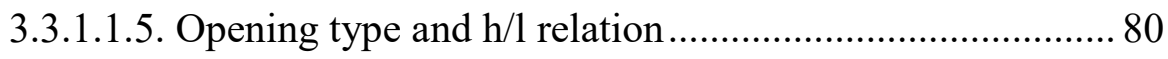

3.3.1.1.6. Opening type and ground topography relation................ 81

3.3.1.1.7. Opening type and material usage relation ....................... 83

3.3.1.1.8. Ratio between height and length, and material usage relation

3.3.1.1.9. Ratio between height and length, and ground topography relation

3.3.1.1.10. Ground topography and material usage relation .86

3.3.1.2. Failure mechanisms .88

3.3.1.2.1. Mechanisms in different wall profile and opening type combinations

3.3.1.2.2. Mechanisms in different wall profile and $h / 1$ combinations 106

3.3.1.2.3. Mechanisms in different wall profile and ground topography combinations 108

3.3.1.2.4. Mechanisms in different wall profile and material usage combinations 108

3.3.1.2.5. Mechanisms in different opening type and $\mathrm{h} / \mathrm{l}$ combinations.

3.3.1.2.6. Mechanisms in different opening type and ground topography combinations 
3.3.1.2.7. Mechanisms in different opening type and material usage combinations

3.3.1.2.8. Mechanisms in different $\mathrm{h} / \mathrm{l}$ ratio and material usage combinations.

3.3.1.2.9. Mechanisms in different $\mathrm{h} / \mathrm{l}$ ratio and ground topography combinations

3.3.1.2.10. Mechanisms in different material usage and ground topography combinations

3.3.2. Results of triple combination 120

3.3.2.1. Collapse angles 120

3.3.2.2. Failure mechanisms 123

CHAPTER 4. DISCUSSION OF IMPACT OF CHARACTERISTICS. 129

4.1. Impact of each effective characteristic 129

4.1.1. The wall profile. 129

4.1.2. The opening organization 138

4.1.3. The proportional relations 143

4.2. Impact of characteristics on each other 145

4.3. Vulnerability Assessment Framework 152

4.3.1. Vulnerability assessment of case studies 156

4.3.1.1. Towers in Caria 156

4.3.1.1.1. Vulnerability of Alinda Tower. 158

4.3.1.1.2. Vulnerability of Latmos Tower. 159

4.3.1.2. Towers in Cilicia 161

4.3.1.2.1. Vulnerability of Gömeç Tower 162

4.3.1.2.2. Vulnerability of Sarayın Tower 163

4.3.1.3. Towers in Pamphylia 165

4.3.1.3.1. Vulnerability of Perge Tower. 165 
CHAPTER 5. CONCLUSION 169

REFERENCES 172

APPENDICES

APPENDIX A. STONE CHARACTERIZATION 181

APPENDIX B. STATISTICAL EVALUATION 184

APPENDIX C. CALCULATION OF IMPACT OF PARAMETERS. 187

APPENDIX D. DATA SET FOR REGRESSION 188 APPENDIX E. DATA SET OF HYPOTHETICAL TOWERS 197 


\section{LIST OF TABLES}

Table

$\underline{\text { Page }}$

Table 1. Number of towers in ancient Hellenistic cities today ........................................ 5

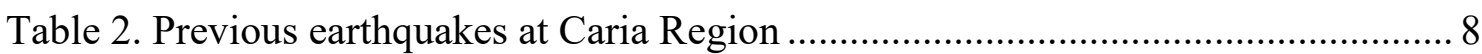

Table 3. Previous earthquakes at the surroundings of Pamphylia ................................. 10

Table 4. Previous earthquakes at the surrounding of Cilicia Region............................. 11

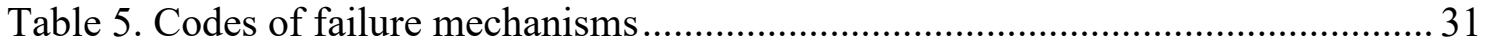

Table 6. Characteristics of Latmos Tower .................................................................... 41

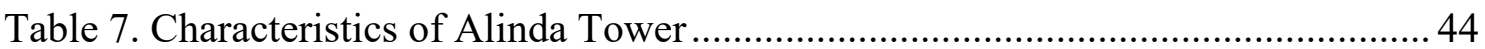

Table 8. Characteristics of Sillyon Tower …............................................................... 50

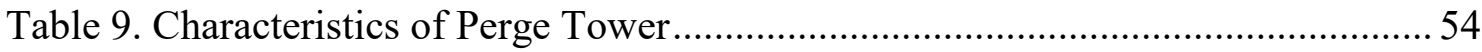

Table 10. Characteristics of Gömeç Tower ...................................................................... 59

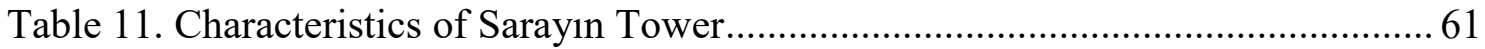

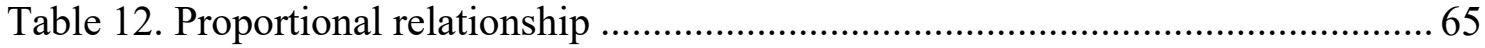

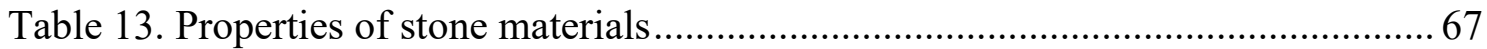

Table 14. Determined properties of materials from literature .......................................... 68

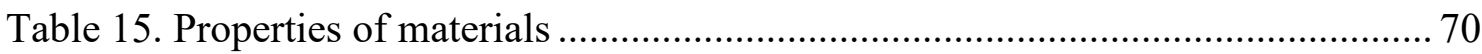

Table 16. Comparison of experiments and simulations................................................ 72

Table 17. Comparison of experiment and simulation results ...................................... 73

Table 18. Collapse angles of towers with openings at in-plane and

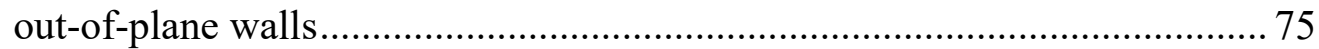

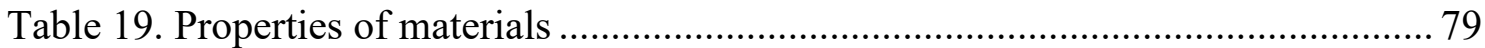

Table 20. Collapse angles in different opening types and $\mathrm{h} / 1$ ratios of wall profile $1 \ldots .80$

Table 21. Collapse angles of different opening types and ground topography for wall profile 1

Table 22. Collapse angles of towers with different openings and materials .................. 84

Table 23. Failure mechanism of towers determined in the analysis ............................. 90

Table 24. Collapse angles in different opening types and $\mathrm{h} / \mathrm{l}$ ratios of wall profiles.... 122

Table 25. Failure mechanisms in different opening types, $\mathrm{h} / \mathrm{l}$ ratios and wall profiles

Table 26. Average performance of sub-qualities regarding each wall profile.............. 130

Table 27. Average performance of sub-qualities regarding opening types .................. 139 


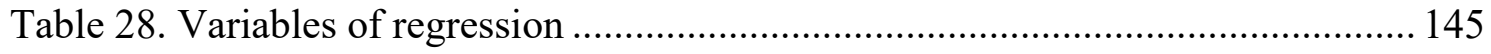

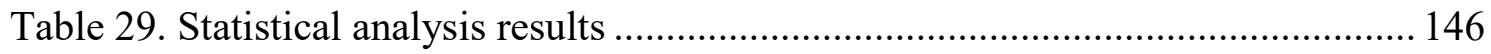

Table 30. Impact values and intervals of parameters................................................. 147

Table 31. Intervals and impact of parameters............................................................. 148

Table 32. Intervals of parameters and their impact on behavior (dominant parameter shown with grey hatch) ............................................ 151

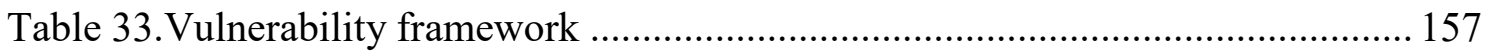




\section{LIST OF FIGURES}

Figure $\quad \underline{\text { Page }}$

Figure 1. Greek cities along the Mediterranean and Black Sea after 2000 BC ............... 2

Figure 2. Distribution of ancient dry masonry towers in Turkey and eastern Greece ...... 4

Figure 3. Ancient regions and earthquake hazard map............................................... 7

Figure 4. Types of dry masonry construction techniques ............................................ 12

Figure 5. Critical dimensions in organization of block ............................................... 14

Figure 6. Ashlar masonry without void and with void between the outer leaves........... 14

Figure 7. Alternating header and stretches usage in isodomic ashlar dry masonry ........ 15

Figure 8. Alternating header and stretches usage in pseudoisodomic

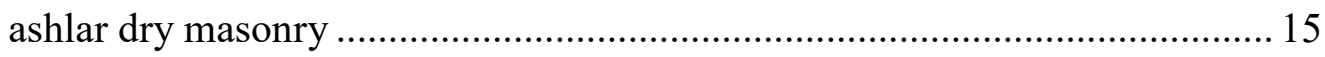

Figure 9. Damage patterns depending on seismic motion direction ............................. 19

Figure 10. Out-of-plane failure mechanisms determined by numerical analysis .......... 20

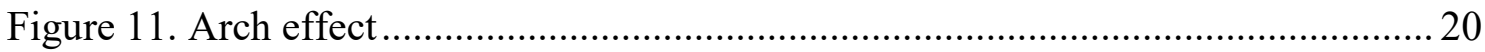

Figure 12. Variation in in-plane failure mechanisms in relation with stone block

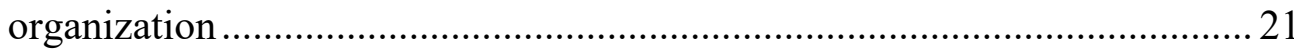

Figure 13. Failure mechanisms determined by numerical analysis ............................ 21

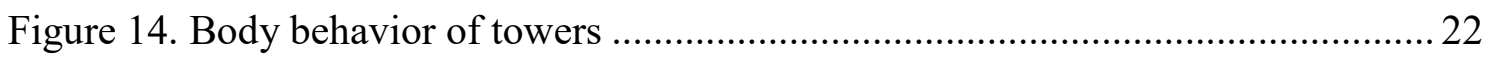

Figure 15. Measurement of wall thicknesses at floor levels ....................................... 27

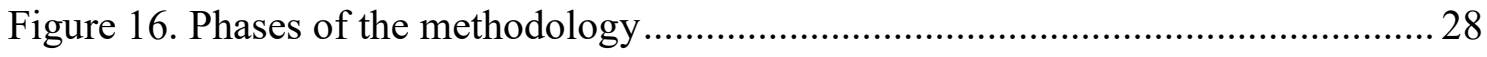

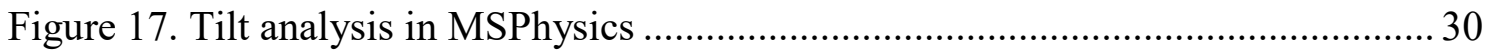

Figure 18. Horizontal acceleration $(\lambda)$ as a component of gravitational acceleration. ... 30

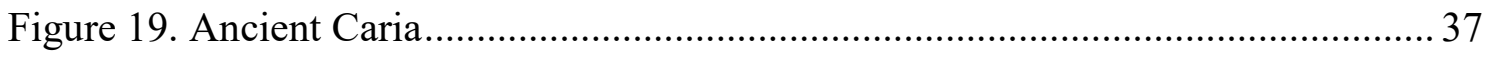

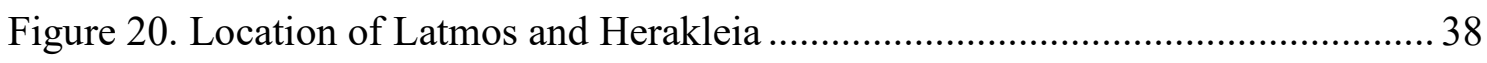

Figure 21. Latmos Tower, northern and western facades .......................................... 39

Figure 22. Alinda ancient city and the location of the case study tower ....................... 42

Figure 23. Location of Pamphylia Region ................................................................. 45

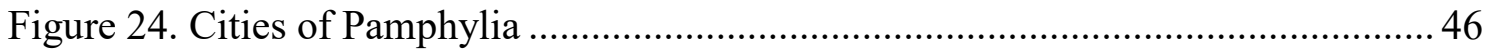

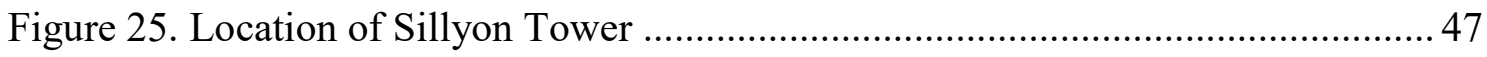

Figure 26. Sillyon Tower, northern and western facade .......................................... 48

Figure 27. Perge ancient city and location of the case study tower............................. 51

Figure 28. Old photograph of Perge Tower .............................................................. 52 


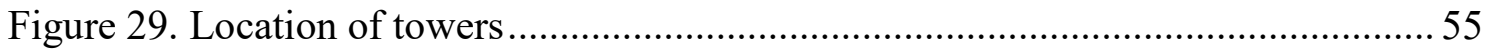

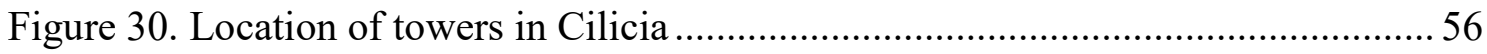

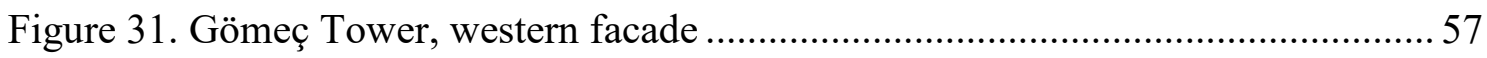

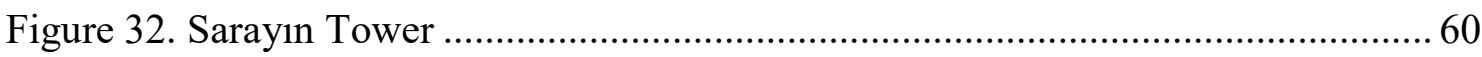

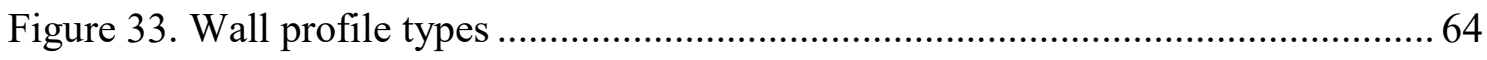

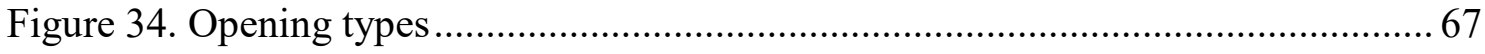

Figure 35. Failure mechanisms observed in experiments and simulations..................... 71

Figure 36. Comparison of experiments and simulations ........................................... 73

Figure 37. Opening types at in-plane position and wall profile relation ........................ 76

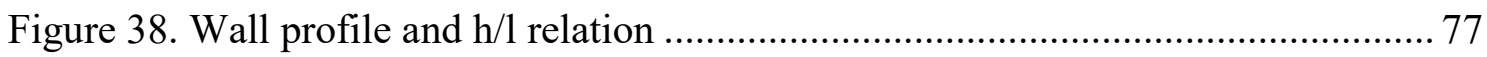

Figure 39. Ground topography and collapse relation of different wall profiles ............. 78

Figure 40. Material and collapse angle relation in different wall profiles ...................... 80

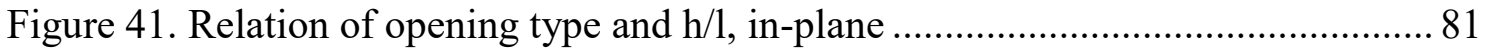

Figure 42. Opening type and ground topography relation at wall profile 1 .................. 83

Figure 43. Openings at in-plane position and collapse angle relation in different

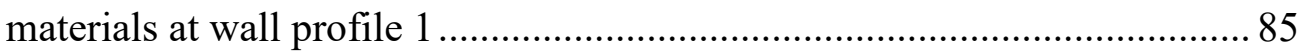

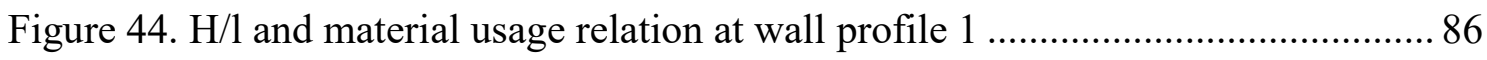

Figure 45 . Ground topography and collapse relation in different $\mathrm{h} / \mathrm{l}$ ratios

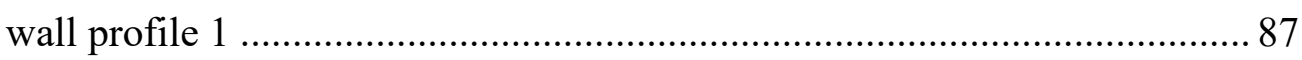

Figure 46. Ground topography in different materials at wall profile 1 ........................ 87

Figure 47. Failure mechanisms of different wall profiles with opening type 1 ............. 92

Figure 48. Similar failure mechanisms of different opening types at wall profile 1 ......94

Figure 49. Similar impact of openings 2-7, 9, 12, 13 at wall profiles 2 ....................... 95

Figure 50. Similar impact of openings 2-7, 9, 12, 13 at wall profiles 3 ....................... 96

Figure 51. Similar impact of openings 2-7, 9, 12, 13 at wall profiles 4 ....................... 97

Figure 52. Similar impact of openings 2-7, 9, 12, 13 at wall profiles 5 ...................... 98

Figure 53. Impact of openings 2-7, 9, 12, 13 at wall profiles..................................... 99

Figure 54. Openings 8 and 11 at in plane (left) and out of plane (right) positions....... 100

Figure 55. Effect of opening 11 on behavior of towers ............................................. 101

Figure 56. Effect of opening 10 on behavior of towers ............................................. 103

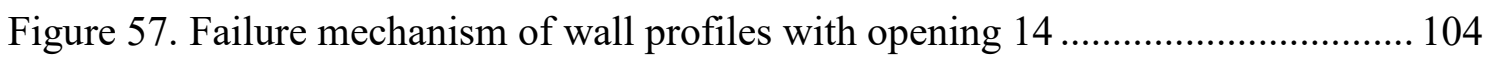

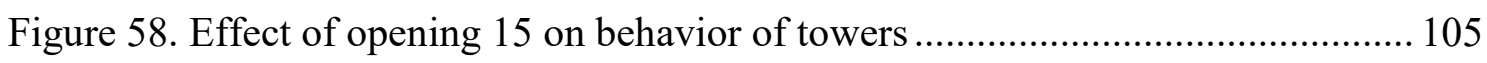

Figure 59. Effect of wall profiles on behavior in different $\mathrm{h} / \mathrm{l}$ ratio .............................. 106

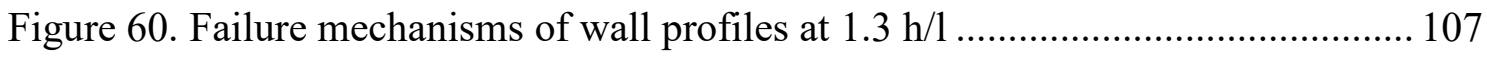


Figure 61. Failure mechanism at different ground topographies 108

Figure 62. Failure mechanisms in walls out of various materials mirror 109

Figure 63. Effect of $\mathrm{h} / \mathrm{l}$ ratio with different opening types

Figure 64. Failure mechanisms in different h/l ratios with opening 10 (in wall profile 1)

Figure 65. Failure mechanisms in different $\mathrm{h} / \mathrm{l}$ ratios with opening 11 in wall profile 1

Figure 66. Opening 8 with various $\mathrm{h} / \mathrm{l}$ ratios

Figure 67 . Failure mechanisms in different h/l ratios with opening 14 in wall profile 1

Figure 68. Failure mechanisms in different $\mathrm{h} / \mathrm{l}$ ratios with opening 15 in wall profile 1

Figure 69. Failure mechanisms of towers at different ground topographies and openings at in-plane position of wall profile 1 115

Figure 70. Opening 10 at out-of-plane position of wall profile 1 115

Figure 71. Usage of different materials and behavior of wall profile 1

Figure 72. Failure mechanisms (mechanism $A+B 2$ ) in different material and $\mathrm{h} / \mathrm{l}$ ratios at wall profile 1

Figure 73. Failure mechanisms (mechanism $\mathrm{B}_{2}+\mathrm{A}$ ) in different $\mathrm{h} / \mathrm{l}$ ratio and ground topography at wall profile

Figure 74. Failure mechanism of towers out of different material on different ground topographies

Figure 75. Failure mechanisms related to wall profile, opening type and $\mathrm{h} / \mathrm{l}$ ratio (op. 10 )

Figure 76. Failure mechanisms related to wall profile, opening type and $\mathrm{h} / \mathrm{l}$ ratio (op. 11 )

Figure 77. Failure mechanisms related to wall profile, opening type and h/l ratio (op. 15) 128

Figure 78. Impact of staggering ratio on structural resistance

Figure 79. Impact of staggering ratio on structural resistance

Figure 80. Collapse of side wall due to in-plane cracking.

Figure 81. Overturning of the facade with vertical cracks at the corners due to the low staggering ratio $(0.7)$.

Figure 82. Variation in staggering ratios of the corners 
Figure 83. Impact of block ratio on failure mechanisms and resistance 135

Figure 84. Impact of brick height on failure mechanisms and resistance

Figure 85. Decrease in out-of-plane resistant with decreasing number of headers

Figure 86. Behavior of horizontally reinforced tower

Figure 87. Impact of lower openings

Figure 88. Collapse mechanism caused by openings at in-plane wall

Figure 89. Failure mechanism with openings

Figure 90. Failure mechanism depending on opening type....

Figure 91. Resistance and behavior of wall profiles in different $\mathrm{h} / \mathrm{l}$ ratios.

Figure 92. Behavior of square box and tower.

Figure 93. Decreasing $\mathrm{h} / \mathrm{l}$ ratio and behavior (from left to right) ....

Figure 94. Possible failures of tower

Figure 95. Existing failures of Alinda Tower; northern (left) and southern (right) facades

Figure 96. Possible failures of the tower

Figure 97. Existing failures of Latmos Tower; northern facade.

Figure 98. Probable failure mechanisms under lateral loading from the direction of southern facade 162

Figure 99. Present situation of Gömeç Tower; northern facade 163

Figure 100. Probable failure mechanisms under lateral loading from the direction of eastern facade (right) 164

Figure 101. Present situation of Sarayın Tower 164

Figure 102. Probable failure mechanisms under lateral loading from the direction of eastern facade

Figure 103. Present situation of Perge Tower. 166

Figure 104. Probable failure mechanisms under lateral loading from the direction of eastern facade 167

Figure 105. Present situation of Sillyon Tower; northern and westerns facades 168 


\section{LIST OF ABBREVATIONS}

Op.

Sym.

Ass.

Adj.

Wall p. or W.

Out or o

In or $\mathrm{i}$.

Col. Angle

Stag. Ratio

$\mathrm{s} / \mathrm{h}$

$\mathrm{bl} / \mathrm{bh}$

$\mathrm{h} / 1$

$\mathrm{t} / \mathrm{h}$

$\mathrm{t} / 1$

Vul.

VS

DT

$2 \mathrm{~T}$

Mec.

XRD

SEM
Opening

Symmetrical

Asymmetrical

Adjacent to corner

Wall profile

Opening at out-of-plane position

Opening at in-plane position

Collapse angle

Staggering ratio

Staggering ratio

Ratio between block length and height

Ratio between height and length

Ratio between thickness and height

Ratio between thickness and length

Vulnerability

Vertical splitting

Detachment

Total overturning

Mechanism

X-ray Diffraction

Scanning Electron Microscope/Microscopy 


\section{CHAPTER 1}

\section{INTRODUCTION}

It is known that ancient dry masonry structures were constructed considering techniques and precautions that were formulated by experiments, and that were to minimize the effect of earthquake (Krikov 1992; Yavuz 2001; Stiros 1995). The determination of these precautions is important for the conservation of integrity of dry masonry buildings. In order to decipher design principles of dry masonry towers against lateral loading; structural and morphological characteristics, material usage and environmental conditions of buildings should be searched.

\subsection{Ancient dry masonry towers}

The geography in which the above-mentioned dry masonry towers are documented so far is western and southern coasts of Turkey and also coasts of Greece (McNicoll 1997, Morris and, Papadopoulos 2005). In 2000 BC, sea colonies from Greece and Balkan Peninsula had moved to Asia. This migration had caused confusion in Asia Minor and Greece. The period between the migration and the establishment of new cities is known as the Dark Age (1200-800 BC). Greeks spread along the coastal areas in Western, Eastern and Northern Anatolia (Figure 1). Cities in western, southern and northern parts of Anatolia had been established in Archaic period. Ionians established 12 new cities; Miletos, Myus, Priene, Ephesos, Kolophon, Lebedos, Teos, Klazomenai, Phokaia, Chios, Erythrai and Samos. Aeolians established Kyme, Larisa, Neontheikos, Temnos, Killa, Notion, Aigiroessa, Pitane, Aigai, Myrina, Gryneion and Smyrna. Dorians established Halikarnassos, Cnidos, Lindos, Ialysos, Kameiros (in Rhodos) and Kos. There were already settlements in Anatolia, when Greeks came. Lydians conquered Phrygia in $7^{\text {th }}$ century BC. Then, Persians conquered Anatolia in the 6th century BC. Anatolia was under the control of Persians until the invasion of Alexander the Great who was a ruler in the northern part of the Greek peninsula. Alexander the Great had started his military expedition in 334 BC from Gallipolli Penninsula. He had first taken control of Sardes, and then, he moved to the south: Ephesus, Miletos, Tralleis, and then Caria. He followed 
the southern coastline of Anatolia. To take control of Phyrygia, he went to Kelainai, Gordion and Ankyra (Akarca 1998, 6-15; Oransay 2012, 111-123).

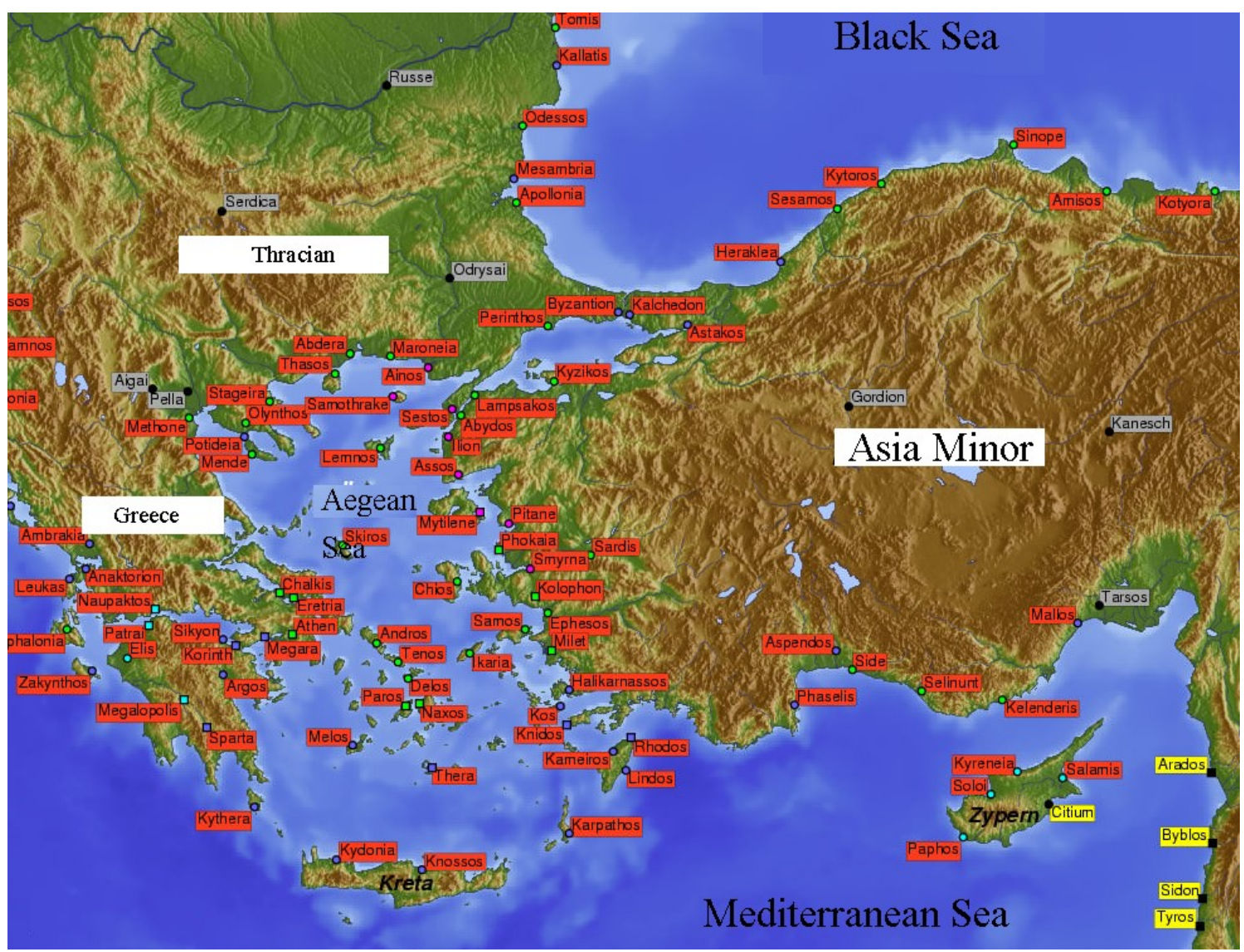

Figure 1. Greek cities along the Mediterranean and Black Sea after 2000 BC (Source: Benowar 2012)

He crossed Gülek Stait which is known as the door of Cilicia. Then, he took control of Mersin and Tarsus. He continued his attacks to the Syria and Palestine. After his death (323 BC), Hellenistic Kingdoms were established in Anatolia. Both news cities were established, and previous ones were developed (Akarca 1998, 6-15; Oransay 2012, 111-123). Hellenistic kingdoms were Pergamon, Ptolemaios (Southwestern Anatolia), Seleukos (Eastern Anatolia), Galat (Ankyra, Tolistoboglar Pessinus, Trokmeler Tavium), Pontus (Eastern Black Sea), Cappadocia (northern part is independent) and Commagene (Southeastern Anatolia). Bithynia region became independent, since it was not taken by Alexander (Akarca 1998, 6-15; Oransay 2012, 111-123). 
In this period known as the Hellenistic period, grid planned cities were surrounded by city walls reinforced with towers. Independent watchtowers in the environs were also provided. In the Roman era, however, these defense structures were only constructed in the zones under military risk (Kaya 2017, 34).

Today, the defense structures are mostly in ruins or altered. In Figure 2, the cities that have sustained their ancient dry masonry towers are illustrated with symbols (Table 1). Ancient dry masonry towers together city walls were constructed in Hellenistic periods (300-400 BC), while individual watch towers were constructed in early Roman Period (133 BC-65 BC) (McNicoll 1997, 8-11; Akarca 1998, 141-148). In Caria, Pamphylia, Lydia and Ionia regions, there are many towers documented together with city walls from the Hellenistic period, while individual towers from the early Roman period are observed in the Cilicia region and southeastern areas (McNicoll 1997, 8-11; Akarca 1998, 141-148).

The towers were built at strategic locations. The city walls passing through the flat terrains were divided by the towers with equal intervals. The city walls passing through the hills were supported by towers at strategic locations. At the borders between sea and land, towers were frequently built (McNicoll 1997, 8-11; Akarca 1998, 141-148). Towers could be square, rectangular, round or polygonal in plan. Rectangular and square towers are more widespread. The first towers were not higher than fortification walls: these were one-storied structures with slit windows. In the beginning of the $4^{\text {th }}$ century, the characteristics of the towers started to change with the invention of the catapult. The height and number of storeys of the towers increased. To increase the shooting range, towers with 3 and 4 storeys were built (app. 13- 14 meters). Square and rectangular openings were used for catapult shots. Small sized square windows were used for lightweight catapults $(80 \times 80 \mathrm{~cm})$. Large rectangular windows were used for heavy catapults. The windows had wooden covers. At the ground or first storeys, there were slit windows for watching the enemies and illumination (10-12 $\mathrm{cm}$ wide, $1.00 \mathrm{~m} \mathrm{high})$.

The tower floors were generally made of wood. The beams were usually placed in holes left in the interior surfaces of the walls of the tower body, or they were placed on the stones projected from the walls. Beam holes were placed at the side walls, rather than the walls facing the enemy. The heights of the upper storeys were less than the lower floors. The connection between the floors was provided by wooden interior ladders. 

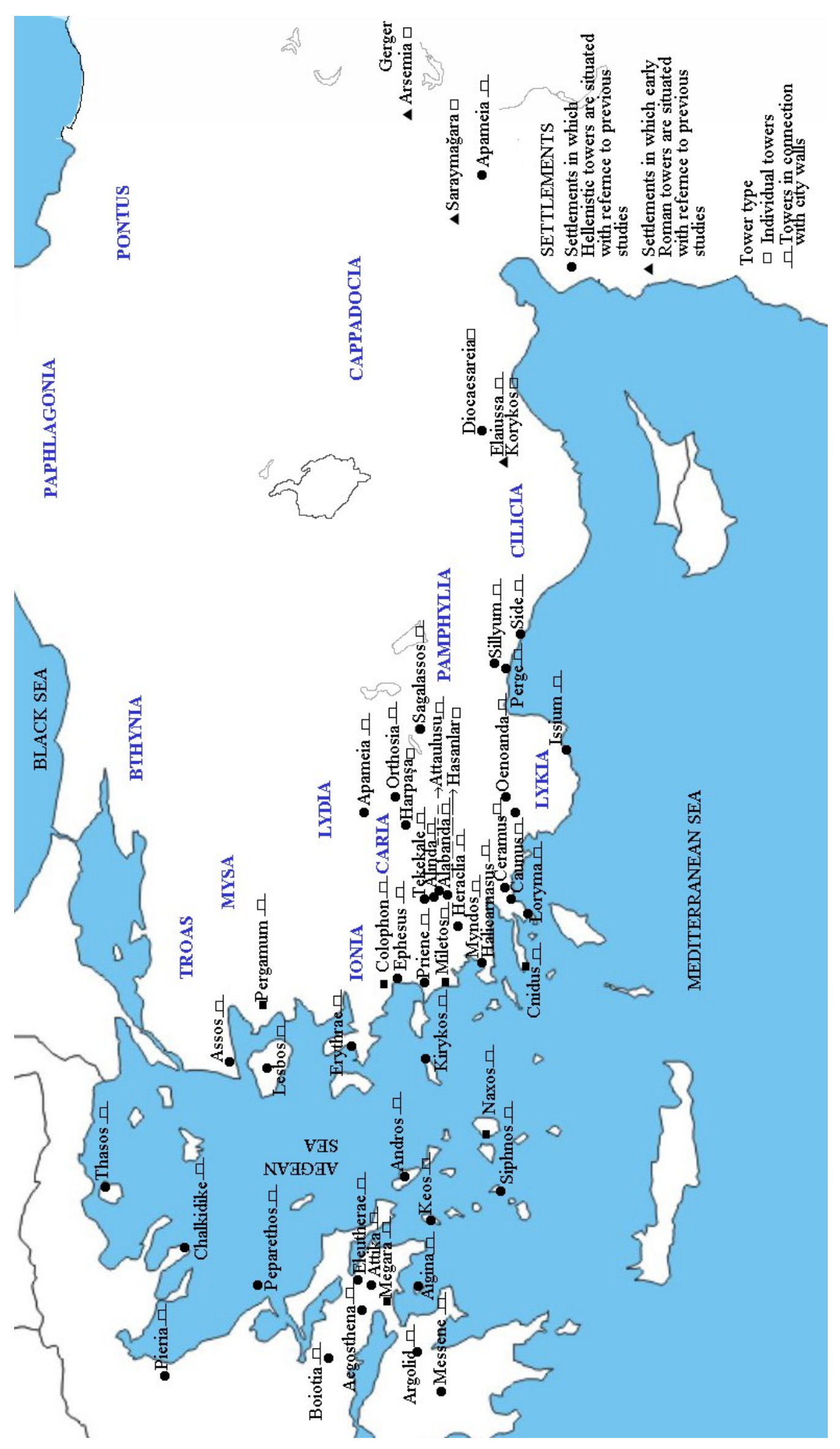

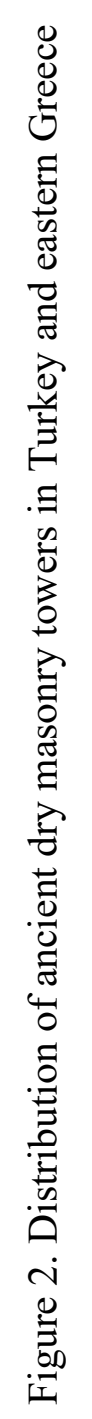


Table 1. Number of towers in ancient Hellenistic cities today

\begin{tabular}{|c|c|c|c|}
\hline Place & Number of towers & Place & Number of towers \\
\hline Halicarnassus & 18 (McNicoll 1997) & Orthosia & 1 (Çorbacıŏglu 2008) \\
\hline Myndos & 16 (McNicoll 1997) & Hasanlar & 1 (Çorbacıŏglu 2008) \\
\hline Alinda & 19 (McNicoll 1997) & Harpaşa & 1 (Çorbacıŏglu 2008) \\
\hline Alabanda & 30 (McNicoll 1997) & Tekekale & 1 (Çorbacıoğlu 2008) \\
\hline Tekekale & 2 (McNicoll 1997) & Andros & 1 (Moris and, Papadopoulos 2011) \\
\hline Priene & 26 (McNicoll 1997) & Sagalassos & 3 (Waelkens and, Lools 2000) \\
\hline Cnidus & 38-40 (McNicoll 1997) & Thasos & 33 (Moris and, Papadopoulos 2011) \\
\hline Erythrae & 4 (McNicoll 1997) & Siphons & 56 (Moris and, Papadopoulos 2011) \\
\hline Latmos & 115 (McNicoll 1997) & Keos & $\begin{array}{l}\text { Over } 70 \text { (Moris and, Papadopoulos } \\
\text { 2011) }\end{array}$ \\
\hline Ephesus & 42 (McNicoll 1997) & Naxos & 1 (Moris and, Papadopoulos 2011) \\
\hline Oenoanda & 2 (McNicoll 1997) & Chalkidie & 1 (Moris and, Papadopoulos 2011) \\
\hline Perge & 39 (McNicoll 1997) & Assos & 12 (McNicoll 1997) \\
\hline Sillyum & 4 (McNicoll 1997) & Caunus & 6 (McNicoll 1997) \\
\hline Side & 8 (McNicoll 1997) & Elaiussa & 11 (Durugönül 1998) \\
\hline Ceramus & 13 (McNicoll 1997) & Apameia & 27 (Kaya 2017) \\
\hline Miletus & 9 (McNicoll 1997) & Diocaesareia & 1 (McNicoll 1997) \\
\hline Isium & 2 (McNicoll 1997) & Attaulusu & 1 (Çorbacıoğlu 2008) \\
\hline
\end{tabular}

Ground storeys could be filled with stone and soil. Unfilled ground floors were used as storage. There was a door entered from the citadel at the ground level of the towers for service necessity. The terrace roof was inclined slightly towards the two opposite sides in the Hellenistic periods ( $4^{\text {th }}$ century BC) (McNicoll 1997, 8-11; Akarca 1998, 141-148). 
In dry masonry towers, a particular style of masonry could be used due to different reasons. First, aesthetic ideals had an influence. Secondly, sturdiness of the wall against attack of the enemies was considered. Thirdly, cost was effective. Type of stone material available in the site and previous experiences of earthquake effected the wall style as well (McNicoll 1997, 8-11).

\subsubsection{Earthquake threat for dry masonry towers}

There are many factors threatening the integrity of buildings such as earthquake, landslide, settlement, weathering, vandalism, etc. However, heavy weather conditions may have minimal impact on the integrity of dry masonry towers since large sized and heavy stone blocks are stiffer and more stable against weather conditions, heavy weather conditions mostly cause erosion on stone faces. Similarly, landslide in the environs of the towers is not expected since they are constructed on bed rock. However, earthquake can cause loss of the integrity of the dry masonry towers, since they are vulnerable to lateral loading due to their intrinsic characteristics. Therefore, while discussing vulnerability of dry masonry towers, earthquake threat should be underlined.

The regions in which ancient dry masonry towers have been documented (Caria, Ionia, Lycia, Pamphylia and Cilicia) were overlapped with the map of earthquake hazard (AFAD 2018). This overlapping presents that Lydia, Ionia, Caria and Lycia Regions have the largest ground acceleration values, Pamphylia has medium ground acceleration, and Cilicia has the smallest ground acceleration value (AFAD 2018) (Figure 3).

\subsubsection{Earthquakes in Caria Region}

In $100 \mathrm{~km}$ proximity of surrounding area, 180- 190 earthquakes are recorded from 1900 until now. In surrounding of Latmos, between 4 and 5 in magnitude, there are 141 earthquakes. Between 5 and 6 , there are 34 and between 6 and 7, 8 earthquakes. In the surrounding of Alinda, between 4 and 5 in magnitude, there are 146 earthquakes. Between 5 and 6, there are 36 earthquakes and between 6 and 7, 7 earthquakes. In ancient periods, there are not recorded earthquakes higher than 6 magnitudes in approximately $100 \mathrm{~km}$ proximity of area. Earthquakes higher than 7 magnitudes is approximately $600 \mathrm{~km}$ far from the area in the ancient period (BDTIM 2017). 

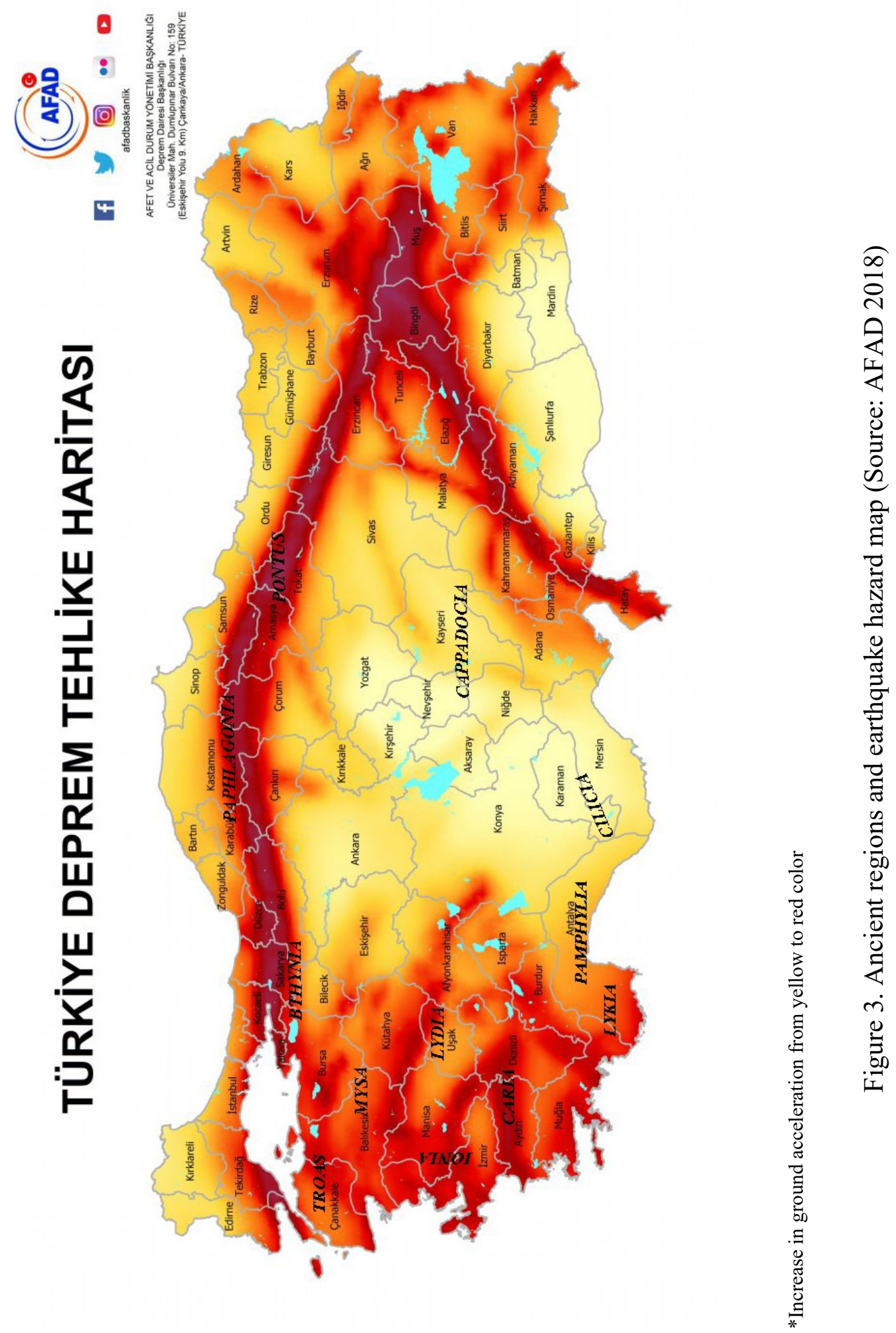
Table 2. Previous earthquakes at Caria Region (Source: BDTíM 2017)

\begin{tabular}{|c|c|c|c|c|c|}
\hline YEAR & $\begin{array}{c}\text { MAGNITU } \\
\text { DE (Richter } \\
\text { scale) } \\
\end{array}$ & Center & YEAR & $\begin{array}{l}\text { MAGNITUDE } \\
\text { (Richter scale) } \\
\end{array}$ & Center \\
\hline $304 \mathrm{BC}$ & $6-6.9$ & İzmir, Aydın & 1941 & 6 & Denizova \\
\hline $17 \mathrm{BC}$ & 6.6 & Manisa, Aydın & 1941 & 6 & Muğla \\
\hline $26 \mathrm{BC}$ & 6.6 & Aydin & 1952 & 4.6 & Güzeltepe \\
\hline $155 \mathrm{AD}$ & 7.3 & Fethiye,Mugla,Rhodos & 1954 & 5 & Samos \\
\hline $177 \mathrm{AD}$ & 7.3 & Sisam, Sakız, İzmir & 1954 & 5.4 & Bodrum Karabağ \\
\hline 1653 & 6.6 & Aydin & 1954 & 5 & Samos \\
\hline 1751 & 7.3 & Sisam & 1954 & 5.5 & Samos \\
\hline 1846 & 6.6 & Sisam, Söke & 1955 & 6.8 & $\begin{array}{c}\text { Atburgazı,Söke,Ay } \\
\text { dın }\end{array}$ \\
\hline 1851 & 6.6 & Fethiye,Mugla,Rhodos & 1955 & 5.3 & Didim \\
\hline 1873 & 6.6 & Sisam, Söke, Aydın & 1955 & 5.3 & Yalıköy \\
\hline 1895 & 6.6 & Aydın & 1955 & 6.8 & Aydın, Söke, Balat \\
\hline 1899 & 6.6 & $\begin{array}{l}\text { Nazilli, Aydın, Denizli, } \\
\text { Uşak }\end{array}$ & 1957 & 7.1 & Fethiye, Rhodos \\
\hline 1904 & 6.2 & Samos & 1959 & 5.9 & Köyceğiz, Muğla \\
\hline 1904 & 6 & Özdere & 1961 & 6.3 & Rodos \\
\hline 1908 & 5 & Aydın & 1966 & 5.4 & Aydın \\
\hline 1918 & 5.2 & Kuşadası & 1966 & 5.2 & Aydin \\
\hline 1927 & 4.5 & Kapıkırı & 1985 & 4.3 & Nalbantlar \\
\hline 1928 & 5.2 & Torbalı & 1989 & 5.1 & Kultak \\
\hline 1928 & 6.5 & Bayındır & 1989 & 5 & Kultak \\
\hline 1941 & 6.5 & Zeytin Village, Aydın & 1996 & 5.1 & Samos \\
\hline 1941 & 5.2 & Mugla & 2005 & 5.1 & Çökertme \\
\hline 1941 & 6 & Denizova & 2005 & 5.1 & Çökertme \\
\hline 1941 & 5.2 & Torbalı & 2009 & 5 & Samos \\
\hline 1941 & 5.3 & Kavaklidere & & & \\
\hline 1941 & 6.5 & Zeytin Village, Aydın & & & \\
\hline
\end{tabular}

The highest earthquakes in the surrounding area were seen in Fethiye, Muğla, which is approximately $600 \mathrm{~km}$ far from the ancient cities, in $155 \mathrm{AD}$ and Sisam, İzmir, 
which is approximately $600 \mathrm{~km}$ far from the ancient cities, in $177 \mathrm{AD}$ (magnitude 7.3) (BDTİM 2017) (Table 2).

\subsubsection{Earthquakes in Pamphylia Region}

Pamphylia region is under high earthquake threat due to high ground acceleration (AFAD 2018). In $100 \mathrm{~km}$ proximity of the surrounding area, 125 earthquakes are recorded from 1900 until now. In the surroundings, between 4 and 5 in magnitude, there are 105 earthquakes. Between 5 and 6 , there are 19 earthquakes and between 6 and 7, there is one earthquake. In ancient periods, earthquakes higher than 7 were recorded for approximately $500 \mathrm{~km}$ away from the area, in Cyprus and Rhodes directions (BDTIM 2017) (Table 3).

The Pamphylia plain was affected and damaged by earthquakes originating from Rhodes and Crete (Erel and Adatepe 2007, 242). The highest earthquakes in the surrounding area were seen in Rhodes and Cyprus, which are approximately 300 and 400 $\mathrm{km}$ far from the ancient cities, in $222 \mathrm{BC}$ and Mediterranean Sea in 1408 (magnitude 7 or higher in Richter scale).

\subsubsection{Earthquakes in Cilicia Region}

Cilicia Region is under low earthquake threat due to low ground acceleration (AFAD 2018). In $100 \mathrm{~km}$ proximity of the surrounding area, 17 earthquakes have been recorded from 1900 until now. Distribution of these earthquakes: In surrounding of the area, between 4 and 5 in magnitude, there are 12 earthquakes. Between 5 and 6 , there are 5 earthquakes. In ancient periods, earthquakes between 6 and 7 approximately $350 \mathrm{~km}$ away from the area were recorded. Only one earthquake higher than 7 in Cilicia Region was recorded and this was in 1268. There were lots of earthquakes higher than 6 magnitudes in Antiokheis (Antakya) which is about $300 \mathrm{~km}$ far from the ancient towers. The area was shaken and damaged by earthquakes on the Death Sea fault, Cyprus, Cilicia, Eastern Anatolian fault and Syria. The highest earthquake in the area was seen in 1268 (magnitude 7 or higher) (BDTIM, 2017) (Table 4). 
Table 3. Previous earthquakes at the surroundings of Pamphylia (Source: BDTİM 2017)

\begin{tabular}{|c|c|c|}
\hline YEAR & $\begin{array}{l}\text { MAGNITUDE } \\
\text { (Richter scale) } \\
\end{array}$ & LOCATION \\
\hline BC 222 & 7 or higher & Rhodes, Cyprus-(Tsunami) \\
\hline BC 185 & $6-6.9$ & Rhodes, Cyprus \\
\hline 142 & $6-6.9$ & Rhodes, Myra (Demre) \\
\hline $226(227)$ & $6-6.9$ & Rhodes, Crete, Sw Anatolian \\
\hline 303 & $4-4.9$ & Rhodes \\
\hline 336 & $6-6.9$ & Rhodes \\
\hline 21.07.365 & $6-6.9$ & Crete, Cyprus Tsunami \\
\hline 08081304 & 10 & Rdodes, Crete, Cyprus \\
\hline 30.12 .1408 & 7 or higher & Mediterranean Tsunami \\
\hline 1914-10-03 & 6.9 & Burdur \\
\hline 1924-09-10 & 5 & Değirmenli \\
\hline $1925-12-18$ & 5.1 & Kestel \\
\hline $1927-06-05$ & 5.5 & Antalya Bay, Mediterranean \\
\hline 1930-09-11 & 5.9 & Yeşilbağ, Değirmenözü \\
\hline $1937-05-29$ & 5 & Antalya Golf, Mediterranean \\
\hline 1939-01-02 & 5.3 & Antalya Golf, Mediterranean \\
\hline 1941-01-20 & 6.5 & Crete \\
\hline 1953-09-10 & 6.3 & Crete \\
\hline 1961-09-15 & 6 & Crete \\
\hline $1965-03-26$ & 5.2 & Antalya coast \\
\hline 1969-03-04 & 5.2 & Bilginler \\
\hline $1971-02-22$ & 5.1 & Yelten \\
\hline 09-05-1966 & 5 & Aşağıoba \\
\hline 1977-06-01 & 5.9 & Antalya Golf, Mediterranean \\
\hline $1979-05-28$ & 5.3 & Antalya Golf, Mediterranean \\
\hline 1981-04-26 & 5.2 & Antalya Golf, Mediterranean \\
\hline 11-03-1991 & 5.1 & Nebiler \\
\hline 2013-12-08 & 5 & Antalya Golf, Mediterranean \\
\hline 2013 & 6 & Antalya Golf, Mediterranean \\
\hline 2014-09-04 & 5.3 & Antalya Golf, Mediterranean \\
\hline
\end{tabular}


Table 4. Previous earthquakes at the surrounding of Cilicia Region (Source: BDTIM 2017)

\begin{tabular}{|c|c|c|c|c|c|}
\hline YEAR & $\begin{array}{l}\text { MAGNITUDE } \\
\text { (Richter scale) } \\
\end{array}$ & LOCATION & YEAR & $\begin{array}{l}\text { MAGNITUDE } \\
\text { (Richter scale) } \\
\end{array}$ & LOCATION \\
\hline $148 \mathrm{BC}$ & $6-6.9$ & Antiokheia & 972 & $5-5.9$ & Antiokheia \\
\hline $69 \mathrm{BC}$ & $6-6.9$ & Antiokheia & 1053 & $6-6.9$ & Antiokheia \\
\hline $37 \mathrm{BC}$ & $6-6.9$ & Antiokheia & 1072 & $6-6.9$ & $\begin{array}{l}\text { Antiokheia } \\
\text { Halep, }\end{array}$ \\
\hline 37 & $6-6.9$ & Antiokheia & 1098 & $5-5.9$ & $\begin{array}{l}\text { Antiokheia } \\
\text { Mümbiç, }\end{array}$ \\
\hline 79 & $5-5.9$ & Antiokheia & 1109 & $6-6.9$ & $\begin{array}{l}\text { Antiokheia } \\
\text { Ceyhan, }\end{array}$ \\
\hline 115 & $6-6.9$ & Antiokheia & 1114 & $6-6.9$ & \\
\hline 117 & $5-5.9$ & Antiokheia & 1190 & $6-6.9$ & surrounfings \\
\hline 220 & $6-6.9$ & Antiokheia & 1212 & $5-5.9$ & $\begin{array}{l}\text { Antiokheia } \\
\text { Kilikya }\end{array}$ \\
\hline 272 & $6-6.9$ & Antiokheia & 1268 & App.7 (viki) & (Çukurova) \\
\hline 290 & $6-6.9$ & $\begin{array}{l}\text { Ceyhan, Tarsus, } \\
\text { İçel }\end{array}$ & 1514 & $5-5.9$ & $\begin{array}{c}\text { Içel, Adana, } \\
\text { Maraş } \\
\text { Antakya, }\end{array}$ \\
\hline 341 & $6-6.9$ & Antiokheia & 1822 & $6-6.9$ & $\begin{array}{c}\text { İskenderun, Kilis } \\
\text { Antiokheia, }\end{array}$ \\
\hline 345 & $5-5.9$ & $\begin{array}{c}\text { Antiokheia } \\
\text { Crete, Cyprus }\end{array}$ & 1854 & $5-5.9$ & Samandağ \\
\hline 365 & $6-6.9$ & Tsunami & 1855 & $5-5.9$ & Ceyhan, Adana \\
\hline 387 & $5-5.9$ & Antiokheia & 1872 & $5-5.9$ & $\begin{array}{c}\text { Antakya, Halep } \\
\text { Antiokheia, }\end{array}$ \\
\hline 458 & $6-6.9$ & $\begin{array}{l}\text { Antiokheia } \\
\text { Antiokheia, }\end{array}$ & 1873 & $5-5.9$ & Samandağ \\
\hline 506 & $6-6.9$ & Samandağ & 1896 & $5-5.9$ & $\begin{array}{c}\text { Adana, Mersin } \\
\text { Marmaris,Muğla, }\end{array}$ \\
\hline 518 & $6-6.9$ & $\begin{array}{l}\text { Antiokheia } \\
\text { Antiokheia, }\end{array}$ & 26.06.1896 & $5-5.9$ & $\begin{array}{c}\text { Adana } \\
\text { Ceyhan- }\end{array}$ \\
\hline 526 & $6-6.9$ & Samandağ & 20.3 .1945 & 6 & $\begin{array}{c}\text { Misis(ADANA) } \\
\text { Ceyhan - }\end{array}$ \\
\hline 527 & $5-5.9$ & Antiokheia & 22.10 .1952 & 5.6 & $\begin{array}{l}\text { Misis(ADANA) } \\
\text { Akdeniz, Erdemli }\end{array}$ \\
\hline 529 & $6-6.9$ & Antiokheia & 1947-12-09 & 5.6 & $\begin{array}{c}\text { coast } \\
\text { Akdeniz, Mersin }\end{array}$ \\
\hline 534 & $6-6.9$ & İçel & 2015-07-29 & 5.2 & $\begin{array}{l}\text { Sarımsaklı coast } \\
\text { Akdeniz, Mersin }\end{array}$ \\
\hline 557 & $5-5.9$ & Antiokheia & $1921-10-05$ & 5.5 & bay \\
\hline 581 & $5-5.9$ & Antiokheia & $1926-03-17$ & 5.5 & Camilimanda \\
\hline 587 & $6-6.9$ & Antiokheia & & & \\
\hline 639 & $5-5.9$ & Antiokheia & & & \\
\hline 835 & $5-5.9$ & Antiokheia & & & \\
\hline 867 & $6-6.9$ & Antiokheia & & & \\
\hline
\end{tabular}

\subsection{Dry stone masonry}

In archaic period, dry masonry walls were constructed out of polygonal stones with angular and rounded sides. Lesbian blocks had rounded sides, while polygonal blocks had rectilinear sides (Figure 4, 1-2-3). Polygonal stones perfectly fit into each 
other, creating almost a monolithic wall with good cohesion (Yavuz 2001, 365). Thus, integrity of the wall was provided with the help of the form of the stone blocks. Since application of these techniques were considerably difficult and time-consuming, trapezoidal and ashlar blocks were preferred in later periods. While trapezoidal blocks (Figure 4, 4) with parallel top and bottom sides, but curved lateral sides had been used in the $4^{\text {th }}$ and $5^{\text {th }}$ centuries BC, ashlar masonry composed of square-cut rectangular stone blocks had been common in Hellenistic period (Figure 4, 5-8) (Orlandos 1968, 128-138; Nossov 2012, 26-29). Greeks laid courses of stone blocks and joints of blocks were organized by interchanging the direction of the blocks. This masonry technique was described by Vitruvius Pollione in "De Architectura" (first century B.C.). All courses of isodomum technique were of equal height. If continuous horizontal joints are created, but rows varied in height; then it was called as pseudisodomum. Typical examples of such masonry were named as opus quadratum composed of overlapping squared stones by the Romans (Vitrivius 1914, 52; Giuffre` 1991, 61-91).

Walls laid using trapezoidal or rectangular masonry were made stronger with tying elements such as headers and stretchers or clamps and dowels. These tying mechanisms were developed as a precaution to provide the integrity of the wall (Orlandos 1968, 128-138; Nossov 2012, 26-29).
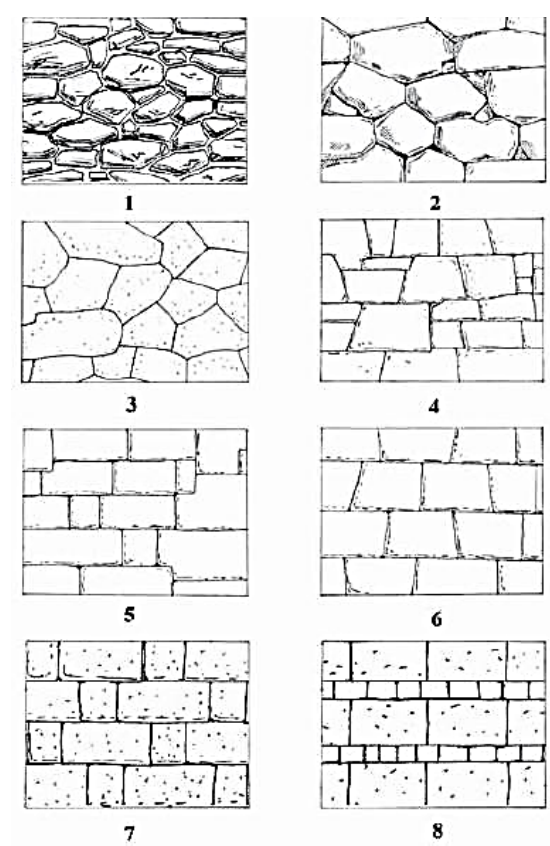

Figure 4. Types of dry masonry construction techniques (Source: Nossov 2012, 29) 


\subsubsection{Precautions for sustainability of structural strength in dry masonry walls}

Integration of dry masonry wall blocks is achieved by either external structural element such as clamps and dowels or with appropriate organization of the blocks themselves: provision of headers and stretchers.

\subsubsection{Organization of blocks}

The structural sustainability of dry masonry walls is mainly based on organization of blocks with appropriate staggering. Blocks should be organized regularly and joint between blocks at upper and lower course should not overlap with each other. However, depending on dimension and types of the stone blocks available in the construction site, different techniques were used to integrate the stone blocks (Giuffre`1991, 61-91).

\subsection{Staggering}

Arrangement of stone blocks with regular dimensions and patterns may provide the best layout for structural integrity of dry masonry constructions. Staggering of blocks, which is the ratio between horizontal distance between joints and height of the related course, is critical for organization of stone blocks. High staggering ratio $(\mathrm{s} / \mathrm{h}$ : maximum distance between joints/height of the course) improves the in-plane behavior of the wall (Ceradini 1992; D'ayala, and Speranza 2003, 480) (Figure 5). Arrangement of blocks is also related with the form of the blocks (ratio between block length and height $\mathrm{bl} / \mathrm{bh}$ ). In preliminary studies, the variation in either staggering ratio $(\mathrm{s} / \mathrm{h})\left(\mathrm{D}^{\prime}\right.$ 'Ayala and Speranza 2003) or ratio between block length and height (bl/bh) is examined (Giuffre, Pagnoni and, Tocci 1994). In these studies, joints are accepted as positioned in the middle of the upper and lower blocks, so the two ratios $(\mathrm{s} / \mathrm{h}$ and $\mathrm{bl} / \mathrm{bh})$ are always proportional to each other. 


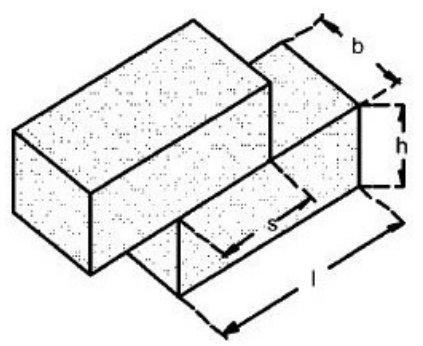

Figure 5. Critical dimensions in organization of blocks (Source: D'ayala, and Speranza 2003, 481)

\subsection{Header and stretchers}

The headers, laid perpendicularly to the course wall, strengthen the wall, keep the wall leaves together and ensure the monolithic behavior of the two leaves (Vitrivius 1914, 52; Ceradini 1992; Karlsson 1992, 86; Saner 1995, 350; Yavuz 2001, 365).

The ashlar dry masonry walls with alternating header and stretchers can be varied according to their thickness and bonding type. As the thickness of the wall increases, void between the parallel stretcher shells is created. For thicker walls, the wall is composed of three shells; two parallel stretchers and void between them. The void might be kept empty or filled in with rubble stone (Figure 8), (Adam 2005, 109-110, Orlandos 1968, 148).
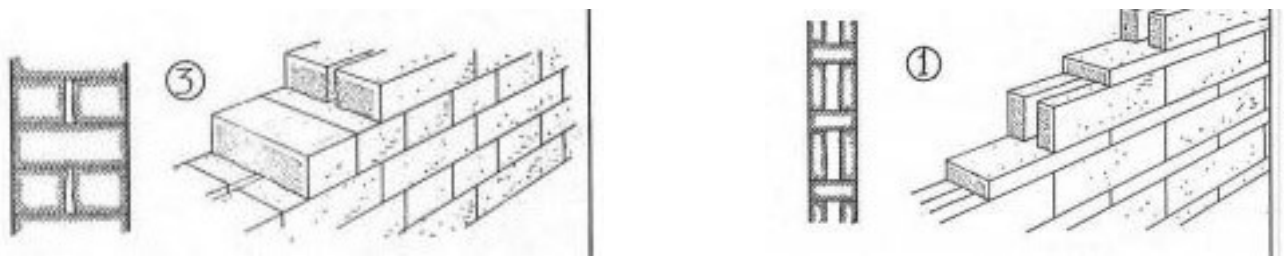

Figure 6. Ashlar masonry without void and with void between the outer leaves (Source: Orlandos 1968, 143, 148)

Alternating header and stretcher usage are observed in both isodomic and pseudoisodomic masonry (Figure 7, Figure 8). 

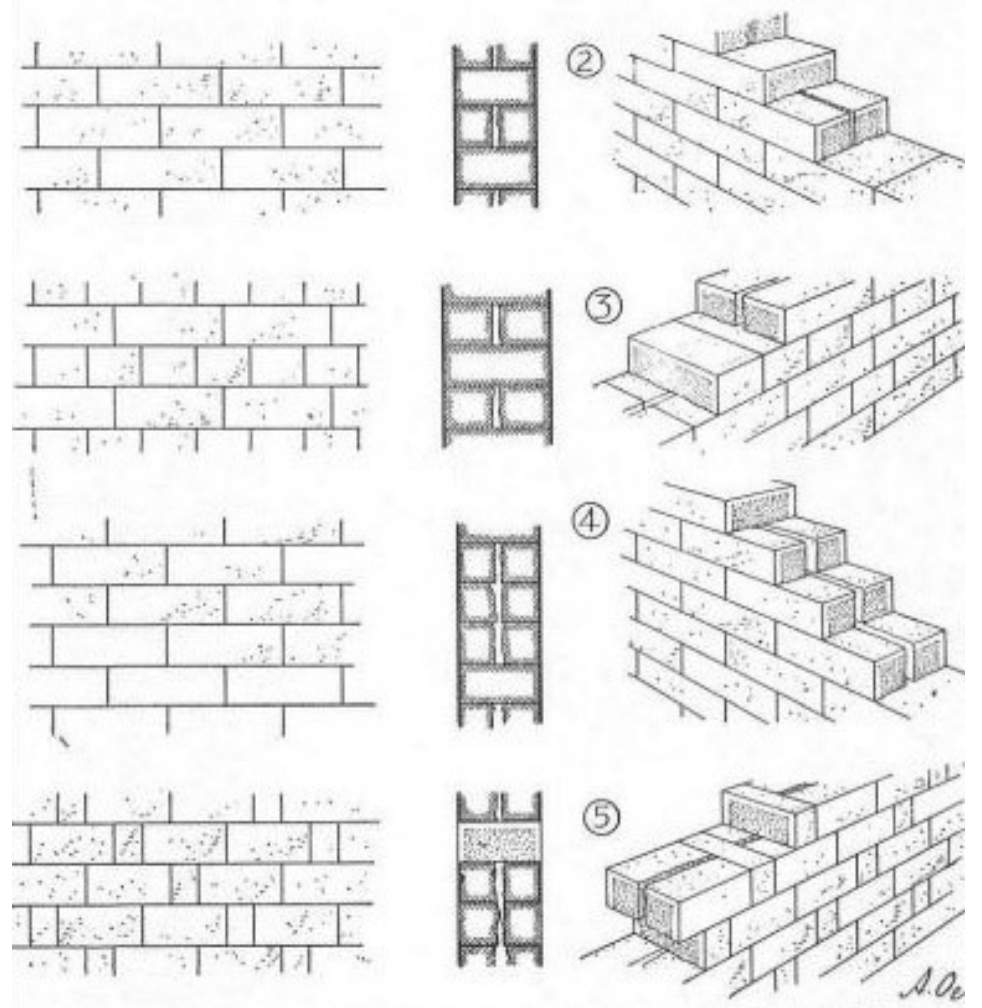

Figure 7. Alternating header and stretches usage in isodomic ashlar dry masonry (Source: Orlandos 1968, 143)
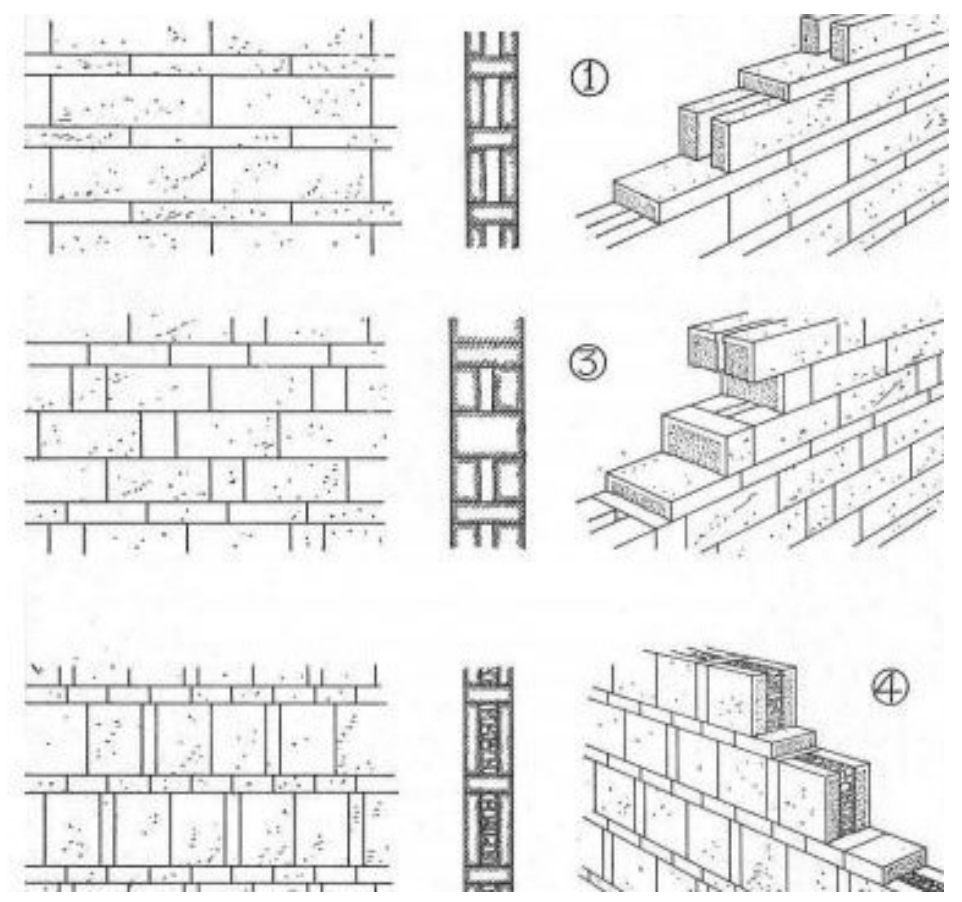

Figure 8. Alternating header and stretches usage in pseudoisodomic ashlar dry masonry (Source: Orlandos 1968, 148) 


\subsubsection{External structural elements (clamps and dowels)}

Iron clamps and dowels were generally used to fasten together the blocks of stone in ashlar dry masonry construction. An iron clamp that fit into channels carved into the ends of the stone blocks stitched blocks together horizontally. Similarly, iron dowels were used to fasten the drums of columns or blocks vertically, preventing them from sliding under shear. Clamps and dowels were used against probable stone movements due to foundation settlement or earthquakes (Mark 1993, 77).

\subsection{Structural vulnerability of masonry structures}

Vulnerability is defined as estimation of the level of loss associated with particular hazard (Stovel 1998, 7). The physical vulnerability indicates the susceptibility to the hazard due the physical characteristics of the cultural heritage or weaknesses. Vulnerability is also related with value of the cultural heritage (UNESCO et all. 2010, 8). Vulnerability assessment is critical for disaster risk preparedness or assessment since disaster risk is a product of hazard and vulnerability. While a hazard is phenomenon such as earthquake, which can cause disruption or damage to cultural heritage, vulnerability is related to cultural heritage's weaknesses against a hazard due to its specific characteristics (UNESCO et al. 2010, 8).

The first step for disaster preparedness is understanding the existing risk well. Detailed information on the physical characteristics of the structure, weaknesses and strengths of characteristics should be determined. The Manual for Risk Preparedness for the Cultural Heritage prepared by Herb Stovel (2004) on behalf of the International Centre for the Study of the Preservation and Restoration of Cultural Property (ICCROM), the United Nations Educational, Scientific and Cultural Organization (UNESCO), the International Council on Monuments and Sites (ICOMOS), the World Heritage Centre (WHC) emphasizes that vulnerability assessment is a component of risk assessment. There are basic steps to define vulnerability of a cultural heritage (UNESCO and World Heritage Committee 2004, 16):

1. Characteristics of the cultural heritage should be identified. It will be useful to distinguish between different physical elements. 
2. Vulnerability of each characteristic should be assessed for threat. This involves identifying the sub-qualities of characteristics and behavior of sub-qualities so that the possible impacts of the threat on those characteristics can be assessed.

Structural vulnerability of dry masonry structures against lateral loading is still a current research topic. There is lack of knowledge on structural behavior of dry masonry due to its peculiar techniques used in the past centuries. Structural vulnerability of masonry structures against seismic forces requires a detailed survey of the buildings and characterization of the morphology of the masonry walls and mechanical characteristics of the masonry (European Parliament 2007, 7).

Earthquake protection strategies should focus on preparation and response, since earthquakes cannot be predicted or prevented. Therefore, precautions should be determined to reduce risk at the source and improve earthquake resistance (World UNESCO and World Heritage Convention 2004, 28). For this, preliminary analysis listed in the below should be carried out.

- Analysis of past earthquakes

- Analysis of vulnerability of the building, detailed analysis of structural and morphological characteristics and probable failure mechanisms (UNESCO and World Heritage Convention 2004, 28)

Detailed vulnerability analysis should include data about geometry, the characteristics of masonry texture (single or multiple leaf walls, connection, between the leaves, joints empty or filled with mortar, physical, chemical and mechanical characteristics of the components (mortar, brick, stone), the characteristics of masonry as a composite material, deterioration with age (Bindai Valuzzi and Ceradini 2006, 347).

Determination of vulnerability of historic masonry towers in terms of behavior and failure mechanisms is critical for achievement of their seismic risk reduction (Quiroz 1977, 30). Seismic vulnerability aspects of towers are related to:

- Morphologic characteristics:

- Plan and facade organization depending on position and dimension of openings effect the vulnerability of towers.

- Height/Length Ratio (Slenderness): Since the towers are vertical structures, slenderness is important sub-quality effecting seismic performance. 
- Characteristics of masonry with material properties: Wall profile, organization and dimension of stone blocks and types of stone blocks are significant for structural vulnerability.

- Boundary conditions: Presence of adjacent buildings are important for vulnerability against seismic forces.

\subsubsection{Failure mechanisms of masonry structures under lateral loading related to their characteristics}

Although the structural typology of masonry buildings varies in different regions, their damage resulting from lateral forces can be generalized. These damages as determined through analysis of the earthquake damage patterns (Tomazevic 2000,31) are as in the below:

- Cracks at the corners and at wall intersections

- Cracks between walls and floors

- Diagonal in-plane cracks in walls

- Out-of-plane collapse of walls

- Partial disintegration of collapse of structural walls

- Partial or complete collapse of the building

According to Giuffrè's (1993) definition, damages can be interpreted on the basis of two fundamental collapse mechanisms. The first mechanism, the out-of-plane failure mode or "First Damage Mode", occurs due to the seismic actions perpendicular to the out-of-plane wall. This causes the overturning of the whole wall panel or collapse a significant portion of it. This behavior represents the highest vulnerability when connections between orthogonal walls are particularly poor. It was prevented by interlocking of intersecting walls by using ties in the past (Magenes, and Penna 2011, 4). The second mechanism, the in-plane failure mode or second damage mode (Giuffrè 1993), occurs due to the forces parallel to the wall (Carocci and Baggio 1993; Carocci 2001, 154). Diagonal cracks are observed related to the shear forces. Shear failure usually effects the upper parts of masonry buildings, where compressive stresses are low, and the response acceleration is high (Tomazevic 2000, 150).

Failures are observed at in-plane and out-of-plane walls of four-sided structures depending on direction of seismic action. At the walls which are perpendicular to lateral 
force, out-of-plane bending are observed, and vertical cracks occur at the corners and in the middle of the walls. Shear stress causes diagonal cracks in the walls parallel to lateral force (Tomazevic 2000, 31) (Figure 9).

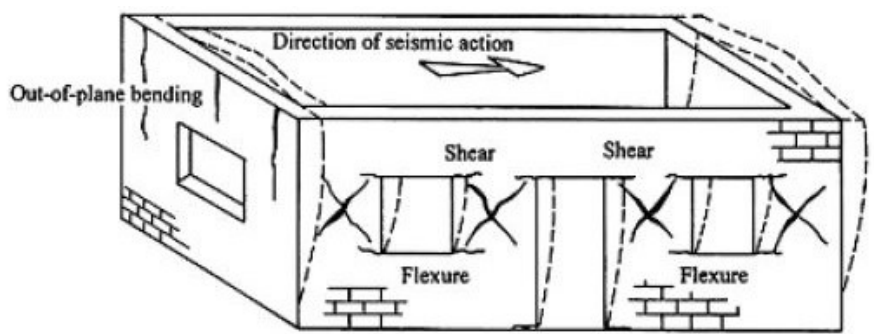

Figure 9. Damage patterns depending on seismic motion direction (Source: Tomazevic $2000,31)$

The occurrence of different failure mechanisms is based on lateral loading and characteristics of the building such as morphology, the masonry characteristics (arrangement of stone blocks and joints between them, in-plane and cross-section masonry pattern), boundary conditions and characteristics of materials (blocks and interfaces) (Binda, Saisi, and Tiraboschi 2000, 202; Restrepo-Velez, Magenes, and Griffith 2014) as mentioned previous part (1.3). The analysis of failure patterns can clearly identify the weak and good points of different structural systems (Tomazevic 2000, 31).

Depending on characteristics of structures, failure mechanisms vary as out-ofplane, in-plane, hybrid and body. Out of plane failures depend on the quality and strength of the connections with the other elements of the structure, party walls, internal loadbearing partitions, floors, and roof structures (Mechanism A, D, E). For symmetrical corner connections, without proper constraint at one corner and both corners, the wall collapses as Mechanism A and D, respectively (Figure 10) (D'ayala, and Speranza 2003, 480; Ceradini 1992).

If the structure is not strengthened, the only restraint against overturning is the friction of the contact surface, and this gives rise to different types of failures (D'ayala, and Speranza 2003, 498). However, if the structural vulnerability has been controlled by means of ties, simple overturning is prevented, while mechanisms relying on arch effect 
develop (Mechanism F, G). Mechanism G occurs, when wall span is rather long: trapezoidal central portion of the wall is affected (Shi et al. 2016, 39) (Figure 11).

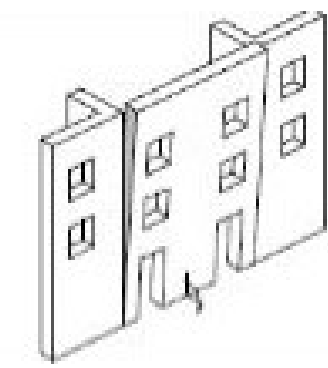

Mechanism A Overturning of out-of-plane wall

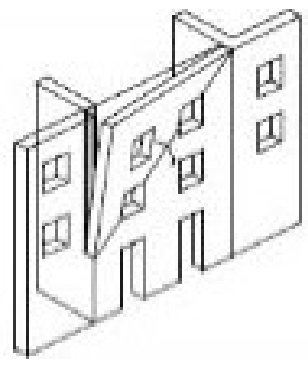

Mechanism D Partial overturning of out-ofplane wall

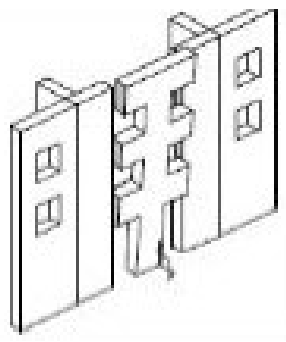

Mechanism E Vertical strip overturning

Figure 10. Out-of-plane failure mechanisms determined by numerical analysis (Source: D'ayala, and Speranza 2003, 495)
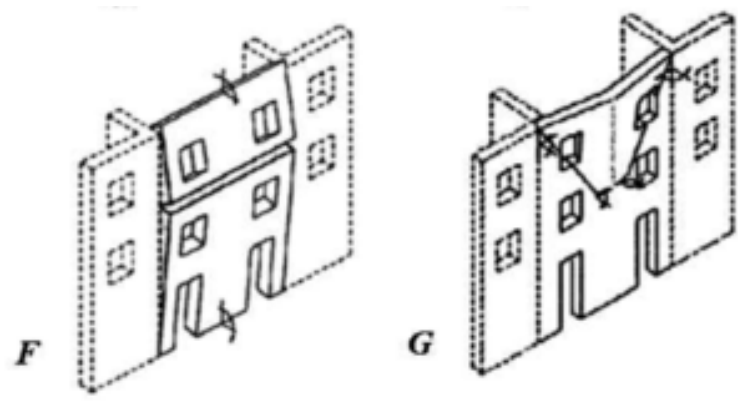

Figure 11. Arch effect (Source: D'ayala, and Speranza 2003, 499)

In-plane behavior of masonry walls change in accordance with arrangement of stone blocks (Figure 5). In a wall with small sized stone blocks and small staggering ratio, collapse of triangular portion of side walls with in-plane shear cracking is observed. If the staggering ratio and length of stone blocks increase, collapse of trapezoidal portion of side walls is observed (Figure 12) (Giuffre 2010, 50-52). In higher staggering ratios, total body failure of the whole wall is seen. 


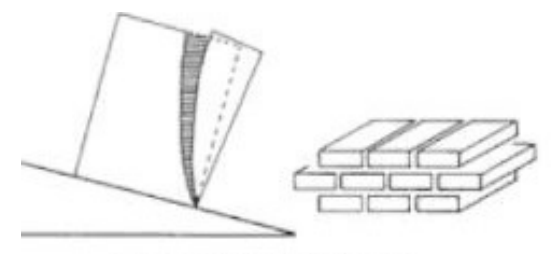

LOW TENSILE STRENGTH

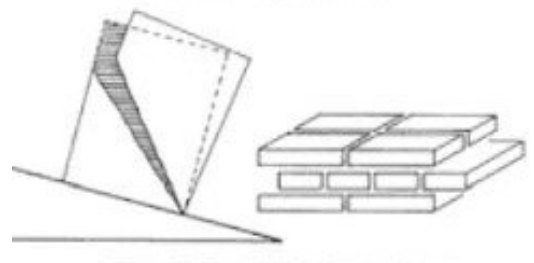

MEDIUM TENSILE STRENOTH

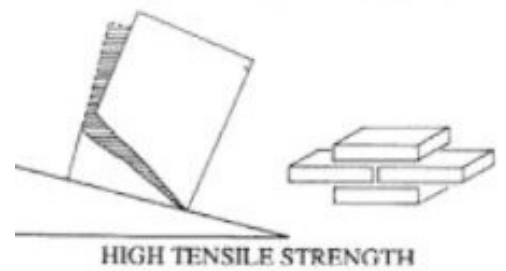

Figure 12. Variation in in-plane failure mechanisms in relation with stone block organization (Source: Giuffre 2010, 50-52)

If organization of corners are strong, shear stress causes diagonal cracks at inplane walls. this is followed by collapse of triangular portions of in-plane walls together with the out-of-plane wall. These mechanisms (Mechanism B1 and B2) results from inplane behavior. Due to the direction of lateral force and position of openings, corner failure may occur (mechanism C) (Figure 13). Hybrid mechanism is composed of failures both at in-plane and out-of-plane walls (Mechanism $\left.\mathrm{B}_{2}+\mathrm{A}\right)$.

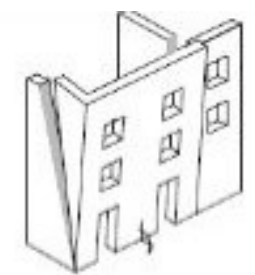

Mechanism B1

Collapse of one side wall due to the in-plane shear cracking

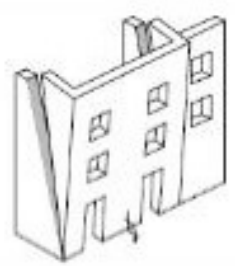

Mechanism B2

Collapse of two side walls due to the in-plane shear cracking

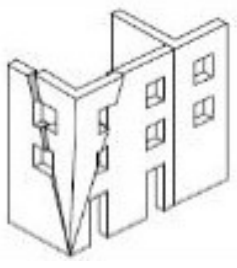

Mechanism C

Corner failure

Figure 13. Failure mechanisms determined by numerical analysis (Source: D'ayala, and Speranza 2003, 495) 
When resistance of walls and their connections are good enough against lateral loading, body behavior takes place because of slenderness (height/length) of the towers. Header blocks perpendicular to the face of the wall connecting various leaves together supports body behavior (Giuffre`1991, 61-91). Studies and experimental tests have demonstrated clearly the function of the header stones in ensuring the monolithic behavior of the two shells of the wall and in improving its out-of-plane resistance (D'ayala, and Speranza 2003, 480; Ceradini 1992).

This behavior may vary as bending (a), bending-shear (b), rocking parallel to base (c) and rocking together with foundation (d) (Figure 14), (Preciado, Sperbeck, and Ramirez-Gaytan 2016, 52). Bending starts with horizontal cracks at the facade followed by in-plane cracking of the body. Bending behavior can be combined with vertical splitting or diagonal cracking (Figure 14e) (Milani, Shehu, and Valente 2018, 213-214).

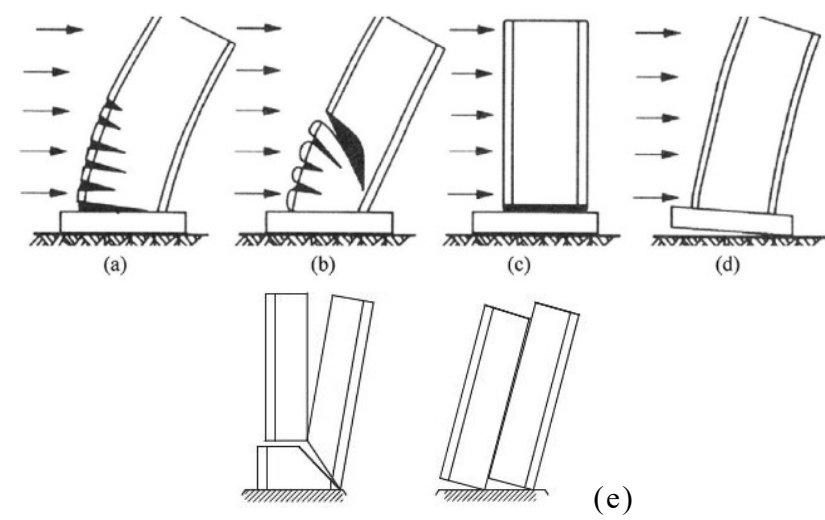

Figure 14. Body behavior of towers (Source: Preciado, Sperbeck, and Ramirez-Gaytan 2016, 52; Milani, Shehu, and Valente 2018, 213-214)

\subsection{Literature Review}

Possible causes of structural vulnerability of dry masonry walls have been tested with various methods in preliminary studies. First, methods used in literature are introduced. Since it is recognized that each preliminary study focused on relatively limited sub-qualities of characteristics, evaluation methods in presence of multicharacteristics affecting each other is also researched considering statistical tools adapted to different disciplines. 


\subsubsection{Studies on structural resistance and behavior of dry masonry}

Numerous studies have been carried out to determine sub-qualities related to morphological and structural characteristics and material usage, which affect the vulnerability of dry masonry structures. Sub-qualities of morphological characteristics vary as proportional relationship between wall length and height (slenderness) and the presence, area and position of openings. Wall thickness, number and connection of shells, organization, dimensions and connection of stone blocks, staggering of blocks and vertical loads such as roof, floor are sub-qualities effecting resistance of structural characteristics.

Most of the studies in literature examine only a single quality or two qualities by analyzing in-plane or out-of-plane behavior of a wall or a wall with two side walls (Giuffre 1996; Vaculik et al. 2004; De Felice 2011; Jimenez 2011; Foti, Vacca, and Facchini 2018). There are many studies focusing on sub-qualities related to arrangement of blocks: size of stone blocks, staggering ratio and usage of header stones. De Felice (2011) studied stone size and number of headers; Foti, Vacca, and Facchini (2018) studied masonry pattern and Giuffre (1996) studied usage of header stones between shells. Organization of blocks were also examined in relation with material characteristics (Giuffre, Pagnoni, and Tocci 1994; Vaculik, 2012; Godio, Stefanou, and Sab (2017). Regardless of characteristics of masonry and morphology are studied by Vaculik et al. (2004) and Jimenez (2011) in terms of opening organizations with boundary conditions and slenderness with reinforcement, respectively.

If the studies that investigate more than two sub-qualities related to characteristics are mentioned, Giuffre, Pagnoni, and Tocci 1994 studied organization of blocks, vertical loading and horizontal connection along the top portion of a wall with its self-weight and without side walls. Shi, D'ayala, and Prateek (2008) and Shi (2016) studied the effect of proportional relationship between length and height (slenderness), friction coefficient and corner connections on lateral capacity of dry masonry. Vaculik (2012) investigated effect of dimension of walls (height and length), openings, vertical loads, arrangement and friction coefficient of the stone blocks on out-of-plane strength of a masonry wall. Restrepo-Velez, Magenes, and Griffith (2014) studied six different sub-qualities related different characteristics: effects of different wall lengths, position of openings, connection of stone blocks, vertical loads, height and story number of buildings. Bui et al. (2017) studied the same configurations with Restrepo-Velez, Magenes, and Griffith (2014) to 
test the validity of the used method. However, in these studies, there are no configurations with combinations of sub-qualities to examine the effect of these sub-qualities to each other and which quality is more effective in which combinations.

Among the methods preferred for understanding of structural vulnerability of the configurations comprehending multi-characteristics, the quasi-static analysis stands forward. The quasi-static analysis is based on equilibrium and strength methods (Jimenez 2011; DeJong 2009). In quasi-static tilt analysis carried out by taking into account the equilibrium conditions, the structures are tilted by degrees with a tilt table, the failure mechanisms of the structures are observed, and the collapse angles are determined. At the collapse position, the horizontal component of the gravitational acceleration of the tilt table defines the level of collapse (DeJong 2009). Tilt analysis can be carried out by physical models in the laboratory environment (Giuffre, Pagnoni, and Tocci 1994; Vaculik et al. 2004; Shi, D'ayala, and Prateek 2008; Jimenez 2011; Restrepo-Velez, Magenes, and Griffith 2014), while simulation of 3D models can also be carried out in computer environment with different approaches (Azevado, and Sincraian 2000; De Felice 2005; Da Costa 2012). The validity of analysis in computer environment is done with the experimental results (Giuffre, Pagnoni, and Tocci 1994; De Felice and, Giannini 2001; Vaculik 2012; Bui et al. 2017; Foti, Vacca, and Facchini 2018).

Despite the high reliability of the experimental analysis in the laboratory environment, experiments are time-consuming and necessitate high-budget, extra human power is required. In cases where a large number of analysis are required, need of human force and working time increase. Simulation of 3D models carried out in computer environment validated by experimental methods presents a quick and practical idea about the lateral load resistance of dry masonry (Bui et al. 2017). The video game industry has been using and developing advanced rigid-body simulation tools over the past decades. They may contribute to traditional engineering tools in terms of speed, ease of use and flexibility (De Jong, Wormnes, and Tiso 2014)

\subsubsection{Studies on statistical evaluation}

Since review of literature on structural behavior of dry masonry presented that the relation between the sub-qualities that affect vulnerability has not been considered so far, an appropriate technique for this evaluation has been searched. Multiple regression 
analysis is a statistical technique that analyzes the relationship between two or more independent variables and estimates the value of the dependent variables. In multiple regression, the objective is to build a model that relates a dependent variable to more than one independent variable. Regression analysis is used in different research areas such as economy (Angleche, Manole, and Anghel 2015; Duran and Lopes 2015; Duran 2017; Uysal, and Aydemir 2016) medicine (Pervaiz, et al. 2017; Önder, and Batıün 2016; Başgelmez, and Yıldız 2017), educational sciences (Ünal, Tarhan, and Köksal 2017; Yavuz et al. 2017), agriculture (Kelechi 2012) and engineering (Kanıt, and Baykan 2004). In these studies, variables vary between five and sixteen. Coefficient of variables with a linear relationship with dependent variable are determined.

In regression analysis, the important point is the evaluation of coefficient values. The coefficient values of variables in the regression analysis cannot be compared with each other, when the units of the variables are different from each other. In order to compare the variables with each other, an impact analysis was performed using the standard deviation value and coefficients of each parameter. In this way, the effect of the variables could be compared with each other (Ünal et al. 2017; Yavuz et al. 2017; Ertekin, and Özmen 2017).

\subsection{Problem definition and aim}

Masters in the antiquity revealed the ways of constructing dry masonry towers that were resistant to the earthquake in accordance with the characteristics of their sites. Earthquake behavior of towers had been tried to be improved by appropriate building geometry and construction techniques. The relation between the original characteristics and behavior of the structures should be deciphered before the intervention decisions are determined. Since building geometry and construction technique are important factors in structural behavior, different building types and different construction techniques should be studied one by one. In this study, tower building type constructed in dry masonry technique is focused on. Dry masonry towers in ancient Caria, Pamphylia and Cilicia, which have different ground accelerations, are examined. So, possible variations stemming from the site's earthquake potential are questioned. The aim is to identify the structural behavior of dry masonry towers under lateral loading so that decision making phase regarding their restoration projects can be supported. Emphasis is made on collapse 
angles and failure mechanisms of the towers to present a preliminary assessment framework. This allows to put forward an idea for basic behavior of the towers. Internalization of behavior of towers will help the architect specialized in restoration to restitute the partially demolished towers through the analysis of their failures and damages. Within this frame, the relationship between the structural characteristics and behavior of six dry masonry towers under lateral loading in ancient Caria, Pamphylia and Cilicia on the Aegean and Mediterranean coasts are examined. Parameters that play role in structural vulnerability of ancient dry masonry towers are determined.

Characteristics that affect structural vulnerability of dry masonry construction systems have been searched in numerous studies. Proportional relationships between height and length, opening number, position and area, arrangement and dimension of stone blocks, density and friction coefficient of materials, and vertical loads were determined as significant sub-qualities of characteristics affecting structural vulnerability of dry masonry depending on direction of seismic action in literature. However, data to be tested were not gathered from real dry masonry buildings; they were completely fictional. Also, impact of these sub-qualities on each other has not been studied in an integrated way.

\subsection{Methodology and tools}

The way followed includes combination of the quasi-static analysis and tools of the statistical discipline with conventional methods of the discipline of architectural conservation. The work was realized in four phases: documentation of characteristics of case study towers, impact analysis of these characteristics, examination of results and discussion (Figure 16).

Documentation phase is composed of selection of the case studies and determination of characteristics of case studies. While selecting case studies, building type is evaluated as a factor that should be kept constant in the analysis. Since different building types have different forms and sizes, comparison may not be carried out on equal terms among them. Watch towers constructed out of dry masonry have similar forms and sizes; so, comparison of minor variations become possible for evaluating their impact on structural strength. Thus, individual towers or towers that are part of a city wall constructed in the southern and western coasts of Turkey in ancient periods are 
researched. The towers that have sustained their integrity and authenticity or whose reliable information is available are chosen as case studies. These are the six dry masonry Hellenistic towers in Caria, Pamphylia and Cilicia. Their structural and morphological characteristics are documented by traditional documentation techniques and material usage of case study towers are investigated with laboratory analysis.

Documentation is composed of series of phases. Laser meter, steel tape, range rod and ladder were used. At towers on inclined topography, wall thicknesses of the upper stories were reached from the exterior by standing on the bedrock. Wall thickness of upper portions of towers at plane areas were measured from the inside with the help of a ladder and a steel tape. Some towers are filled with earth; this made easy to reach the upper portions of the walls (Figure 15). Dimension of stone blocks and position of joints were measured with a steel tape at the lower parts, but photos parallel to facades were taken without tilting the camera in horizon direction. Then, these photos were rectified by Zoner Photo Studio X and used to draw the arrangement of stone blocks at the upper parts. Data coming from rectifications were combined with measured data at Autodesk 2018 by overlapping the reference points.
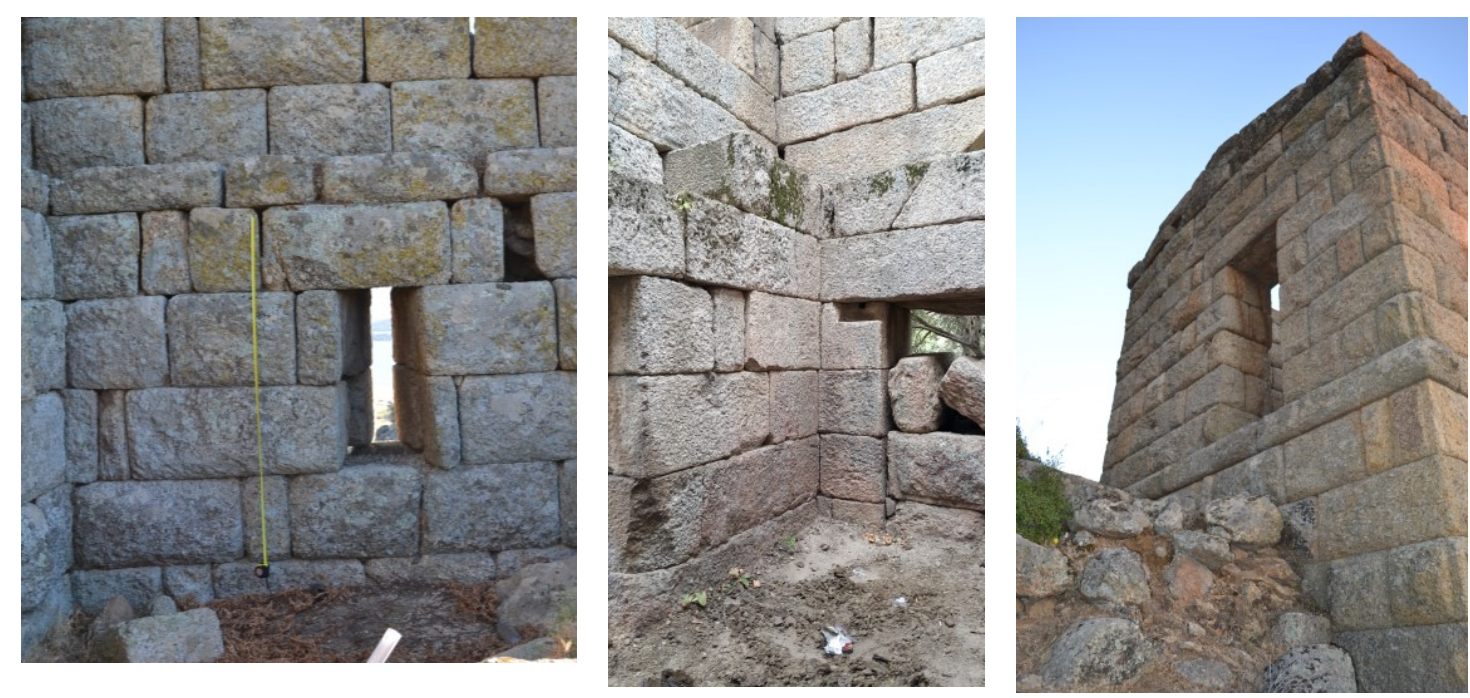

Figure 15. Measurement of wall thicknesses at floor levels

Data about structural and morphologic characteristics, material usage and ground topography of the towers are classified: 
- Wall profile types in terms of organization of leaves and blocks are documented.

- Ratios between wall thickness, length and height, and opening types in terms of position, area and number are documented.

- Types of materials used in the stone blocks are determined.

- Ground topographies are documented.

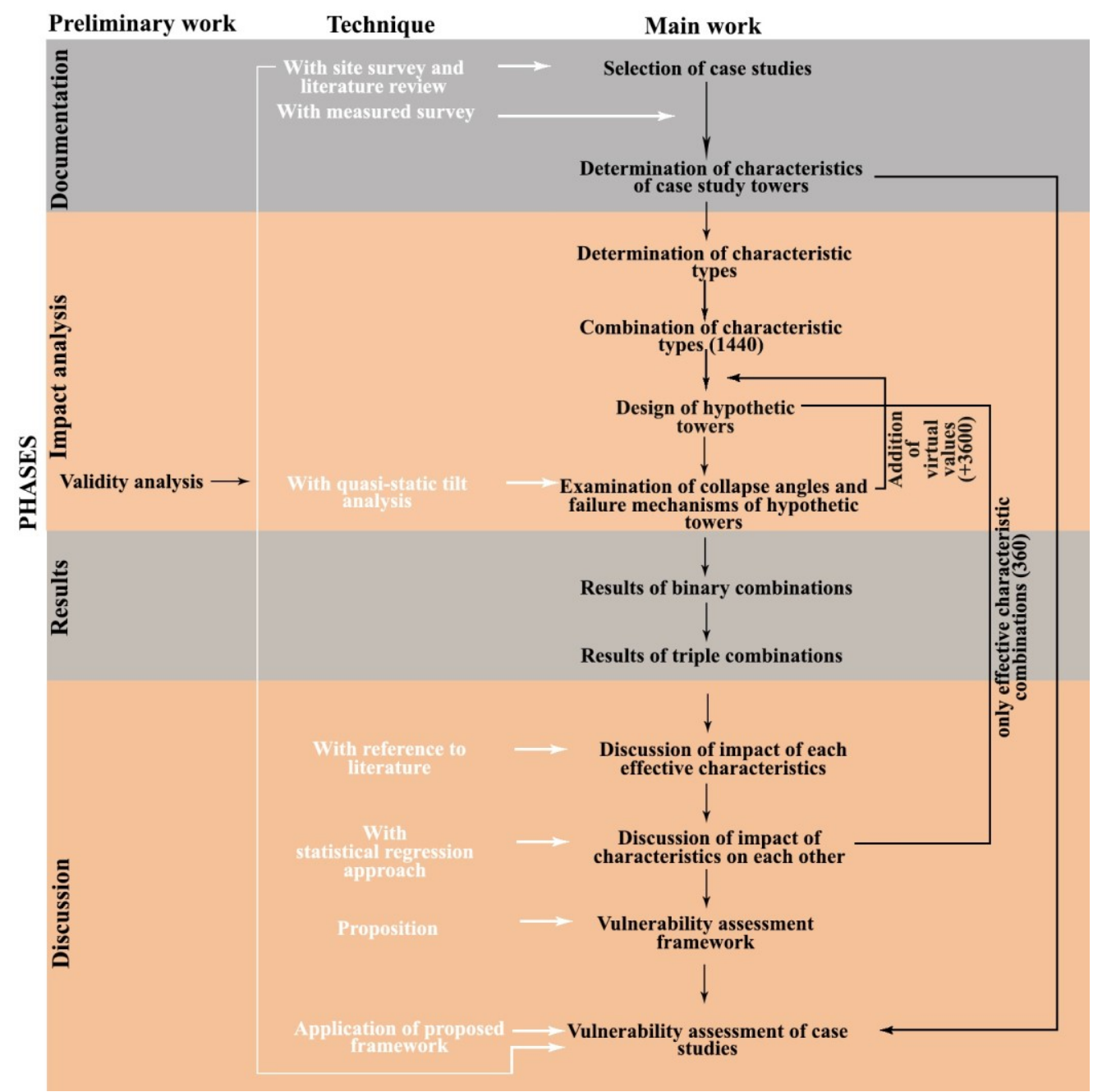

Figure 16. Phases of the methodology

Impact analysis phase consists of determination and combination of characteristics types of real towers, design of hypothetic towers and analysis of collapse angles and failure mechanisms of hypothetic towers. With combination of characteristics, hypothetic towers are designed and modelled. Tilt analysis of hypothetic towers is carried 
out to determine impact of characteristics on collapse angle and behavior. Hypothetical towers are modeled as individual rigid blocks brought together without any connecting element in SketchUp 2013. This was preferred because the real towers are composed of rigid blocks that are not connected to each other. In order to determine the seismic behavior of the hypothetical towers, MS Physics 0.9.9 software is used for the quasi-static tilt analysis simulation based on the equilibrium state. MS Physics software provides rigid block, group, and component densities based on connection states, and physical simulation. In MSPhysics, an object can be modelled with a specific shape, specific state, density, contact and magnet characteristics. Gravity, update timestep, and solver model values can be adjusted (Extension Warehouse 2017). In the simulations, friction coefficient is taken into consideration, but elasticity coefficient is ignored based on studies in literature (D'Ayala and Speranza 2003). The update time step is taken as 1/120 since smaller update time step provides more accurate simulation results and prevents collisions from deteriorating. Since the towers are composed of many moving blocks, the iterative value is taken as 16 (Synytsia 2016). The elements of floors and roofs, and relation of the tower with the city walls are not taken into consideration, since majority of the towers have limited information for these characteristics. Authentic construction technique and building geometry that have preserved their integrity to a great extend are focused on. Similarly, structural failures stemming from previous lateral loading, settlement, vandalism, weathering, etc. are not included in the modeling process. The case study towers are modelled with their original geometry and constructional characteristics excluding their roofs, floors and juxtaposing city wall.

Constant horizontal acceleration was applied to each virtual model by tilting the ground plane of the model. The amount of tilt was increased one degree by one degree, until total collapse occurred (Figure 17). Critical angles of crack, partial and total collapses were determined.

In tilt analysis, base of each tower is quasi-statically tilted until collapse occurs. The horizontal component of the ground acceleration at the level of collapse may be interpreted as a value corresponding to the peak ground acceleration. The horizontal acceleration $(\lambda)$ equals the horizontal component of the gravitational acceleration: $\lambda=\mathrm{m}_{\mathrm{g}}$ $x \sin \Theta$ (DeJong 2009) (Figure 18). While this equivalent static loading does not represent the effects of dynamics as presented through seismic loading, it makes possible to measure the lateral load bearing capacity of the structure until it collapses. 


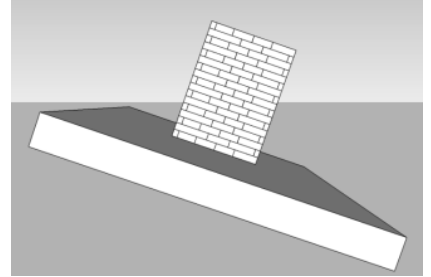

19 degree

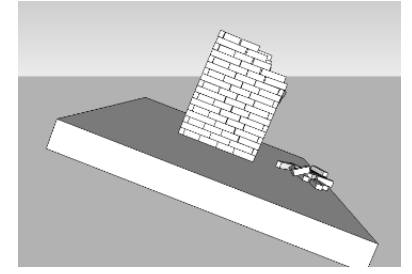

22 degree

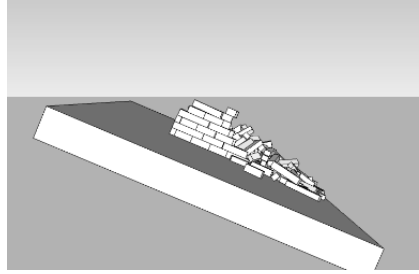

23 degree

Figure 17. Tilt analysis in MS Physics

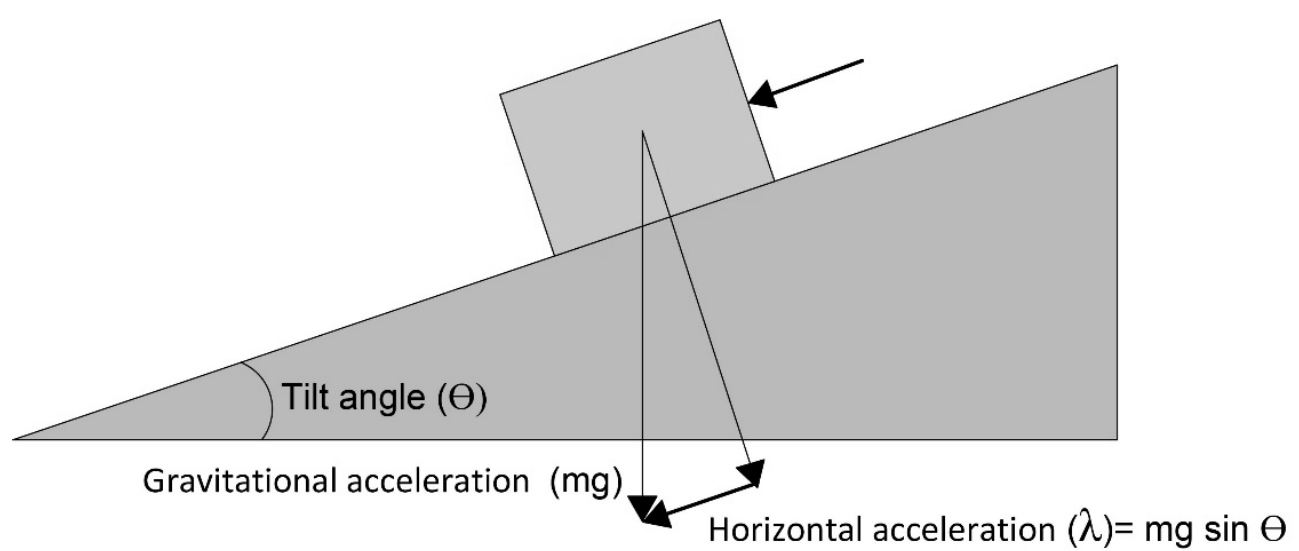

Figure 18. Horizontal acceleration $(\lambda)$ as a component of gravitational acceleration.

Each designed tower is tilted in two directions considering variation in the position of openings: openings at in-plane and out-of-plane walls. The highest collapse angle is always taken into consideration for the evaluation.

Analysis results are examined in terms of collapse angles and failure mechanisms. In-plane and out of plane behavior of walls are evaluated with regard to definitions developed by Giuffre (1993), and D’Ayala and Speranza (2003). Total tower failure mechanisms are identified with the help of the studies of Bazan and Meli (2003), and Milanu, Shehu and Valente (2018). All failure mechanisms in their sequence of happening are described with reference to literature. Additional definitions are proposed, if necessary (Table 5).

Abundant collapse angle and failure mechanism results, gained by tilt analysis, necessitate a stepped evaluation, thus grouping of characteristic types as binary and triple combinations is made. First, 10 binary combinations listed in the below are examined. 
- wall profile- opening type

- wall profile-h/l

- wall profile-material usage

- wall profile-ground topography

- opening type-h/1

- opening type-material usage

- opening type-ground topography

- h/l-material usage

- $\mathrm{h} / \mathrm{l}$-ground topography

- material-ground topography

Table 5. Codes of failure mechanisms

\begin{tabular}{c||c} 
Failure mechanism codes in previous studies & Proposed failure mechanism codes \\
\hline \hline $\mathrm{A}$ & $\mathrm{B}_{2 \mathrm{~T}}$ \\
$\mathrm{SG}$ & $\mathrm{B}_{2}+\mathrm{A}$ \\
$\mathrm{B}_{1}$ & $\mathrm{~B}_{1}+\mathrm{A}$ \\
$\mathrm{B}_{2}$ & $\mathrm{~B}_{1}+\mathrm{A}+\mathrm{G}$ \\
& $\mathrm{B}_{1+2 \mathrm{~T}}$ \\
& $\mathrm{~B}_{2 \mathrm{~T}+\mathrm{VS}}$ \\
& $\mathrm{B}_{2 \mathrm{~T}+\mathrm{DT}}$
\end{tabular}

While interpreting a specific binary combination, all other characteristic types are kept constant. The constants are taken as average or ideal values documented in the real towers. These constants are listed in the below:

- Wall profile 1

- Ratio between wall height and length: 2

- Material: Limestone

- Ground topography: on inclined ground

- Opening type: opening 1

In order to evaluate the impact of characteristics that present variation in a very narrow range, namely, slenderness ( $\mathrm{h} / \mathrm{l}$ ratio) and material usage; the real limits are 
broadened. Examination of binary combinations makes possible to filter effective characteristics. These characteristics are further examined in triple combinations.

Then, impact of characteristics is discussed with reference to literature review. Since studies on behavior of four sided dry masonry structures are limited (Jimenez 2011, Restrepo-Velez, Magenes, and Griffith 2014); studies on a dry masonry wall portion (Giuffre, Pagnoni and, Tocci 1994; Giuffre 1996; De Felice and, Giannini 2001), and dry masonry walls with one or two side walls (D'Ayala, and Speranza 2003; Restrepo-Velez, Magenes, and Griffith 2014; Shi, D'ayala, and Prateek 2008; Bui et al. 2017) are also taken into consideration. Sub-qualities that shape each characteristic is effective on structural behavior of towers are clarified. While investigating impact of a sub-quality, the best performance intervals of the other characteristics are taken into consideration.

Furthermore, it has been tested whether the sub-qualities are a parameter affecting the resistance of the structure and if there is a parameter, impact value of a sub-quality is determined with statistical evaluation. By using the data set gathered from tilt analysis of hypothetic towers, multiple regression analysis is carried out with the help of the Eviews software. The sub-qualities are identified as variables (X); collapse angle is identified as dependent variable (Y) for statistical evaluation.

Multiple regression analysis helps predicting the value of the dependent variable $\mathrm{Y}$ for given values of independent variables $\mathrm{X}_{1}, \mathrm{X}_{2}, \ldots, \mathrm{X}_{\mathrm{k}}$. In general, the multiple regression equation of $\mathrm{Y}$ on $\mathrm{X}_{1}, \mathrm{X}_{2}, \ldots, \mathrm{X}_{\mathrm{k}}$ is given by:

$$
\mathrm{Y}=\mathrm{constant}+\mathrm{b}_{1} \mathrm{X}_{1}+\mathrm{b}_{2} \mathrm{X}_{2}+\ldots \ldots \ldots \ldots \ldots \ldots \ldots+\mathrm{b}_{\mathrm{k}} \mathrm{X}_{\mathrm{k}} \text { (Eviews 2017). }
$$

$b_{1}, b_{2}, b_{3}, \ldots, b_{k}$ are called regression coefficients. $Y$ is the dependent variable. Thus, if $b_{1}=2.5$, then $Y$ will increase by 2.5 units, when $\mathrm{X}_{1}$ is increased by 1 unit.

With regression analysis, the coefficients and probability of the variables and probability and acceptance of regression model are determined. If the probability of coefficients and the model is close to zero, it means that the results are significant, and variables are accepted as parameters affecting regression model (Eviews 2017). Coefficient of determination (R-squared) shows the proportion in which the independent variable is explained through the variables. R-squared always lies between 0 and 1 . The statistic will equal one, if the regression fits perfectly, and zero, if it fits no better than the simple mean of the dependent variable (Eviews 2017).

Each parameter unit increases or decreases the strength of the unit's structure by 1 unit. For example, if the coefficient of the stone depth is 0.032 ; this means that when the stone depth increases by $1 \mathrm{~cm}$, the degree of collapse angle increases by 0.032 degrees. 
However, if the parameters have different unit types, comparison of parameters cannot be carried out. In order to compare the parameters with each other, an impact analysis is performed using the standard deviation value and coefficients of each parameter with the formula in the below:

Impact value $=$ Coefficient of independent v. x Standard Deviation (Independent v.)

/Standard Deviation (Dependent v.)

With the help of the impact values (Appendix C), dominancy of parameters can be compared with each other (Ünal et al. 2017; Yavuz et al. 2017; Ertekin, and Özeren 2017). At last, vulnerability framework is proposed with the help of the impact values of parameters gained by statistical evaluation and failure mechanisms related to the parameters. The framework is based on data coming from only analysis of hypothetic towers, but not on data of previous studies. So, it is specific to dry masonry towers only.

Vulnerability is assessed in incremental steps with the help of the impact values of parameters; ranking vulnerability at levels such as very high, high, medium, low, considerably low and critical. Vulnerability rankings are determined for openings at inplane position, since always the worst case is considered. Types of failures as body, inplane, hybrid and out-of-plane are evaluated separately for positioning of openings at inplane and out-of-plane walls. At the end, the framework is applied on case study towers.

\subsection{Content of the study}

This study is composed of five chapters; introduction, documentation, impact analysis, discussion and conclusion.

In the first chapter, dry masonry construction techniques and their behaviors under lateral loading are introduced. Then, structural analysis methods used in investigating the failure mechanisms of dry masonry structures and statistical analysis methods used for the assessment of abundant data regarding various disciplines are presented with reference to literature review.

In the second chapter, case studies are identified with reference to measured survey, visual analysis and literature review. Their structural characteristics are described in in detail.

In the third chapter, classification is made to define the types of each characteristic documented in the previous chapter. These possible types are combined with each other; 
in turn, hypothetic towers are designed. Hypothetic towers are analyzed with quasi-tilting method, which is validated with experimental results in laboratory and literature. In turn, maximum collapse angles and related failure mechanisms are obtained for all possibilities. Results regarding various combinations are grouped. First, the results regarding towers in which two characteristics present variation and the rest are kept constant are evaluated. These are named as binary combinations. It is seen wall profile is the most effective characteristic in determining the collapse angle and failure mechanisms. In addition, opening type and $\mathrm{h} / \mathrm{l}$ ratio are effective in specific situations. So, these three characteristics should be evaluated together: Triple combinations are evaluated in terms of collapse angles and failure mechanisms.

In the fourth chapter, impact of effective characteristics on structural resistance and behavior of towers are discussed with reference to literature review. The parameters that shape the effective characteristics and their relative effect on overall structural strength of a tower are evaluated statistically. Impact values of parameters are determined. Then, vulnerability assessment framework for towers is proposed by using all discussed data. At last, this framework is applied to the case study towers (Figure 16).

In conclusion, all outputs regarding the structural strength and weakness of dry masonry towers are summarized.

\subsection{Terminology}

Characteristic: A distinguishing structural and morphologic quality of a tower; e.g. wall profile, material usage, etc.

Effective characteristic: Characteristics effective in structural resistance of a tower; e.g. wall profile, opening organization.

Ineffective characteristic: Characteristics ineffective in structural resistance of a tower; e.g. ground topography.

Characteristic type: A specific characteristic of towers possessing definite qualities; e.g. wall profile type 1, opening type 14, etc.

Sub-quality: Qualities affecting dominancy of characteristics on resistance and behavior; e.g. staggering ratio and stone depth are sub-qualities of wall profile, opening area and number are sub-qualities of opening organization, etc. 
Variable: Distinguishing sub-qualities of characteristics for use in statistical approach; e.g. staggering ratio, etc.

Dependent variable: A variable that depends on other variables; collapse angle.

Independent variable: A variable that is not changed by the other variables; e.g. staggering ratio, etc.

Parameter: Significant variables (sub-qualities) according to results of statistical approach; e.g. staggering ratio, etc.

Hypothetic tower: A tower designed with combination of possible characteristic types; e.g. wall profile 1 , opening organization $14, \mathrm{H} / \mathrm{L}$ ratio 2 , ground topography flat and limestone usage.

Update timestep: "Timestep" is the time interval for which simulation will progress during next "step".

Iterative Value: A procedure that involves repetition of steps (iteration) to achieve the desired outcome.

Resistance: Structural strength against lateral loading.

Failure mechanism: The physical process in which structural resistance ability is lost as a result of excessive lateral loading.

Collapse angle: The highest angle of resistance of a tower against lateral loading just before collapse occurs.

Vulnerability: Capability of or susceptibility to lateral loading.

Risk: The potential negative impact of lateral loading. 


\section{CHAPTER 2}

\section{CHARACTERISTICS OF CASE STUDY TOWERS}

The six case study towers in Caria, Pamphylia and Cilicia regions are introduced within their geographical and historical contexts.

\subsection{Towers in Caria}

First; Latmos and Alinda towers are identified; then, the earthquake history of the region is summarized.

\subsubsection{Latmos Tower}

Latmos Tower is located in Herakleia on Mount Latmus, which is the current Beşparmak Mountains, Kapıkırı, on the eastern shore of Lake Bafa. The Mount Latmus is located $150 \mathrm{~km}$ at the south of Izmir, halfway between the cities of Söke and Milas. Its northern part belongs to Aydın, while its southern part belongs to Muğla. In the antiquity, this region formed the north-western part of Caria. Caria in the southwest of Asia Minor was bordered by Ionia in its north-west, Lydia at its north, Phrygia and Pisidia at its east (Figure 19), (Peschlow-Bindokat 2014, 16).

It is not known when the city of Latmos was exactly established, however, literary and epigraphical sources demonstrated that the city was built at the $6^{\text {th }}$ century BC. According to prehistoric rock paintings and settlements, the earliest evidence of human life belonged to Hittite Empire in the $2^{\text {nd }}$ millennium BC. In the time of colonization, around the transition from $2^{\text {nd }}$ to the $1^{\text {st }}$ millennium $\mathrm{BC}$, the Ionians, who had immigrated to Asia Minor, removed the Carians from the coast areas to the Carian hinterlands. However, with the help of the rock wilderness of the Latmos, the city was not affected by colonization and the area had always belonged to Carians. Until the end of the $5^{\text {th }}$ century BC, Latmos was a settlement without fortifications. In that period the city was part of the Delian-Attic Leage, as its neighbours Myus and Priene were. Probably in the first quarter of the $4^{\text {th }}$ century $\mathrm{BC}$, the city was enclosed with a wall. In its layout, the fortification 
wall of Latmos is a typical great circuit wall. The fortifications consisted of a wall ring with fourteen towers and three forts (McNicoll 1997, 77-79; Peschlow-Bindokat 2014, 98-104).

In the beginning of the $3^{\text {rd }}$ century BC, Pleistarchheia, Macedonian Commander, controlled the large parts of Caria and made the Herakleai capital of its empire. Part of the Carians founded a new settlement on the southwest slope of the mountain in $300 \mathrm{BC}$. In that period, the city was named as Pleistarchheia, later, it was called as Herakleia. At Herakleia, the city walls are still partly preserved up to their total height, whereas the walls of Latmos were entirely pulled down when the town was abandoned (PeschlowBindokat 2014, 116) (Figure 20).

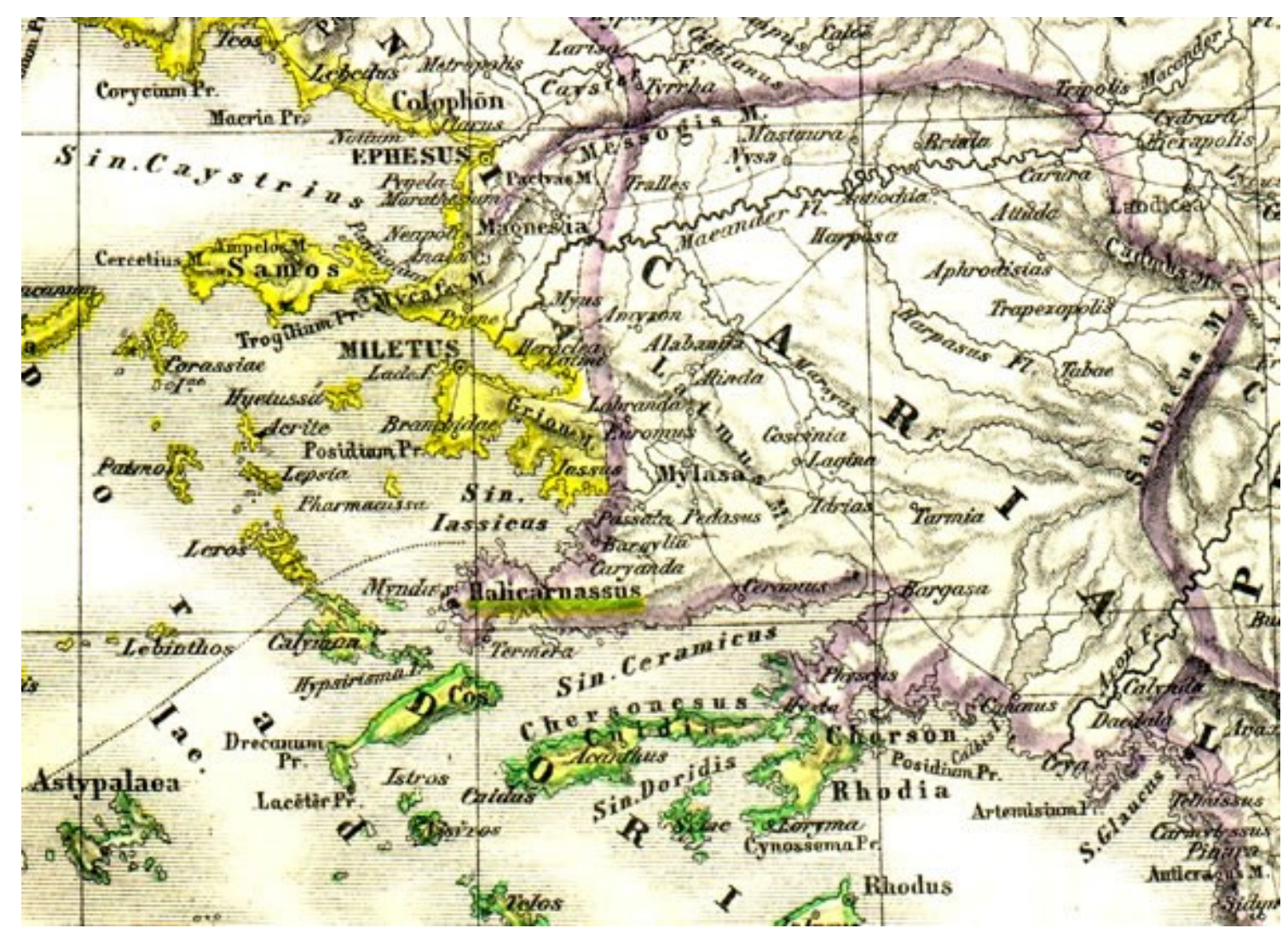

Figure 19. Ancient Caria (Source: Kiepert 1903)

The city had its greatest power during the Hellenistic period, with its harbor and transshipment position. In contrast to the organically grown old Carian settlement of Latmos, Herakleia had regular city plan recognized as a typical Greek-Hellenistic City (Peschlow-Bindokat 2014, 117-118). However, in the Roman Period the city lost its 
earlier importance. In the $1^{\text {st }}$ century $\mathrm{BC}$, the Bafa Lake formed with land movements, and the direct relation of city and sea was lost. Marine trade completely ended. The settlement was abandoned. In the $1^{\text {st }}$ century AD, the Christian Missioners had settled in the city. A number of monasteries were constructed in the area (T.C. Muğla Valiliği and Muğla Hizmet Vakfi 2019).

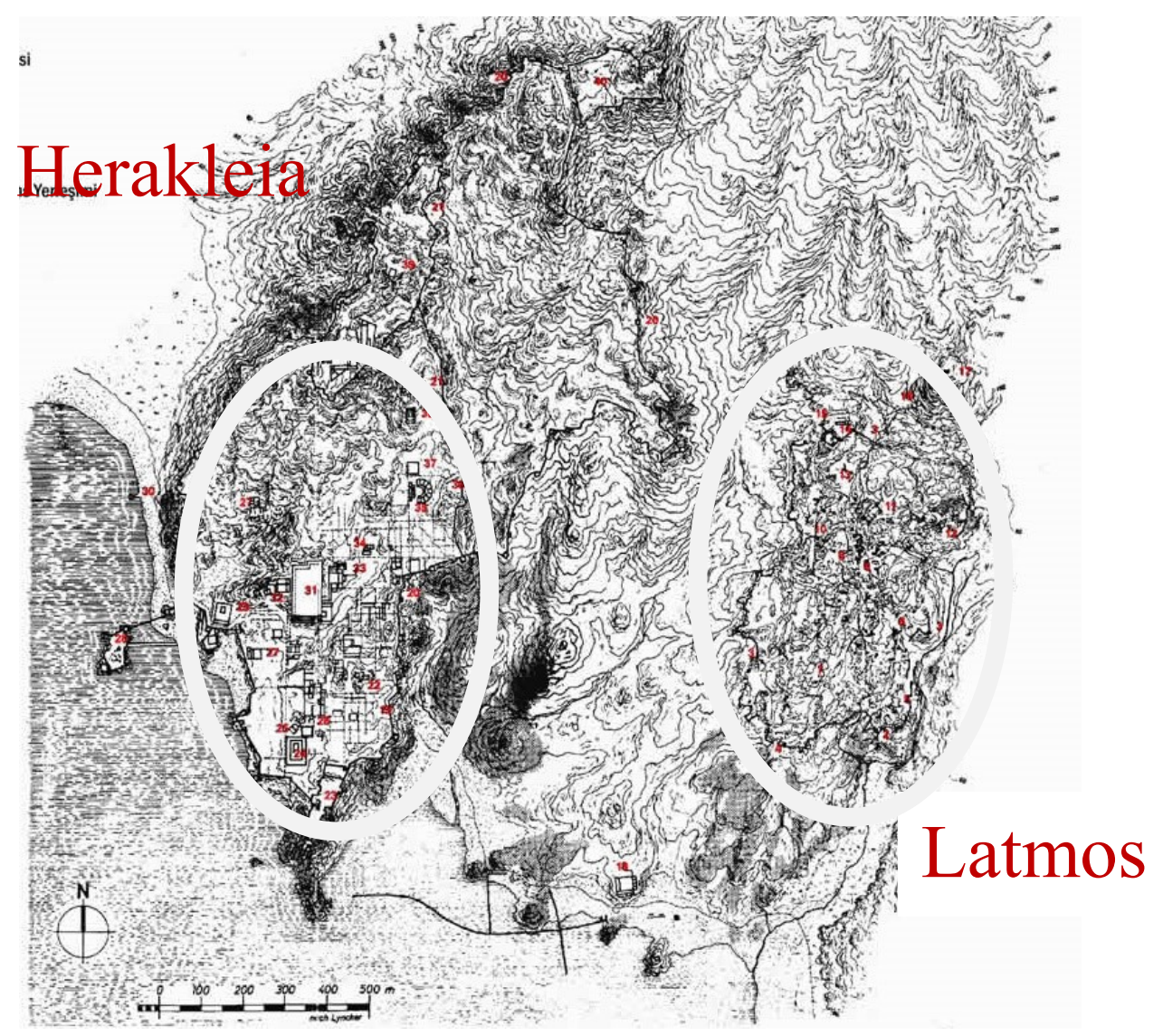

Figure 20. Location of Latmos and Herakleia (Source: Peschlow-Bindokat 2014, 100-101 from Lyncker 1912)

Herakleia ancient city was surrounded by fortification walls supported with towers irregularly. The case study tower at the upper citadel is still standing up to the level of its roof. Nearly squared planned $(6.15 \times 6.9 \mathrm{~m})$ tower is constructed as an isodomic masonry structure with header and stretcher blocks (Emplecton). The tower is approximately 42 square meters. Since the two storied tower is located on a hill skirt, the height of facades present differences depending on their positions. The highest facade facing the Lake Bafa is approximately $1069 \mathrm{~cm}$, while the shortest facade facing the 
mountain is approximately $925 \mathrm{~cm}$. The tower (Table 6) is connected with city walls from the southern and northern facades. There are two entrances at the northern and southern facades. At the lower storey, arrow slits for shooting are provided as seen in southern and western facades. At the upper storey, symmetrical openings $(90 \times 150 \mathrm{~cm})$ are positioned on the western and northern facades. There are asymmetrical two openings $(75 \times 160$, $143 \times 210 \mathrm{~cm}$ ) on the southern facade. The larger opening is adjacent to the corner. On the eastern facade, there is an asymmetrical opening $(95 \times 265 \mathrm{~cm})$ in the middle (Figure 21$)$.

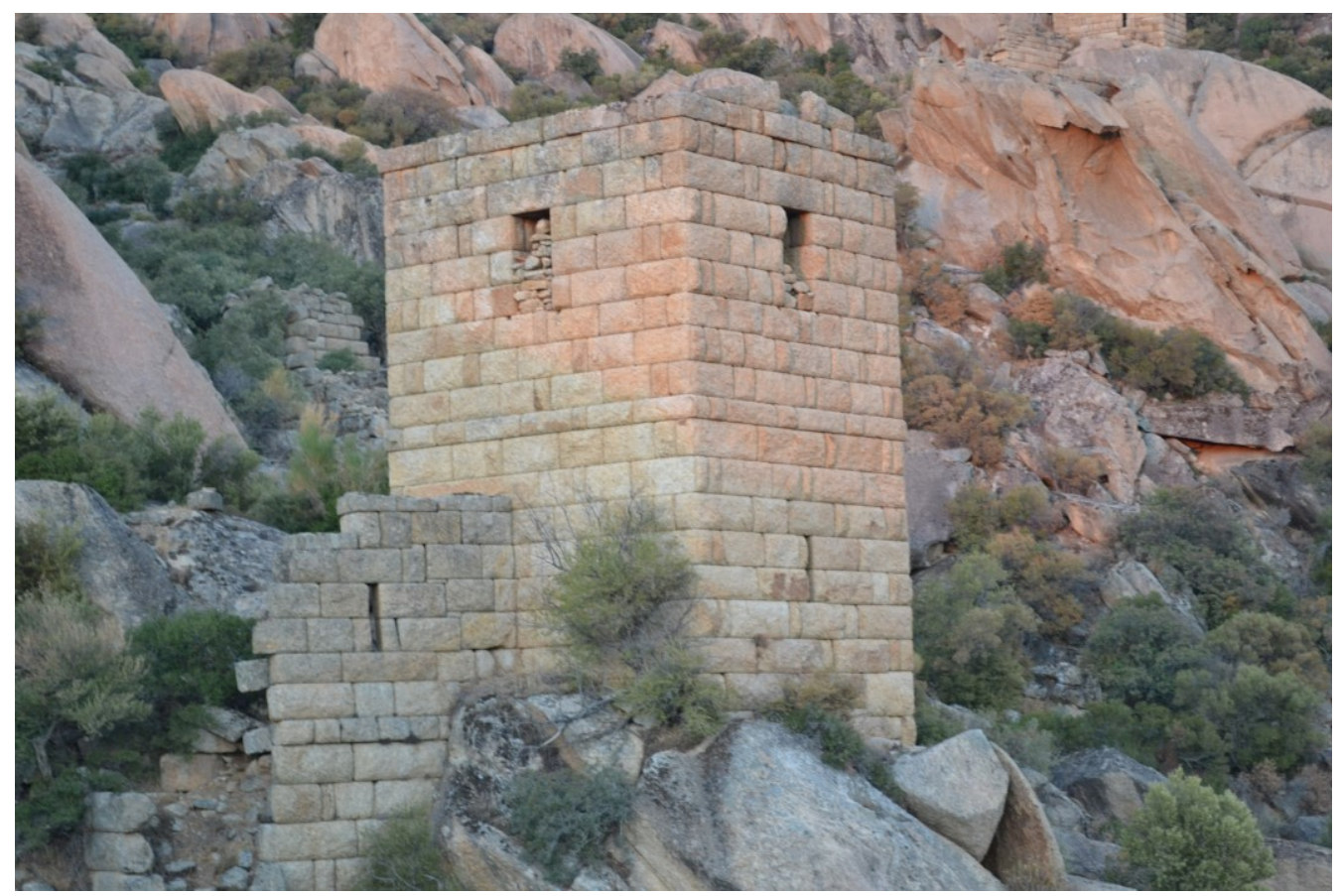

Figure 21. Latmos Tower; northern and western facades

Characteristics of the masonry system is examined from units to wall. Two types of units are observed: header stones are longitudinal units, while stretchers are transverse

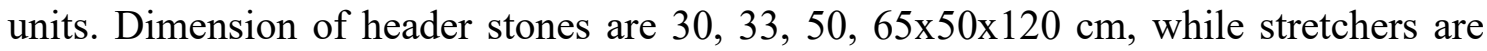
about $100-150 \times 50 \times 50 \mathrm{~cm}$. The masonry walls are composed of two outer leaves and a gap between them. The leaves are connected with header stones that do not touch each other and distributed evenly. Position of joints between blocks is described with staggering ratio (ratio between minimum length between joints and course height). Staggering ratio is between 0.6 and 0.1 . Shorter lengths of header stones cause decrease in staggering ratio. 
Wall thickness of the walls show differences in accordance with the story system. At the lower story, wall thickness is about $115-120 \mathrm{~cm}$, while at the upper story, it is about $90 \mathrm{~cm}$. After approximately $500 \mathrm{~cm}$ from the ground, wall thickness decreases.

Distribution of headers are similar in each facade. Area of headers are approximately $4-7 \%$ at the corners and 8-10\% at the middle. Headers are observed at the intersection of corners. Two neighboring walls, western and northern wall have asymmetric corners, while the other neighboring walls have symmetric corners.

Beam holes $(25 \times 25 \mathrm{~cm})$ for wooden floors are observed approximately $550 \mathrm{~cm}$ from the ground level. Wooden floor was probably composed of eight beams with $60 \mathrm{~cm}$ intervals. First and last beams are located on the thicker ground floor wall. Stone blocks on the very top were provided to carry the pitched roof.

The tower has sustained its original morphologic and structural characteristic, except the timber floor and the roof. The dry masonry walls have almost no structural failure, they have just minor problems such as diagonal stepped cracks and slight out of plumpness of the wall (Table 6).

\subsubsection{Alinda Tower}

Alinda is an ancient inland city in Caria, Asia Minor (Anatolia). It is situated on a hilltop near Demircideresi, Karpuzlu, Aydın in western Turkey and overlooks the plain of Karpuzlu. The remains of ancient Alinda extend over the eastern slope of a mountain ridge that rises from the edge of Karpuzlu plain. In the antiquity, the fortified town was responsible of the protection of the main route passing by Alabanda (Çine) and connecting Tralleis (modern Aydin) at the north and Physkos (modern Marmaris) at the south (McNicoll 1997, 26; Konecny and Ruggendorfer 2014, 709).

According to the tribute lists of the Delian League, Alinda was a party to the treaty from the year of its foundation in 478/7 BC, together with 40 other communities in the Ionian-Karian region (McNicoll 1997, 26). An honorary inscription giving information about Hellenistic Period of Alinda was found in Karakol, a village in the eastern part of the Karpuzlu plain. The inscription is dedicated to Dionytas and Apollas, rulers of Olympichos, who controlled Caria between 240 and 220 BC (Laumonier 1934, 291-298; Konecny and Ruggendorfer 2014, 711). 


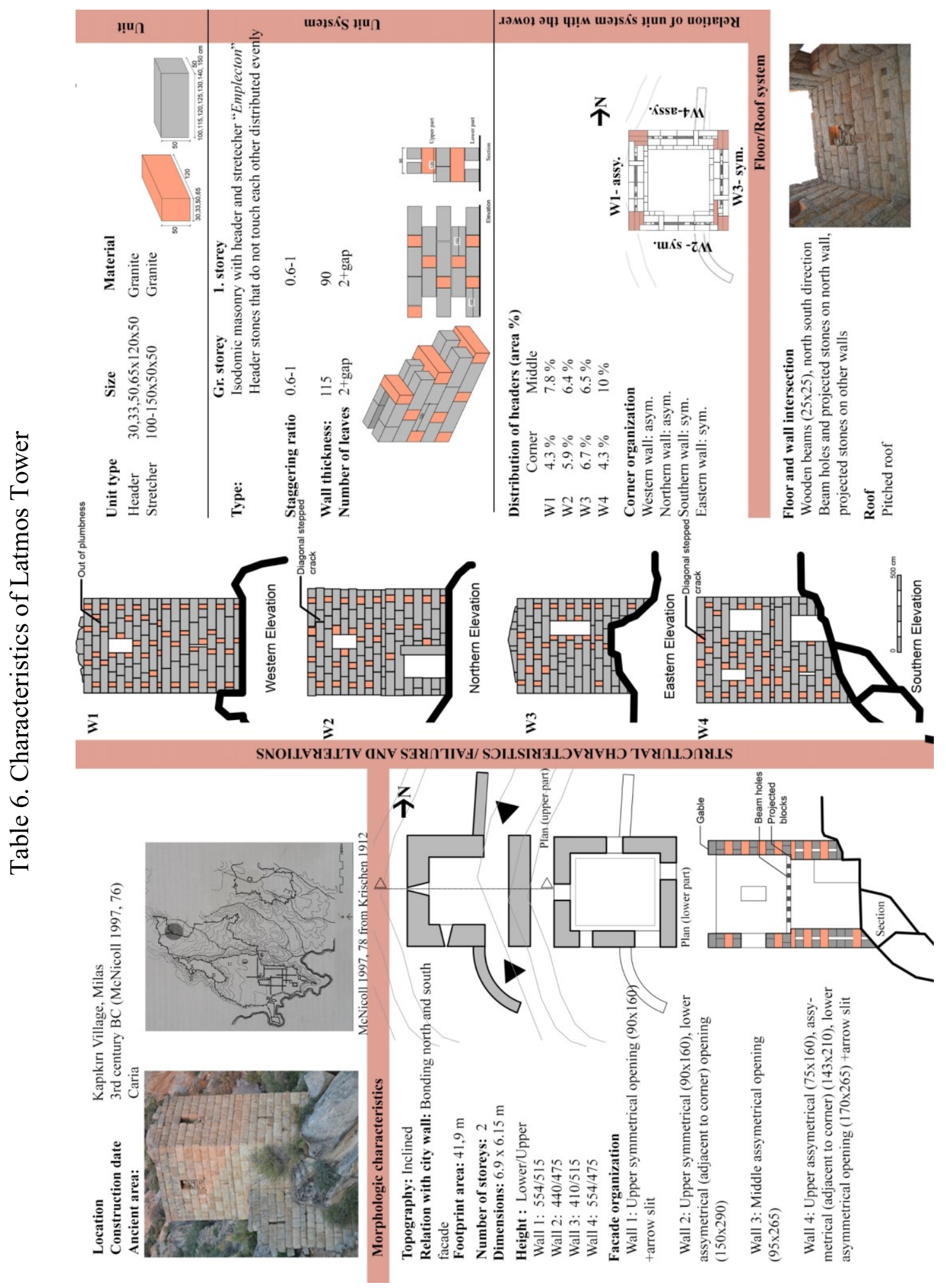


After removal of Princess Ada from Halicarnassus by Pixodarus in $341 \mathrm{BC}$, she came to Alinda. She remained in Alinda until the arrival of Alexander in $334 \mathrm{BC}$. Alexander recognized her as the satrap of Caria, then, the city was rapidly Hellenized. Probably fortifications were constructed before 341 BC. The length of the walls that enclose the settlement was $400 \mathrm{~m}$ whose of $2000 \mathrm{~m}$ are still extant and visible. It has a total of nineteen towers. Several towers are still standing up till their upper stories (McNicoll 1997, 26) (Figure 22).

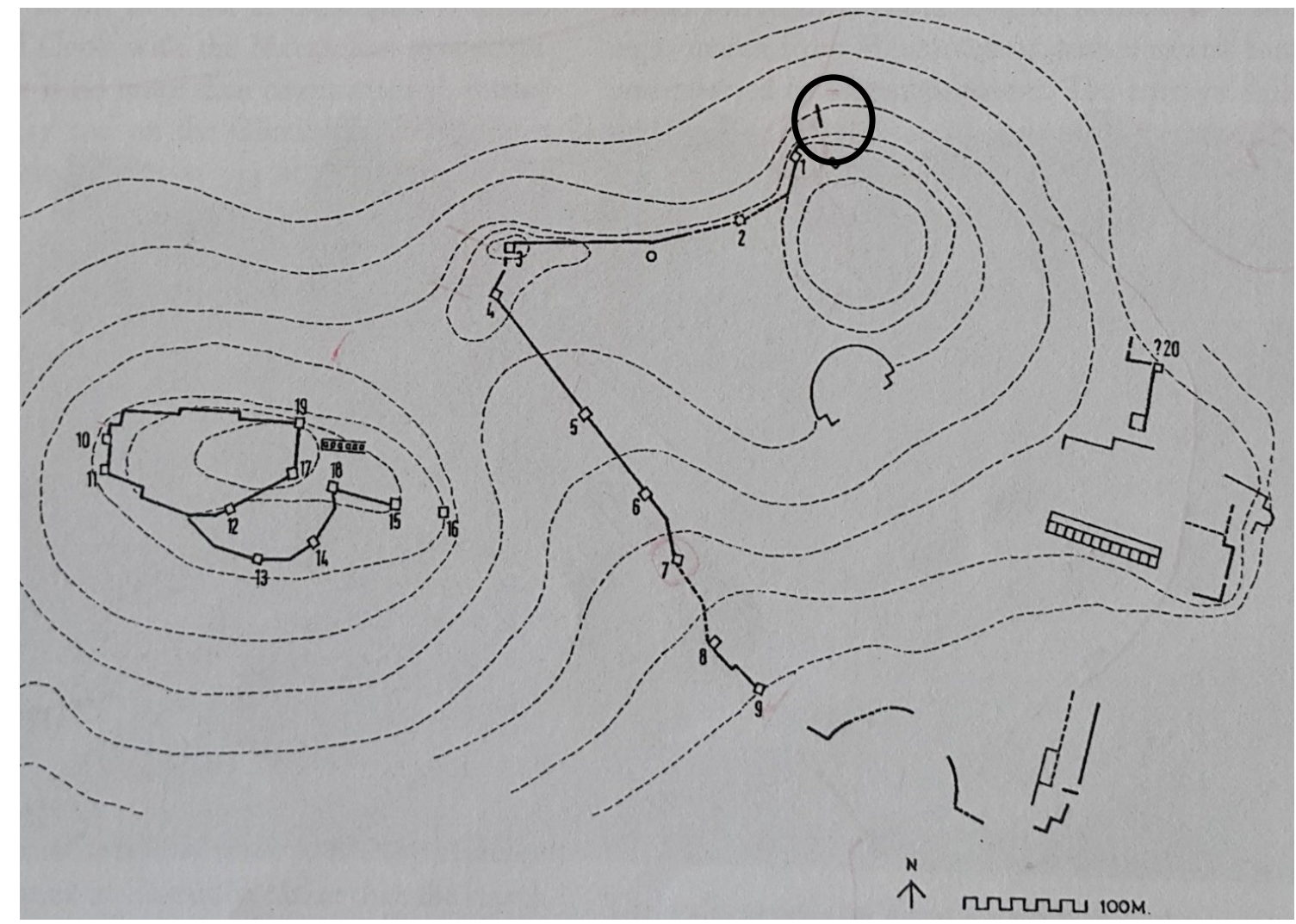

Figure 22. Alinda ancient city and the location of the case study tower (Source: McNicoll 1997, 27)

The case study tower was located at the east of the city. The tower, located on inclined topography, has three stories. The upper floor is approximately $6.25 \mathrm{~m}$., while ground storey's height show differences depending on inclined topography. Therefore, the mezzanine floor's position varies between $3.10-7.80 \mathrm{~m}$ from the ground. The total height of facades shows differences depending on their positions. The highest facade facing the plain is approximately $1405 \mathrm{~cm}$, while the shortest facade facing backyard is approximately $935 \mathrm{~cm}$. The tower is connected with city wall from the southwest and 
northeast facades. The floor coverage is approximately $47 \mathrm{~m}^{2}$. There are two entrances at the southwestern and southeastern facades. The southwestern entrance opens to the exterior of the city. Except southeastern facade, small sized openings $(100 \times 100 \mathrm{~cm})$ are positioned asymmetrically and symmetrically. On the southeastern facade, one symmetrical large $(172 \times 330 \mathrm{~cm})$ and two symmetrical small sized $(100 \times 100 \mathrm{~cm})$ openings are positioned. The large opening was probably the entrance of the upper floor. The upper floor may be accessed via wall walks that continue as timber floor projection (McNicoll 1997, 28-30). Position of timber beams can be observed from the facade.

The tower is constructed as isodomic masonry (emplecton) composed of headers and stretchers. Headers are about $30,33,50,65 \times 50 \times 120 \mathrm{~cm}$ in dimension, while stretchers are $100-150 \times 50 \times 50 \mathrm{~cm}$ in dimension. The length of only one stretcher on the southwestern wall reaches $590 \mathrm{~cm}$. Usage of such a long stone is rare for dry masonry tower technology. Staggering ratio is between 0.75 and 2 .

The masonry walls are composed of two outer leaves and a gap between leaves. The leaves are connected with header stones that do not touch each other and are distributed evenly. Area of headers in each wall are approximately $1.6-3 \%$ at the corners and $6-8 \%$ in the middle. However, on the southwestern facade, headers are just positioned in the middle (4\%).

Wall thicknesses present differences in accordance with their stories. At the ground story, wall thicknesses are about $115-140 \mathrm{~cm}$, while at the upper one, wall thicknesses may decrease to $90 \mathrm{~cm}$.

Headers are observed at the corners. The two neighboring walls, southeastern and northeastern walls have asymmetric corners, while the other neighboring walls have symmetric corners.

Wooden floor beams were probably positioned on thicker ground floor wall, while there are no traces about the direction of the beams. However, beams' holes (app. 30x30 $\mathrm{cm}$ ) are observed on the southeastern facade for to support the projection reaching the upper floor.

The tower has sustained its original morphologic and structural characteristics, except its timber floors and roof. Diagonal stepped cracks are observed above and below the openings. The diagonal cracks are seen at the lower part of the southeastern facade. Separation of upper blocks is observed due to the loss of the timber roof (Table 7). 


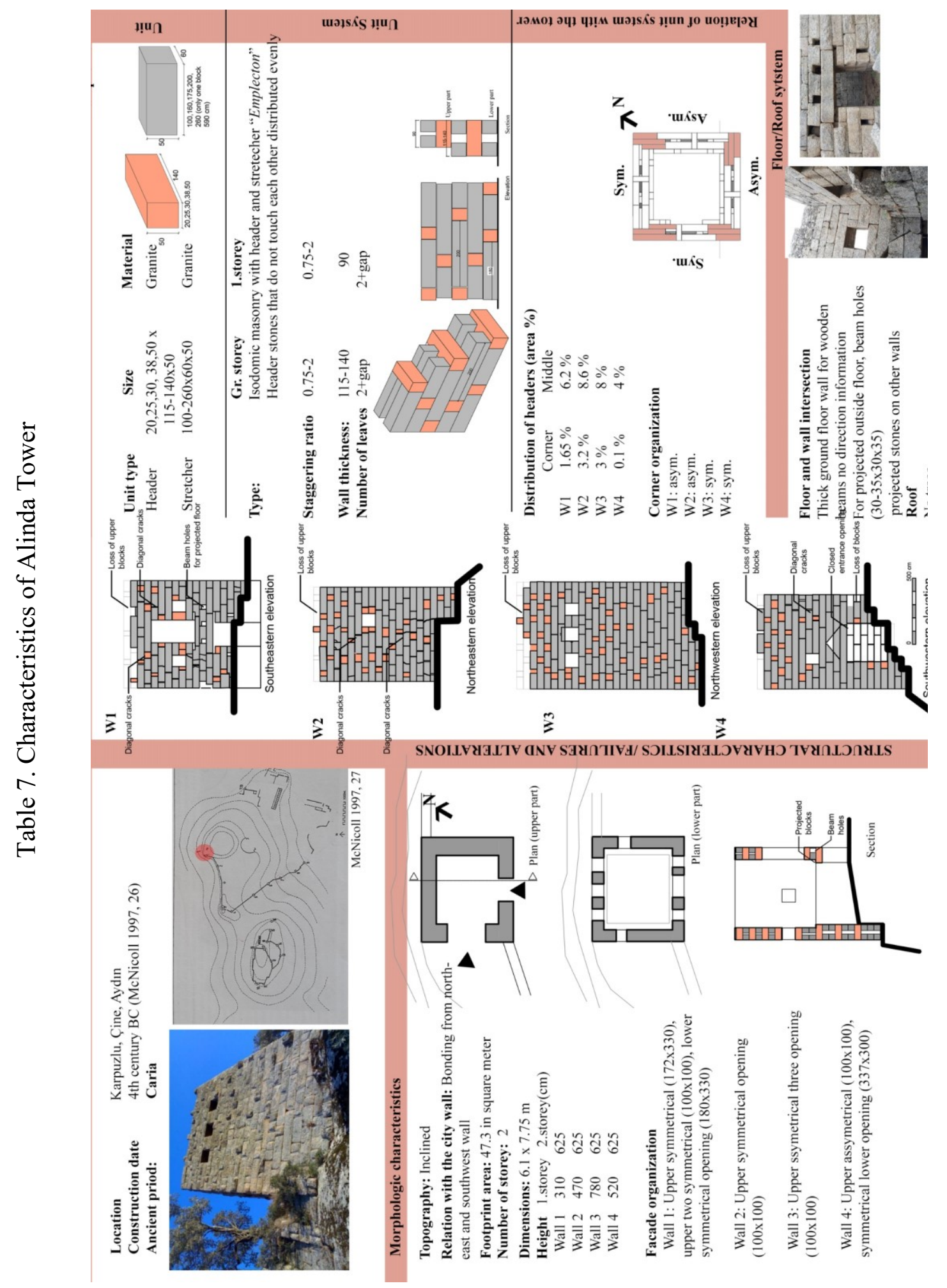




\subsection{Towers in Pamphylia}

Sillyon and Perge Towers in Pamphylia region are identified.

\subsubsection{Sillyon Tower}

Sillyon Tower is located in Sillyon Ancient City (1 BC, 1 AD), Pamphylia, southern Anatolia. It is on a $210 \mathrm{~m}$ high butte $28 \mathrm{~km}$ at the northeast of Antalya (Bryce 2009, 653).

Side, Aspendos, Sillyon, Perge, Magydos, Olbia and Phasalis were the seven cities that emerged in Pamphylia in the Archaic period (before 700 BC) (Figure 23). Two other cities were established in the Hellenistic Period: Attaleia, Korakesion. The first seven can be classified as four coastal (Side, Phasalis, Magydos and Olbia) and three inland (Sillyon, Perge and Aspendos) cities (Figure 24). The three inland cities were founded at the quarter century BC, after Phasalis (Grainger 1939, 4).

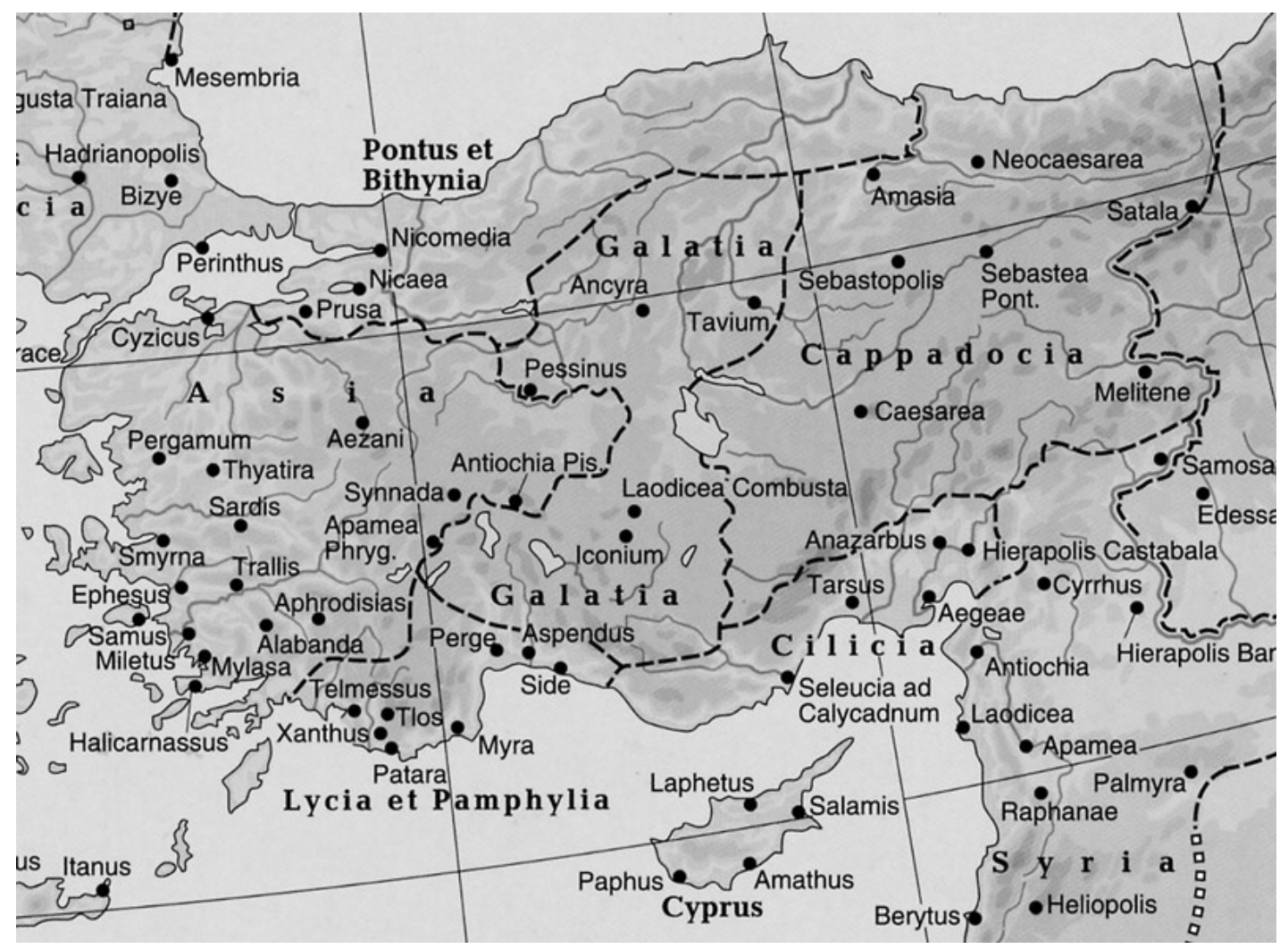

Figure 23. Location of Pamphylia Region (Source: Brandt and Kolb 2005) 


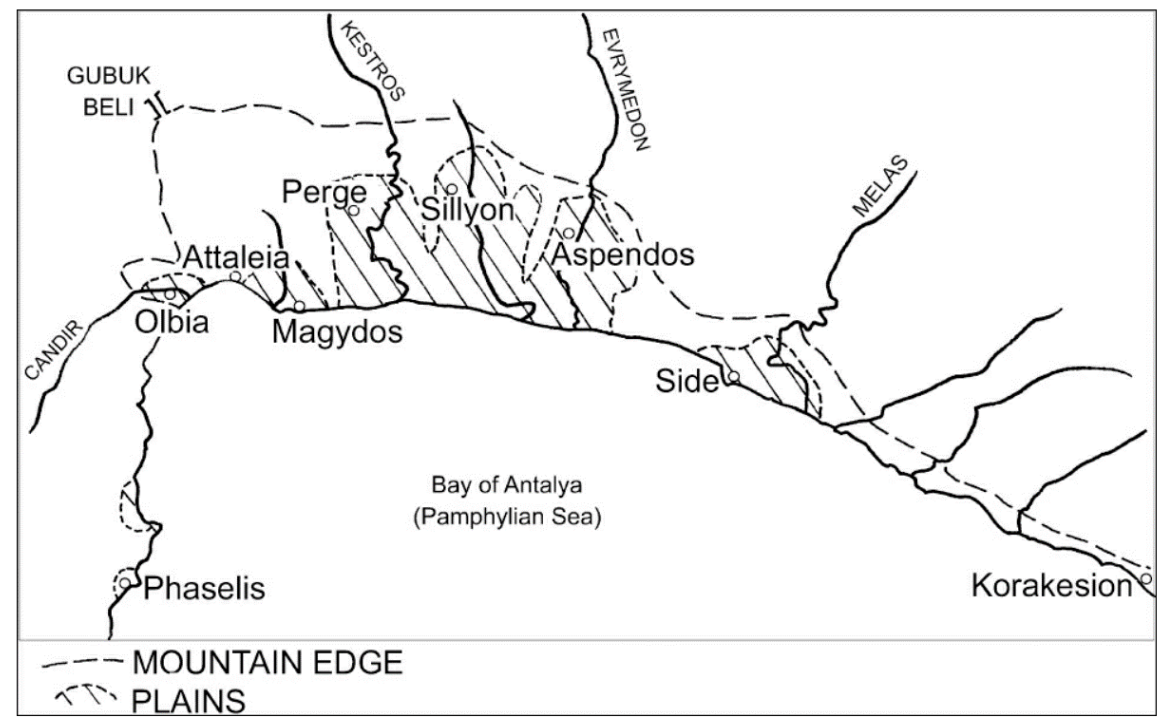

Figure 24. Cities of Pamphylia (Source: Grainger 1939, 4)

Sillyum is located near Asar Köy, 12 km at the north-east of Perge (Strabon 1991; McNicoll 1997, 136). It was one of the settlements in southern Anatolia whose foundation was associated with the legendary Mopsus, who was the founder of several Pamphylian towns (Bryce 2009, 522-523).

The recorded history of the city is limited. The city is mentioned for the first time in the Periplus of Pseudo-Scylax, an ancient Greek periplus describing the sea route around the Mediterranean and Black Sea (fourth century BCE) (McNicoll 1997, 136). After that time Alexander the Great' army came to the place, however, it failed to take the city due to the Barbarians and foreign mercenaries (Arrian 1884, 72). Sillyum and Termessus in Pisidia are famous as the only cities in the southern Asia Minor which managed to stand out against the Macedonian forces. According to Arrian, Alexander found a Persian garrison during his occupation of Sillyon in 334 BC (1884). That is direct written evidence for Persian involvement in Pamphylia (Grainger 1939, 3). The city was reconstructed under the Seleucids. In later times, when most of western Asia Minor was under Kingdom of Pergamon, Sillyon remained as a free city by a decision of the Roman Senate (Gernot 2003, 439-443).

Sillyon is comprised of two parts; the upper sill and the lower ground. Most of the ruins are found in the sill. Lower ground was developed later. Over the years, the settlement expanded to the southeast, partly due to the need of its inhabitants to be close to their farms in the plain. During the Imperial period, the area was strengthened with a new fortification (McNicoll 1997, 137; Sielhorst 2011, 31-46). A two-storied defensive 
tower with six windows has survived intact (McNicoll 1997, 139). Sillyon's remains include city walls, a city gate, a temple, a theater, an odeum, simple rectangular tombs and domestic architecture. In Sillyon, city walls were composed of a number of towers such as gate towers and bastion towers (Özer and Taşkıran 2012, 204). However, most of the towers were demolished. The case study tower has sustained its authenticity and integrity (Figure 26). It is located at a less inclined topography at the west of the city.

The nearly squared planned $(6.8 \times 5.75 \mathrm{~m})$ tower was constructed as an isodomic masonry structure at its ground floor and pseudoisodomic masonry at its upper floors. The tower is approximately 3.9 square meters. It has two stories in addition to the ground floor. The height of the tower is approximately $10.25 \mathrm{~m}$ (Figure 26).

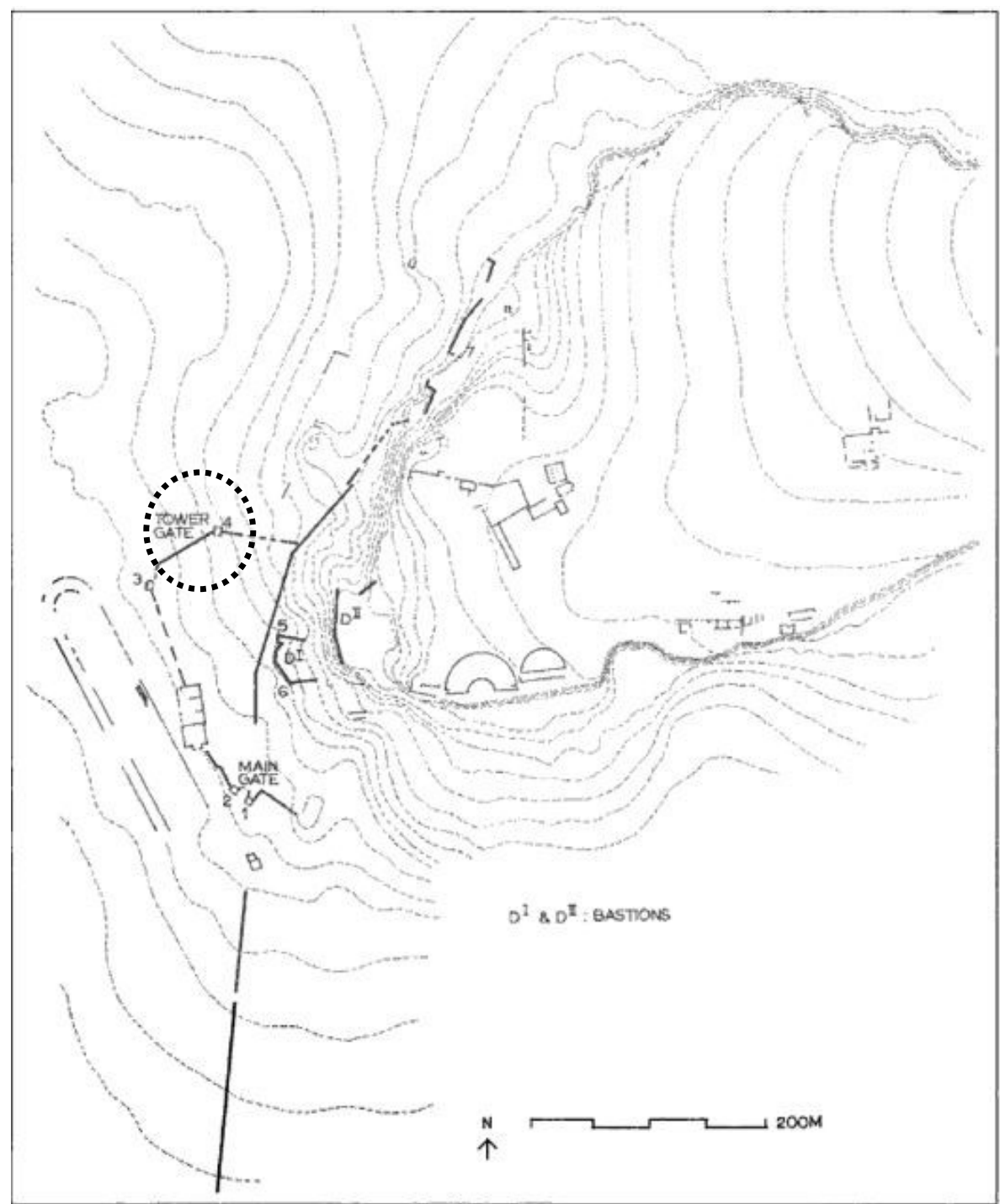

Figure 25. Location of Sillyon Tower (Source: McNicoll 1997, 138) 


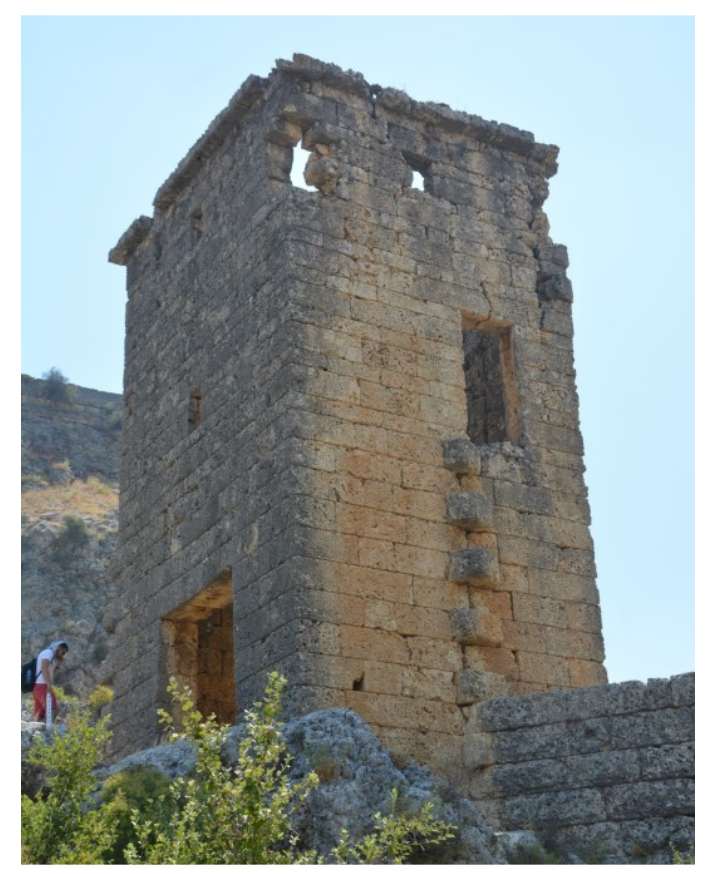

Figure 26. Sillyon Tower, northern and western facade

The city wall is perpendicular to the tower's east and west facades. There are two entrances at the north and south facades. The wall walks of the city wall continue throughout the tower. The tower's ground floor is a gate with a flat arched entrance at the north facade and a semicircular arched entrance at the south facade. On each facade, at the last story, there is a symmetrical opening $(50 \times 75 \mathrm{~cm})$, while in the middle story, dimension and location of the openings present differences. On the southern and northern facades, small sized symmetrical openings $(50 \times 75)$ are positioned, while on the eastern $(105 \times 217 \mathrm{~cm})$ and western facades $(105 \times 300 \mathrm{~cm})$, size of the openings are relatively larger, and openings' positions are asymmetrical. The opening on the western facade is adjacent to the corner.

The masonry system is examined from unit to building whole. Ground story is composed of rectangular blocks that have uniform dimensions $(100-120 \times 50 \times 75 \mathrm{~cm})$, at the upper stories except the mentioned rectangular blocks, shorter adjacent row stone

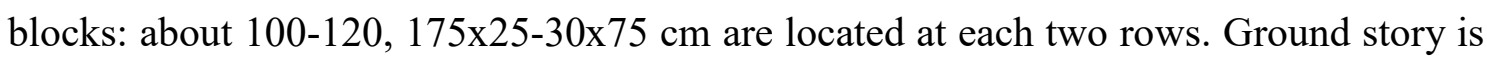
isodomic masonry, while upper two stories are constructed as pseudoisodomic masonry. Squat blocks are located in each sequential course. Approximately 25-30\% of each wall are composed of squat stone blocks. Depending on the organization of blocks, staggering ratio at the lower (0.6-1) and upper-parts (1.5-2) present differences. With the help of the squat blocks, the staggering ratio at the upper part is approximately 1.75 . The thickness 
of the walls is equal to the depth of the stone blocks $(75 \mathrm{~cm})$, thus wall profile is composed of one leaf (Table 8).

When corner organizations of walls are examined, two neighboring walls, south and west wall have asymmetric corners, while the other neighboring walls (north and east) have symmetric corners.

The lost wooden floor system was probably composed of beams (app. 15$20 \times 15 \times 20 \mathrm{~cm})$. Beam holes of each story are observed at the inner walls. According to beam holes, the direction of beams is from east and west, along the long side.

The tower has sustained its original morphologic and structural characteristic, except wooden floors. There is no trace of gabling at the roof. The most problematic structural failure is vertical cracks observed in all of the facades. Also, diagonal stepped cracks are observed at the top and bottom portions of the upper and middle openings.

\subsubsection{Perge Tower}

The tower is located in Perge ancient city, two kilometers at the north of Aksu Village, Antalya. Perge, which was one of the inland cities of Pamphylia, on the south west of Sillyon and west of the Aksu Çay (Cestrus). According to Strabon, Perge was established by colonists from Argos (Pekman 1989, 5-6). Also, the name of "Perge" and "Kestros" were recorded in an inscription found around Boğazköy and dated to $13^{\text {th }} \mathrm{BC}$. In addition to this document, archaeological remains date to the late Chalcolithic and early Bronze age (Pekman 1989, 5-6; Abbasoğlu 2007, 21-22).

In the 7th century BC, Greek colonies and local people settled (Abbasoğlu 2001, 1). Perge became a Hellenistic city in the $4^{\text {th }}$ century BC. The city developed from the hillskirts of the acropolis towards the plain area (Abbasoğlu 2001, 1). The city walls were probably constructed in $4^{\text {th }}$ century BC in Hellenistic Period. In $333 \mathrm{BC}$, the city was conquered by Alexander the Great without any resistance (Arrian 1884, 26; Pekman 1973, 18-19). In $100 \mathrm{BC}$, the city became a part of Cilicia. In the $2^{\text {nd }} \mathrm{AD}$, the city lived its most brilliant period (Abbasoğlu 2000, 44).

The city is composed of three parts: the Acropolis at the north; the Lower City, which was surrounded by early Hellenistic Fortifications; and the Southern Extension, a part of which was also fortified with a wall in a later period (Akarca1987, 81) (Figure 27). 


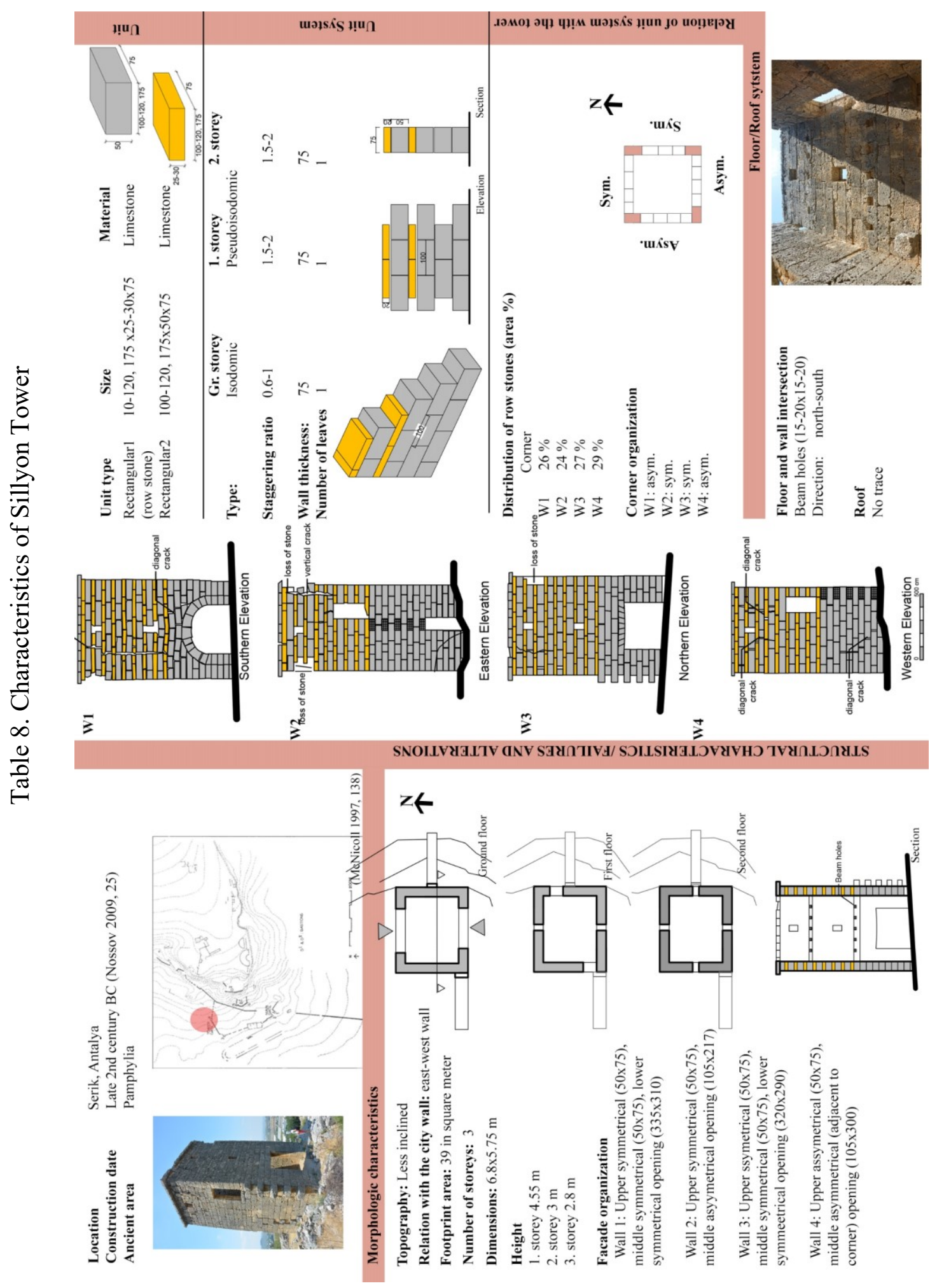




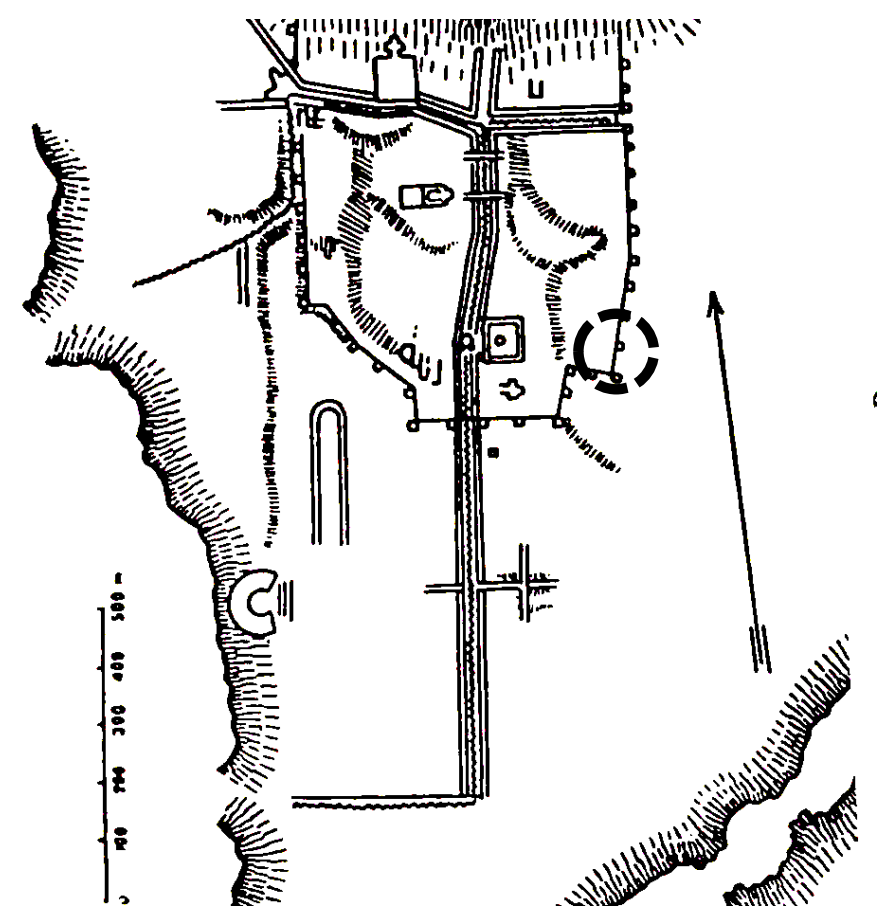

Figure 27. Perge ancient city and location of the case study tower (Source: Akarca 1998, 81)

The Acropolis was established at the northern portion of the hill and was served by an ancient road leading to the Attalia direction. Spreading over the valley beneath the hill, the Lower City is laid out in a grid-iron pattern (Akarca 1987, 81). The borders of the lower city are marked with the remains of a Hellenistic Fortification and the city itself identified a residential area and a number of social constructions, including a bath, palestra, agora and a well-developed water system with a Nymphaeum and channels. The third part of city is a later-period southern extension to the lower city and is composed of two parts: part one was fortified with a later period addition to the old fortifications, while part two was not fortified. The additional fortifications enclose the Basilica, the Southern Bath and the Agora inside the city, while important structures like the stadium and the theatre are placed outside.

The Hellenistic towers of Perge project out of the city walls (McNicoll 2014, 128). The case study tower is one of the towers bonded to the older wall at the east of the city. The wall walks run behind it. However, all of the towers were demolished or had lost their integrity. Old photographs give data about the integrity of the towers (Figure 28). The case study tower, located on a plane ground, has three storeys with the ground storey. 
Square planned tower, constructed as an isodomic masonry, is approximately 46 square meters. The height of the tower is approximately $13.7 \mathrm{~m}$.

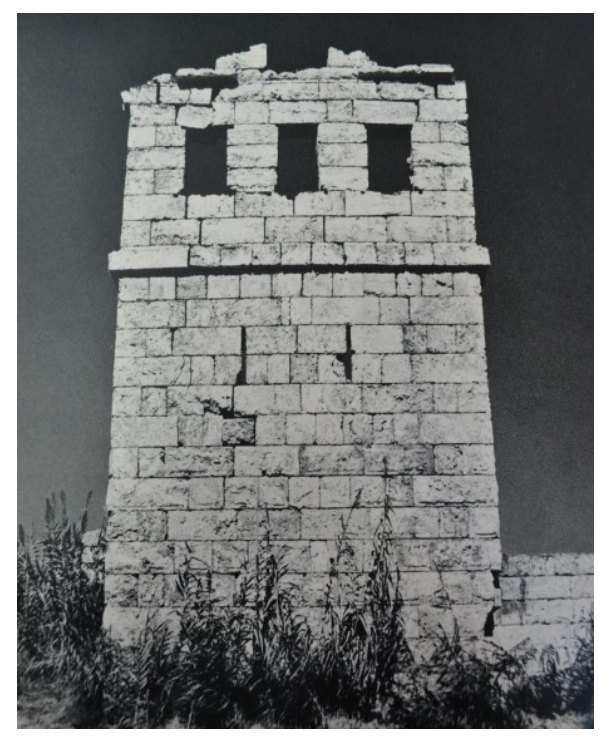

Figure 28. Old photograph of Perge Tower (Source: Martin 1967, 33)

The city wall is bonded to the tower from its north and south. The entrance is located at the inner side of the city walls on the western facade. At the middle stories, there are slits facing the north and south directions and two slits facing the east of the city. At upper story, there are three symmetrical openings (90x150 cm).

Ground and first stories' walls are constructed with stretchers (100-120x50x60 $\mathrm{cm})$ and header blocks (60x50x120 cm), however, upper walls are composed of just stone blocks: 100-120x50x60 cm in dimension. Ground and first story walls are constructed with adjacent header stones lying along the wall depth in each sequential course, while header blocks are not used at the top floor. Depending on the usage of header stones, staggering ratio changed at the upper and lower stories. Staggering ratio at the upper story is between 0.6 and 1, while ratio is 0.3 at the lower two stories. Approximately $25 \%$ of each wall is composed of header stones at two lower stories.

The thickness of the walls at the lower two stories are equal to the depth of the header blocks: $120 \mathrm{~cm}$. Lower stories are composed of two outer leaves without a gap. Upper wall is composed of one leaf: $60 \mathrm{~cm}$.

When walls are examined in terms of corner intersections, all walls have mirror symmetrical corner organization due to their masonry technique. 
The lost wooden beams of the floors were located at the thicker lower walls from north to south direction, however, traces are insufficient for determining the dimension of the beams.

Except its eastern wall, all the other walls were demolished. Upper parts of the north and south walls were separated in form of diagonal steps. Upper part of the western facade had totally collapsed (Table 9).

\subsection{Towers in Cilicia}

Gömeç and Sarayın Tower located in Cilicia Region are identified.

\subsubsection{Gömeç Tower}

The case study watchtower is located in the district of Erdemli in Mersin province, about three kilometres at the north of Kizkalesi and 20 kilometres at the southwest of Erdemli. There are a number of towers in the area. The older tower of Gücük is about 200 $\mathrm{m}$ away from the case study. Sarayın Tower is two kilometres southeast, and Akkum Tower is three kilometers southwest of the Gömeç Tower (Durugönül 1998, 12) (Figure 29, Figure 30).

The tower is located in Rough Cilicia. There is limited information on Rough Cilicia in the $10^{\text {th }}$ and $20^{\text {th }}$ century BC. According to remains, Rough Cilicia might have been located in the borders of Tarhundaşşa Kingdom or Hittite Empire. In $10^{\text {th }}$ century $\mathrm{BC}$, this area had been probably within the boundaries of Assyria. The area was named as "Hilakku" (Zoroğlu 1994, 440). In 612 BC, Assyrian administration was terminated (Sevin 1984, 286). Colonies were established in the area (Mansel 1970, 169). Then, the region "Pirundu" until the border of Gazipaşa at the west was taken under the rule of Babylon (Zoroğlu 1994), 440. After that, the area was taken under the rule of Persians (547-400 BC), Macedonian Empire (333 BC) and Seleucids. Towards the end of the $2^{\text {th }}$ century BC, piracy and slave trade were prevalent. In this period, the watchtowers were constructed in the area for security. Romans fought against pirates, then in $67 \mathrm{BC}$, Romans took the control of the area over (Koşay 1968, 298). During the period of Seleucids and Roman Empire, the watchtowers had been probably constructed in the area for security. 


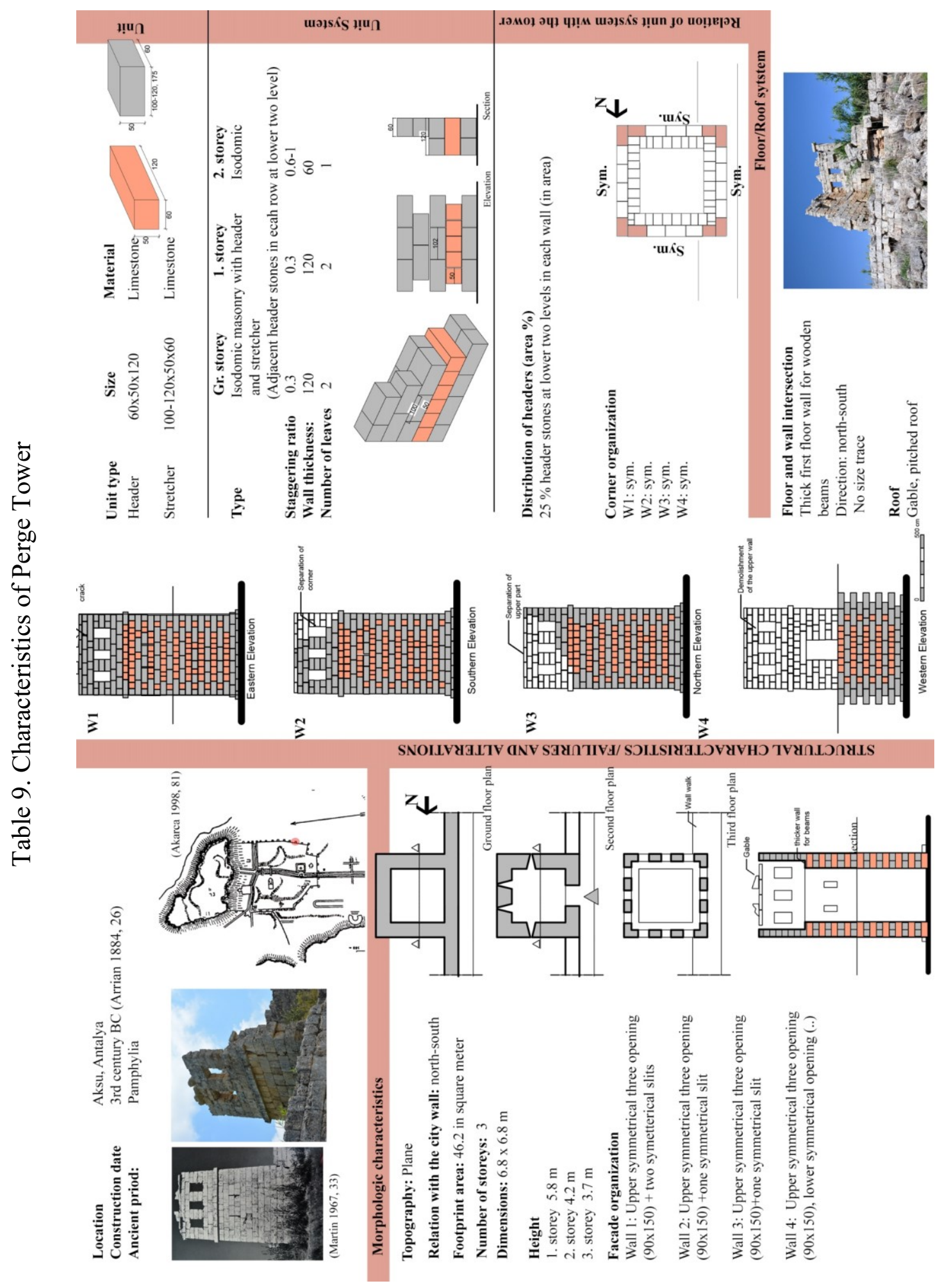




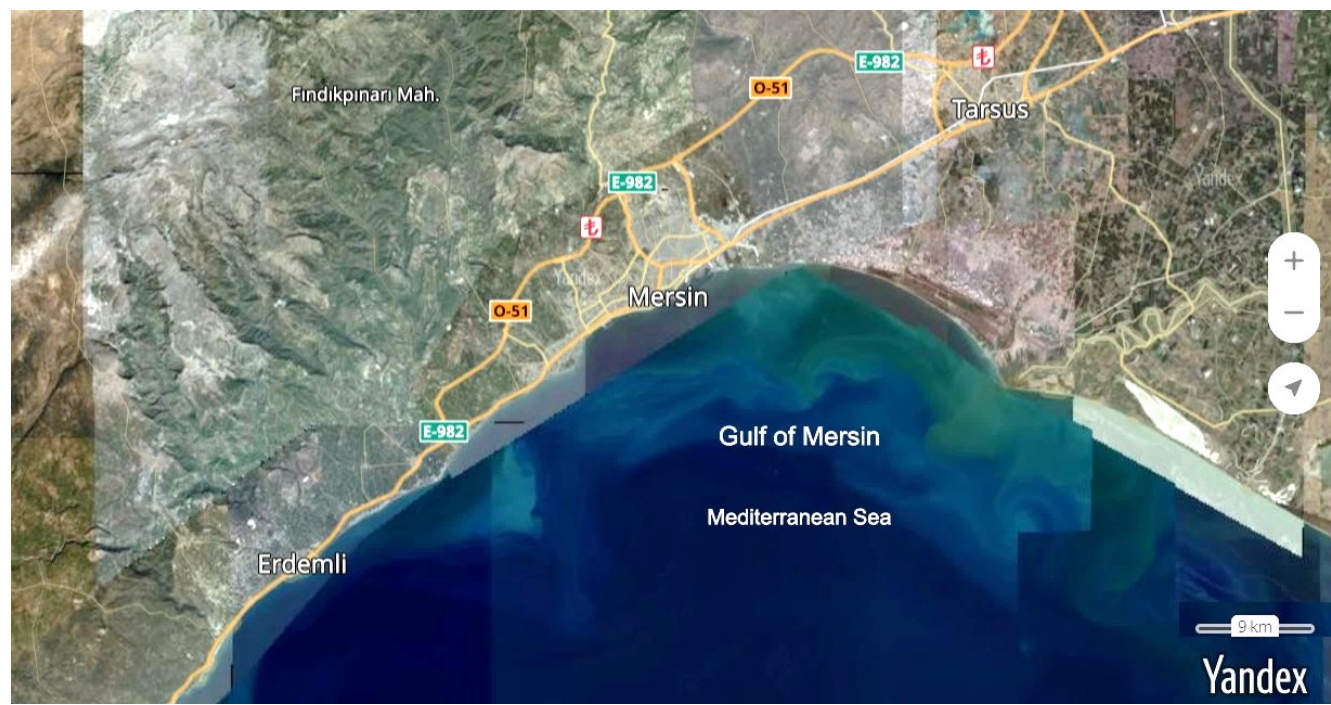

Figure 29. Location of towers (Source: YandexMaps 2018)

In Rough Cilicia, particularly in the area between the river Kalykadnos (modern Göksu) and the Lamos (modern Limonlu), there are many Late Hellenistic and Roman towers. Some of these were free-standing, some were parts of fortresses. There are five free-standing towers in the isodomic style (Akkum, Boyan, Gömeç, Sarayın and Yalama). They were probably built between the end of Seleucid rule in $133 \mathrm{BC}$, the defeat of the pirates by Pompey in 65 BC (Durugönül 1998, 94-96; Kaplan 2014, 72).

The studied tower was located on the ancient Roman road from Korykos to OlbaDiocasearea. It is known that it was built for guarding pirate activities along the coast of Korykos. It also knows that these towers were also used for storing grain (MitfordAndrews 1980, 1247). The squared planned $(4.75 \times 4.75 \mathrm{~m})$ tower is constructed isodomic masonry. The tower is approximately 22.6 square meters. It has four storeys with ground storey. Beam holes in each storey are observed at the inner walls. The height of the tower is approximately 10.86 meters. City wall remains have not been observed around the tower. There is an asymmetrical entrance $(100 \times 180 \mathrm{~cm})$, and small $(100 \times 100 \mathrm{~cm})$ openings in the middle and upper storeys of the western facade. However, the openings in the middle were closed by cut stone blocks. There are small sized openings (100x100 $\mathrm{cm}$ ), which have been closed later, at the upper stories of the northern and southern facades (Figure 31). 


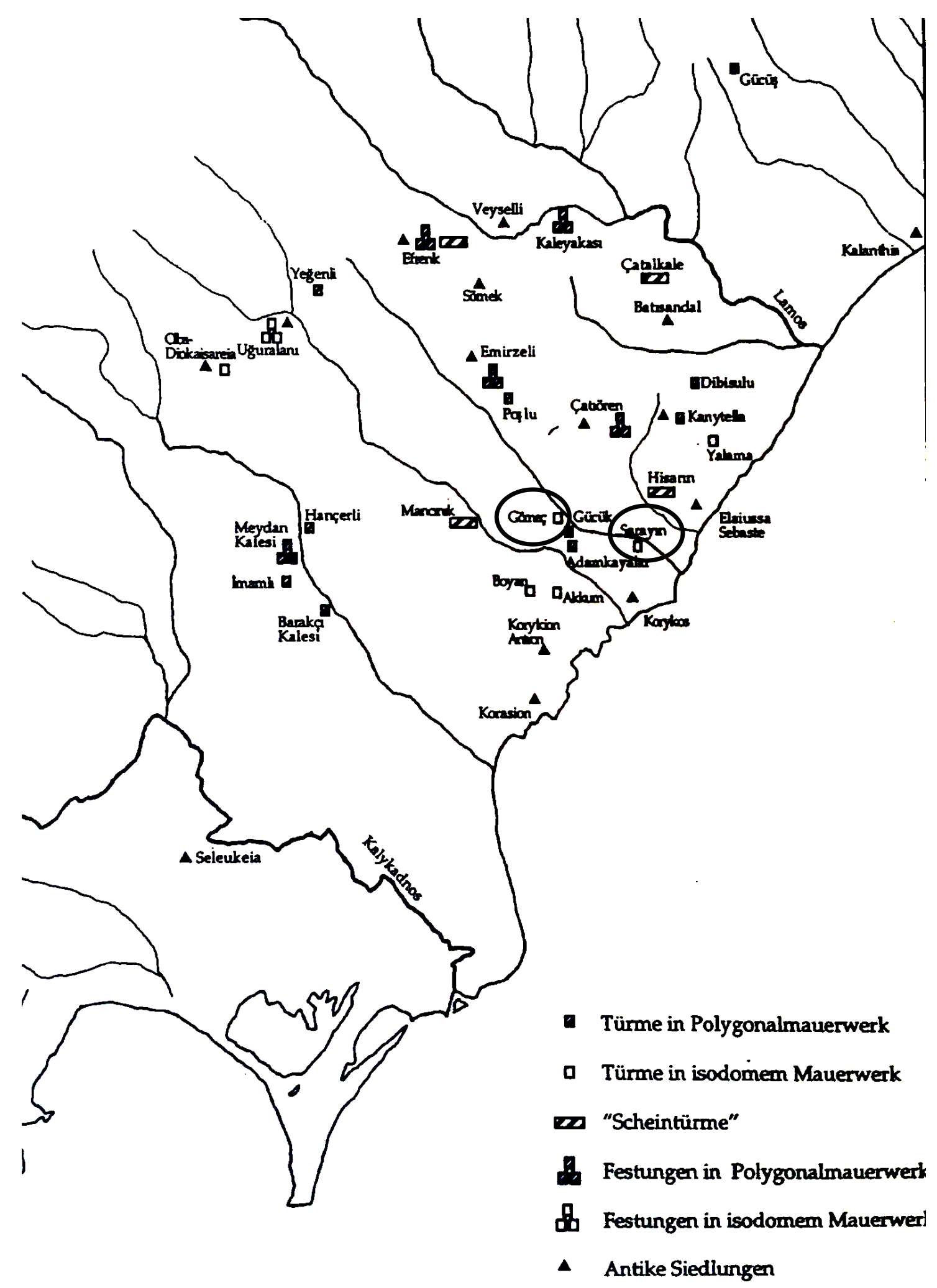

Figure 30. Location of towers in Cilicia (Source: Durugönül 1998, 12) 


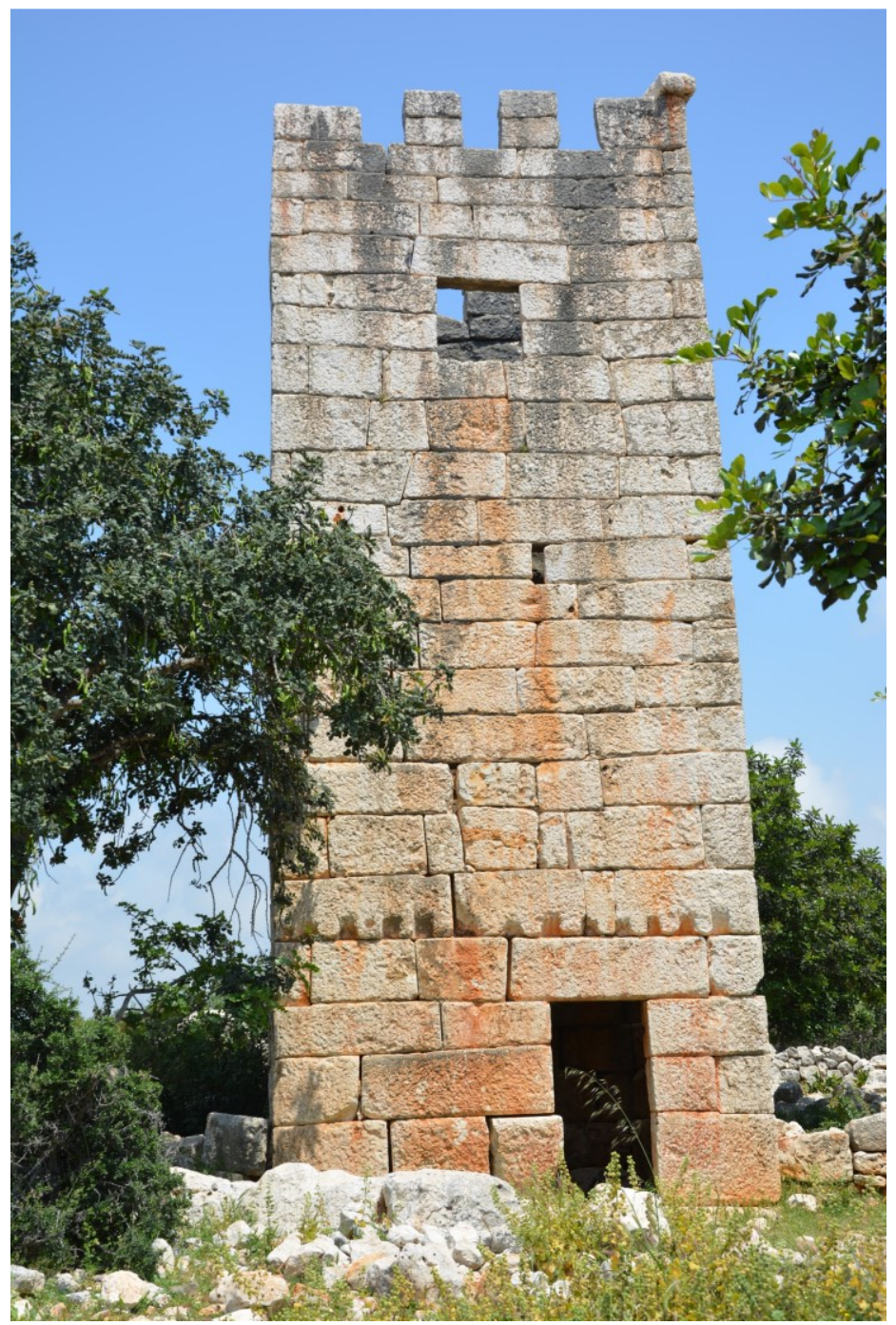

Figure 31. Gömeç Tower, western facade

The masonry system is examined from unit to all building. The masonry system is composed of rectangular blocks $(75-100 \times 50 \times 60 \mathrm{~cm})$ and trapezoidal blocks (35100x50x60 cm). Trapezoidal blocks are distributed randomly between the rectangular blocks. Staggering ratio changes between 0.2 and 0.6. Upper and lower courses' joints are overlapped randomly. Joints are not always at the same line due to high stone blocks. The thickness of the wall is equal to depth of the stone blocks $(60 \mathrm{~cm})$, thus wall profile is composed of a single leaf.

The number of trapezoidal joints is between 2 and 8 at the western, eastern and southern walls, while 20 joints are observed at the northern wall.

When corner organizations of walls are examined, two neighboring walls, north and west walls have asymmetric corners; while the other neighboring walls (south and east) have symmetric corners. 
Floor system of the tower is examined with the help of the beam holes (15-20x15$20 \mathrm{~cm}$ ). The direction of the beams changes in each story level; beams are located from east to west direction at the first and third stories, while beams are located from north to south direction at the second story. According to finishing blocks of the tower, the roof seems to be designed as a terrace.

The tower has sustained its integrity except timber floors and roof. However, some openings have been filled in with cut and rubble stones, and joints were filled with mortar in some places. The main structural problem is erosion of sides of rectangular blocks and this causes formation of wide joints between the blocks (Table 10).

\subsubsection{Sarayın Tower}

The tower is located in the Erdemli district of Mersin, Turkey about three kilometers northeast of Kızkalesi, two kilometers west of Ayaş. It is located at the east of the road, which leads to the north on the outskirts of Kizkalesi, the ancient Korykos along the eastern side of the valley Şeytan Deresi. The tower is located about two kilometers northwest of Gömeç tower. Sarayın is one of the watchtowers that had been constructed against pirates in Seleucid and Roman periods between 133 BC and 65 BC (Durugönül 1998, 54-78).

The approximately squared planned $(5.9 \times 5.8 \mathrm{~m})$ tower is constructed as isodomic masonry. It is approximately 34 square meters. It has four stories including the ground story. Projected stone blocks are observed at the inner walls at each story level. The height of the tower is approximately 10.86 meters. No city wall remains are observed around the tower. There is an asymmetrical entrance adjacent to corner $(150 \times 200 \mathrm{~cm})$, a small asymmetrical opening $(100 \times 100 \mathrm{~cm})$ in the middle, and a small symmetrical opening at the upper story of the western facade. There are small sized $(100 \times 100 \mathrm{~cm})$ symmetrical openings, which are filled in, on other facade walls.

The masonry system is composed of rectangular blocks (65-100x 50x 25,30,35,60 $\mathrm{cm})$. Staggering ratio changes between 0.5 and 0.8 . Upper and lower course joints overlap randomly in some places. The wall thickness of the ground floor is $75 \mathrm{~cm}$, while the thickness of upper floors is $60 \mathrm{~cm}$. Each opposite wall (north-south) have asymmetrical corners, while the other two walls have symmetrical corner organizations. 


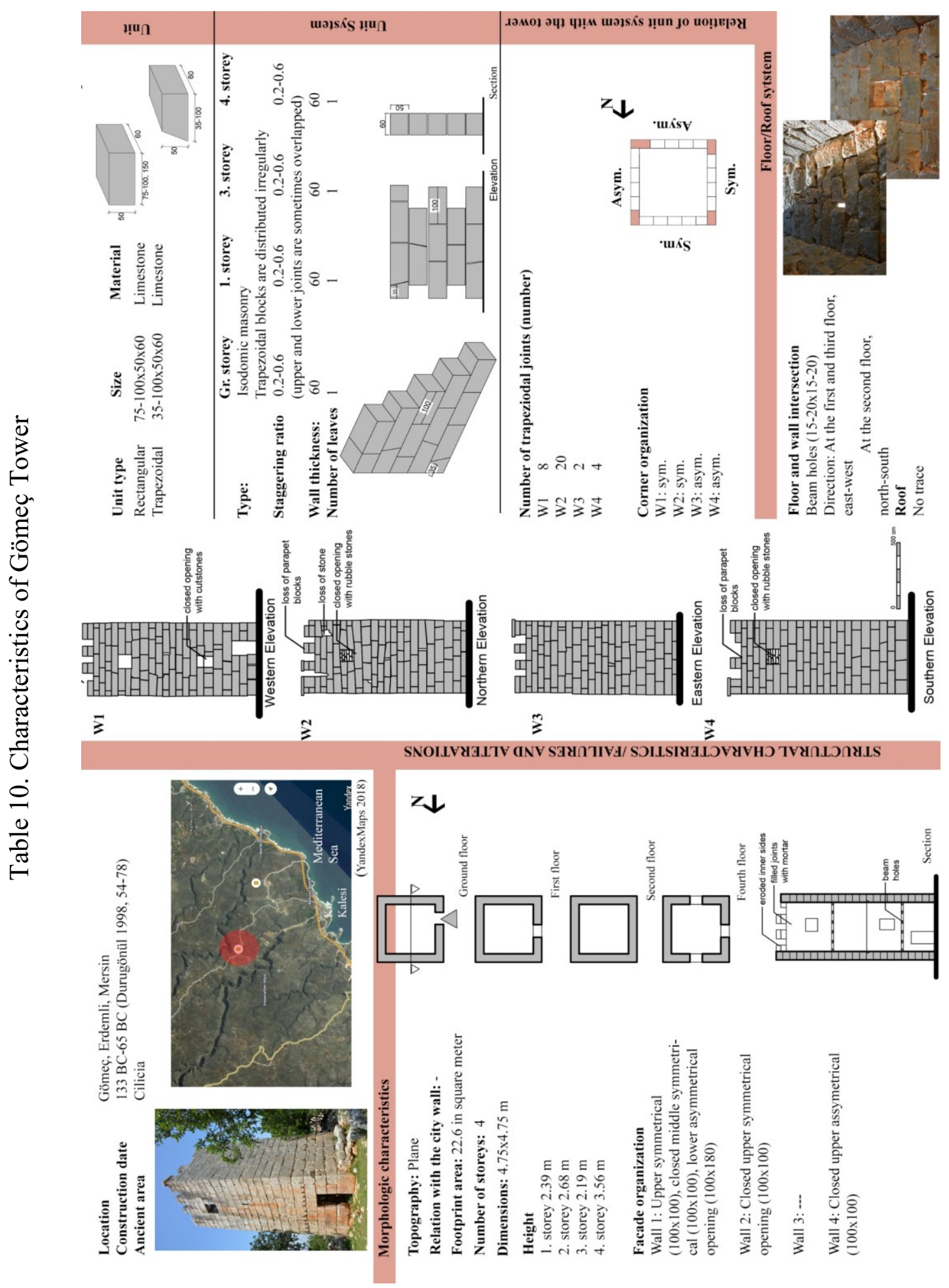


Floor system can be examined with the help of the projected stone blocks at each story. Projected story levels from north to south direction are observed at the second and third floors. At the first floor, beams are positioned on the thicker ground floor wall. There are no traces regarding dimensions and number of wooden beams. According to finishing blocks of the tower, the roof seems to be designed without roof (Table 11).

The tower has sustained its integrity except its timber floors. However, some openings are filled with cut and rubble stones, and inner joints were filled with mortar in some places. The main structural problem is erosion of sides of rectangular blocks and this causes formation of wide joints between the blocks (Figure 32).

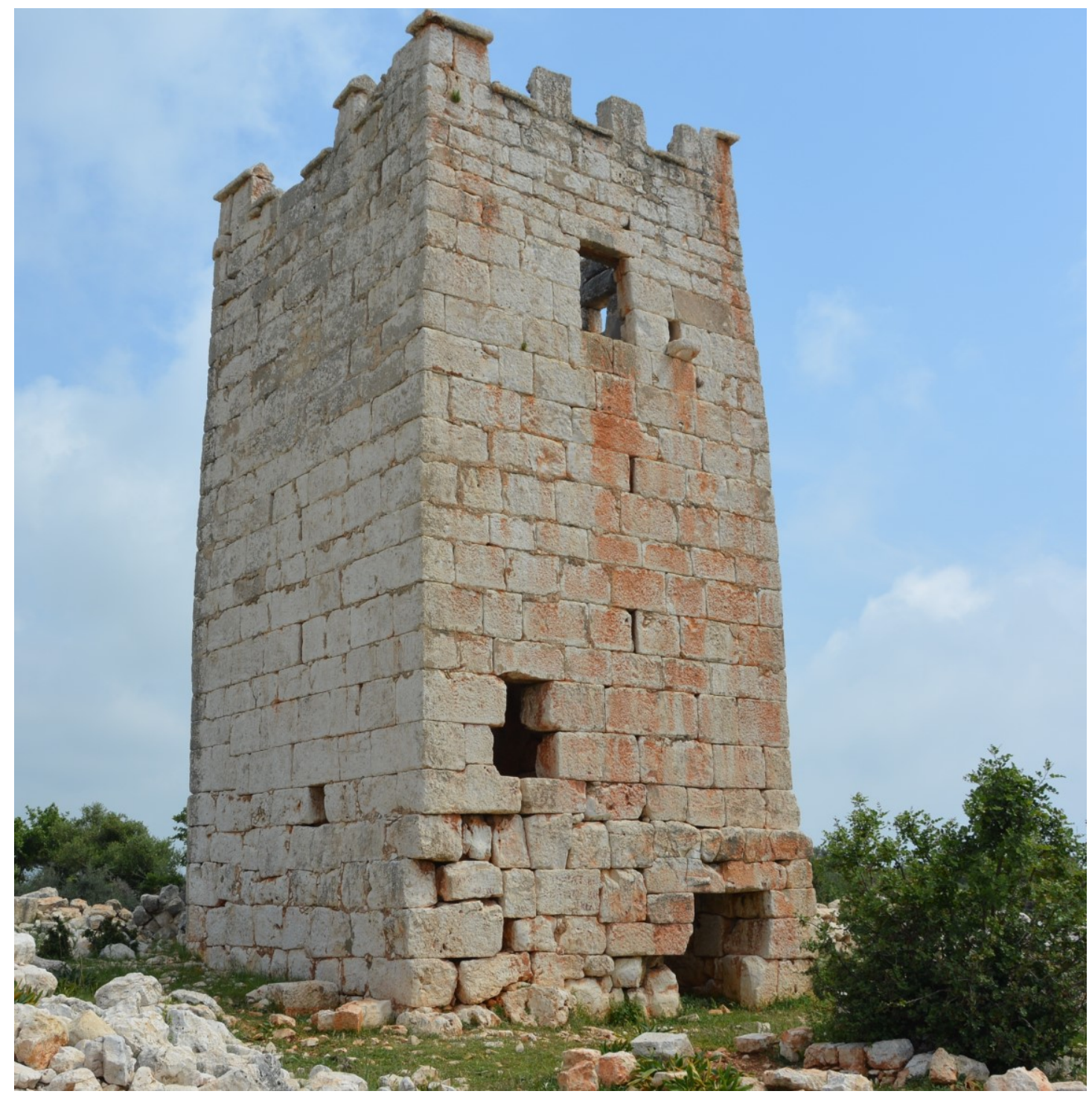

Figure 32. Sarayın Tower 


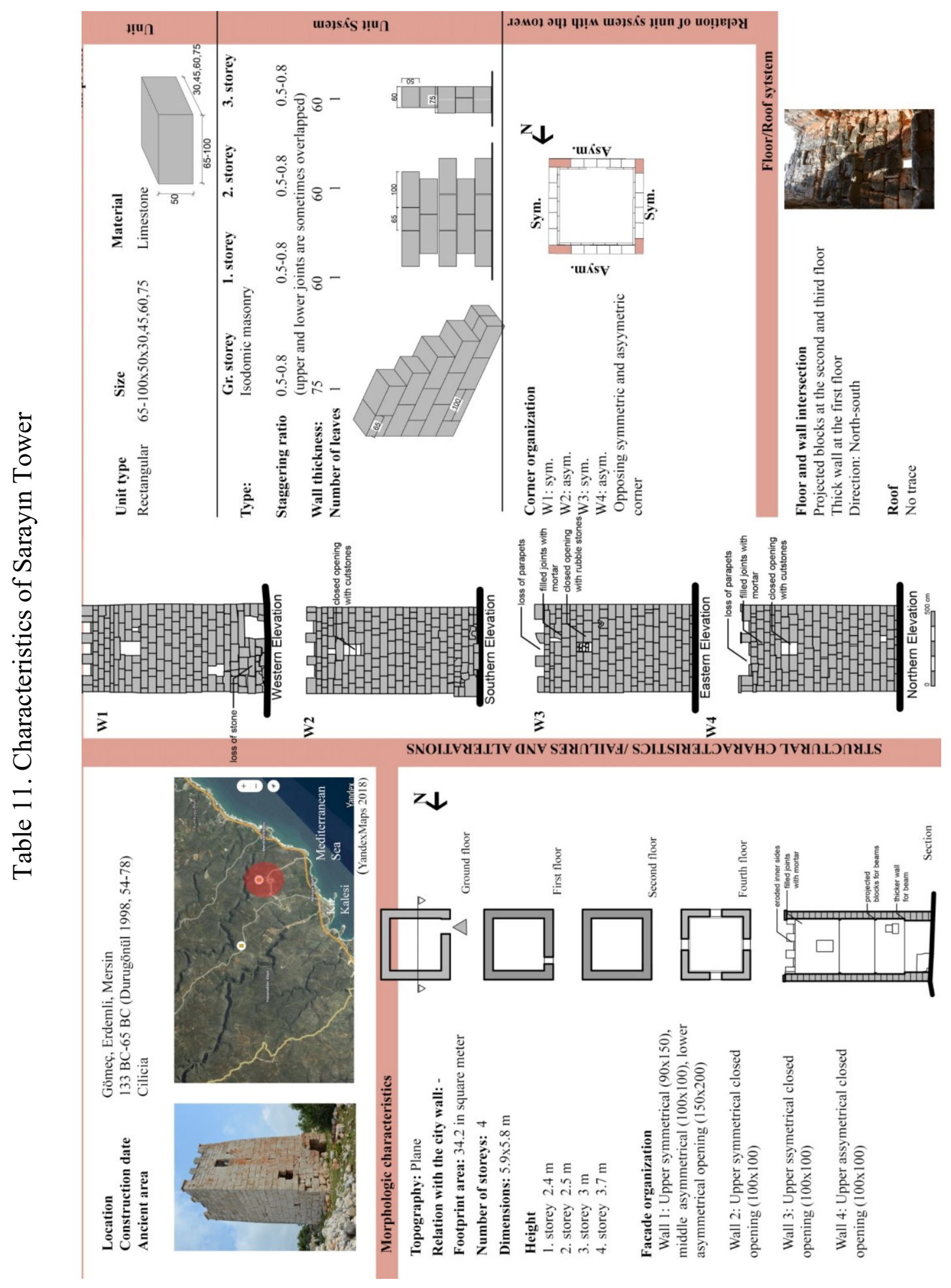




\section{CHAPTER 3}

\section{IMPACT ANALYSIS OF CHARACTERISTICS}

To analyze impact of characteristics of dry masonry ancient towers on their structural resistance and behavior, a hypothetical process is designed. First, types of structural, morphologic and material characteristics of towers are identified based on data gathered through documentation. Then, hypothetic towers are designed by combining these characteristics' types with each other to analyze how they affect the resistance of the structure in different combinations. After analysis of hypothetic towers, results of simulation are examined by grouping types.

\subsection{Design of Hypothetic Towers}

Design phase is composed of two parts; determination of characteristics' types and combination of these types.

\subsubsection{Determination of characteristic types}

Structural characteristics of towers vary in accordance with wall profiles composed of different dimensions, forms and organizations of blocks. Towers with stone blocks out of granite or limestone are possible. Dimension, number and position of an opening; proportional relationship between height and length of a tower, and flat or inclined ground topography are the possibilities of morphologic characteristics. Thus, all these possibilities are considered in the design hypothetic towers.

\subsubsection{Wall profile types}

Wall profiles show differences in terms of wall thickness, number of leaves, connection of leaves and corners, organization, size and form of stone blocks (Figure 33). 6 wall profiles are determined. 
- Wall profile 1 represents the wall profile of Gömeç Tower. It has a single-leaf with a thickness of $60 \mathrm{~cm}$. Trapezoidal blocks are placed irregularly between rectangular blocks. The length of the stone blocks varies between 36 and $150 \mathrm{~cm}$, but stone blocks with a length of $75 \mathrm{~cm}$ are predominant. On each facade, there are one or two stone blocks approximately $150 \mathrm{~cm}$ long. The height of the blocks is $50 \mathrm{~cm}$ and the thickness is about $60 \mathrm{~cm}$. Corner organizations are composed of two symmetric and two asymmetrical connections. The staggering ratio of stone blocks $(\mathrm{s} / \mathrm{h})$ is generally small; it ranges between 0.2 and 0.6. Stone blocks where the joints overlap, and the staggering ratio is zero are also seen.

- Wall profile 2 represents the wall profile of Sarayın Tower. The wall varies in number of leaves and thickness after 3 meters. The wall thickness is $75 \mathrm{~cm}$ at lower elevations and $60 \mathrm{~cm}$ at upper elevations. The lower part is double-leafed, and the upper part is single-leafed. There is no connection element between the walls. The length of the stone blocks varies between 65 and $100 \mathrm{~cm}$. The height of the blocks varies between 35 and $60 \mathrm{~cm}$. The staggering ratio $(\mathrm{s} / \mathrm{h})$ of the stone blocks varies between 0.5 and 0.8 .

-Wall profile 3 represents the wall profile of Perge Tower. The number of leaves, wall thickness and block organization change after 7 meters from the bottom. Wall thickness is $120 \mathrm{~cm}$ at lower levels and $60 \mathrm{~cm}$ at upper levels. In the lower part, doubleleafed and two adjacent rows of header stones are arranged. The upper part is single leaf and there is no header stone. The length of the stone blocks varies between $100-120 \mathrm{~cm}$ and the length of the header stones used at the bottom is $60 \mathrm{~cm}$. The height of the blocks is $50 \mathrm{~cm}$ and their thicknesses are $60 \mathrm{~cm}$. The staggering ratio $(\mathrm{s} / \mathrm{h})$ of the stone blocks is about 0.3 at the ground and first stories due to the usage of header stones adjacent to each other and between 0.6 and 1 at the second story.

- Wall profile 4; represents the wall profile of the Sillyon Tower. The wall profile is a single-leafed masonry system with a wall thickness of $75 \mathrm{~cm}$. The organization of stone blocks changes after about 5-6 m. The lower levels are made of stone blocks with a height of $50 \mathrm{~cm}$, while the upper elevations consist of a row of cut stone blocks of 25 $30 \mathrm{~cm}$ in height. The length of the stone blocks varies between 100-120 cm. While the staggering ratio $(\mathrm{s} / \mathrm{h})$ varies between 1.5 and 2 at the first and second stories, the staggering ratio at the ground story is between 0.6 and 1 .

-Wall profiles 5 and 6 have $115-130 \mathrm{~cm}$ and $90 \mathrm{~cm}$ thicknesses in their lower and upper parts, respectively. On facades because of slope; wall thickness changes after 3.5 and 6.5 meters from the ground story in wall profile 5, and after 3.5 and $4.5 \mathrm{~m}$ from the 
ground story in wall profile 6 . The wall profiles consist of a gap between the outer leaves. The leaves are connected with header stones that do not touch each other. The difference between the two wall profiles is the length of the stone blocks. In the wall profile 6 , the length of the stone blocks is between 100 and $260 \mathrm{~cm}$, and in the wall profile 5 , the length of the stone blocks is between 100 and $150 \mathrm{~cm}$. Depending on the location of the joints; the staggering ratio of the wall profile 5 varies between 0.6 and 1, whereas the staggering ratio of profile 6 ranges between 0.75 and 2 .

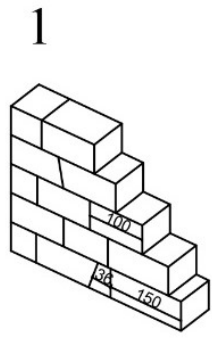

2

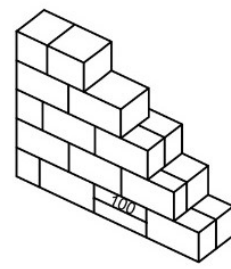

3

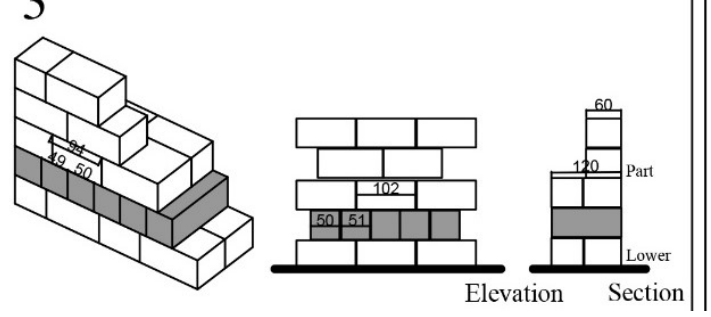

4

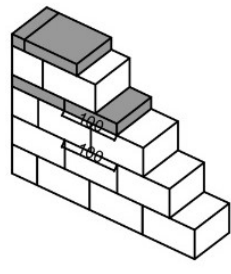

5
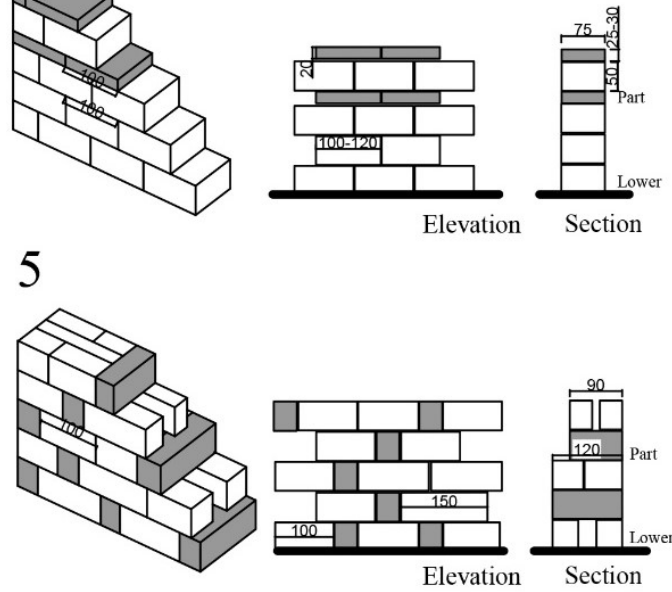

6
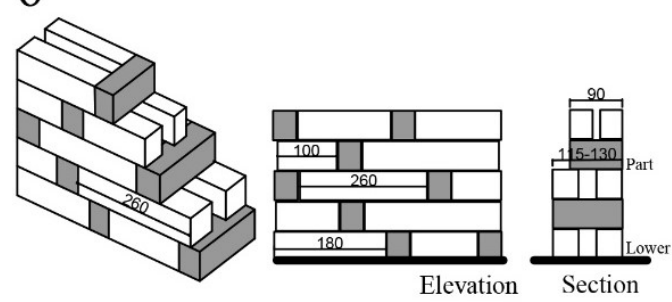

Figure 33. Wall profile types

\subsubsection{Proportional relationships}

The dimensions of documented towers are listed in the below (Table 12). All towers have different wall thicknesses changing between 60 and $115 \mathrm{~cm}$. Wall thicknesses present variation depending on story level. Number of stories change between 2 and 4 , heights of the towers vary between 1086 and $1405 \mathrm{~cm}$. Length of the walls vary between 475 and $775 \mathrm{~cm}$. 


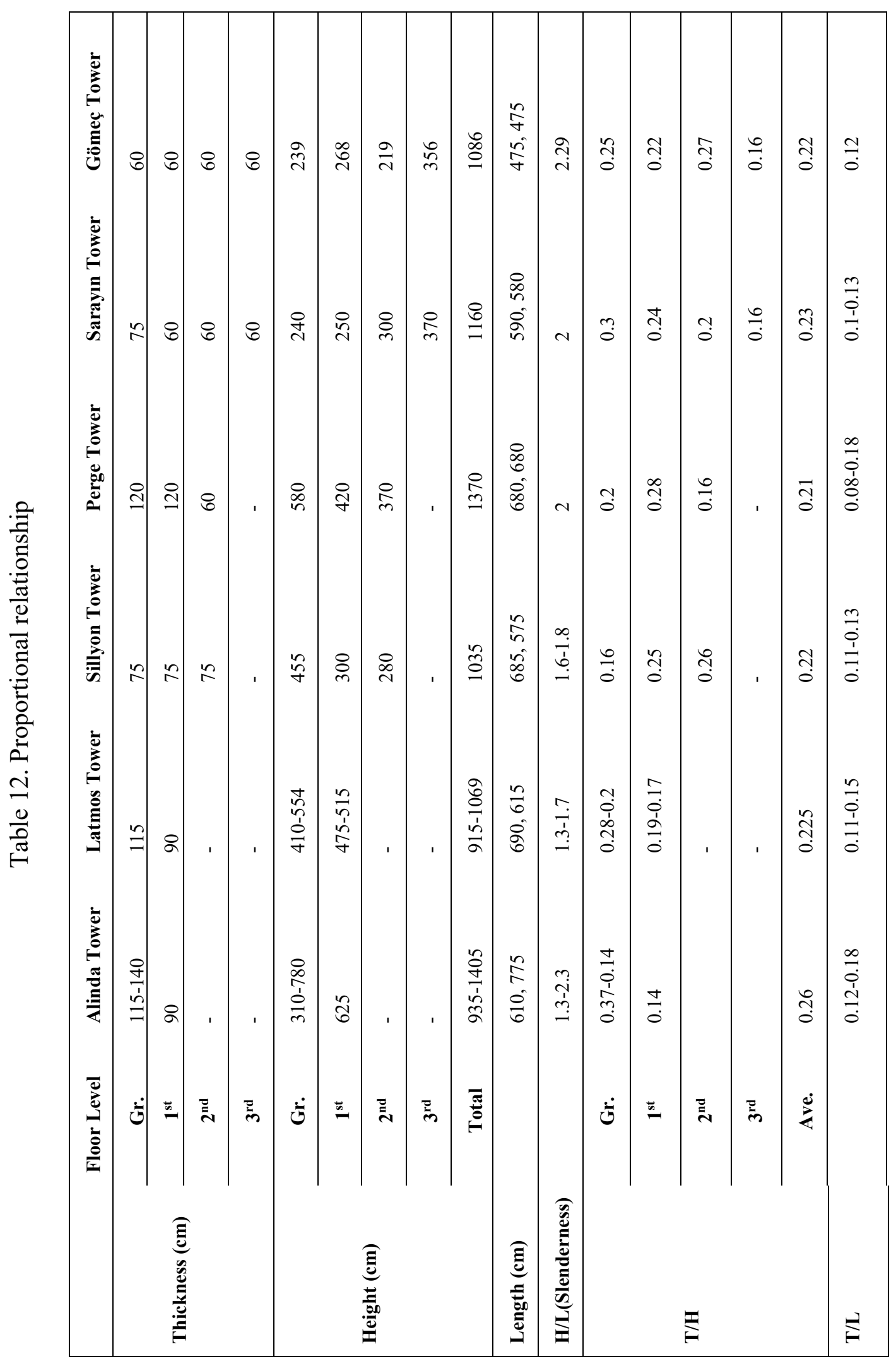


Although each tower has different wall thicknesses, the ratio between thickness and height (0.21-0.26) and thickness and length (0.1-0.18) are approximately the same. These are evaluated as ideal values found with trial and error. The ratio between height and length, however, change between 1.6 and 2.3. Since some towers are positioned at inclined ground, walls situated on bedrock are low; thus, the h/l ratio is small (1.3). This ratio is calculated only from bedrock side facade.

Studies in literature demonstrate that the ratio between height and length (slenderness) is critical for structural behavior of towers (Shi, D'Ayala, and Jain 2008; Romaro 2011; Casolo et al. 2013). The effect of $t / 1$ and $t / h$ ratios are generally studied in a wall without side walls (De Felice, and Giannini 2001). If the towers are studied in terms of $\mathrm{t} / \mathrm{h}$ and $\mathrm{t} / \mathrm{l}$, height and length values become very different to achieve the same $t / h$ or $t / 1$ ratios with different wall thicknesses, because wall thicknesses vary between $60-155 \mathrm{~cm}$. Therefore, effect of proportional relationship on behavior of towers is studied by focusing on $\mathrm{h} / \mathrm{l}$ ratio. The effect of wall thickness is tested under the heading of wall profile (Section 3.1.1.1). Towers with four different $\mathrm{h} / 1$ ratios $(1.6,1.8,2$ and 2.3$)$ are designed. While designing towers that have these ratios, height and length values are kept in the range of the real values of the towers $(1000 \leq h \leq 1405,475 \leq 1 \leq 775)$. Extra-long or high towers are not designed.

\subsubsection{Opening organization types}

Opening types vary depending on their position, size and number. Position of the openings are categorized as top, middle or ground, and symmetrical, asymmetrical or asymmetrical adjacent to corner. Size of openings vary as small sized $(50 \times 75,100 \times 100)$, medium sized $(75 \times 160,90 \times 160)$ and large sized $(95 \times 270,95 \times 270,100 \times 230$ and $180 \times 300$ $\mathrm{cm})$. There are a number of possible combinations; thus, 15 opening types are determined. The top openings (op. 1, 2, 3, 8 and 11) are analyzed by considering two options with or without ground opening (Figure 34). A tower without an opening is not taken into consideration, since it is not possible as revealed in the documented examples. An opening type is positioned at only one wall of the tower; other three walls are designed with symmetrical small sized opening that has ideal position and minimum area (op. 1). 


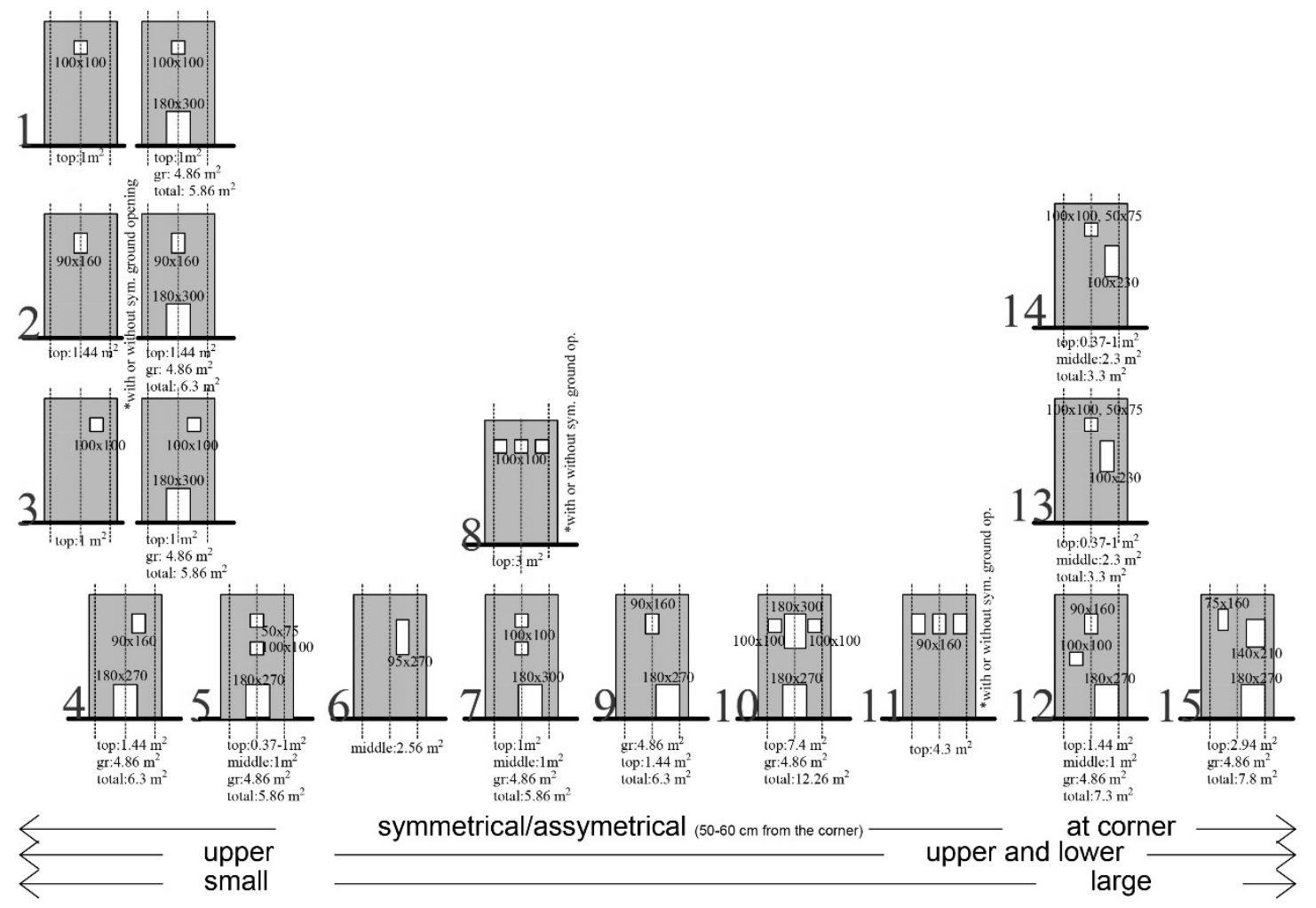

Figure 34. Opening types

\subsubsection{Material usage}

Based on laboratory analysis, two types of stone are determined; granite and limestone (Appendix A). General properties of these materials are listed in the below (Byerlee 1978; Zhu 2012; Arpaz 2015) (Table 13).

Table 13. Properties of stone materials

\begin{tabular}{|l|}
\hline Granite: \\
Density: $2600-2900 \mathrm{~kg} / \mathrm{m}^{3}$ \\
Friction coefficients of granite on \\
granite: $0.6-0.7$ (Fanning 1892,396$)$ \\
Modulus of elasticity: $10-70 \mathrm{GPa}$ \\
Porosity: $0.5-1.5 \%$
\end{tabular}

\section{Limestone:}

Density: $1900-2600 \mathrm{~kg} / \mathrm{m}^{3}$

Friction coefficients of limestone on

limestone: 0.6- 0.7 (Colas et al. 2016)

Modulus of elasticity: $15-55 \mathrm{GPa}$

Porosity: 5-30\%

In the studies about behavior of dry masonry in literature, the modulus of elasticity of the materials is neglected, because the displacements due to elastic deformation are 
negligible due to joint sliding and the tilting-tests are static. Density (weight) and coefficient of friction values are taken into consideration (De Felice, and Giannini 2001; Restrepo-Vélez, Magenes, and Grifftih 2014; Bui et. al 2017). The behavior of dry-stone masonry is mostly related to the frictional resistance of the joints (Naik and, Menon 1990, 541). Friction coefficient of rock stone in masonry change between 0.6 and 0.7 (Concrete Institute 1909, 144), so there is not a considerable difference between coefficients of rocks. Also, finishing techniques of stone masonry as chisel pointing change the friction coefficient of the stones. For example, friction coefficient of pointed dressed granite on granite is 0.7, while friction of fine cut granite on granite is 0.58 (Fanning 1892, 396). Density of materials change depending on hardness or softness of the material (Colas et. al 2016). In this study, the general values of fine cut stones in masonry from literature are taken into consideration to compare effectiveness of density and friction (Table 14).

Table 14. Determined properties of materials from literature

\begin{tabular}{l|c|cc} 
& Material type & Friction $(\mu)$ & $\begin{array}{c}\text { Determined General } \\
\text { Density Value }\end{array}$ \\
\hline \hline \multirow{2}{*}{ Granite } & Limestone & 0.72 & 2560 \\
& & $($ Colas et al. 2016) & (ASTM C568 2016) \\
& & 0.6 & 2750 \\
& $($ Jay 1908, 224) & $($ Zhu 2012) \\
\hline \hline
\end{tabular}

\subsubsection{Ground topography}

The towers are either positioned on plane or inclined topography.

\subsubsection{Combination of characteristic types}

Since characteristic types could be refined after reaching significant results clarifying behavior and resistance of towers, combination of characteristic types are composed of a series of phases. First; configurations are designed based on real towers' data. However, results of some configurations composed of $\mathrm{h} / \mathrm{l}$ ratio and material usage are similar, therefore, to prove the advantage of these historic preferences, the real limits are broadened for $\mathrm{h} / \mathrm{l}$ ratio and material usage. After interpretation of results, 
configurations composed of effective characteristic types are used for the assessment by eliminating ineffective ones.

\section{Configurations based on real towers}

While designing hypothetic towers, six wall profile type, four ratios between wall height and length, 15 opening, two material and two ground topography types are combined with each other. All possible towers are defined. Each of these towers is a permutation. If number of each characteristic type is multiplied by each other, 1440 tower combinations are created. While designing hypothetic towers, impact of an opening type is analyzed at only one wall of the tower; other three walls are designed with symmetrical small sized opening that has ideal position and minimum area (op. 1). The impact of opening type is taken into consideration depending on its in-plane and out-of-plane position.

Number of hypothetic towers (based on real towers) $=$

Wall profile type $\mathrm{x} / \mathrm{h} \times \mathrm{x}$ opening type $\mathrm{x}$ material type $\mathrm{x}$ ground topography type=

$$
6 \times 4 \times 15 \times 2 \times 2=1440
$$

\section{Configurations beyond real towers with virtual values}

According to analysis of hypothetic towers based on real towers, results of configurations composed of $\mathrm{h} / \mathrm{l}$ ratio and material usage were almost similar, therefore, to prove the advantage of these historic preferences, the real limits are broadened for $\mathrm{h} / \mathrm{l}$ ratio and material usage. Therefore, the following characteristic types are added to configurations:

-The real ratio between wall height and length varies between 1.6 and 2.3. To determine the effect of $\mathrm{h} / \mathrm{l}$, these values are taken between 1 and 2.5 (by adding $\mathrm{h} / \mathrm{l}$ ratios $1,1.3$ and 2.5$)$.

- Density and friction of limestone and granite are similar (Table 6). Limestone has higher friction without regard to finishing of stone and lower density in comparison to granite, this difference does give an opinion about reverse relation of friction and density. To be able to evaluate the rationality of this reverse relationship, different rock materials with different density and friction coefficient are tried to be tested, however with reference to literature, it is seen that density values of rocks change between 2000 and $2900 \mathrm{~kg} / \mathrm{m}^{3}$ (Carmicheal, and Clein 2019), friction coefficient of dry stone on dry stone is determined between 0.6 and 0.7 (Concrete Institute 1909, 144; Jay 1908, 224). There is no strong dependence of friction on rock type (Byerlee 1978, 618), surface finishing techniques as rough or fine pointing change friction coefficients (Fanning 1892, 
396) (Table 15). Although comparison with another rock type does not probably help to evaluate the effect of friction and density, a sandstone type which has similar friction with limestone and slightly lower density in comparison to limestone is analyzed as a virtual rock stone material. Comparison with lower friction and density values is required for evaluation, however the values of rock materials are similar. Nevertheless, brick is also used as virtual material with lower density and similar friction with granite, however there are not materials to be used in towers with smaller friction coefficient lower than 0.6.

Table 15. Properties of materials

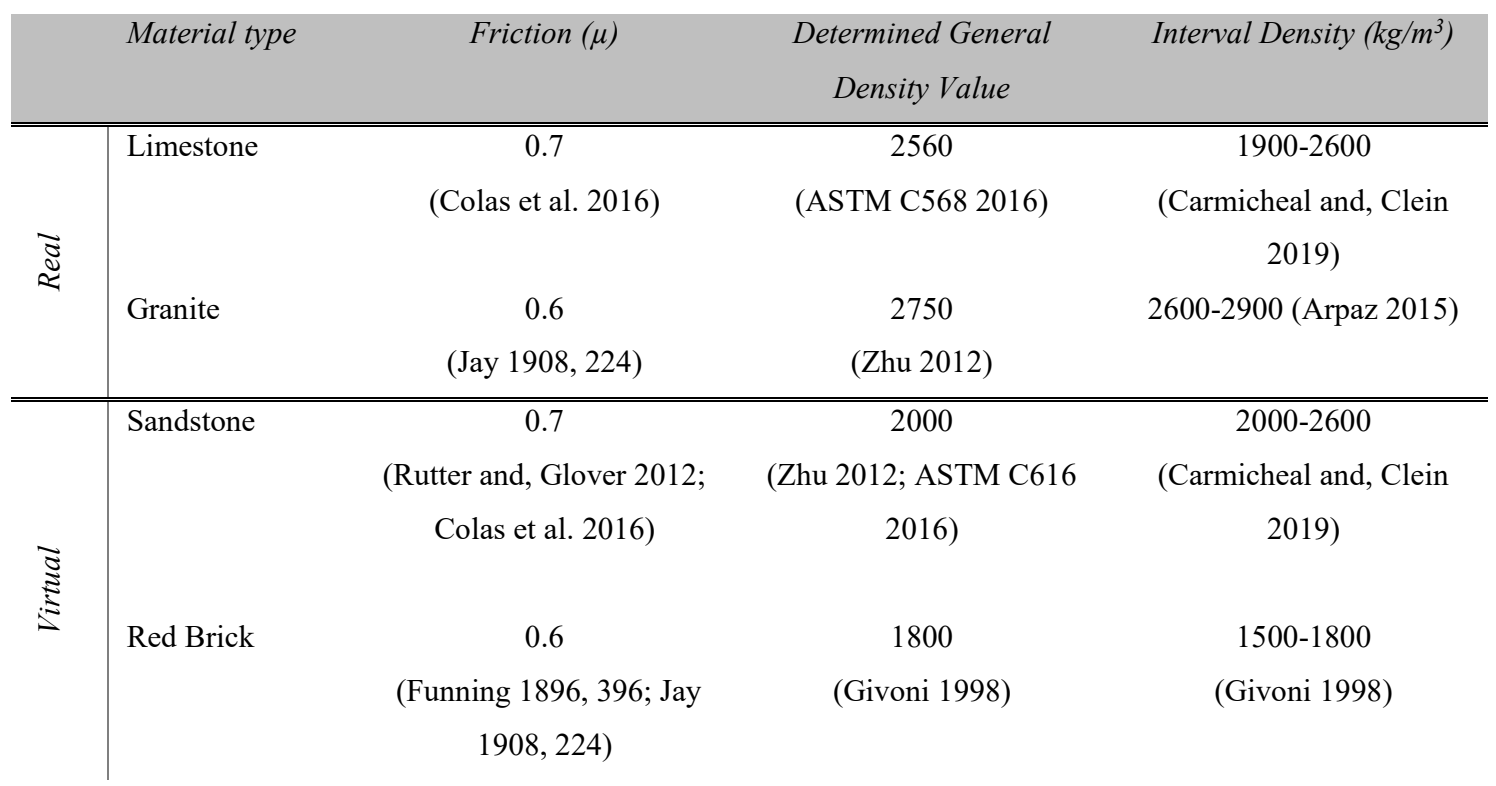

Additional configurations ( $3 \mathrm{~h} / 1$ ratio and 2 material type) increase number of hypothetic towers up to 5040 .

Number of hypothetic towers (with additional configurations) (See Appendix E) $=$ Wall profile type $\mathrm{x} \mathrm{h} / \mathrm{l}$ opening type $\mathrm{x}$ material type $\mathrm{x}$ ground condition type $=$ $6 \times 7 \times 15 \times 4 \times 2=5040$

At the results part, all hypothetic towers are examined, effective types are determined between the configurations.

\subsection{Validation of Analysis Method}

Preliminary analyses have been carried out to test the validity of the MsPhysics software to be used for simulation of behavior of hypothetic towers against lateral 
loading. Simulation based on quasi-static tilt analysis is validated based on the experimental results both in literature (Restrepo-Vélez, Magenes, and Griffith 2014, 128) and at laboratory.

\subsubsection{Comparison with experimental results of Restrepo-Vélez, Magenes, and Griffith (2014)}

Restrepo-Vélez, Magenes, and Griffith (2014) studied the behavior of dry masonry walls under lateral force with an experimental study. Walls constructed in a laboratory environment were tilted by placing on a wooden table; collapsing angles and mechanisms of different configurations were found. Based on the wall sizes and properties of materials produced by Restrepo-Vélez, Magenes, and Griffith (2014), 3D models were created in Sketch-up software, and the failure mechanisms were investigated by tilting these models with a virtual table in MsPhysics. The results of the simulation were compared with the experimental results (Restrepo-Vélez, Magenes, and Griffith 2014, 1-28). The damage mechanisms of real and virtual models were similar (Figure 35) and the collapse angles had the same curve graphically. However, the simulation results were about 3 degrees lower than the results of experimental method (Table 16).
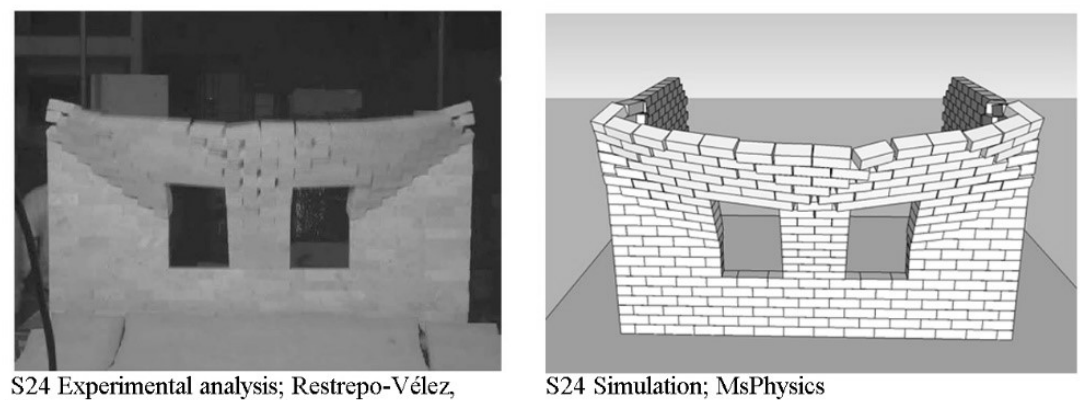
Magenes, and Griffith (2014)

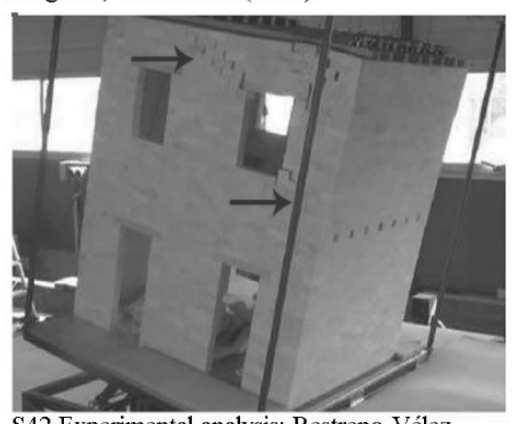

S42 Experimental analysis; Restrepo-Vélez Magenes, and Griffith (2014)

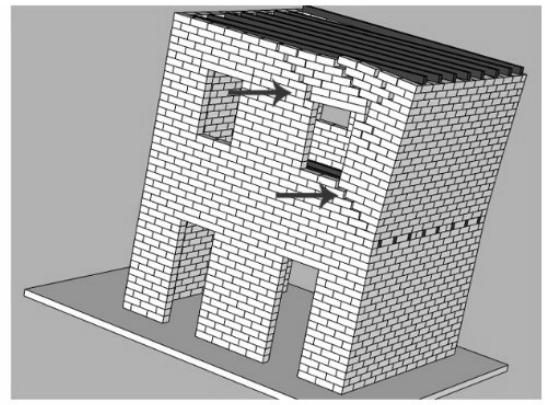

S42 Simulation; MsPhysics

Figure 35. Failure mechanisms observed in experiments and simulations 
Table 16. Comparison of experiments and simulations

\begin{tabular}{|c|c|c|c|c|}
\hline \multirow{2}{*}{$\begin{array}{c}\text { Configurations } \\
\text { Restrepo-Vélez, } \\
\text { Magenes, and Griffith } \\
\text { (2014) }\end{array}$} & \multicolumn{2}{|c|}{$\begin{array}{c}\text { Results of experimental analysis } \\
\text { Restrepo-Vélez, Magenes, and Griffith } \\
\text { (2014) }\end{array}$} & \multicolumn{2}{|c|}{ Results of simulation } \\
\hline & Collapse angle & $\begin{array}{c}\text { Lateral } \\
\text { acceleration }\end{array}$ & Collapse angle & $\begin{array}{c}\text { Lateral } \\
\text { acceleration }\end{array}$ \\
\hline S1 & 15 & $0.254 \mathrm{~g}$ & 12 & $0.207 \mathrm{~g}$ \\
\hline S4 & 9 & $0.161 \mathrm{~g}$ & 8 & $0.139 \mathrm{~g}$ \\
\hline S5 & 20 & $0.349 \mathrm{~g}$ & 16 & $0.275 \mathrm{~g}$ \\
\hline S6 & 12 & $0.208 \mathrm{~g}$ & 9 & $0.15 \mathrm{~g}$ \\
\hline S7 & 17 & $0.291 \mathrm{~g}$ & 14 & $0.241 \mathrm{~g}$ \\
\hline S8 & 21 & $0.362 \mathrm{~g}$ & 18 & $0.309 \mathrm{~g}$ \\
\hline S10 & 12 & $0.213 \mathrm{~g}$ & 10 & $0.17 \mathrm{~g}$ \\
\hline S11 & 5.5 & $0.097 \mathrm{~g}$ & 6 & $0.104 \mathrm{~g}$ \\
\hline S12 & 7 & $0.129 \mathrm{~g}$ & 7 & $0.121 \mathrm{~g}$ \\
\hline S13 & 10 & $0.181 \mathrm{~g}$ & 9 & $0.15 \mathrm{~g}$ \\
\hline S14 & 14.5 & $0.251 \mathrm{~g}$ & 14 & $0.24 \mathrm{~g}$ \\
\hline S15 & 11.5 & $0.199 \mathrm{~g}$ & 11 & $0.19 \mathrm{~g}$ \\
\hline S16 & 8 & $0.139 \mathrm{~g}$ & 7 & $0.12 \mathrm{~g}$ \\
\hline $\mathbf{S 2 3}$ & 8.5 & $0.144 \mathrm{~g}$ & 6 & $0.10 \mathrm{~g}$ \\
\hline S24 & 9.1 & $0.156 \mathrm{~g}$ & 7 & $0.12 \mathrm{~g}$ \\
\hline S42 & 13.7 & $0.236 \mathrm{~g}$ & 12 & $0.207 \mathrm{~g}$ \\
\hline
\end{tabular}

\subsubsection{Comparison with experimental results}

By using wooden blocks $(6.6 \times 2.1 \times 1.5 \mathrm{~cm})$, a tower composed of 20 rows was modelled at the laboratory. A tilting table was formed with wooden platforms connected to each other with a hinge and an angle meter was placed between the platforms. The upper platform was elevated from one side, the tilting angle at the moment of collapse was recorded with the angle meter. Coefficient of static friction of wooden blocks to be required in simulation is equal to the tangent of the critical angle of failure. Angle failure of a wooden block was found approximately 50 degrees. Therefore, the friction coefficient of a wooden block was accepted as 1.19 in simulations. 
Table 17. Comparison of experiment and simulation results

Collapse angle (degrees)

\begin{tabular}{c|cc} 
& Experimental & Simulation \\
\hline 20 rows & 21 & 18 \\
15 rows & 25 & 23
\end{tabular}
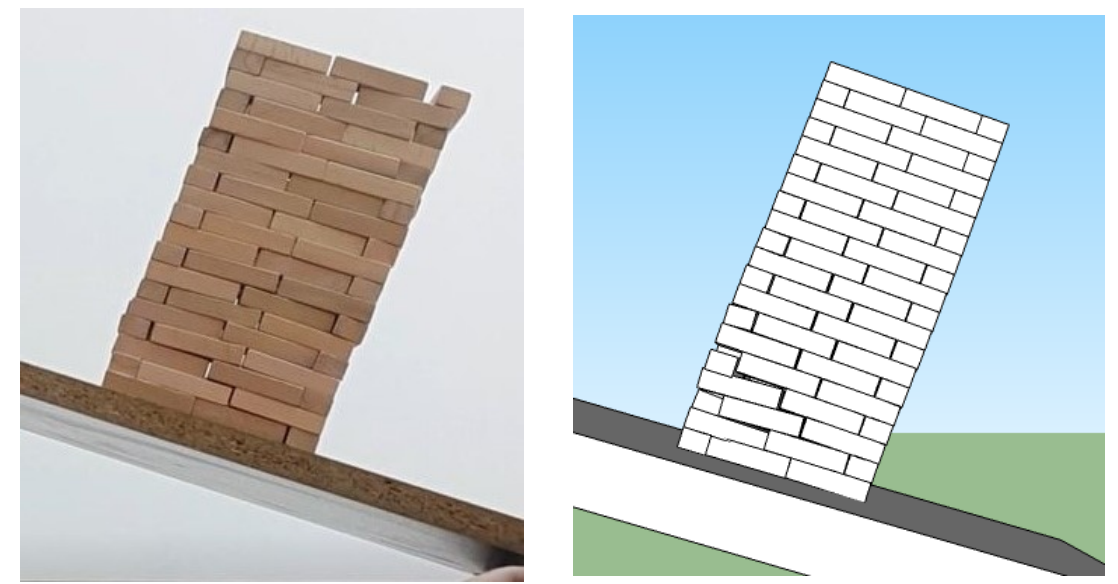

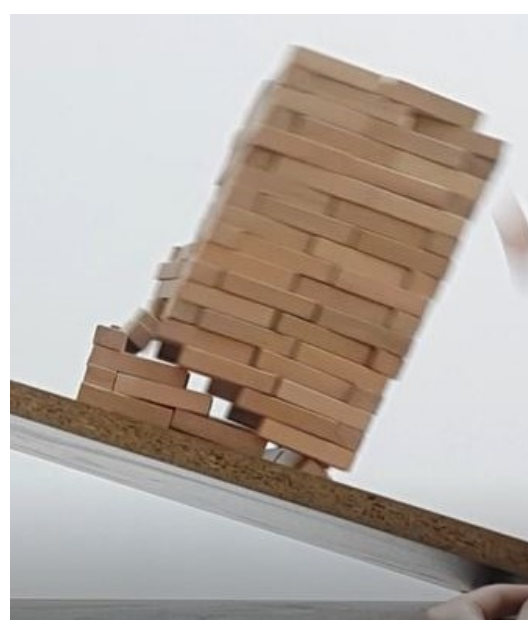

20 rows experimental results

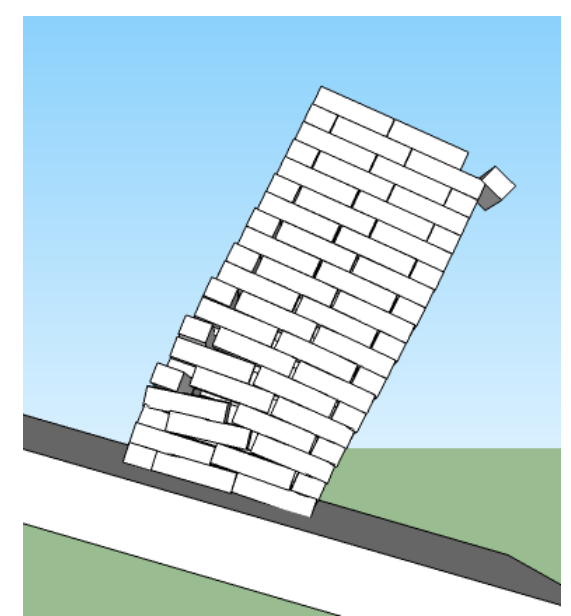

20 rows simulation results

Figure 36. Comparison of experiments and simulations

The damage mechanisms of real and virtual models were similar (Figure 36) and the collapse angles were 3 degrees lower than the results of experimental method (Table 17). Thus, MsPhysics software is evaluated as sufficient and practical for understanding relationship of characteristics under lateral load. MsPhysics is selected to be used to determine the behavior of hypothetic towers under increasing lateral loads. 


\subsection{Evaluation of results of analysis}

Results of analysis are evaluated in terms of collapse angle and failure mechanisms. In-plane and out-of-plane behavior of walls or behavior of the tower are evaluated with regard to definitions developed by Giuffre (1993); D'ayala and Speranza (2003); Preciado et. al (2016); Milanu, Shehu and Valente (2018). Also, combined failure mechanisms are determined. To examine results, characteristic types are grouped as binary and triple combinations. Analysis of towers including opening organization is done in two steps, the position of openings at in-plane wall and out-of-plane wall are examined separately to determine the effect of opening depending on direction of lateral loading. Effects of openings on out-of-plane behavior are analyzed both at the facade on tilting direction and opposite direction. The smalles collapse angle is taken into consideration.

After examining binary combinations, according to impact of characteristics, triple combination composed of effective characteristics is also examined.

\subsubsection{Results of binary combinations}

Analysis results of hypothetic towers with binary combinations of characteristic types are presented in terms of collapse angle and failure mechanisms against lateral loading.

\subsubsection{Collapse angles}

Impact of characteristics on collapse angles are examined.

\subsection{Wall profile and opening type relation}

Relationship of wall profile and opening type is evaluated, when other characteristics are kept constant. Effect of different opening types on wall behavior and collapse angle are examined depending on lateral load direction. Openings are analyzed depending on their in-plane and out-of-plane positions separately (Table 18). Since the 
opening type 1 has the same opening organization at each facade, one collapse angle is written in the table.

Table 18. Collapse angles of towers with openings at in-plane and out-of-plane walls

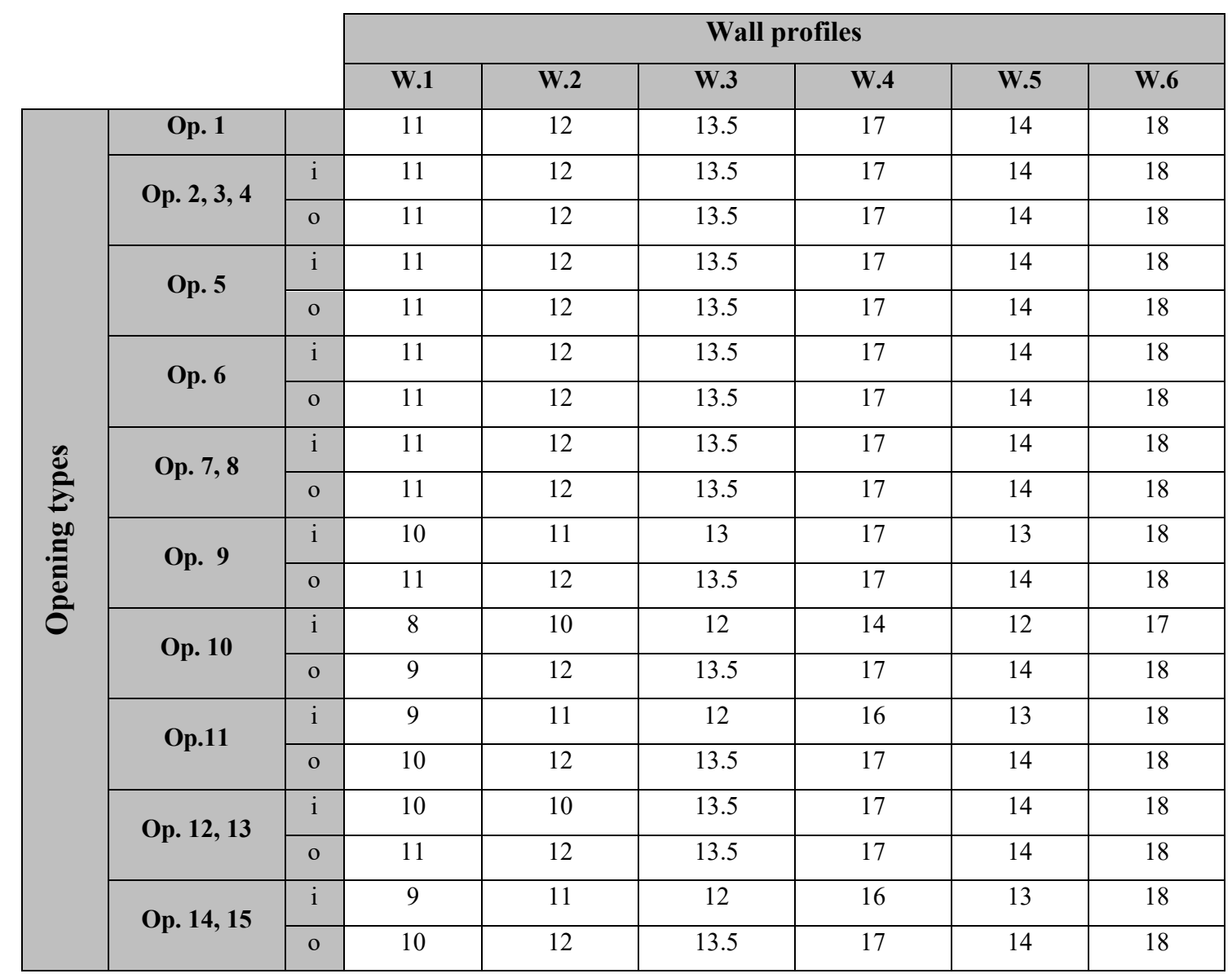

According to results, when openings at in-plane position, the collapse angle is approximately up to 3 degrees smaller than openings at out-of-plane position. This difference is seen generally with opening types 9-15. The resistance of the wall profile types against lateral loading is evaluated as $6,4,5,3,2$ and 1 from the durable to the nondurable.

If the resistance of towers that have different opening types are compared with each other; towers that have opening types 1-9 whose overall area is between 1 and $3 \mathrm{~m}^{2}$ at the top and in the middle and which are not adjacent to corner; collapse at the highest angles. Openings $12\left(7.3 \mathrm{~m}^{2}\right)$ and $13\left(3.3 \mathrm{~m}^{2}\right)$ composed of asymmetrical middle and symmetrical top openings follow openings 1-9. Openings 10, 11 and 14, 15 that are composed of large sized or adjacent to corner middle and top openings, cause collapse at 
the lowest angles. Opening $10\left(12.26 \mathrm{~m}^{2}\right)$ is composed of symmetric two small openings $(100 \times 100 \mathrm{~cm})$ and a wide opening between them $(180 \times 300 \mathrm{~cm})$ at the top stories. Opening $11\left(14.4 \mathrm{~m}^{2}\right)$ consists of three symmetrical openings at the top level (each 90x160 $\mathrm{cm}$ ) giving way to a large opening area in total. The opening $14\left(3.3 \mathrm{~m}^{2}\right)$ is composed of a small sized symmetrical top $(100 \times 100 \mathrm{~cm})$ and a middle medium sized opening adjacent to corner $(100 \times 230 \mathrm{~cm})$. The opening $15\left(7.8 \mathrm{~m}^{2}\right)$ is composed of three asymmetrical openings; whose of two are adjacent to the same corner, and with large total opening area $(75 \times 160,140 \times 210$ and $180 \times 300 \mathrm{~cm}$ from top to bottom).

Collapse angle curves of the wall profiles with different openings are generally similar, however, negative effect of problematic openings $(10,11,14$ and 15) on collapse angle are high at wall profile 1 that has lowest resistance. Negative effect of openings on collapse angle are low at wall profile 6 that has highest resistance against lateral loading. Only opening 10 in wall profile 6 decreases collapse angle 1 degree compared to other opening types of the same wall profile. However, most of the openings 10, 11, 14 and 15 decrease collapse angles between 1 and 3 degrees in other wall profiles in comparison to wall profile 6 , while only openings between 1 and 9 do not effect collapse angles of wall profile 1-5. Effect of opening types on collapse angle changes depending on resistance and compositions of wall profile (Figure 37).

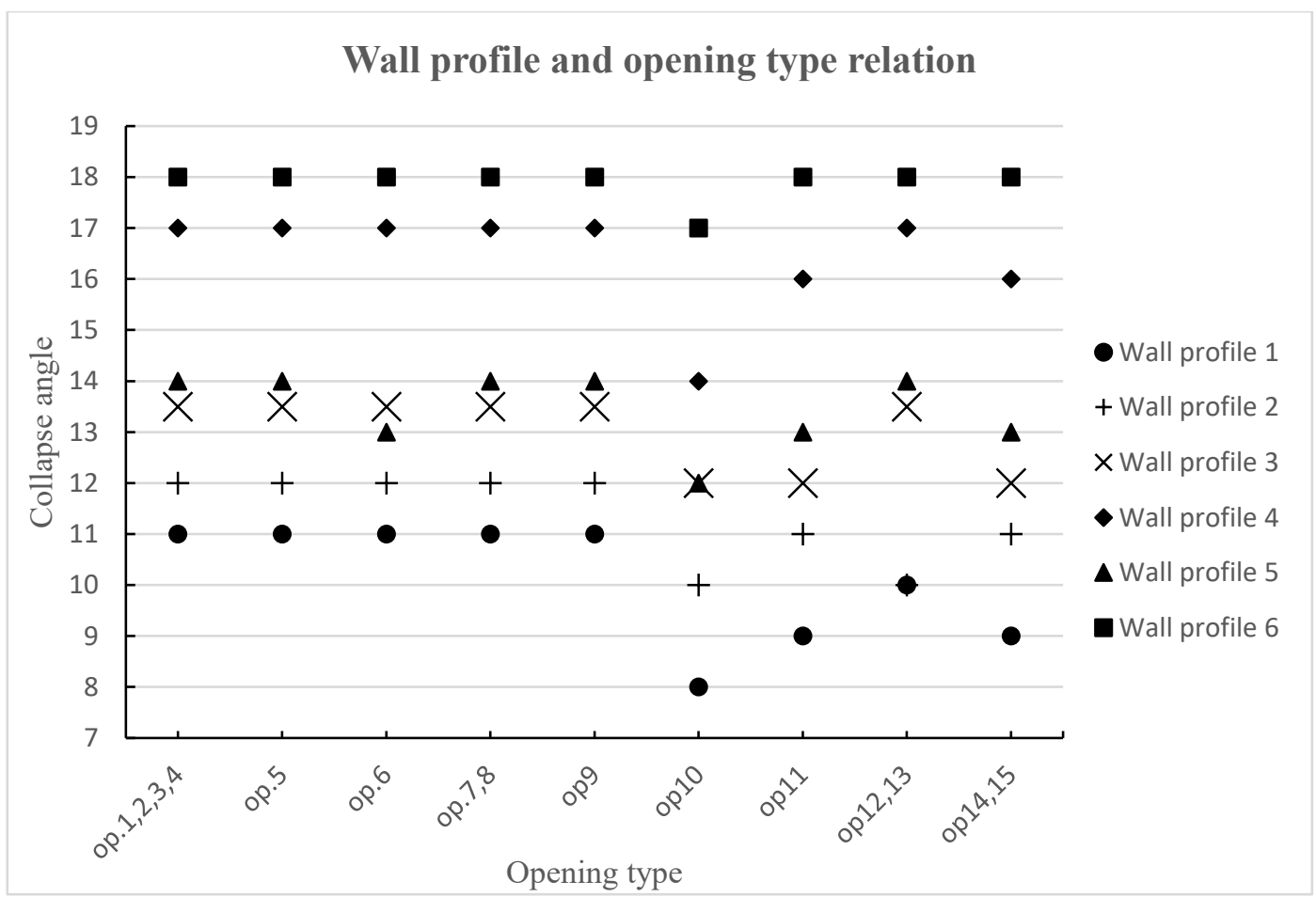

Figure 37. Opening types at in-plane position and wall profile relation 


\subsection{Wall profile and ratio between height and length relation}

Relationship of wall profile and $\mathrm{h} / \mathrm{l}$ ratio is evaluated, when other characteristics are kept constant. The resistance of the wall profile types against lateral loading is evaluated as $6,4,5,3,2$ and 1 from the durable to the non-durable as mentioned in section 4.1.1. In this part, virtual $\mathrm{h} / \mathrm{l}$ values in addition to real values, $1,1.3$ and 2.5 , are used to determine $\mathrm{h} / \mathrm{l}$ effect on wall profile (Figure 38 ).

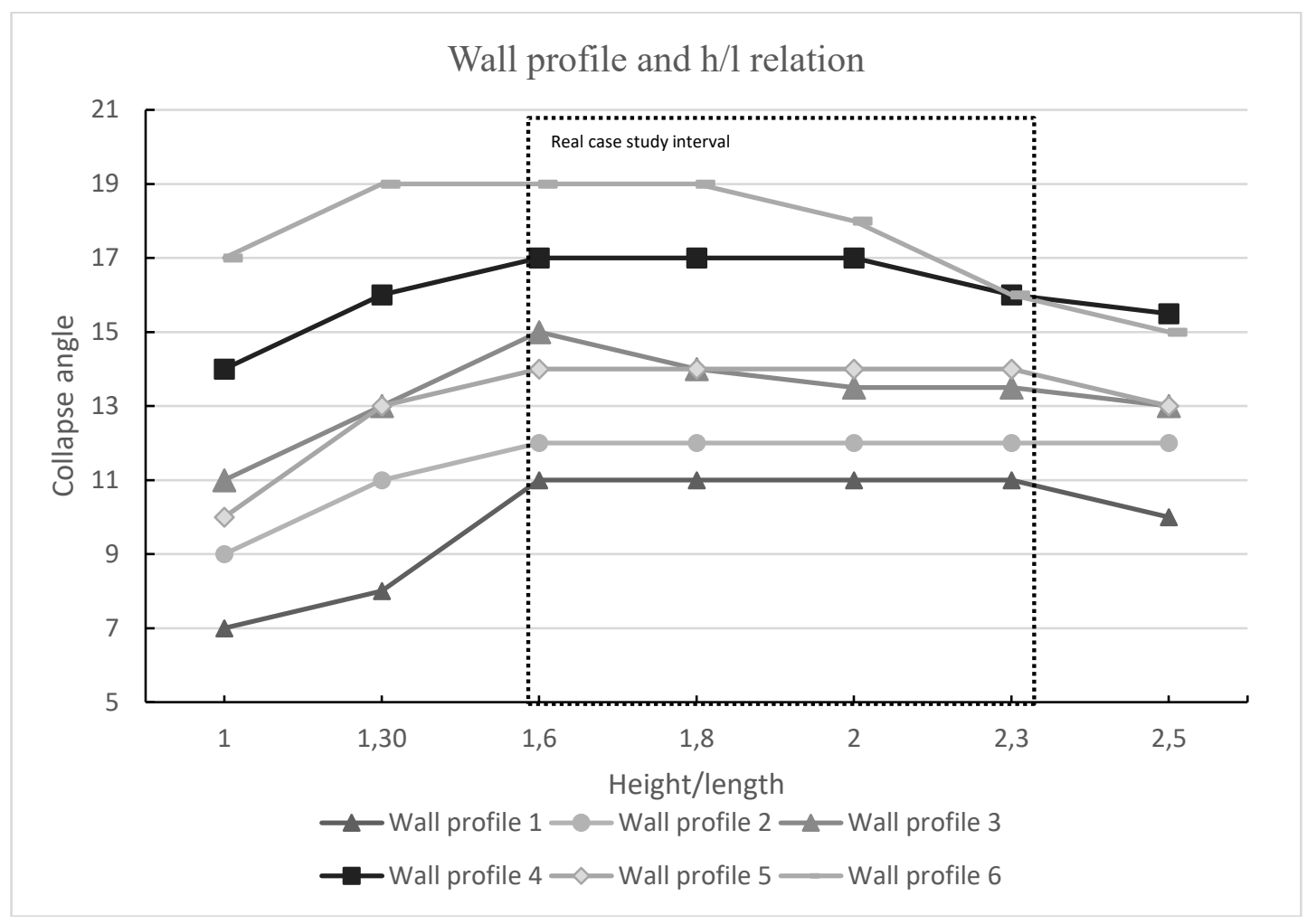

Figure 38. Wall profile and $\mathrm{h} / \mathrm{l}$ relation

The collapse angles of towers whose $\mathrm{h} / \mathrm{l}$ ratios are between 1.6 and 2 are mostly constant and have the highest values. The highest interval of each wall profile show differences between 1.6 and 2.3. For wall profile 6 , the highest interval is between 1.6 and 1.8, while for wall profile 4 the highest interval is between 1.6 and 2. For wall profiles 1,2 and 5, the interval is the same (1.6 and 2.3), however wall profile 3 has the highest point (1.6). When the ratio decreases and increases from this interval, this causes decrease in collapse angle. This shows that these intervals are ideal for structural resistance of towers (Figure 38 ). 


\subsection{Wall profile and ground topography relation}

Relationship of wall profile and ground topography is evaluated, when other characteristics are kept constant. The towers are located on plane or inclined topography. The towers on inclined ground are tilted both in the direction of the inclination and its reverse. When the towers are tilted from the highest wall towards the lowest one, the collapse angle increases 1 degree in each wall profile, excluding wall profile 6 providing 3 degrees advantage. However, wall profile 1 is not affected by the advantage of inclination. At the reverse direction, the collapse angle is equivalent to the tower located on plane area (Figure 39).

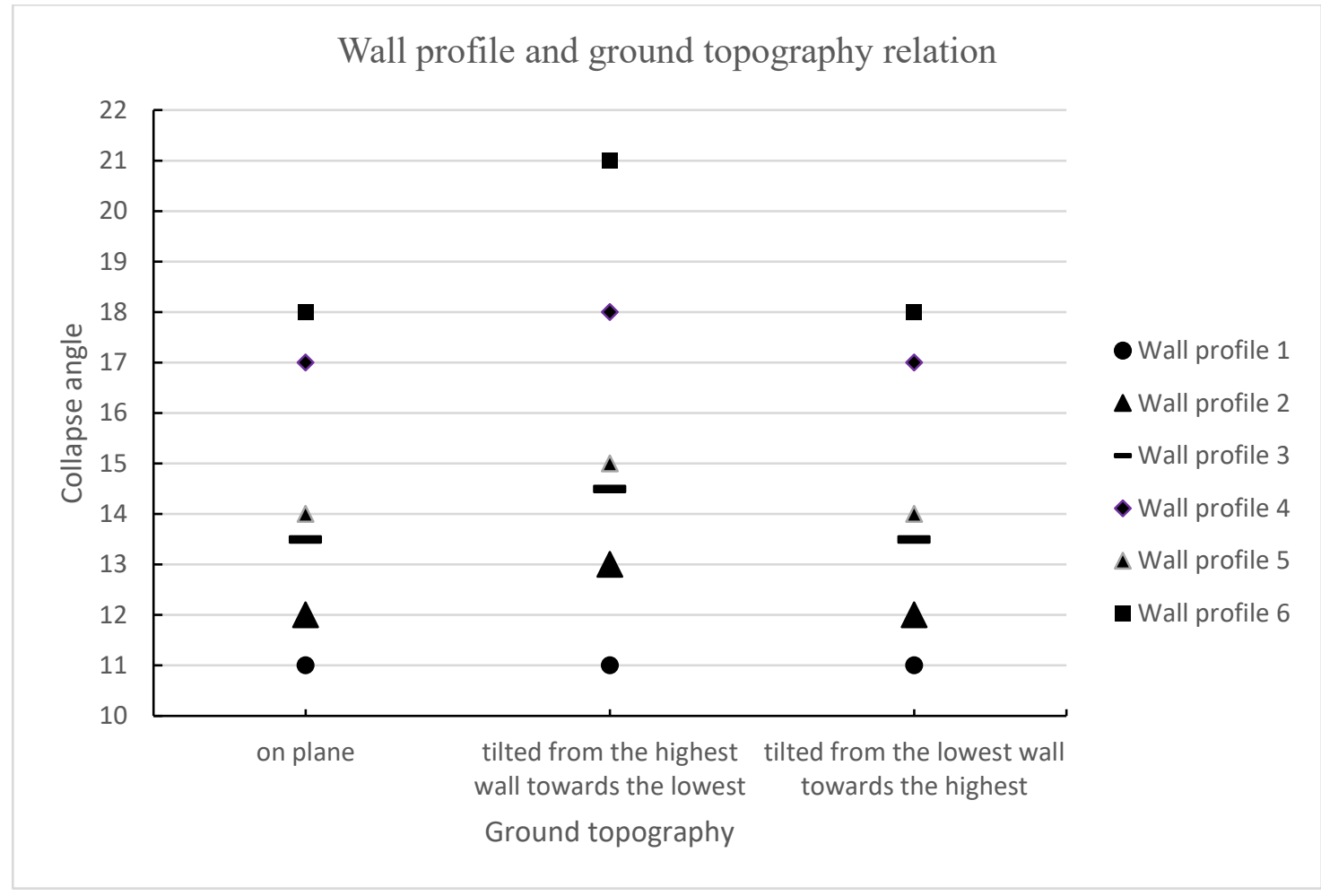

Figure 39. Ground topography and collapse relation of different wall profiles

\subsection{Wall profile and material usage relation}

Relationship of wall profile and material is evaluated, when other features are kept constant. Considering the studies on dry masonry, it was decided to neglect the modulus of elasticity, since the tilting-test is static. Density (or weight) and coefficient of friction 
values are taken into consideration (De Felice and, Giannini 2001; Restrepo-Vélez, Magenes, and Grifftih 2014; Bui et. al 2017). Limestone has higher friction and lower density in comparison to granite, this difference does give an opinion about reverse relation of friction and density (Table 19).

Table 19. Properties of materials

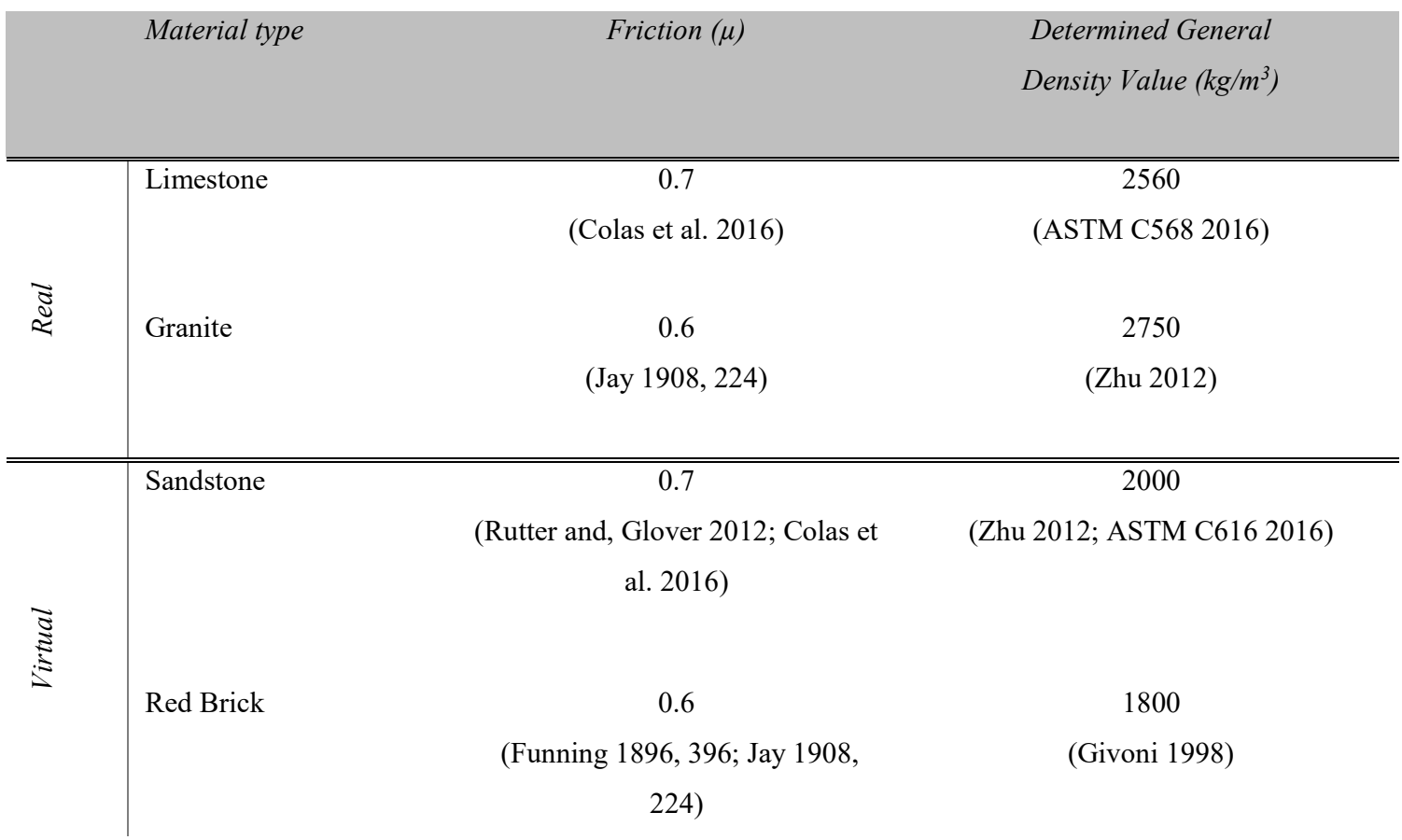

To be able to evaluate the rationality of this reverse relationship, sandstone which has similar friction with limestone and slightly lower density in comparison to limestone is analyzed. It is recorded that collapse angles of limestone and sandstone is similar; this shows that slight decrease in density $\left(560 \mathrm{~kg} / \mathrm{m}^{3}\right)$ does not affect the collapse angle. Then, brick, which has similar friction with granite and much lower density value in comparison to the other three materials $\left(950 \mathrm{~kg} / \mathrm{m}^{3}\right)$, is tested. Brick usage causes decrease in collapse angle. So, it is considered the lower the density, the lower the collapse angle. Limestone, granite and sandstone are all stones with an average density between 2000 and 2750 their collapse angles are considerably similar (Figure 40). Effectiveness of friction coefficient is not examined, since there is no material used in towers with friction coefficient lower than 0.6. 


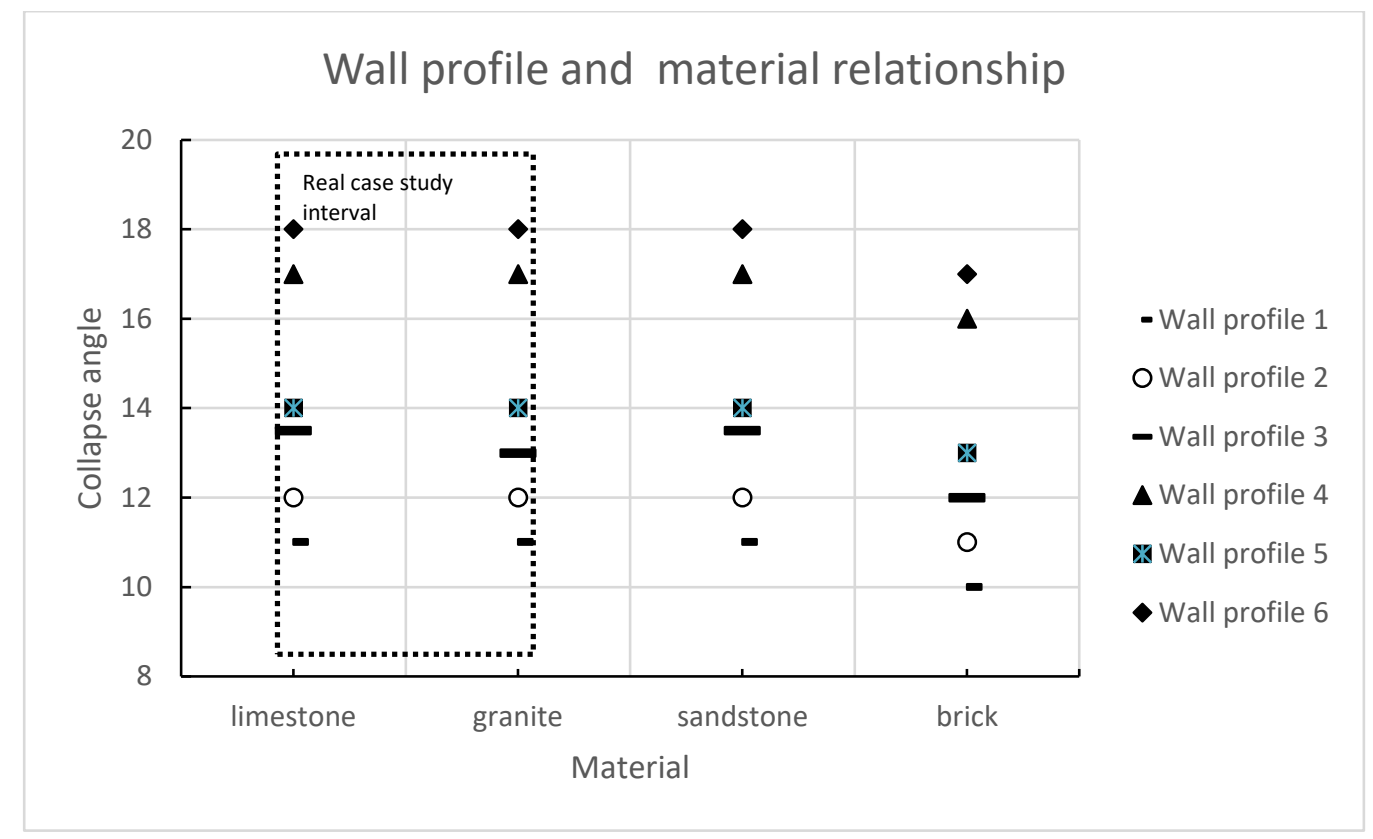

Figure 40. Material and collapse angle relation in different wall profiles

\subsection{Opening type and $h / 1$ relation}

Relationship of opening type and $\mathrm{h} / \mathrm{l}$ is evaluated, when other characteristics are kept constant. Effect of different opening types on collapse angle with different $\mathrm{h} / \mathrm{l}$ ratios are examined depending on lateral load direction. Openings are analyzed at in-plane and out-of-plane positions separately (Table 20). According to results, when openings at inplane position, the collapse angle is approximately up to 3 degrees smaller than openings at out-of-plane position. Since the lowest collapse angle is taken into consideration, the collapse angles when openings at in-plane position is examined.

Table 20. Collapse angles in different opening types and $\mathrm{h} / \mathrm{l}$ ratios of wall profile 1

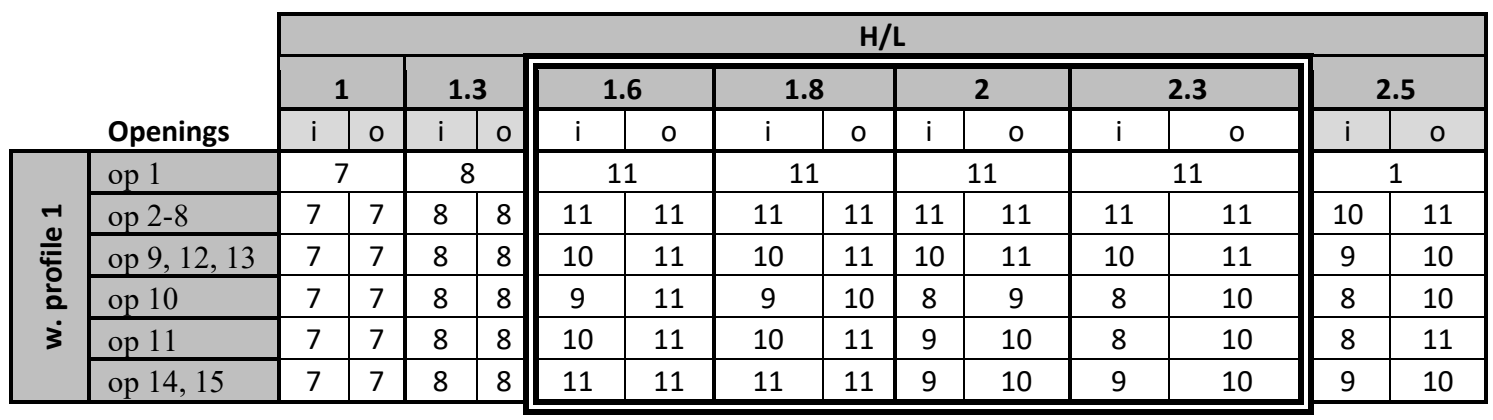


Collapse angle curves of the opening types in different ratios are similar; each opening type has an interval of better resistance. Decrease and increase from this interval cause decrease in collapse angle. For constant wall profile type (1), the collapse angles of towers have the highest values between 1.6 and 2.3, which is the real interval (Figure 41). As mentioned in the previous sections, opening 10 causes collapse at the lowest angle in each ratio. Negative effect of small sized openings not adjacent to corner (op. 1-8) are minimum. 1.6 and $1.8 \mathrm{~h} / 1$ ratios provide the best performance for the poor openings $(10$, $11,14,15)$. In-plane walls show lower resistance.

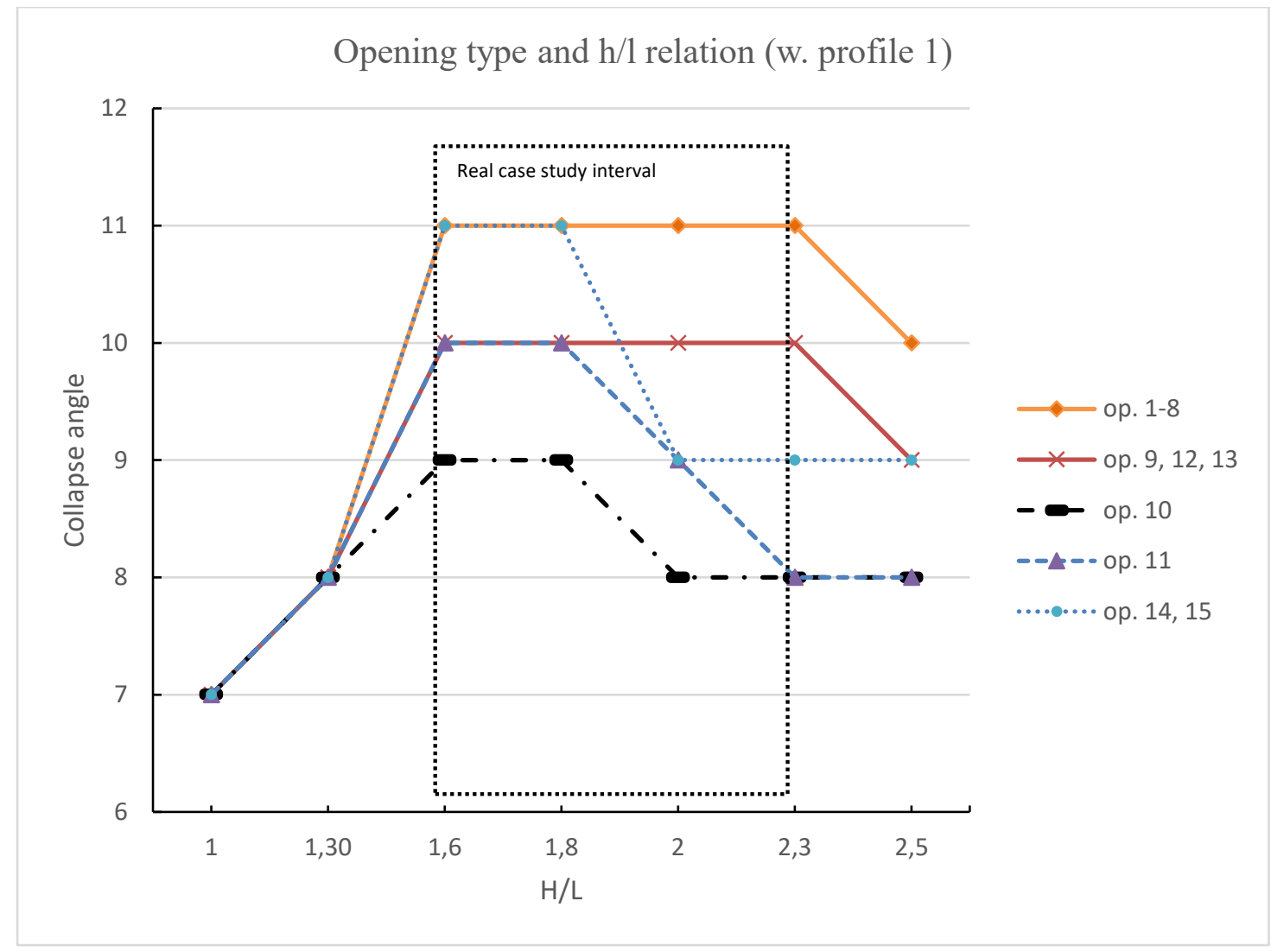

Figure 41. Relation of opening type and h/l, in-plane

\subsection{Opening type and ground topography relation}

Relationship of opening type and ground topography is evaluated, when other characteristics are kept constant. Effect of different opening types on collapse angle in different ratios are examined depending on lateral load direction. Openings are analyzed 
at in-plane and out-of-plane walls separately (Table 21). As determined in the previous sections, when the tower is tilted from the highest wall towards the lowest, the collapse angle increases. For constant wall profile 1 that has the lowest resistance against lateral load, tilting from the highest wall does not change the collapse angle at the towers that have small sized openings (opening 1-8). However, tilting from the highest provides advantage for the towers that have large and asymmetrical openings (op. 9-15) (Figure 42).

Table 21. Collapse angles of different opening types and ground topography for wall profile 1

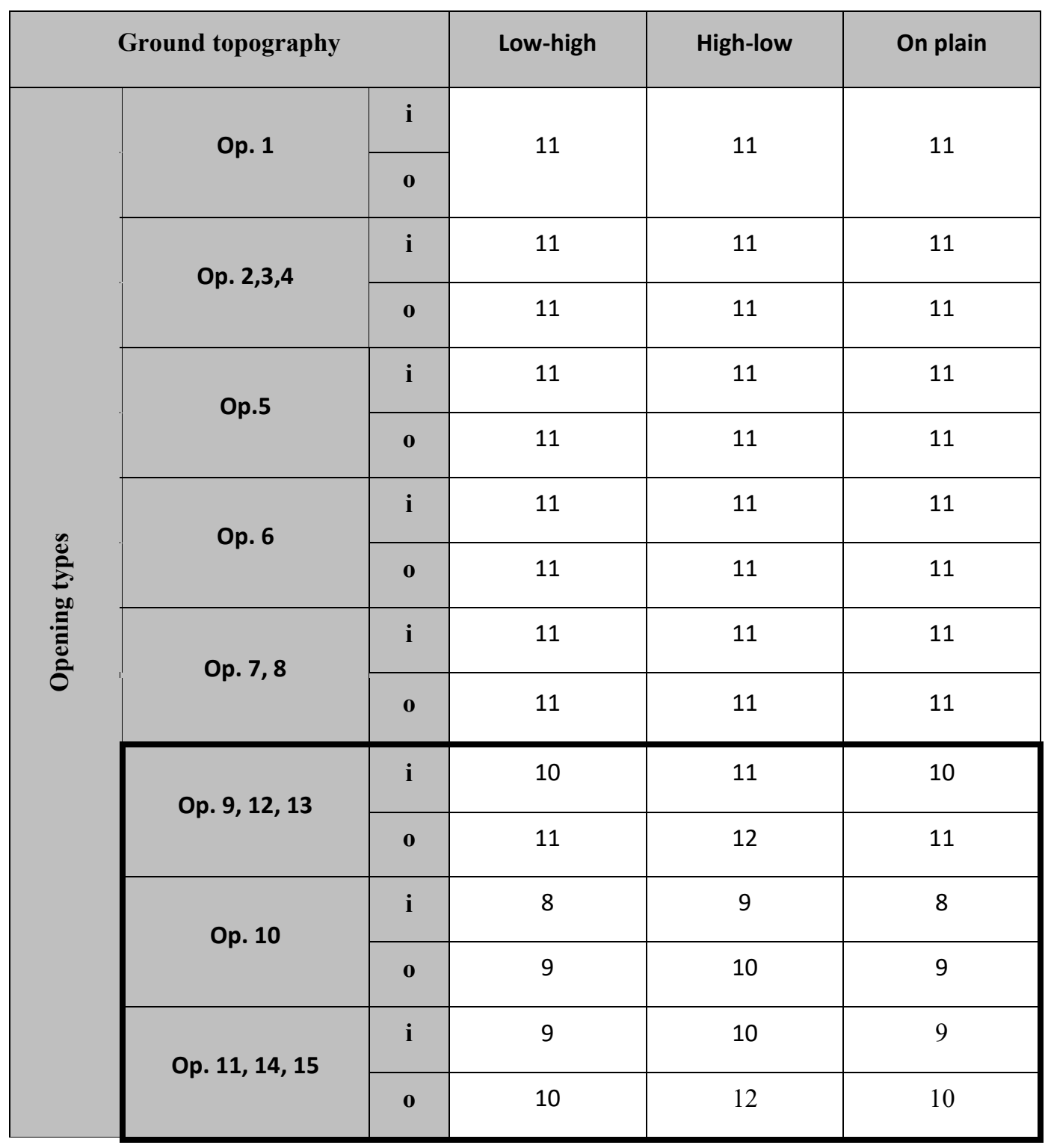




\section{Opening type-ground topography relation (w. profile 1)}

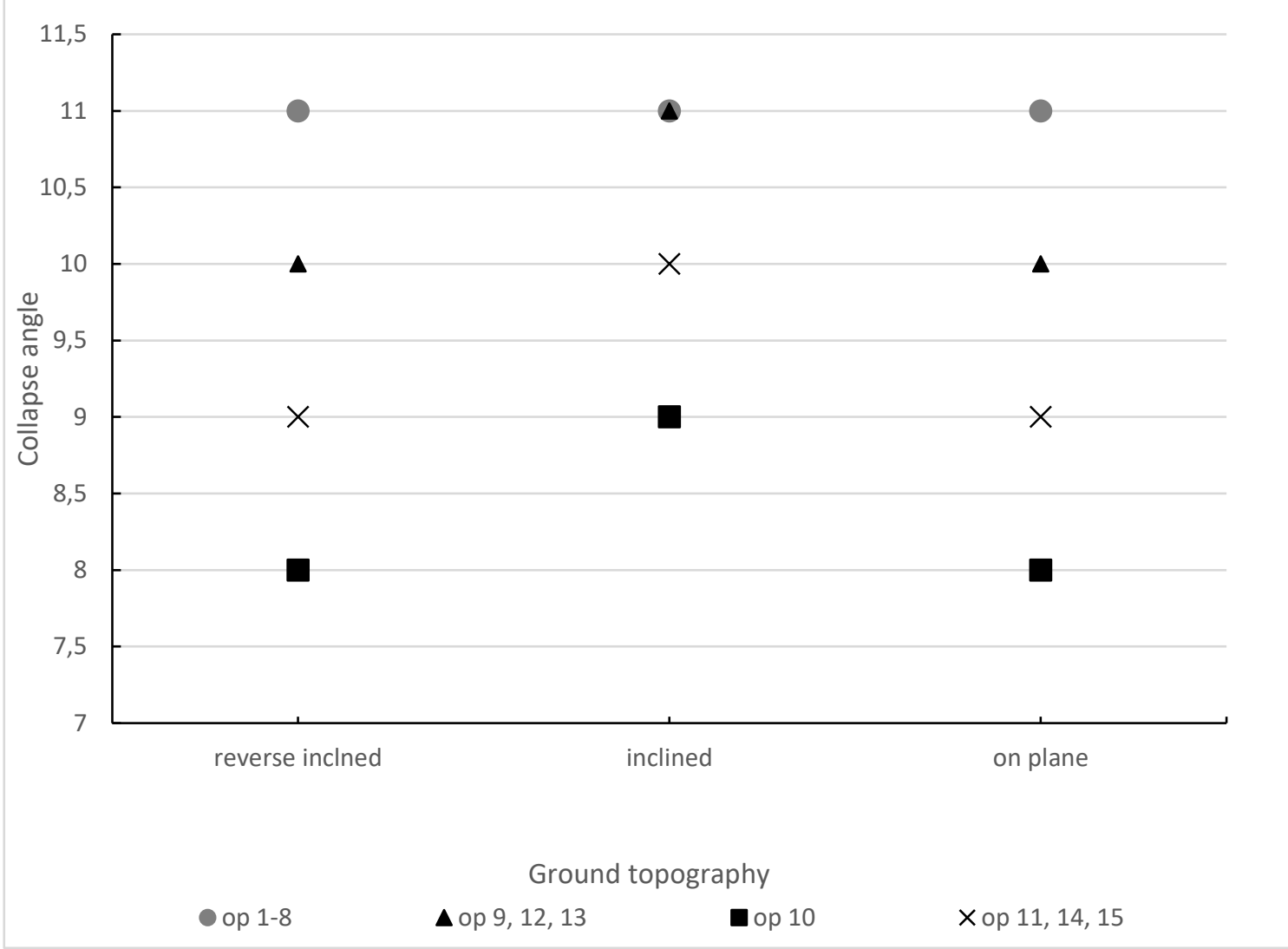

Figure 42. Opening type and ground topography relation at wall profile 1

\subsection{Opening type and material usage relation}

Relationship of opening type and material usage is evaluated, when other characteristics are kept constant. Effect of different opening types on wall behavior and collapse angle in different ratios are examined depending on lateral load direction. Openings are analyzed at in-plane and out-of-plane walls separately (Table 22).

Brick decreases collapse angle in comparison to rocks as mentioned in 4.1.4. At constant wall profile 1 , brick becomes ineffective for the towers with large sized and asymmetrical openings since these openings themselves have major negative impact on structural resistance (opening 9-11, 14, 15, and 12, 13) (Figure 43). Only in opening 12 and 13 , sandstone and brick have a minor negative effect at in plane positions. 
Table 22. Collapse angles of towers with different openings and materials

\begin{tabular}{|c|c|c|c|c|c|c|}
\hline & & & & & ials & \\
\hline & & & Limestone & Granite & Sandstone & Brick \\
\hline & Op. 1 & 1 & 11 & 11 & 11 & 10 \\
\hline & & $\mathrm{i}$ & 11 & 11 & 11 & 10 \\
\hline & Op. $2,0,4$ & 0 & 11 & 11 & 11 & 10 \\
\hline & & $\mathrm{i}$ & 11 & 11 & 11 & 10 \\
\hline & & o & 11 & 11 & 11 & 10 \\
\hline & & $\mathrm{i}$ & 11 & 11 & 11 & 10 \\
\hline & & o & 11 & 11 & 11 & 10 \\
\hline & & $\mathrm{i}$ & 11 & 11 & 11 & 10 \\
\hline & & 0 & 11 & 11 & 11 & 10 \\
\hline$\stackrel{\infty}{.0}$ & & $\mathrm{i}$ & 10 & 10 & 10 & 10 \\
\hline & & o & 11 & 11 & 11 & 10 \\
\hline & & $\mathrm{i}$ & 8 & 8 & 8 & 8 \\
\hline & & o & 9 & 9 & 9 & 9 \\
\hline & & $\mathrm{i}$ & 9 & 9 & 9 & 9 \\
\hline & & o & 10 & 10 & 10 & 10 \\
\hline & & $\mathrm{i}$ & 10 & 10 & 9 & 9 \\
\hline & & 0 & 11 & 10 & 10 & 10 \\
\hline & & $\mathrm{i}$ & 9 & 9 & 9 & 9 \\
\hline & & 0 & 10 & 10 & 10 & 10 \\
\hline
\end{tabular}




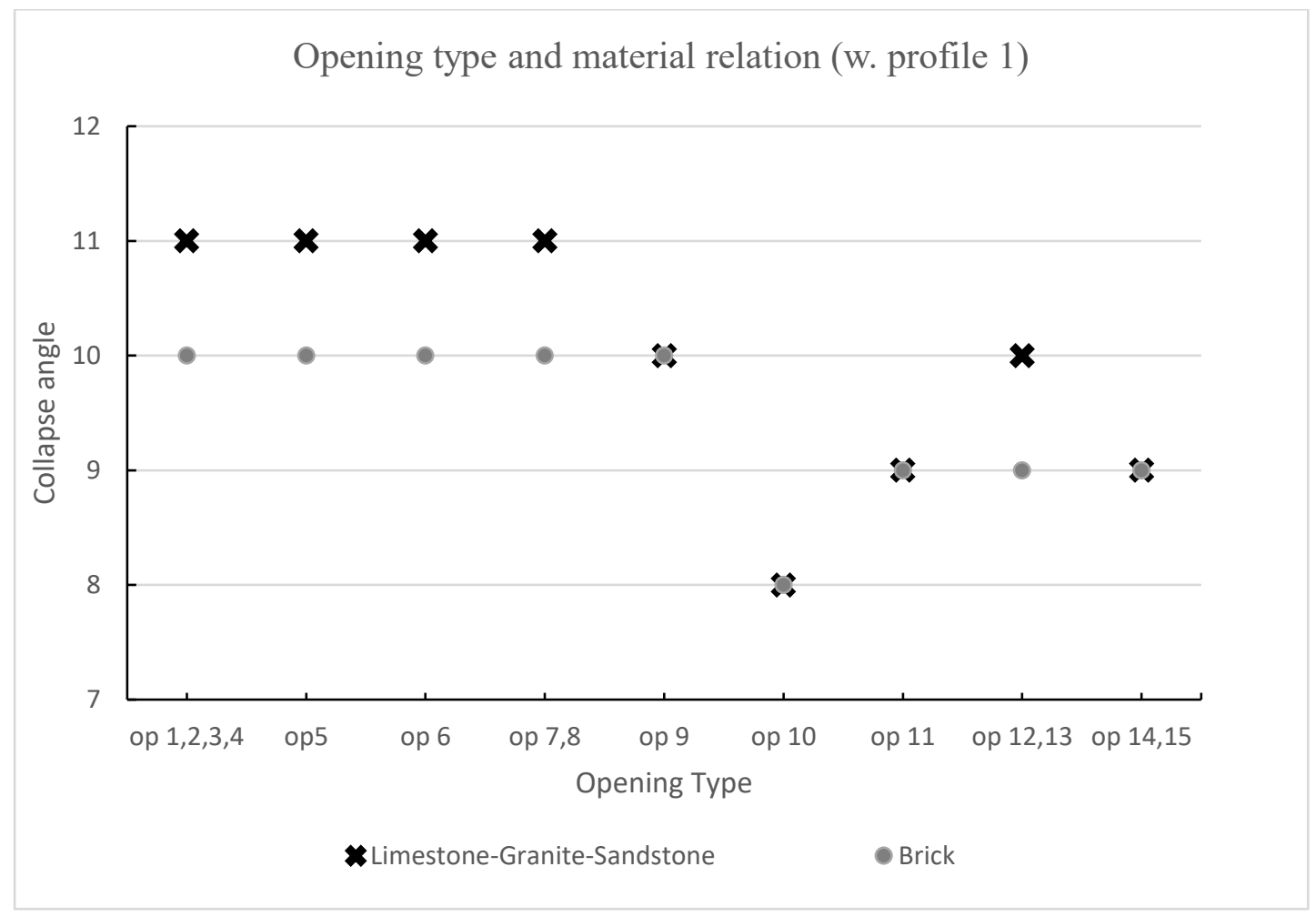

Figure 43. Openings at in-plane position and collapse angle relation in different materials at wall profile 1

\subsection{Ratio between height and length, and material usage relation}

Relationship of ratio between height and length and material usage is evaluated, when other characteristics are kept constant. As mentioned in the previous sections, the effect of usage of different stone types is similar. In different ratios, brick material decreases resistance against lateral loading considerably. Collapse angle of towers constructed with brick material is 1 degree lower than natural stones in all ratios. (Figure 44).

\subsection{Ratio between height and length, and ground topography relation}

Relationship of ratio between height and length, and ground topography is evaluated, when other characteristics are kept constant. As determined in the previous 
sections, when the tower is tilted from the highest wall towards the lowest, the collapse angle increases. However, when bedrock and proportion relationship is evaluated, advantage of tilting from the highest wall is only seen in virtual ratios $(\mathrm{h} / \mathrm{l}: 1,1.3)$. The positive effect of the slope in the low towers is seen directly (Figure 45).

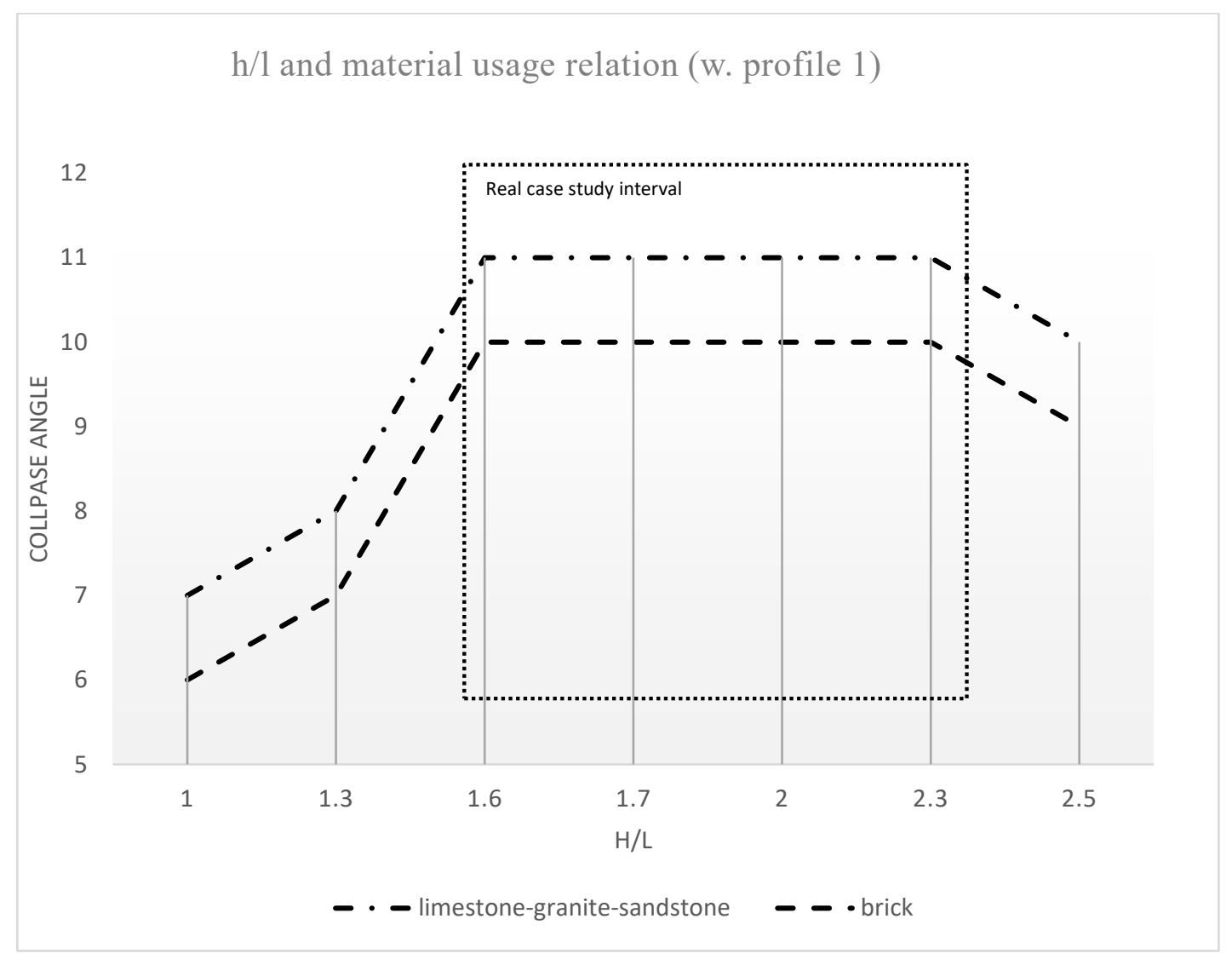

Figure $44 . \mathrm{H} / 1$ and material usage relation at wall profile 1

\subsection{Ground topography and material usage relation}

Relationship of ground topography and material usage is evaluated, when other characteristics are kept constant. Towers constructed with natural stones collapse at higher angles and they are not affected by ground topography differences, while towers constructed with brick have low resistance. So, ground topography provides an advantage for towers out of vulnerable material (Figure 46). 


\section{$\mathrm{h} / \mathrm{l}$ and ground topography relation}

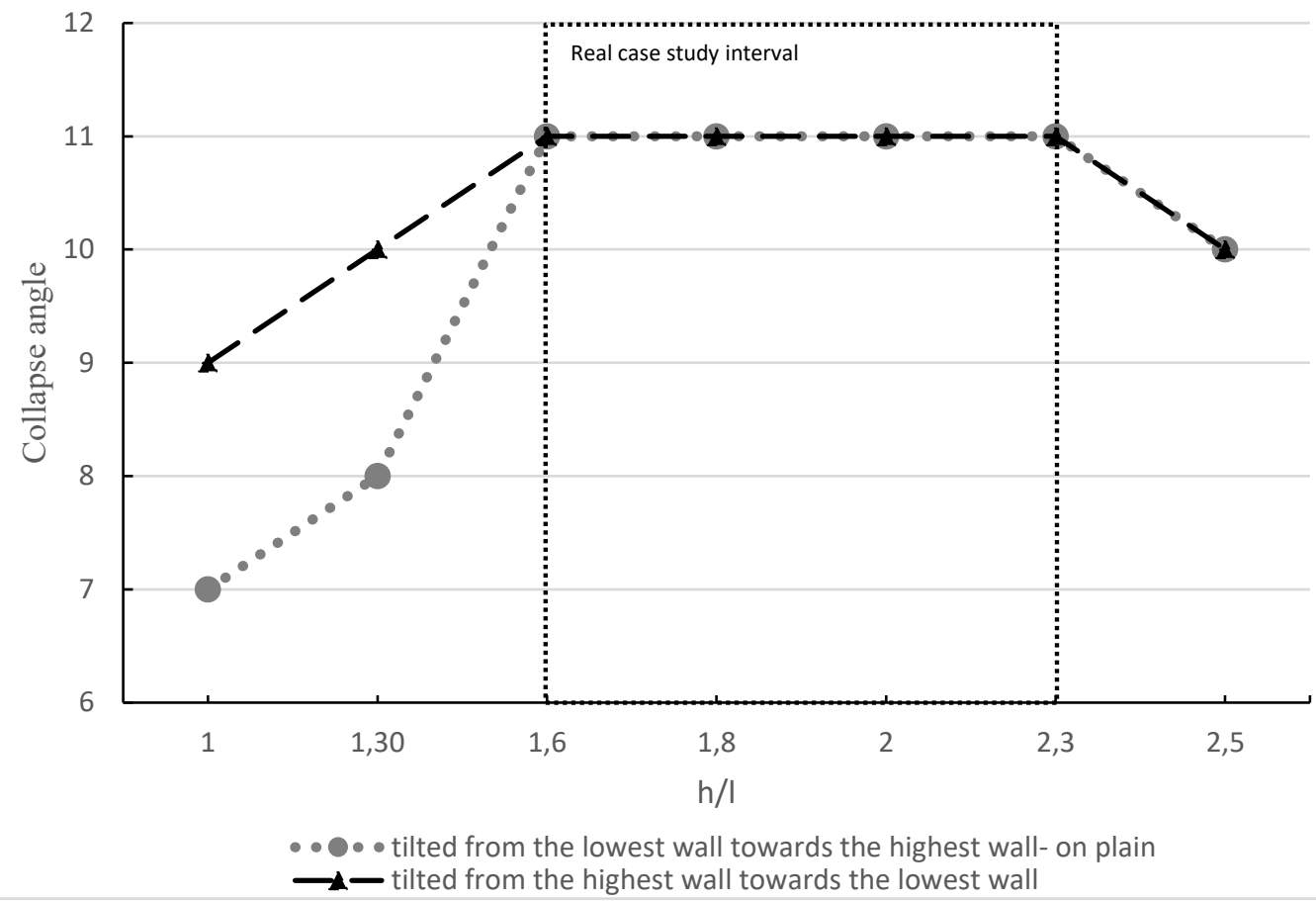

Figure 45 . Ground topography and collapse relation in different $\mathrm{h} / \mathrm{l}$ ratios wall profile 1

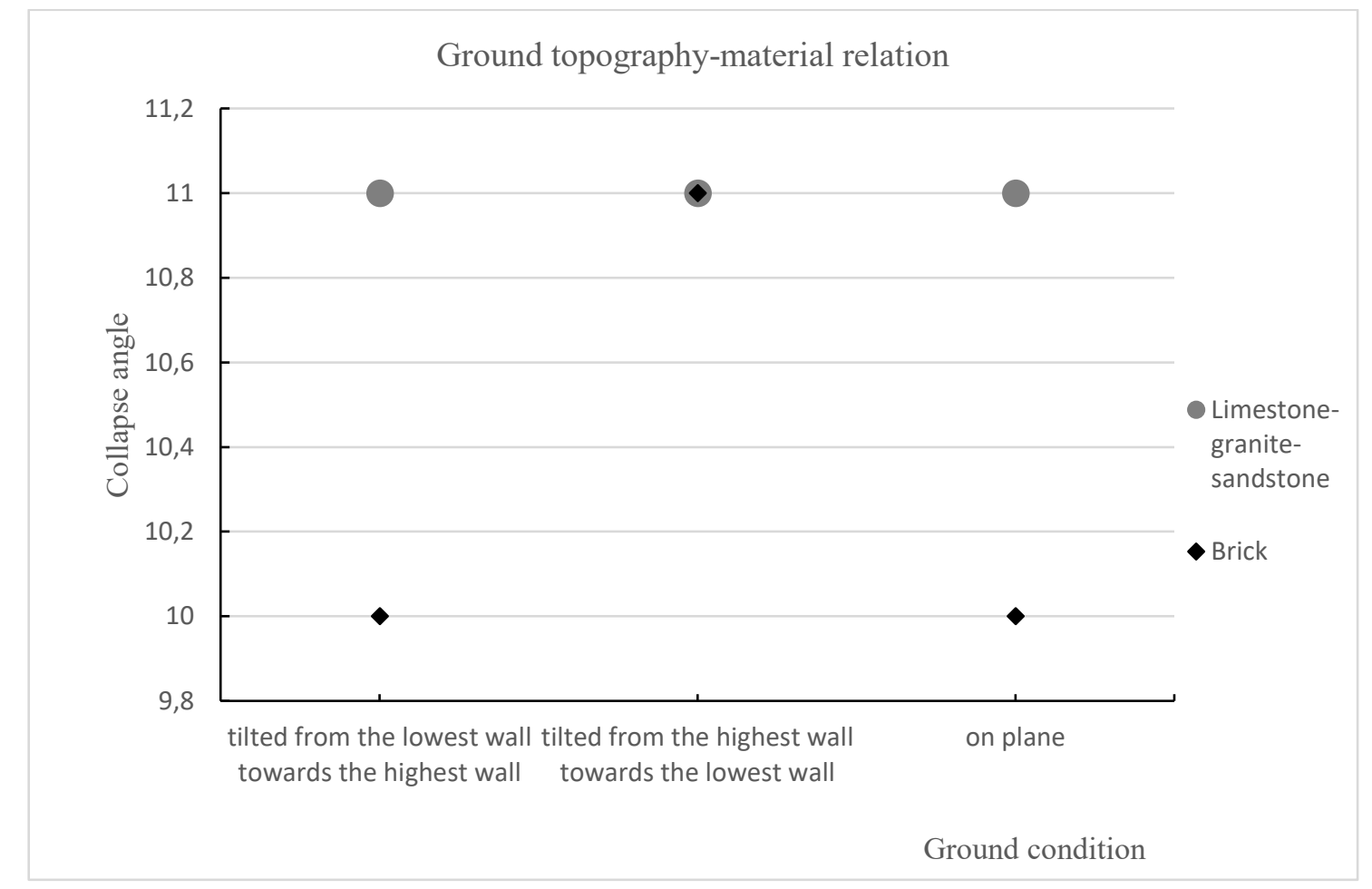

Figure 46. Ground topography in different materials at wall profile 1 


\subsubsection{Failure mechanisms}

There are four types of failure mechanisms determined in the analysis: out-ofplane, in-plane, hybrid and total body failures (Table 23) (Giuffre 1993; D'ayala and Speranza 2003; Preciado et. al 2016; Milanu, Shehu and Valente 2018). Total body failure can be combined with in-plane or out-of-plane wall failures. These mechanisms are listed in the below:

Out-of-plane failure mechanisms:

- Mechanism A: overturning of the facade wall due to the vertical cracking at the corner connections

- Mechanism G: detachment of facade walls due to the diagonal cracking downwards from the corners of the facade

In-plane failure mechanisms:

- Mechanism $B_{1}$ : collapse of one side wall with the facade wall due to the diagonal in-plane cracking

- Mechanism $B_{2:}$ collapse of two side walls with the facade wall due to the diagonal in-plane cracking

Hybrid failure mechanisms:

- Mechanism $\mathrm{B}_{2}+\mathrm{A}$ : collapse of two side walls with facade wall due to diagonal in-plane cracking, followed by overturning of the facade wall due to the vertical cracking at the corner connections

- Mechanism $B_{2}+\mathrm{G}$ : collapse of two side walls with facade wall due to diagonal in-plane cracking, followed by detachment of facade wall due to the diagonal cracking downwards from the corners of the facade.

- Mechanism $\mathrm{B}_{1}+\mathrm{A}$ : collapse of one side wall with facade wall due to diagonal in-plane cracking, followed by overturning of the facade wall due to the vertical cracking at the corner connections.

- Mechanism $\mathrm{B}_{1}+\mathrm{A}+\mathrm{G}$ : collapse of one side wall with facade wall due to diagonal in-plane cracking, followed by overturning of the facade wall due to the vertical cracking at the corner connections and also, at the same time, diagonal cracking upwards from the corners resulting in detachment of the facade wall.

Total body failures: 
- Mechanism $\mathrm{B}_{2 \mathrm{~T}}$ : diagonal in-plane cracking at the body of the tower by shear stresses, followed by horizontal cracking of the rear facade resulting in total overturning of the tower due to bending.

- Mechanism $B_{2 T+v s}$ : diagonal in-plane cracking at the body of the tower by shear stresses and horizontal cracking of the rear facade, followed by vertical in-plane cracking of side walls resulting in total overturning combined with vertical splitting.

Total body failures combined with in-plane and out-of-plane wall failures:

- Mechanism $\mathrm{B}_{2 \mathrm{~T}+\mathrm{DT}}$ : diagonal in-plane cracking at the body of the tower by shear stresses, followed by horizontal cracking of the rear facade combined with detachment of the openings at rear facade due to the bending.

- Mechanism $\mathrm{B}_{1+2 \mathrm{~T}}$ : diagonal in-plane cracking at one side wall and at the body of the tower, resulting in collapse of the side wall and then total overturning of the tower.

\subsection{Mechanisms in different wall profile and opening type combinations}

Failure mechanisms of wall profile and opening type combinations are based on primarily wall profile type; and secondarily dimensions and position of openings at a facade. Mechanisms related to wall profile and opening type are evaluated, when other characteristics are kept constant. Openings are evaluated by taking into consideration their in-plane and out-of-plane positions separately. Impact of an opening type is analyzed at one wall of the tower; other three walls are designed with symmetrical small sized opening that has ideal position and minimum area (op. 1).

First, behavior of towers with different wall profiles consisting of a symmetrical small sized opening (opening type 1) with or without ground opening that has minimum top opening area $\left(1 \mathrm{~m}^{2}\right)$ and ideal position, are investigated for determination of typical failure mechanism types of the wall profiles. The in-plane and out-of-plane behavior of towers with opening type 1 are not investigated separately, since all facades have opening type 1 . 
Table 23. Failure mechanism of towers determined in the analysis

\section{FAILURE MECHANISMS OF TOWERS}

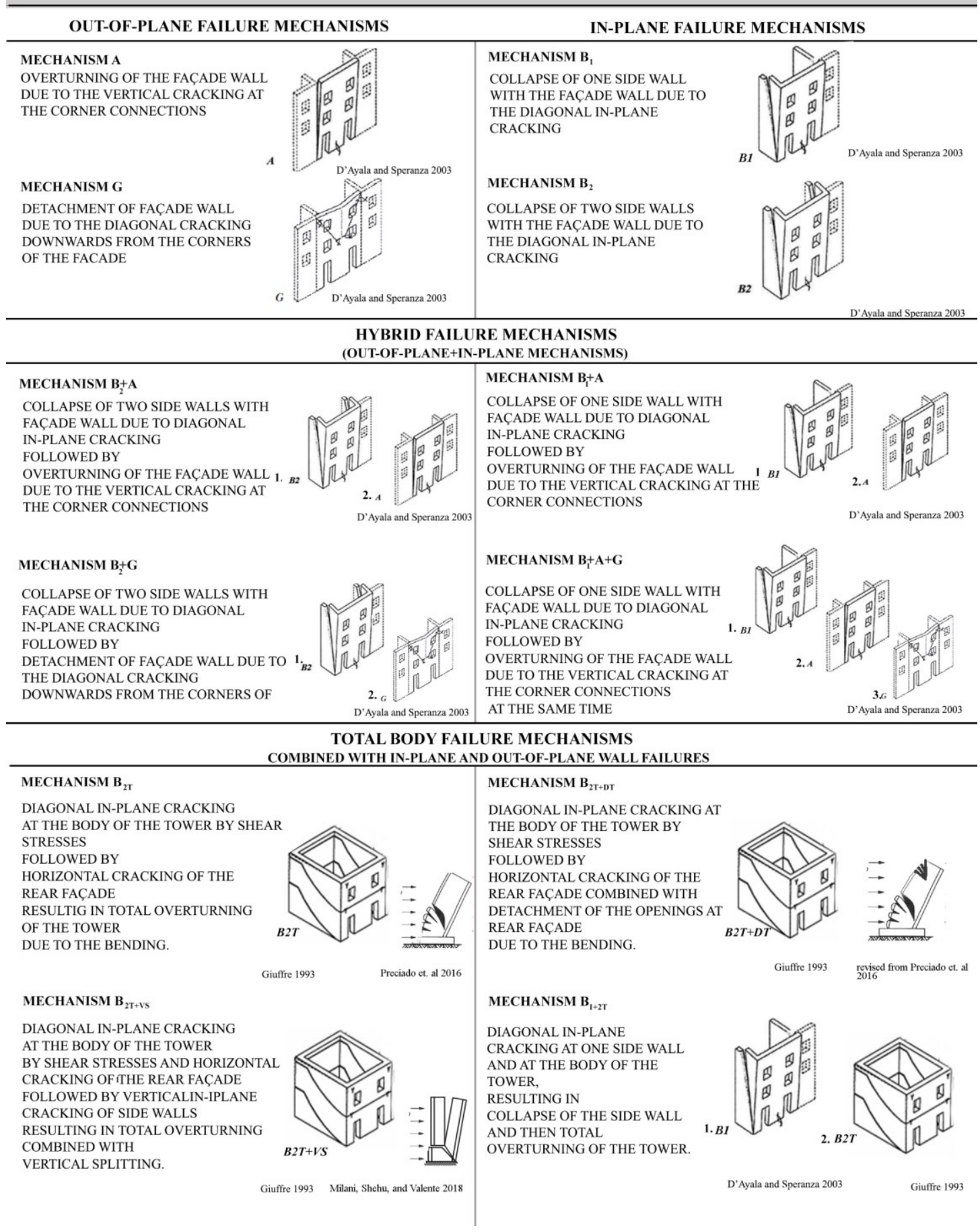

Respective phases of failure mechanisms are presented for each wall profile type in Figure 47. Diagonal in-plane cracking at two side walls result in collapse of two side walls together with facade wall. This failure is followed by out-of-plane overturning of facade wall due to vertical cracking at the corner connection of wall profile 1, 2 and 3 
(Mechanism $\left.\mathrm{B}_{2}+\mathrm{A}\right)$. However, diagonal in-plane cracking at two side walls results in collapse of two side walls together with facade wall at wall profile 4 (Mechanism $B_{2}$ ). At wall profiles 1, 2 and 3, blocks positioned at lower parts of the side walls slide, while sliding is not observed at the wall profile 4 . At wall profiles 1, 2 and 3, side walls collapse with acute angles, demolishing high portions. The height of the demolishing portion is short due to the relatively larger angle of the cracks at wall profile 4. In-plane diagonal cracks causing collapse of side walls is related to shear stresses at the top openings of wall profiles 2, 3 and 4. Diagonal in-plane cracking of wall profile 1 is directly related to the wall profile organization, independent from opening.

Mechanisms of wall profile 5 and 6 is considerably different from wall profile 1 , 2, 3 and 4, since towers constructed with wall profile 5 and 6 present total body behavior; overturning of the tower, in place of wall behavior (mechanism $\mathrm{B}_{2 \mathrm{~T}}$ ). This body behavior comes from in-plane shear, thus it is similar with mechanism $\mathrm{B}_{2}$, however a triangular wall portion collapses at mechanism $\mathrm{B}_{2}$, while trapezoidal shaped body of the tower is overturning at $\mathrm{B}_{2 \text { total. }}$ At wall profile 5, diagonal cracking at the towers body by shear stress is followed by vertical in-plane cracking of the body. At last, total overturning is combined with vertical splitting (mechanism $\mathrm{B}_{2 \mathrm{~T}+\mathrm{VS}}$ ). The tower constructed with wall profile 6 , which collapses at the highest angle, presents only total overturning at 18 degrees due to the horizontal cracking of the body followed by in-plane cracks caused by shear stress (Mechanism B $2 \mathrm{~T}$ (Figure 47).

Up to $18^{\circ}$ collapse angle, wall profile 6 does not present any in-plane and out-ofplane failure at side or facade walls. At $18^{\circ}$ degrees, it presents total body behavior. Also, although wall profile 5 does not collapse at higher angles $\left(14^{\circ}\right)$, it also shows total body behavior. This shows that total body behavior is related to wall profile, since wall profile 4 collapses at higher angle $\left(17^{\circ}\right)$, however it collapses due to the wall behavior. Total behavior does not directly correspond to high resistance against lateral loading.

Other opening types are analyzed depending on their in-plane and out-of-plane positions separately. All collapse phases are examined, and failure mechanism is represented with one phase. Openings types are grouped according to their effectiveness on behavior of wall profile types as effective and less effective ones. Less effective openings are (Figure 34) medium sized symmetrical top opening with or without symmetrical ground opening (op. $2 ; 1.4 \mathrm{~m}^{2}$ ) and asymmetrical small sized opening (op. $3 ; 1 \mathrm{~m}^{2}$ ) with or without symmetrical ground opening and medium sized asymmetrical top opening with symmetrical ground opening (op. $4 ; 1.4 \mathrm{~m}^{2}$ top op. area), symmetrical 
ground and symmetrical top and middle small sized openings (op. 5;2 $\mathrm{m}^{2}$ top and middle op. area), asymmetrical middle medium sized opening (op. $6 ; 2.56 \mathrm{~m}^{2}$ ), asymmetrical ground opening and symmetrical top and middle small sized openings (op. 7;2 $\mathrm{m}^{2}$ top and middle op. area), ground opening adjacent to corner and symmetrical small sized top opening (op. 9; $1.4 \mathrm{~m}^{2}$ top op. area), ground opening adjacent to corner, asymmetrical small sized middle and symmetrical medium sized top opening (op. 12; $2.44 \mathrm{~m}^{2}$ top op. area) and asymmetrical middle large sized and small top sized opening (op. $13 ; 3.3 \mathrm{~m}^{2}$ ).

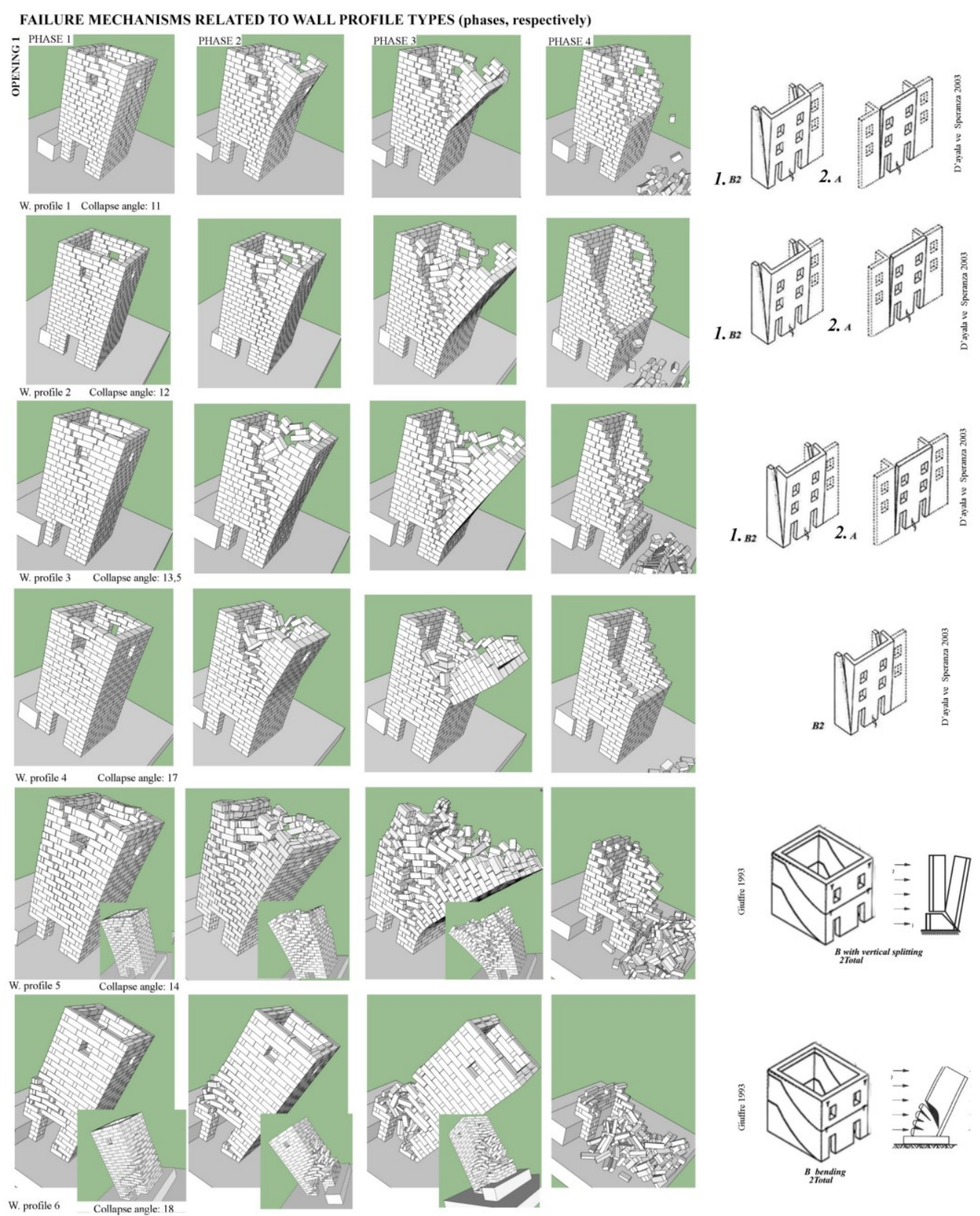

Figure 47. Failure mechanisms of different wall profiles with opening type 1 
These openings at in-plane position generally do not change the mechanisms of the wall profiles with opening 1 , while openings at out-of-plane position cause detachment of out-of-plane wall due to the diagonal cracks downwards from the corners almost in all wall profiles (Mechanism G). Effective openings are symmetrical small sized three top openings with or without ground opening (op. $8 ; 3 \mathrm{~m}^{2}$ top op. area), symmetrical large sized top opening with two small sized top opening and ground opening (op. $10 ; 7.4 \mathrm{~m}^{2}$ top op. area), symmetrical medium sized three top openings with or without ground opening (op. $11 ; 4.3 \mathrm{~m}^{2}$ op. area), middle medium sized opening adjacent to corner and small top sized opening (op. $14 ; 3.3 \mathrm{~m}^{2}$ ) and medium sized top opening adjacent to corner, asymmetrical small sized top opening with ground opening adjacent to corner (op. $15 ; 2.9 \mathrm{~m}^{2}$ ). These openings at in-plane position causes different mechanisms depending on wall profiles. Opening 8,11 and 15 at in-plane position can cause collapse of one side in-plane wall (mechanism $B_{1}$ ), while opening 10 cause fasten collapse of two side walls due to in-plane shear stress at the openings (mechanism B2) in all profile types regardless of their resistance. The only difference between opening 14 $\left(3.3 \mathrm{~m}^{2}\right)$ and opening 13 is adjacent position of the middle opening, opening 14 can cause diagonal cracking as wedge shape while collapsing of two side walls due to the in-plane cracking (mechanisms $\mathrm{B}_{2}$ ) depending on wall profile type.

First, less effective opening types $(2-7,9,12,13)$ are presented for each wall profile. Then, effective ones are examined in detail.

At the wall profile 1, less effective opening types at in-plane position present almost the same mechanism with opening 1 (mechanism $\mathrm{B}_{2}+\mathrm{A}$ ). Diagonal in-plane cracking is not related to the openings 2-7,9, collapse occurs due to the characteristics of the wall profile independent from openings, however openings 6, 12 and 13 composed of asymmetrical top openings cause diagonal in-plane cracking at openings (Figure 48).

Openings at out-of-plane position cause detachment of facade wall due to the diagonal cracks downwards from the corner with sliding of top blocks of side walls (mechanism G) (Figure 48). There is not any impact of asymmetrical ground openings (9) on form of collapsing portion.

At wall profiles 2, symmetrical top openings (2, 5, 7 and 9) at in-plane position cause diagonal in-plane cracking at the openings and mechanism of wall profile with opening 1 sustains (mechanism $\mathrm{B}_{2}+\mathrm{A}$ ); diagonal in-plane cracking at two side walls resulting in collapse of two side walls with facade wall and this failure is followed by out- 
of-plane overturning of the facade wall due to vertical cracking at the corner connections. However, asymmetrical openings (3, 4, 6, 12 and 13) cause directly collapse of two side walls without vertical cracking at the corners (mechanism B2). Depending on position and size of openings at in-plane position, angle of crack and form of collapsed portion change.

\section{FAILURE MECHANISMS IN DIFFERENT OPENINGS AT WALL PROFILE 1}

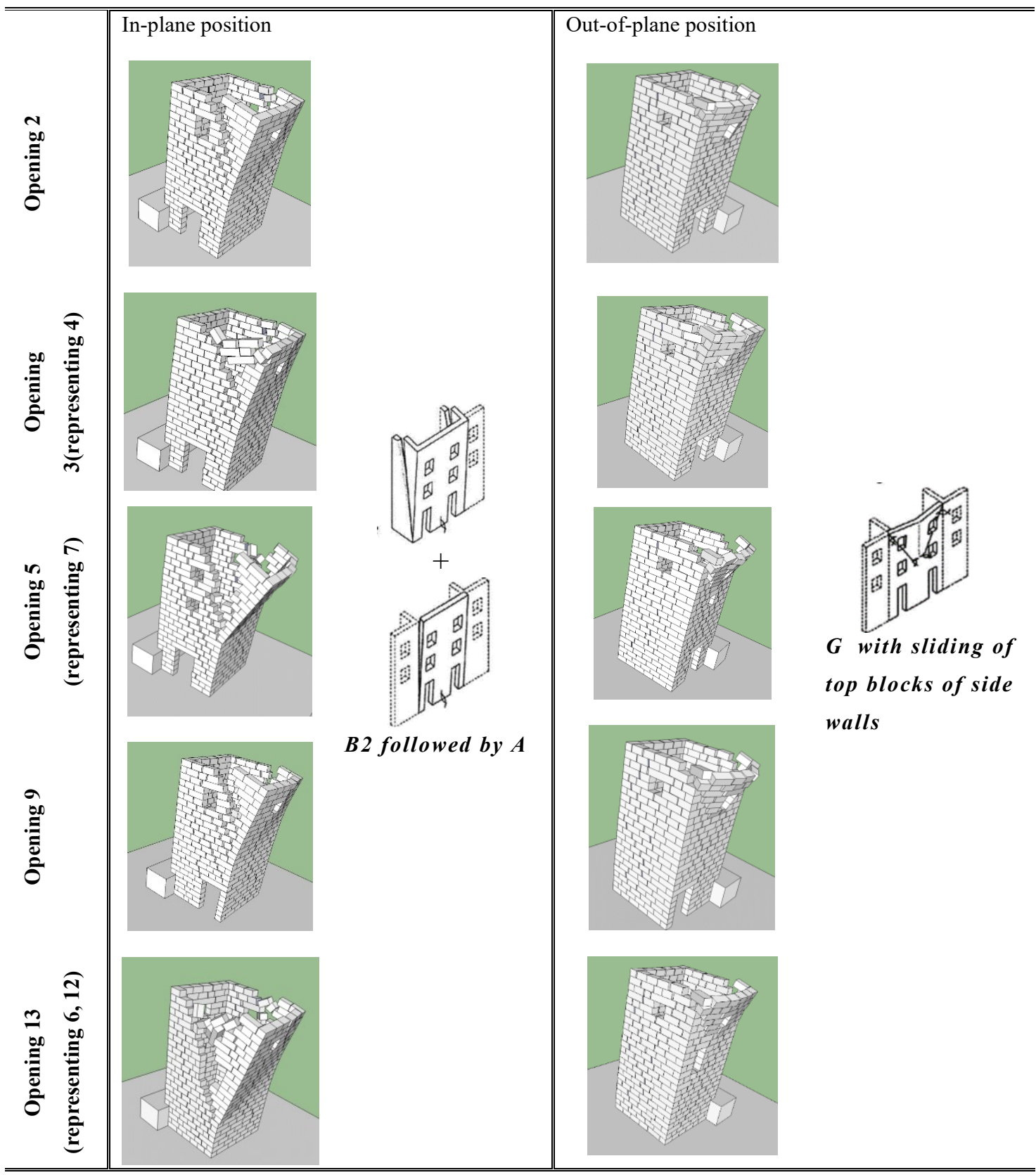

Figure 48. Similar failure mechanisms of different opening types at wall profile 1 
For example, a middle and top opening (op. 5, 7 and 12) and middle medium sized openings (op. 6 and 13) cause increase in height of the collapsed portion due to the cracking at their top and bottom (Figure 49). There is not any impact of asymmetrical ground openings (9) on form of collapsing portion, its mechanism is similar with opening 2. All openings at out-of-plane position cause diagonal cracking downward from the corners resulting in detachment of facade wall with sliding of top blocks of side walls (mechanism G).

\section{FAILURE MECHANISMS IN DIFFERENT OPENINGS AT WALL PROFILES 2}

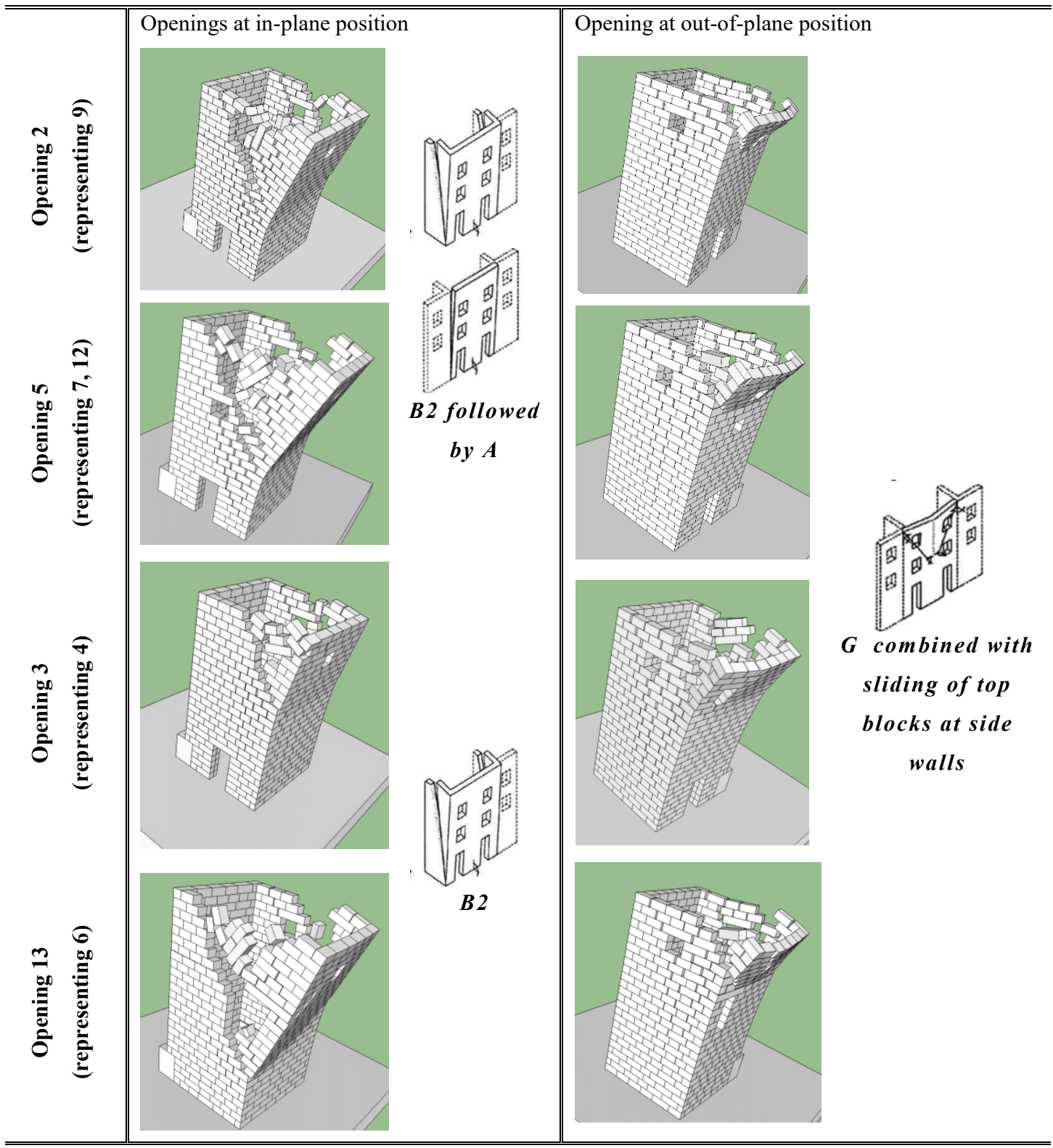

Figure 49. Similar impact of openings 2-7, 9, 12, 13 at wall profiles 2 
At wall profiles 3, less effective opening types at in-plane position presents the same mechanism with opening 1 as wall profile 1 and 2 (mechanism $\left.B_{2}+A\right)$. Depending on position and size of openings at in-plane position, angle of crack and form of collapsed portions change. For example, a middle and a top opening or medium sized asymmetrical openings (op. 5-7, 12-13) cause cracks at their top and bottom, height of the collapsed portion increases. Openings at out-of-plane position cause only collapse of two sized walls due to the in-plane cracks (mechanism $\mathrm{B}_{2}$ ). (Figure 50). There is not any impact of asymmetrical ground openings (9) on the form of collapsed portion, its mechanism is similar with opening 2 .

FAILURE MECHANISMS IN DIFFERENT OPENINGS AT WALL PROFILE 3

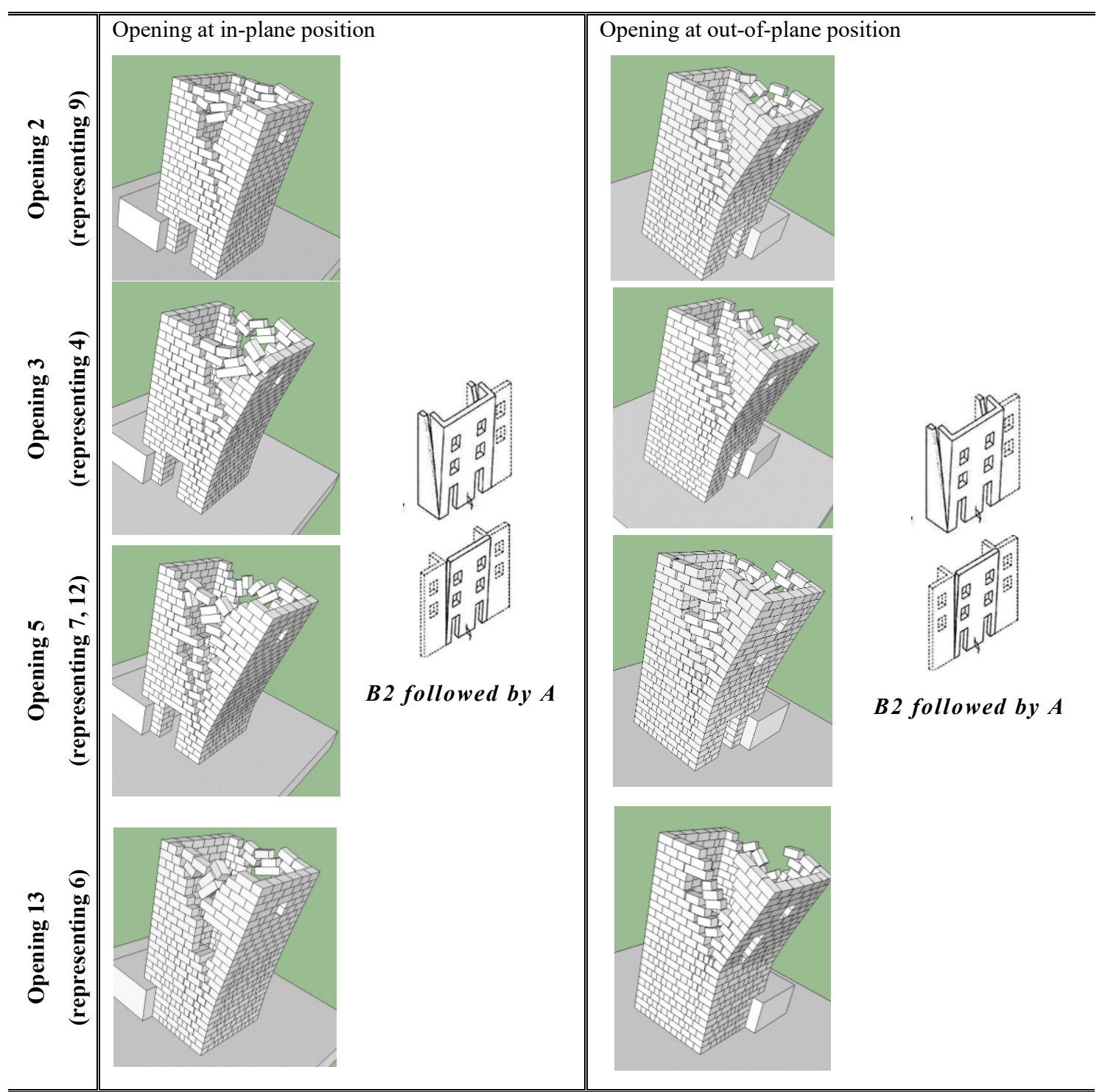

Figure 50. Similar impact of openings 2-7, 9, 12, 13 at wall profiles 3 
At wall profiles 4, less effective opening types at in-plane position present the same mechanism with opening 1 (mechanism $\left.B_{2}\right)$. Depending on position and size of openings at in-plane position, angle of crack and form of collapsing portion change. For example, a middle and a top opening or medium sized asymmetrical openings (op. 5-7, 12-13) cause cracks at their top and bottom, height of the collapsed portion increases. Openings at out-of-plane position cause collapse of two side walls due to the in-plane cracking (mechanism $\mathrm{B}_{2}$ ), also vertical cracks can be observed at the corner connections (Figure 51). With the help of the characteristic of wall profile, the openings do not cause detachment.

FAILURE MECHANISMS IN DIFFERENT OPENINGS AT WALL PROFILE 4

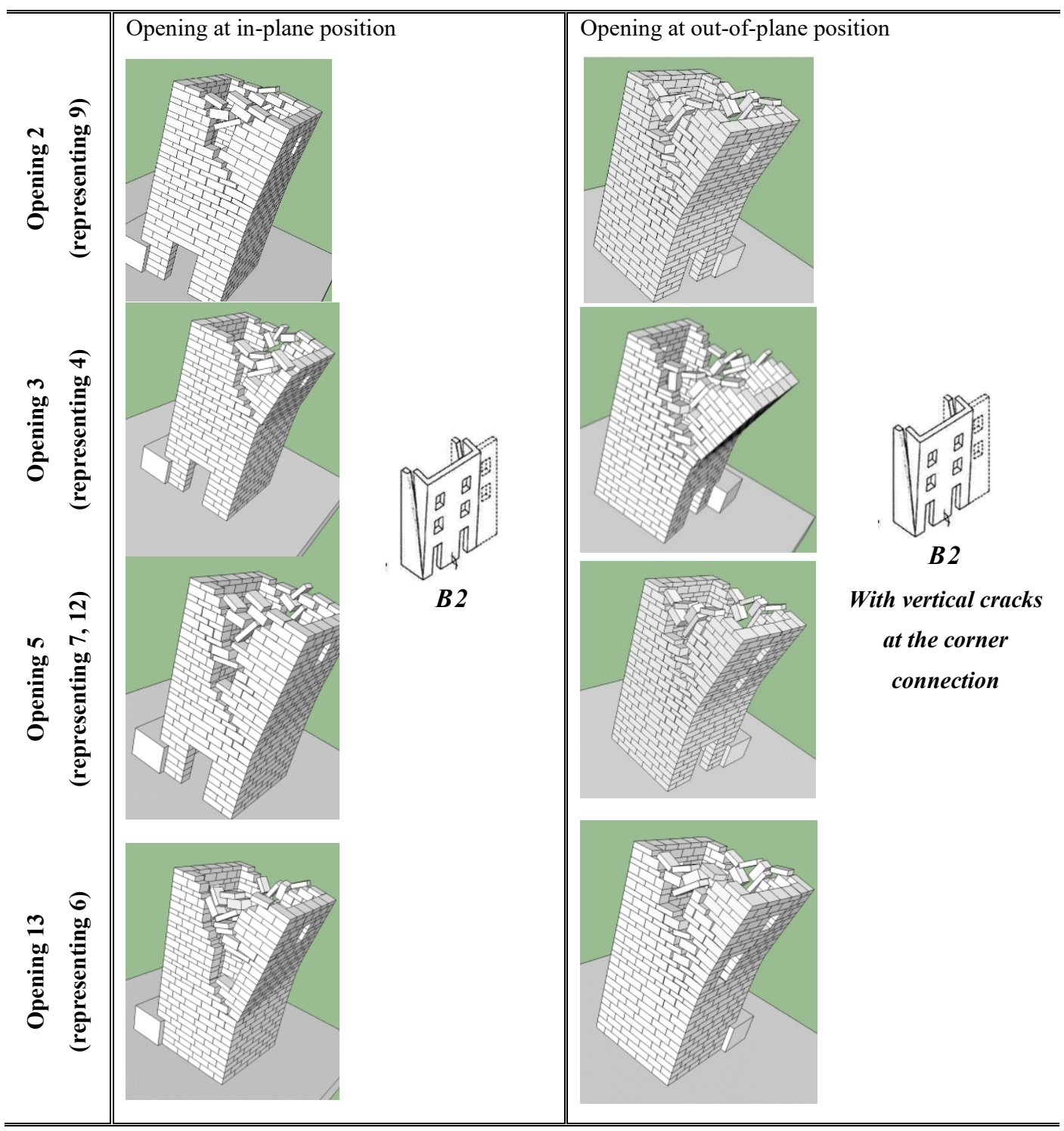

Figure 51. Similar impact of openings 2-7, 9, 12, 13 at wall profiles 4 
At wall profile 5, openings at in-plane position, except asymmetrical small or medium sized (op. 3 and 4), sustain failure mechanism of opening 1; diagonal cracking at the tower's body by shear stress and horizontal cracking at the rear facade is followed by vertical in-plane cracking of the tower body and total overturning is combined with vertical splitting (mechanism $\mathrm{B}_{2 \mathrm{~T}+\mathrm{Vs}}$ ). However, asymmetrical small or medium sized top openings (openings 3 and 4) do not cause vertical splitting due to their position and the tower present only total overturning due to bending (Figure 52).

Openings at out-of-plane position also cause total overturning with detachment of rear facade due to the bending (mechanism $\mathrm{B}_{2 \mathrm{~T}+\mathrm{DT}}$ ). For openings 3 and 4 , total overturning is combined with vertical splitting (Figure 52).

\section{FAILURE MECHANISMS IN DIFFERENT OPENINGS AT WALL PROFILE 5}

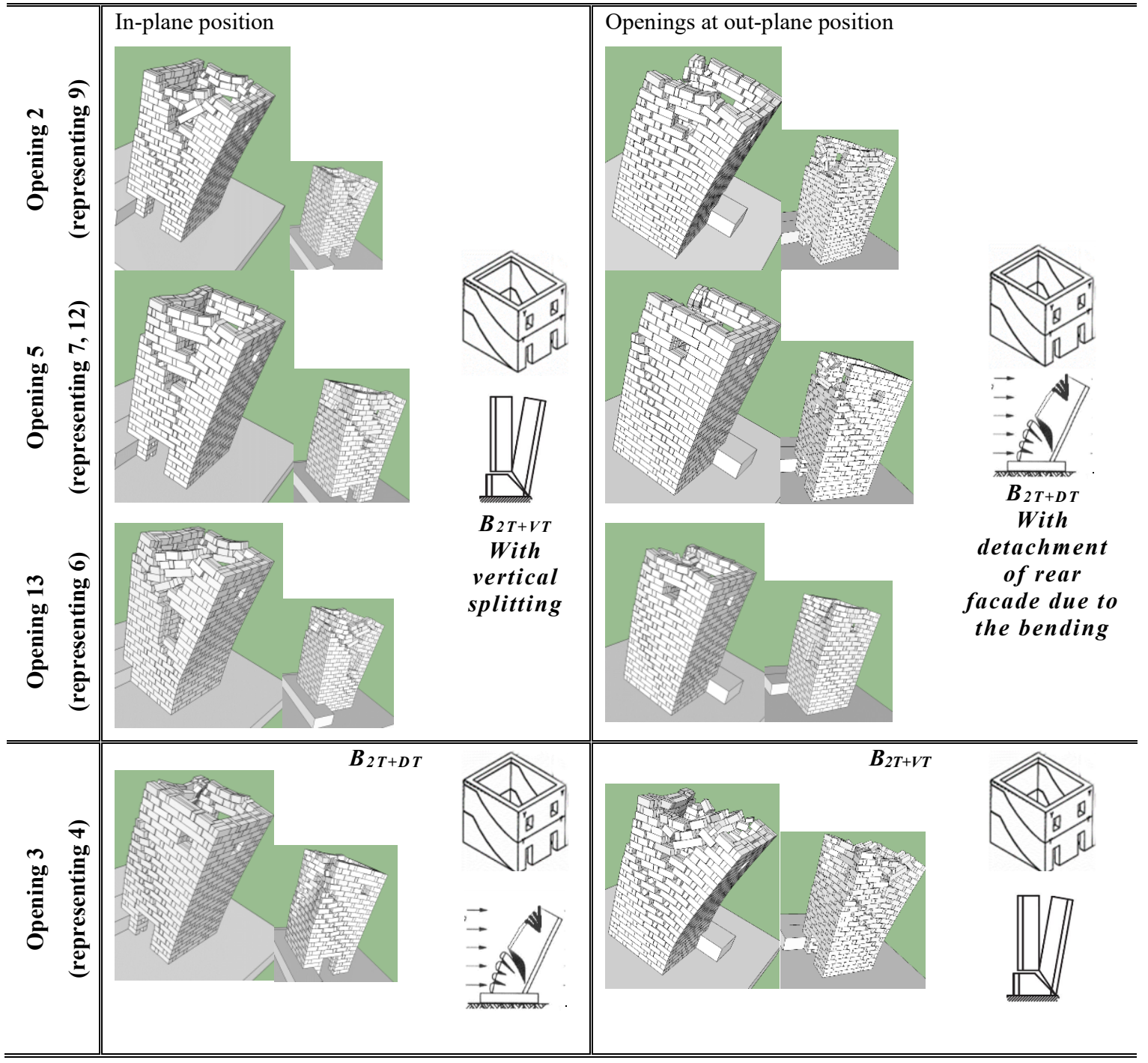

Figure 52. Similar impact of openings 2-7, 9, 12, 13 at wall profiles 5 
At wall profile 6, both openings at in-plane and out-of-plane position present the same mechanism with opening 1 , the tower presents total overturning due to bending at higher collapse angles $\left(18^{\circ}\right)$. However, opening 13 at in-plane cause vertical cracking at the body of the tower, the towers present total overturning combined with vertical splitting (mechanism $\mathrm{B}_{2 \mathrm{~T}+\mathrm{VS}}$ ) (Figure 53).

\section{FAILURE MECHANISMS IN DIFFERENT OPENINGS AT WALL PROFILE 6}

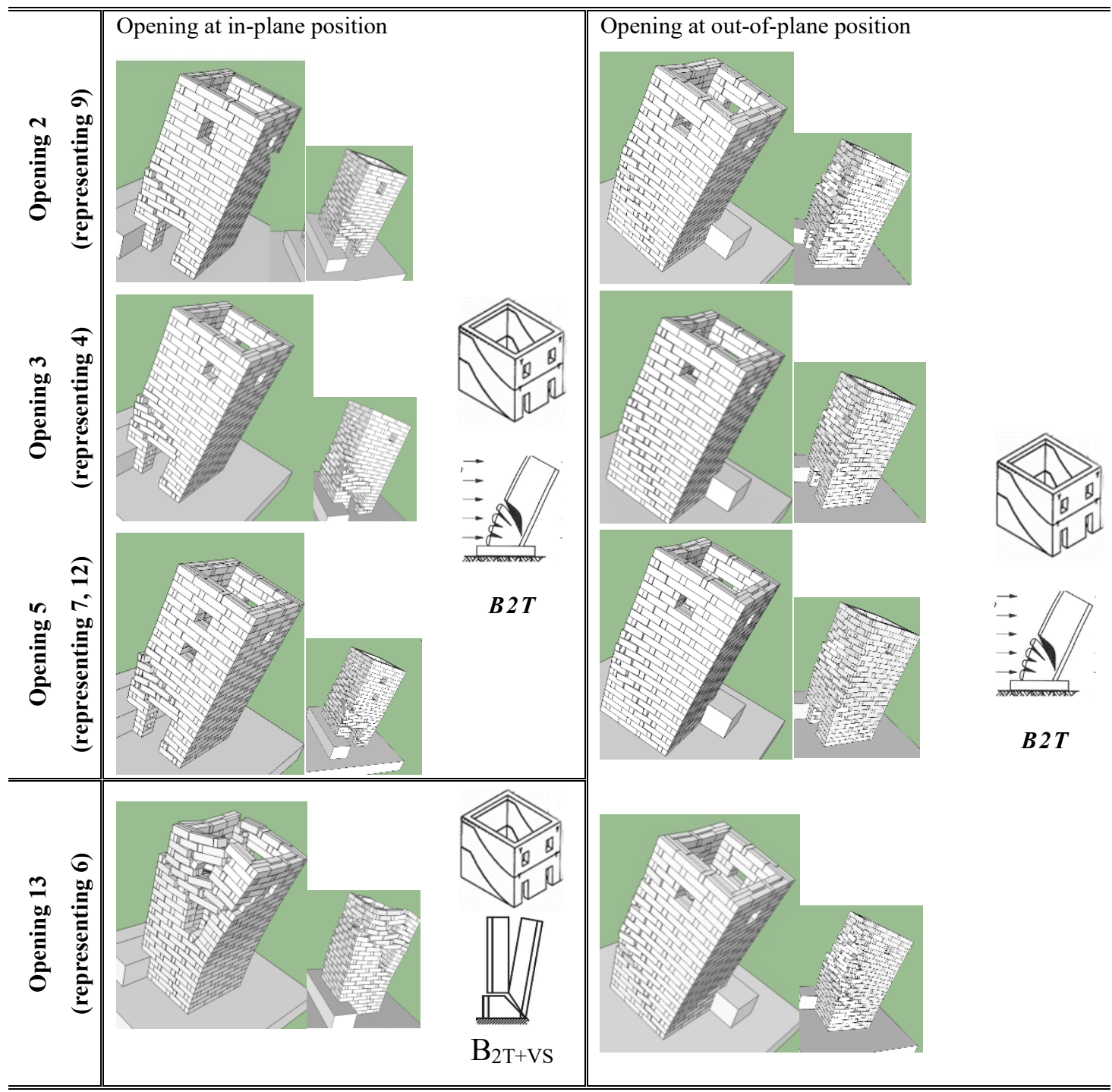

Figure 53. Impact of openings 2-7, 9, 12, 13 at wall profiles

Openings $(2-7,9,12$ and 13) at in-plane and out of plane positions generally present similar mechanisms with respect to wall profiles. However, effective openings 8 , $10,11,14$ and 15 can cause change in these mechanisms depending on characteristics of 
wall profiles. Opening 8 ( $3 \mathrm{~m}^{2}$ top op. area), opening 10 (7.4 $\mathrm{m}^{2}$ top op. area) with large sized top opening (180x300) and small sized two top openings $(100 \times 100 \mathrm{~cm})$, opening $11\left(14.4 \mathrm{~m}^{2}\right)$ with three top openings each $(90 \times 160 \mathrm{~cm})$, opening $15\left(2.9 \mathrm{~m}^{2}\right.$ top op. area) with medium sized top opening $(140 \times 210 \mathrm{~cm})$ adjacent to corner and asymmetrical top opening $(75 \times 160 \mathrm{~cm})$ affect behavior of wall profiles prominently.

First, impact on symmetrical small or medium sized three top openings with or without ground opening is examined (op. 8 and 11). Opening 8 and 11 at in-plane position cause collapse of two side walls due to the diagonal in-plane cracking (Mechanism $\mathrm{B}_{2}$ ) at wall profile 2, 3 and 4, while collapse of one side wall occur at wall profile 1 and 5 due to the in-plane cracking at the opening (mechanism $\mathrm{B}_{1}$ ). Also, at wall profile 6 , in-plane diagonal cracking at the openings and at the tower's body due to the in-plane shear stress result in collapse of the side wall followed by total overturning (mechanism $\mathrm{B}_{1+2 \mathrm{~T}}$ ).

Opening 8 and 11 positioned at out-of-plane wall cause detachment of the facade wall due to the diagonal cracks downwards from the corners (mechanism $G$ ) at wall profile 1 and 2. However, at wall profile 3 and 5 mechanism $\mathrm{G}$ is combined with some other mechanisms. At wall profile 3, collapse of two side walls with facade wall due to the in-plane diagonal cracking is followed by detachment of facade wall due to diagonal cracks downwards from the corners at the openings (mechanism $\mathrm{B}_{2}+\mathrm{G}$ ). At wall profile 5 , total overturning of the tower due to the in-plane body cracking and horizontal cracking at the rear facade is combined with detachment of rear facade due to the bending (mechanism $\mathrm{B}_{2 \mathrm{~T}+\mathrm{DT}}$ ). Wall profile 4 and 6 sustain their typical mechanisms in spite of the effective openings (Figure 54, Figure 55).

Effect of opening $8\left(3 \mathrm{~m}^{2}\right)$ which has three top openings, on failure mechanisms is similar with opening 11, although its effect on collapse angle is less in comparison to wall profile 11 as seen in heading 3.3.1.1.1 (Figure 54).

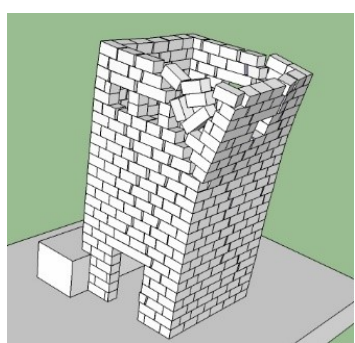

B 1

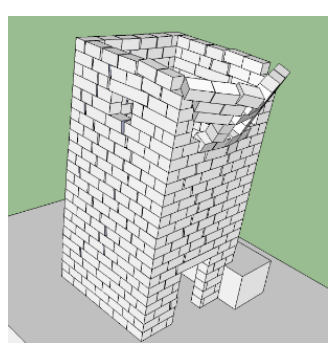

G

Figure 54. Openings 8 and 11 at in plane (left) and out of plane (right) positions 


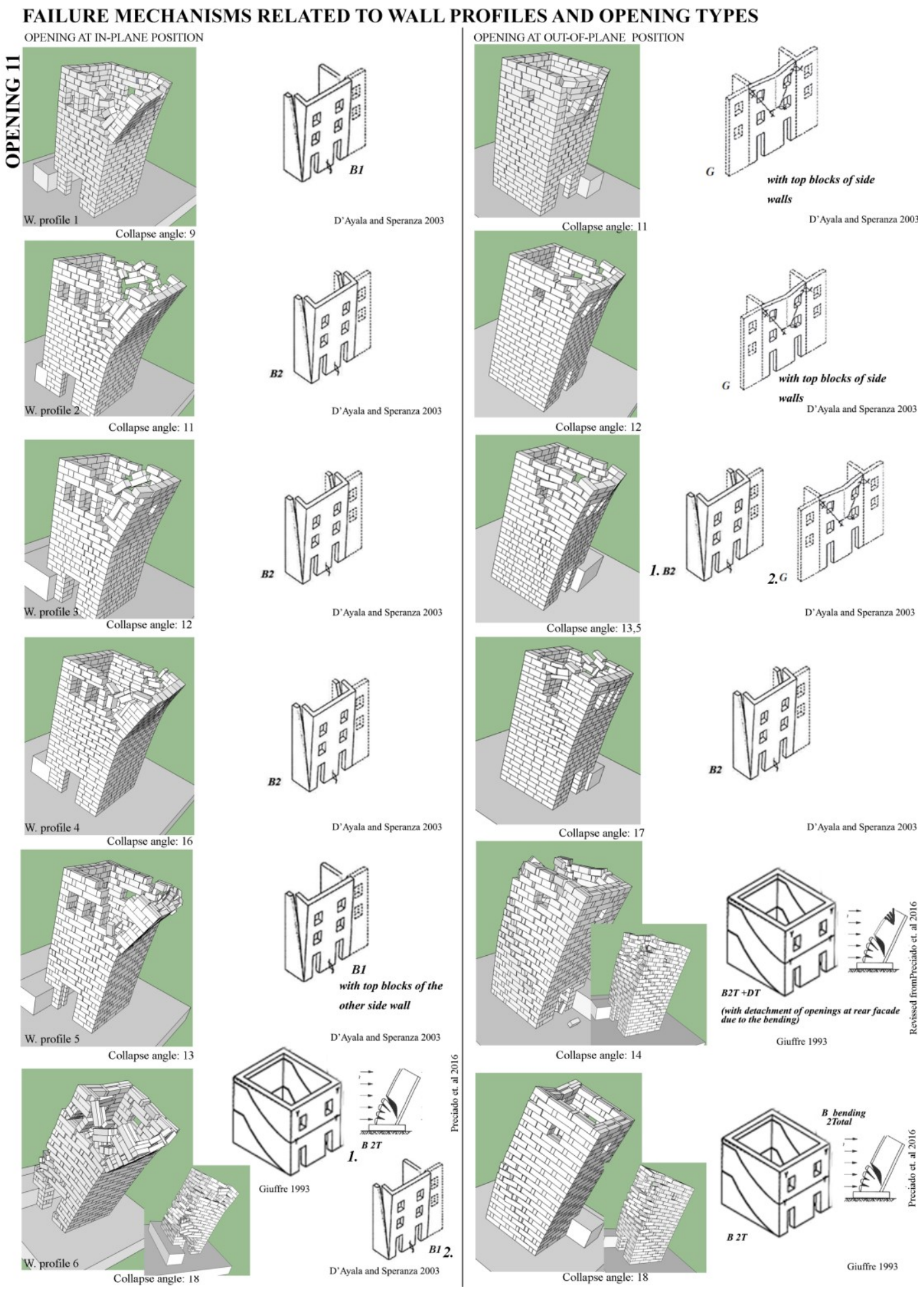

Figure 55. Effect of opening 11 on behavior of towers

Opening 10 (Figure 35), which has a large overall upper opening area, $\left(7.4 \mathrm{~m}^{2}\right.$ top openings, $4.86 \mathrm{~m}^{2}$ ground opening) at in-plane position, causes collapse of two side walls due to the diagonal in-plane cracking at the openings in all profile types (Mechanism $\mathrm{B}_{2}$ ). Wall profile 1, 2 and 3 (mechanism $\mathrm{B}_{2}+\mathrm{A}$ ) and wall profile 4 (mechanism $\mathrm{B}_{2}$ ) sustains 
their typical failure mechanisms, however openings decrease collapse angles considerably and increase the area of the collapse portions in comparison to less effective openings $(2-7,9)$. Wall profile 5 and 6 do not present total body behavior due to the effect of opening, they present only mechanism $\mathrm{B}_{2}$ by shear stresses at openings, also rear wedge facade portion collapse due to the opening close to the corner and rear facade (Figure 56).

Opening 10 at out-of-plane position sustains the typical failure mechanisms of wall profiles 1 (mechanism G), 2 (mechanism G), 3 (mechanism G), and 5 (Mechanism $\left.\mathrm{B}_{2 \mathrm{~T}+\mathrm{DT}}\right)$ but collapse at lower collapse angles in comparison to less effective openings (mechanism G). It causes occurrence of collapse of two side wall due to the in-plane diagonal cracking followed by detachment of the facade due to the diagonal cracks downwards from the corner (mechanism $B_{2}+G$ ) at wall profile 4 . However, opening at out-of-plane position do not cause any failure mechanism at wall profile 6 , wall profile sustains typical mechanism; total overturning (Figure 56).

Middle large sized opening adjacent to corner with small sized top opening at inplane position (op. $14 ; 3.3 \mathrm{~m}^{2}$ ) causes mainly collapse of two side walls due to the diagonal in-plane cracking. However, this mechanism is followed by diagonal cracking of collapsed orthogonal walls as wedge portions at wall profile 2, 3, 5 and 6. Sequence of cracking as a wedge portion comes from other failure mechanism, since it is not the main effect of the failure. Wall profile 1 and 4 sustain their failure mechanisms without diagonal cracking of orthogonal walls (mechanism $\mathrm{B}_{2}+\mathrm{A}$ and $\mathrm{B}_{2}$, respectively).

Wall profiles sustain their typical failure mechanisms when opening at out-ofplane position, however, collapse angle of towers decrease in comparison to ineffective openings (Figure 57).

Opening 15 (2.9 $\mathrm{m}^{2}$ top op. area) that has top medium sized opening adjacent to corner with asymmetrical top small sized opening at in-plane position causes collapse of the side wall related to opening adjacent to corner (mechanism $B_{1}$ ) at wall profile 1, 4 and 5 prominently. However, collapse of two side walls occurs at wall profile 2 and 3 (mechanism $\mathrm{B}_{2}$ ). Wall profile 6 sustain its typical failure mechanisms (mechanism $\mathrm{B}_{2 \mathrm{~T}}$ ).

When openings are at out-of-plane position, detachment of facade wall occur due to diagonal cracking downwards from the corners. At wall profiles 5 and 6 , total overturning is combined with detachment of openings at rear facade due to the bending (Figure 58). 


\section{FAILURE MECHANISMS RELATED TO WALL PROFILES AND OPENING TYPES}
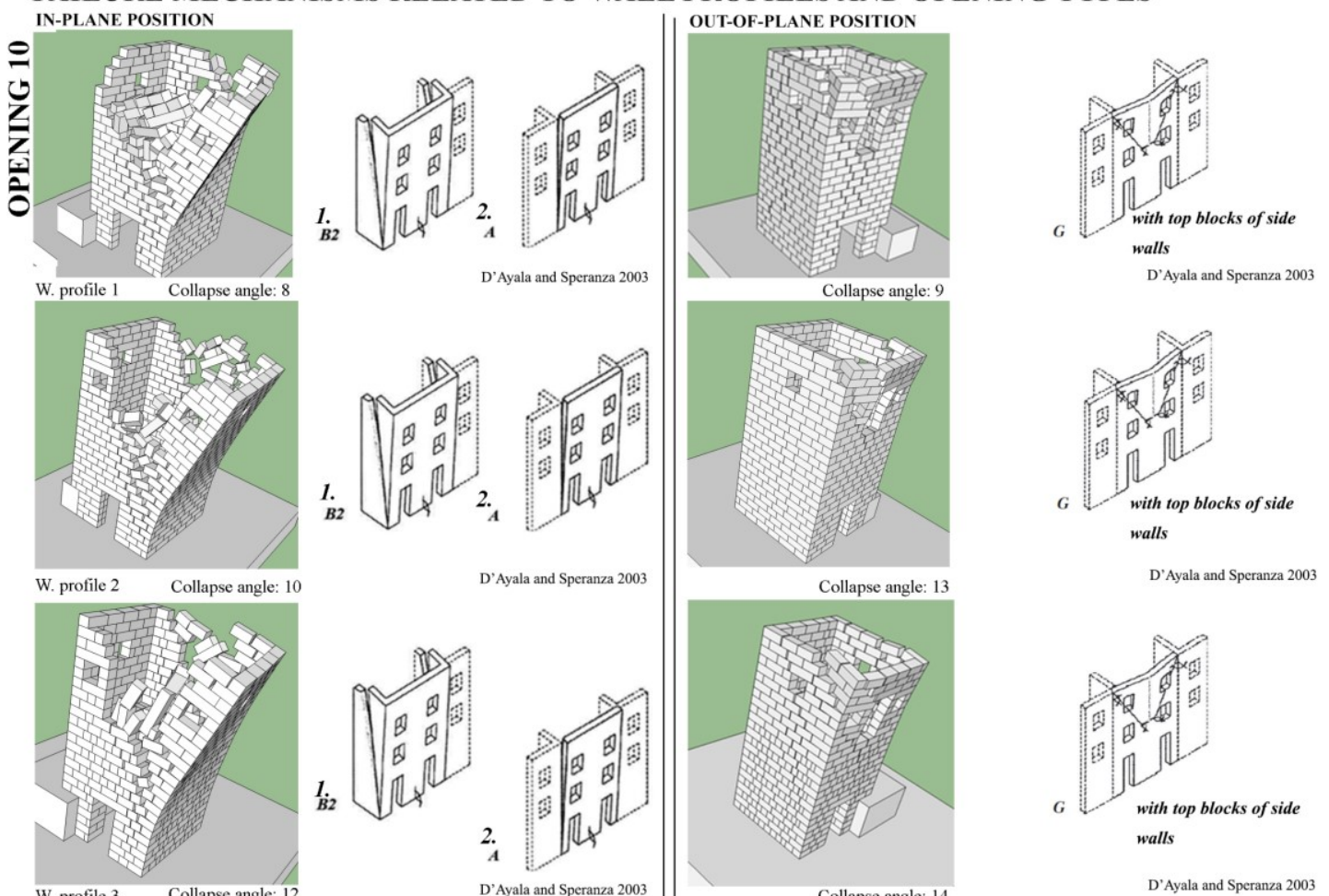

walls
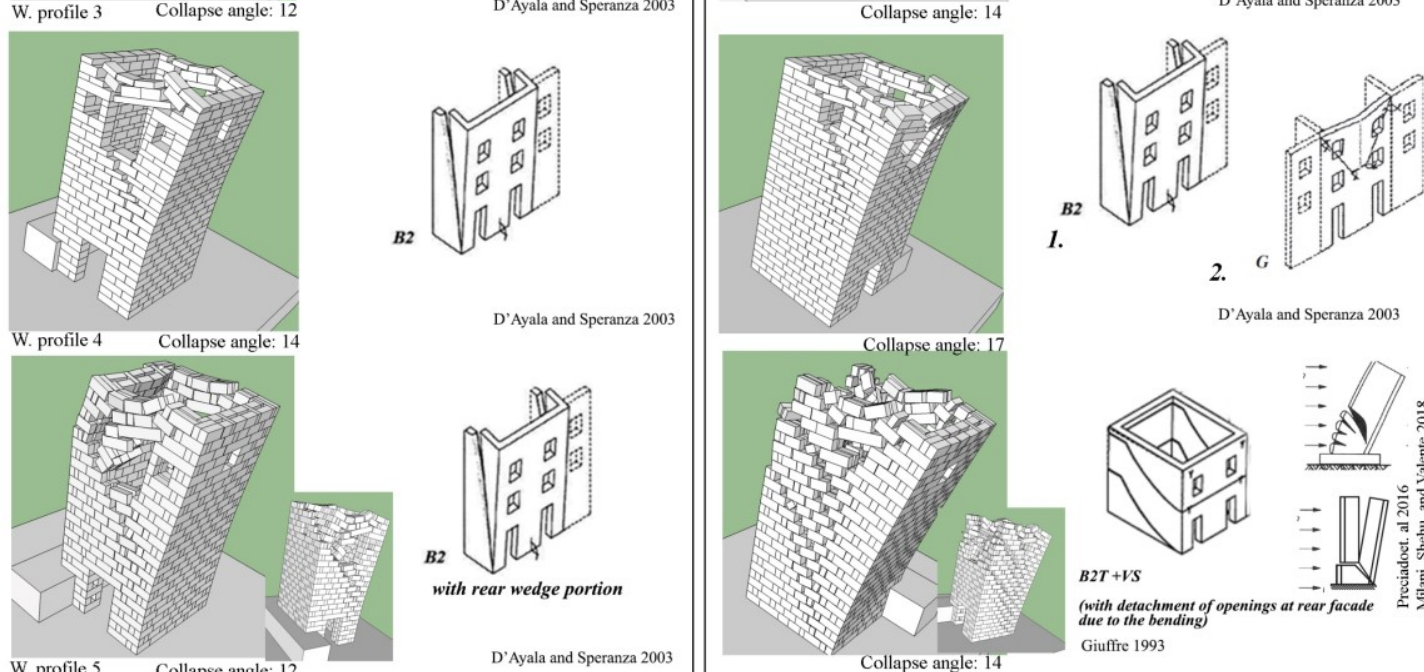

D'Ayala and Speranza 2003
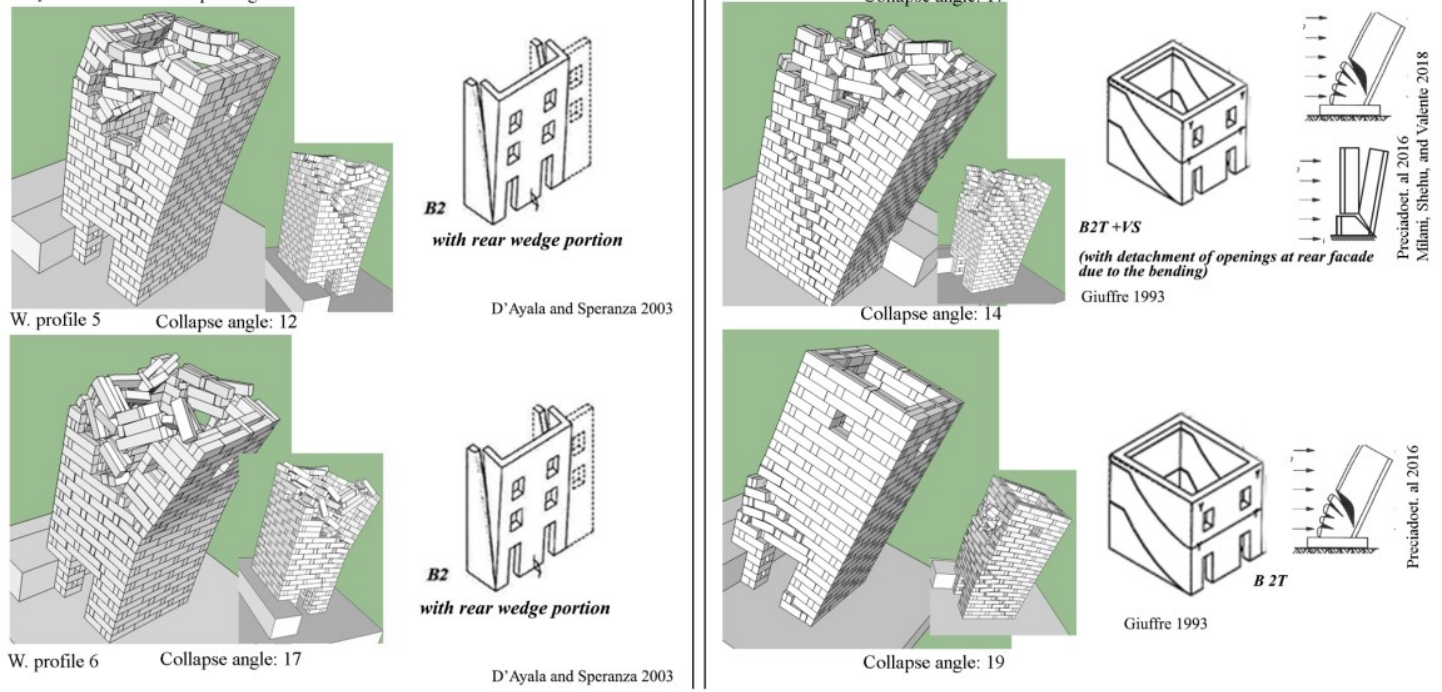

Figure 56. Effect of opening 10 on behavior of towers 


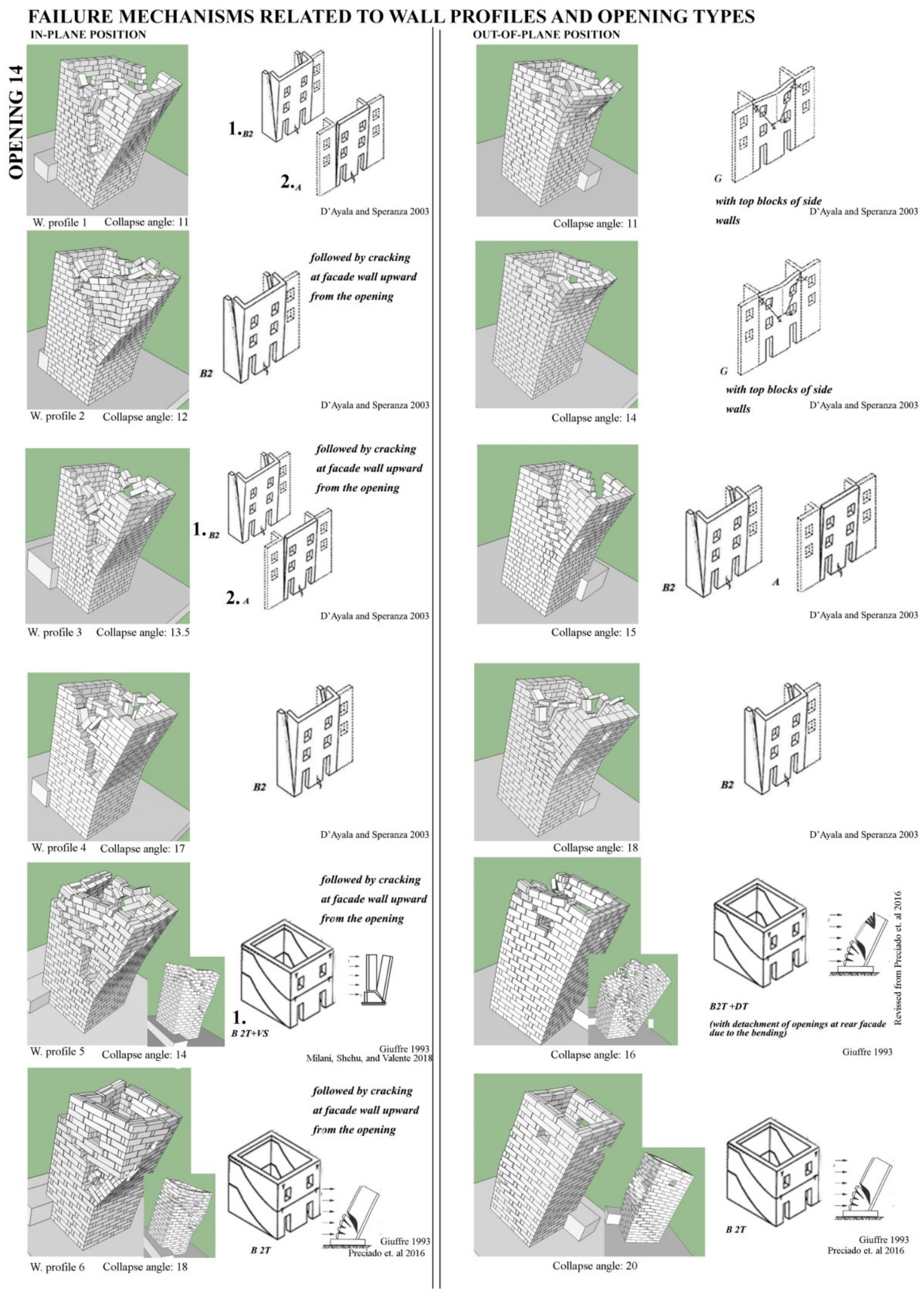

Figure 57. Failure mechanism of wall profiles with opening 14 


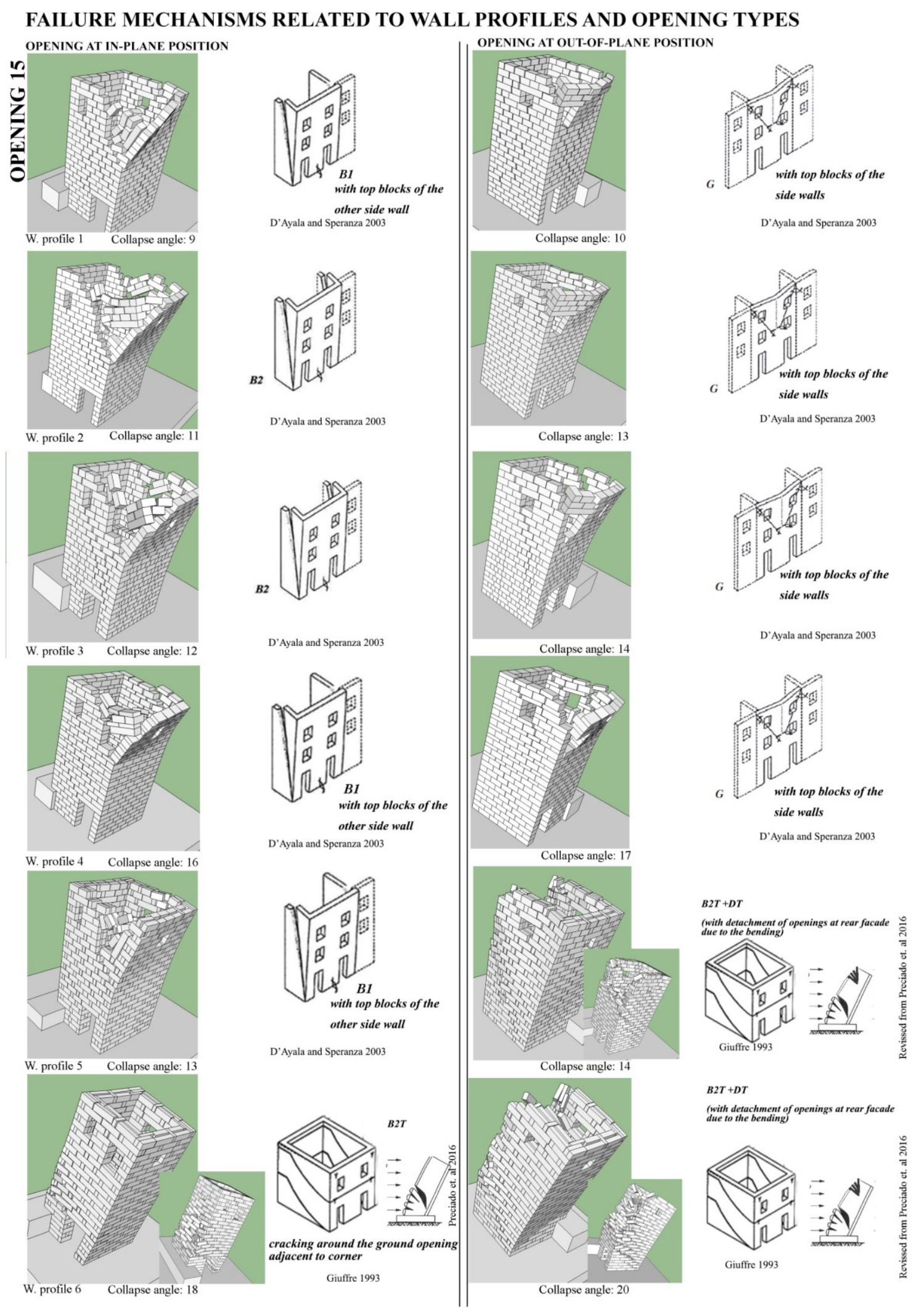

Figure 58. Effect of opening 15 on behavior of towers 


\subsection{Mechanisms in different wall profile and $h / l$ combinations}

Failure mechanisms of wall profile and $h / 1$ ratio combinations are based on primarily wall profile type and secondarily h/l ratios. Mechanisms related to wall profile and $\mathrm{h} / \mathrm{l}$ combinations is evaluated, when other characteristics are kept constant. Wall profiles generally sustain their typical failure mechanisms for $\mathrm{h} / \mathrm{l}$ ratios between 1.6 and 2.3 (Figure 47, Figure 59). Only wall profile 5 does not sustain its typical mechanism in 1.6 and $2.3 \mathrm{~h} / 1$ ratios. Wall profile 5 in $1.6 \mathrm{~h} / 1$ ratio presents collapse of two side walls due to the diagonal in-plane crackings (mechanism $\mathrm{B}_{2}$ ), however wall profile 5 present total overturning with vertical splitting in other ratios (mechanism $\mathrm{B}_{2 \mathrm{~T}}$ with vertical splitting presented in Figure 47 in detail). In 2.3 ratio, vertical splitting is not observed, the tower is overturning due to the bending (mechanism $\mathrm{B}_{2 \mathrm{~T}}$ ) (Figure 59).

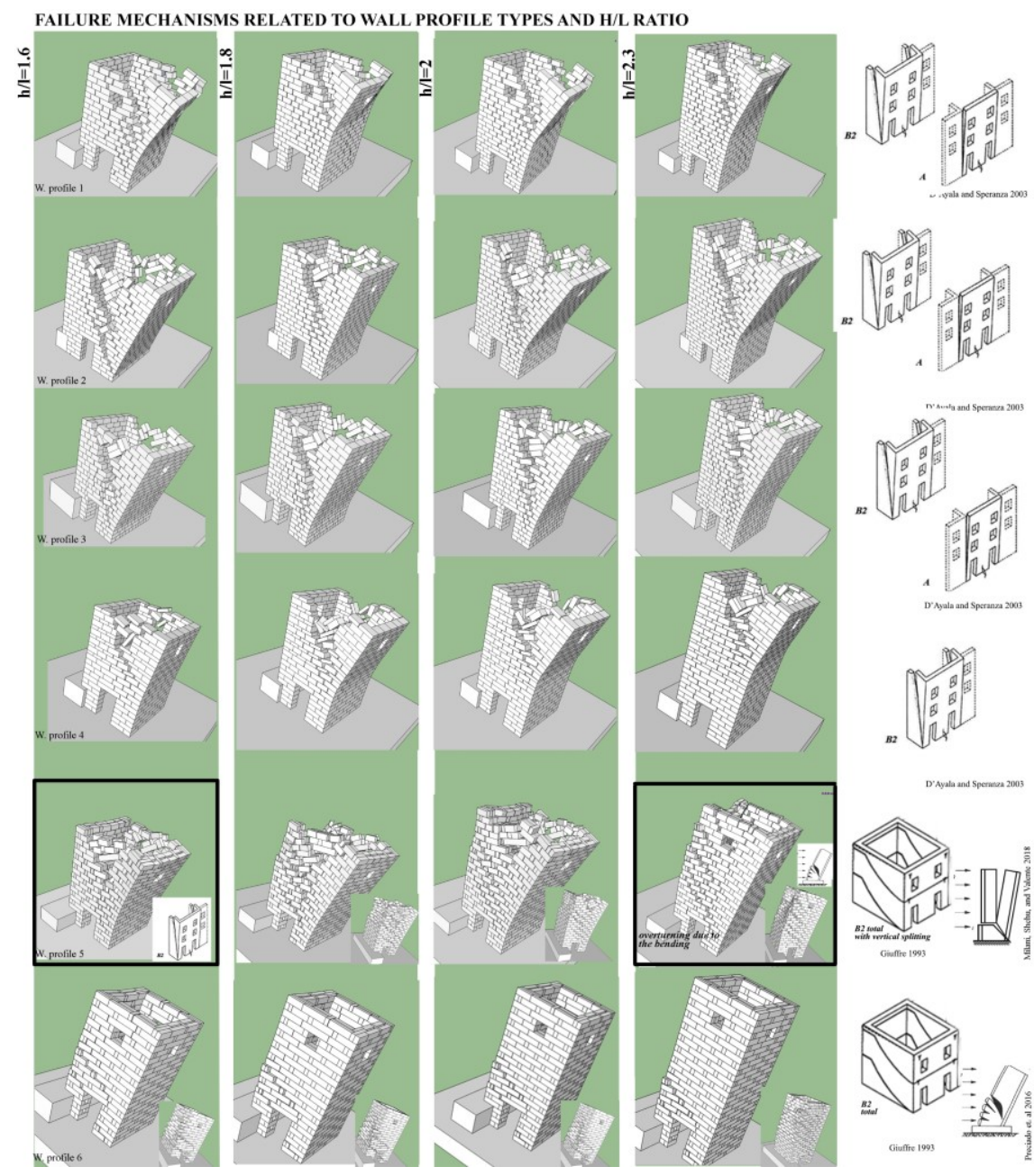

Figure 59. Effect of wall profiles on behavior in different $\mathrm{h} / \mathrm{l}$ ratio 
If the ratio is 1.3 or smaller than 1.3 , mechanisms change due to the small $\mathrm{h} / 1$ ratio. $\mathrm{h} / \mathrm{l}$ ratio smaller than 1.3 causes generally overturning of facade wall due to the vertical cracks at the corners. At wall profile 2 and 3, overturning of only the facade wall occurs due to the vertical cracks at side walls and sliding of top blocks (mechanism A) (Figure 60). However, at wall profile 1 , detachment of out-of-plane facade wall due to the diagonal cracks at the upper corners of side walls is observed (mechanism G).

At wall profile 4, collapse of two side walls is followed by vertical cracking at the corner connection (mechanism $\mathrm{B}_{2}+\mathrm{A}$ ). At wall profile 5, in place of overturning, collapse of two side walls due to in-plane cracking occurs as $1.6 \mathrm{~h} / 1$ ratio. Wall profile 6 sustains its typical behavior, however due to the bending, detachment of the rear facade is also observed (mechanism $\mathrm{B}_{2+\mathrm{DT}}$ ) (6).

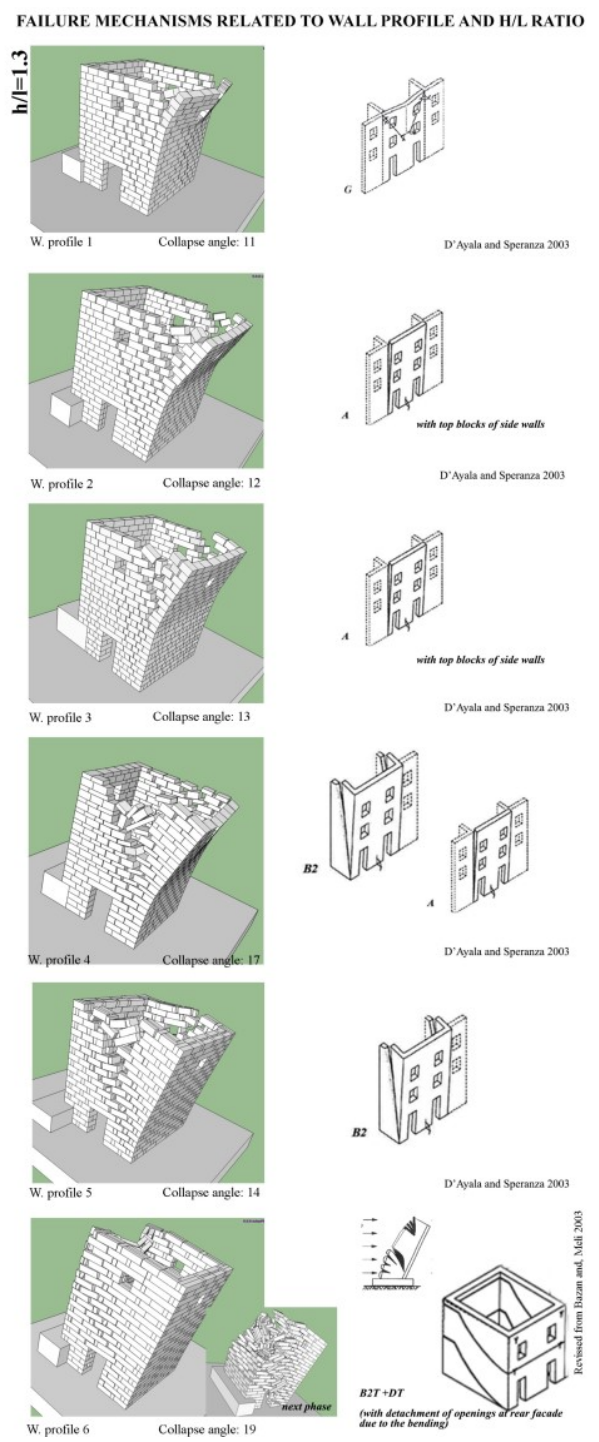

Figure 60 . Failure mechanisms of wall profiles at $1.3 \mathrm{~h} / 1$ 


\subsection{Mechanisms in different wall profile and ground topography combinations}

Possible ground topographies do not change the failure mechanisms of wall profile types (Figure 61).
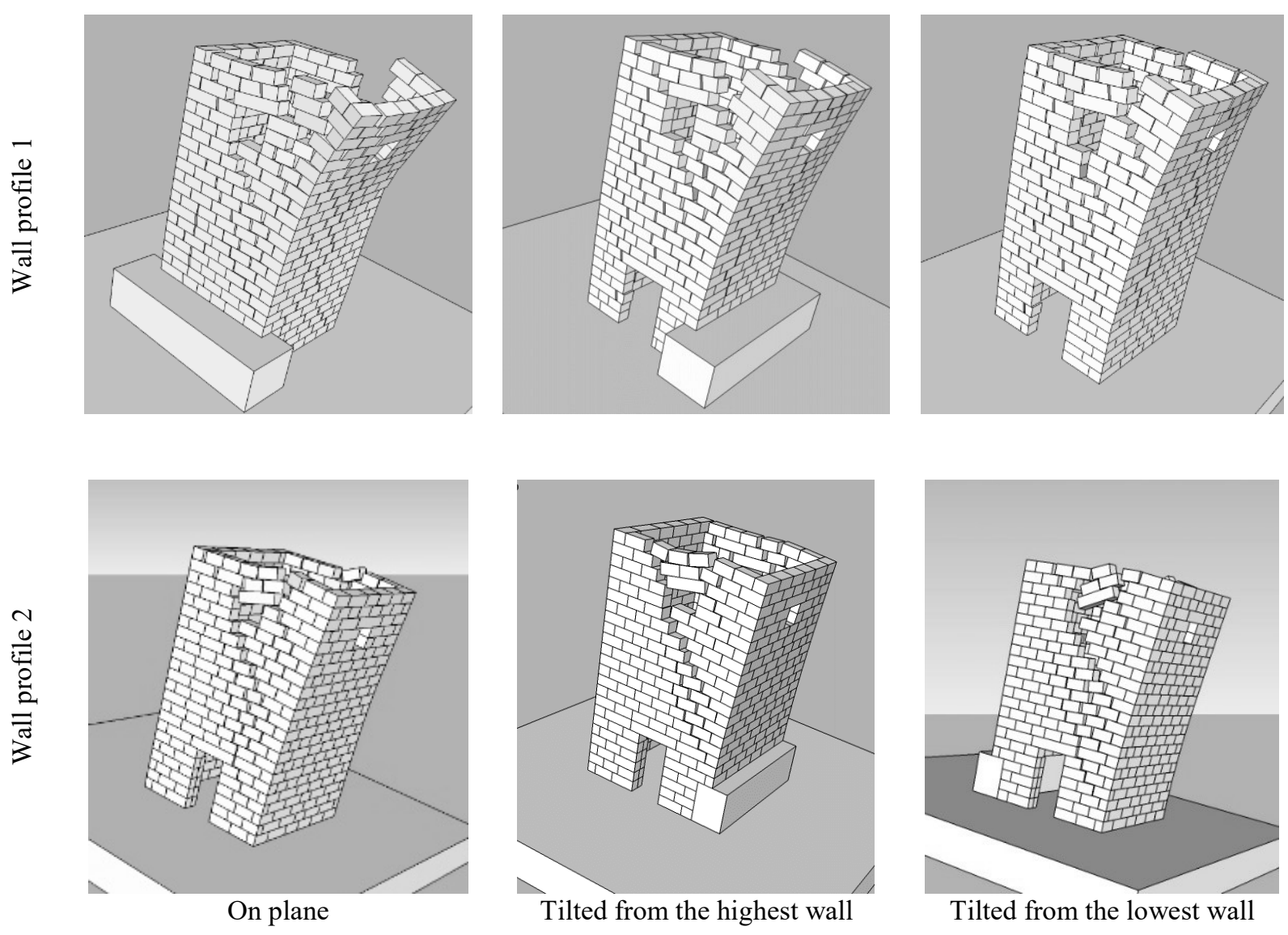

towards the lowest

Tilted from the lowest wall towads the highest

Figure 61. Failure mechanism at different ground topographies

\subsection{Mechanisms in different wall profile and material usage combinations}

Different material usage does not affect failure mechanism of wall profile (Figure $62)$. 


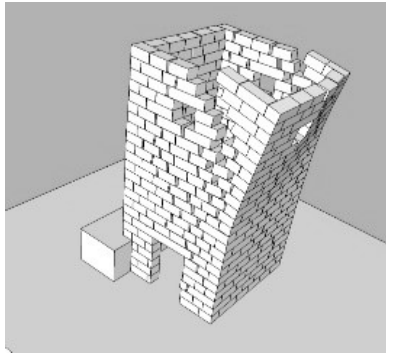

Limestone

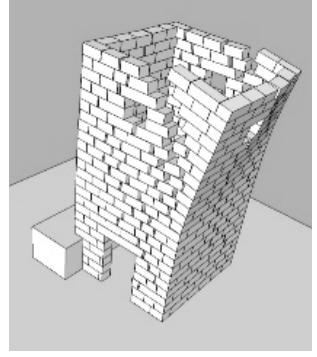

Granite

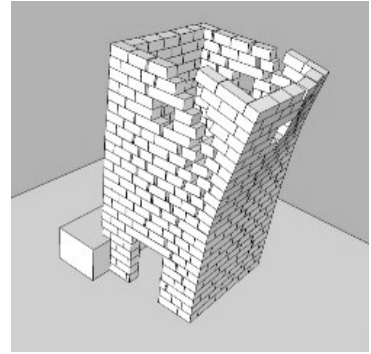

Sandstone

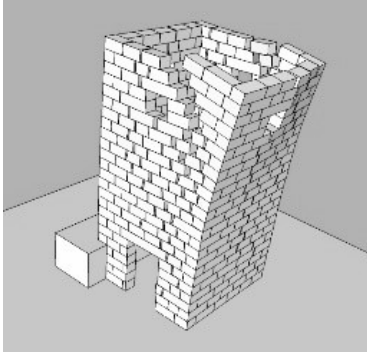

Brick

Figure 62. Failure mechanisms in walls out of various materials mirror

\subsection{Mechanisms in different opening type and $h / l$ combinations}

Failure mechanism of opening type and $\mathrm{h} / \mathrm{l}$ combinations are based on primarily opening type and secondarily $\mathrm{h} / \mathrm{l}$ ratios. Mechanisms related to wall profile and opening type is evaluated, when other characteristics are kept constant.

In section 3.3.1.2.1, impact of openings is analyzed. Effect of small, medium sized top openings or middle openings not adjacent to corner $(2-7,9,12,13)$ is almost similar. Ratios smaller than 1.3 cause decrease in collapse angle by sustaining mechanisms of openings at out-of-plane position (mechanism $\mathrm{G}$ ), however, small h/1 ratio changes failure mechanisms when openings at in-plane position. $\mathrm{h} / \mathrm{l}$ ratio with less effective openings 2$7,9,12,13$ causes detachment of facade wall due to the diagonal cracks downwards from the corners of the wall profile 1 (Mechanism G) (Figure 63).

Effective openings in terms of failure mechanisms are opening $10\left(7.4 \mathrm{~m}^{2}\right)$ with large sized top opening $(180 \times 300 \mathrm{~cm})$ and small sized two top openings $(100 \times 100 \mathrm{~cm})$, opening $8\left(3 \mathrm{~m}^{2}\right)$ with three top openings, opening $8\left(3 \mathrm{~m}^{2}\right)$ and $11\left(4.3 \mathrm{~m}^{2}\right)$ with three top openings $(90 \times 160 \mathrm{~cm})$ and opening $14\left(3.3 \mathrm{~m}^{2}\right)$ and $15\left(2.94 \mathrm{~m}^{2}\right.$ top op. area) with middle and top openings adjacent to corner as mentioned in the section 3.3.1.2.1.

$\mathrm{H} / \mathrm{L}$ ratio smaller than 1.3 generally causes detachment of out-of-plane wall (mechanism G), however, openings 8, 10,11, 14 and 15 become more effective in determination of mechanisms for all $\mathrm{h} / \mathrm{l}$ ratios including ratios smaller than 1.3. Opening 10 at in-plane position of wall profile 1 causes collapse of two side walls due to the inplane cracking followed by overturning of the facade due to vertical cracking at the 
connection of corner (mechanism $\mathrm{B}_{2}+\mathrm{A}$ ) in all $\mathrm{h} / \mathrm{l}$ ratios from 1.3 to 2.3 . However, at ratios between 1.6 and 2.3, rear wedge portion of the tower collapse with side walls.

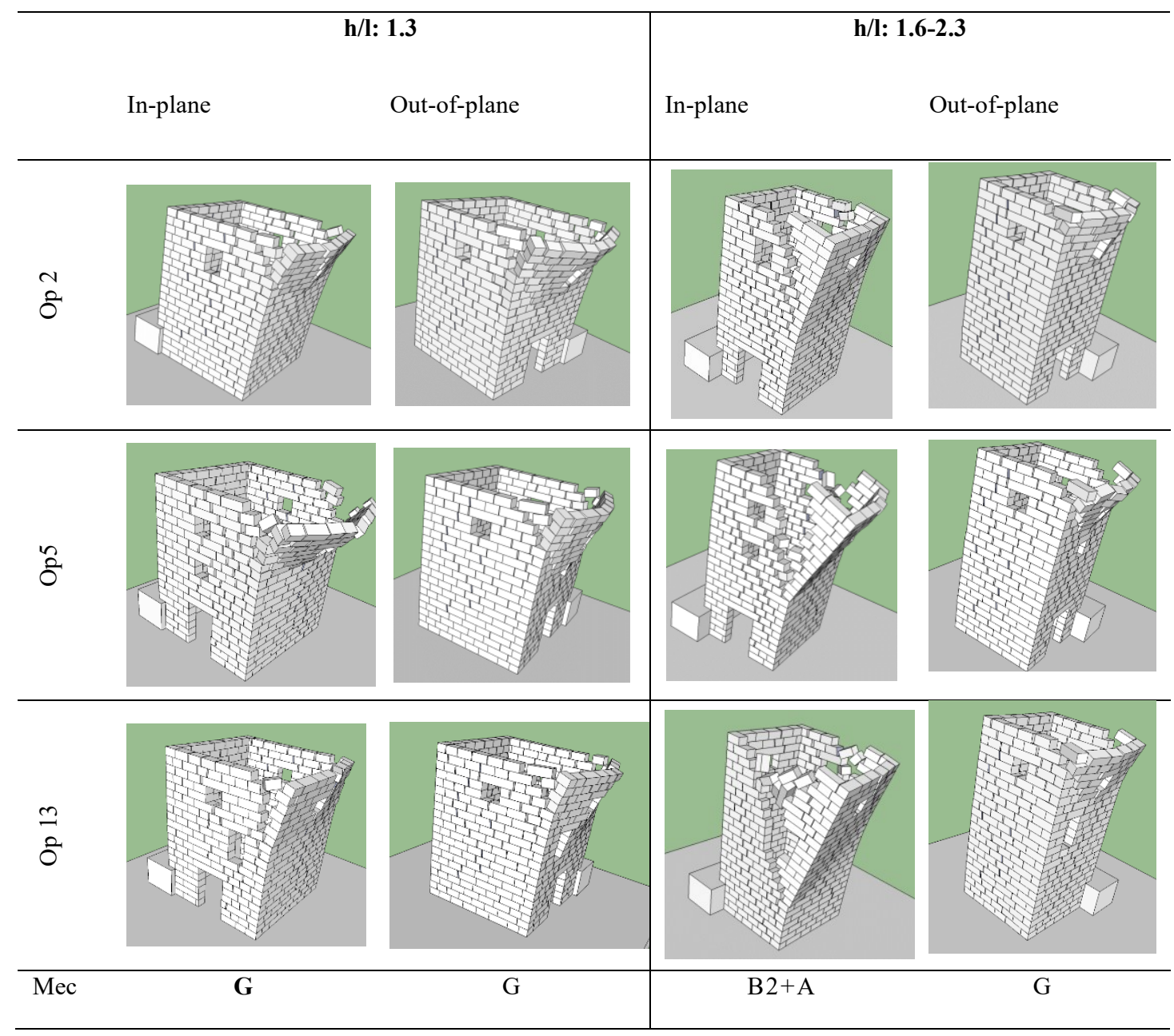

Figure 63. Effect of $\mathrm{h} / \mathrm{l}$ ratio with different opening types

The opening fastens occurrence of failure, the tower collapses at lower collapse angles at ratios smaller than 1.3 and higher than 2 (Figure 64). When opening 10 is at outof-plane position at ratios between 1.6 and 2.3, wall profile sustain its typical mechanism; detachment of out-of-plane walls with sliding of top blocks of side walls (mechanism G), (Figure 64).

Small and medium sized three top openings (op. 8 and 11) at in-plane position of wall profile 1 cause collapse of one side wall due to in-plane cracking at opening (mechanism B1) between 1.6 and $2.3 \mathrm{~h} / 1$ ratios, at $1.3 \mathrm{~h} / 1$ ratio, as well as collapse of the one side, overturning of the facade wall due to the vertical cracks at the corner connection 
followed by detachment of the facade due to diagonal cracking downwards from the corner occurs due to the effect of small $\mathrm{h} / \mathrm{l}$ (mechanism $\mathrm{B} 1+\mathrm{A}+\mathrm{G}$ ). Openings at out-ofplane position sustain typical mechanism: detachment of facade wall with diagonal cracks downward from the corners (mechanism G) is seen at all ratios (Figure 65, Figure 66).

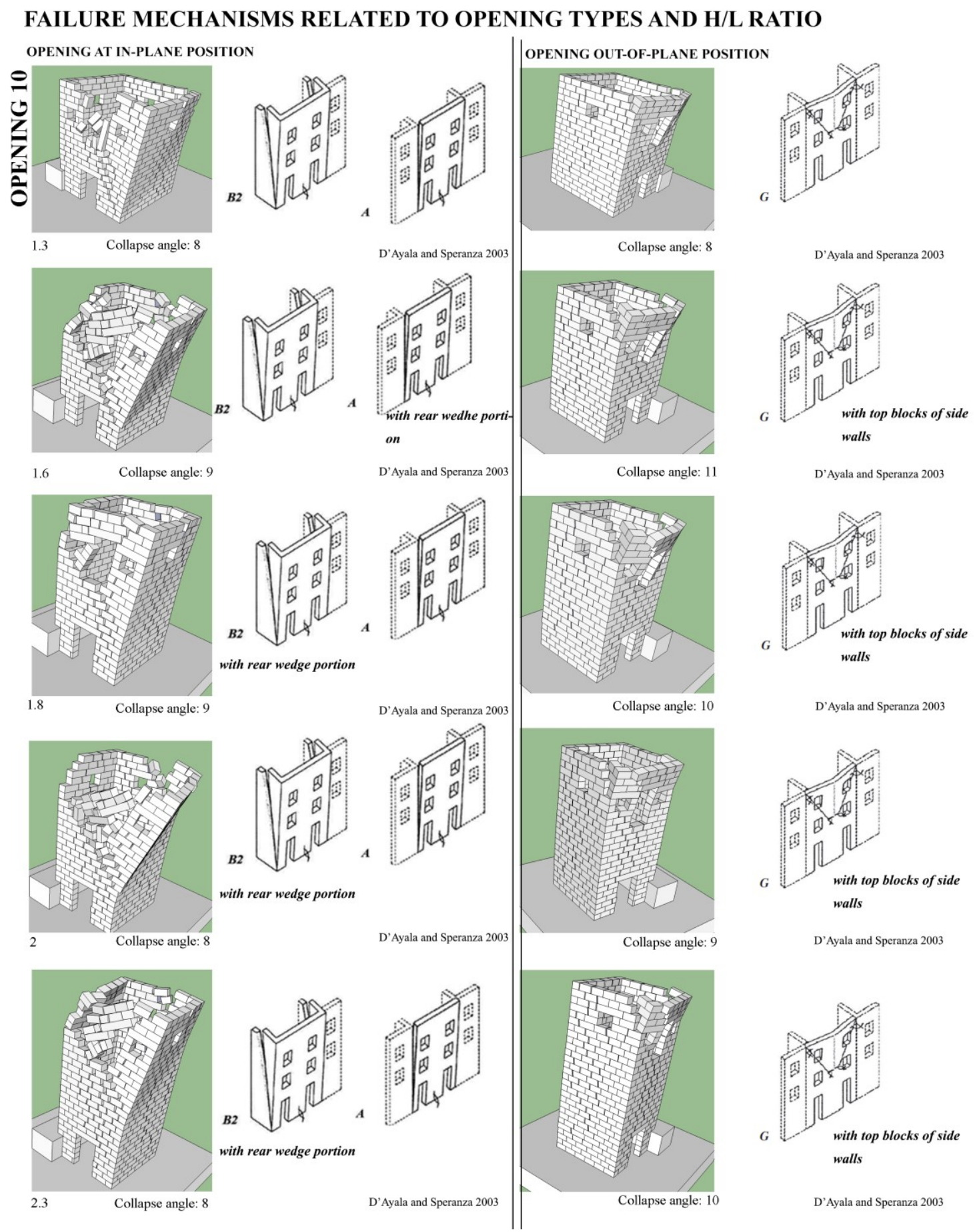

Figure 64. Failure mechanisms in different $\mathrm{h} / \mathrm{l}$ ratios with opening 10 (in wall profile 1 ) 


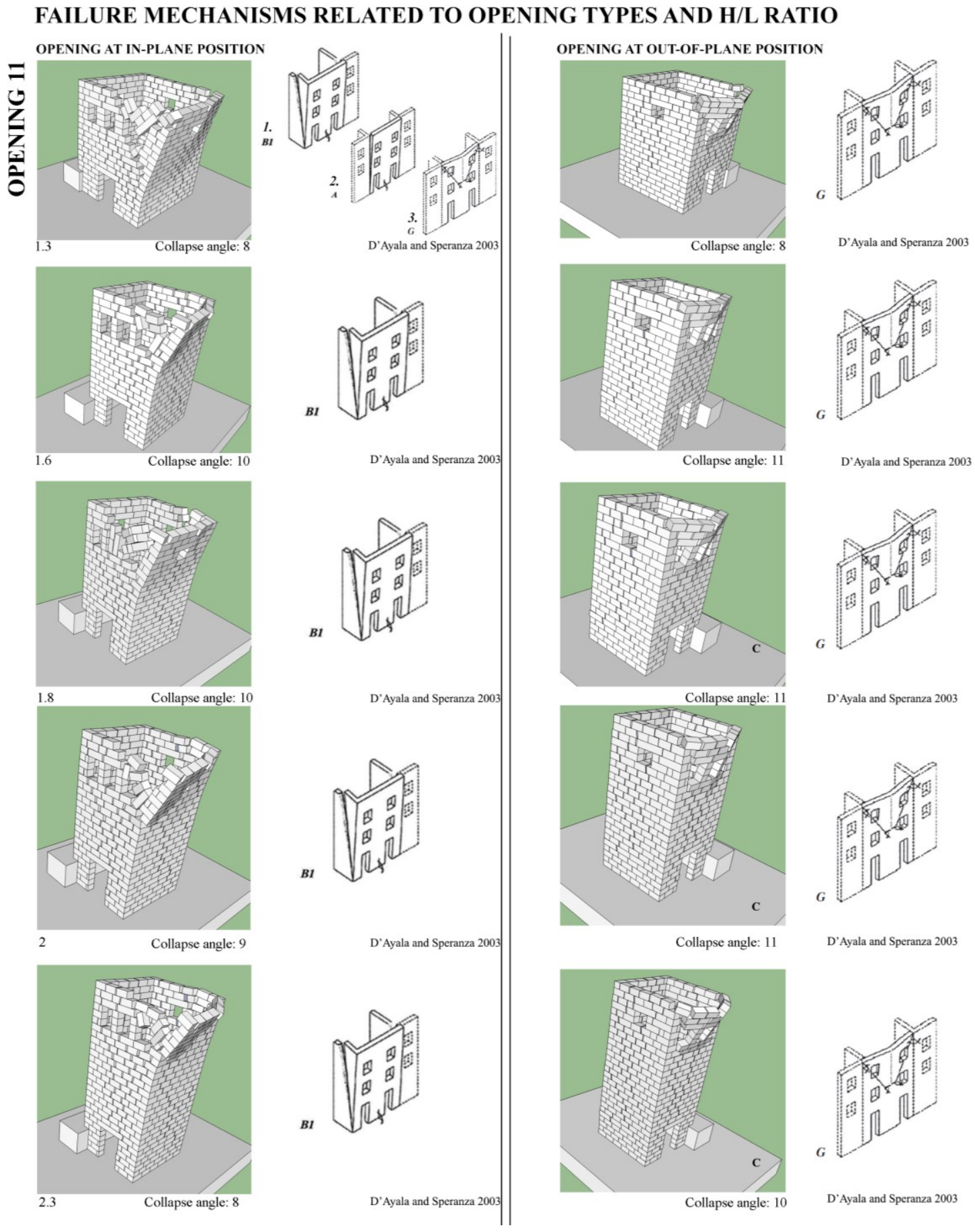

Figure 65 . Failure mechanisms in different $\mathrm{h} / \mathrm{l}$ ratios with opening 11 in wall profile 1 


\begin{tabular}{|c|c|c|c|c|}
\hline & \multicolumn{2}{|c|}{$\mathrm{h} / \mathrm{l}: 1.3$} & \multicolumn{2}{|c|}{$h / 1: 1.6-2.3$} \\
\hline & $\begin{array}{c}\text { Opening at in-plane } \\
\text { position }\end{array}$ & $\begin{array}{l}\text { Opening at out-of- } \\
\text { plane position }\end{array}$ & $\begin{array}{c}\text { Opening at in-plane } \\
\text { position }\end{array}$ & $\begin{array}{c}\text { Opening at out-of-plane } \\
\text { position }\end{array}$ \\
\hline$\overbrace{}^{\infty}$ & & & & \\
\hline Mec. & $\mathrm{B} 1+\mathrm{A}+\mathbf{G}$ & G & $\mathrm{B} 1+\mathrm{A}$ & $\bar{G}$ \\
\hline
\end{tabular}

Figure 66. Opening 8 with various $\mathrm{h} / \mathrm{l}$ ratios

Opening 14 at in-plane position causes collapse of two side walls due to the inplane cracking followed by overturning of the facade due to the vertical cracking at the corner connections at ratios between 1.8 and 2.3. However, this mechanism is followed by cracking upwards from the corner of the facade wall as a wedge shape at ratios between 1 and 1.6, however cracking does not cause corner failure, it is observed while collapsing side wall with facade wall (Figure 67).

Opening 14 at out-of-plane position sustain typical mechanism G; detachment of the facade wall with sliding of top blocks of side walls (Figure 67).

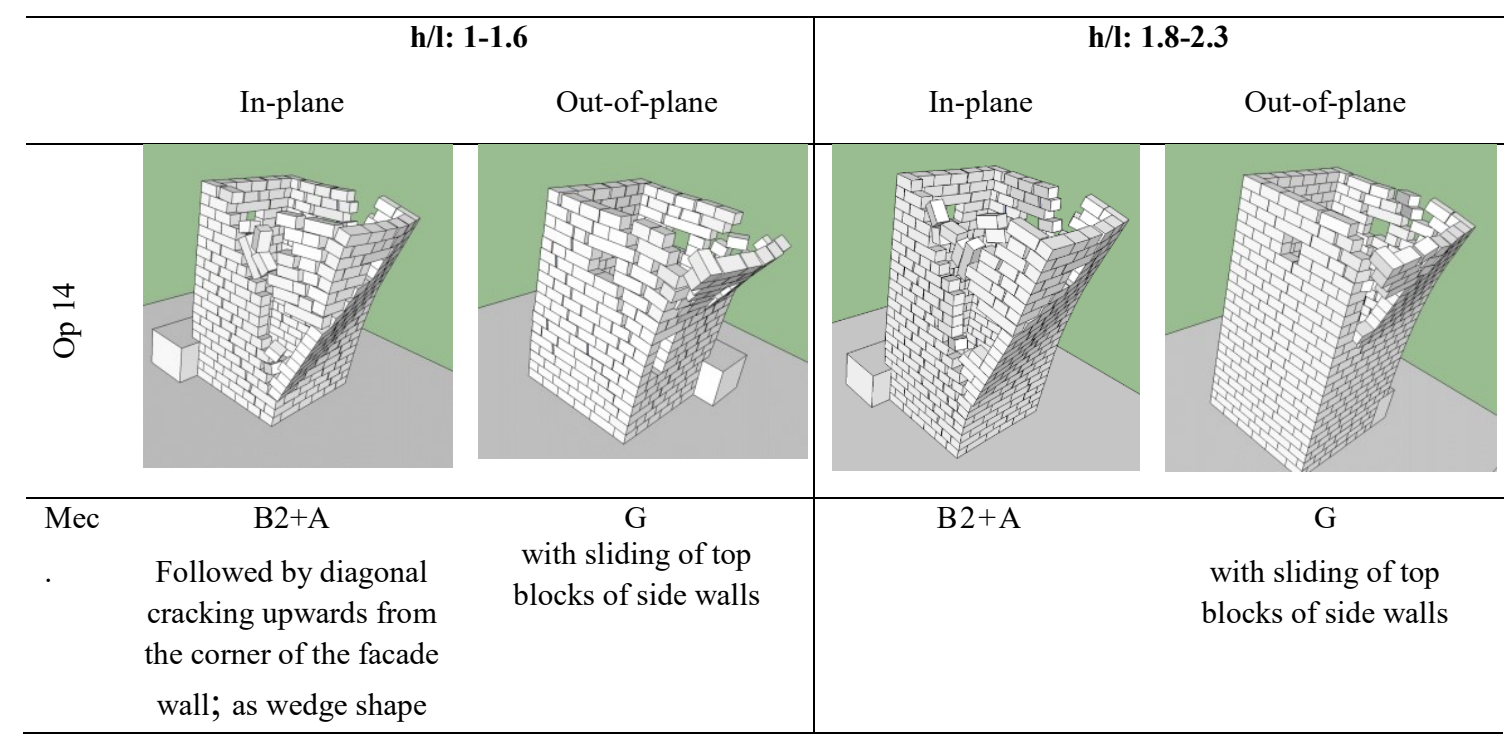

Figure 67. Failure mechanisms in different h/1 ratios with opening 14 in wall profile 1 
Medium sized asymmetrical top opening (op. 15) at in-plane position of wall profile 1 causes collapse of the side wall due to diagonal in-plane cracking (mechanism $\mathrm{B}_{1}$ ) in all $\mathrm{h} / \mathrm{l}$ ratios from 1.6 to 2.3 , however collapse of the side wall is followed by overturning of the facade wall due to the vertical cracking at the connections at ratios smaller than 1.3 .

Openings at out-of-plane position sustains typical mechanism of the wall profile; detachment of out of plane walls (mechanism $\mathrm{G}$ ) in $\mathrm{h} / \mathrm{l}$ ratios between 1.3 and 2.5. However, at ratios between 1.6 and 2.3, sliding of the top blocks at side walls is observed. (Figure 68).

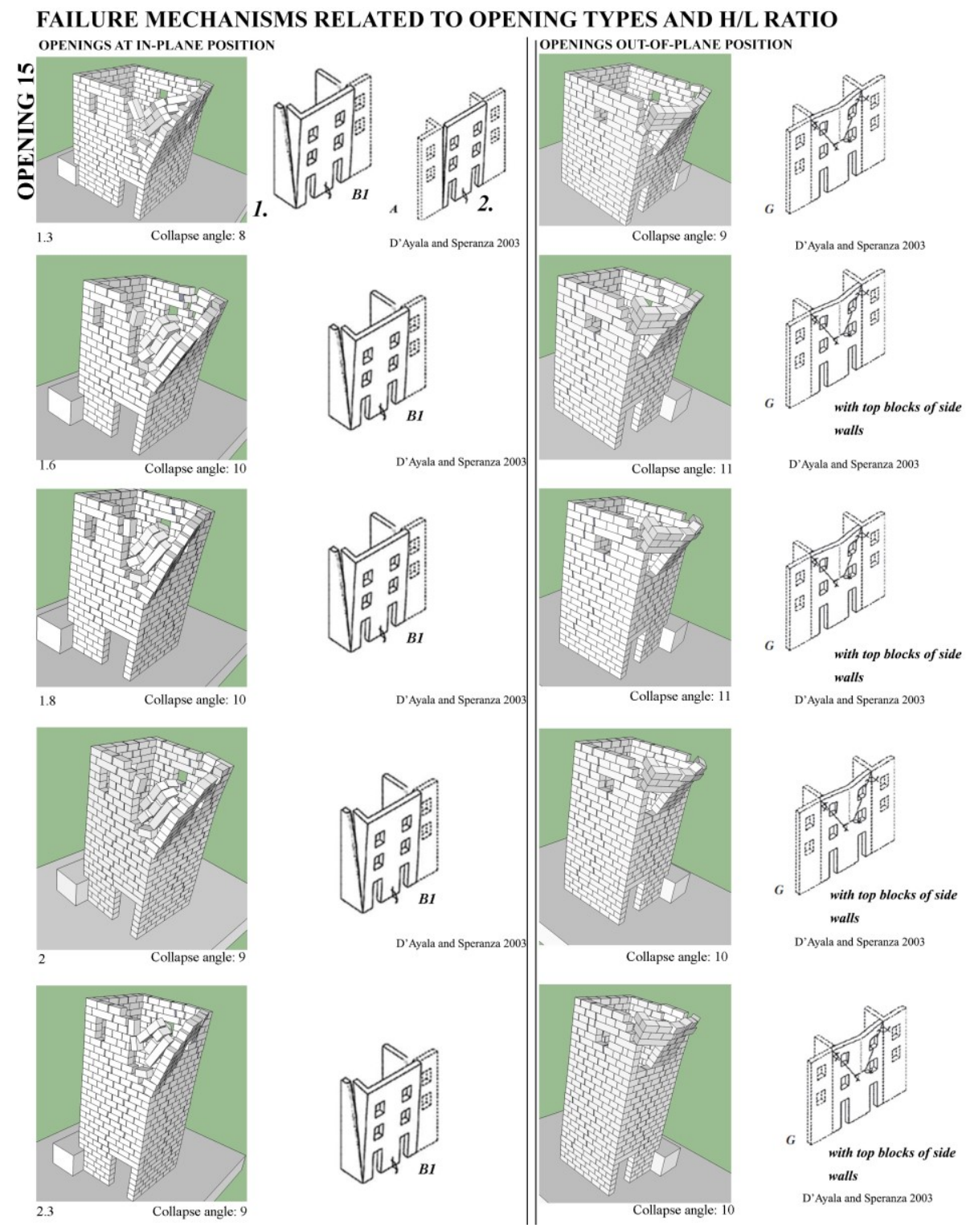

Figure 68 . Failure mechanisms in different $\mathrm{h} / \mathrm{l}$ ratios with opening 15 in wall profile 1 


\subsection{Mechanisms in different opening type and ground topography combinations}

Variation in ground topography does not change specific failure mechanisms of wall profiles with all opening types at in-plane (Figure 69) and out-of-plane positions (Figure 70).

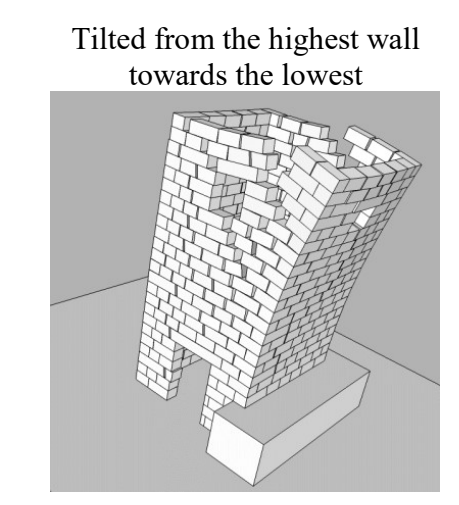

Opening 2

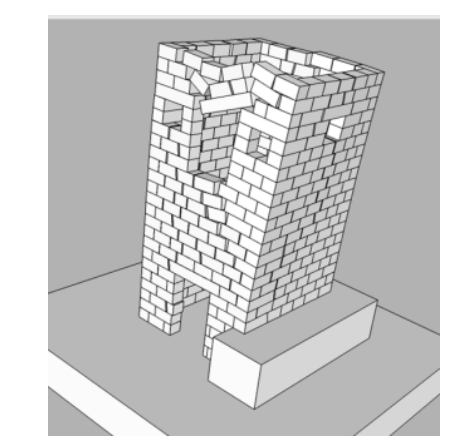

Opening 10
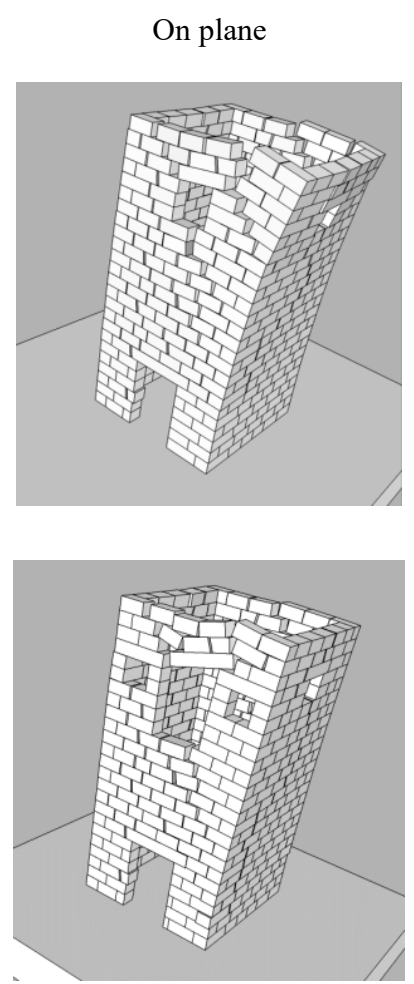

Figure 69. Failure mechanisms of towers at different ground topographies and openings at in-plane position of wall profile 1

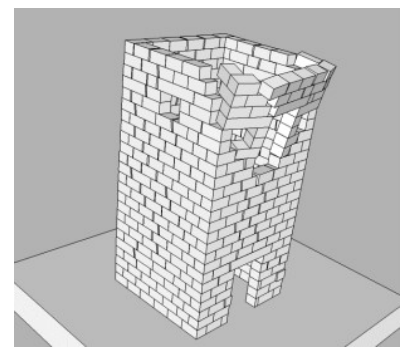

On plane

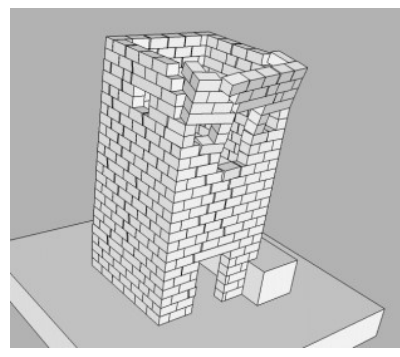

On inclined

Figure 70. Opening 10 at out-of-plane position of wall profile 1 


\subsection{Mechanisms in different opening type and material usage combinations}

Opening effect on behavior does not change in different material usage (Figure $68)$.
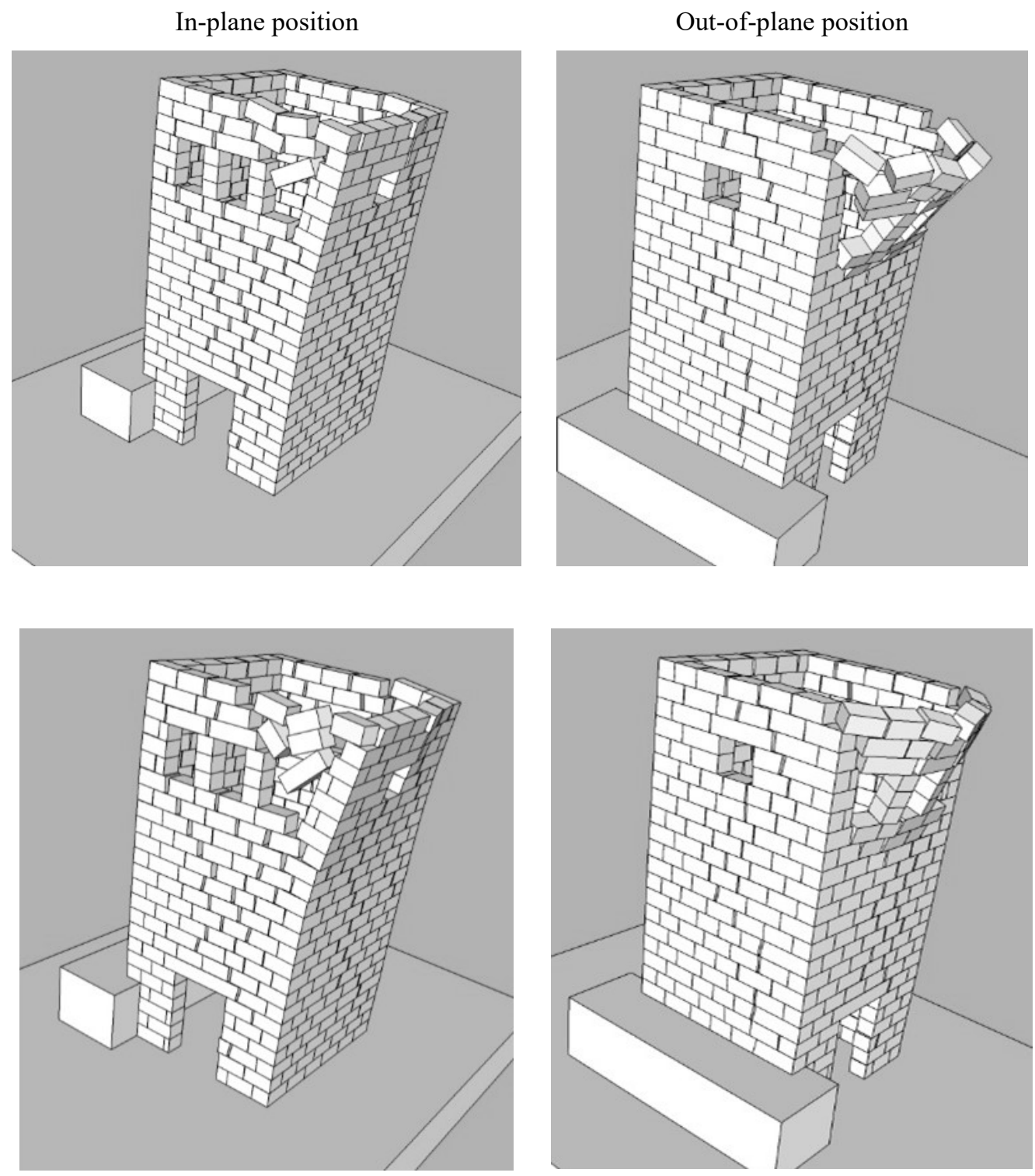

Figure 71. Usage of different materials and behavior of wall profile 1 


\subsection{Mechanisms in different $h / l$ ratio and material usage combinations}

Variation in material usage does not affect failure mechanisms in different $\mathrm{h} / \mathrm{l}$ ratios (Figure 72).
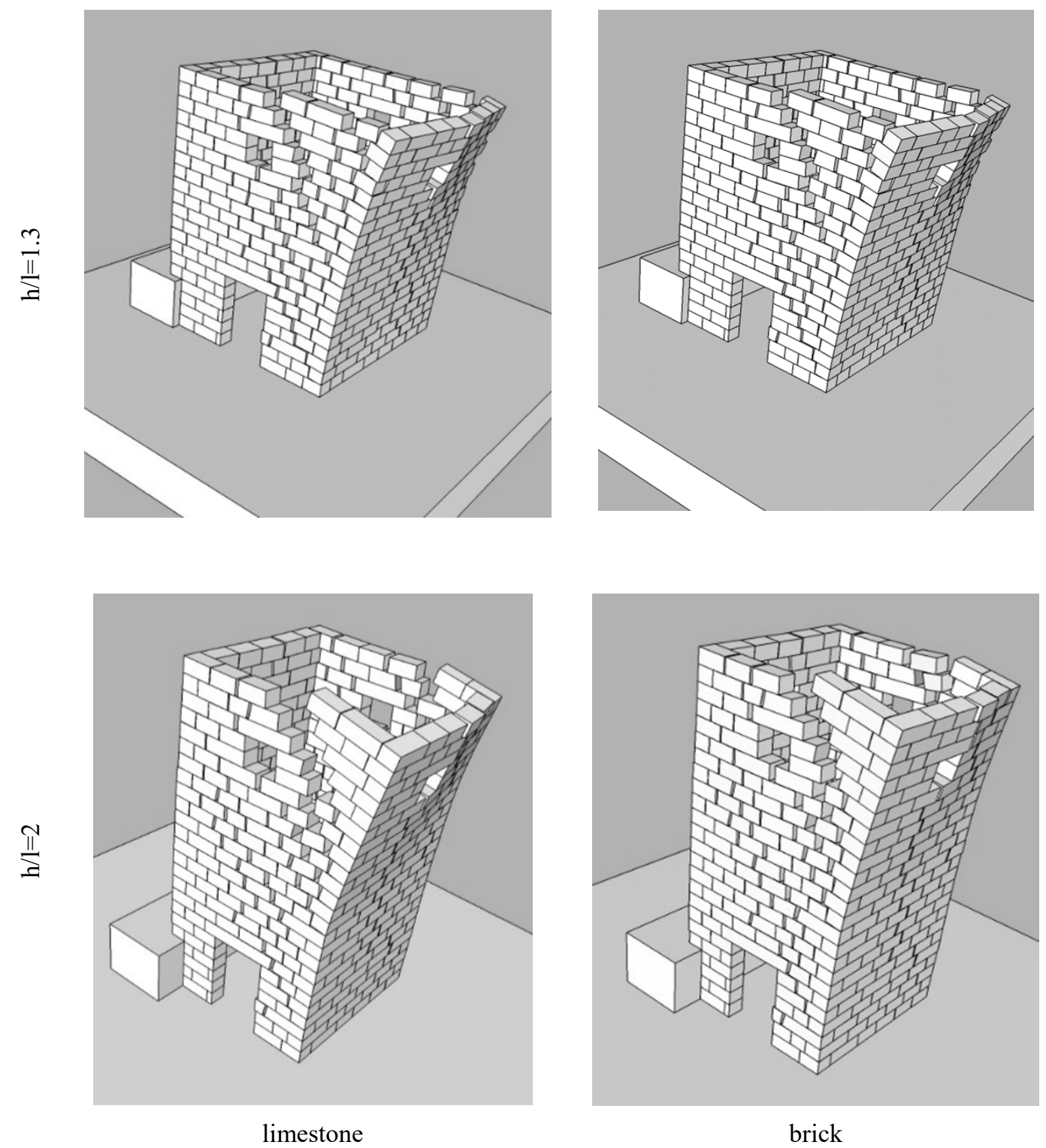

Figure 72. Failure mechanisms (mechanism $\mathrm{A}+\mathrm{B} 2$ ) in different material and $\mathrm{h} / \mathrm{l}$ ratios at wall profile 1 


\subsection{Mechanisms in different $h / l$ ratio and ground topography combinations}

As mentioned, previous sections, different $\mathrm{h} / \mathrm{l}$ ratios effect failure mechanisms, however, ground topography does not change the impact of $h / 1$ ratios on the tower resistance. Lower parts of the walls slide except the inclination direction.
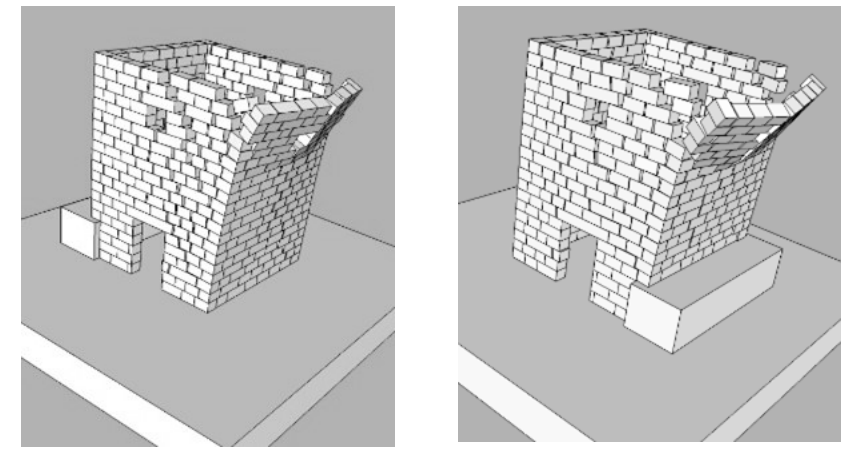

$\mathrm{h} / \mathrm{l}=1.3$

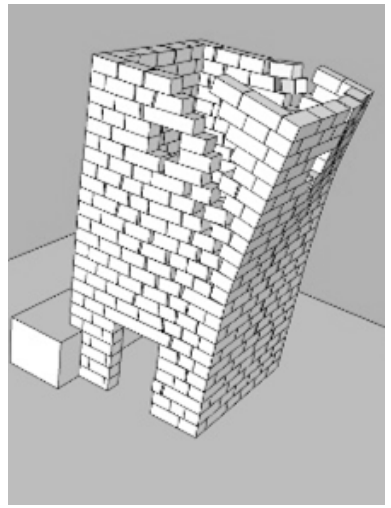

Tilted from the highest wall towards the lowest

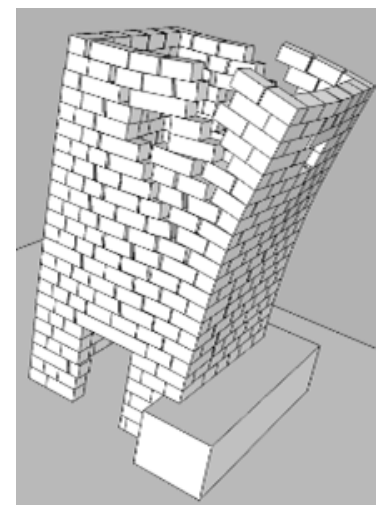

$\mathrm{h} / \mathrm{l}=2$
Tilted from the lowest wall towards the highest
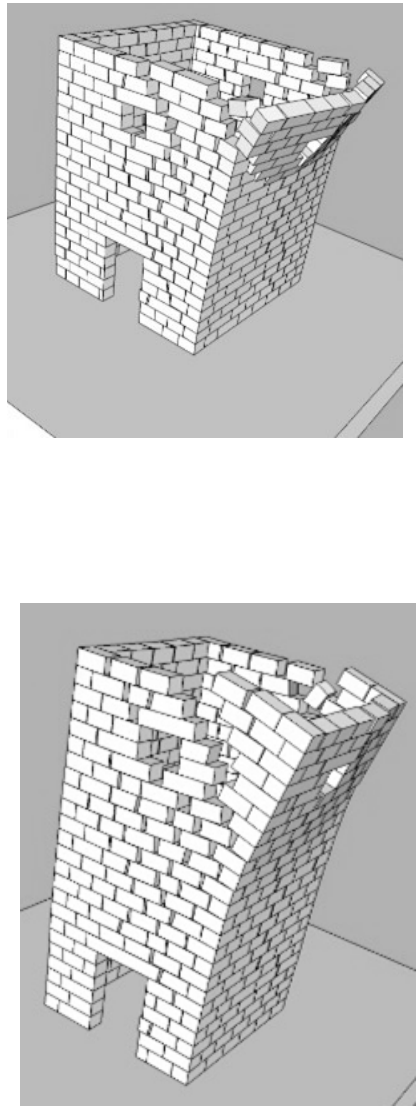

On plane

Figure 73. Failure mechanisms (mechanism $\mathrm{B}_{2}+\mathrm{A}$ ) in different $\mathrm{h} / \mathrm{l}$ ratio and ground topography at wall profile 


\subsection{Mechanisms in different material usage and ground topography combinations}

Variation in ground topography and material usage does not affect failure mechanisms (Figure 74).

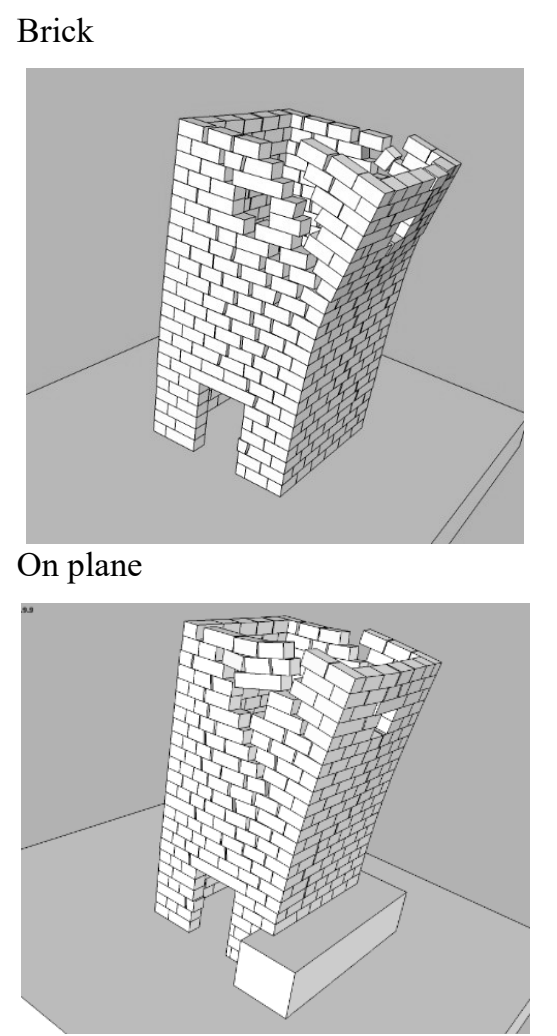

Granite

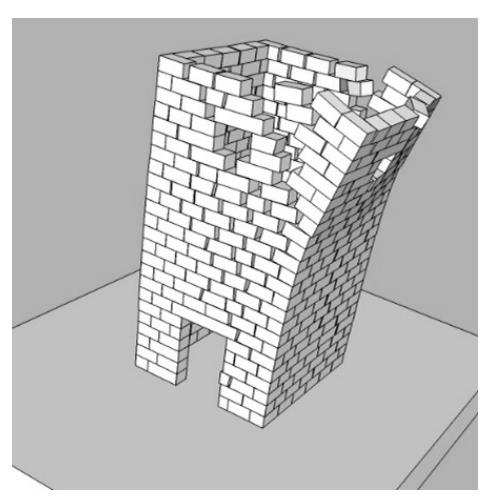

Tilted from the highest wall towards the lowest
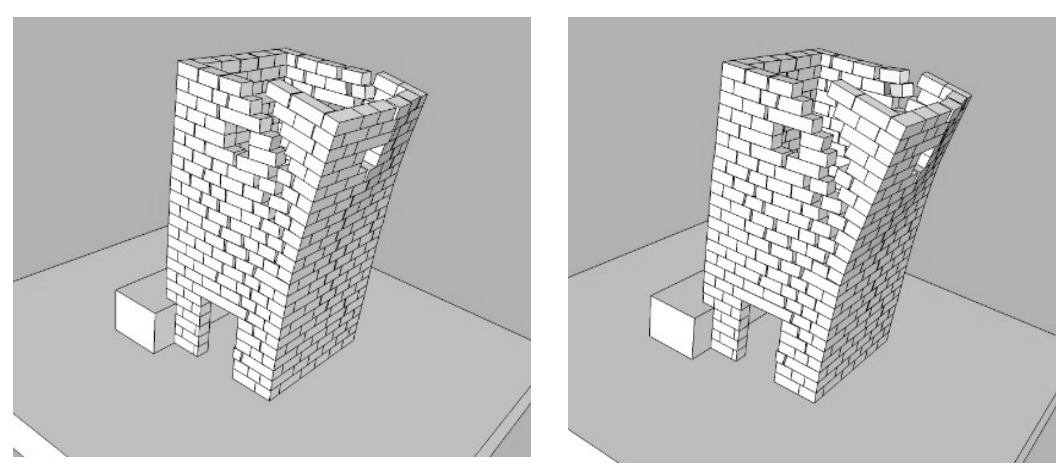

Tilted from the lowest wall towards the highest

Figure 74. Failure mechanism of towers out of different material on different ground topographies 


\subsubsection{Results of triple combination}

Results of binary combinations show that wall profile is the most effective characteristic in determining the collapse angle and failure mechanisms. Collapse angle differs at most 4 degrees for the variation of the other characteristics, while it differs up to 12 degrees for the variation in wall profiles. At the same time, each wall profile presents typical mechanism specific to the profile. As evaluated in the binary combinations; opening type and $\mathrm{h} / \mathrm{l}$ ratio become effective in specific situations in terms of collapse angle and failure mechanisms depending on wall profile type, for example, opening 15 does not change typical failure mechanism and collapse angle of the wall profile 6 , but it changes mechanisms in different wall profiles. Openings and h/l ratio can change collapse angle up to 4 degrees depending on what they combine with. Therefore, wall profile, opening types and $\mathrm{h} / \mathrm{l}$ ratio should be evaluated together to determine their effectiveness. However, binary combinations composed of material or ground topography present that their impact on collapse angle of the towers is minimal (1-degree difference) compared to other types. They do not affect failure mechanisms, so determination of effectiveness of them is not required in triple combinations.

\subsubsection{Collapse angles}

Collapse angle results of triple combinations are evaluated by taking into consideration best and worst collapse angle performance by focusing each characteristic separately; wall profile, opening organization and $\mathrm{h} / \mathrm{l}$ ratio.

Collapse angle curves of the opening types in different ratios of each wall profile are similar; each wall profile has an interval of better resistance. This interval shows differences depending on wall profile and opening types (Table 24).

When wall profiles are compared with each other in different ratios and with different opening types, wall profile 6 (Table 24; illustrated with red frame) collapses at the highest angles (19 degrees), while wall profile 1 collapses at the lowest angles (Table 24 ; illustrated with grey frame).

At the table, best and worst $\mathrm{h} / \mathrm{l}$ ratios for each wall profile is illustrated with orange and beige color, respectively. The worst $\mathrm{h} / \mathrm{l}$ ratios for wall profiles are ratios smaller than 1.3 and higher than $2.3 \mathrm{~h} / 1$ ratios (the lowest 2 degrees of each wall is accepted as the 
worst). However, wall profile 1 is mostly only affected by $h / 1$ ratios smaller than 1.3. Effectiveness of $\mathrm{h} / \mathrm{l}$ ratios at other wall profiles changes depending on opening organizations. Opening 10 is mostly cause the lowest collapse angle at ratios smaller than 1.3 and higher than 2.3. Wall profile 4 has the lowest collapse angles with opening 10 at ratios smaller than 1.6 and higher than 2. For wall profile 1, 2 and 3, regardless of the opening types, $\mathrm{h} / \mathrm{l}$ ratio smaller than 1.3 cause the lowest collapse angle. Wall profile 5 is also mainly affected by small $\mathrm{h} / \mathrm{l}$ ratios with most of the openings (op. 6, 9-11, 14 and 15). However, wall profile 6 is affected by $\mathrm{h} / \mathrm{l}$ ratios higher than 2.3 with all types of openings.

Common ratio for each wall profile that show the best resistance is 1.6. However, ratio intervals of each wall profile present differences. For wall profile 1, 2, 3, 4 and 5, the collapse angles of towers are higher for $\mathrm{h} / \mathrm{l}$ ratios between 1.6 and 1.8. For wall profile $6, \mathrm{~h} / \mathrm{l}$ interval for the best resistance is larger than other (between 1.3 and 1.8). When openings are at out-of-plane position at the best $\mathrm{h} / \mathrm{l}$ interval of wall profiles; all wall profiles present their best performance with slight decrease stemming from the weakness of the opening type (Table 24; illustrated with grey color). Also, wall profile 2, 4 and 5 present best performances except the best $\mathrm{h} / \mathrm{l}$ intervals (at $2 \mathrm{~h} / \mathrm{l}$ ratio).

Effect of openings at in-plane and out-of-plane positions in different ratios of each wall profile are examined in the below. In general, when opening is at out of plane positions, the tower provides better resistance. The worst opening types at each wall profile and $\mathrm{h} / \mathrm{l}$ ratio is illustrated with red bold letter. The common worst opening type that decreases angle of collapse at a maximal amount at all wall profile types and ratios is opening 10 (Table 24; illustrated with red letters). Also, as well as opening 10, openings 11 and 14, 15 decrease the collapse angles at a maximal amount depending on wall profile and $\mathrm{h} / \mathrm{l}$ ratios. Wall profile 1 is affected by openings at ratios higher than 1.6 , wall profile 2 is affected by openings at ratios higher than 1.3, wall profile 6 is affected at ratios between 1 and 2, while effect of opening 10 at wall profiles 4 and 5 is seen at all ratios, effect of other openings is not distributed at all ratios. Wall profile 3 is affected by openings at alla ratios.

As a result, towers designed with wall profile 1 and opening 10 at ratios higher than 2 and lower than 1.3 collapse at the smallest angle, while towers designed with wall profile 6 and with openings 1-9, 12-14, between 1.6 and 1.8 ratios collapse at the highest collapse angle. 
Table 24. Collapse angles in different opening types and $\mathrm{h} / \mathrm{l}$ ratios of wall profiles

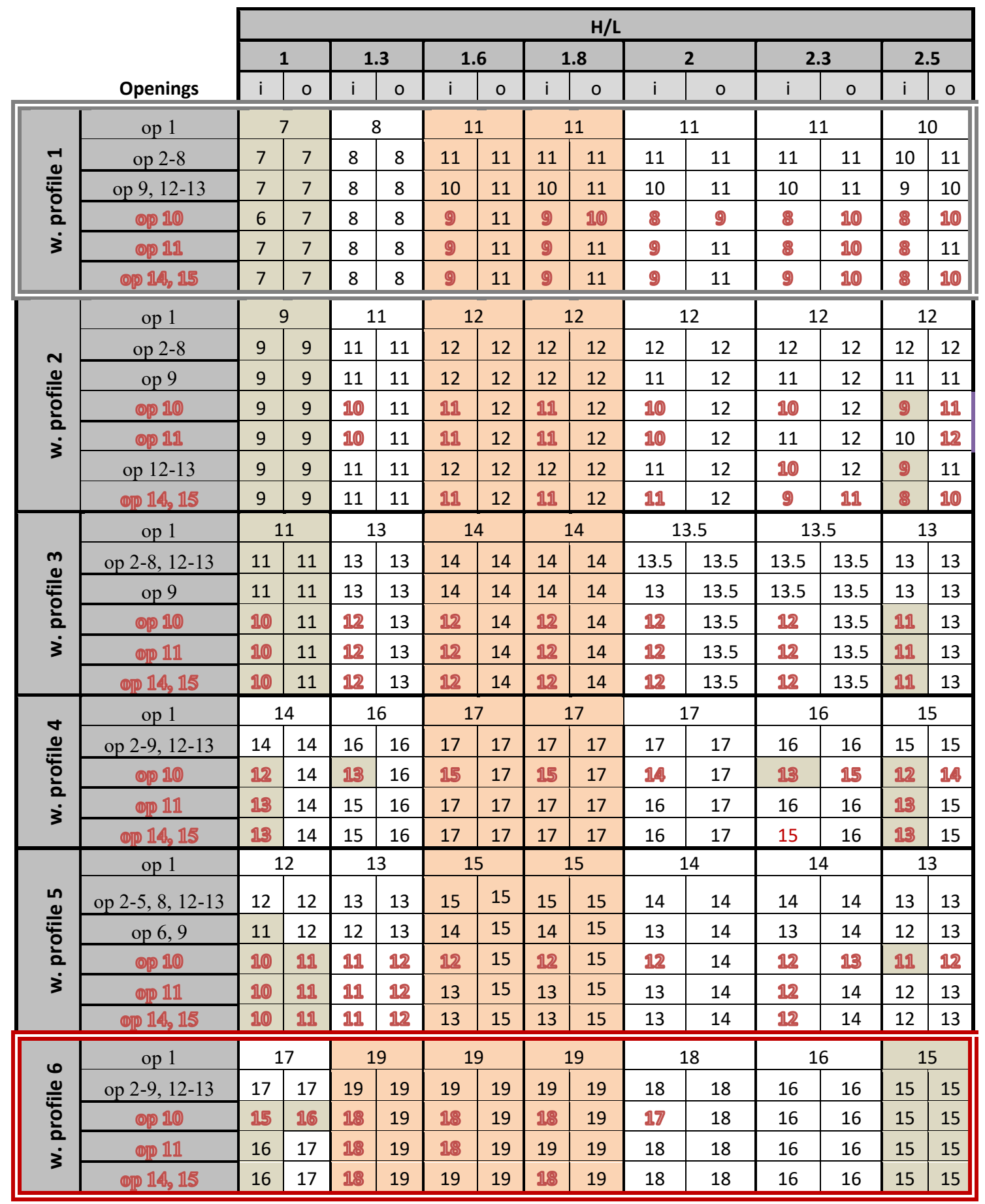

* Red rectangular frame: the wall profile type demonstrating the best performance under lateral loading.

*Grey rectangular frame: the wall profile type demonstrating the worst performance under lateral loading.

*Orange color: best $\mathrm{h} / \mathrm{l}$ performance intervals of each wall profile type.

*Beige color: worst h/l performance intervals of each wall profile type.

*Red bold letter: opening types causing the worst resistance. 


\subsubsection{Failure mechanisms}

There are typical failure mechanisms depending on primarily characteristics of wall profiles, secondarily opening organizations and $\mathrm{h} / \mathrm{l}$ ratios. Effect of opening types 8 , $10,11,14$ and 15 , and $\mathrm{h} / 1$ ratio higher than 1.8 or smaller than 1.3 on mechanisms are determined by results of binary combinations, however, it is seen that effectiveness of characteristics change depending on wall profile types. Therefore, results of three effective characteristics are further examined to decipher the dominant one (Table 25, Figure 75, Figure 76, Figure 77).

The best and worst performance intervals in terms of collapse angles is overlapped with failure mechanism distribution. The relationship between resistance and failure mechanism of wall profile types is discussed.

First, failure mechanisms of wall profiles with less effective openings and at $h / 1$ ratios providing best performance is compared with each other. Wall profile 6 that has the highest collapse angle does not present any in-plane or out-of-plane failure at side or facade walls, it presents total body behavior (mechanism $\mathrm{B}_{2 \mathrm{~T}}$ ) (Table 25; illustrated with purple color), however the weakest wall profile 1 presents especially out-of-plane behavior; mechanism A (Table 25; illustrated with pink color) as well as in-plane mechanisms. The other weakest wall profiles 2 and 3 also present typically out-of-plane mechanism A, with in-plane mechanisms. Wall profile 4 demonstrating the second highest performance does not present out-of-plane mechanism, but it presents only inplane mechanism (mechanism $\mathrm{B}_{2}$ ). However, although wall profile 5 collapses at lower angles in comparison to wall profile 4, it presents total behavior. This can stem from subqualities of characteristics of walls profiles. As a result, wall profiles that have lower resistance, lower than $14^{\circ}$ collapse angle, present generally out-of-plane failure mechanism, however, wall profiles collapsing at angles higher than $15^{\circ}$ present in-plane or total behavior.

The wall profiles with openings at out-of-plane position proves also this situation. Detachment of facade wall with diagonal cracks downwards from the corners (mechanism $\mathrm{G}$ ) is seen, when there are openings at out of plane position. The weaker the wall profile, the widespread the out-of-plane mechanism; G. The stronger wall profiles present better performance. Profile 4 generally presents in-plane failure mechanism (mechanism $\mathrm{B}_{2}$ ), and wall profile 6 presents total behavior (mechanism $\mathrm{B}_{2 \mathrm{~T}}$ ). However, wall profile 5 presents total overturning combined with detachment of rear facade (mechanism $B_{2 T+D T}$ ). 
Relation of collapse angles and failure mechanisms can be seen at $\mathrm{h} / \mathrm{l}$ ratios presenting worst and best performance. Total and in-plane failures are replaced with outof-plane failures at $\mathrm{h} / \mathrm{l}$ ratios smaller than 1.3. At $\mathrm{h} / \mathrm{l}$ ratios smaller than 1.3 , the stronger wall profiles 4 and 5 start to present wall behavior in place of hybrid or total body behavior in the borders of ineffective openings (illustrated with blue letters) (mechanism $\mathrm{B}_{2}+\mathrm{A}$ or $\left.\mathrm{G}\right)$. Also, even if the strongest wall profile 6 sustains its total body behavior, detachment of rear facade is added to the mechanism (mechanism $\mathrm{B}_{2 \mathrm{~T}+\mathrm{DT}}$ ) at $\mathrm{h} / \mathrm{l}$ ratios smaller than 1.3 (Table 25; illustrated with blue letters). Although $\mathrm{h} / \mathrm{l}$ ratios higher than 2 decreases collapse angle, typical behavior of towers is sustained (Table 25; illustrated with purple letters). The strongest wall profile sustains its total overturning mechanism and bends due to its slenderness.

At $\mathrm{h} / \mathrm{l}$ intervals presenting the best performance in terms of collapse angle, the typical mechanisms are sustained in the towers with less effective openings. However, effective openings change the mechanisms even at the best $\mathrm{h} / \mathrm{l}$ intervals (illustrated with bold black colors at orange columns). Weakest collapse angles (indicated with bold black letters) are seen in openings $10,11,14$ and 15 . There is not necessarily a change in the failure mechanism type because of the opening 10 in these thresholds, since both opening 10 causes mechanism $B_{2}$, collapse of two side walls with in-plane diagonal cracks, and $\mathrm{B}_{2}$ is the most widespread failure observed in the lowest collapse angles of all wall profiles. Effect of opening 10 can be seen also at wall profiles (5 and 6), due to the effect of opening 10 , only mechanism $\mathrm{B}_{2}$ occurs in place of total overturning.

Mechanism $\mathrm{B}_{1}$ is directly related to the opening types at in-plane position: it is mostly seen in openings 8 and 11, 14 and 15. Change of failure with the effect of openings at the best and worst $\mathrm{h} / \mathrm{l}$ intervals is indicated with bold black colors.

When openings are located at out-of-plane position, there is not necessarily a change in the failure mechanisms of weaker wall profiles. However, effects of openings at out-of-plane position can be seen at wall profiles 5 and 6 that have typical total behavior. Openings cause either only mechanism $\mathrm{G}$ at wall profile 5 or combination of detachment of rear facade wall with overturning due to the bending at wall profile 6 (mechanism $\mathrm{B}_{2 \mathrm{~T}+\mathrm{DT}}$ ) (indicated with bold green letters). 
Table 25. Failure mechanisms in different opening types, h/1 ratios and wall profiles

\begin{tabular}{|c|c|c|c|c|c|c|c|c|c|c|c|}
\hline & \multirow[b]{2}{*}{ Opening } & \multicolumn{2}{|c|}{$1-1.3$} & \multicolumn{2}{|c|}{1.6} & \multicolumn{2}{|c|}{1.8} & \multicolumn{2}{|c|}{2} & \multicolumn{2}{|c|}{$2.3-2.5$} \\
\hline & & $\mathrm{i}$ & 0 & $\mathrm{i}$ & 0 & $\mathrm{i}$ & 0 & $\mathrm{i}$ & 0 & $\mathrm{i}$ & 0 \\
\hline \multirow{7}{*}{$\begin{array}{l}\vec{a} \\
\frac{0}{\underline{\underline{k}}} \\
\frac{0}{0} \\
\dot{3}\end{array}$} & 1 & \multicolumn{2}{|c|}{ G } & \multicolumn{2}{|c|}{$\mathrm{B}_{2}+\mathrm{A}$} & \multicolumn{2}{|c|}{$\mathrm{B}_{2}+\mathrm{A}$} & \multicolumn{2}{|c|}{$\mathrm{B}_{2}+\mathrm{A}$} & \multicolumn{2}{|c|}{$\mathrm{B}_{2}+\mathrm{A}$} \\
\hline & $2-7$ & G & G & $\mathrm{B}_{2}+\mathrm{A}$ & G & $B_{2}+A$ & G & $B_{2}+A$ & $\mathrm{G}^{\mathrm{ST}}$ & $B_{2}+A$ & G \\
\hline & $9,12,13$ & G & G & $\mathrm{B}_{2}+\mathrm{A}$ & G & $\mathrm{B}_{2}+\mathrm{A}$ & G & $\mathrm{B}_{2}+\mathrm{A}$ & G ST & $B_{2}+A$ & G \\
\hline & 10 & $B_{2}+A$ & G & $\mathbf{B}_{2}+\mathbf{A}$ & G & $B_{2}+A$ & G & $\mathrm{B}_{2}+\mathrm{A}$ & G ST & $\mathrm{B}_{2}+\mathrm{A}$ & $\mathrm{G}$ \\
\hline & $\mathbb{S}, \mathbb{1 1}$ & $B_{1}+A+G$ & G & $B_{1}$ & G & $B_{1}$ & G & $\mathrm{B}_{1}$ & $\mathrm{G}^{\mathrm{ST}}$ & $\mathrm{B}_{1}$ & G \\
\hline & 14 & $\mathrm{~B}_{2}+\mathrm{A}$ & $\mathrm{G}$ & $B_{2}+A$ & $\mathrm{G}$ & $B_{2}+A$ & G & $B_{2}+A$ & G & $B_{2}+A$ & G \\
\hline & 15 & $B_{1}+A$ & G & $B_{1}$ & G & $B_{1}$ & G & $\mathrm{B}_{1}$ & G & $\mathrm{B}_{1}$ & G \\
\hline \multirow{7}{*}{ 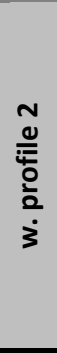 } & 1 & \multicolumn{2}{|c|}{ A } & \multicolumn{2}{|c|}{$B 2+A$} & \multicolumn{2}{|c|}{$B 2+A$} & \multicolumn{2}{|c|}{$B 2+A$} & \multicolumn{2}{|c|}{$B 2+A$} \\
\hline & $2-9$ & $\mathrm{~A}$ & G & $\mathrm{B}_{2}+\mathrm{A}$ & $\mathrm{G}$ & $B_{2}+A$ & G & $\mathrm{B} 2+\mathrm{A}$ & G & $\mathrm{B}_{2}+\mathrm{A}$ & $\mathrm{G}$ \\
\hline & $\begin{array}{c}3-7,12 \\
13 \\
\end{array}$ & $\mathrm{~B}_{2}+\mathrm{A}$ & G & $\mathrm{B}_{2}$ & G & $\mathrm{B}_{2}$ & G & $\mathrm{B}_{2}$ & G & $B_{2}+A$ & G \\
\hline & 10 & $B 2+A$ & G & $\mathrm{B}_{2}+\mathrm{A}$ & G & $\mathrm{B}_{2}+\mathrm{A}$ & G & $\mathrm{B}_{2}+\mathrm{A}$ & G & $\mathrm{B}_{2}+\mathrm{A}$ & G \\
\hline & $\mathbb{8}, \mathbb{1 1}$ & $\mathrm{B} 2+\mathrm{A}$ & G & $B_{2}$ & G & $\mathbf{B}_{2}$ & G & $B_{2}$ & $\mathrm{G}$ & $B_{2}$ & G \\
\hline & 14 & $\mathrm{~B} 2+\mathrm{A}$ & G & $B_{2}$ & G & $B_{2}$ & G & $B_{2}$ & G & $B_{2}$ & G \\
\hline & 15 & $B_{1}$ & G & $B_{2}$ & G & $B_{2}$ & G & $B_{2}$ & G & $B_{2}$ & G \\
\hline \multirow{7}{*}{$\begin{array}{l}m \\
0 \\
\frac{0}{\underline{k}} \\
\frac{\partial}{2} \\
\dot{3}\end{array}$} & 1 & \multicolumn{2}{|c|}{$\mathrm{A}$} & \multicolumn{2}{|c|}{$\mathrm{B}_{2}+\mathrm{A}$} & & & & & & \\
\hline & $2-7$ & $A$ & G & $B_{2}+A$ & $B_{2}+A$ & $B_{2}+A$ & $B_{2}+A$ & $B_{2}+A$ & $\mathrm{~B}_{2}+\mathrm{A}$ & $B_{2}+A$ & $B_{2}+A$ \\
\hline & $9,12,13$ & A & G & $\mathrm{B}_{2}+\mathrm{A}$ & $\mathrm{B}_{2}+\mathrm{G}$ & $\mathrm{B}_{2}+\mathrm{A}$ & $B_{2}+A$ & $\mathrm{~B}_{2}+\mathrm{A}$ & $\mathrm{B}_{2}+\mathrm{A}$ & $B_{2}+A$ & $B_{2}+A$ \\
\hline & 10 & $B_{2}$ & G & $B_{2}$ & $\mathrm{~B}_{2}+\mathrm{G}$ & $B_{2}$ & $\mathrm{~B}_{2}+\mathrm{G}$ & $B_{2}$ & $\mathrm{~B}_{2}+\mathrm{G}$ & $B_{2}$ & $\mathrm{~B}_{2}+\mathrm{A}$ \\
\hline & $\mathbb{8}, \mathbb{1 1}$ & $\mathrm{B}_{2}+\mathrm{A}$ & $\mathrm{G}$ & $B 2+A$ & G & $B_{2}+A$ & G & $B_{2}+A$ & G & $\mathrm{B}_{2}$ & G \\
\hline & 14 & $\mathrm{~B}_{2}+\mathrm{A}$ & $B_{2}+A$ & $B 2+A$ & $B_{2}+A$ & $B_{2}+A$ & $B_{2}+A$ & $B_{2}+A$ & $\mathrm{~B}_{2}+\mathrm{A}$ & $B_{2}+A$ & $\mathrm{~B}_{2}+\mathrm{A}$ \\
\hline & 15 & $B_{1}$ & G & $B_{1}$ & G & $B_{2}$ & G & $B_{2}$ & G & $B_{2}$ & G \\
\hline & 1 & & & & & & & & & & \\
\hline & $2-8$ & $\mathrm{~B}_{2}+\mathrm{A}$ & $\mathrm{B}_{2}+\mathrm{A}$ & $B_{2}$ & $\mathrm{~B}_{2}$ & $\mathrm{~B}_{2}$ & $\mathrm{~B}_{2}$ & $B_{2}$ & $\mathrm{~B}_{2}$ & $\mathrm{~B}_{2}$ & $B_{2}$ \\
\hline$\stackrel{0}{=}$ & $9,12,13$ & $\mathrm{~B}_{2}+\mathrm{A}$ & $B_{2}+A$ & $B_{2}$ & $\mathrm{~B}_{2}$ & $\mathrm{~B}_{2}$ & $B_{2}$ & $\mathrm{~B}_{2}$ & $\mathrm{~B}_{2}$ & $B_{2}$ & $\mathrm{~B}_{2}$ \\
\hline 는 & 10 & $\mathrm{~B}_{2}$ & $\mathrm{~B}_{2}+\mathrm{G}$ & $\mathrm{B}_{2}$ & $B_{2}+G$ & B2 & $B_{2}+G$ & $\mathrm{~B}_{2}$ & $\mathrm{~B}_{2}+\mathrm{G}$ & $B_{2}$ & $\mathrm{~B}_{2}+\mathrm{G}$ \\
\hline$\stackrel{2}{3}$ & $\mathbb{B}, \mathbb{1 1}$ & $B_{1}$ & $\mathrm{~B}_{2}$ & $\mathrm{~B}_{2}$ & $B_{2}$ & $\mathrm{~B}_{2}$ & $\mathrm{~B}_{2}$ & $\mathrm{~B}_{2}$ & $\mathrm{~B}_{2}$ & $\mathrm{~B}_{2}$ & $\mathrm{~B}_{2}$ \\
\hline & 14 & $\mathrm{~B}_{2}$ & $B_{2}$ & $B_{2}$ & $\mathrm{~B}_{2}$ & $\mathrm{~B}_{2}$ & $B_{2}$ & $\mathrm{~B}_{2}$ & $\mathrm{~B}_{2}$ & $B_{2}$ & $\mathrm{~B}_{2}$ \\
\hline & 15 & $B_{1}$ & $B_{2}$ & $\mathrm{~B}_{2}$ & $\mathrm{~B}_{2}$ & $B_{2}$ & $\mathrm{~B}_{2}$ & $B_{1}$ & $\mathrm{~B}_{2}$ & $B_{1}$ & $\mathrm{~B}_{2}$ \\
\hline & 1 & & & & & & & & & & \\
\hline & $\begin{array}{c}2,5-7,9 \\
12,13\end{array}$ & $\mathrm{~B}_{2}$ & G & $B_{2 T+V T}$ & $\mathrm{~B}_{2 \mathrm{~T}+\mathrm{DT}}$ & $\mathrm{B}_{2 \mathrm{~T}+\mathrm{VT}}$ & $B_{2 T+D T}$ & $B_{2 T+V T}$ & $B_{2 T+D T}$ & $\mathrm{~B}_{2 \mathrm{~T}+\mathrm{VT}}$ & $B_{2 T+D T}$ \\
\hline 婁 & 3,4 & $\mathrm{~B}_{2}$ & G & $B_{2 T+D T}$ & $\mathrm{~B}_{2 \mathrm{~T}+\mathrm{VT}}$ & $\mathrm{B}_{2 \mathrm{~T}+\mathrm{DT}}$ & $\mathrm{B}_{2 \mathrm{~T}+\mathrm{VT}}$ & $\mathrm{B}_{2 \mathrm{~T}+\mathrm{DT}}$ & $B_{2 T+V T}$ & $\mathrm{~B}_{2 \mathrm{~T}+\mathrm{DT}}$ & $B_{2 T+D T}$ \\
\hline 흠 & 10 & $B_{2}$ & G & $B_{2}$ & $B_{2}+G$ & $B_{2}$ & $\mathrm{~B}_{2}+\mathrm{G}$ & $B_{2}$ & $B_{2 T+D T}$ & $B_{2}$ & $B_{2 T+D T}$ \\
\hline 3 & $\$, 11$ & $B_{1}$ & G & $B_{1}$ & $\mathrm{G}$ & $B_{1}$ & G & $B_{1}$ & $B_{2 T+D T}$ & $B_{1}$ & $B_{2 T+D T}$ \\
\hline & 14 & $B_{2}$ & G & $B_{2}$ & G & $\mathrm{B}_{2 \mathrm{~T}+\mathrm{VT}}$ & $\mathrm{B}_{2 T+D T}$ & $\mathrm{~B}_{2 \mathrm{~T}+\mathrm{VT}}$ & $B_{2 T+D T}$ & $\mathrm{~B}_{2 \mathrm{~T}+\mathrm{VT}}$ & $B_{2 T+D T}$ \\
\hline & 15 & $B_{1}$ & G & $B_{1}$ & G & $B_{1}$ & G & $\mathbf{B}_{1}$ & $B_{2 T+D T}$ & $B_{1}$ & $B_{2 T+D T}$ \\
\hline & 1 & & & & & & & & & & \\
\hline & $2-7,9,12$ & $B_{2 T+D T}$ & $\mathrm{~B}_{2 \mathrm{~T}+\mathrm{DT}}$ & $B_{2 T}$ & $B_{2 T}$ & $B_{2 T}$ & $B_{2 T}$ & $B_{2 T}$ & $B_{2 T}$ & $B_{2 T}$ & $B_{2 T}$ \\
\hline$\stackrel{0}{v}$ & 13 & $B_{2 T+D T}$ & $B_{2 T+D T}$ & $B_{2 T}$ & $\mathrm{~B}_{2 \mathrm{~T}+\mathrm{DT}}$ & $B_{2 T}$ & $B_{2 T+D T}$ & $B_{2 T}$ & $B_{2 T}$ & $B_{2 T}$ & $B_{2 T}$ \\
\hline 는 & 10 & $B_{2}$ & $B_{2 T+D T}$ & $\mathbf{B}_{2}$ & $B_{2 T+D T}$ & $B_{2}$ & $B_{2 T+D T}$ & $B_{2}$ & $B_{2 T+D T}$ & $B_{2 T}$ & $B_{2 T}$ \\
\hline$\div$ & $\$, 11$ & $B_{1}+G$ & $B_{2 T+D T}$ & $B_{1}+G$ & $B_{2 T+D T}$ & $B_{1}+G$ & $B_{2 T+D T}$ & $B_{1+2 T}$ & $B_{2 T}$ & $B_{2 T}$ & $B_{2 T}$ \\
\hline & 14 & $B_{2}+G$ & $B_{2 T+D T}$ & $B_{2}+G$ & $B_{2 T+D T}$ & $B_{2 T}$ & $B_{2 T}$ & $B_{2 T}$ & $B_{2 T}$ & $B_{2 T}$ & $B_{2 T}$ \\
\hline & 15 & $B_{1}$ & $B_{2 T+D T}$ & $B_{1}$ & $\mathrm{~B}_{2 \mathrm{~T}+\mathrm{DT}}$ & $B_{1}$ & $\mathrm{~B}_{2 \mathrm{~T}+\mathrm{DT}}$ & $B_{2 T}$ & $B_{2 T+D T}$ & $B_{2 T}$ & $B_{2 T}$ \\
\hline
\end{tabular}

*Table 25 contains the legend of Table 24. Letters also represent the change of failures. Purple: total body behavior;

Pink: out-of-plane behavior due to the wall profiles. Blue: out-of-plane behavior due to $\mathrm{h} / \mathrm{l}$ ratios smaller than 1.3.

Bold Black: change of failure with effects of openings. Green: effect of openings at out-of-plane position. 


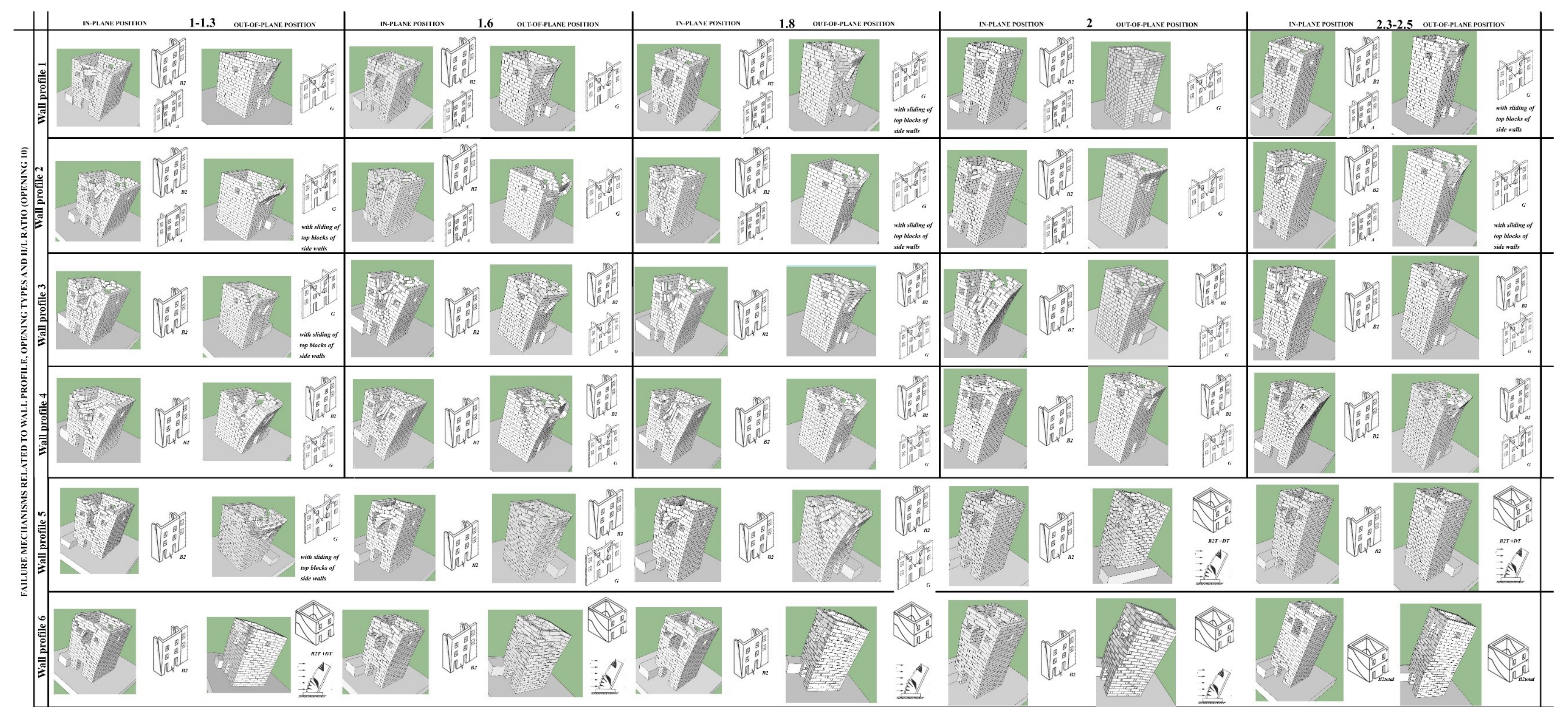

Figure 75. Failure mechanisms related to wall profile, opening type and h/l ratio (op. 10) 


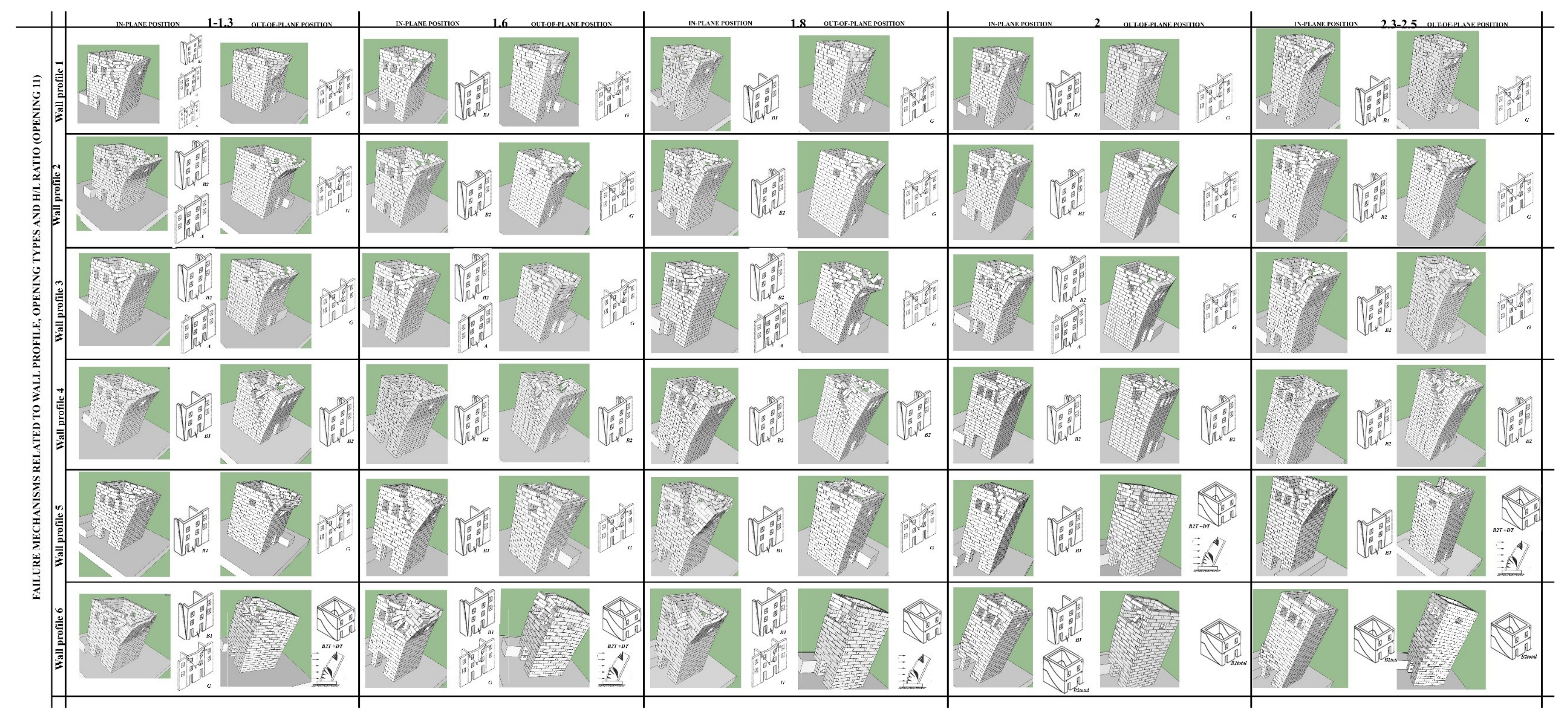

Figure 76. Failure mechanisms related to wall profile, opening type and h/l ratio (op. 11) 


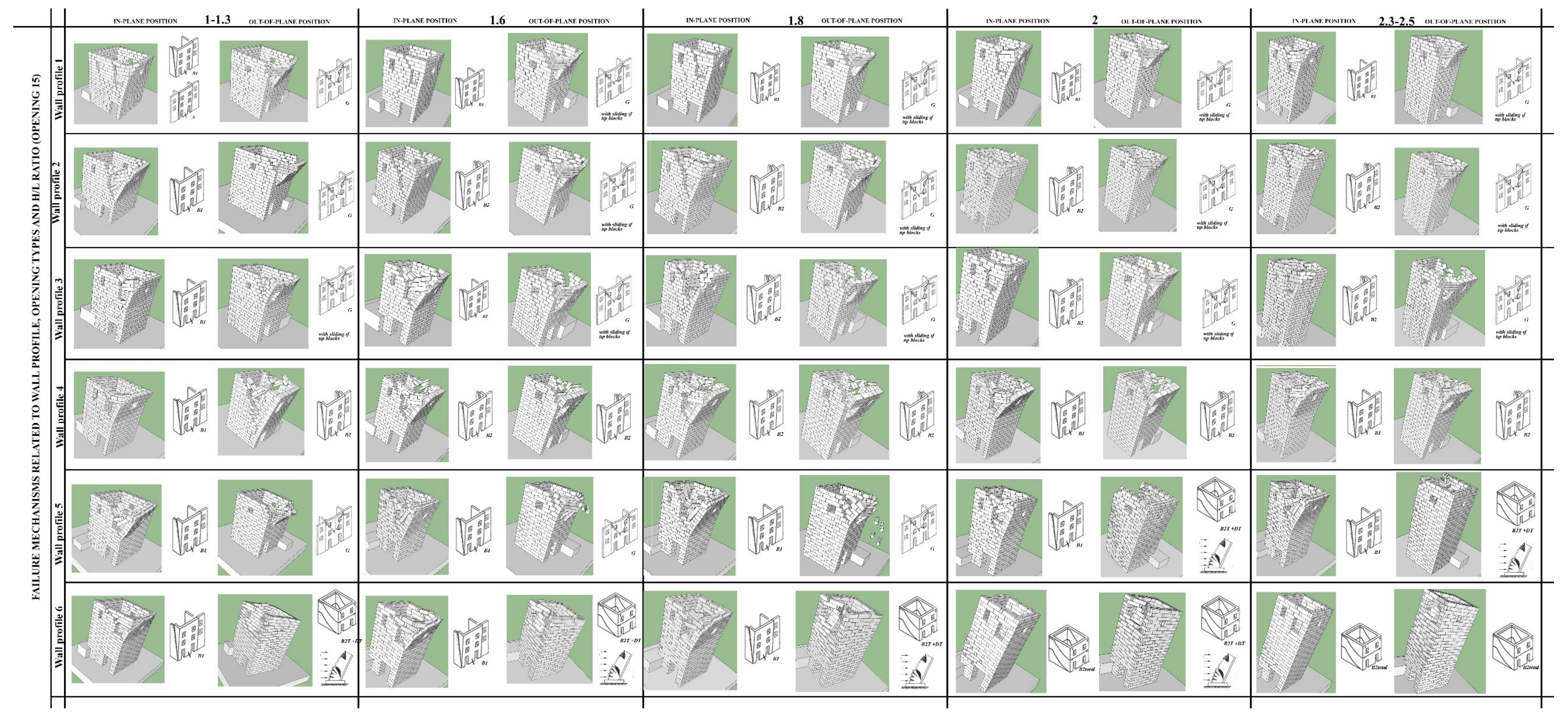

Figure 77. Failure mechanisms related to wall profile, opening type and h/l ratio (op. 15) 


\section{CHAPTER 4}

\section{DISCUSSION OF IMPACT OF CHARACTERISTICS}

In this chapter, impact of effective characteristics on structural resistance and behavior of towers are discussed with reference to literature review. The structures examined in previous studies are not mostly four-sided, they are generally a wall portion with one or two side walls. So, one to one correspondence of results of the study with results in literature is not possible. The sub-qualities that shape the effective characteristics are determined. Furthermore, it has been tested whether the sub-qualities are a parameter affecting the resistance of the structure and if there is a parameter, impact value of a sub-quality is determined with statistical evaluation. Nevertheless, the subqualities and their relative impact on overall structural strength of a tower are evaluated statistically to enrich the discussion. Finally, a framework for vulnerability assessment of the towers is proposed.

\subsection{Impact of each effective characteristic}

The results of analysis demonstrate variation in performance of towers in relation with sub-qualities in wall profiles, opening organizations and proportional relations. So, these are the three effective characteristics.

\subsubsection{The wall profile}

Analysis of wall profile types have revealed that the organization of blocks and the wall section are effective on the structural resistance and behavior of a profile. Subqualities of a wall profile related to organization of blocks are staggering ratio $(\mathrm{s} / \mathrm{h})$, and the ratio between block length and height $\mathrm{bl} / \mathrm{bh}$. In literature, either staggering ratio (D'Ayala and Speranza 2003) or ratio between block length and height (Giuffre, Pagnoni and, Tocci 1994) is examined, since joints are accepted as positioned in the middle of the upper and lower blocks. So, the two ratios ( $\mathrm{s} / \mathrm{h}$ and $\mathrm{bl} / \mathrm{bh})$ are always proportional to each other: it is not necessary to analyze these sub-qualities separately. However, at real dry 
masonry towers, the joints are not always positioned in the middle of the blocks, therefore, these two sub-qualities should be taken into consideration separately. The performance of a wall section is related with its stone depth, number of leaves and header usage. If the wall is one leafed, as seen in the upper portions of the towers, the stone depth is a subquality. If the wall section is composed of double leaves, usage of header is taken as a sub-quality as well.

Impact of these five sub-qualities; namely, staggering ratio, ratio between block length and height, number of leaves, upper stone depth, and usage of headers; on towers presenting average collapse angles and failure mechanisms are discussed in the below (Table 26). According to average collapse angles, horizontal acceleration is calculated: $\lambda$ $=\mathrm{mg} \times \sin$ (collapse angle). While investigating effect of a sub-quality, the best performance intervals of other characteristics is taken into consideration; h/l ratios between 1.6 and 2; asymmetrical or symmetrical one or two openings whose area is up to $3 \mathrm{~m}^{2}$.

Table 26. Average performance of sub-qualities regarding each wall profile

\begin{tabular}{|c|c|c|c|c|c|c|c|c|c|}
\hline & \multicolumn{2}{|c|}{$\begin{array}{c}\text { Organization of } \\
\text { blocks }\end{array}$} & \multicolumn{3}{|c|}{ Wall section } & \multicolumn{2}{|c|}{$\begin{array}{l}\text { Typical failure } \\
\text { mechanism }\end{array}$} & \multicolumn{2}{|c|}{ Ave. resistance } \\
\hline & $\begin{array}{l}\text { Ave. } \\
\mathrm{s} / \mathrm{h}\end{array}$ & $\begin{array}{c}\text { Ave. } \\
\text { Block } \\
1 / \mathrm{h}\end{array}$ & $\begin{array}{c}\text { Number } \\
\text { of } \\
\text { leaves }\end{array}$ & $\begin{array}{l}\text { Upper } \\
\text { stone } \\
\text { depth }\end{array}$ & $\begin{array}{c}\text { Usage } \\
\text { of } \\
\text { headers }\end{array}$ & $\begin{array}{l}\text { Op. at in- } \\
\text { plane }\end{array}$ & $\begin{array}{l}\text { Op. at out- } \\
\text { of-plane }\end{array}$ & $\begin{array}{c}\text { Ave. } \\
\text { collapse } \\
\text { angle }\end{array}$ & $\lambda$ \\
\hline Wp. 1 & 0.4 & 1.5 & 1 & 60 & 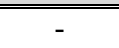 & $\mathrm{B} 2+\mathrm{A}$ & $\mathrm{G}$ & 9.3 & $0.16 \mathrm{~g}$ \\
\hline Wp. 2 & 0.65 & 2 & 1 & 60 & - & $\mathrm{B} 2+\mathrm{A}$ & $\mathrm{G}$ & 10.9 & $0.19 \mathrm{~g}$ \\
\hline Wp. 3 & 0.8 & 2 & 1 & 60 & $\begin{array}{c}\text { Lower: } \\
25 \%\end{array}$ & $\mathrm{~B} 2+\mathrm{A}$ & $\mathrm{B} 2+\mathrm{G}$ & 12.7 & $0.22 \mathrm{~g}$ \\
\hline Wp. 4 & 1.7 & 3 & 1 & 75 & - & $\mathrm{B} 2$ & $\mathrm{~B} 2$ & 15.8 & $0.27 \mathrm{~g}$ \\
\hline Wp. 5 & 0.8 & 2.4 & 2 & 50 & $\begin{array}{l}\text { Upper } \\
11 \%\end{array}$ & $\begin{array}{l}\mathrm{B} 2 \mathrm{~T}+\mathrm{VS} \\
\mathrm{B} 2 \mathrm{~T}+\mathrm{DT} /\end{array}$ & $\mathrm{B} 2 \mathrm{~T}+\mathrm{DT}$ & 13 & $0.22 \mathrm{~g}$ \\
\hline Wp. 6 & 1.8 & 4 & 2 & 50 & $\begin{array}{l}\text { Upper } \\
11 \%\end{array}$ & $\mathrm{~B} 2 \mathrm{~T}$ & $\mathrm{~B} 2 \mathrm{~T}+\mathrm{DT}$ & 17.9 & $0.3 \mathrm{~g}$ \\
\hline
\end{tabular}

\section{Staggering ratio}

Average staggering ratios of wall profiles vary between 0.4 and 1.8. According to average resistance results, staggering ratio is dominant on determination of resistance. 
Wall profiles 1, 2, 3 and 4 are composed of a single leaf, while wall profiles 5 and 6 are out of double leaves with header stones. However, regarding the wall sections, the resistance of wall profiles increases proportional to staggering ratios from 0.4 to 1.8 (Figure 78).

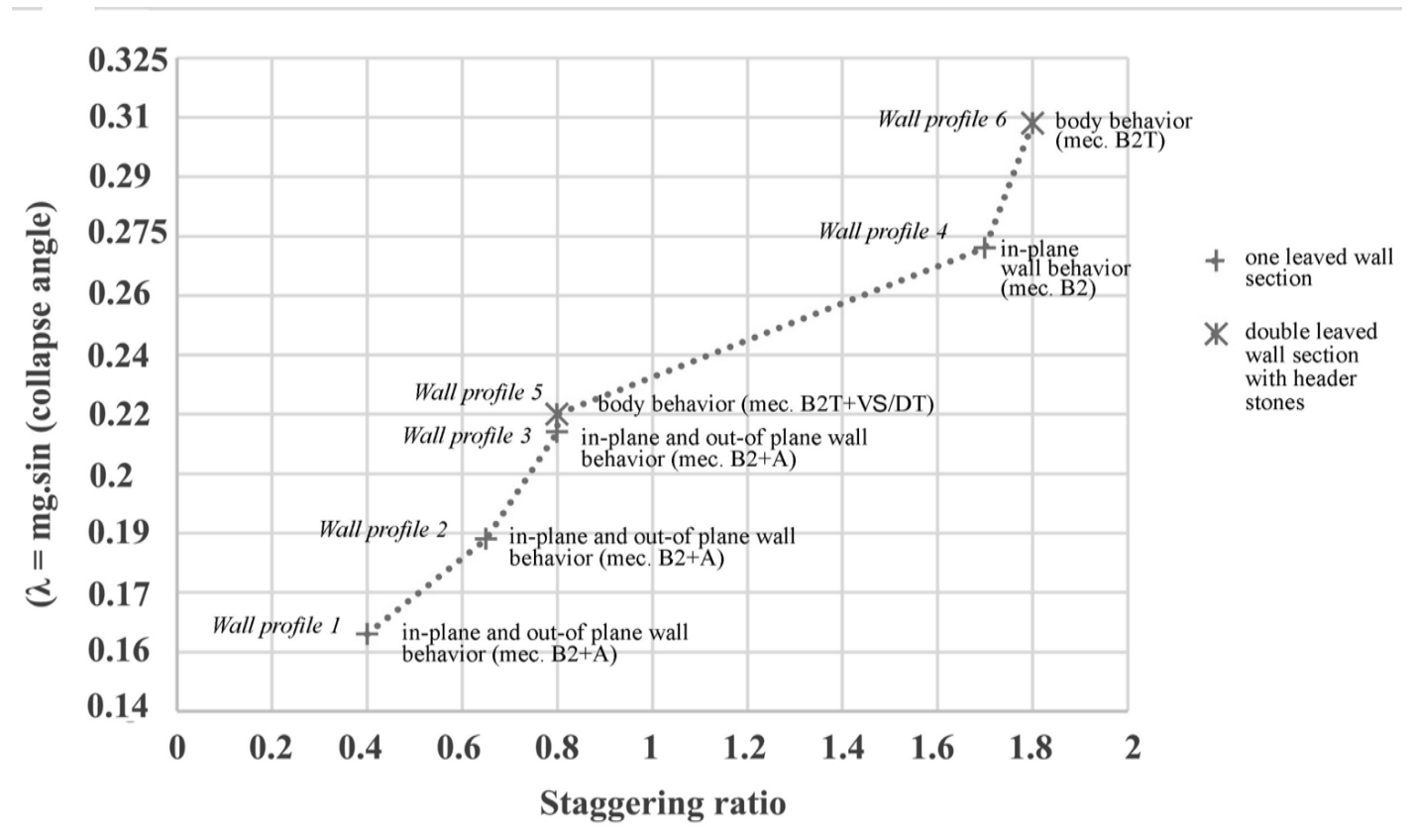

Figure 78. Impact of staggering ratio on structural resistance

The wall profiles that have the highest staggering ratios are wall profiles 4 $(\mathrm{s} / \mathrm{h}=1.7)$ and $6(\mathrm{~s} / \mathrm{h}=1.8)$. They have the highest structural resistance in dependent from differentiation in their wall sections. While usage of long blocks up to $200 \mathrm{~cm}$ increases staggering ratio of wall profile 6 , usage of short blocks (height $=25-30 \mathrm{~cm}$ ) in every two rows increases average staggering ratios of the wall profile 4 . In the analytical study of D'Ayala and Speranza $(2003,488)$, the advantage of high staggering ratio is also proved. The staggering ratio from 0 to 1.8 increases resistance $(\lambda)$ at $h / 1$ ratios between 1.25 and 2.5; similar with the results of the case study towers (Figure 79).

High staggering ratio increases resistance; however, the behavior of wall profiles is not only related with staggering ratios. Wall profile 6 that is composed of double leaves presents body behavior, while wall profile 4 that is composed of a single leaf presents inplane behavior (Figure 78) 


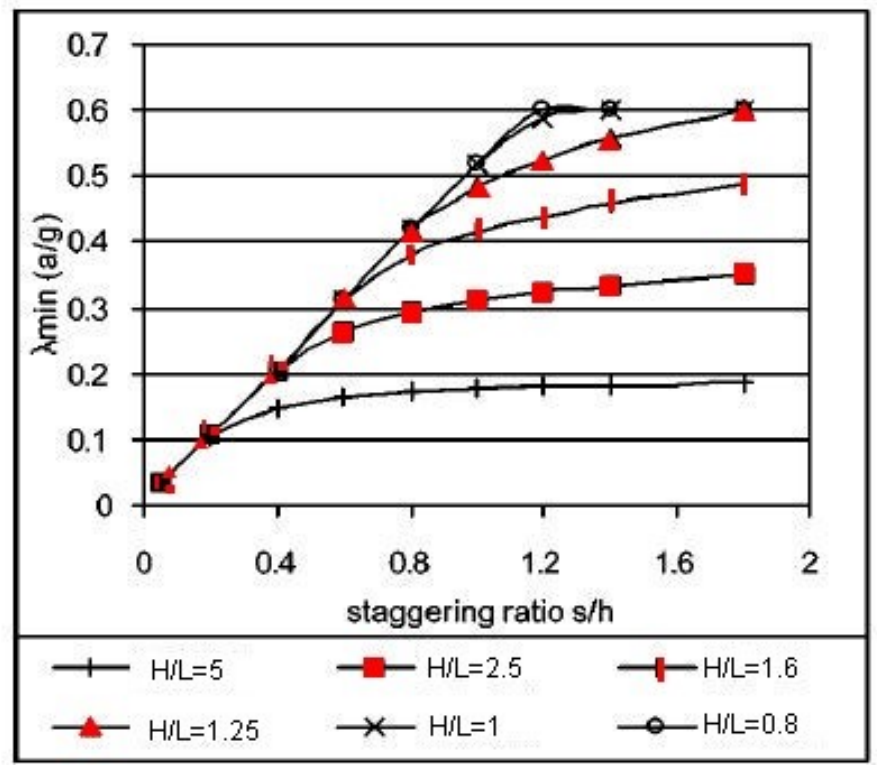

Figure 79. Impact of staggering ratio on structural resistance (Source: revised from D’Ayala and Speranza 2003, 488)

In the studies of Jimenez $(2011,86)$, Restrepo-Velez, Magenes, and Griffith (2014, 10, 26) and Shi, D'ayala, and Prateek (2008, 5-6), the walls composed of a single leaf with staggering ratios between 1 and 1.5 present in-plane failure mechanism similar with wall profile 4 (Figure 80). Thus, an appropriate double leafed organization gives way to total body behavior, in turn, structural resistance increases.
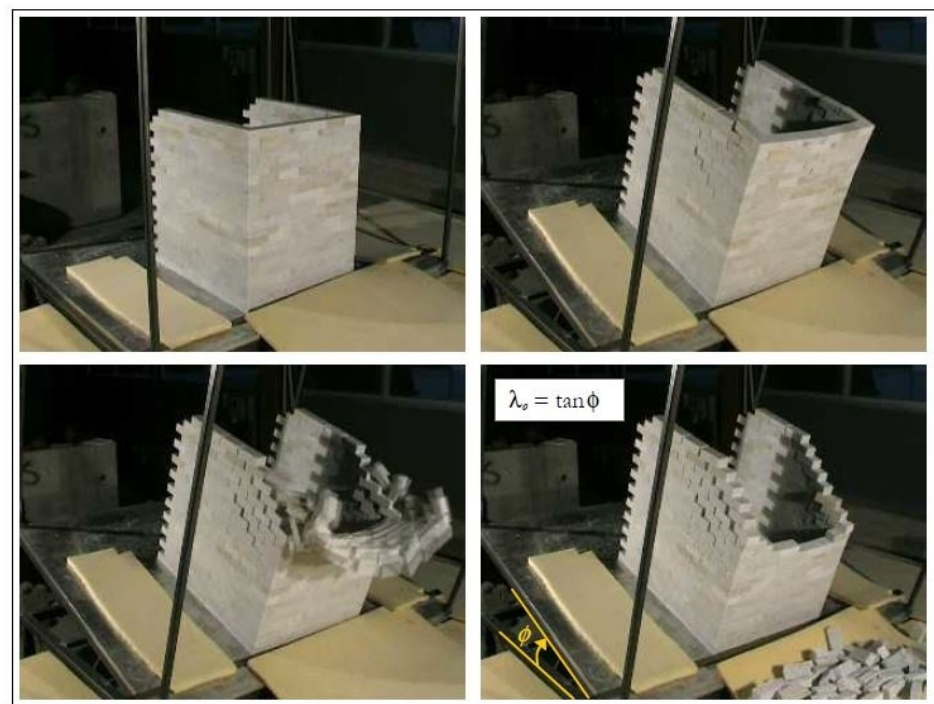

Figure 80. Collapse of side wall due to in-plane cracking (Source: Vaculik 2012, 234 from Restrepo-Velez and Magenes 2009) 
When the staggering ratio is smaller than 1 , if the wall profiles are not composed of double leaves with header stones, the out-of-plane failure (overturning of the facade due to vertical cracks at the corners) is seen. Staggering ratios are between 0.4 and 0.8 in the wall profiles 1, 2 and 3, since joints are positioned close to each other or they overlap. Small staggering ratio weakens the corner connections and make the tower corners unstable against the lateral load. Overturning of the out-of-plane facade wall occurs since the staggering ratio of the blocks at the corners are small $(0.4 \leq \mathrm{s} / \mathrm{h} \leq 0.8)$. In the studies of Restrepo-Velez, Magenes, and Griffith $(2014,6)$ and Shi, D'ayala, and Prateek (2008, 56 ), overturning of the facade wall is observed as well due to the small staggering ratio (0.7) (Figure 81). Increase in staggering ratio supports behavior as revealed in in-plane wall or body behaviors. Small staggering ratios cause decrease in resistance of out-ofplane walls. High staggering ratio strengthen corner connection, since it provides full interlocking of corners to the side walls and gives way to in-plane behavior.

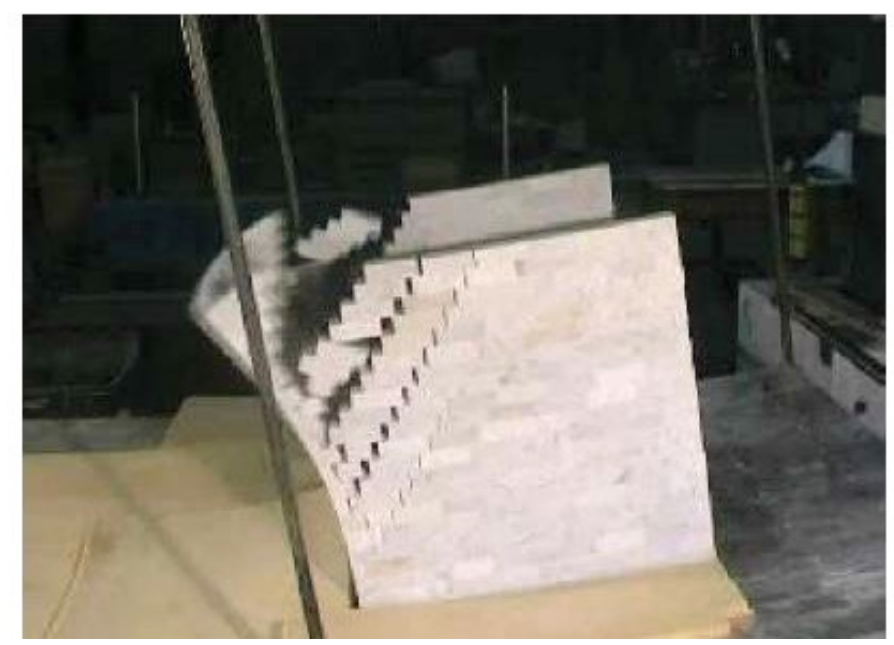

Figure 81. Overturning of the facade with vertical cracks at the corners due to the low staggering ratio (0.7) (Source: Restrepo-Velez, Magenes, and Griffith 2014, 6)

In the study of Shi, D'ayala, and Prateek $(2008,5)$, different corner configurations with staggering ratios $0.2,1$ and 1.5 are used to simulate different damage mechanisms. Small staggering ratio (0.2) causes overturning due to the vertical cracks at the corners, while strong connection causes entire collapse of the out-of-plane wall together with the top three courses of the side walls (Figure 82). 


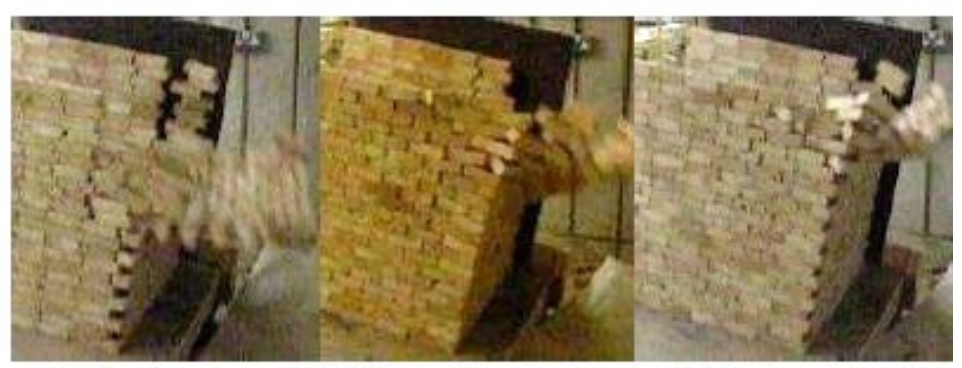

(a) Mechanism A (b) Mechanism D (c) Mechanism B1 $\mathrm{s} / \mathrm{h}: \mathbf{0 . 2}$ s/h: 1 $\mathrm{s} / \mathrm{h}: \mathbf{1 . 5}$

Figure 82. Variation in staggering ratios of the corners (Source: Shi, D'ayala, and Prateek 2008, 5)

When the collapsed portions of the towers composed of a single leaf with staggering ratios from 0.4 and 1.7 are compared, larger triangular portions are lost at small staggering ratios $(\mathrm{s} / \mathrm{h} \leq 0.8)$ in comparison to high $(1.7)$ ones. In the analytical study of D'Ayala and Speranza (2003: 494-497), the number of stories collapsing is less at high staggering ratio $\left(\mathrm{B}_{2}, \mathrm{~s} / \mathrm{h}=1.2\right)$ in comparison to low staggering ratio $\left(\mathrm{B}_{2}, \mathrm{~s} / \mathrm{h}=0.3\right)$ during the detachment of the triangular portion (mechanism $\mathrm{B}_{2}$ ).

When failures of wall profiles composed of double leaves with headers are compared with each other, it is seen that double leafed walls with high staggering (1.8) provides total body behavior at highest collapse angles, however, small staggering (0.8) cause vertical splitting as well as total body behavior.

\section{Ratio between stone block length and height (bl/bh)}

When the joints are positioned in the middle of the upper and lower blocks, the ratio between stone length and height is directly proportional to the staggering ratio. For example, in the study of Shi, D'Ayala and Join (2008, 5-6), by using smaller bricks, staggering ratios becomes smaller. Decreasing both sub-qualities causes decrease in resistance and out-of-plane failure mechanisms due to the poor corner connections. However, in this study, joints of stone blocks are not always positioned in the middle. Therefore, the average ratios of staggering and stone block dimensions are not proportional to each other. So, bl/bh is examined separately. 
The results present that high block ratios increase structural resistance of towers. Wall profile 6 has similar staggering ratios with wall profile 4 , but wall profile $6(\mathrm{bl} / \mathrm{bh}=4)$ has higher $\mathrm{bl} / \mathrm{bh}$ ratio in comparison to wall profile $4(\mathrm{bl} / \mathrm{bh}=3)$. The wall profile 6 has higher structural resistance (Figure 78, Table 26).

The study of De Felice and Giannini (2001, 270) demonstrates the decreasing level of seismic resistance in parallel with the decreasing ratio between block height and length and also increasing height of the blocks decrease the quality of the masonry fabric with the same stone length (Figure 83).

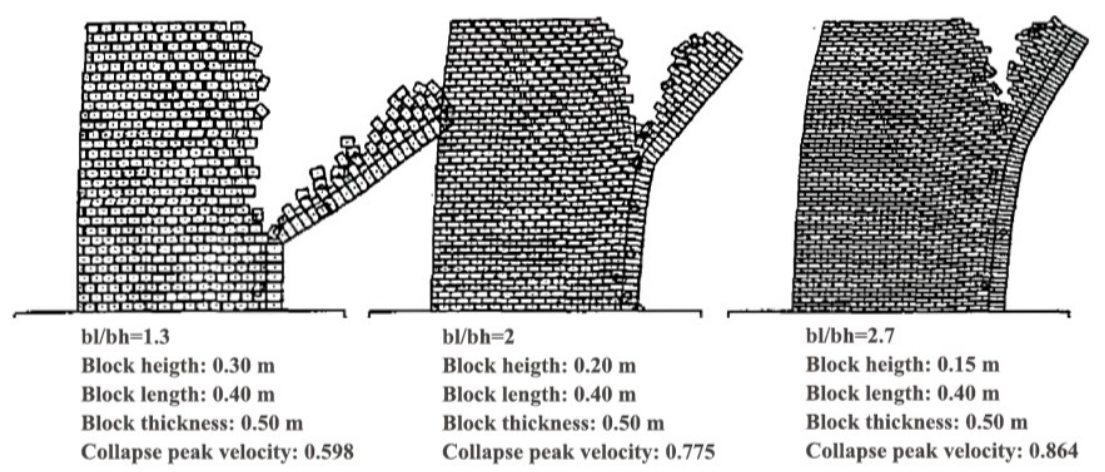

Figure 83. Impact of block ratio on failure mechanisms and resistance (Source: De Felice and Giannini 2001, 270)

In the study of Giuffre, Pagnoni and, Tocci (1994, 267-271) decrease in length of bricks in masonry walls leads to lower out-of-plane seismic capacity (Figure 81). This explains why the out-of-plane capacity of wall profile 6 with high bl/bh ratio is high (4) (Figure 84).

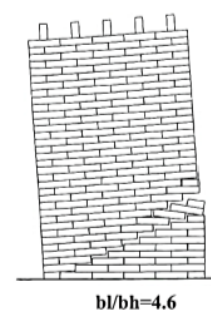

$\lambda=0.33$

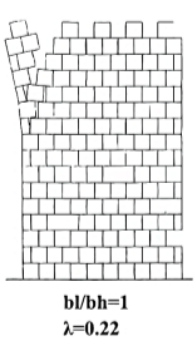

$\lambda=0.22$

Figure 84. Impact of brick height on failure mechanisms and resistance (Source: Giuffre, Pagnoni and, Tocci 1994, 268) 
Increase in structural strength proportional to stone length was presented in previous studies. This study proves that analysis of only stone length or only staggering ratio for dry masonry towers can be deceptive in terms of structural resistance. Wall profiles 3 and 5 have same staggering ratios, but they have different ratios between stone length and height, so they have different resistance. Similarly, wall profiles 2 and 3 have same stone ratios, but different staggering ratios, and they present different structural resistance.

\section{Stone depth}

In single leafed wall profiles whose wall thickness is equal to the depth of the stone blocks, stone depth directly effects the behavior of wall. In literature, advantage of depth of the blocks are generally studied on wall portions. In the study of Shi, D'ayala, and Prateek (2008), increase in brick depth in masonry walls leads to higher out-of-plane seismic capacity.

Wall profile 4 has longer stone depth $(75 \mathrm{~cm})$ in comparison to wall profile 1,2 and $3(60 \mathrm{~cm})$. Wall profiles 1, 2 and 3 present out-of-plane failure (G or DT) when there are openings at out-of-plane position, however wall profile 4 does not present any out-ofplane failure, even if there are openings at out-of-plane position (Table 26).

\section{Usage of headers}

The systematic header stone distribution, namely, providing a distance between each header stone so that they do not neighbor each other, and placing fewer header stones at the sides compared to the central area (3\% at the edges and $8 \%$ at the center); increase the monolithic behavior of the two leaves and improve out-plane resistance. The tower presents a total overturning by starting with diagonal body cracking and horizontal cracking at out-of-plane wall.

The wall profiles that have highest resistance are wall profiles 6 and 4 due to their high staggering ratios. While profile 4 with a single leaf presents in-plane failure mechanism, doubled leafed wall profile 6 connected with headers presents total body failure. The headers support monolithic behavior (Figure 78).

When wall profile 5 (double leafed) and 3 (single leafed) that have smaller staggering ratios (0.8) are compared with each other, wall profile 3 presents out-of-plane failure, but wall profile 5 presents body behavior. 
In literature, effect of header stones connecting wall leaves on resistance against lateral force is generally studied with a wall portion without side walls (Ceradini 1992; D’ayala, and Speranza 2003, 480; Gençer et al. 2017, 84; Gençer, Hamamcioğlu Turan, and Aktaş 2019). In the study of Giuffre (1996, 117), Ceradini (1992) and De Felice $(2011,479)$, the number of header blocks at wall section influence the strength capacity. The interlocking between the external leaves of masonry is crucial to provide an out-ofplane seismic capacity (Figure 85).

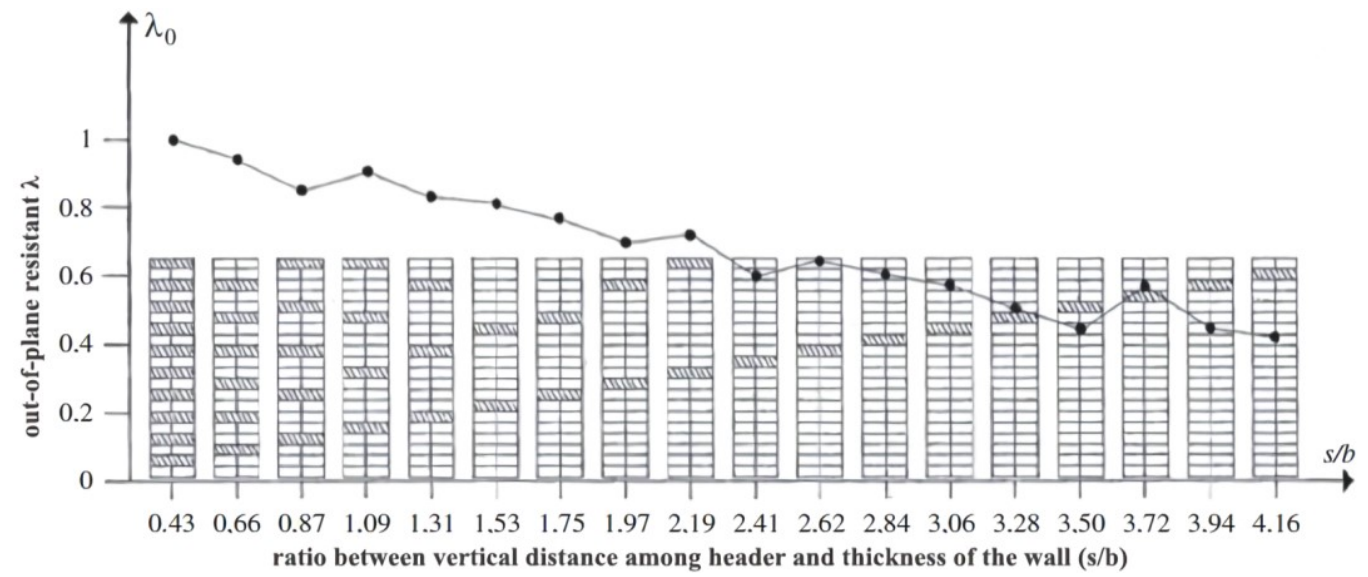

Figure 85. Decrease in out-of-plane resistant with decreasing number of headers (Source: revised by De Felice 2011, 479 and Giuffre 1996, 117)

Wall profiles 5 and 6 are composed of header stones connecting the two outer leaves. They present total body behavior. However, the resistance of wall profile 5 is lower than wall profile 6 due to its low staggering ratio. Low staggering ratio causes vertical splitting in addition to total body behavior. This proves that header usage provides more advantage in behavior compared to that in resistance. If the header usage is supported with high staggering ratio and high $\mathrm{bl} / \mathrm{bh}$ ratio, the resistance increases, and the tower presents total body behavior (Figure 78). The usage of header stones with appropriate block dimensions and organizations is critical in terms of resistance and behavior.

Wall profile 3 that have header stones used only in the lower part of the towers cannot provide contribution to the resistance of the structure. Also, the header stones adjacent to each other in two rows reduce the strength of the towers considerably because 
they cause decrease in staggering ratio. Wall profile 3 proves that headers may cause decrease in structural resistance, if they are used inappropriately.

The effect of header stones on behavior resembles towers that have horizontal reinforcement through a single square ring beam (with black paste glue at the top) at the top of the dry masonry models (Jimenez 2011, 84). As the reinforcement integrates the structure to act as a whole, the first crack appears at a great acceleration, no single block falls off the top, before global overturning which takes place at slightly higher acceleration as well (Figure 86). This shows that advantage of header stones is similar with horizontal reinforcement of the towers.
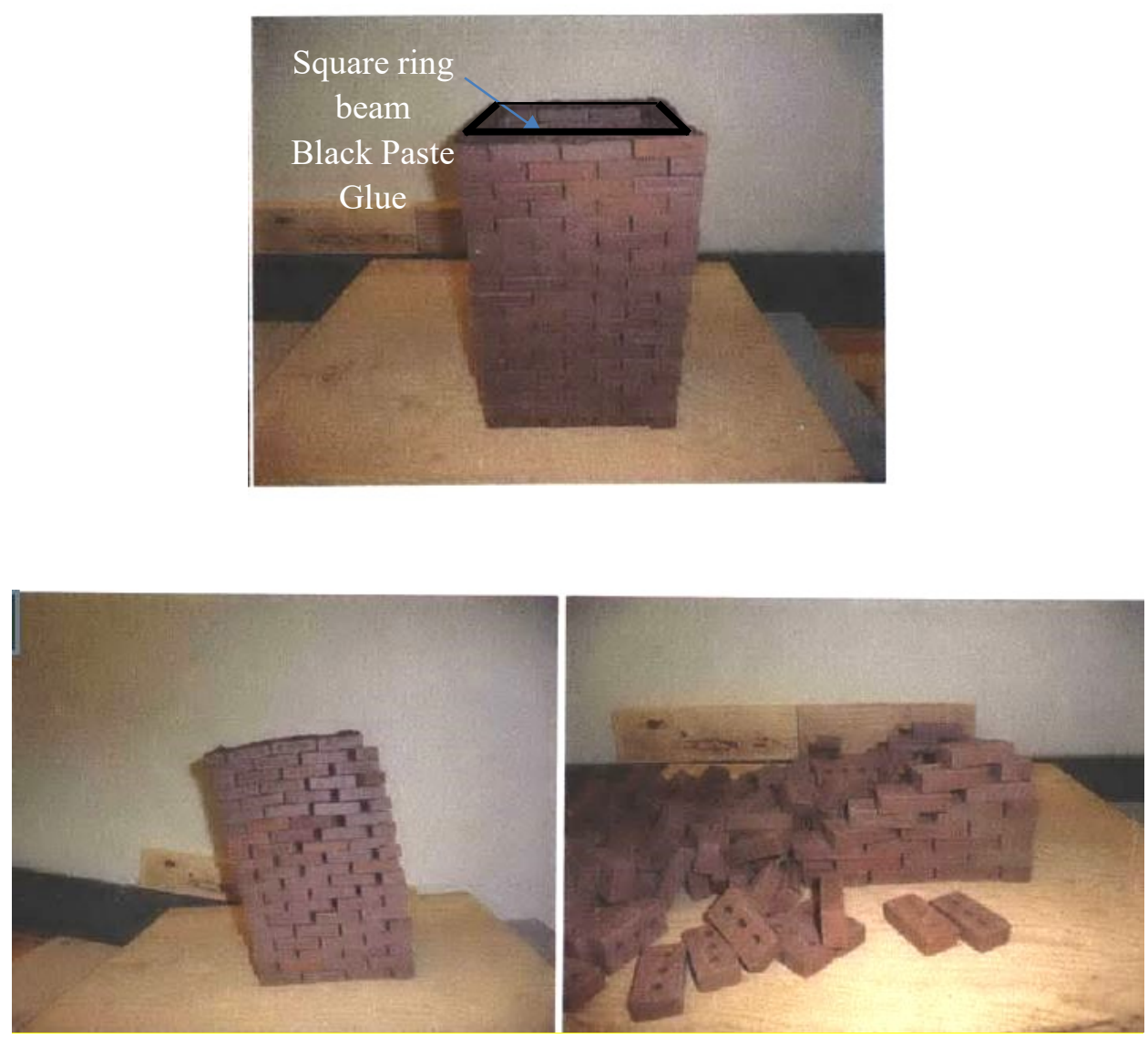

Figure 86. Behavior of horizontally reinforced tower (Source: Jimenez 2011, 117-118)

\subsubsection{The opening organization}

The openings affect the structural resistance and behavior in accordance with their sub-qualities such as area, number, and position. It is seen that increasing the number of 
openings and their area and positioning them considering an even distribution within the facade composition and decreasing their distance to the corners reduce the resistance (Gençer et al. 2017, 84; Gençer, Hamamcioğlu-Turan and, Aktaş 2019 in press; Table 27)).

Table 27. Average performance of sub-qualities regarding opening types

\begin{tabular}{|c|c|c|c|c|c|c|c|}
\hline & Distribution & $\begin{array}{l}\text { Distance } \\
\text { to corner } \\
\text { (cm) }\end{array}$ & $\begin{array}{c}\text { Area } \\
\text { (upper) } \\
\left(\mathbf{m}^{2}\right)\end{array}$ & $\begin{array}{c}\text { Number } \\
\text { (upper) }\end{array}$ & $\begin{array}{l}\text { Common } \\
\text { In-plane }\end{array}$ & $\begin{array}{c}\text { echanism } \\
\text { Out-of- } \\
\text { plane }\end{array}$ & $\begin{array}{c}\text { Ave. } \\
\text { decrease in } \\
\text { c. angle / } \lambda\end{array}$ \\
\hline Op.1 & Sym. & $200-250$ & 1 & 1 & $\begin{array}{c}\text { Typical } \\
\text { mechanism } \\
\text { of wall pr. }\end{array}$ & $\begin{array}{c}\text { Typical } \\
\text { mechanism } \\
\text { of wall pr. }\end{array}$ & - \\
\hline $\begin{array}{c}\text { Op. } 2,5 \text {, } \\
7,9\end{array}$ & Sym. & $200-250$ & $1.4-2$ & 1 or 2 & $\begin{array}{c}\text { Typical } \\
\text { mechanism } \\
\text { of wall pr. }\end{array}$ & $\begin{array}{c}\text { Typical } \\
\text { mechanism } \\
\text { of wall pr. }\end{array}$ & - \\
\hline $\begin{array}{c}\text { Op. 3, } 4 \text {, } \\
6\end{array}$ & Asym. & $50-60$ & $1-2.5$ & 1 & $\begin{array}{c}\text { Typical } \\
\text { mechanism } \\
\text { of wall pr. }\end{array}$ & $\begin{array}{c}\text { Typical } \\
\text { mechanism } \\
\text { of wall pr. }\end{array}$ & - \\
\hline Op. 8 & Sym. & $20-30$ & 3 & 3 & $\begin{array}{c}\text { Typical } \\
\text { mechanism } \\
\text { of wall pr. }\end{array}$ & $\begin{array}{c}\text { Typical } \\
\text { mechanism } \\
\text { of wall pr. }\end{array}$ & $\begin{array}{c}0.19 / \\
0.003 \mathrm{~g}\end{array}$ \\
\hline $\begin{array}{c}\text { Op. 12, } \\
13\end{array}$ & Asym. & 50 & $1-1.5$ & 2 & $\begin{array}{c}\text { Typical } \\
\text { mechanism } \\
\text { of wall pr. }\end{array}$ & $\begin{array}{c}\text { Typical } \\
\text { mechanism } \\
\text { of wall pr. }\end{array}$ & $\begin{array}{c}0.21 / \\
0.003 \mathrm{~g}\end{array}$ \\
\hline Op. 10 & Sym. & $20-30$ & $\begin{array}{c}7.4 \\
\text { (a large } \\
5 \mathrm{~m}^{2} \text { ) }\end{array}$ & 3 & B2 & G & $\begin{array}{l}1.02 / \\
0.02 \mathrm{~g}\end{array}$ \\
\hline Op. 11 & Sym. & $20-30$ & 3 & 3 & B1 & G & $\begin{array}{l}0.62 / \\
0.01 \mathrm{~g}\end{array}$ \\
\hline Op. 14 & Adj. & 0 & 1 & 2 & B2 & G & $\begin{array}{l}0.69 / \\
0.01 \mathrm{~g}\end{array}$ \\
\hline Op. 15 & Adj. & 0 & 2.95 & 2 & B1 & G & $\begin{array}{l}0.69 / \\
0.01 \mathrm{~g}\end{array}$ \\
\hline
\end{tabular}

Relation of three sub-qualities are discussed for towers with average collapse angles and failure mechanisms. Upper openings affect structural resistance more in comparison to lower openings. If a facade is composed of lower and upper openings, primarily the upper opening is taken into consideration. Although the lower openings are 
adjacent to corner, they are not primary factors determining structural resistance and behavior (Figure 87).
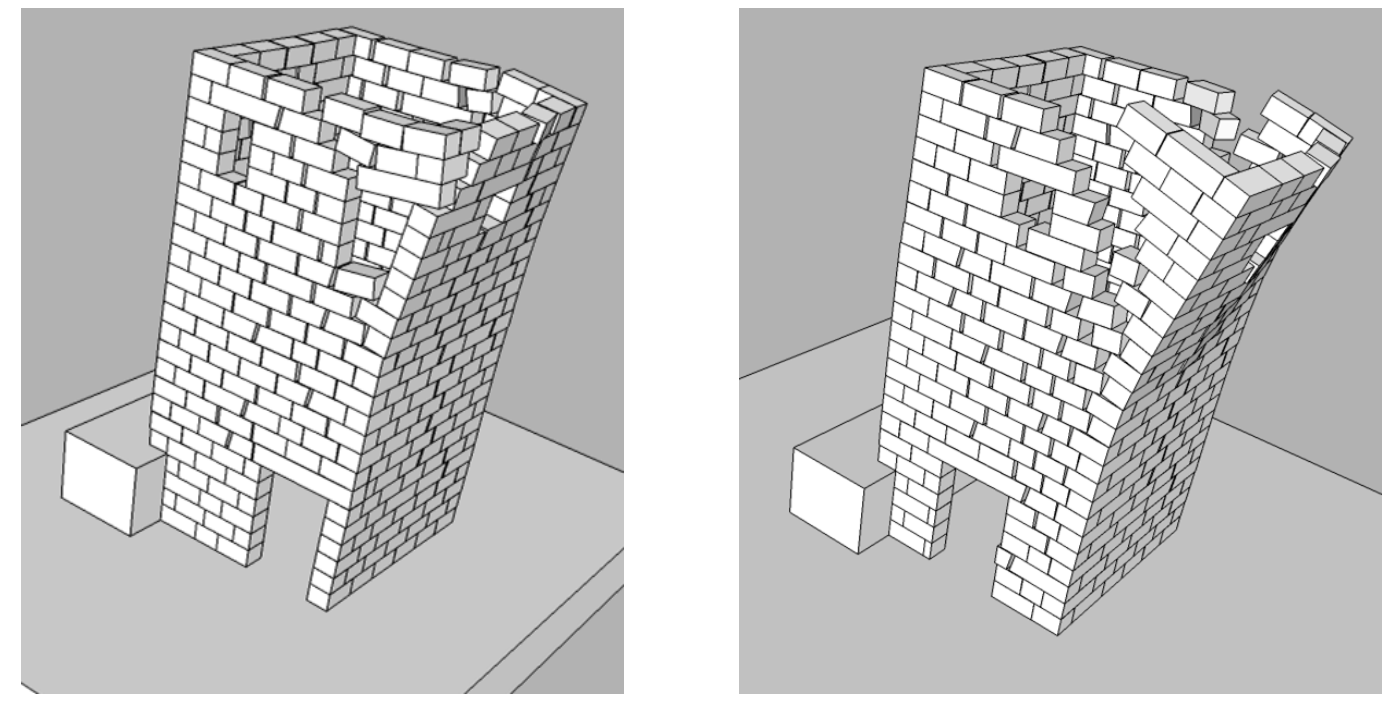

Figure 87. Impact of lower openings

One or two symmetrical or asymmetrical openings up to $3 \mathrm{~m}^{2}$ at in-plane position or out-of-plane position that do not reduce the resistance significantly are determined as ineffective. However, their effect on behavior change depending on the properties of wall profiles.

Ineffective openings at in-plane position generally cause collapse of side walls due to in-plane shear cracking at wall profiles that are single leafed. In the study of Preciado, Sperbeck and, Gaytan $(2006,53)$ and Felice and Giannini $(2001,270)$ the inplane failure mechanism is observed due to the cracks above and below the openings.

In the study of Restrepo-Velez, Magenes, and Griffith $(2014,10)$, openings at inplane position cause diagonal cracks above the openings followed by collapse of side walls. Overturning occurs relatively faster in comparison to a wall without openings. The model, named as S42, with similar sub-qualities with the case study towers, shows similar behavior with case study towers that have similar staggering ratios (0.8) (Figure 88). However, openings cannot cause in-plane failure at wall profiles that have staggering ratio smaller than 0.4 , since the tower presents out-of-plane behavior due to the poor corner connection caused by small staggering at small collapse angles before the effect of openings are seen. 


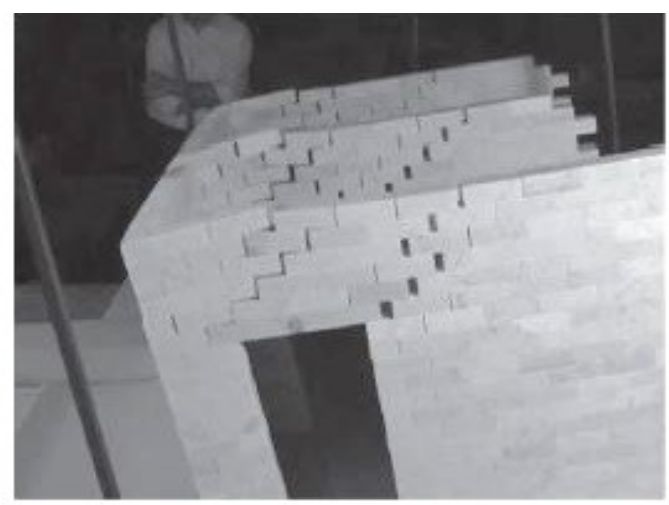

(a) Test S22

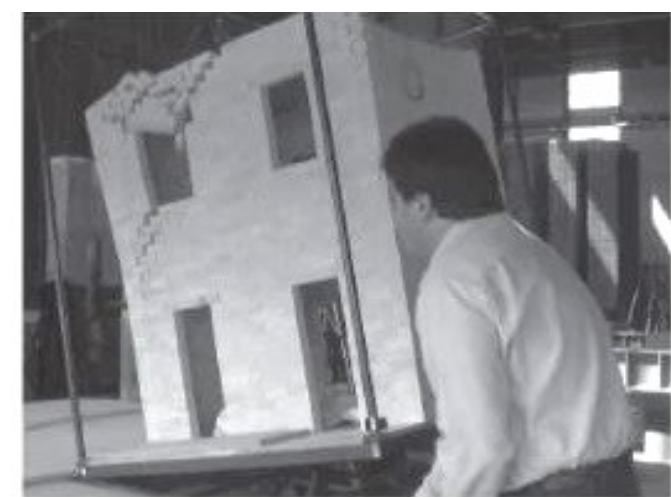

(b) Test $\mathrm{S} 42$

Figure 88. Collapse mechanism caused by openings at in-plane wall (Source: RestrepoVelez, Magenes, and Griffith 2014, 10)

Ineffective openings at out-of-plane position generally present detachment of the out-of-plane facade of the walls; regardless of openings position. This is proved by the studies of Restrepo-Velez, Magenes, and Griffith $(2014,9,20)$ and Vaculik et al. (2004, 4-5), (Figure 89, Figure 90). These studies demonstrate cracking patterns stemming from different opening types at out-of-plane position. Diagonal cracks at the lower and upper parts cause detachment of the wall (Figure 89, Figure 90). In the cases of this study, however, the double-leafed and one-leafed wall profiles that have high staggering ratios $(\geq 1.7)$ are not affected by one or two openings up to $3 \mathrm{~m}^{2}$. Even though ineffective openings at out-of-plane position change the behavior of towers, they do not affect resistance of tower. Small sized openings less than $3 \mathrm{~m}^{2}$ do not affect resistance of towers both at in-plane and out-of-plane position.

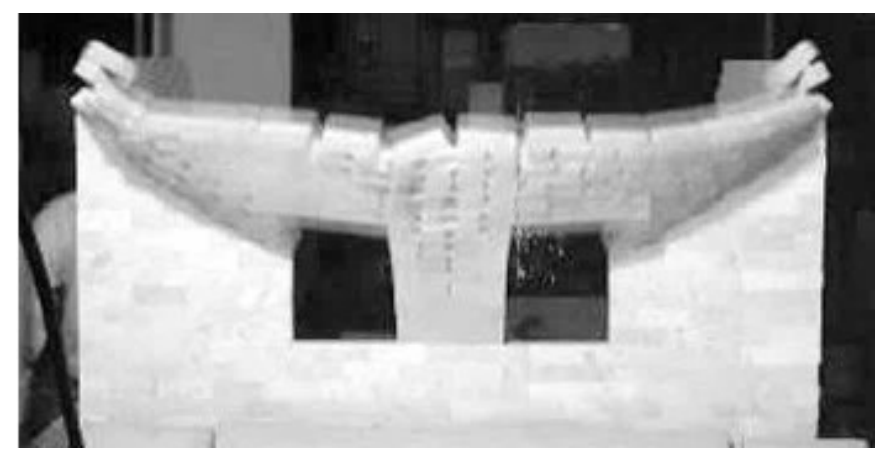

Figure 89. Failure mechanism with openings (Source: Restrepo-Velez, Magenes, and Griffith 2014, 9 


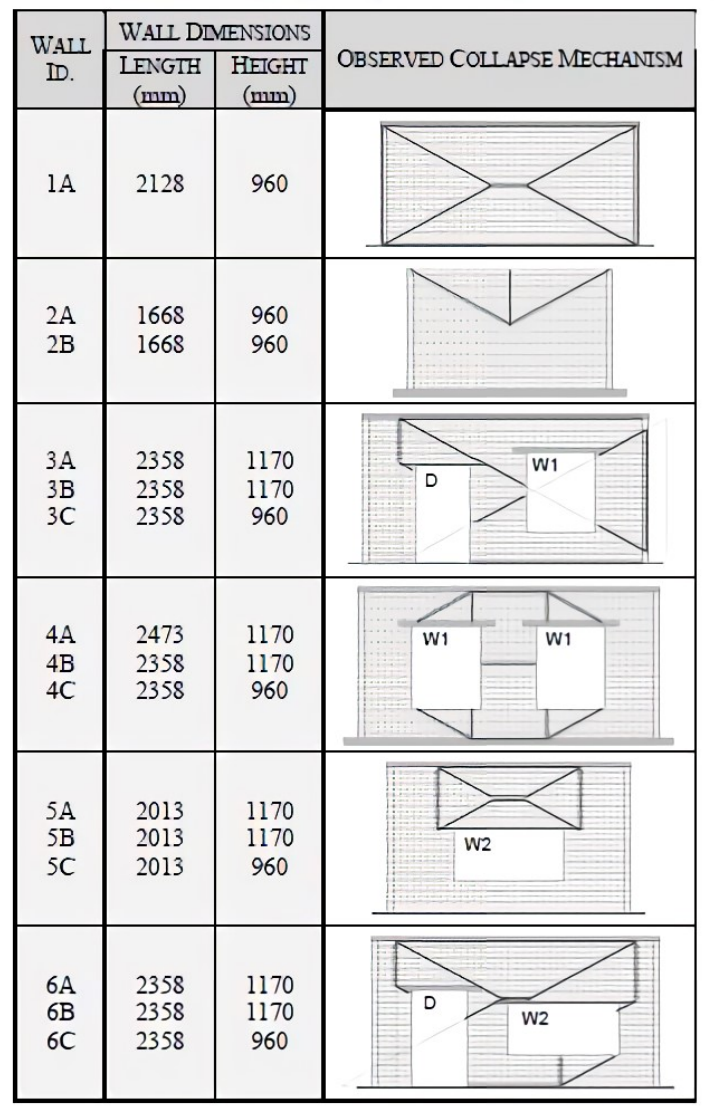

D: $460 \times 780 \mathrm{~cm}$

W1: $575 \times 660 \mathrm{~cm}$

W2: $920 \times 420$

Figure 90. Failure mechanism depending on opening types (Source: Vaculik et al. 2004, 4)

Effective opening types in terms of resistance and behavior are composed of more than 2 openings or larger than $5 \mathrm{~m}^{2}$ or closed to corner (max. $30 \mathrm{~cm}$ ). If openings are closed to corner or if they are more than two in number at in-plane position, they cause in-plane cracking of the only one side wall at which the opening is positioned. However, openings at out-of-plane position cause detachment of out-of-plane wall. Single leafed wall profiles that have both high staggering ratios and high stone depth are not affected by openings close to corner: they present in-plane failure with the help of out-of-plane resistance.

While a large sized upper opening, that has an area more than $5 \mathrm{~m}^{2}$, at in-plane position causes collapse of side walls due to in-plane shear cracking, large sized opening at out-of-plane position (more than $5 \mathrm{~m}^{2}$ ) causes out-of-plane failures regardless of wall profile characteristics. 


\subsubsection{The proportional relations}

Studies in literature demonstrate that for the high buildings as towers, the ratio between height and length (slenderness) is a critical sub-quality in terms of behavior of the building (Shi, D’Ayala, and Prateek 2008; Romaro 2011; Casolo et al. 2013). However, effect of ratio between wall thickness and height $(\mathrm{t} / \mathrm{h})$ and wall thickness and length $(\mathrm{t} / \mathrm{l})$ on behavior are generally studied in a wall without side walls (De Felice and Giannini 2001). Also, due to the different wall thicknesses of towers changing from 60 $\mathrm{cm}$ to $115 \mathrm{~cm}$, examining of $\mathrm{t} / \mathrm{l}$ and $\mathrm{t} / \mathrm{h}$ are not logical (see the related sections in Chapter $3)$.

\section{$\mathrm{H} / \mathrm{L}$ relation}

When ratio between height and length is lower than 1.3 or higher than 2 , long or high facades are being considered. High and long walls cause decrease in resistance against lateral loading. While higher $\mathrm{h} / \mathrm{l}$ ratio does not affect the behavior, detachment of out-of-plane wall with diagonal cracks is seen due to the arch effect at $\mathrm{h} / \mathrm{l}$ ratios smaller than 1.3 regardless of wall profile type (Figure 91).

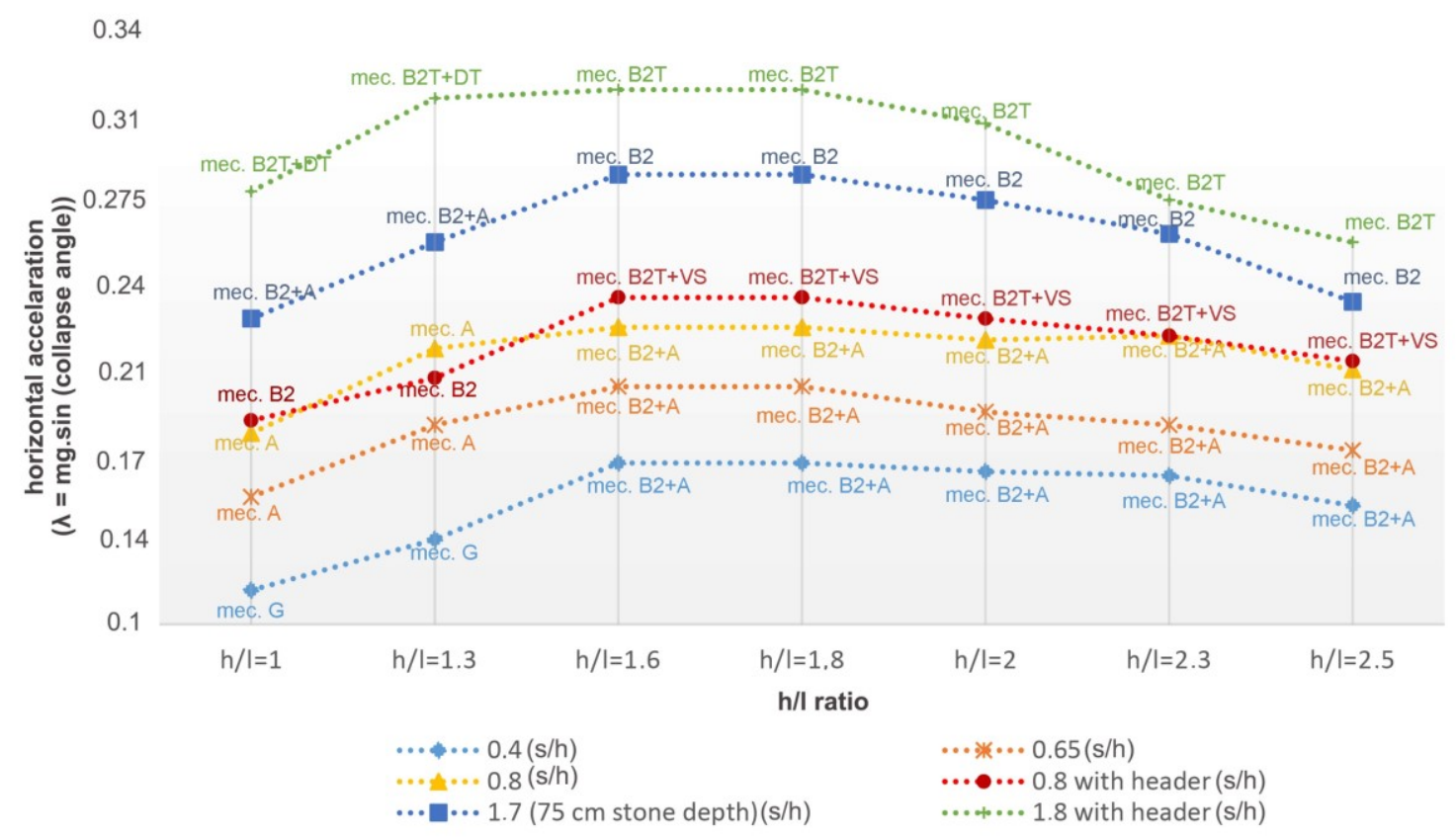

Figure 91. Resistance and behavior of wall profiles in different $\mathrm{h} / \mathrm{l}$ ratios 
In the study of Jimenez $(2011,77)$, while a square box with $0.4 \mathrm{~h} / 1$ ratio presents out-of-plane failure; detachment of facade walls due to the arch effect, a square tower with $1.6 \mathrm{~h} / 1$ ratio presents in-plane behavior. Failures are observed at smaller accelerations at the square box $(\lambda: 0.131 \mathrm{~g})$. Although towers in the study of Jimenez $(2011,77)$ have different stone block organization in comparison to real case study towers, small h/1 ratios generally cause out-of-plane failure (Figure 92).

In the study of Shi, D'ayala, and Prateek $(2008,5)$, Restrepo-Velez, Magenes, and Griffith $(2014,7)$ and Bui et al. $(2017,284-287)$ with decreasing $h / 1$, the arching behavior is more pronounced (Figure 93).

Effect of $h / 1$ ratio on resistance of dry masonry structures present variation with regard to staggering ratio. In the study of D'Ayala and Speranza $(2003,501)$, the increase of the staggering ratio produces an improvement of seismic performance only for $\mathrm{h} / \mathrm{l}$ ratios higher than 1 . For example, the positive effect of high staggering ratio $(\geq 1.7)$ on behavior is not seen at wall profiles 4 and 6 at $\mathrm{h} / 1$ ratios smaller than 1.3 . The towers present out-of-plane failure due to the arch effect; typical failure and resistance of towers is not achieved.

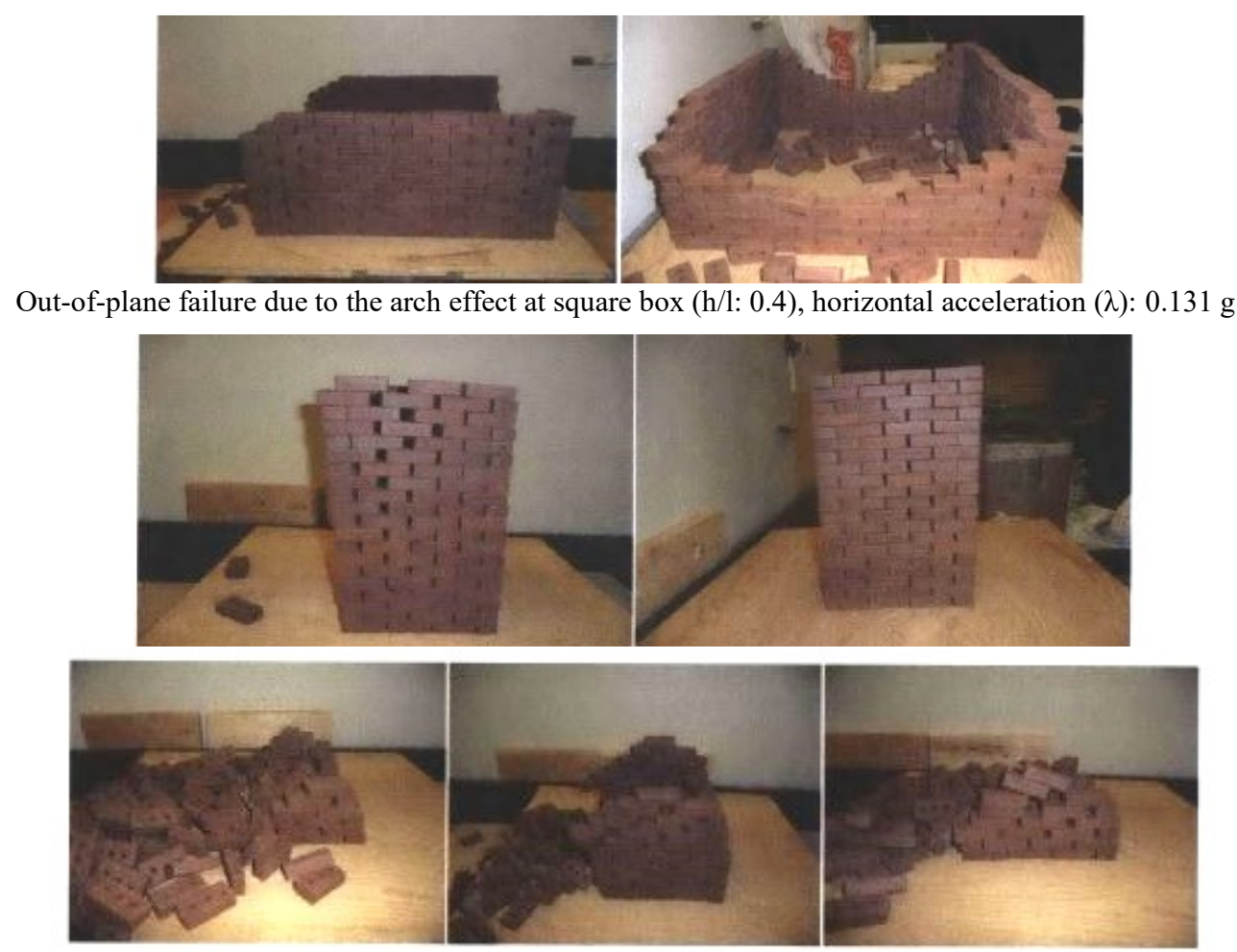

In-plane behavior at square tower (h/1:1.6), horizontal acceleration $(\lambda)$ : $0.211 \mathrm{~g}$

Figure 92. Behavior of square box and tower (Source: Jimenez 2011, 77, 83) 


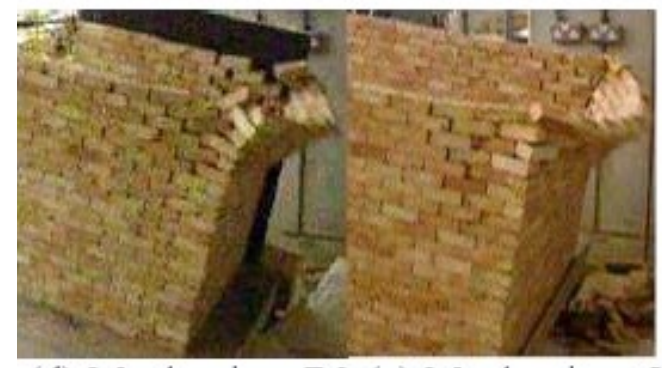

(d) Mechanism B2 (e) Mechanism G h/l:1 h/l:0.7

Figure 93. Decreasing h/1 ratio and behavior (from left to right) (Source: Shi, D'ayala, and Prateek 2008, 5)

\subsection{Impact of characteristics on each other}

Impact of effective characteristics on each other is discussed with the help of the statistical evaluation, namely, regression analysis, regarding the collapse angle results of hypothetic towers (see Appendix D). The effective characteristics are wall profile, opening organization and proportional relations. The sub-qualities of effective characteristics are staggering ratio, ratio between block length and height, stone depth, distribution of upper headers, upper opening area, number and position, and ratio between height and length. By using data about sub-qualities, regression analysis is carried out. These sub-qualities are called as independent variable effecting structural behavior and resistance. The collapse angle is directly related with these sub-qualities; so, it is the dependent variable in the statistical evaluation (Table 28).

Table 28. Variables of regression

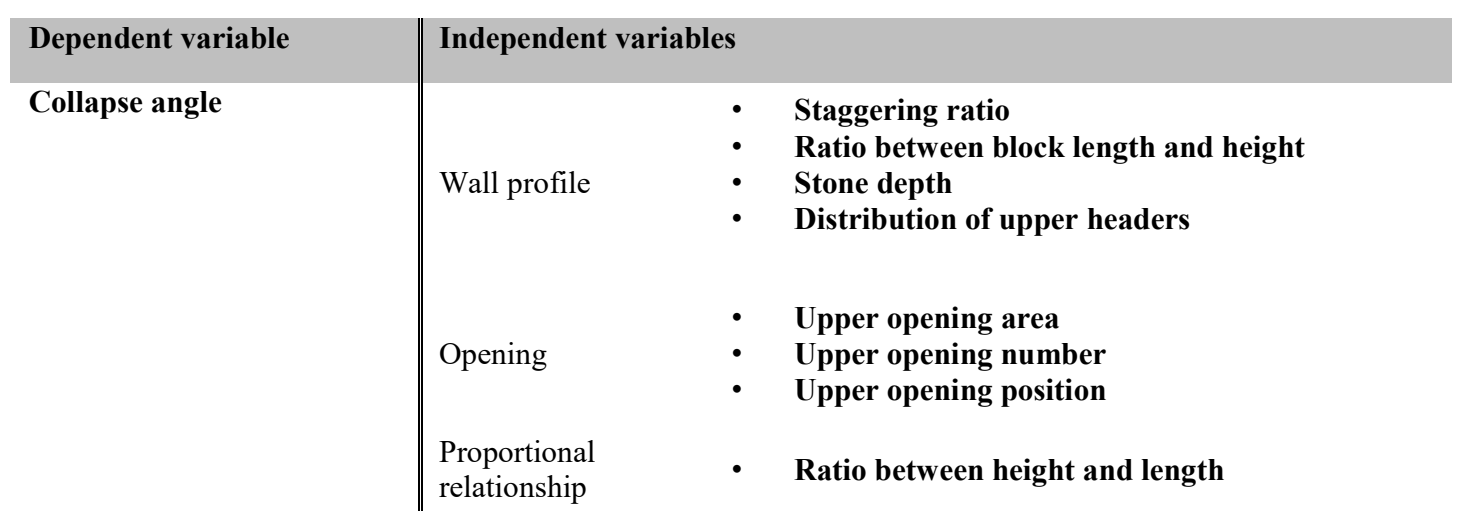


Linear relationship between dependent variable and independent variables are determined before regression analysis. The relation between height and length proportion and collapse angle within the limits of the real towers shows linearity (Appendix B). With regression analysis, the coefficients and probability of the variables affecting the structural resistance and probability and acceptance of regression model have been determined (Table 29).

When the probability of variables is less than $5 \%$, regression analysis is significant. The validity of the regression model is also emphasized by the test $\mathrm{F}$ value (probability); statistically superior value; by the fact that the value of the test sample (F statistic) is zero. This means that all variables jointly can influence collapse angle. This indicates a strong evidence of parameters (Table 29).

Table 29. Statistical analysis results

Dependent Variable: COLLAPSE ANGLE

Method: Least Squares

Date: 02/23/19 Time: 18:34

Sample(adjusted): 1360

Included observations: 360 after adjusting endpoints

\begin{tabular}{lclcc}
\hline \hline \multicolumn{1}{c}{ Variable } & Coefficient & Std. Error & t-Statistic & Probability \\
\hline \hline Block Length/Height *** & $\mathbf{0 . 7 7 4 1 7 0 * * *}$ & 0.253346 & 3.055781 & $\mathbf{0 . 0 0 2 4}$ \\
Height/Length*** & $\mathbf{- 1 . 8 7 3 8 3 2 * * *}$ & 0.132541 & -14.13770 & $\mathbf{0 . 0 0 0 0}$ \\
Opening Area*** & $\mathbf{- 0 . 1 9 3 8 1 4 * * *}$ & 0.025186 & -7.695450 & $\mathbf{0 . 0 0 0 0}$ \\
Opening Number*** & $-\mathbf{0 . 1 7 1 2 1 6 * * *}$ & 0.078331 & -2.185799 & $\mathbf{0 . 0 2 9 5}$ \\
Opening Position*** & $\mathbf{- 0 . 1 0 3 3 8 5 * * *}$ & 0.037915 & -2.726727 & $\mathbf{0 . 0 0 6 7}$ \\
Staggering Ratio** & $\mathbf{2 . 2 6 3 7 0 9 * * *}$ & 0.464579 & 4.872603 & $\mathbf{0 . 0 0 0 0}$ \\
Stone Depth*** & $\mathbf{0 . 1 3 1 6 2 1 * * *}$ & 0.031136 & 4.227269 & $\mathbf{0 . 0 0 0 0}$ \\
Upper Header Usage*** & $\mathbf{0 . 3 7 2 8 1 2 * * *}$ & 0.066929 & 5.570241 & $\mathbf{0 . 0 0 0 0}$ \\
Constant*** & $\mathbf{5 . 0 6 7 5 4 4 * * *}$ & 1.885607 & 2.687487 & $\mathbf{0 . 0 0 7 5}$ \\
\hline \hline R-squared & $\mathbf{0 . 9 4 5 8 7 8}$ & Mean dependent var & 13.89583 \\
Adjusted R-squared & $\mathbf{0 . 9 4 4 6 4 4}$ & S.D. dependent var & 2.764097 \\
S.E. of regression & 0.650332 & Akaike info criterion & 2.002014 \\
Sum squared resid & 148.4489 & Schwarz criterion & 2.099166 \\
Log likelihood & -351.3624 & F-statistic & 766.7899 \\
Durbin-Watson stat & 1.384484 & Probability(F-statistic) & $\mathbf{0 . 0 0 0 0 0 0}$ \\
\hline \hline
\end{tabular}

*** represents statistical significance between $1-5 \%,{ }^{* *}$ at $5-10 \%,{ }^{*}$ higher than $10 \%$ level.

Both R-squared (R2) and Adjusted R-squared (adjusted R2) show the proportion in which the collapse angle is explained through the parameters. R-squared value is about 95\%. $95 \%$ indicates that the model explains most of the variability of the response data. Henseler et al. (2009) identifies acceptance level of R2 values as $75 \%, 50 \%$, and $25 \%$ : 
substantial, moderate and weak, respectively. This shows that the regression model is substantial. The regression result shows that all the coefficients are statistically very significant.

Based on the values of R-squared and F-statistic tests and residuals (see Appendix B; Figure B-2), it can be stated that the model which describes the parameters effecting structural resistance of dry masonry towers can be used to make reliable proposals for the structural vulnerability of dry masonry towers against lateral load. Coefficient of parameters that effect structural resistance negatively and positively are determined. However, the parameters cannot be compared because they have different coefficient units. In order to compare the parameters with each other, an impact values of parameters with same unit are calculated by using the standard deviation value and coefficients of each parameter. In this way, the impact of the parameters can be compared with each other. While discussing these parameters, intervals of parameters should be taken into consideration (Table 30).

Table 30. Impact values and intervals of parameters

\begin{tabular}{|c|c|c|c|}
\hline Analysis interval & Definition & $\begin{array}{c}\text { Numeric } \\
\text { value }\end{array}$ & $\begin{array}{c}\text { Impact } \\
\text { Value }\end{array}$ \\
\hline $0.4-1.8$ & Staggering ratio (s/h) & 1.8 & 4.4 \\
\hline $0.5-0.75 \mathrm{~m}$ & Stone depth & $0.75 \mathrm{~m}$ & 3 \\
\hline $1.5-4$ & Block length/height (bl/h) & 4 & 2 \\
\hline $0-11 \%$ & Distribution of upper headers & 3 & 0.06 \\
\hline $1-3$ & Upper opening number & 0 & -0.4 \\
\hline $0-3 \mathrm{~m}$ & Upper opening position & & -1.5 \\
\hline $1-5 \mathrm{~m}^{2}$ & An upper opening area & 5 & -1.8 \\
\hline $1.6-2.3$ & Proportional relationship between height and & 2.3 & \\
\hline
\end{tabular}

The impact value represents the highest numerical value of interval of each parameter. When impact of parameters is listed from their positive impact to negative impact, the parameters providing considerably positive impact on resistance are about wall profile; staggering ratio, stone depth and ratio between block length and height while the parameters decreasing resistance highly are about morphology; $\mathrm{h} / \mathrm{l}$ ratio and opening 
area (Table 31). Numerical intervals of parameters are determined according to results of analysis and properties of hypothetic towers. The table illustrates the increase in resistance from orange color to beige color (Table 31). Missing parts of interval of staggering ratio (colored with grey color) are completed with the help of the literature review at section 4 (D'Ayala and Speranza 2003, 488).

Impact of parameters are determined according to their intervals. With the help of the table, the dominancy of parameters according to their intervals is discussed when they are combined (Table 31).

The parameter presenting highest positive impact is staggering ratio higher than 1.7. Wall profile parameters have three times higher positive impact values than the opening organization and proportional relationship parameters. This demonstrates that when highest staggering ratio is combined with any other parameter, it is not affected, unless all other parameters of morphologic characteristics are taken with their negative aspects.

Table 31. Intervals and impact of parameters

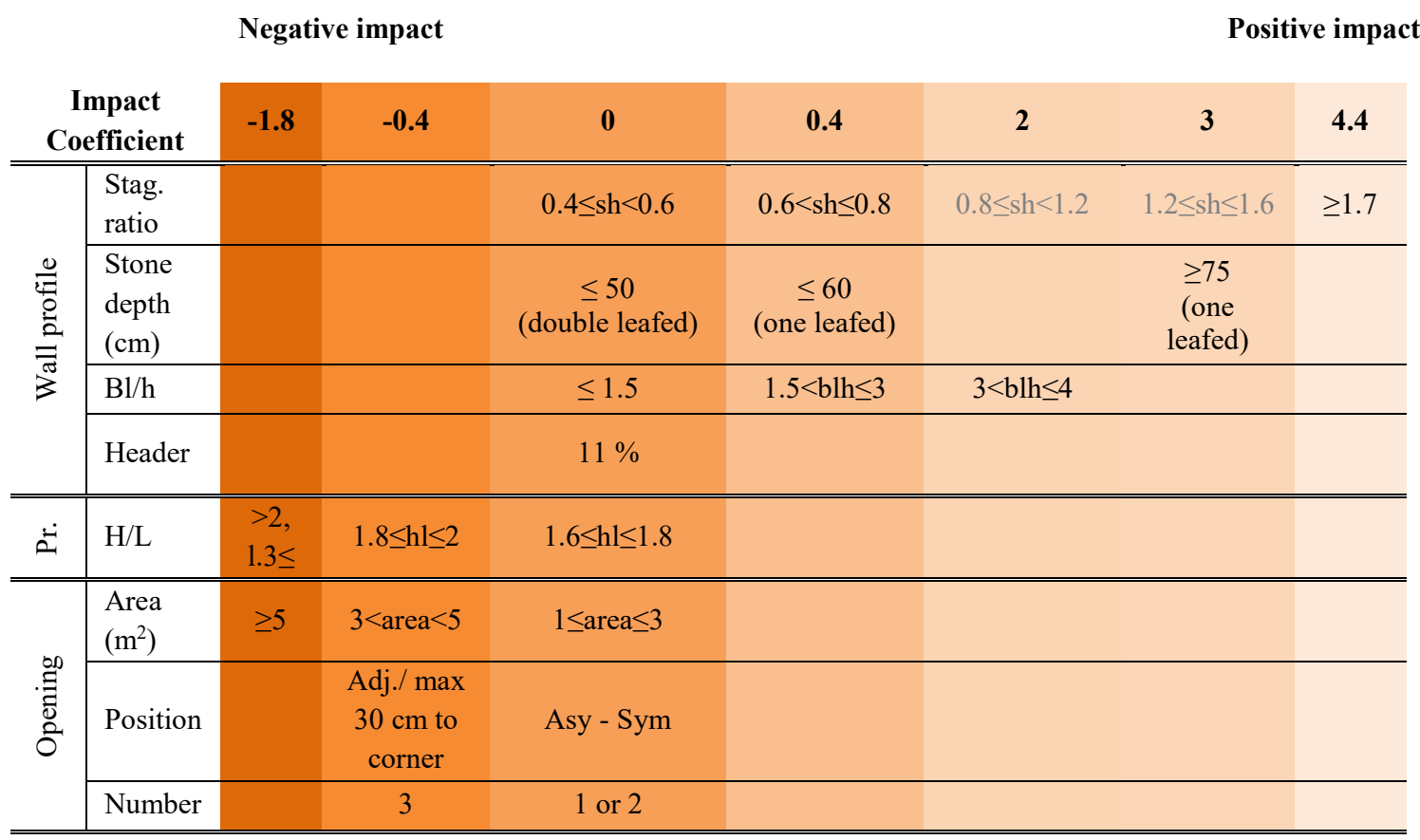

$\overline{\text { *The data coming from the real tower are colored black, the data supported by literature about staggering ratio are }}$ proposed by grey.

Stone depth longer than $75 \mathrm{~cm}$ and block ratio higher than 3 provides also positive impact. The wall profile parameters that cause the lowest resistance are staggering ratio 
smaller than 0.4 , stone depth shorter than $60 \mathrm{~cm}$, block ratio smaller than 1.5. Header usage decreases resistance when it is combined with parameters that have lowest impact, however it increases resistance when it is combined with parameters that have higher impact values.

The morphologic parameters causing highest decrease in resistance are an opening size larger than $5 \mathrm{~m}^{2}$ and $\mathrm{h} / \mathrm{l}$ ratio higher than 2 . These parameters cause decrease in resistant when they are combined with wall profile parameters, except for highest impact value as staggering ratio higher than 1.7 and stone depth higher than $75 \mathrm{~cm}$. If the worst $\mathrm{h} / \mathrm{l}$ ratio and opening configuration are combined with parameters that have highest impact, they can decrease resistance.

Morphologic parameters that have minimum negative impact value; h/l ratio between 1.8 and 2, openings larger than $3 \mathrm{~m}^{2}$, more than 2 in number or close to corner $(\max 30 \mathrm{~cm})$ cause decrease in resistance, when they are combined with parameters of wall profiles that have impact value of 0.4 and 0 .

Symmetric opening with an area between 1 and $3 \mathrm{~m}^{2}$, and $\mathrm{h} / 1$ ratio between 1.6 and 1.8 do not decrease resistance with all other positive wall profile parameters (Table $31)$.

The parameters effecting resistance can cause different behavior, therefore, relationship of behavior and parameters' interval is discussed separately (Table 32). The behavior of towers changes from out-of-plane to body behavior depending on parameters. Dominant parameters as header usage, low $(\leq 0.8)$ and high staggering ratio $(\geq 1.7)$, stone depth, large sized openings $\left(\geq 5 \mathrm{~m}^{2}\right)$, openings close to corner $(\max .30 \mathrm{~cm})$, and more than two in number are discussed.

High staggering $(\geq 1.7)$ and high block ratio $(\geq 3)$ increase out-of-plane behavior and provides in-plane or body behavior. Usage of headers at double leafed walls are not effective on better lateral resistance of towers, however it is a dominant parameter for better structural behavior. Stone depth longer than $75 \mathrm{~cm}$ prevents out-of-plane behavior and sustains in-plane behavior. Staggering ratio smaller than 0.8 causes out-of-plane failure due to weakness of corners.

The $\mathrm{h} / \mathrm{l}$ ratio interval between 1.6 and 2 is appropriate for best performance of towers. When this ratio is beyond the limits of real towers, lower than 1.3 , this causes arch effect and out-of-plane behavior.

Openings adjacent to corner and close to corner up to $30 \mathrm{~cm}$ cause in-plane failure of the side walls. Openings larger than $5 \mathrm{~m}^{2}$ cause in-plane failure of two side walls. These 
behaviors are common, when the openings are at in-plane position. The opening at outof-plane position generally cause the out-of-plane failure or detachment of out-of-plane wall together with bending. Dominancy of parameters on behavior are listed in the below.

- Header usage combined with high staggering $(\geq 1.7)$ and high block ratio $(\geq 3)$ increase out-of-plane behavior and provides body behavior.

- If header usage with high staggering $(\geq 1.7)$ and high block ratio $(\geq 3)$ is combined with large sized opening, opening close to corner and more than 2 openings, this causes in-plane behavior at ratios 1.6 and 2.

- If header usage with high staggering $(\geq 1.7)$ and high block ratio $(\geq 3)$ are combined with openings at out-of-plane position except with large sized opening, opening close to corner and more than 2 openings, this causes out-of-plane failure together with body failure at ratios between 1.3 and 1.8

- If header usage with low staggering $(0.4<\operatorname{sh} \leq 0.8)$ and low block ratio $(\leq 1.5)$ is combined with large sized opening, opening close to corner and more than 2 openings, this causes in-plane behavior at all ratios.

- If header usage is combined with low staggering $(0.4 \leq \mathrm{sh}<0.8)$ and low block ratio $(\leq 1.5)$, this causes in-plane behavior together with body behavior.

- If header usage with low staggering $(0.4<\mathrm{sh} \leq 0.8)$ and low block ratio $(\leq 1.5)$ is combined with openings at out-of-plane position except with large sized opening, opening close to corner and more than 2 openings; this causes out-of-plane failure together with body failure at ratios between 2 and 2.3.

- If header usage with low staggering $(0.4 \leq \mathrm{sh}<0.8)$ and low block ratio $(\leq 1.5)$ is combined with large sized opening, opening close to corner and more than 2 openings at out-of-plane position; this causes out-of-plane failure at ratios between 1.3 and 1.8 .

- Staggering ratio higher than 1.7, block ratio higher than 3 and stone depth longer than $75 \mathrm{~cm}$ provide in-plane behavior for one leafed wall section regardless of opening and $\mathrm{h} / \mathrm{l}$.

- Staggering ratio between 0.4 and 0.8 , block ratio smaller than 2 and stone depth lower than $60 \mathrm{~cm}$ cause hybrid behavior composed of in-plane and out-of-plane failure for one leafed wall.

- When $\mathrm{h} / \mathrm{l}$ ratio is beyond 1.3 , this causes arch effect and out-of-plane behavior at one leafed wall regardless of opening and $\mathrm{h} / \mathrm{l}$. 


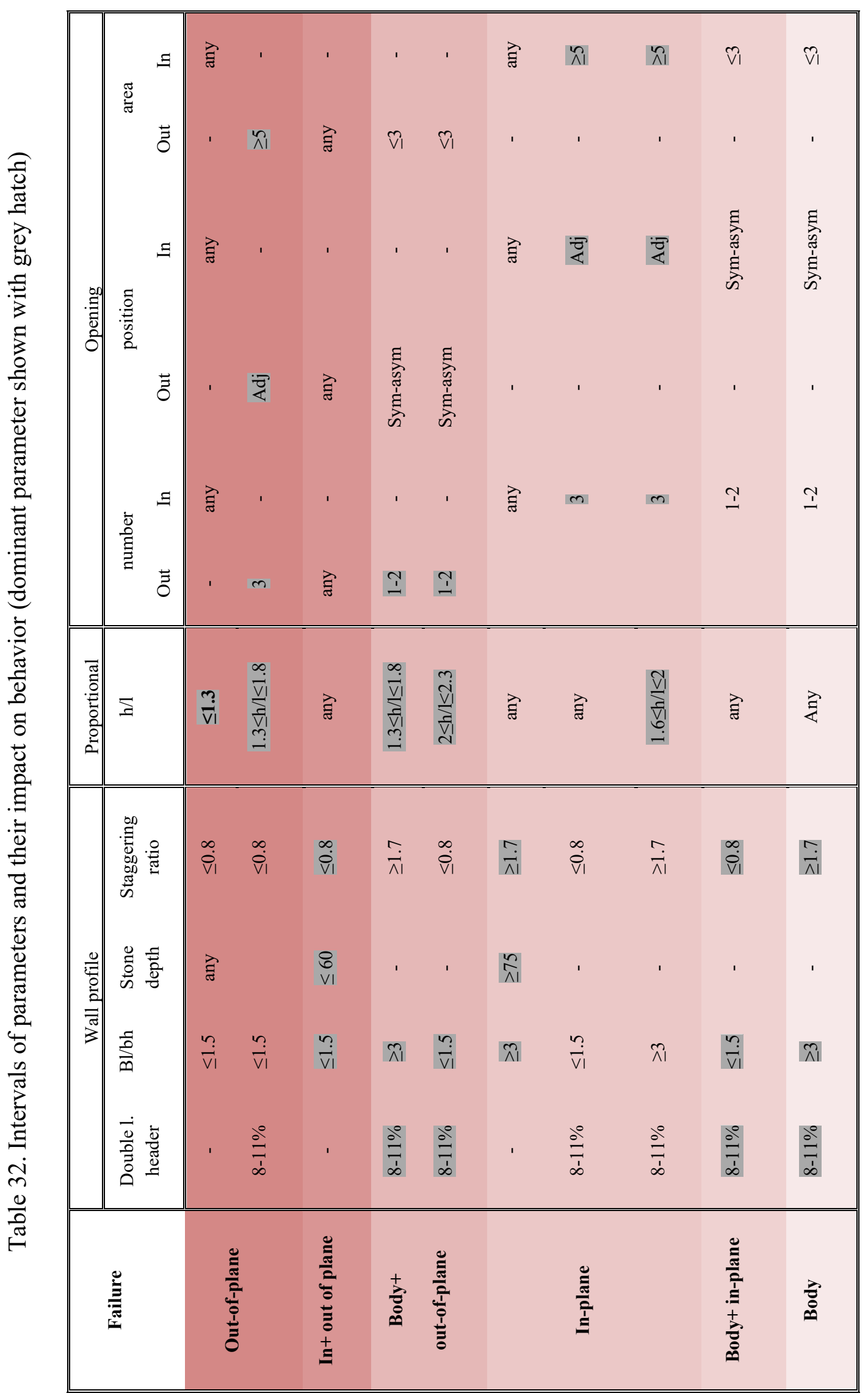




\subsection{Vulnerability Assessment Framework}

Impact of intervals of parameters and their dominance are determined according to each other in terms of resistance and behavior in section 4.2 (Table 31 and Table 32). With determination of dominancy, vulnerability framework for dry masonry towers is proposed. While proposing vulnerability, the data gathered from hypothetic towers are used only. Since the literature data are related to behavior of dry masonry walls and it is not specific to dry masonry towers, it was not used for vulnerability framework.

Vulnerability should be assessed in incremental steps with the help of the impact values of parameters; ranking vulnerability at levels such as high, medium, low, considerably low and critical (Table 31). Vulnerability rankings are determined for openings at in-plane position, since the worst case is always considered. When the openings are at out-of-plane position, the vulnerability rankings are similar with in-plane position, however the vulnerability decreases when an opening is larger than $5 \mathrm{~m}^{2}$, close to corner and more than two in number at out-of-plane position in comparison to in-plane position. Nevertheless, failures are determined according to both in-plane and out-ofplane position of openings.

Considerably low vulnerability corresponds to the towers that are constructed within the following limits:

- Staggering ratio higher than 1.7 with stone ratio higher than 3 for double leafed wall profiles with header stones, for all opening types except larger than $5 \mathrm{~m}^{2}$, for $\mathrm{h} / \mathrm{l}$ ratio higher than 2 or smaller than 1.3 .

- Staggering ratio higher than 1.7 with stone ratio between 1.5 and 3, stone depth higher than $75 \mathrm{~cm}$ for one leafed wall profiles, for all opening types except larger than $5 \mathrm{~m}^{2}$ and all $\mathrm{h} / \mathrm{l}$ ratios except higher than 2 or smaller than 1.3 .

Low vulnerability corresponds to the towers that are constructed within the following limits:

- Staggering ratio higher than 1.7 , stone ratio higher than 3 for double leafed wall profiles with header stones, for an opening larger than $5 \mathrm{~m}^{2}$, and $\mathrm{h} / 1$ ratio higher than 2 or smaller than 1.3.

- Staggering ratio higher than 1.7 with stone ratio between 1.5 and 3, stone depth higher than $75 \mathrm{~cm}$ for one leafed wall profiles, for opening types larger than $5 \mathrm{~m}^{2}$ and $\mathrm{h} / \mathrm{l}$ ratios between 1.6 and 2 . 
- Staggering ratio higher than 1.7 with stone ratio between 1.5 and 3, stone depth higher than $75 \mathrm{~cm}$ for one leafed wall profiles, for all opening types except larger than $5 \mathrm{~m}^{2}$ and all $\mathrm{h} / 1$ ratios higher than 2 or smaller than 1.3 .

Medium vulnerability corresponds to the towers that are constructed within the following limits:

- Staggering ratio higher than 1.7 with stone ratio between 1.5 and 3, stone depth higher than $75 \mathrm{~cm}$ for one leafed wall profiles with opening types larger than 5 $\mathrm{m}^{2}$, and $\mathrm{h} / 1$ ratios higher than 2 or smaller than 1.3 .

- Staggering ratio between 0.6 and 0.8 , stone ratio smaller than 1.5 , stone depth shorter than $60 \mathrm{~cm}$ for one or double leafed wall profiles, for all opening types except larger than $5 \mathrm{~m}^{2}$, more than 2 in number, and maximum $30 \mathrm{~cm}$ in distance to corner, all $\mathrm{h} / \mathrm{l}$ ratios except higher than 1.8 or smaller than 1.3.

High vulnerability corresponds to the towers that are constructed within the following limits:

- Staggering ratio between 0.6 and 0.8 , stone ratio smaller than 1.5 , stone depth shorter than $60 \mathrm{~cm}$ for one or double leafed wall profiles with opening types larger than $5 \mathrm{~m}^{2}$, more than 2 in number, and maximum $30 \mathrm{~cm}$ in distance to corner and with $\mathrm{h} / \mathrm{l}$ ratios between 1.6 and 1.8 .

- Staggering ratio between 0.6 and 0.8 , stone ratio smaller than 1.5 , stone depth shorter than $60 \mathrm{~cm}$ for one or double leafed wall profiles with all opening types except larger than $5 \mathrm{~m}^{2}$, more than 2 in number, and maximum $30 \mathrm{~cm}$ in distance to corner and with $\mathrm{h} / \mathrm{l}$ ratios higher than 1.8 or smaller than 1.3 .

- Staggering ratio smaller than 0.4 , stone ratio smaller than 1.5 , stone depth shorter than $60 \mathrm{~cm}$ for one leafed wall profiles with all opening types except larger than $5 \mathrm{~m}^{2}$, more than 2 in number, and maximum $30 \mathrm{~cm}$ in distance to corner at $\mathrm{h} / 1$ ratios 1.6 and 2 .

Considerably high vulnerability corresponds to the towers that are constructed within the following limits:

- Staggering ratio between 0.6 and 0.8 , stone ratio smaller than 1.5 , stone depth shorter than $60 \mathrm{~cm}$ for one or double leafed wall profiles with opening types larger than $5 \mathrm{~m}^{2}$, more than 2 in number, and maximum $30 \mathrm{~cm}$ in distance to corner at $\mathrm{h} / \mathrm{l}$ ratios higher than 1.8 or smaller than 1.3 . 
- Staggering ratio smaller than 0.4 , stone ratio smaller than 1.5 , stone depth shorter than $60 \mathrm{~cm}$ for one leafed wall profiles with all types larger than $5 \mathrm{~m}^{2}$, more than 2 in number, and maximum $30 \mathrm{~cm}$ in distance to corner and with $\mathrm{h} / 1$ ratios between 1.8 and 2 .

- Staggering ratio smaller than 0.4 , stone ratio smaller than 1.5 , stone depth shorter than $60 \mathrm{~cm}$ for one leafed wall profiles with all opening types except larger than $5 \mathrm{~m}^{2}$, more than 2 in number, and maximum $30 \mathrm{~cm}$ in distance to corner and with $\mathrm{h} / \mathrm{l}$ ratios higher than 2 or smaller than 1.3.

Critical vulnerability corresponds to the towers that are constructed within the following limits:

- Staggering ratio smaller than 0.4 , stone ratio smaller than 1.5 , stone depth shorter than $60 \mathrm{~cm}$ for one leafed wall profiles with all opening types larger than $5 \mathrm{~m}^{2}$, more than 2 in number, and closed maximum $30 \mathrm{~cm}$ in distance to corner at $\mathrm{h} / 1$ ratios higher than 2 or smaller than 1.3.

Types of failures observed in a tower are related with predominance of parameters with respect to each other, and they should be evaluated separately for positioning of openings at in-plane and out-of-plane walls.

\section{Only body failure:}

- Double leafed wall sections with headers (11\%) and staggering ratio higher than 1.7, ratio between length and height of stone blocks higher than 3 combined with either opening at in plane position between 1 and $3 \mathrm{~m}^{2}$ in area or at most two asymmetric or symmetric openings and any $\mathrm{h} / \mathrm{l}$ ratio.

\section{Body failure with in-plane failure (vertical splitting):}

- Double leafed wall sections with headers and staggering ratios smaller than 0.8 and ratio between length and height of stone blocks smaller than 2 with openings at in plane position between 1 and $3 \mathrm{~m}^{2}$ in area or at most two asymmetric or symmetric openings at in-plane position and any $\mathrm{h} / \mathrm{l}$ ratio.

\section{In-plane failure:}

- Double leafed wall sections with headers and staggering ratio higher than 1.7, ratio between length and height of stone blocks higher than 3 with opening at inplane position larger than $5 \mathrm{~m}^{2}$ in area or at least three openings at in-plane 
position or openings closed to corner at most $30 \mathrm{~cm}$ at in-plane position and $\mathrm{h} / \mathrm{l}$ ratio between 1.6 and 2 .

- Double leafed wall sections with headers and staggering ratios smaller than 0.8 and ratio between length and height of stone blocks smaller than 2 with openings at in-plane position larger than $5 \mathrm{~m}^{2}$ in area or at least three openings at in-plane position or openings closed to corner at most $30 \mathrm{~cm}$ at in-plane position and any $\mathrm{h} / \mathrm{l}$ ratio.

- One leafed wall section and staggering ratio higher than 1.7, ratio between length and height of stone blocks higher than 3 and stone depth longer than $75 \mathrm{~cm}$ combined with any opening type at in-plane position and all $\mathrm{h} / \mathrm{l}$ ratios except smaller than 1.3

\section{Body and out-of-plane behavior:}

- Double leafed wall profiles with staggering ratios smaller than 0.8 and ratio between length and height of stone blocks smaller than 2 and any openings positioned at out-of-plane position at any $\mathrm{h} / \mathrm{l}$ ratios.

- Double leafed wall sections with headers and staggering ratio higher than 1.7 , ratio between length and height of stone blocks higher than 3 with an opening area larger than $5 \mathrm{~m}^{2}$ or at least three openings or openings closed to corner at most 30 $\mathrm{cm}$ at out-of-plane position and $\mathrm{h} / \mathrm{l}$ ratio between 1.6 and 2 .

\section{In-plane and out-of-plane failure (overturning due to vertical cracks):}

- One leafed wall section and staggering ratios smaller than 0.8 , ratio between length and height of stone blocks smaller than 2 and stone depth shorter than 60 $\mathrm{cm}$ combined with any opening type at in-plane position and $\mathrm{h} / \mathrm{l}$ ratio.

- One leafed wall section and staggering ratio higher than 1.7 , ratio between length and height of stone blocks higher than 3 and stone depth longer than $75 \mathrm{~cm}$ combined with any opening type at in-plane position at $\mathrm{h} / \mathrm{l}$ ratios smaller than 1.3.

\section{Out-of-plane failure (detachment):}

- One leafed wall section with staggering ratio smaller than 0.8 , ratio between length and height of stone block smaller than 2 and any stone depth and opening organizations at $\mathrm{h} / \mathrm{l}$ ratio smaller than 1.3 .

- One leafed wall section with any staggering ratio, stone depth and ratio between length and height of stone block with any opening organization at out-of-plane position at any ratio. 
Relation of parameters with vulnerability rankings and failure mechanisms is proposed as matrices (Table 33). This framework is specific to the characteristics of the studied dry masonry towers only. It is not a general output for all other dry masonry buildings. It can be calibrated for other dry masonry towers that have different characteristics.

Since vulnerability is a component of risk assessment, results of this framework can be used as a coefficient of risk assessment against lateral loading (UNESCO et al. $2010,8)$. If this framework is combined with data on frequency and intensity of previous earthquakes, risk assessment of towers can be carried out. The framework may evolve into a risk assessment against lateral loading with further work in the future.

\subsubsection{Vulnerability assessment of case studies}

First, earthquake risk in the environs of the case studies in terms of frequency and severity are presented by examining earthquake history (see Chapter 2). The vulnerability framework is applied to the case studies. Probable and existing failures of case studies are compared with the results of the framework. At last, a preliminary risk assessment against lateral loading is carried out.

\subsubsection{Towers in Caria}

Alinda and Latmos Towers in Caria are approximately $70 \mathrm{~km}$ in distance to each other. This region is under high earthquake threat due to extremely high ground acceleration (AFAD 2018). In $100 \mathrm{~km}$ proximity of the case studies, 180-190 earthquakes have been recorded from 1900 until present. In environs of Latmos, 141 earthquakes have taken place between 4 and 5 in magnitude. Between 5 and 6, there are 34 and between 6 and 7, there are 8 earthquakes. In the environs of Alinda, between 4 and 5 in magnitude, there are 146 earthquakes. Between 5 and 6, there are 36 earthquakes; and between 6 and 7 , there are 7 earthquakes. For ancient periods, there are no recorded earthquakes higher than magnitude 6 in approximately $100 \mathrm{~km}$ proximity of the area. Earthquakes higher than 7 magnitudes is approximately $600 \mathrm{~km}$ far from the area in ancient period (BDTIM 2017). 
Table 33.Vulnerability framework

\begin{tabular}{|c|c|c|c|c|c|c|c|c|c|c|c|c|c|c|c|c|}
\hline & \multicolumn{4}{|c|}{$\leq 1.3$ (beyond the limits of case studies) } & \multicolumn{4}{|c|}{$1.6 \leq \mathrm{h} / \leq 1.8$} & \multicolumn{4}{|c|}{$1.8<\mathrm{h} / \leq 2$} & \multicolumn{4}{|c|}{$\mathrm{h} / \mathbf{> 2}$} \\
\hline & 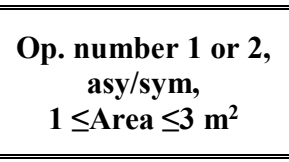 & $\begin{array}{l}\text { An opening area } \\
\geq 5 \mathrm{~m}^{2}\end{array}$ & $\begin{array}{c}\text { Op. number more } \\
\text { than } 3 \leq \\
1 \leq \mathrm{Area} \leq 3 \mathrm{~m}^{2} \\
\end{array}$ & 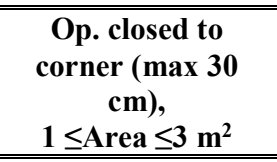 & $\begin{array}{c}\text { Op. number } 1 \text { or } \\
\text { 2, asysysym, } \\
1 \leq \text { Area } \leq 3 \mathrm{~m}^{2} \\
\end{array}$ & $\begin{array}{c}\text { An opening area } \\
\geq 5 \mathrm{~m}^{2}\end{array}$ & 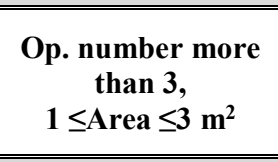 & 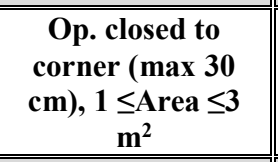 & $\begin{array}{c}\text { Op. number } 1 \text { or } \\
2, \text { asylsymm, } \\
1 \leq A \text { rea } \leq 3 \mathrm{~m}^{2} \\
\end{array}$ & $\begin{array}{c}\text { An opening area } \\
\geq 5 \mathrm{~m}^{2}\end{array}$ & $\begin{array}{c}\text { op. number more } \\
\text { than } 3,1 \leq \Delta \leq \mathrm{Area} \leq 3 \\
\mathrm{~m}^{2}\end{array}$ & $\begin{array}{c}\text { Op. cosed to } \\
\text { corren }(\max 30 \\
\text { cm) } 30 \\
\end{array}$ & $\begin{array}{c}\text { Op. number } 1 \text { or } \\
\text { 2, asysysym, } \\
1 \leq \text { Area } \leq 3 \mathrm{~m}^{2} \\
\end{array}$ & $\underset{\substack{\text { An opening area } \\
\geq 5 \mathrm{~m}^{2}}}{ }$ & $\begin{array}{c}\text { Op. number more } \\
\text { than } 3,1 \leq \Delta \text { area } \leq 3 \\
\mathrm{~m}^{2}\end{array}$ & 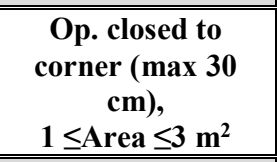 \\
\hline 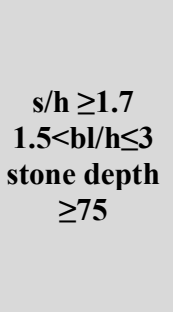 & $\begin{array}{l}\text { Vul. Ranking: Low } \\
\text { Proposed failure: } \\
\text { Op. at in-plane: } \\
\text { Intout-of-plane } \\
\text { (overturing) } \\
\text { Op. at out-of-plane: } \\
\text { Intout-of-plane } \\
\text { (overturning) }\end{array}$ & $\begin{array}{l}\text { Vul. Ranking: } \\
\text { Medium } \\
\text { Proposed failure: } \\
\text { Op. at in-plane: } \\
\text { Intout-of-plane } \\
\text { Op. at out-offlane: } \\
\text { In-plane }\end{array}$ & $\begin{array}{l}\text { Vul. Ranking: } \\
\text { Low } \\
\text { Propos failure: } \\
\text { Op. at in-plane: } \\
\text { In-plane } \\
\text { Op. at out-of- } \\
\text { plane: In-plane }\end{array}$ & $\begin{array}{l}\text { Vul. Ranking: } \\
\text { Low } \\
\text { Proposed failure: } \\
\text { Op. at in-plane: } \\
\text { In-plane } \\
\text { Op. at out-of-plane: } \\
\text { In-plane }\end{array}$ & $\begin{array}{l}\text { Vul. Ranking: } \\
\text { Considerably. Low } \\
\text { Proposed failure: } \\
\text { Op. at in-plane: } \\
\text { In-plane } \\
\text { Opa. at out-fo- } \\
\text { plane: In-plane }\end{array}$ & $\begin{array}{l}\text { Vul. Ranking: } \\
\text { Low } \\
\text { Pow apoulure: } \\
\text { Op. at in-plane: } \\
\text { In-plane } \\
\text { Op. at out-of-plane: } \\
\text { Intout-of-plane }\end{array}$ & $\begin{array}{l}\text { Vul. Ranking: } \\
\text { Considerably Low } \\
\text { Proposed failure: } \\
\text { Op. at in-plane: } \\
\text { In-plane } \\
\text { Op. at out-of- } \\
\text { plane: In-plane }\end{array}$ & $\begin{array}{l}\text { Vul. Ranking: } \\
\text { Considerably Low } \\
\text { Proposed failure: } \\
\text { Op. at in-plane: } \\
\text { In-plane } \\
\text { Opa.tout-of- } \\
\text { plane: In-plane }\end{array}$ & $\begin{array}{l}\text { Vul. Ranking: } \\
\text { Considerably Low } \\
\text { Proposed failure: } \\
\text { Op. at in-plane: } \\
\text { In-plane } \\
\text { Op. at out-of-plane: } \\
\text { In-plane }\end{array}$ & $\begin{array}{l}\text { Vul. Ranking: } \\
\text { Low } \\
\text { Proposed failure: } \\
\text { Op. at in-plane: } \\
\text { In-plane } \\
\text { Op. at out-of-plane: } \\
\text { Intout-of-plane }\end{array}$ & $\begin{array}{l}\text { Vul. Ranking: } \\
\text { Considerably Low } \\
\text { Proposed failure: } \\
\text { Op. at in-plane: } \\
\text { In-plane } \\
\text { Op. at out-of- } \\
\text { plane: In-plane }\end{array}$ & $\begin{array}{l}\text { Vul. Ranking: } \\
\text { Considerably Low } \\
\text { Proposed failure: } \\
\text { Op. at in-plane: } \\
\text { In-plane } \\
\text { Op. at out-of-plane: } \\
\text { In-plane }\end{array}$ & $\begin{array}{l}\text { Vul. Ranking: } \\
\text { Low } \\
\text { Proposed failure: } \\
\text { Op. at in-plane: } \\
\text { In-plane } \\
\text { Opa. at out-of- } \\
\text { plane: In-plane }\end{array}$ & $\begin{array}{l}\text { Vul. Ranking: } \\
\text { Medium } \\
\text { Proposed failure: } \\
\text { Op. at in-plane: } \\
\text { In-plane } \\
\text { Op. at out-of-plane: } \\
\text { Intout-of-plane }\end{array}$ & $\begin{array}{l}\text { Vul. Ranking: } \\
\text { Low } \\
\text { Propos failure: } \\
\text { Op. at in-plane: } \\
\text { In-plane } \\
\text { Op. at out-of- } \\
\text { plane: In-plane }\end{array}$ & $\begin{array}{l}\text { Vul. Ranking: } \\
\text { Low } \\
\text { Proposed failure: } \\
\text { Op. at in-plane: } \\
\text { In-plane } \\
\text { Op. at out-of-plane: } \\
\text { In-plane }\end{array}$ \\
\hline $\begin{array}{c}0.6<\mathrm{s} / \mathbf{h} \leq 0.8 \\
\text { bl/h } \leq 2 \\
\text { stone } \\
\text { depth } \leq 60\end{array}$ & $\begin{array}{l}\text { Vul. Ranking: } \\
\text { Considerably high } \\
\text { Proposed failure: } \\
\text { Op. at in-lane: } \\
\text { Out-of-plane } \\
\text { (vorerturning) } \\
\text { Op. at out-of-plane: } \\
\text { Out-of-plane } \\
\text { (detachment) }\end{array}$ & $\begin{array}{l}\text { Vul. Ranking: } \\
\text { Considerably high } \\
\text { Proposed faliure: } \\
\text { Op. at in-plane: } \\
\text { Intout-foplane } \\
\text { Op. at out-of-plane: } \\
\text { Outtof-plane } \\
\text { (detachment) }\end{array}$ & $\begin{array}{l}\text { Vul. Ranking: } \\
\text { Considerably high } \\
\text { Proposed failure: } \\
\text { Op. at in-plane: } \\
\text { In-plane } \\
\text { Op. at out-of- } \\
\text { plane: Intout-of- } \\
\text { plane } \\
\text { (detachment) }\end{array}$ & $\begin{array}{l}\text { Vul. Ranking: } \\
\text { Considerably high } \\
\text { Proposed falure: } \\
\text { Op. at in-plane: } \\
\text { Intout-folpane } \\
\text { Op. at out-of-plane: } \\
\text { outtof-plane } \\
\text { (detachment) }\end{array}$ & $\begin{array}{l}\text { Vul. Ranking: } \\
\text { Medium } \\
\text { Proposed failure: } \\
\text { Op. at in-plane: } \\
\text { Intout-of-plane } \\
\text { (overturning) } \\
\text { Op. at out-of- } \\
\text { plane: Intout-of- } \\
\text { plane } \\
\text { (detachment) }\end{array}$ & $\begin{array}{l}\text { Vul. Ranking: } \\
\text { High } \\
\text { Proposed failure: } \\
\text { Op. at in-plane: } \\
\text { Intout-of-plane } \\
\text { (vverturning } \\
\text { Op. at out-of-plane: } \\
\text { Intout-of-plane } \\
\text { (detachment) } \\
\end{array}$ & $\begin{array}{l}\text { Vul. Ranking: } \\
\text { High } \\
\text { Proposed failure: } \\
\text { Op. at in-plane: } \\
\text { Intout-of-plane } \\
\text { (overturning) } \\
\text { Op. at out-of } \\
\text { plane: Out-of-plane } \\
\text { (detachment) }\end{array}$ & $\begin{array}{l}\text { Vul. Ranking: } \\
\text { High } \\
\text { Proposed failure: } \\
\text { Op. at in-plane: } \\
\text { Intout-of-plane } \\
\text { (overturning) } \\
\text { Op. at out-of- } \\
\text { plane: Out-of- } \\
\text { plane } \\
\text { (detachment) }\end{array}$ & $\begin{array}{l}\text { Vul. Ranking: } \\
\text { Medium } \\
\text { Proposed failure: } \\
\text { Op. at in-plane: } \\
\text { Intout-of-plane } \\
\text { (overturning) } \\
\text { Op. at out-of-plane: } \\
\text { Intout-of-plane } \\
\text { (detachment) }\end{array}$ & $\begin{array}{l}\text { Vul. Ranking: } \\
\text { High } \\
\text { Proposed failure: } \\
\text { Op. at in-lane: } \\
\text { Intout-of-plane } \\
\text { (vorturning) } \\
\text { Op. at out-of-plane: } \\
\text { Intout-of-plane } \\
\text { (detachment) }\end{array}$ & $\begin{array}{l}\text { Vul. Ranking: } \\
\text { High } \\
\text { Proposed failure: } \\
\text { Op. at in-plane: } \\
\text { Intout-of-plane } \\
\text { (overturning) } \\
\text { Op. at out-of- } \\
\text { plane: Out-of-plane } \\
\text { (detachment) }\end{array}$ & $\begin{array}{l}\text { Vul. Ranking: } \\
\text { High } \\
\text { Proposed failure: } \\
\text { Op. at in-plane: } \\
\text { Intout-of-plane } \\
\text { (vorturning) } \\
\text { Op. at out-of-plane: } \\
\text { Out-fof-plane } \\
\text { (detachment) }\end{array}$ & $\begin{array}{l}\text { Vul. Ranking: } \\
\text { High } \\
\text { Proposed failure: } \\
\text { Op. at in-plane: } \\
\text { In+out-of-plane } \\
\text { (overturning) } \\
\text { Op. at out-of- } \\
\text { plane: In+out-of- } \\
\text { plane } \\
\text { (detachment) }\end{array}$ & $\begin{array}{l}\text { Vul. Ranking: } \\
\text { Considdrably High } \\
\text { Proposed failure: } \\
\text { Op. at in-plane: } \\
\text { Intout-of-plane } \\
\text { (overturning } \\
\text { Op. at out-of-plane: } \\
\text { Intout-of-plane } \\
\text { (detachment) }\end{array}$ & $\begin{array}{l}\text { Vul. Ranking: } \\
\text { Considerably High } \\
\text { Proposed failure: } \\
\text { Op. at in-plane: } \\
\text { Intout-of-plane } \\
\text { (overturning) } \\
\text { Op. at out-of- } \\
\text { plane: Out-of-plane } \\
\text { (detachment) }\end{array}$ & $\begin{array}{l}\text { Vul. Ranking: } \\
\text { Considerably High } \\
\text { Proposed failure: } \\
\text { Op. at in-plane: } \\
\text { Intout-of-plane } \\
\text { (overturning) } \\
\text { Op. at out-of-plane: } \\
\text { Out-of-plane } \\
\text { (detachment) }\end{array}$ \\
\hline 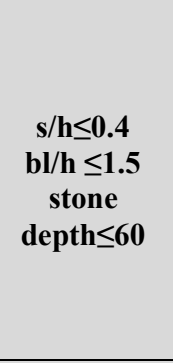 & $\begin{array}{l}\text { Vul. Ranking: } \\
\text { Considerably High } \\
\text { Proposed failure: } \\
\text { Op. at in-plane: Out- } \\
\text { of-plane } \\
\text { (detachment) } \\
\text { Op. at out-of-plane: } \\
\text { Out-of-plane } \\
\text { (detachment) }\end{array}$ & \begin{tabular}{|l} 
Vul. Ranking: \\
Caticical \\
Proposed failure: \\
Op. at in-lane: \\
Intout-of-plane \\
(overturning) \\
Op. at out-of-plane: \\
Out-of-plane \\
(detachment) \\
\end{tabular} & $\begin{array}{l}\text { Vul. Ranking: } \\
\text { Critical } \\
\text { Proposed failure: } \\
\text { Op. at in-plane: } \\
\text { Intout-of-plane } \\
\text { (detachment) } \\
\text { Op. at out-of- } \\
\text { plane: Out-of-plane } \\
\text { (detachment) } \\
\end{array}$ & $\begin{array}{l}\text { Vul. Ranking: } \\
\text { Critical } \\
\text { Proposed failure: } \\
\text { Op. at in-plane: } \\
\text { Intout-of-plane } \\
\text { (overturning) } \\
\text { Op. at out-of-plane: } \\
\text { Outtof-plane } \\
\text { (detachment) }\end{array}$ & $\begin{array}{l}\text { Vul. Ranking: } \\
\text { High } \\
\text { Proposed failure: } \\
\text { Op. at in-plane: } \\
\text { Intout-of-plane } \\
\text { (overturning) } \\
\text { Op. at out-of- } \\
\text { plane: Out-of-plane } \\
\text { (detachment) } \\
\end{array}$ & $\begin{array}{l}\text { Vul. Ranking: } \\
\text { Considerably High } \\
\text { Proposed failure: } \\
\text { Op. at in-plane: } \\
\text { Intout-of-plane } \\
\text { (vverturning } \\
\text { Op. at out-of-plane: } \\
\text { Out-of-plane } \\
\text { (detachment) }\end{array}$ & $\begin{array}{l}\text { Vul. Ranking: } \\
\text { Considerably High } \\
\text { Proposed failure: } \\
\text { Op. at in-plane: In- } \\
\text { plane (overturing } \\
\text { op. at out-of- } \\
\text { plape. Out-of-plane } \\
\text { (detachment) }\end{array}$ & $\begin{array}{l}\text { Vul. Ranking: } \\
\text { Considerably High } \\
\text { Proposed failure: } \\
\text { Op. at in-plane: } \\
\text { In-plane } \\
\text { Op. at out-of- } \\
\text { plane: } \\
\text { Out-foflane } \\
\text { (detachment) } \\
\end{array}$ & $\begin{array}{l}\text { Vul. Ranking: } \\
\text { High } \\
\text { Proposed failure: } \\
\text { Op. at in-plane: } \\
\text { Intout-of-plane } \\
\text { (overturning } \\
\text { Op. at out-of-plane: } \\
\text { Out-of-plane } \\
\text { (detachment) }\end{array}$ & $\begin{array}{l}\text { Vul. Ranking: } \\
\text { Considerably High } \\
\text { Proposed failure: } \\
\text { Op. at in-plane: } \\
\text { Intout-of-plane } \\
\text { (overturning) } \\
\text { Op. at out-of-plane: } \\
\text { Outtof-plane } \\
\text { (detachment) }\end{array}$ & $\begin{array}{l}\text { Vul. Ranking: } \\
\text { Considerably High } \\
\text { Proposed failure: } \\
\text { Op. at in-plane: } \\
\text { In-plane } \\
\text { Op. at out-of- } \\
\text { plane: Out-of-plane } \\
\text { (detachment) }\end{array}$ & $\begin{array}{l}\text { Vul. Ranking: } \\
\text { Considerably High } \\
\text { Proposed failure: } \\
\text { Op. at in-plane: } \\
\text { In-plane } \\
\text { Op. at out-of-plane: } \\
\text { Outtof-plane } \\
\text { (detachment) }\end{array}$ & $\begin{array}{l}\text { Vul. Ranking: } \\
\text { Considerably High } \\
\text { Proposed failure: } \\
\text { Op. at in-plane: } \\
\text { Intout-of-plane } \\
\text { (overturning) } \\
\text { Op. at out-of- } \\
\text { plane: } \\
\text { Out-of-plane } \\
\text { (detachment) }\end{array}$ & $\begin{array}{l}\text { Vul. Ranking: } \\
\text { Critical } \\
\text { Proposed failure: } \\
\text { Op. at in-lane: } \\
\text { Intout-of-plane } \\
\text { (overturning } \\
\text { Op. at out-of-plane: } \\
\text { Out-of-plane } \\
\text { (detachment) }\end{array}$ & 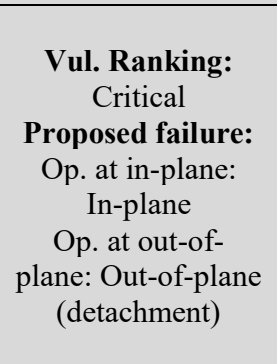 & $\begin{array}{l}\text { Vul. Ranking: } \\
\text { Critical } \\
\text { Proposed failure: } \\
\text { Op. at in-plane: } \\
\text { In-plane } \\
\text { Op. at out-of-plane: } \\
\text { Out-of-plane } \\
\text { (detachment) }\end{array}$ \\
\hline 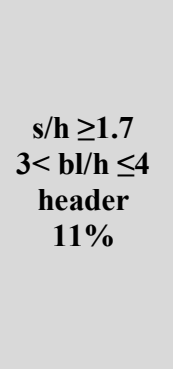 & $\begin{array}{l}\text { Vul. Ranking: } \\
\text { Considerably Low } \\
\text { Proposed failure: } \\
\text { Op.at in-plane: } \\
\text { Body+out-of-plane } \\
\text { Op. at out-of-plane: } \\
\text { Body+out-of-plane } \\
\text { (detachment) }\end{array}$ & $\begin{array}{c}\text { Vul. Ranking: } \\
\text { Low } \\
\text { Proposed failure: } \\
\text { Op. at in-plane: In- } \\
\text { plane } \\
\text { Op. at out-of-plane: } \\
\text { Bodytout-of-plane } \\
\text { (detachment) }\end{array}$ & $\begin{array}{l}\text { Vul. Ranking: } \\
\text { Considerably Low } \\
\text { Proposed failure: } \\
\text { Op. at in-plane: } \\
\text { Intout-of-plane } \\
\text { Op. at out-of- } \\
\text { plane: Body+out- } \\
\text { of plane } \\
\text { (detachment) }\end{array}$ & $\begin{array}{l}\text { Vul. Ranking: } \\
\text { Consididerbly Low } \\
\text { Proposed failure: } \\
\text { Op. at in-plane: } \\
\text { In-plane } \\
\text { Op. at out-of-plane: } \\
\text { Bodytout-of-plane } \\
\text { (detachment) }\end{array}$ & $\begin{array}{l}\text { Vul. Ranking: } \\
\text { Consididably Low } \\
\text { Proposed failure: } \\
\text { Op. at in-plane: } \\
\text { Boddy } \\
\text { Op. ad out-of- } \\
\text { plane: } \\
\text { Body }\end{array}$ & $\begin{array}{l}\text { Vul. Ranking: } \\
\text { Considdrably Low } \\
\text { Proposed failure: } \\
\text { Oo. at in-plane: } \\
\text { In-plane } \\
\text { Op. at out-of-plane: } \\
\text { Bodytotut-of-plane } \\
\text { (detachment) }\end{array}$ & $\begin{array}{l}\text { Vull Ranking: } \\
\text { Considerably Low } \\
\text { Proposed falure: } \\
\text { Op. at in-plane: } \\
\text { Body } \\
\text { Opp. at out-of-plane: } \\
\text { Body+out-of-plane } \\
\text { (detachment) }\end{array}$ & $\begin{array}{l}\text { Vul. Ranking: } \\
\text { Considerably Low } \\
\text { Proposed failure: } \\
\text { Op. at in-plane: } \\
\text { Body } \\
\text { Op. at out-of- } \\
\text { plane: Body+out- } \\
\text { of-plane } \\
\text { (detachment) }\end{array}$ & $\begin{array}{l}\text { Vul. Ranking: } \\
\text { Considerably Low } \\
\text { Proposed failure: } \\
\text { Op. at in-plane: } \\
\text { Body } \\
\text { Op. at out-of-plane: } \\
\text { Body }\end{array}$ & $\begin{array}{l}\text { Vul. Ranking: } \\
\text { Considerably Low } \\
\text { Proposed failure: } \\
\text { Op. at in-plane: } \\
\text { In-plane } \\
\text { Op. at out-of-plane: } \\
\text { Body+out-of-plane } \\
\text { (detachment) }\end{array}$ & $\begin{array}{l}\text { Vul. Ranking: } \\
\text { Considerably Low } \\
\text { Proposed failure: } \\
\text { Op. at in-plane: } \\
\text { Body } \\
\text { Op. at out-of- } \\
\text { plane: Body+out- } \\
\text { of plane } \\
\text { (detachment) }\end{array}$ & $\begin{array}{l}\text { Vul. Ranking: } \\
\text { Considerably Low } \\
\text { Proposed failure: } \\
\text { Op. at in-plane: } \\
\text { Body } \\
\text { Op. at out-offplane: } \\
\text { Bodytout-of-plane } \\
\text { (detachment) }\end{array}$ & $\begin{array}{l}\text { Vul. Ranking: } \\
\text { Considerably Low } \\
\text { Proposed failure: } \\
\text { Op. at in-plane: } \\
\text { Body } \\
\text { Op. at out-of- } \\
\text { plane: Body }\end{array}$ & $\begin{array}{l}\text { Vul. Ranking: } \\
\text { Low } \\
\text { Proposed failure: } \\
\text { Op. at in-plane: } \\
\text { Body } \\
\text { Op. at out-of-plane: } \\
\text { Bodytotut-of-plane } \\
\text { (detachment) }\end{array}$ & $\begin{array}{l}\text { Vul. Ranking: } \\
\text { Considerably Low } \\
\text { Proposed failure: } \\
\text { Op. at in-plane: } \\
\text { Body } \\
\text { Op. at out-of- } \\
\text { plane: Body+out- } \\
\text { of plane } \\
\text { (detachment) }\end{array}$ & $\begin{array}{l}\text { Vul. Ranking: } \\
\text { Considerably Low } \\
\text { Proposed failure: } \\
\text { Op. at in-plane: } \\
\text { Body } \\
\text { Op. at out-of-plane: } \\
\text { Body }\end{array}$ \\
\hline $\begin{array}{l}0.6 \operatorname{cssh} \leq 0.8 \\
\text { blh } \leq 2 \\
\text { header } \\
11 \%\end{array}$ & $\begin{array}{l}\text { Vul. Ranking: } \\
\text { Considerably high } \\
\text { Proposed failure: } \\
\text { Op. at in-plane: } \\
\text { In-plane } \\
\text { Op. at out-of-plane: } \\
\text { Outtof-plane } \\
\text { (detachment) }\end{array}$ & $\begin{array}{l}\text { Vul. Ranking: } \\
\text { Considerably high } \\
\text { Proposed failure: } \\
\text { Op. at in-plane: } \\
\text { In-plane } \\
\text { Op. at out-of-plane: } \\
\text { Outtof-plane } \\
\text { (detachment) }\end{array}$ & 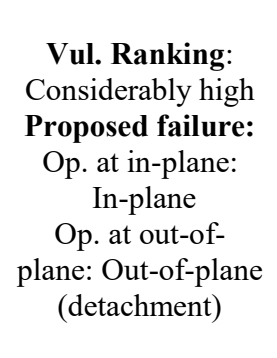 & $\begin{array}{l}\text { Vul. Ranking: } \\
\text { Considerably high } \\
\text { Proposed failure: } \\
\text { Op. at in-plane: } \\
\text { In-plane } \\
\text { Op. at out-of-plane: } \\
\text { Ott-of- } \\
\text { plane(detachment) }\end{array}$ & $\begin{array}{l}\text { Vul. Ranking: } \\
\text { Medium } \\
\text { Proposed failure: } \\
\text { Op. at in-plane: } \\
\text { Body+in-plane } \\
\text { Op. at out-of- } \\
\text { plane: Body+out- } \\
\text { of-plane } \\
\text { (detachment) }\end{array}$ & $\begin{array}{l}\text { Vul. Ranking: } \\
\text { High } \\
\text { Proposed failure: } \\
\text { Oo. at in-plane: } \\
\text { In-phan } \\
\text { Op. at out-of-plane: } \\
\text { Intout-of-plane } \\
\text { (detachment) }\end{array}$ & 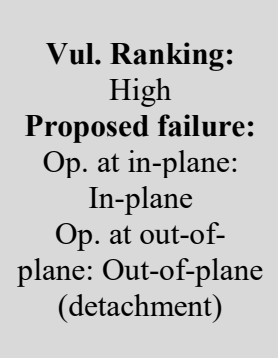 & $\begin{array}{l}\text { Vul. Ranking: } \\
\text { High } \\
\text { Proposed failure: } \\
\text { Op. at in-plane: } \\
\text { In-plane } \\
\text { Op. at out-of- } \\
\text { plane: Out-of- } \\
\text { plane } \\
\text { (detachment) }\end{array}$ & 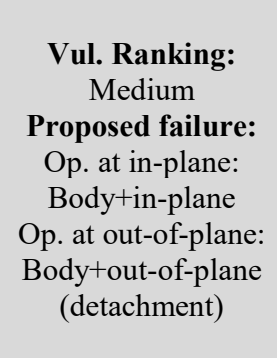 & $\begin{array}{l}\text { Vul. Ranking: } \\
\text { High } \\
\text { Proposed failure: } \\
\text { Op. at in-plane: } \\
\text { In-plane } \\
\text { Op. at out-of-plane: } \\
\text { Intout-of-plane } \\
\text { (detachment) }\end{array}$ & 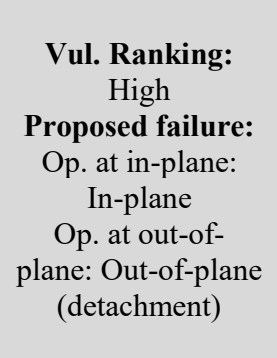 & $\begin{array}{l}\text { Vul. Ranking: } \\
\text { High } \\
\text { Proposed failure: } \\
\text { Op. at in-plane: } \\
\text { In-plane } \\
\text { Op. at out-of-plane: } \\
\text { Out-of-plane } \\
\text { (detachment) }\end{array}$ & $\begin{array}{l}\text { Vul. Ranking: } \\
\text { High } \\
\text { Proposed failure: } \\
\text { Op. at in-plane: } \\
\text { Body-in-lane } \\
\text { Op. at out-of-- } \\
\text { plane: } \\
\text { Bodytin-plane }\end{array}$ & $\begin{array}{l}\text { Vul. Ranking: } \\
\text { Considerably figh } \\
\text { Proposed failure: } \\
\text { Op. at in-plane: } \\
\text { In-plane } \\
\text { Op. at out-of-plane: } \\
\text { Bodytotut-of-plane } \\
\text { (detachment) }\end{array}$ & $\begin{array}{l}\text { Vul. Ranking: } \\
\text { Considerably High } \\
\text { Proposed failure: } \\
\text { Op. at in-plane: } \\
\text { In-plane } \\
\text { Op. at out-of- } \\
\text { plane: Body+out- } \\
\text { of plane } \\
\text { (detachment) }\end{array}$ & 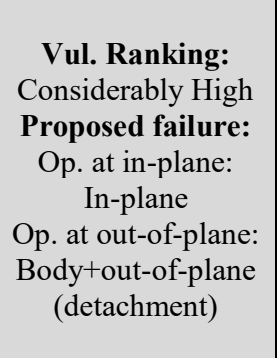 \\
\hline
\end{tabular}




\subsection{Vulnerability of Alinda Tower}

Alinda Tower has low vulnerability with the help of the characteristics of its wall profile, although weakness of $\mathrm{h} / \mathrm{l}$ ratio and opening organization increase vulnerability. It has high staggering ratio (higher than 1.8) and ratio between block length and height is higher than 4. Since walls are composed of leaves, stone depth is also small $(45-50 \mathrm{~cm})$, however these leaves are connected with header stones. Although the tower has the weakest opening organization (one large sized, $5 \mathrm{~m}^{2}$ ) and the northwestern facade has a high $\mathrm{h} / \mathrm{l}$ ratio (2.3), wall profile characteristics provide advantage against weakness of the other morphologic characteristics (Figure 95). Control of vulnerability of the large sized openings and high facade should be achieved with appropriate measures of intervention.

\section{- Possible Failures}

Header usage supported with high staggering ratio and high block ratio becomes significant for behavior. The headers provide integrity of the walls and staggering, and block ratio increase corner connections. The tower may show body behavior in case of lateral loading; total overturning beginning with in-plane diagonal body cracking and horizontal cracking at the out-of-plane facade. However, depending on direction of lateral loading, when the large sized opening is at in-plane position, collapse of the two side walls may be observed (Figure 94).

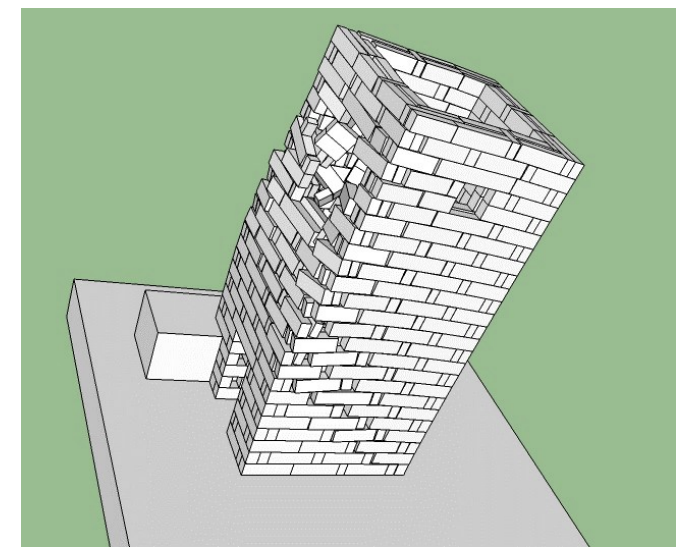

Total body failure; Large sized opening at out-ofplane position

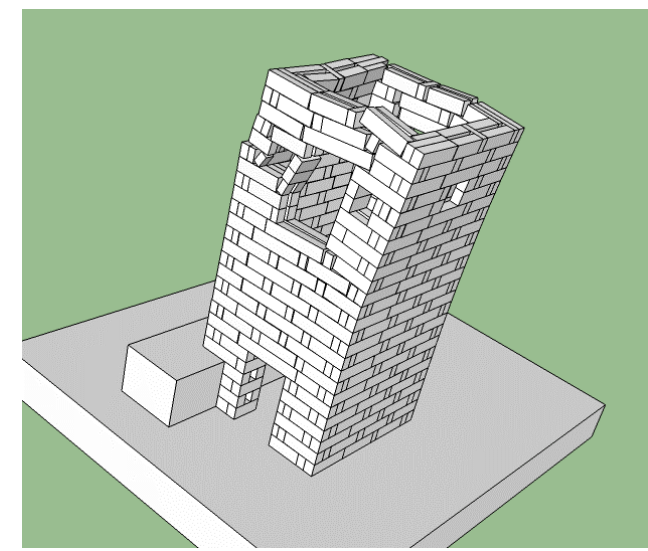

In-plane failure; Large sized opening at in-plane position

Figure 94. Possible failures of tower 


\section{- Present failures}

Diagonal stepped cracking is observed above and below the openings at the southwestern, southeastern and northeastern facades. The failure presents similarities with simulation results for the southeastern facade at out-of-plane position.

The diagonal cracks are seen at the lower part of the southeastern and southwestern facade. The failure presents similarities with simulation results for the southeastern facade at in-plane position (Figure 95).
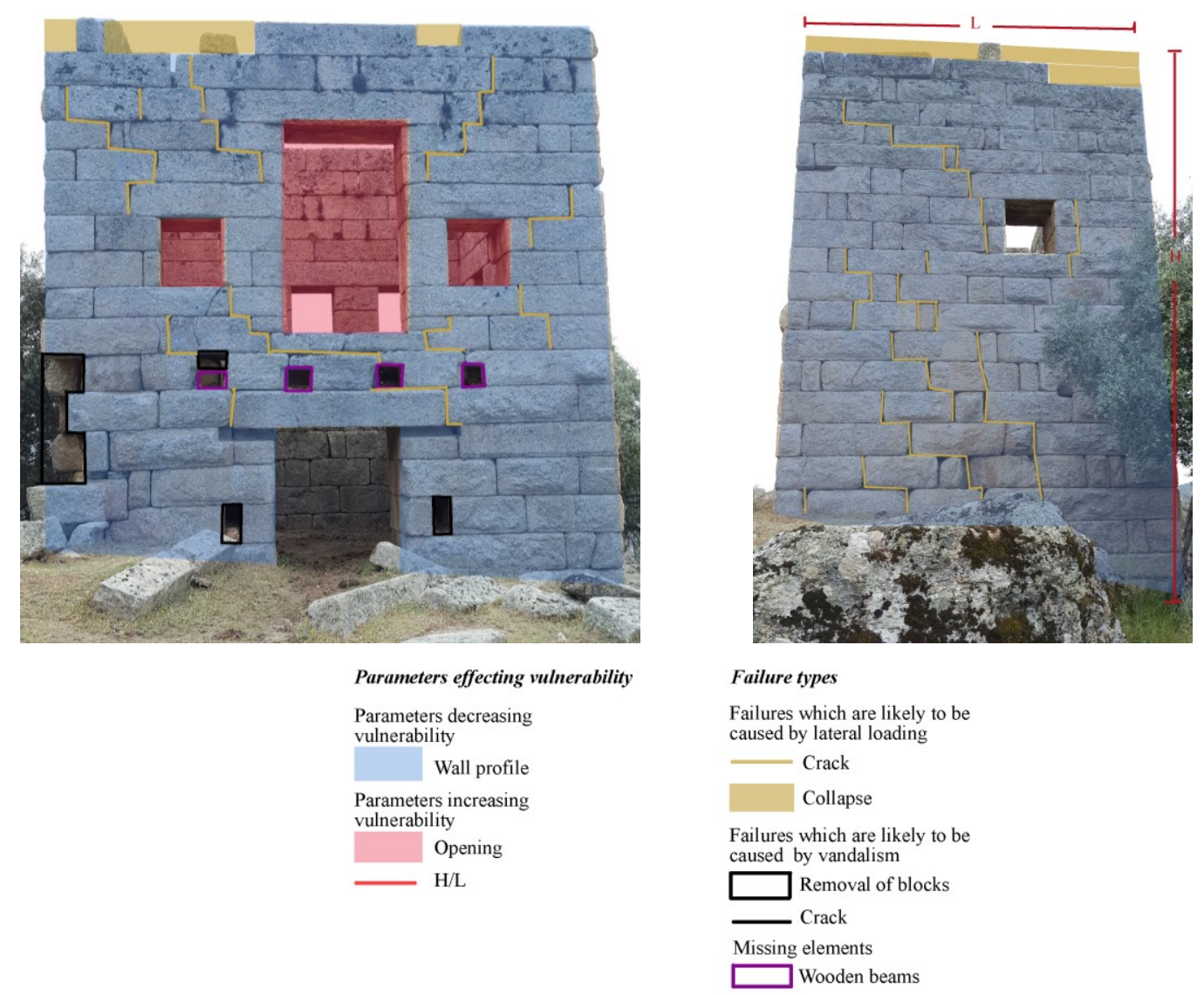

Figure 95. Existing failures of Alinda Tower; northern (left) and southern (right) facades

\subsection{Vulnerability of Latmos Tower}

Latmos tower has high vulnerability due to the weakness of wall profile and opening organization. Although walls are composed of leaves connected with headers, small staggering ratio (0.8) and medium ratio between stone lengths and height (2.4) increase vulnerability. Asymmetrical opening adjacent to corner also increase 
vulnerability. $\mathrm{H} / \mathrm{l}$ ratio (1.7) is ideal for vulnerability (Figure 97). Control of the weakness stemming from the original wall profile should be achieved with appropriate measures of intervention.

\section{- Possible Failures}

When the opening adjacent to corner is at in-plane position, in-plane failure may be observed due to the small staggering and block ratio, while when openings at out-ofplane position, detachment of the out-of-plane wall can occur. In spite of usage of header stones, body behavior is not seen due to the weakness of arrangement and dimension of blocks (Figure 96).

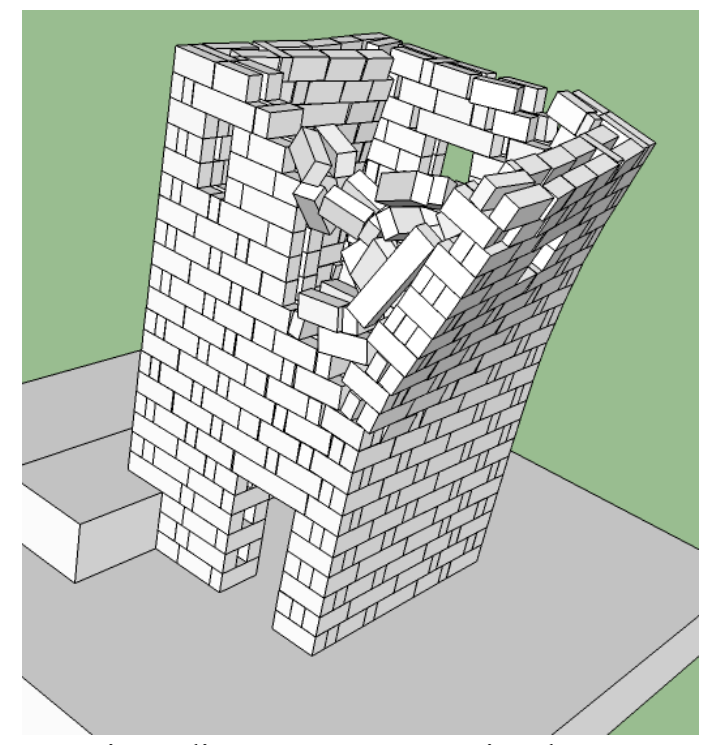

Opening adjacent to corner at in-plane position;

In-plane failure

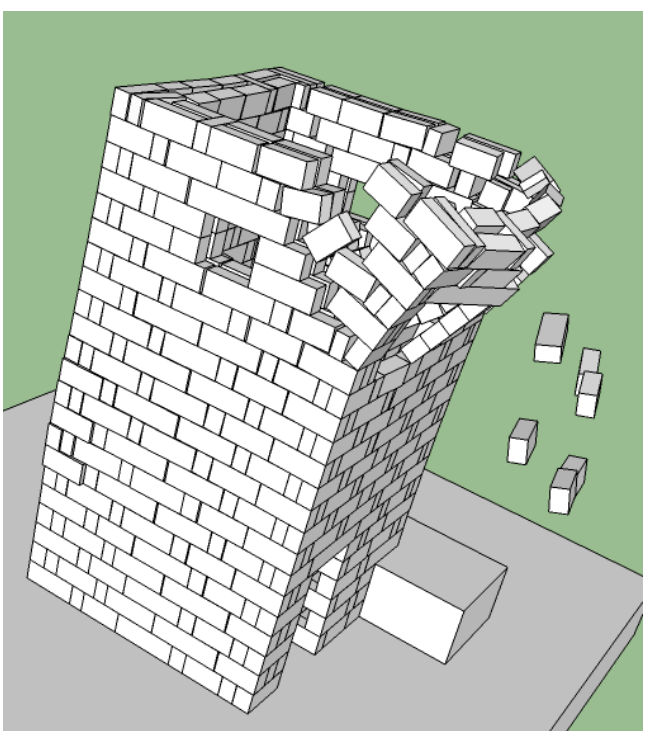

Opening adjacent to corner at out-of-plane position;

Out-of-plane failure with top blocks of the side walls

Figure 96. Possible failures of the tower

\section{- Present Failures}

Today, the tower conserves its integrity, however, there are diagonal cracks at upper parts of walls at the northern facade. These failures may present similarities with simulation results for lateral loading from the direction of the bedrock (eastern facade) (Figure 97). 


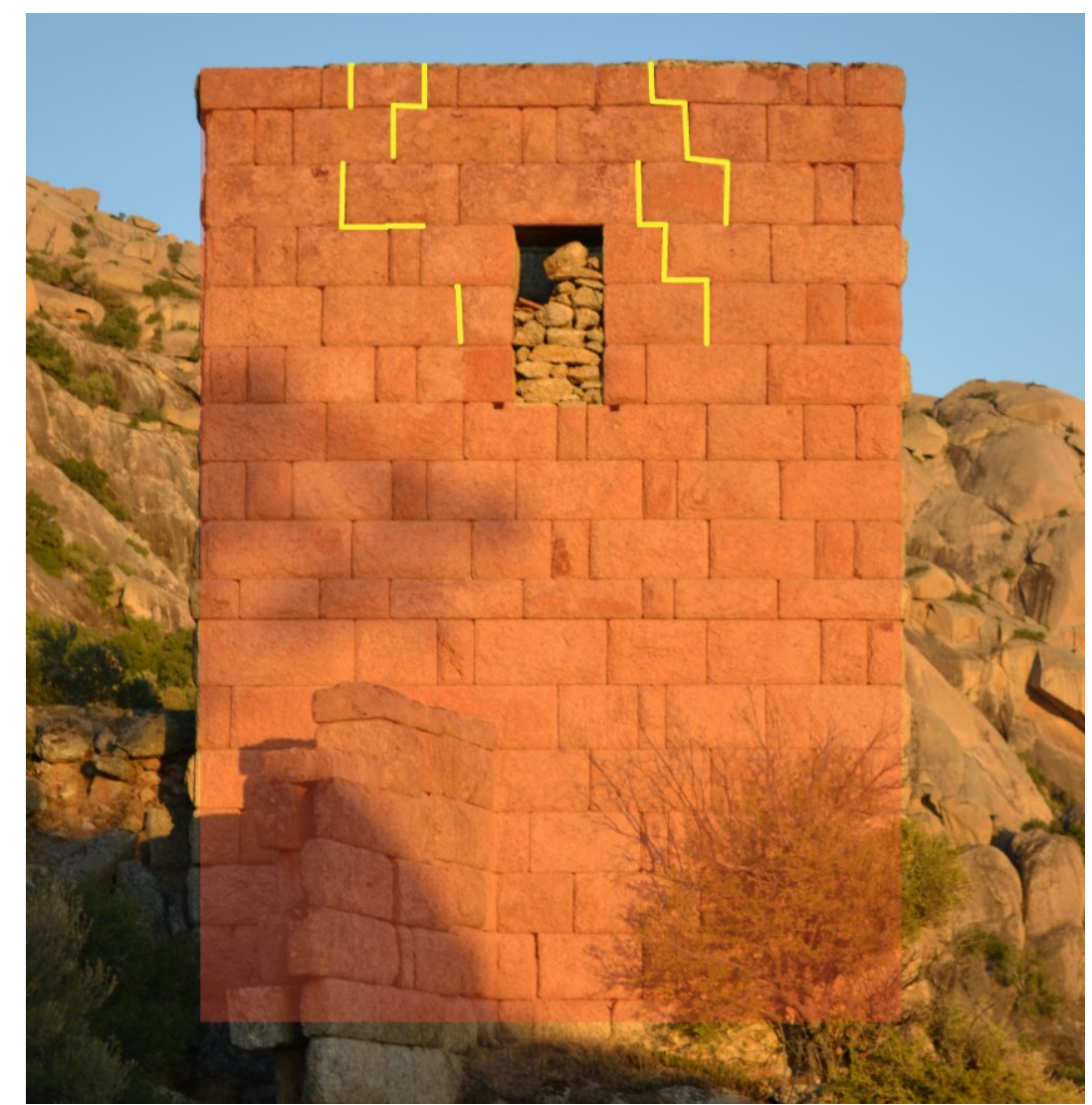

\section{Parameters effecting vulnerability}

Parameters increasing vulnerability

Wall profile

\section{Failure types}

Failures which are likely to be caused by lateral loading

Crack

Figure 97. Existing failures of Latmos Tower; northern facade

\subsubsection{Towers in Cilicia}

Gömeç and Sarayın Towers in Cilicia Region are approximately $2 \mathrm{~km}$ away from each other. This region is under low earthquake threat due to low ground acceleration (AFAD 2018). In $100 \mathrm{~km}$ proximity of the surrounding area, 17 earthquakes have been recorded from 1900 until now: between 4 and 5 in magnitude, there are 12 earthquakes recorded. Between 5 and 6 , there are 5 earthquakes. In ancient periods, recorded earthquakes are between 6 and 7, approximately $350 \mathrm{~km}$ away from the area. There is one recorded earthquake higher than 7 in Cilicia Region in 1268 (BDTIM 2017). 


\subsection{Vulnerability of Gömeç Tower}

Gömeç Tower has considerably high vulnerability due to its wall profile characteristics and $\mathrm{h} / \mathrm{l}$ ratio, although it has symmetrical small sized openings. It has small staggering ratio (0.4), small ratio between stone length and height (1.5) and narrow stone depth $(60 \mathrm{~cm})$, and also $\mathrm{h} / 1$ ratio is 2.3 (Figure 99). Control of the weakness stemming from the original wall profile and high $\mathrm{h} / \mathrm{l}$ ratio should be achieved with appropriate measures of intervention.

\section{- Possible failures}

Since the openings are ineffective, the behavior is directly related to the wall profile characteristics. Since the corner connections are weak due to their small staggering ratio and short blocks, the tower may present basically hybrid behavior; collapse of side in-plane walls followed by overturning of the out-of-plane wall with vertical cracks at the corners regardless of lateral load direction (Figure 98).

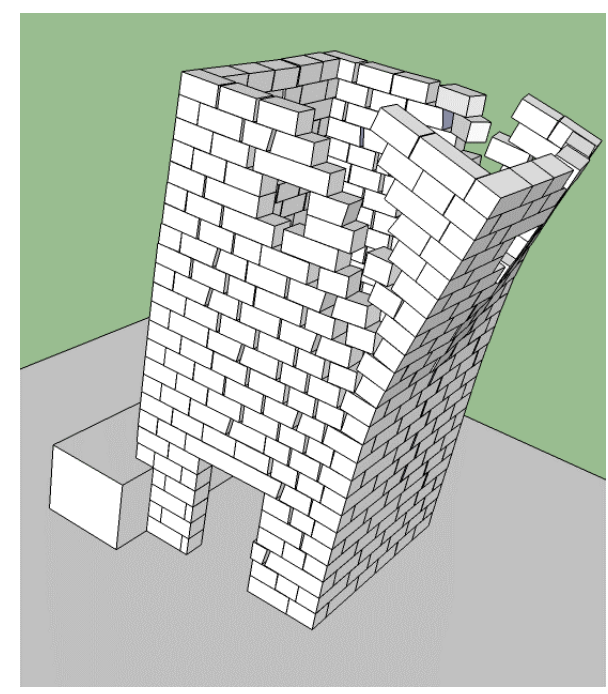

Figure 98. Probable failure mechanisms under lateral loading from the direction of southern facade

\section{- Present failures}

The joints of upper parts and upper openings of tower are filled with mortar and stone blocks. This may be a latter intervention after a possible failure. Therefore, any sign of structural failure cannot be traced at present (Figure 98). 


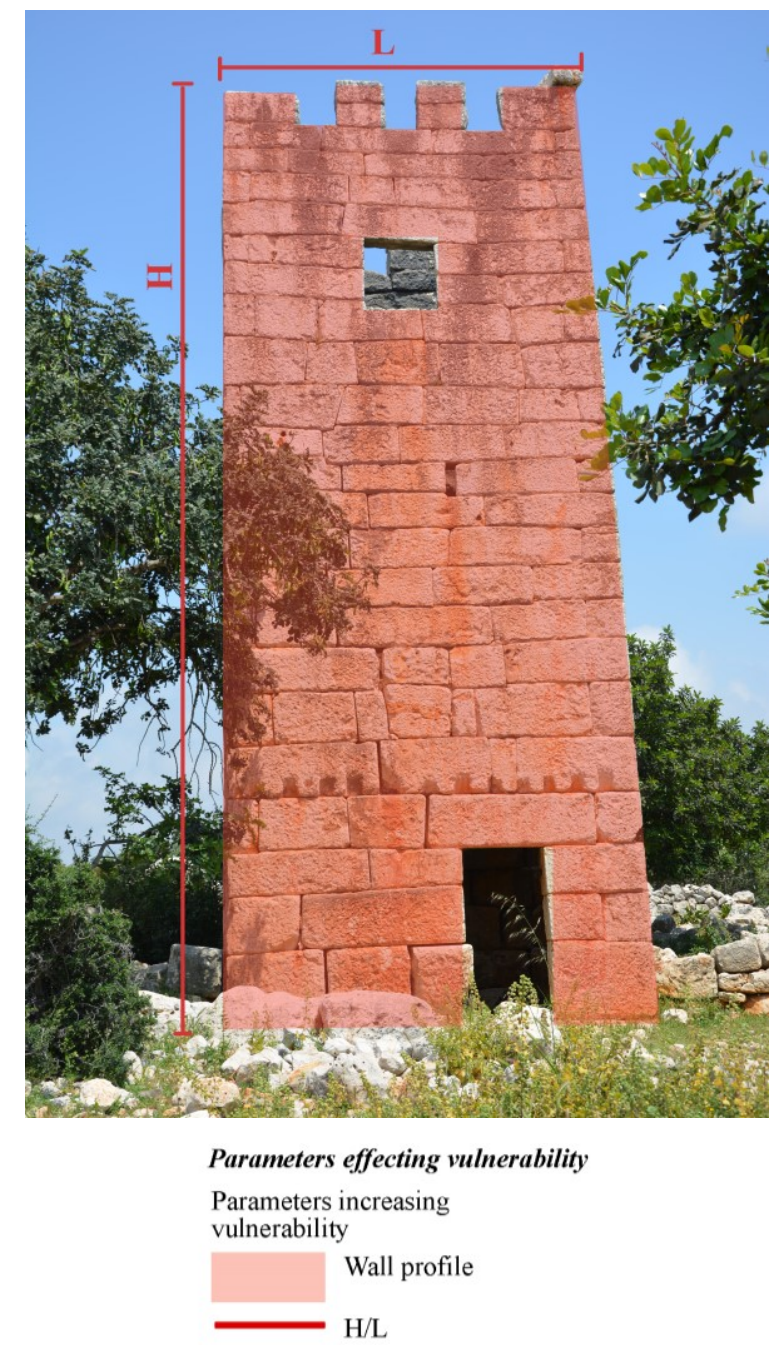

Figure 99. Present situation of Gömeç Tower; northern facade

\subsection{Vulnerability of Sarayın Tower}

Sarayın Tower has medium vulnerability. It has small staggering ratio (0.6-0.8), medium ratio between stone length and height (2) and short stone depth $(60 \mathrm{~cm})$. Symmetrical small sized openings and $\mathrm{h} / \mathrm{l}$ ratio (2) do not affect vulnerability (Figure 101). Control of the weakness stemming from the original wall profile should be achieved with appropriate measures of intervention.

\section{- Possible Failures}

Since the corner connections are weak due to their small staggering ratio and medium block ratio, the tower may present in-plane and out-of-plane behavior together, in-plane diagonal cracking followed by overturning of the facade due to the vertical cracks at the corners (Figure 100). 


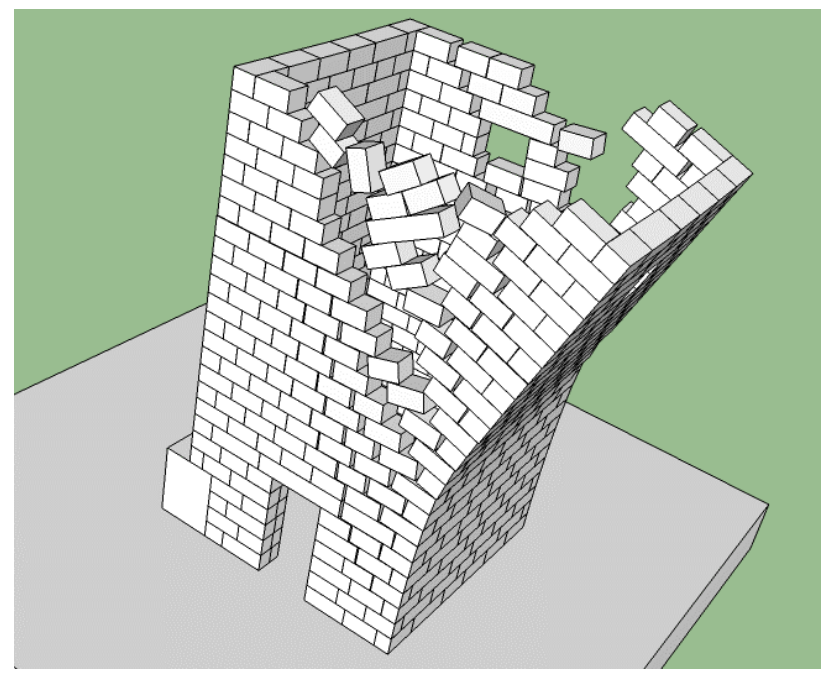

Figure 100. Probable failure mechanisms under lateral loading from the direction of eastern facade (right)

\section{- Present Failures}

Present situation of the tower does not give information on its structural problems, joints of upper parts and upper openings of tower are filled with mortar and stone blocks (Figure 101). Upper parts are thought to be constructed later, since the dimension of blocks are smaller at the upper parts. This may be a latter intervention after a possible failure.

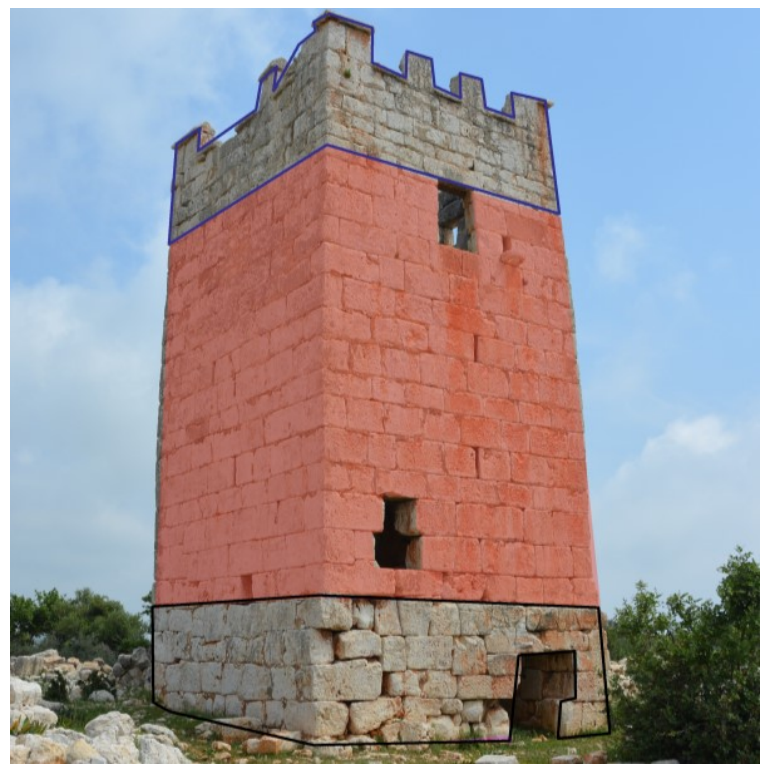

Parameters effecting vulnerability

Parameters increasing vulnerability

Wall profile

\section{Failure types}

Failures which are likely to be caused by vandalism followed by intervention $\square$ Sliding of blocks Latter intervention $\square$ Mortar in joints

Figure 101. Present situation of Sarayın Tower 


\subsubsection{Towers in Pamphylia}

Perge and Sillyon Towers in Pamphylia Region are approximately $18 \mathrm{~km}$ away from each other. This region is under high earthquake threat due to high ground acceleration (AFAD 2018). In $100 \mathrm{~km}$ proximity of the surrounding area, 125 earthquakes are recorded from 1900 until today. In the surroundings of Latmos, between 4 and 5 in magnitude, there are 105 earthquakes. Between 5 and 6, there are 19 earthquakes and between 6 and 7, there is one earthquake (BDTİM 2017).

\subsection{Vulnerability of Perge Tower}

Perge Tower has high vulnerability due to both its wall profile and opening characteristics. At lower level, staggering ratio decreases to 0.3 , while it changes between 0.6 and 1 at the upper level. Ratio between stone length and height is medium (2), however, depth of stones is $60 \mathrm{~cm}$. As well as weaknesses of wall profile, the tower is composed of upper medium sized $(90 \times 160 \mathrm{~cm})$ symmetrical three openings at each facade. $\mathrm{H} / \mathrm{L}$ ratio does not affect vulnerability (h/l: 2) (Figure 103). Control of the weakness stemming from the original wall profile and opening characteristics should be achieved with appropriate measures of intervention.

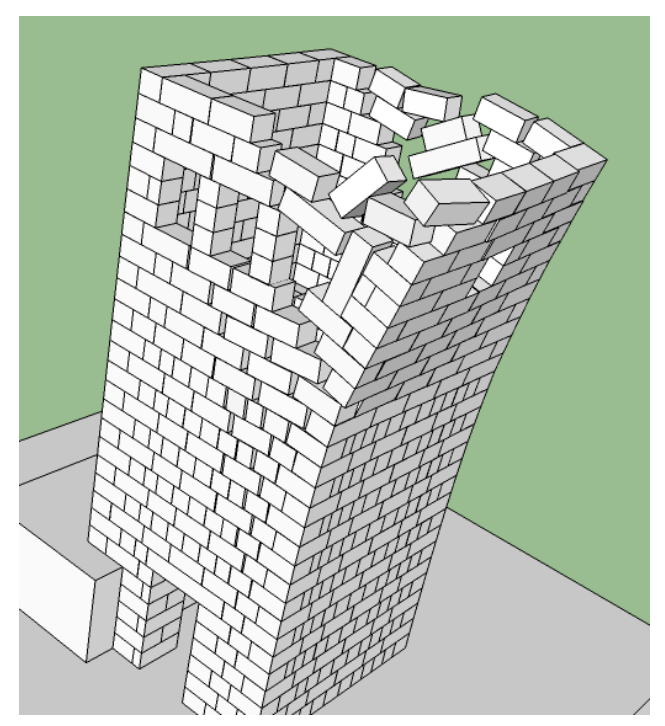

Figure 102. Probable failure mechanisms under lateral loading from the direction of eastern facade 


\section{- Possible failures}

Since three openings are located at each facade, it not necessary to discuss the inplane or out-of-plane position of openings separately. Possible failure in case of lateral loading may be hybrid failure mechanism; and collapse of two side walls due to the inplane cracking followed by overturning of the facade wall due to the vertical cracks at the corners caused by small staggering ratio (Figure 102).

\section{- Present failures}

Today, western facade wall of the tower is not present, and the related side walls were demolished partially as well. This demolishment might be caused by hybrid failure mechanism similar with the simulation results. The lateral loading might be perpendicular to western facade (Figure 103).

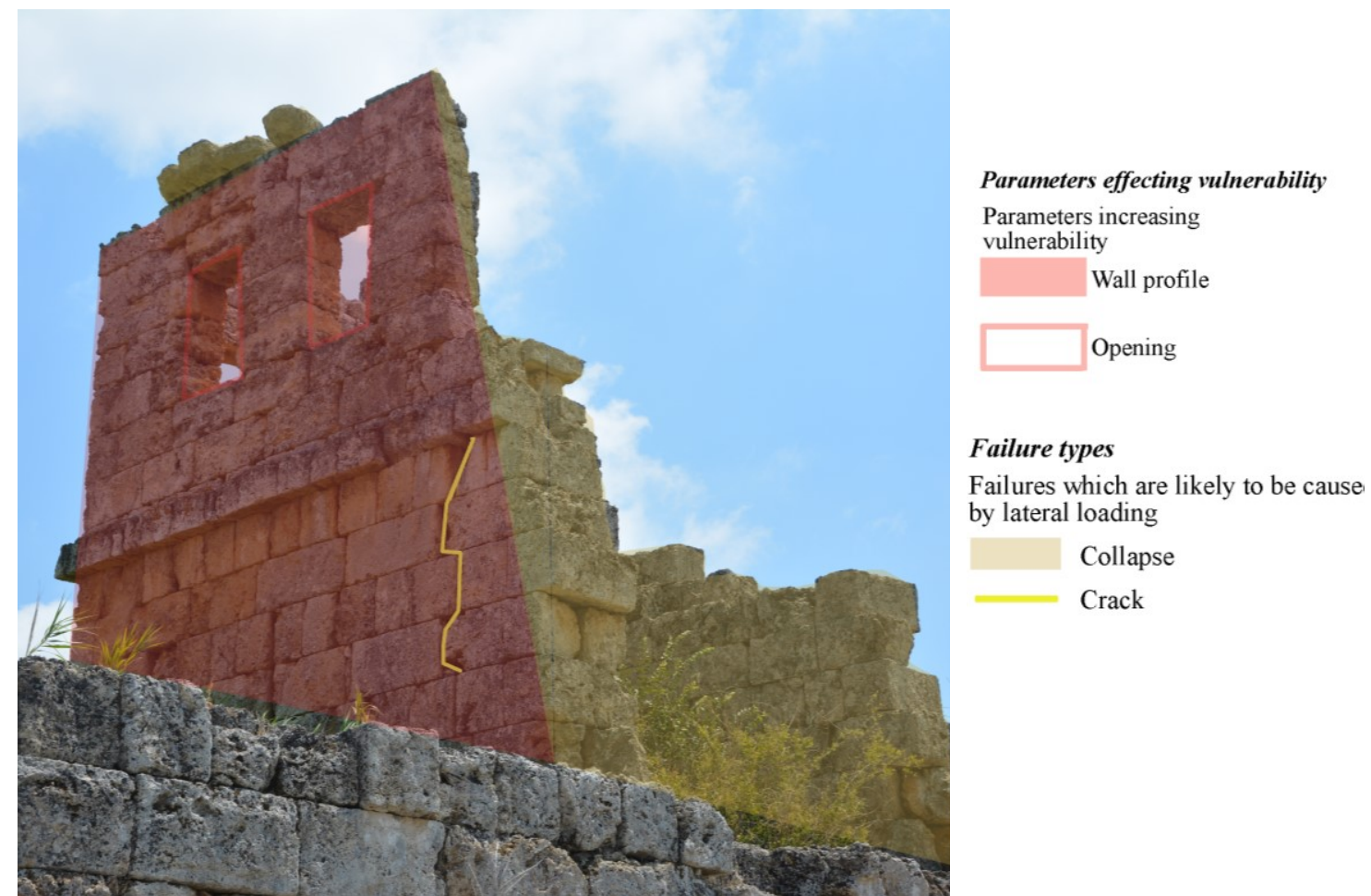

Figure 103. Present situation of Perge Tower

\subsection{Vulnerability of Sillyon Tower}

Sillyon tower has considerably low vulnerability with the help of the characteristics of wall profile and ideal $\mathrm{h} / \mathrm{l}$ ratio $(\mathrm{h} / \mathrm{l}$ between 1.6 and 1.8$)$. It has high 
staggering ratio (average 1.7) and high block length and height ratio (3) with the help of the blocks in $25 \mathrm{~cm}$ in height, in each row at the upper parts. One leafed wall has also longer stone depth $(75 \mathrm{~cm})$. The opening adjacent to corner $(105 \times 300 \mathrm{~cm})$ at western facade increases vulnerability (Figure 105). Control of the weakness stemming from the original corner opening should be achieved with appropriate measures of intervention.

\section{- Probable failures}

The tower presents probable in-plane behavior regardless of the opening type and position of the opening type with the help of the high staggering ratio (Figure 104).

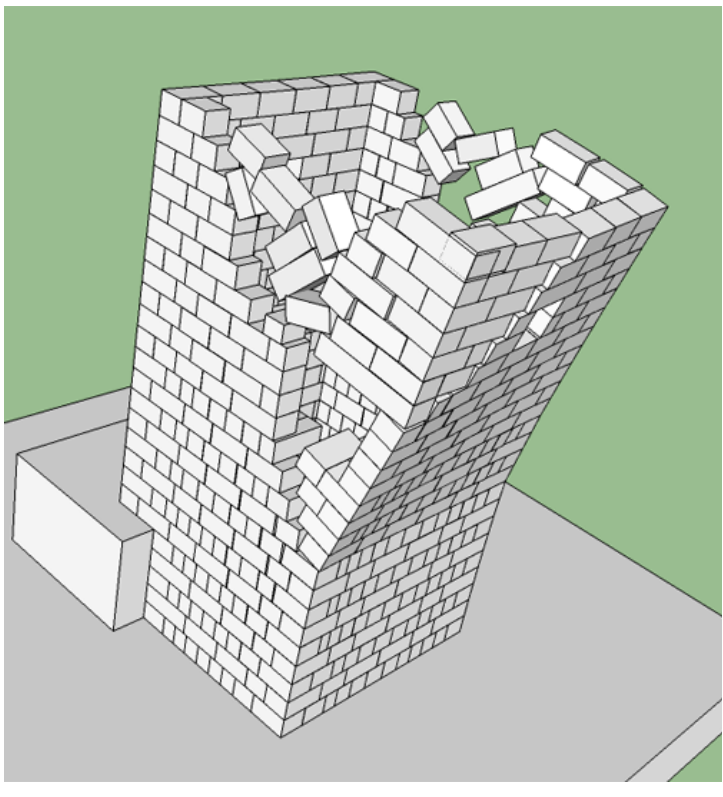

Adjacent opening at in-plane position (lateral lading from the southern facade)

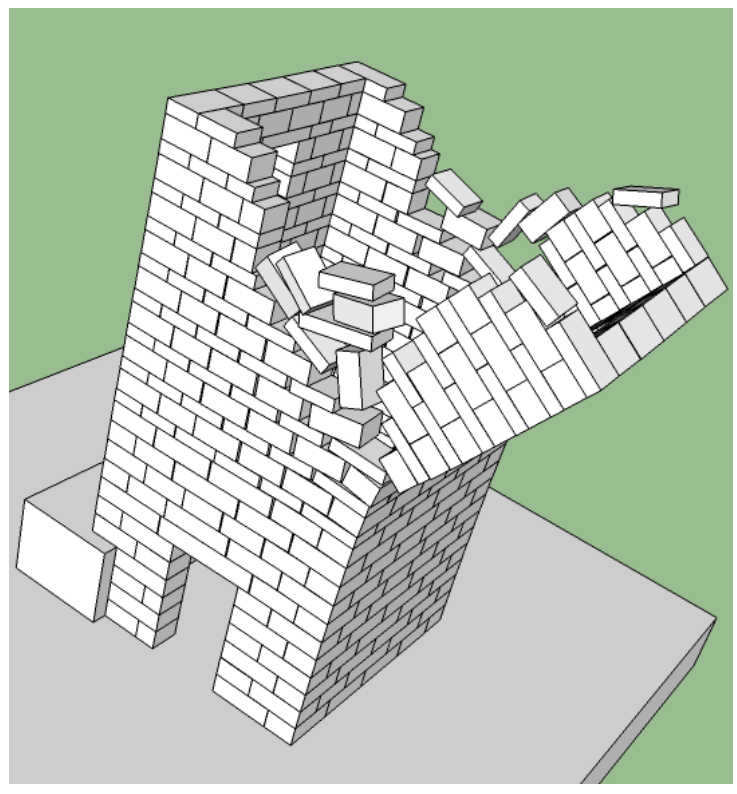

Adjacent opening at out-of-plane position (lateral lading from the eastern facade)

Figure 104. Probable failure mechanisms under lateral loading from the direction of eastern facade

\section{- Present failures}

Today, at upper parts, diagonal cracks are observed, but the main problem of the tower is vertical cracks due to settlement. Therefore, since the reasons of probable and present failures are different, they do not correlate (Figure 105). Nevertheless, it may be stated that the tower has not faced with a severe lateral loading yet. 


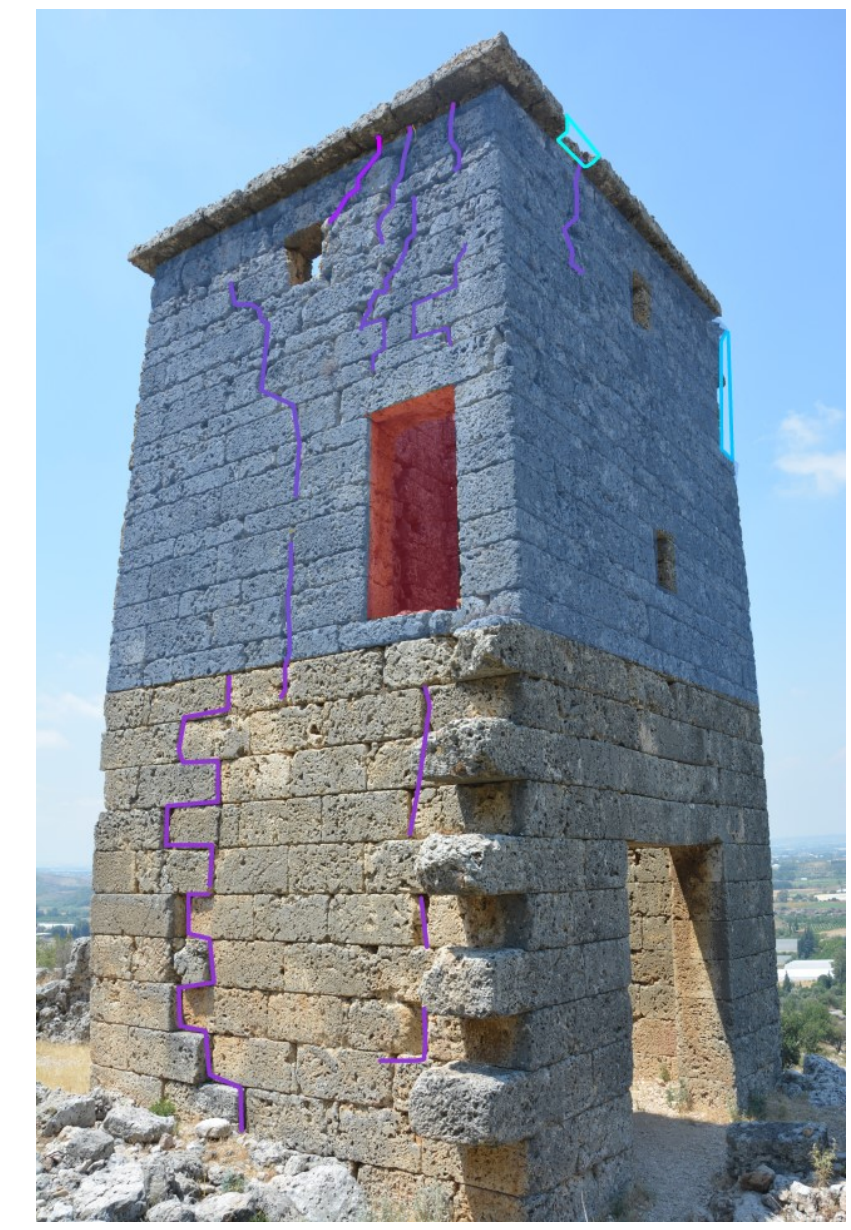

Parameters effecting vulnerability

Parameters decreasing

vulnerability

Wall profile

Parameters increasing vulnerability

Opening

\section{Failure types}

Failures which are likely to be caused by settlement

$$
\text { - Crack }
$$

Failures which are likely to be caused by aging

Demolishment of blocks

Figure 105. Present situation of Sillyon Tower; northern and westerns facades

Consequently, according to risk assessment of case study towers, it is seen that the towers located at low earthquake threat could have been constructed by taking into consideration precautions against earthquake. However, towers are at high earthquake threat could have been reinforced with high staggering ratio, long stone depth, long stone blocks or header usage regardless of the fact that some of these characteristics have little effect on structural improvement. Precautions preferred in the construction of ancient towers prove that there could be awareness of earthquake risk status of their sites. 


\section{CHAPTER 5}

\section{CONCLUSION}

This study proves that there was consciousness of precautions necessary for structural resistance of dry masonry under earthquake risk in ancient periods. However, this knowledge was not always benefitted from, as a consequence of probable local limitations in relation with budget, time, building material or masters. The study clarifies the parameters that are effective on structural resistance of ancient dry masonry towers under lateral loading. The authentic qualities of these parameters should be sustained in conservation work.

The parameters effecting structural resistance are listed in the order of high impact to low as staggering ratio, stone depth, ratio between block length and height, proportional relationship between height and length, opening area, number and position and even distribution of header stones. These results show that primary parameters effecting structural resistance are about organization of blocks, while parameters of building morphology such as height-length relations and opening areas are secondary parameters. It was revealed that parameters should always be considered in relation with each other.

- In order to minimize the damage of the structure, regular organization of stone blocks ( $\mathrm{s} / \mathrm{h} \geq 1.7$ ) should be supported with appropriate block ratio ( $\mathrm{bl} / \mathrm{h} \geq 3$ ). If only the stones are organized properly, but the ratio between stone length and height is small, the resistance of the tower decreases.

- The advantage of usage of header stones has been observed when they are at appropriate position and used together with other blocks of appropriate dimensions $(\mathrm{bl} / \mathrm{h} \geq 3)$ and organizations $(\mathrm{s} / \mathrm{h} \geq 1.7)$

- Header stones used only in the lower parts of the towers cannot provide contribution to the resistance of the structure.

- Header stones adjacent to each other in two rows reduce the strength of the towers considerably because they cause decrease in staggering ratio.

- The openings affect the structural resistance and behavior in accordance with their sub-qualities such as area, number, and position. It is seen that increasing their number and area, positioning them considering an uneven distribution within the 
facade composition, and decreasing their distance to the corners reduce the resistance. However, the double-leafed and one-leafed wall profiles that have high staggering ratios $(\geq 1.7)$ are not affected by one or two openings up to $3 \mathrm{~m}^{2}$.

- Upper openings affect structural resistance highly in comparison to lower openings. Even if the lower openings are adjacent to a corner, they are not a primary factor determining structural resistance and behavior.

- Small sized openings $(100 \times 100 \mathrm{~cm})$ less than 3 in number do not affect resistance of towers at in-plane and out-of-plane positions. However, they change the behavior of towers at out-of-plane position.

- Single leafed wall profiles that have both high staggering ratios and high stone depths are not affected by openings close to corner at out-of-plane position: they present in-plane failures.

- In certain cases, the priority of impact of the parameters can change: opening organization and proportional relationship can become the dominant parameters in specific combinations. Large sized openings $\left(5 \mathrm{~m}^{2}\right)$ become always dominant in any height to length ratio. Small height to length ratio (1.3) becomes dominant from small or medium sized two openings.

A standardization in ancient construction techniques is determined for proportional relationship between wall height and length, and material usage regarding dry masonry towers. Although wall thicknesses are different, ratio between height and length (1.6-2) are preferred between certain values. These values provide maximum structural vulnerability for towers. For material usage, it has been observed that the rocks used in the construction of the towers; namely, granite and limestone; have similar density (between $2560-2750 \mathrm{~kg} / \mathrm{m}^{3}$ ) and coefficient of friction values (between 6-7.2), and they are inversely proportional with each other for each material. Small changes in values are not effective in structural behavior and durability of towers.

Consequently, with interpretation of results, a framework composed of vulnerability rankings and possible failure mechanisms was proposed for assessment of the dry masonry towers. This framework allows to put forward an idea for basic behavior of the towers. In turn, vulnerability is evaluated, possible failures are foreseen, and preventive measures may be developed. If this framework is combined with data about frequency and intensity of previous earthquakes, risk assessment can be done. 
Application of the framework on case study towers demonstrated that towers under high earthquake threat were designed with strong parameters as high staggering ratio, long stone depth or high block ratio, while there is no precaution against lateral loading in the towers under minimum earthquake risk.

For future work; preventative measures that can be implemented to improve the earthquake resistance of dry masonry towers based on vulnerability framework results can be determined. A framework including intervention decisions for each level of vulnerability and possible failure mechanisms can be proposed. Internalization of structural behavior of dry masonry towers makes possible to propose restitution schemes by observing structural characteristics and failures. 


\section{REFERENCES}

Adam, Jean-Pierre. Roman Building, Materials, and Techniques. Translated by Anthony Mathews. London and Newyork: Routledge, 2005.

Adnan Pekman. Son Kazı Araştırmaları Işı̆̆ında Perge Tarihi: History of Perge. Ankara: Türk Tarih Kurumu, 1989.

Anghelache, Constantin, Alexandru Manole, and Madalina Gabriela Anghel. "Analysis of final consumption and gross investment influence on GDP - multiple linear regression model." Theoretical and Applied Economics 12, no. 3(604) (2015): 137142.

Anton, Synytsia. "MSPhysics.” Sketchucation. Last modified November 16, 2017. Accessed May 5, 2018.

https://sketchucation.com/forums/viewtopic.php?f=323\&t=56852\#p516427.

Arpaz, Ercan. "Determination of Restitution Coefficients for Various Granite Samples." Arab J Geosci 8 (2015): 5285-5294.

ASTM C568. Standard Specification for Limestone Dimension Stone. Geneve: World Trade Organization Technical Barriers to Trade (TBT) Committee, 2016.

ASTM C615. Standard Specification for Granite Dimension Stone. Geneve: World Trade Organization Technical Barriers to Trade (TBT) Committee, 2018.

ASTM C616. Standard Specification for Sandstone Dimension Stone. Geneve: World Trade Organization Technical Barriers to Trade (TBT) Committee, 2016.

Başgelmez, Şükriye, and Mustafa Yıldız. "Cigarette Consumption and Related Factors in Schizophrenia, Schizoaffective Disorder and Delusional Disorder." The Journal of Psychiatry and Neurological Sciences 30, (2017): 233-242.

Benowar, E. "Greek \& Phoenician Colonies." Ancient History Encyclopedia. Last modified April 26, 2012. https://www.ancient.eu/image/108/.

BDTIM. "Deprem tarihçesi." Last modified 2017. http://www.koeri.boun.edu.tr/sismo/2/son-depremler/debrem-bilgi-sistemi/\# 
Binda, Luigia, Antonella Saisi, and Claudia Tiraboschi. "Investigation Procedures for the Diagnosis of Historic Masonries." Construction and Building Materials 14, (2000): 199-233. doi: 10.1016/S0950-0618(00)00018-0.

Binda, Luigia Ada, Maria Rosa Valuzzi, and Giuliana Cardani. "Vulnerability Analysis of the Historical Buildings in Seismic Area by A Multilevel Approach." Asian Journal of Civil Engineering, (Building and Housing) 7, no. 4 (2006): 343-357.

Bryce, Trevor. The Routledge Handbook of the Peoples and Places of Ancient Western Asia: The Near East from the Early Bronze Age to the Fall of the Persian Empire. Routledge: Taylor \& Francis, 2009.

Bui, Tan-Trung, Ali Limam, Vasilis Sarhosis, and Mohammed HJiaj. "Discrete Element Modelling of the In-Plane and Out-Of-Plane Behavior of Dry-Joint Masonry Wall Constructions." Engineering Structures 136, (2017): 277-294. doi: 10.1016/j.engstruct.2017.01.020.

Byerlee, James. "Friction of Rocks." Pure and Applied Geophysics 116, no.4-5 (1978): 615-626.

Carocci, Caterina, and Carlo Baggio. ed. Sicurezza e conservazione dei centri storici: il caso Ortigia: codice di pratica per gli interventi antisismici nel centro storico. Roma: Laterza, 1993.

Carocci, F. Caterina. "Guidelines for The Safety and Preservation of Historical Centers in Seismic Areas." In Historical Constructions. edited by Paulo. B. Lourenço, 145166. Guimaraes: University of Minho, 2001.

Casolo, Siro, Gabriele Milani, Giuseppina Uva, and Claudio Alessandri. “Comparative Seismic Vulnerability Analysis on Ten Masonry Towers in The Coastal Pro Valley in Italy." Engineering Structures 49 (2013):465-490. Doi: 10.1016/j.engstruct.2012.11.03.

Ceradini, Vittorio. "Modellazione, Sperimentazione per lo Studio della Struttura Muraria Storica." PhD diss., University of Rome, 1992.

Colas, Anne Sophie, Denis Garnier, Jean Claude Morel, Thierry Ciblac, and C O'Neill. "Cross Curves of Stability for Dry Stone Retaining Wall Design." In Brick and Block Masonry-Trends, innovations and Challenges, edited by Da Porto Modena, and Valuzzi, 165-170. London: Taylor and Francis, 2016.

Concrete Institute. Transactions and Notes, 1-2. Chicago: The University of Chicago, 1909. 
D'ayala, Dina Francesca, and Elena Speranza. "Definition of Collapse Mechanisms and Seismic Vulnerability of Historic Masonry Buildings." Earthquake Spectra 19, no. 3 (2003): 479-509.

Da Costa, Alexandre Aníbal Meira Guimarães. "Seismic Assessment of the Out-OfPlane Performance of Traditional Stone Masonry Walls." PhD diss., The University of Porto, 2012.

De Felice, Gianmarco, and Renato Giannini. "Out-Of-Plane Seismic Resistance of Masonry Walls.” Journal of Earthquake Engineering 5, no. 2 (2001): 253-271.

De Felice, Gianmarco. “Out-of-plane Fragility of Historic Masonry Walls.” Structural Analysis of Historical Constructions, edited by Claudio Modena, Paulo B. Lourenço, and Pere Roca, 1143-1148. UK: Balkema Publishers, 2004.

De Felice, Gianmarco. "Out-of-Plane Seismic Capacity of Masonry Depending on Wall Section Morphology." International Journal of Architectural Heritage 5, no.4-5, (2011): 466-482. doi: 10.1080/15583058.2010.530339.

De Jong, J.H., Kjetil Wormnes, and Paolo Tiso. "Simulating Rigid-Bodies, Strings and Nets for Engineering Applications Using Gaming Industry Physics Simulators.” In Proceedings of International Symposium on Artificial Intelligence, Robotics and Automation in Space (i-SAIRAS), Canada: Montreal, 2008.

DeJong, Matthew J. "Seismic Assessment Strategies for Masonry Structures." $\mathrm{PhD}$ diss., Massachusetts Institute of Technology, 2009.

Duran, Hasan Engin, and Alexandra Ferreira-Lopes. "Determinants of Co-movement and of Lead and Lag Behavior of Business Cycles in the Eurozone." In Business Research Unit (UNIDE-IUL). Portugal: Lisbon, 2015.

Duran, Hasan Engin. "Bölgesel İstihdam Dalgalanmalarının Şiddeti, Sebep ve Sonuçları: Türkiye Örneği.” Megaron 12, no. 2 (2017): 280-291.

Ertekin, Pınar, and Dilek Özmen. "Bir Üniversite Hastanesinde Çalısan Hemsirelerde İse Yabancilasmayı Yordayan Degiskenlerin Incelenmesi." Hemşirelikte Eğitim ve Araştirma Dergisi 14, no. 1 (2017): 25-30.

European Parliament. Protecting the Cultural Heritage from Natural Disasters. Brussels: European parliament, 2007.

Eviews. "Estimating A Regression Model." Last Modified October 25, 2017. Accessed January 24, 2019. 
http://www.eviews.com/help/helpintro.html\#page/content/demoestimating_a_Regre ssion_Model.html.

Extension Warehouse. "MSPhysics.” Accessed September 9, 2018. https://extensions.sketchup.com/en/content/msphysics.

Fanning, J. Thomas. A Practical Treatise on Hydraulic and Water-Supply Engineering. Nizhegorodskaya Ulitsa: Рипол Классик,1893.

Foti, Dara, Vitantonio Vacca, and I. Facchini. "DEM Modeling and Experimental Analysis of the Static Behavior of a Dry-Joints Masonry Cross Vaults." Construction and Building Materials 170, (2018): 111-120. doi: 10.1016/j.conbuildmat.2018.02.202.

Gençer, Funda, Mine Hamamcıoğlu Turan, Mustafa Vardaroğlu, and Engin Aktaş. "Karya, Alinda ve Latmos' daki iki helenistik kulenin yapısal dayanımının değerlendirilmesi." In Uluslararası Katılımlı 6. Tarihi Yapıların Korunması ve Güçlendirilmesi Sempozyumu, 79-89. Turkey: Trabzon, 2017.

Gençer, Funda, Mine Hamamcıoğlu Turan, and Engin Aktaş. "Helenistik kulelerde yanal yüke ilişkin düzlem içi ve düzlem dışı duvar davranışının duvar profilleri ve açıklık düzenlerine bağlı olarak incelenmesi." Journal of The Faculty of Engineering and Architecture of Gazi University, (2019). In Press Accepted Manuscript.

Giuffre, Antonino. Letture sulla meccanica delle murature storiche. Rome, Italy: Kappa, 1991.

Giuffrè, Antonino. ed. Sicurezza e conservazione dei centri storici: il caso Ortigia: codice di pratica per gli interventi antisismici nel centro storico. Roma: Laterza, 1993.

Giuffre, Antonino, Tommaso Pagnoni, and Cesare Tocci. "In-plane Seismic Behavior of Historical Masonry Walls." In Proceedings of $10^{\text {th }} I B^{2} \mathrm{MaC}$, 263-272. Canada: Calgary, 1994.

Giuffrè, Antonino. "A Mechanical Model for Statics and Dynamics of Historical Masonry Buildings." In Protection of the Architectural Heritage Against Earthquakes, CISM Courses and Lectures (359), edited by V. Petrini and M. Save Udine, 71-152. Italy: Springer-Verlag, 1996.

Giuffre, Antonino. "Statica e dinamica delle costruzioni murarie storiche." Leggendo il libro delle antiche architetture: Aspetti statici del restauro. edited by Cesare Tocci and Caterina F. Carocci. Italy: Gangemi Editore, 2010. 
Giuffre', Antonino. "Mechanics of Historical Masonry and Strengthening Criteria." In XV7 Regional Seminar on Earthquake Engineering (September 18-23), Ravello, 1996.

Givoni, Baruch. Climate Considerations in Building and Urban Design. Newyork: John Wiley \& Sons, 1908.

Godio, Michele, Ioannis Stefanou, and Karam Sab. "Effects of The Dilatancy of Joints and of The Size of the Building Blocks on the Mechanical Behavior of Masonry Structures.” Meccanica 53, (2018): 1629-1643. doi: 10.1007/s11012-017-0688-z.

Henseler, Jörg, Christian M. Ringle, and Rudolf R. Sinkovics. "The Use of Partial Least Squares Path Modeling in International Marketing." Adv Int Market 20 (2009): 277-319.

Jay, В. Augustus. The Mechanics of Engineering. Nizhegorodskaya Ulitsa: Рипол Классик, 1908.

Jimenez, Daniel D. "Empirical Analysis of Masonry Walls: Structural Design and Seismic Reinforcement through Tilting Experiments." PhD diss., Massachusetts Institute of Technology, 2011.

Kanıt, Recep, and U. Naci Baykan. "Bina Yaklaşık Maliyetinin Çoklu Doğrusal Regresyon ile Belirlenmesi.” Politeknik Dergisi 7, no. 4 (2004): 359-367.

Kaplan, Deniz. “Doğu Dağlık Kilikia'da (Olba Bölgesi) Erken İmparatorluk Dönemi'nde İmar Hareketliliğindeki Durgunluk ve Isodom Kuleler: Dağlık KilikiaIsauria İsyanları.” ADALYA XVII (2014): 125-136.

Karlsson, Lars. "Fortification Towers and Masonry Techniques in the Hegemony of Syracuse, 405-211 B.C." Acta Instituti Romani Regni Sueciade, Series in 40, XLIX, edited by Brita Alroth. Stockholm: Minab, 1992.

Kaya, Dicle. “Roma'nin Anadolu'daki Doğu Siniri: Karargâhlar, Köprüler ve Yol Ağlarinin Arkeolojik Açidan İncelenmesi.” Master's Thesis. University of İstanbul, 2017.

Kelechi, A. Chigozie. "Regression and Principal Component Analyses: A Comparison Using Few Regressors." American Journal of Mathematics and Statistics 2, no.1 (2012): 1-5. doi: 10.5923/j.ajms. 20120201.01

Krikov, Boris A. "History of earthquake resistant construction from antiquity to our times." "Translated by Peter I. Zabolotniy Madrid: Acor Artes Graficas, 1992. 
Krischen, Fritz. Die Befestingungen von Heraklia am Latmos, Milet III 2. Edited by ed. T. Wiegand. Berlin, 1922.

Lang, Gernot. Klassische antike Stätten Anatoliens, Band II: Larissa-Zeleia. Books on Demand GmbH, 2003.

Magenes, Guido, and Andrea Penna. "Seismic Design and Assessment of Masonry Buildings in Europe: Recent Research and Code Development Issues." In Proceedings of the 9th Australasian Masonry Conference, 1-21. New Zealand: Queenstown, 2011.

Mansel, Arif Müfid. Ege ve Yunan Tarihi. Ankara: Türk Tarih Kurumu Yayınları, 1970.

Mark, Robert. Architectural Technology up to the Scientific Revolution. The Art and Structure of Large-Scale Buildings. Cambridge: The MIT Press, 1993.

McNicoll, Antony W. Hellenistic Fortifications from the Aegean to the Euphrates. Edited by N. P. Milner. Gloucestershire: Clarendon Press, 1997.

Milani, Gabriele, Rafael Shehu, and Marco Valente. "A Kinematic Limit Analysis Approach for Seismic Retrofitting of Masonry Towers Through Steel Tie Roads." Engineering Structures 160 (2018): 122-228. Doi: 10.1016/j.engstruct.2018.01.033.

Morris, Sarah P. and, John K. Papadopoulos. "Towers and Slaves: An Archaeology of Exploitation." American Journal of Archaeology 109, no.2 (2005): 155-225.

Nossov, S. Konstantine. Greek Fortifications of Asia Minor 500-130 BC: From the Persian Wars to the Roman Conquest. UK: Osprey Publishing, 2012.

Önder, Meral, and Ayșegül Durak Batıgün. "Premature and Normal Menopause: An Evaluation in Terms of Stress, Marital Adjustment and Sex Roles." The Journal of Psychiatry and Neurological Sciences 29, (2016): 129-138.

Oransay, Alptekin. "Hellen Göçleri ve Arkaik Dönem.” In Anadolu Arkeolojisi, edited by Hüseyin Sabri Alanyalı, 110-125. Eskişehir: Anadolu Üniversitesi, 2012.

Orlandos, Anastasios. Les Matèriaux de Construction: Et la Technique Architecturale das Anciens Grecs. Paris: E. de Boccard, 1968.

Pervaiz, Ruqiya, Pınar Tulay, Faisal Faisal, and Nedime Serakıncı. "Incidence of Cancer in the Turkish Republic of Northern Cyprus." Turkish Journal of Medical Sciences 47, (2017): 523-530. 
Peschlow-Bindokat, Anneliese. A carian Mountain Landscape Herakleia on the Latmos. İstanbul: Homer, 2014.

Preciado, Adolfo, Silvio T. Sperbeck, and Alejandro Ramírez-Gaytán. “Seismic Vulnerability Enhancement of Medieval and Masonry Bell Towers ExternallyRestressed with Unbounded Smart Tendons." Engineering Structures 122 (2016): 50-61. Doi: 10.1016/j.engstruct.2016.05.007.

Quiroz, Adolfo Preciado. "Seismic Vulnerability Reduction of Historical Masonry Towers by External Prestressing Devices.” PhD diss., University of Florence, 2011.

Restrepo Velez, Luis F., and Magenes Guido. "Static Tests on Dry Stone Masonry and Evaluation of Static Collapse Multipliers." Techical research report ROSE 2. Pavia: IUSS Press, 2009.

Restrepo Velez, Luis F., Guido Magenes, and Micheal C. Griffith. "Dry Stone Masonry Walls in Bending-Part I: Static Tests." International Journal of Architectural Heritage: Conservation, Analysis, and Restoration 8, no.1 (2014): 1-28. doi: 10.1080/15583058.2012.663059.

Romaro, Federica. “A Study on Seismic Behavior of Masonry Towers.” PhD diss., University of Trento, 2011.

Saner, Turgut. "Some Remarks on the Hellenistic Masonry Techniques in Asia Minor." Asmosia (1995): 347-350.

Sevin, Veli. “Lidyalılar.” In Anadolu Uygarlıkları Ansiklopedisi 2, 276-308. İstanbul: Görsel, 1984.

Shi, Ya-Nan, Dina Francesca D'ayala, and Prateek Jain. "Analysis of Out-Of-Plane Damage Behavior of Unreinforced Masonry Walls." In Proceedings of 14th International Brick \& Block Masonry Conference, Australia: Sydney, 2008.

Shi, Ya-Nan. "Dynamic Behavior of Masonry Structures.” PhD diss., University of Bath, 2016.

Sielhorst, Barbara. "Hellenistic Agorai: Formation, Reception, and Semantics of an Urban Space." In The Agora in the Mediterranean from Homeric to Roman Times International Conference, edited by ed. A. Giannikouri, 31-46. Athens, 2011.

Stiros, Stathis C. "Archaeological Evidence of Antiseismic Constructions in Antiquity." Anali Di Geofisica XXXVIII, no.5-6 (1995): 725-736. 
Stovel, Herb. Risk Preparedness: A Management Manual for World Cultural Heritage. Italy: ICCROM, 1998.

Strabon. Antik Anadolu Coğrafyast: Geographika XII-XIII-XIV. Translated by Adnan Pekman, 249-250. İstanbul: Arkeoloji ve Sanat Yayınları, 1993.

Synytsia, Anton. "MSPhysics 1.0.3 (16 October 2017).” Accessed January 24, 2019. https://sketchucation.com/forums/viewtopic.php? $\mathrm{f}=323 \& \mathrm{t}=56852 \&$ start $=660$.

The Minitab Blog. "Why You Need to Check Your Residual Plots for Regression Analysis: Or, To Err is Human, To Err Randomly is Statistically Divine." Last modified April 5, 2012. http://blog.minitab.com/blog/adventures-in-statistics2/why-you-need-to-check-your-residual-plots-for-regression-analysis.

Timestop Muğla. "Herakleia (Latmos) Ancient City.” Accessed by March 5, 2019. http://www.timestopsmugla.com/en/milas/history/herakleia-(latmos)-ancientcityTomazevic, Miha, Marjana Lutman, and Ljubo Petkovic. "Seismic Behavior of Masonry Walls: Experimental Simulation." Journal of Structural Engineering 122, no.9 (1996): 1040-1047. doi: 10.1061/(ASCE)0733-9445(1996)122:9(1040).

Tomazevic, Miha. Earthquake-resistant Design of Masonry Buildings. London: Imperial College Press, 2000.

Touliatos, Panagiotis. G. “Traditional Aseismic Techniques in Greece.” In Proceedings of the International Workshop Les Systemes Nationaux Faces aux Seismes Öajeurs, edited by L. Mendes Victor. Lisbon: Centro de Geofisica, Universidade de Lisboa, 1993.

Ünal, Fatma, Sinem Tarhan, and Eda Çürükvelioğlu Köksal. “Toplumsal Cinsiyet Algısını Yordamada Cinsiyet, Sınıf, Bölüm ve Toplumsal Cinsiyet Oluşumunun Rolü.” Bartin University Journal of Faculty of Education 6, (2017): 227-236.

UNESCO, and World Heritage Convention. Caribbean Capacity Building Programme, Risk Preparedness, Module 3. La Bahana: UNESCO, 2004.

UNESCO, ICCROM, ICOMOS, and IUCN. Managing Disaster Risks for World Heritage. France: United Nations Educational, Scientific and Cultural Organization, 2010.

Uysal, Doğan, and Emel Ersun Aydemir. “Türkiye'de Yükseköğretim Kavramı ve Yükseköğretimin İstihdam ve Ekonomiye Etkisinin Analizi.” Selçuk Üniversitesi Sosyal Bilimler Dergisi 35, (2016): 275-284. 
Vaculik, Jaroslav, Michael J. Griffith, Jamila Hogarth, and J. Todd. "Out-of-Plane Flexural Response Tests Using Dry-Stack Masonry.” In Proceedings of Australian Earthquake Engineering Society Conference, South Australia: Mt Gambier, 2004.

Vaculik, Jaroslav. "Unreinforced Masonry Walls Subjected to Out-Of-Plane Seismic Action." PhD diss., The University of Adelaide, 2012.

Vitrivius. The Ten Books on Architecture. Translated by Morgan M. H. Cambridge: Harvard University Press, 1914.

Yavuz, Ayşı1. "Geleneksel Kargir Yapılarda Depreme Karşı Geliştirilen Önlemler." Türkiye'de Risk altındaki Doğal ve Kültürel Miras, edited by Haluk Sezgin, 363370. İstanbul: Türkiye Anıt Çevre Turizm Değerlerini Koruma Vakfı, 2001.

Yavuz, Ayş11. "Historic Buildings and Earthquake Factor in Their Design.” In Proceedings of the Seminar Protection of Architectural Heritage Against Earthquakes. 101-115. Ankara: Ministery of Public Works and Settlement, 1993.

Yavuz, H. Çiğdem, R. Nükhet Demirtaşlı, Seher Yalçın, and Münevver İlgün Dibek. "Türk Öğrencilerin TIMSS 2007 ve 2011 Matematik Başarısında Öğrenci ve Öğretmen Özelliklerinin Etkileri.” Ĕgitim ve Bilim 42, no. 189 (2017): 27-47.

Zhu, T. Yu., "Some Useful Numbers on the Engineering Properties of Materials." GEOL 615. Stanford University: Department of Geophysics, 2012.

Zoroğlu, Levent. Kelenderis I, Kaynaklar Kalıntılar Buluntular. Ankara: Dönmez Ofset Basımevi, 1994.

Zoroğlu, Levent. “Kelenderis'in İlk Çağ Tarihi Hakkında Notlar”, TTKY 9 (1994): 437448. 


\section{APPENDIX A}

\section{STONE CHARACTERIZATION}

Experimental studies are carried out with the six stone samples collected from the towers. During sampling, stones were collected by hand from the exterior sides of towers without harming their authenticity.

For the characterization of stone used in towers, mineralogical and chemical compositions are determined. For determination of mineralogical compositions of the stones, stone samples taken from the case study towers were investigated with X-ray Diffraction (XRD) analysis performed by using a Philips X-Pert Pro X-ray Diffractometer. Chemical compositions of the samples were determined by Philips XL 30S-FEG Scanning Electron Microscope (SEM) equipped with X-Ray Energy Dispersive System (EDS).

- Chemical Compositions of Stones

Major chemical compositions of stones were determined by SEM-EDS analysis.

Table A.1. Chemical composition of stone blocks of towers

\begin{tabular}{|c|c|c|c|c|c|c|c|}
\hline Sample from & $\mathbf{C a O} \%$ & $\mathbf{S i O}_{2} \%$ & $\mathbf{A l}_{2} \mathbf{O}_{3} \%$ & $\mathbf{M g O} \%$ & $\mathbf{N a}_{2} \mathbf{O} \%$ & $\mathbf{K}_{2} \mathbf{O} \%$ & $\mathbf{F e O ~ \% ~}$ \\
\hline Gömeç Tower & 97.96 & 1.29 & 0.75 & - & - & - & - \\
\hline Sarayın Tower & 96.89 & 2.24 & 0.87 & - & - & - & - \\
\hline Perge Tower & 97.56 & 1.35 & 0.57 & 0.52 & - & - & - \\
\hline Sillyon Tower & 96.65 & 1.78 & 0.62 & 0.95 & - & - & - \\
\hline Alinda Tower & 4.38 & 63.38 & 16.77 & 2.34 & 3.41 & 3.91 & 5.04 \\
\hline Latmos Tower & 1.21 & 62.95 & 22.03 & - & 4.65 & 7.90 & 1.27 \\
\hline
\end{tabular}

SEM/EDS analyses of the stone samples from Gömeç, Sarayın, Sillyon and Perge Towers show that stones were composed primarily of calcium oxide $(\mathrm{CaO})$. The minor elements were silica $\left(\mathrm{SiO}_{2}\right)$ and aluminum oxide $\left(\mathrm{Al}_{2} \mathrm{O}_{3}\right)$. The samples contain $97 \%$ calcium oxide $(\mathrm{CaO})$. Limestone contains higher than $56 \%$ calcium oxide. Major chemical compositions of stones were similar to the compositions of limestone (Weeks 194, 27; Nath and, Dutta 2010, 121) (Table A-1). 
SEM/EDS analyses of the stone samples from Alinda and Gömeç Towers show that stones were composed primarily of silica $\left(\mathrm{SiO}_{2}\right)$ and aluminum oxide $\left(\mathrm{Al}_{2} \mathrm{O}_{3}\right)$. The minor elements were aluminum oxide $\left(\mathrm{Al}_{2} \mathrm{O}_{3}\right)$, magnesium oxide $(\mathrm{MgO})$, sodium oxide $\left(\mathrm{Na}_{2} \mathrm{O}\right)$, potassium oxide $\left(\mathrm{K}_{2} \mathrm{O}\right)$ and iron oxide $(\mathrm{FeO})$. The samples contain $63 \%$ silica $\left(\mathrm{SiO}_{2}\right)$ and $16-20 \%$ aluminum oxide $\left(\mathrm{Al}_{2} \mathrm{O}_{3}\right)$. Major chemical compositions of stones were similar to the compositions of granite (Weeks 194, 19) (Table A-1).

- Mineralogical Compositions of Stones

Mineralogical characteristics of stones of towers were determined by XRD analysis.

XRD analyzes of stone samples from Perge, Sillyon, Gömeç and Sarayın Towers show that the stones are dominated by the minerals of calcite. Limestone is composed of mainly calcite (Karayazılı 2013,71-72) similar to stones from Perge, Sillyon, Gömeç and Sarayın Towers (Figure A-1).

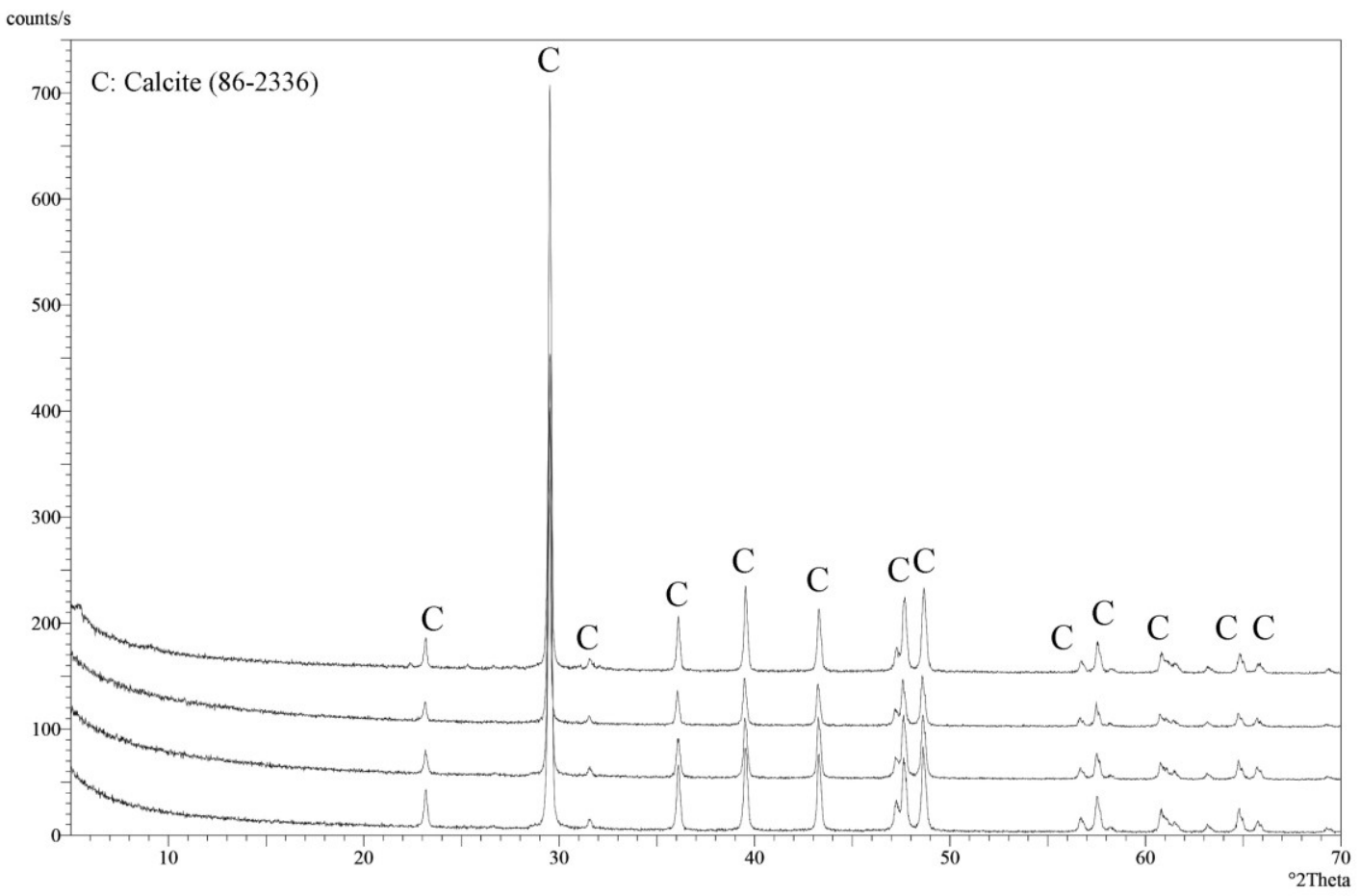

Figure A.1. XRD pattern of stones from Sillyon, Perge, Sarayın and Gömeç Towers (from bottom to the top) 
XRD analyzes of stone samples from Alinda and Latmos Towers show that the stones are dominated by the minerals of muscovite, quarts, albite and orthoclase. Granite is composed of mainly quartz, muscovite, and albite (Park et al. 2014, 246) similar to stones from Alinda and Latmos Towers, (Figure A-2).

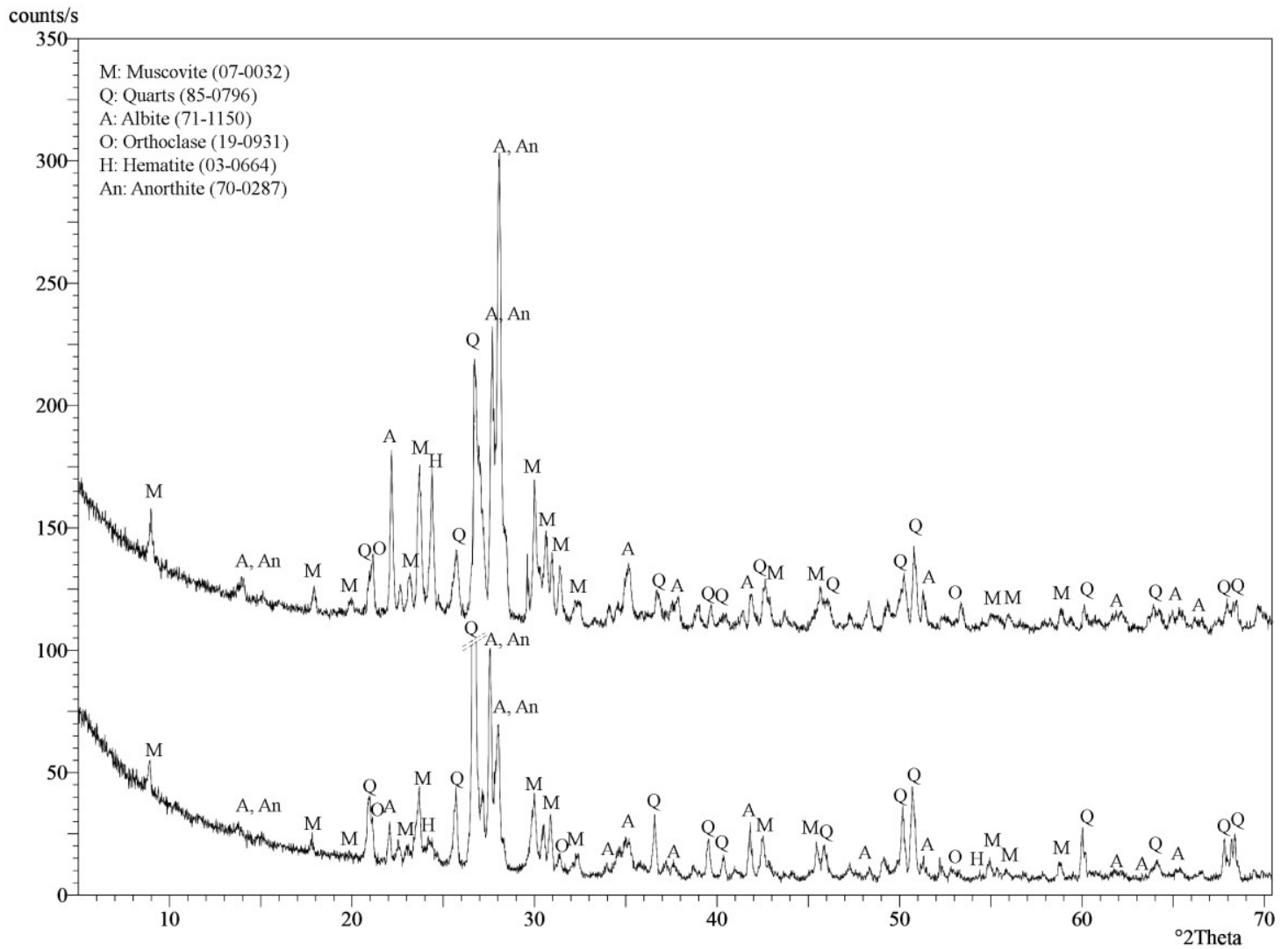

Figure A.2. XRD pattern of stones from Alinda (below) and Latmos (above) Towers 


\section{APPENDIX B}

\section{STATISTICAL EVALUATION}

Linearity of variables: Linear relationship between dependent variable and independent variables are determined before regression (Figure B-1).
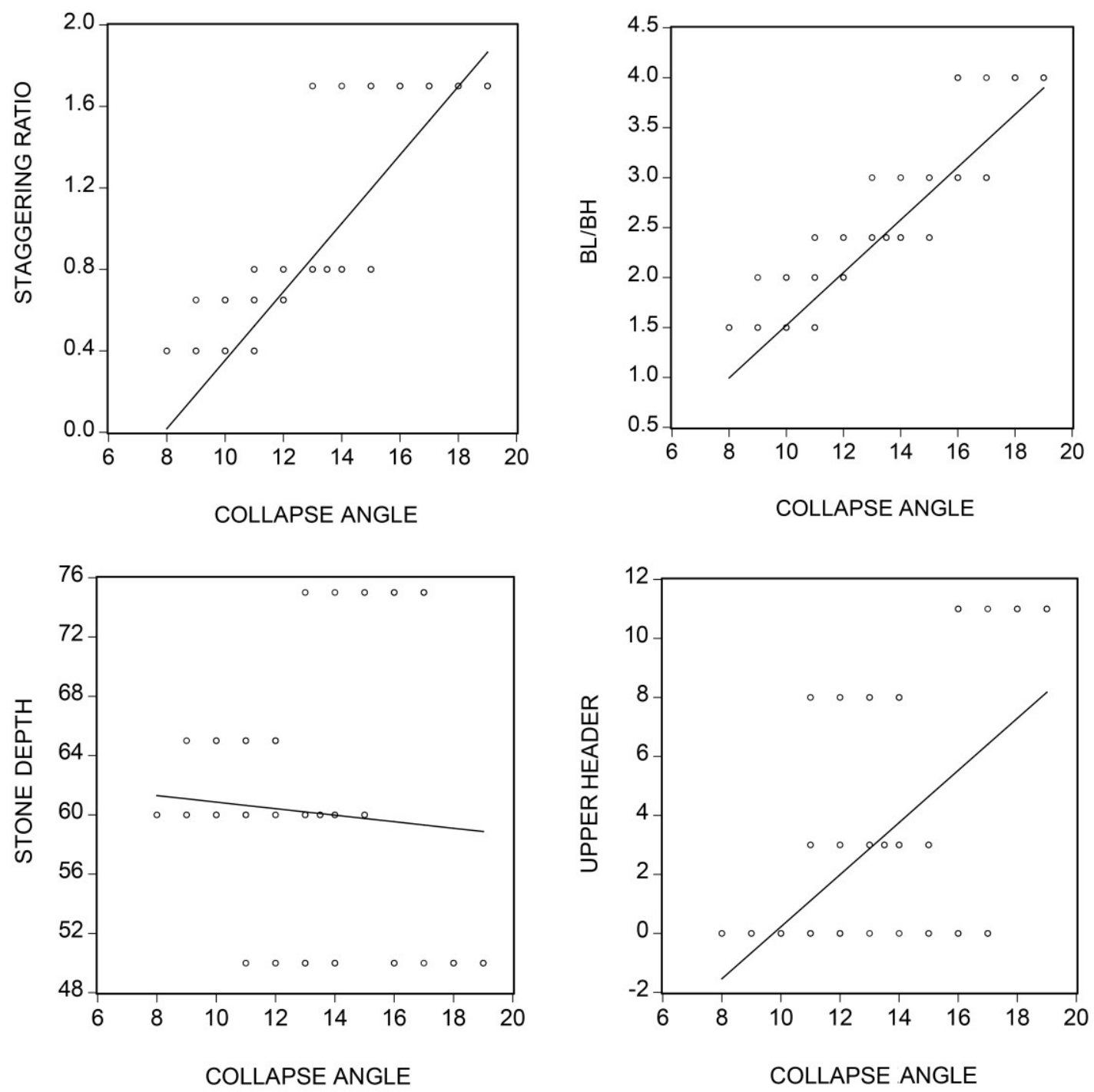

Figure B.1. Relationship of dependent and independent variables (staggering ratio and stone depth, stone ratio (bl/bh) and upper header) 


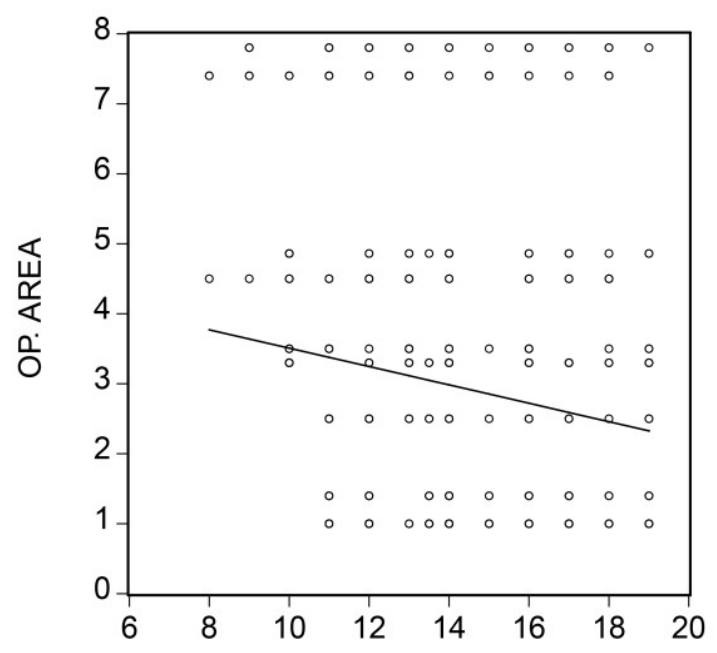

COLLAPSE ANGLE

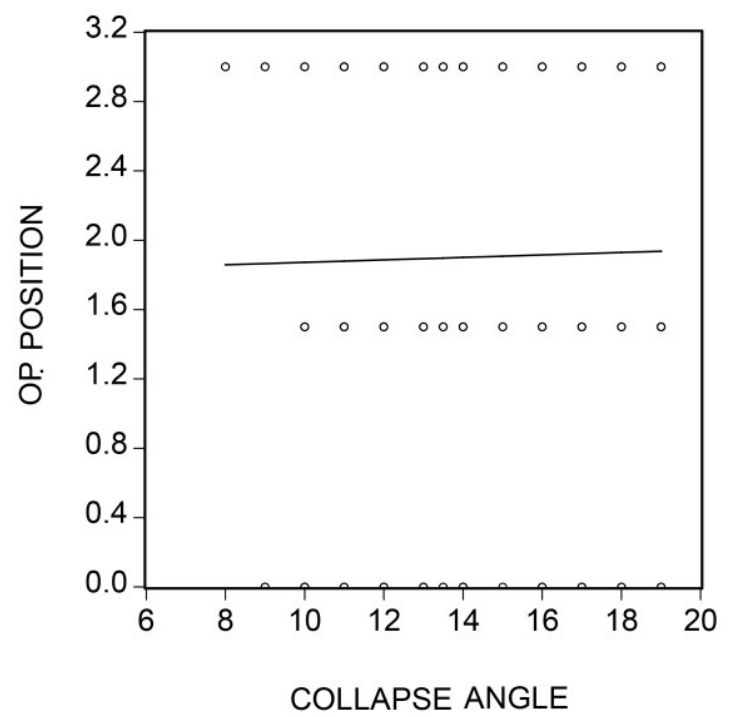

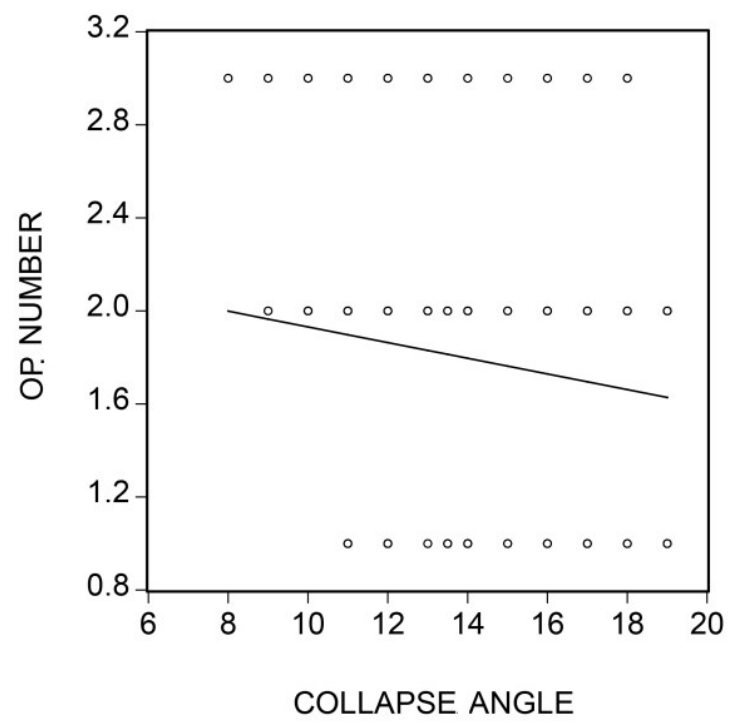

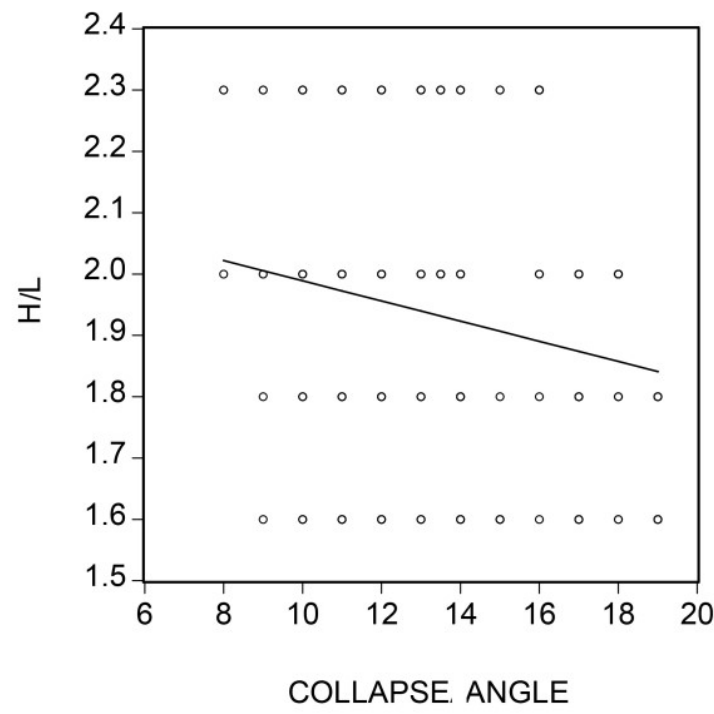

Figure B.2. Relationship of dependent and independent variables (op. area, op. position, op. number and $\mathrm{h} / \mathrm{l}$ ratio)

The residual plots: After regression analysis, before examining the statistical measures for goodness-of-fit, the residual plots are checked. When looking at residual (Residual $=$ Observed value - Fitted value) plots, if the points fall randomly around the line, then the model is not biased and correct on average. In the graph below, they are randomly scattered around zero for the entire range of fitted values (Figure B-2) (Minitab $\mathrm{B} \log 2012)$. 


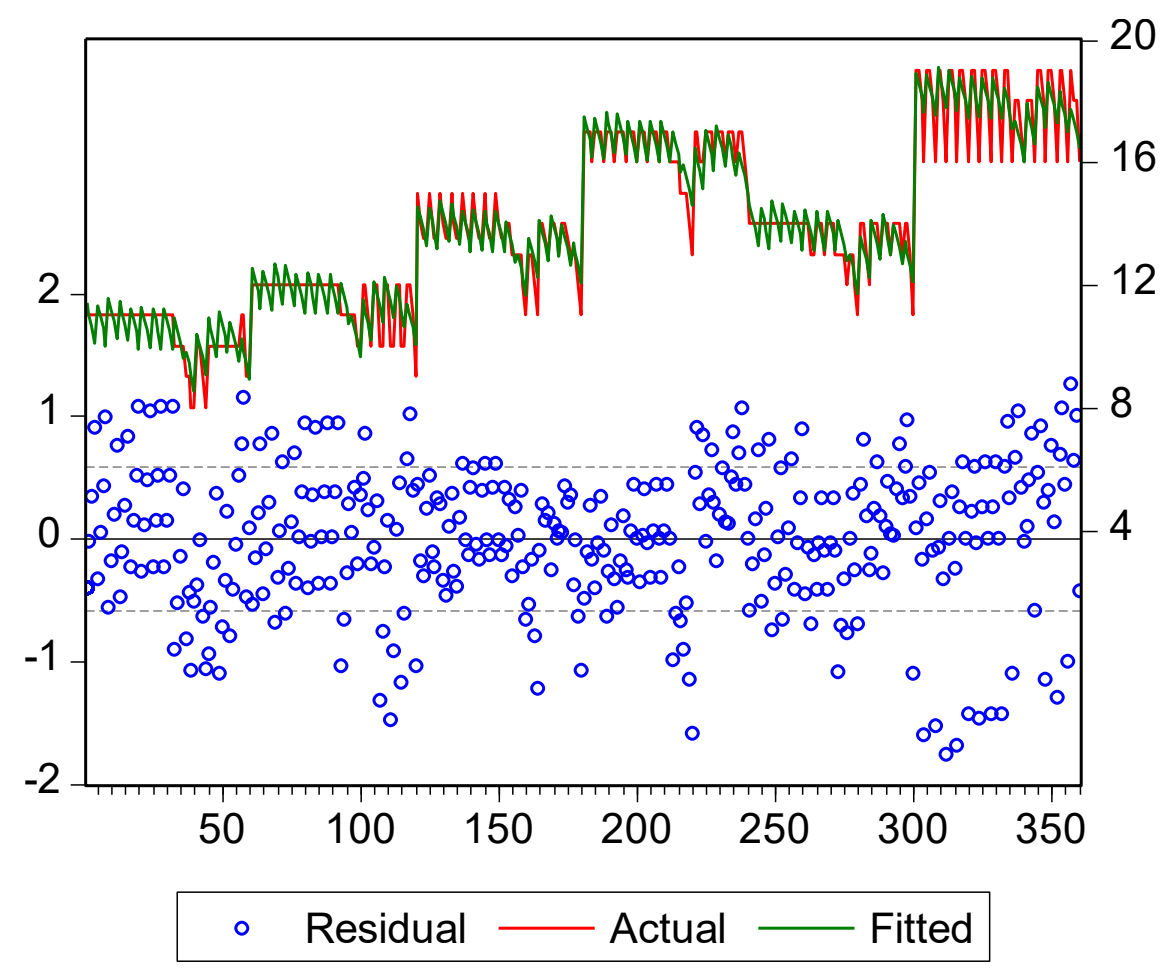

Figure B.3. Residuals 


\section{APPENDIX C \\ CALCULATION OF IMPACT VALUES OF PARAMETERS}

In order to compare the parameters with each other, an impact analysis is performed using the standard deviation value and coefficients of each parameter with the formula in the below (Table C-1): Impact value $=$ Coefficient of independent v. $x$ Standard Deviation (Independent v.) /Standard Deviation (Dependent v.)

Standard deviation of dependent variable (collapse angle) $=2.76$

Table C.1. Calculation of impact values of coefficients

\begin{tabular}{lccc||cc}
$\begin{array}{l}\text { Independent } \\
\text { variables }\end{array}$ & coefficients & SD (indep.) & SD (dep.) & Impact value & x10 \\
Staggering ratio & 2.3 & 0.531265 & 2.76 & 0.442064498 & 4.4 \\
Stone depth & 0.1 & 8.672307 & 2.76 & 0.313748298 & 3.1 \\
bl/bh & 0.8 & 0.825027 & 2.76 & 0.238783691 & 2.4 \\
Upper header & 0.4 & 0.043522 & 2.76 & 0.006298164 & 0.1 \\
Op. number & -0.17 & 0.654106 & 2.76 & -0.040229444 & -0.4 \\
Op. position & -0.1 & 1.159195 & 2.76 & -0.041937559 & -0.4 \\
Op. area & -0.19 & 2.222842 & 2.76 & -0.15279489 & -1.5 \\
h/1 & -1.9 & 0.258962 & 2.76 & -0.178006657 & -1.8
\end{tabular}




\section{APPENDIX D}

\section{DATA SET FOR REGRESSION}

Table D.1. Data set for regression

\begin{tabular}{|c|c|c|c|c|c|c|c|c|c|c|}
\hline $\begin{array}{l}\text { w. p. } \\
\text { type }\end{array}$ & op. type & $\begin{array}{c}\text { collapse } \\
\text { angle }\end{array}$ & $h / l$ & $\begin{array}{c}\text { staggering } \\
\text { ratio }\end{array}$ & bl/bh & $\begin{array}{l}\text { stone } \\
\text { depth }\end{array}$ & $\begin{array}{c}\text { upper } \\
\text { header }\end{array}$ & $\begin{array}{c}\text { op. } \\
\text { number }\end{array}$ & $\begin{array}{c}\begin{array}{c}\text { op. } \\
\text { position }\end{array} \\
\end{array}$ & $\begin{array}{c}\text { op. } \\
\text { area }\end{array}$ \\
\hline \multirow[t]{35}{*}{ wallp1 } & op. 1-4 & 11 & 1.6 & 0.4 & 1.5 & 60 & 0 & 1 & 3 & 1 \\
\hline & & 11 & 1.8 & 0.4 & 1.5 & 60 & 0 & 1 & 3 & 1 \\
\hline & & 11 & 2 & 0.4 & 1.5 & 60 & 0 & 1 & 3 & 1 \\
\hline & & 11 & 2.3 & 0.4 & 1.5 & 60 & 0 & 1 & 3 & 1 \\
\hline & op. 2 & 11 & 1.6 & 0.4 & 1.5 & 60 & 0 & 1 & 3 & 1.4 \\
\hline & & 11 & 1.8 & 0.4 & 1.5 & 60 & 0 & 1 & 3 & 1.4 \\
\hline & & 11 & 2 & 0.4 & 1.5 & 60 & 0 & 1 & 3 & 1.4 \\
\hline & & 11 & 2.3 & 0.4 & 1.5 & 60 & 0 & 1 & 3 & 1.4 \\
\hline & op. 3 & 11 & 1.6 & 0.4 & 1.5 & 60 & 0 & 1 & 1.5 & 1 \\
\hline & & 11 & 1.8 & 0.4 & 1.5 & 60 & 0 & 1 & 1.5 & 1 \\
\hline & & 11 & 2 & 0.4 & 1.5 & 60 & 0 & 1 & 1.5 & 1 \\
\hline & & 11 & 2.3 & 0.4 & 1.5 & 60 & 0 & 1 & 1.5 & 1 \\
\hline & op. 4 & 11 & 1.6 & 0.4 & 1.5 & 60 & 0 & 1 & 1.5 & 1.4 \\
\hline & & 11 & 1.8 & 0.4 & 1.5 & 60 & 0 & 1 & 1.5 & 1.4 \\
\hline & & 11 & 2 & 0.4 & 1.5 & 60 & 0 & 1 & 1.5 & 1.4 \\
\hline & & 11 & 2.3 & 0.4 & 1.5 & 60 & 0 & 1 & 1.5 & 1.4 \\
\hline & op. 5 & 11 & 1.6 & 0.4 & 1.5 & 60 & 0 & 2 & 3 & 1 \\
\hline & & 11 & 1.8 & 0.4 & 1.5 & 60 & 0 & 2 & 3 & 1 \\
\hline & & 11 & 2 & 0.4 & 1.5 & 60 & 0 & 2 & 3 & 1 \\
\hline & & 11 & 2.3 & 0.4 & 1.5 & 60 & 0 & 2 & 3 & 1 \\
\hline & op. 6 & 11 & 1.6 & 0.4 & 1.5 & 60 & 0 & 1 & 1.5 & 2.5 \\
\hline & & 11 & 1.8 & 0.4 & 1.5 & 60 & 0 & 1 & 1.5 & 2.5 \\
\hline & & 11 & 2 & 0.4 & 1.5 & 60 & 0 & 1 & 1.5 & 2.5 \\
\hline & & 11 & 2.3 & 0.4 & 1.5 & 60 & 0 & 1 & 1.5 & 2.5 \\
\hline & op. 7-8 & 11 & 1.6 & 0.4 & 1.5 & 60 & 0 & 2 & 3 & 1 \\
\hline & & 11 & 1.8 & 0.4 & 1.5 & 60 & 0 & 2 & 3 & 1 \\
\hline & & 11 & 2 & 0.4 & 1.5 & 60 & 0 & 2 & 3 & 1 \\
\hline & & 11 & 2.3 & 0.4 & 1.5 & 60 & 0 & 2 & 3 & 1 \\
\hline & op. 8 & 11 & 1.6 & 0.4 & 1.5 & 60 & 0 & 2 & 3 & 1 \\
\hline & & 11 & 1.8 & 0.4 & 1.5 & 60 & 0 & 2 & 3 & 1 \\
\hline & & 11 & 2 & 0.4 & 1.5 & 60 & 0 & 2 & 3 & 1 \\
\hline & & 11 & 2.3 & 0.4 & 1.5 & 60 & 0 & 2 & 3 & 1 \\
\hline & op. 9 & 10 & 1.6 & 0.4 & 1.5 & 60 & 0 & 2 & 1.5 & 3.5 \\
\hline & & 10 & 1.8 & 0.4 & 1.5 & 60 & 0 & 2 & 1.5 & 3.5 \\
\hline & & 10 & 2 & 0.4 & 1.5 & 60 & 0 & 2 & 1.5 & 3.5 \\
\hline
\end{tabular}

(cont. on next page) 
Table D.1. (cont.)

\begin{tabular}{|c|c|c|c|c|c|c|c|c|c|c|}
\hline & & 10 & 2.3 & 0.4 & 1.5 & 60 & 0 & 2 & 1.5 & 3.5 \\
\hline & op. 10 & 9 & 1.6 & 0.4 & 1.5 & 60 & 0 & 3 & 3 & 7.4 \\
\hline & & 9 & 1.8 & 0.4 & 1.5 & 60 & 0 & 3 & 3 & 7.4 \\
\hline & & 8 & 2 & 0.4 & 1.5 & 60 & 0 & 3 & 3 & 7.4 \\
\hline & & 8 & 2.3 & 0.4 & 1.5 & 60 & 0 & 3 & 3 & 7.4 \\
\hline & op. 11 & 10 & 1.6 & 0.4 & 1.5 & 60 & 0 & 3 & 3 & 4.5 \\
\hline & & 10 & 1.8 & 0.4 & 1.5 & 60 & 0 & 3 & 3 & 4.5 \\
\hline & & 9 & 2 & 0.4 & 1.5 & 60 & 0 & 3 & 3 & 4.5 \\
\hline & & 8 & 2.3 & 0.4 & 1.5 & 60 & 0 & 3 & 3 & 4.5 \\
\hline & op. 12 & 10 & 1.6 & 0.4 & 1.5 & 60 & 0 & 2 & 1.5 & 3.3 \\
\hline & & 10 & 1.8 & 0.4 & 1.5 & 60 & 0 & 2 & 1.5 & 3.3 \\
\hline & & 10 & 2 & 0.4 & 1.5 & 60 & 0 & 2 & 1.5 & 3.3 \\
\hline & & 10 & 2.3 & 0.4 & 1.5 & 60 & 0 & 2 & 1.5 & 3.3 \\
\hline & op. 13 & 10 & 1.6 & 0.4 & 1.5 & 60 & 0 & 2 & 0 & 3.3 \\
\hline & & 10 & 1.8 & 0.4 & 1.5 & 60 & 0 & 2 & 0 & 3.3 \\
\hline & & 10 & 2 & 0.4 & 1.5 & 60 & 0 & 2 & 0 & 3.3 \\
\hline & & 10 & 2.3 & 0.4 & 1.5 & 60 & 0 & 2 & 0 & 3.3 \\
\hline & op. 14 & 10 & 1.6 & 0.4 & 1.5 & 60 & 0 & 2 & 0 & 4.86 \\
\hline & & 10 & 1.8 & 0.4 & 1.5 & 60 & 0 & 2 & 0 & 4.86 \\
\hline & & 10 & 2 & 0.4 & 1.5 & 60 & 0 & 2 & 0 & 4.86 \\
\hline & & 10 & 2.3 & 0.4 & 1.5 & 60 & 0 & 2 & 0 & 4.86 \\
\hline & op. 15 & 11 & 1.6 & 0.4 & 1.5 & 60 & 0 & 2 & 0 & 7.8 \\
\hline & & 11 & 1.8 & 0.4 & 1.5 & 60 & 0 & 2 & 0 & 7.8 \\
\hline & & 9 & 2 & 0.4 & 1.5 & 60 & 0 & 2 & 0 & 7.8 \\
\hline & & 9 & 2.3 & 0.4 & 1.5 & 60 & 0 & 2 & 0 & 7.8 \\
\hline wallp2 & op. 1-4 & 12 & 1.6 & 0.65 & 2 & 65 & 0 & 1 & 3 & 1 \\
\hline & & 12 & 1.8 & 0.65 & 2 & 65 & 0 & 1 & 3 & 1 \\
\hline & & 12 & 2 & 0.65 & 2 & 65 & 0 & 1 & 3 & 1 \\
\hline & & 12 & 2.3 & 0.65 & 2 & 65 & 0 & 1 & 3 & 1 \\
\hline & op. 2 & 12 & 1.6 & 0.65 & 2 & 65 & 0 & 1 & 3 & 1.4 \\
\hline & & 12 & 1.8 & 0.65 & 2 & 65 & 0 & 1 & 3 & 1.4 \\
\hline & & 12 & 2 & 0.65 & 2 & 65 & 0 & 1 & 3 & 1.4 \\
\hline & & 12 & 2.3 & 0.65 & 2 & 65 & 0 & 1 & 3 & 1.4 \\
\hline & op. 3 & 12 & 1.6 & 0.65 & 2 & 65 & 0 & 1 & 1.5 & 1 \\
\hline & & 12 & 1.8 & 0.65 & 2 & 65 & 0 & 1 & 1.5 & 1 \\
\hline & & 12 & 2 & 0.65 & 2 & 65 & 0 & 1 & 1.5 & 1 \\
\hline & & 12 & 2.3 & 0.65 & 2 & 65 & 0 & 1 & 1.5 & 1 \\
\hline & op. 4 & 12 & 1.6 & 0.65 & 2 & 65 & 0 & 1 & 1.5 & 1.4 \\
\hline & & 12 & 1.8 & 0.65 & 2 & 65 & 0 & 1 & 1.5 & 1.4 \\
\hline & & 12 & 2 & 0.65 & 2 & 65 & 0 & 1 & 1.5 & 1.4 \\
\hline & & 12 & 2.3 & 0.65 & 2 & 65 & 0 & 1 & 1.5 & 1.4 \\
\hline & op. 5 & 12 & 1.6 & 0.65 & 2 & 65 & 0 & 2 & 3 & 1 \\
\hline & & 12 & 1.8 & 0.65 & 2 & 65 & 0 & 2 & 3 & 1 \\
\hline
\end{tabular}

(cont. on next page) 
Table D.1. (cont.)

\begin{tabular}{|c|c|c|c|c|c|c|c|c|c|c|}
\hline & & 12 & 2 & 0.65 & 2 & 65 & 0 & 2 & 3 & 1 \\
\hline & & 12 & 2.3 & 0.65 & 2 & 65 & 0 & 2 & 3 & 1 \\
\hline & op. 6 & 12 & 1.6 & 0.65 & 2 & 65 & 0 & 1 & 1.5 & 2.5 \\
\hline & & 12 & 1.8 & 0.65 & 2 & 65 & 0 & 1 & 1.5 & 2.5 \\
\hline & & 12 & 2 & 0.65 & 2 & 65 & 0 & 1 & 1.5 & 2.5 \\
\hline & & 12 & 2.3 & 0.65 & 2 & 65 & 0 & 1 & 1.5 & 2.5 \\
\hline & op. 7-8 & 12 & 1.6 & 0.65 & 2 & 65 & 0 & 2 & 3 & 1 \\
\hline & & 12 & 1.8 & 0.65 & 2 & 65 & 0 & 2 & 3 & 1 \\
\hline & & 12 & 2 & 0.65 & 2 & 65 & 0 & 2 & 3 & 1 \\
\hline & & 12 & 2.3 & 0.65 & 2 & 65 & 0 & 2 & 3 & 1 \\
\hline & op. 8 & 12 & 1.6 & 0.65 & 2 & 65 & 0 & 2 & 3 & 1 \\
\hline & & 12 & 1.8 & 0.65 & 2 & 65 & 0 & 2 & 3 & 1 \\
\hline & & 12 & 2 & 0.65 & 2 & 65 & 0 & 2 & 3 & 1 \\
\hline & & 12 & 2.3 & 0.65 & 2 & 65 & 0 & 2 & 3 & 1 \\
\hline & op. 9 & 11 & 1.6 & 0.65 & 2 & 65 & 0 & 2 & 1.5 & 3.5 \\
\hline & & 11 & 1.8 & 0.65 & 2 & 65 & 0 & 2 & 1.5 & 3.5 \\
\hline & & 11 & 2 & 0.65 & 2 & 65 & 0 & 2 & 1.5 & 3.5 \\
\hline & & 11 & 2.3 & 0.65 & 2 & 65 & 0 & 2 & 1.5 & 3.5 \\
\hline & op. 10 & 11 & 1.6 & 0.65 & 2 & 65 & 0 & 3 & 3 & 7.4 \\
\hline & & 11 & 1.8 & 0.65 & 2 & 65 & 0 & 3 & 3 & 7.4 \\
\hline & & 10 & 2 & 0.65 & 2 & 65 & 0 & 3 & 3 & 7.4 \\
\hline & & 10 & 2.3 & 0.65 & 2 & 65 & 0 & 3 & 3 & 7.4 \\
\hline & op. 11 & 12 & 1.6 & 0.65 & 2 & 65 & 0 & 3 & 3 & 4.5 \\
\hline & & 12 & 1.8 & 0.65 & 2 & 65 & 0 & 3 & 3 & 4.5 \\
\hline & & 11 & 2 & 0.65 & 2 & 65 & 0 & 3 & 3 & 4.5 \\
\hline & & 10 & 2.3 & 0.65 & 2 & 65 & 0 & 3 & 3 & 4.5 \\
\hline & op. 12 & 12 & 1.6 & 0.65 & 2 & 65 & 0 & 2 & 1.5 & 3.3 \\
\hline & & 12 & 1.8 & 0.65 & 2 & 65 & 0 & 2 & 1.5 & 3.3 \\
\hline & & 10 & 2 & 0.65 & 2 & 65 & 0 & 2 & 1.5 & 3.3 \\
\hline & & 10 & 2.3 & 0.65 & 2 & 65 & 0 & 2 & 1.5 & 3.3 \\
\hline & op. 13 & 12 & 1.6 & 0.65 & 2 & 65 & 0 & 2 & 0 & 3.3 \\
\hline & & 12 & 1.8 & 0.65 & 2 & 65 & 0 & 2 & 0 & 3.3 \\
\hline & & 10 & 2 & 0.65 & 2 & 65 & 0 & 2 & 0 & 3.3 \\
\hline & & 10 & 2.3 & 0.65 & 2 & 65 & 0 & 2 & 0 & 3.3 \\
\hline & op. 14 & 12 & 1.6 & 0.65 & 2 & 65 & 0 & 2 & 0 & 4.86 \\
\hline & & 12 & 1.8 & 0.65 & 2 & 65 & 0 & 2 & 0 & 4.86 \\
\hline & & 10 & 2 & 0.65 & 2 & 65 & 0 & 2 & 0 & 4.86 \\
\hline & & 10 & 2.3 & 0.65 & 2 & 65 & 0 & 2 & 0 & 4.86 \\
\hline & op. 15 & 12 & 1.6 & 0.65 & 2 & 65 & 0 & 2 & 0 & 7.8 \\
\hline & & 12 & 1.8 & 0.65 & 2 & 65 & 0 & 2 & 0 & 7.8 \\
\hline & & 11 & 2 & 0.65 & 2 & 65 & 0 & 2 & 0 & 7.8 \\
\hline & & 9 & 2.3 & 0.65 & 2 & 65 & 0 & 2 & 0 & 7.8 \\
\hline wallp3 & op. 1-4 & 15 & 1.6 & 0.8 & 2.4 & 60 & $3 \%$ & 1 & 3 & 1 \\
\hline
\end{tabular}

(cont. on next page) 
Table D.1. (cont.)

\begin{tabular}{|c|c|c|c|c|c|c|c|c|c|}
\hline & 14 & 1.8 & 0.8 & 2.4 & 60 & $3 \%$ & 1 & 3 & 1 \\
\hline & 13.5 & 2 & 0.8 & 2.4 & 60 & $3 \%$ & 1 & 3 & 1 \\
\hline & 13.5 & 2.3 & 0.8 & 2.4 & 60 & $3 \%$ & 1 & 3 & 1 \\
\hline op. 2 & 15 & 1.6 & 0.8 & 2.4 & 60 & $3 \%$ & 1 & 3 & 1.4 \\
\hline & 14 & 1.8 & 0.8 & 2.4 & 60 & $3 \%$ & 1 & 3 & 1.4 \\
\hline & 13.5 & 2 & 0.8 & 2.4 & 60 & $3 \%$ & 1 & 3 & 1.4 \\
\hline & 13.5 & 2.3 & 0.8 & 2.4 & 60 & $3 \%$ & 1 & 3 & 1.4 \\
\hline op. 3 & 15 & 1.6 & 0.8 & 2.4 & 60 & $3 \%$ & 1 & 1.5 & 1 \\
\hline & 14 & 1.8 & 0.8 & 2.4 & 60 & $3 \%$ & 1 & 1.5 & 1 \\
\hline & 13.5 & 2 & 0.8 & 2.4 & 60 & $3 \%$ & 1 & 1.5 & 1 \\
\hline & 13.5 & 2.3 & 0.8 & 2.4 & 60 & $3 \%$ & 1 & 1.5 & 1 \\
\hline op. 4 & 15 & 1.6 & 0.8 & 2.4 & 60 & $3 \%$ & 1 & 1.5 & 1.4 \\
\hline & 14 & 1.8 & 0.8 & 2.4 & 60 & $3 \%$ & 1 & 1.5 & 1.4 \\
\hline & 13.5 & 2 & 0.8 & 2.4 & 60 & $3 \%$ & 1 & 1.5 & 1.4 \\
\hline & 13.5 & 2.3 & 0.8 & 2.4 & 60 & $3 \%$ & 1 & 1.5 & 1.4 \\
\hline op. 5 & 15 & 1.6 & 0.8 & 2.4 & 60 & $3 \%$ & 2 & 3 & 1 \\
\hline & 14 & 1.8 & 0.8 & 2.4 & 60 & $3 \%$ & 2 & 3 & 1 \\
\hline & 13.5 & 2 & 0.8 & 2.4 & 60 & $3 \%$ & 2 & 3 & 1 \\
\hline & 13.5 & 2.3 & 0.8 & 2.4 & 60 & $3 \%$ & 2 & 3 & 1 \\
\hline op. 6 & 15 & 1.6 & 0.8 & 2.4 & 60 & $3 \%$ & 1 & 1.5 & 2.5 \\
\hline & 14 & 1.8 & 0.8 & 2.4 & 60 & $3 \%$ & 1 & 1.5 & 2.5 \\
\hline & 13.5 & 2 & 0.8 & 2.4 & 60 & $3 \%$ & 1 & 1.5 & 2.5 \\
\hline & 13.5 & 2.3 & 0.8 & 2.4 & 60 & $3 \%$ & 1 & 1.5 & 2.5 \\
\hline op. 7-8 & 15 & 1.6 & 0.8 & 2.4 & 60 & $3 \%$ & 2 & 3 & 1 \\
\hline & 14 & 1.8 & 0.8 & 2.4 & 60 & $3 \%$ & 2 & 3 & 1 \\
\hline & 13.5 & 2 & 0.8 & 2.4 & 60 & $3 \%$ & 2 & 3 & 1 \\
\hline & 13.5 & 2.3 & 0.8 & 2.4 & 60 & $3 \%$ & 2 & 3 & 1 \\
\hline op. 8 & 15 & 1.6 & 0.8 & 2.4 & 60 & $3 \%$ & 2 & 3 & 1 \\
\hline & 14 & 1.8 & 0.8 & 2.4 & 60 & $3 \%$ & 2 & 3 & 1 \\
\hline & 13.5 & 2 & 0.8 & 2.4 & 60 & $3 \%$ & 2 & 3 & 1 \\
\hline & 13.5 & 2.3 & 0.8 & 2.4 & 60 & $3 \%$ & 2 & 3 & 1 \\
\hline op. 9 & 14 & 1.6 & 0.8 & 2.4 & 60 & $3 \%$ & 2 & 1.5 & 3.5 \\
\hline & 14 & 1.8 & 0.8 & 2.4 & 60 & $3 \%$ & 2 & 1.5 & 3.5 \\
\hline & 13 & 2 & 0.8 & 2.4 & 60 & $3 \%$ & 2 & 1.5 & 3.5 \\
\hline & 13 & 2.3 & 0.8 & 2.4 & 60 & $3 \%$ & 2 & 1.5 & 3.5 \\
\hline op. 10 & 13 & 1.6 & 0.8 & 2.4 & 60 & $3 \%$ & 3 & 3 & 7.4 \\
\hline & 13 & 1.8 & 0.8 & 2.4 & 60 & $3 \%$ & 3 & 3 & 7.4 \\
\hline & 12 & 2 & 0.8 & 2.4 & 60 & $3 \%$ & 3 & 3 & 7.4 \\
\hline & 11 & 2.3 & 0.8 & 2.4 & 60 & $3 \%$ & 3 & 3 & 7.4 \\
\hline op. 11 & 13 & 1.6 & 0.8 & 2.4 & 60 & $3 \%$ & 3 & 3 & 4.5 \\
\hline & 13 & 1.8 & 0.8 & 2.4 & 60 & $3 \%$ & 3 & 3 & 4.5 \\
\hline & 12 & 2 & 0.8 & 2.4 & 60 & $3 \%$ & 3 & 3 & 4.5 \\
\hline & 11 & 2.3 & 0.8 & 2.4 & 60 & $3 \%$ & 3 & 3 & 4.5 \\
\hline
\end{tabular}

(cont. on next page) 
Table D.1. (cont.)

\begin{tabular}{|c|c|c|c|c|c|c|c|c|c|c|}
\hline & op. 12 & 14 & 1.6 & 0.8 & 2.4 & 60 & $3 \%$ & 2 & 1.5 & 3.3 \\
\hline & & 14 & 1.8 & 0.8 & 2.4 & 60 & $3 \%$ & 2 & 1.5 & 3.3 \\
\hline & & 13.5 & 2 & 0.8 & 2.4 & 60 & $3 \%$ & 2 & 1.5 & 3.3 \\
\hline & & 13 & 2.3 & 0.8 & 2.4 & 60 & $3 \%$ & 2 & 1.5 & 3.3 \\
\hline & op. 13 & 14 & 1.6 & 0.8 & 2.4 & 60 & $3 \%$ & 2 & 0 & 3.3 \\
\hline & & 14 & 1.8 & 0.8 & 2.4 & 60 & $3 \%$ & 2 & 0 & 3.3 \\
\hline & & 13.5 & 2 & 0.8 & 2.4 & 60 & $3 \%$ & 2 & 0 & 3.3 \\
\hline & & 13 & 2.3 & 0.8 & 2.4 & 60 & $3 \%$ & 2 & 0 & 3.3 \\
\hline & op. 14 & 14 & 1.6 & 0.8 & 2.4 & 60 & $3 \%$ & 2 & 0 & 4.86 \\
\hline & & 14 & 1.8 & 0.8 & 2.4 & 60 & $3 \%$ & 2 & 0 & 4.86 \\
\hline & & 13.5 & 2 & 0.8 & 2.4 & 60 & $3 \%$ & 2 & 0 & 4.86 \\
\hline & & 13 & 2.3 & 0.8 & 2.4 & 60 & $3 \%$ & 2 & 0 & 4.86 \\
\hline & op. 15 & 13 & 1.6 & 0.8 & 2.4 & 60 & $3 \%$ & 2 & 0 & 7.8 \\
\hline & & 13 & 1.8 & 0.8 & 2.4 & 60 & $3 \%$ & 2 & 0 & 7.8 \\
\hline & & 12 & 2 & 0.8 & 2.4 & 60 & $3 \%$ & 2 & 0 & 7.8 \\
\hline & & 11 & 2.3 & 0.8 & 2.4 & 60 & $3 \%$ & 2 & 0 & 7.8 \\
\hline wallp4 & op. 1-4 & 17 & 1.6 & 1.7 & 3 & 75 & 0 & 1 & 3 & 1 \\
\hline & & 17 & 1.8 & 1.7 & 3 & 75 & 0 & 1 & 3 & 1 \\
\hline & & 17 & 2 & 1.7 & 3 & 75 & 0 & 1 & 3 & 1 \\
\hline & & 16 & 2.3 & 1.7 & 3 & 75 & 0 & 1 & 3 & 1 \\
\hline & op. 2 & 17 & 1.6 & 1.7 & 3 & 75 & 0 & 1 & 3 & 1.4 \\
\hline & & 17 & 1.8 & 1.7 & 3 & 75 & 0 & 1 & 3 & 1.4 \\
\hline & & 17 & 2 & 1.7 & 3 & 75 & 0 & 1 & 3 & 1.4 \\
\hline & & 16 & 2.3 & 1.7 & 3 & 75 & 0 & 1 & 3 & 1.4 \\
\hline & op. 3 & 17 & 1.6 & 1.7 & 3 & 75 & 0 & 1 & 1.5 & 1 \\
\hline & & 17 & 1.8 & 1.7 & 3 & 75 & 0 & 1 & 1.5 & 1 \\
\hline & & 17 & 2 & 1.7 & 3 & 75 & 0 & 1 & 1.5 & 1 \\
\hline & & 16 & 2.3 & 1.7 & 3 & 75 & 0 & 1 & 1.5 & 1 \\
\hline & op. 4 & 17 & 1.6 & 1.7 & 3 & 75 & 0 & 1 & 1.5 & 1.4 \\
\hline & & 17 & 1.8 & 1.7 & 3 & 75 & 0 & 1 & 1.5 & 1.4 \\
\hline & & 17 & 2 & 1.7 & 3 & 75 & 0 & 1 & 1.5 & 1.4 \\
\hline & & 16 & 2.3 & 1.7 & 3 & 75 & 0 & 1 & 1.5 & 1.4 \\
\hline & op. 5 & 17 & 1.6 & 1.7 & 3 & 75 & 0 & 2 & 3 & 1 \\
\hline & & 17 & 1.8 & 1.7 & 3 & 75 & 0 & 2 & 3 & 1 \\
\hline & & 17 & 2 & 1.7 & 3 & 75 & 0 & 2 & 3 & 1 \\
\hline & & 16 & 2.3 & 1.7 & 3 & 75 & 0 & 2 & 3 & 1 \\
\hline & op. 6 & 17 & 1.6 & 1.7 & 3 & 75 & 0 & 1 & 1.5 & 2.5 \\
\hline & & 17 & 1.8 & 1.7 & 3 & 75 & 0 & 1 & 1.5 & 2.5 \\
\hline & & 17 & 2 & 1.7 & 3 & 75 & 0 & 1 & 1.5 & 2.5 \\
\hline & & 16 & 2.3 & 1.7 & 3 & 75 & 0 & 1 & 1.5 & 2.5 \\
\hline & op. 7-8 & 17 & 1.6 & 1.7 & 3 & 75 & 0 & 2 & 3 & 1 \\
\hline & & 17 & 1.8 & 1.7 & 3 & 75 & 0 & 2 & 3 & 1 \\
\hline & & 17 & 2 & 1.7 & 3 & 75 & 0 & 2 & 3 & 1 \\
\hline
\end{tabular}

(cont. on next page) 
Table D.1. (cont.)

\begin{tabular}{|c|c|c|c|c|c|c|c|c|c|c|}
\hline & & 16 & 2.3 & 1.7 & 3 & 75 & 0 & 2 & 3 & 1 \\
\hline & op. 8 & 17 & 1.6 & 1.7 & 3 & 75 & 0 & 2 & 3 & 1 \\
\hline & & 17 & 1.8 & 1.7 & 3 & 75 & 0 & 2 & 3 & 1 \\
\hline & & 17 & 2 & 1.7 & 3 & 75 & 0 & 2 & 3 & 1 \\
\hline & & 16 & 2.3 & 1.7 & 3 & 75 & 0 & 2 & 3 & 1 \\
\hline & op. 9 & 16 & 1.6 & 1.7 & 3 & 75 & 0 & 2 & 1.5 & 3.5 \\
\hline & & 16 & 1.8 & 1.7 & 3 & 75 & 0 & 2 & 1.5 & 3.5 \\
\hline & & 16 & 2 & 1.7 & 3 & 75 & 0 & 2 & 1.5 & 3.5 \\
\hline & & 15 & 2.3 & 1.7 & 3 & 75 & 0 & 2 & 1.5 & 3.5 \\
\hline & op. 10 & 15 & 1.6 & 1.7 & 3 & 75 & 0 & 3 & 3 & 7.4 \\
\hline & & 15 & 1.8 & 1.7 & 3 & 75 & 0 & 3 & 3 & 7.4 \\
\hline & & 14 & 2 & 1.7 & 3 & 75 & 0 & 3 & 3 & 7.4 \\
\hline & & 13 & 2.3 & 1.7 & 3 & 75 & 0 & 3 & 3 & 7.4 \\
\hline & op. 11 & 17 & 1.6 & 1.7 & 3 & 75 & 0 & 3 & 3 & 4.5 \\
\hline & & 17 & 1.8 & 1.7 & 3 & 75 & 0 & 3 & 3 & 4.5 \\
\hline & & 16 & 2 & 1.7 & 3 & 75 & 0 & 3 & 3 & 4.5 \\
\hline & & 16 & 2.3 & 1.7 & 3 & 75 & 0 & 3 & 3 & 4.5 \\
\hline & op. 12 & 17 & 1.6 & 1.7 & 3 & 75 & 0 & 2 & 1.5 & 3.3 \\
\hline & & 17 & 1.8 & 1.7 & 3 & 75 & 0 & 2 & 1.5 & 3.3 \\
\hline & & 17 & 2 & 1.7 & 3 & 75 & 0 & 2 & 1.5 & 3.3 \\
\hline & & 16 & 2.3 & 1.7 & 3 & 75 & 0 & 2 & 1.5 & 3.3 \\
\hline & op. 13 & 17 & 1.6 & 1.7 & 3 & 75 & 0 & 2 & 0 & 3.3 \\
\hline & & 17 & 1.8 & 1.7 & 3 & 75 & 0 & 2 & 0 & 3.3 \\
\hline & & 17 & 2 & 1.7 & 3 & 75 & 0 & 2 & 0 & 3.3 \\
\hline & & 16 & 2.3 & 1.7 & 3 & 75 & 0 & 2 & 0 & 3.3 \\
\hline & op. 14 & 17 & 1.6 & 1.7 & 3 & 75 & 0 & 2 & 0 & 4.86 \\
\hline & & 17 & 1.8 & 1.7 & 3 & 75 & 0 & 2 & 0 & 4.86 \\
\hline & & 17 & 2 & 1.7 & 3 & 75 & 0 & 2 & 0 & 4.86 \\
\hline & & 16 & 2.3 & 1.7 & 3 & 75 & 0 & 2 & 0 & 4.86 \\
\hline & op. 15 & 17 & 1.6 & 1.7 & 3 & 75 & 0 & 2 & 0 & 7.8 \\
\hline & & 17 & 1.8 & 1.7 & 3 & 75 & 0 & 2 & 0 & 7.8 \\
\hline & & 16 & 2 & 1.7 & 3 & 75 & 0 & 2 & 0 & 7.8 \\
\hline & & 15 & 2.3 & 1.7 & 3 & 75 & 0 & 2 & 0 & 7.8 \\
\hline wallp5 & op. 1-4 & 14 & 1.6 & 0.8 & 2.4 & 50 & $8 \%$ & 1 & 3 & 1 \\
\hline & & 14 & 1.8 & 0.8 & 2.4 & 50 & $8 \%$ & 1 & 3 & 1 \\
\hline & & 14 & 2 & 0.8 & 2.4 & 50 & $8 \%$ & 1 & 3 & 1 \\
\hline & & 14 & 2.3 & 0.8 & 2.4 & 50 & $8 \%$ & 1 & 3 & 1 \\
\hline & op. 2 & 14 & 1.6 & 0.8 & 2.4 & 50 & $8 \%$ & 1 & 3 & 1.4 \\
\hline & & 14 & 1.8 & 0.8 & 2.4 & 50 & $8 \%$ & 1 & 3 & 1.4 \\
\hline & & 14 & 2 & 0.8 & 2.4 & 50 & $8 \%$ & 1 & 3 & 1.4 \\
\hline & & 14 & 2.3 & 0.8 & 2.4 & 50 & $8 \%$ & 1 & 3 & 1.4 \\
\hline & op. 3 & 14 & 1.6 & 0.8 & 2.4 & 50 & $8 \%$ & 1 & 1.5 & 1 \\
\hline & & 14 & 1.8 & 0.8 & 2.4 & 50 & $8 \%$ & 1 & 1.5 & 1 \\
\hline
\end{tabular}

(cont. on next page) 
Table D.1. (cont.)

\begin{tabular}{|c|c|c|c|c|c|c|c|c|c|}
\hline & 14 & 2 & 0.8 & 2.4 & 50 & $8 \%$ & 1 & 1.5 & 1 \\
\hline & 14 & 2.3 & 0.8 & 2.4 & 50 & $8 \%$ & 1 & 1.5 & 1 \\
\hline op. 4 & 14 & 1.6 & 0.8 & 2.4 & 50 & $8 \%$ & 1 & 1.5 & 1.4 \\
\hline & 14 & 1.8 & 0.8 & 2.4 & 50 & $8 \%$ & 1 & 1.5 & 1.4 \\
\hline & 14 & 2 & 0.8 & 2.4 & 50 & $8 \%$ & 1 & 1.5 & 1.4 \\
\hline & 14 & 2.3 & 0.8 & 2.4 & 50 & $8 \%$ & 1 & 1.5 & 1.4 \\
\hline op. 5 & 14 & 1.6 & 0.8 & 2.4 & 50 & $8 \%$ & 2 & 3 & 1 \\
\hline & 14 & 1.8 & 0.8 & 2.4 & 50 & $8 \%$ & 2 & 3 & 1 \\
\hline & 14 & 2 & 0.8 & 2.4 & 50 & $8 \%$ & 2 & 3 & 1 \\
\hline & 14 & 2.3 & 0.8 & 2.4 & 50 & $8 \%$ & 2 & 3 & 1 \\
\hline op. 6 & 14 & 1.6 & 0.8 & 2.4 & 50 & $8 \%$ & 1 & 1.5 & 2.5 \\
\hline & 14 & 1.8 & 0.8 & 2.4 & 50 & $8 \%$ & 1 & 1.5 & 2.5 \\
\hline & 13 & 2 & 0.8 & 2.4 & 50 & $8 \%$ & 1 & 1.5 & 2.5 \\
\hline & 13 & 2.3 & 0.8 & 2.4 & 50 & $8 \%$ & 1 & 1.5 & 2.5 \\
\hline op. 7-8 & 14 & 1.6 & 0.8 & 2.4 & 50 & $8 \%$ & 2 & 3 & 1 \\
\hline & 14 & 1.8 & 0.8 & 2.4 & 50 & $8 \%$ & 2 & 3 & 1 \\
\hline & 14 & 2 & 0.8 & 2.4 & 50 & $8 \%$ & 2 & 3 & 1 \\
\hline & 13 & 2.3 & 0.8 & 2.4 & 50 & $8 \%$ & 2 & 3 & 1 \\
\hline op. 8 & 14 & 1.6 & 0.8 & 2.4 & 50 & $8 \%$ & 2 & 3 & 1 \\
\hline & 14 & 1.8 & 0.8 & 2.4 & 50 & $8 \%$ & 2 & 3 & 1 \\
\hline & 14 & 2 & 0.8 & 2.4 & 50 & $8 \%$ & 2 & 3 & 1 \\
\hline & 13 & 2.3 & 0.8 & 2.4 & 50 & $8 \%$ & 2 & 3 & 1 \\
\hline op. 9 & 13 & 1.6 & 0.8 & 2.4 & 50 & $8 \%$ & 2 & 1.5 & 3.5 \\
\hline & 13 & 1.8 & 0.8 & 2.4 & 50 & $8 \%$ & 2 & 1.5 & 3.5 \\
\hline & 13 & 2 & 0.8 & 2.4 & 50 & $8 \%$ & 2 & 1.5 & 3.5 \\
\hline & 12 & 2.3 & 0.8 & 2.4 & 50 & $8 \%$ & 2 & 1.5 & 3.5 \\
\hline op. 10 & 13 & 1.6 & 0.8 & 2.4 & 50 & $8 \%$ & 3 & 3 & 7.4 \\
\hline & 13 & 1.8 & 0.8 & 2.4 & 50 & $8 \%$ & 3 & 3 & 7.4 \\
\hline & 12 & 2 & 0.8 & 2.4 & 50 & $8 \%$ & 3 & 3 & 7.4 \\
\hline & 11 & 2.3 & 0.8 & 2.4 & 50 & $8 \%$ & 3 & 3 & 7.4 \\
\hline op. 11 & 14 & 1.6 & 0.8 & 2.4 & 50 & $8 \%$ & 3 & 3 & 4.5 \\
\hline & 14 & 1.8 & 0.8 & 2.4 & 50 & $8 \%$ & 3 & 3 & 4.5 \\
\hline & 13 & 2 & 0.8 & 2.4 & 50 & $8 \%$ & 3 & 3 & 4.5 \\
\hline & 12 & 2.3 & 0.8 & 2.4 & 50 & $8 \%$ & 3 & 3 & 4.5 \\
\hline op. 12 & 14 & 1.6 & 0.8 & 2.4 & 50 & $8 \%$ & 2 & 1.5 & 3.3 \\
\hline & 14 & 1.8 & 0.8 & 2.4 & 50 & $8 \%$ & 2 & 1.5 & 3.3 \\
\hline & 14 & 2 & 0.8 & 2.4 & 50 & $8 \%$ & 2 & 1.5 & 3.3 \\
\hline & 13 & 2.3 & 0.8 & 2.4 & 50 & $8 \%$ & 2 & 1.5 & 3.3 \\
\hline op. 13 & 14 & 1.6 & 0.8 & 2.4 & 50 & $8 \%$ & 2 & 0 & 3.3 \\
\hline & 14 & 1.8 & 0.8 & 2.4 & 50 & $8 \%$ & 2 & 0 & 3.3 \\
\hline & 14 & 2 & 0.8 & 2.4 & 50 & $8 \%$ & 2 & 0 & 3.3 \\
\hline & 13 & 2.3 & 0.8 & 2.4 & 50 & $8 \%$ & 2 & 0 & 3.3 \\
\hline op. 14 & 14 & 1.6 & 0.8 & 2.4 & 50 & $8 \%$ & 2 & 0 & 4.86 \\
\hline
\end{tabular}

(cont. on next page) 
Table D.1. (cont.)

\begin{tabular}{|c|c|c|c|c|c|c|c|c|c|c|}
\hline & & 14 & 1.8 & 0.8 & 2.4 & 50 & $8 \%$ & 2 & 0 & 4.86 \\
\hline & & 14 & 2 & 0.8 & 2.4 & 50 & $8 \%$ & 2 & 0 & 4.86 \\
\hline & & 13 & 2.3 & 0.8 & 2.4 & 50 & $8 \%$ & 2 & 0 & 4.86 \\
\hline & op. 15 & 14 & 1.6 & 0.8 & 2.4 & 50 & $8 \%$ & 2 & 0 & 7.8 \\
\hline & & 14 & 1.8 & 0.8 & 2.4 & 50 & $8 \%$ & 2 & 0 & 7.8 \\
\hline & & 13 & 2 & 0.8 & 2.4 & 50 & $8 \%$ & 2 & 0 & 7.8 \\
\hline & & 11 & 2.3 & 0.8 & 2.4 & 50 & $8 \%$ & 2 & 0 & 7.8 \\
\hline \multirow[t]{36}{*}{ wallp6 } & op. 1-4 & 19 & 1.6 & 1.7 & 4 & 50 & $11 \%$ & 1 & 3 & 1 \\
\hline & & 19 & 1.8 & 1.7 & 4 & 50 & $11 \%$ & 1 & 3 & 1 \\
\hline & & 18 & 2 & 1.7 & 4 & 50 & $11 \%$ & 1 & 3 & 1 \\
\hline & & 16 & 2.3 & 1.7 & 4 & 50 & $11 \%$ & 1 & 3 & 1 \\
\hline & op. 2 & 19 & 1.6 & 1.7 & 4 & 50 & $11 \%$ & 1 & 3 & 1.4 \\
\hline & & 19 & 1.8 & 1.7 & 4 & 50 & $11 \%$ & 1 & 3 & 1.4 \\
\hline & & 18 & 2 & 1.7 & 4 & 50 & $11 \%$ & 1 & 3 & 1.4 \\
\hline & & 16 & 2.3 & 1.7 & 4 & 50 & $11 \%$ & 1 & 3 & 1.4 \\
\hline & op. 3 & 19 & 1.6 & 1.7 & 4 & 50 & $11 \%$ & 1 & 1.5 & 1 \\
\hline & & 19 & 1.8 & 1.7 & 4 & 50 & $11 \%$ & 1 & 1.5 & 1 \\
\hline & & 18 & 2 & 1.7 & 4 & 50 & $11 \%$ & 1 & 1.5 & 1 \\
\hline & & 16 & 2.3 & 1.7 & 4 & 50 & $11 \%$ & 1 & 1.5 & 1 \\
\hline & op. 4 & 19 & 1.6 & 1.7 & 4 & 50 & $11 \%$ & 1 & 1.5 & 1.4 \\
\hline & & 19 & 1.8 & 1.7 & 4 & 50 & $11 \%$ & 1 & 1.5 & 1.4 \\
\hline & & 18 & 2 & 1.7 & 4 & 50 & $11 \%$ & 1 & 1.5 & 1.4 \\
\hline & & 16 & 2.3 & 1.7 & 4 & 50 & $11 \%$ & 1 & 1.5 & 1.4 \\
\hline & op. 5 & 19 & 1.6 & 1.7 & 4 & 50 & $11 \%$ & 2 & 3 & 1 \\
\hline & & 19 & 1.8 & 1.7 & 4 & 50 & $11 \%$ & 2 & 3 & 1 \\
\hline & & 18 & 2 & 1.7 & 4 & 50 & $11 \%$ & 2 & 3 & 1 \\
\hline & & 16 & 2.3 & 1.7 & 4 & 50 & $11 \%$ & 2 & 3 & 1 \\
\hline & op. 6 & 19 & 1.6 & 1.7 & 4 & 50 & $11 \%$ & 1 & 1.5 & 2.5 \\
\hline & & 19 & 1.8 & 1.7 & 4 & 50 & $11 \%$ & 1 & 1.5 & 2.5 \\
\hline & & 18 & 2 & 1.7 & 4 & 50 & $11 \%$ & 1 & 1.5 & 2.5 \\
\hline & & 16 & 2.3 & 1.7 & 4 & 50 & $11 \%$ & 1 & 1.5 & 2.5 \\
\hline & op. 7-8 & 19 & 1.6 & 1.7 & 4 & 50 & $11 \%$ & 2 & 3 & 1 \\
\hline & & 19 & 1.8 & 1.7 & 4 & 50 & $11 \%$ & 2 & 3 & 1 \\
\hline & & 18 & 2 & 1.7 & 4 & 50 & $11 \%$ & 2 & 3 & 1 \\
\hline & & 16 & 2.3 & 1.7 & 4 & 50 & $11 \%$ & 2 & 3 & 1 \\
\hline & op. 8 & 19 & 1.6 & 1.7 & 4 & 50 & $11 \%$ & 2 & 3 & 1 \\
\hline & & 19 & 1.8 & 1.7 & 4 & 50 & $11 \%$ & 2 & 3 & 1 \\
\hline & & 18 & 2 & 1.7 & 4 & 50 & $11 \%$ & 2 & 3 & 1 \\
\hline & & 16 & 2.3 & 1.7 & 4 & 50 & $11 \%$ & 2 & 3 & 1 \\
\hline & op. 9 & 19 & 1.6 & 1.7 & 4 & 50 & $11 \%$ & 2 & 1.5 & 3.5 \\
\hline & & 19 & 1.8 & 1.7 & 4 & 50 & $11 \%$ & 2 & 1.5 & 3.5 \\
\hline & & 18 & 2 & 1.7 & 4 & 50 & $11 \%$ & 2 & 1.5 & 3.5 \\
\hline & & 16 & 2.3 & 1.7 & 4 & 50 & $11 \%$ & 2 & 1.5 & 3.5 \\
\hline
\end{tabular}


Table D.1. (cont.)

\begin{tabular}{|c|c|c|c|c|c|c|c|c|c|}
\hline op. 10 & 18 & 1.6 & 1.7 & 4 & 50 & $11 \%$ & 3 & 3 & 7.4 \\
\hline & 18 & 1.8 & 1.7 & 4 & 50 & $11 \%$ & 3 & 3 & 7.4 \\
\hline & 17 & 2 & 1.7 & 4 & 50 & $11 \%$ & 3 & 3 & 7.4 \\
\hline & 16 & 2.3 & 1.7 & 4 & 50 & $11 \%$ & 3 & 3 & 7.4 \\
\hline op. 11 & 18 & 1.6 & 1.7 & 4 & 50 & $11 \%$ & 3 & 3 & 4.5 \\
\hline & 18 & 1.8 & 1.7 & 4 & 50 & $11 \%$ & 3 & 3 & 4.5 \\
\hline & 18 & 2 & 1.7 & 4 & 50 & $11 \%$ & 3 & 3 & 4.5 \\
\hline & 16 & 2.3 & 1.7 & 4 & 50 & $11 \%$ & 3 & 3 & 4.5 \\
\hline op. 12 & 19 & 1.6 & 1.7 & 4 & 50 & $11 \%$ & 2 & 1.5 & 3.3 \\
\hline & 19 & 1.8 & 1.7 & 4 & 50 & $11 \%$ & 2 & 1.5 & 3.3 \\
\hline & 18 & 2 & 1.7 & 4 & 50 & $11 \%$ & 2 & 1.5 & 3.3 \\
\hline & 16 & 2.3 & 1.7 & 4 & 50 & $11 \%$ & 2 & 1.5 & 3.3 \\
\hline op. 13 & 19 & 1.6 & 1.7 & 4 & 50 & $11 \%$ & 2 & 0 & 3.3 \\
\hline & 19 & 1.8 & 1.7 & 4 & 50 & $11 \%$ & 2 & 0 & 3.3 \\
\hline & 18 & 2 & 1.7 & 4 & 50 & $11 \%$ & 2 & 0 & 3.3 \\
\hline & 16 & 2.3 & 1.7 & 4 & 50 & $11 \%$ & 2 & 0 & 3.3 \\
\hline op. 14 & 19 & 1.6 & 1.7 & 4 & 50 & $11 \%$ & 2 & 0 & 4.86 \\
\hline & 19 & 1.8 & 1.7 & 4 & 50 & $11 \%$ & 2 & 0 & 4.86 \\
\hline & 18 & 2 & 1.7 & 4 & 50 & $11 \%$ & 2 & 0 & 4.86 \\
\hline & 16 & 2.3 & 1.7 & 4 & 50 & $11 \%$ & 2 & 0 & 4.86 \\
\hline op. 15 & 19 & 1.6 & 1.7 & 4 & 50 & $11 \%$ & 2 & 0 & 7.8 \\
\hline & 18 & 1.8 & 1.7 & 4 & 50 & $11 \%$ & 2 & 0 & 7.8 \\
\hline & 18 & 2 & 1.7 & 4 & 50 & $11 \%$ & 2 & 0 & 7.8 \\
\hline & 16 & 2.3 & 1.7 & 4 & 50 & $11 \%$ & 2 & 0 & 7.8 \\
\hline
\end{tabular}




\section{APPENDIX E}

\section{DATA SET OF HYPOTHETICAL TOWERS}

First; configurations are designed based on real towers' data. However, results of some configurations composed of $\mathrm{h} / \mathrm{l}$ ratio and material usage are similar, therefore, to prove the advantage of these historic preferences, the real limits are broadened for $\mathrm{h} / \mathrm{l}$ ratio and material usage. After interpretation of results, configurations composed of effective characteristic types are used for the assessment by eliminating ineffective ones.

\section{Configurations based on real towers}

While designing hypothetic towers, six wall profile type, four ratios between wall height and length, 15 opening, two material and two ground topography types are combined with each other. All possible towers are defined. Each of these towers is a permutation. If number of each characteristic type is multiplied by each other, 1440 tower combinations are created.

The impact of opening type is taken into consideration depending on its in-plane and out-of-plane position.

Number of hypothetic towers (based on real towers) $=6 \times 4 \times 15 \times 2 \times 2=1440$

\section{Configurations beyond real towers with virtual values}

Additional configurations ( $3 \mathrm{~h} / 1$ ratio and 2 material type) increase number of hypothetic towers up to 5040 .

Number of hypothetic towers (with additional configurations) $=6 \times 7 \times 15 \times 4 \times 2$ $=5040$

The presentation of the data set is as follows. Combinations that have topography differences are given in opposing columns. "Plane" represents both the tilting results of the towers positioned on plane topography and tilting results of the towers on inclined topography to the reverse direction of bedrock. Hypothetical towers based on real towers are illustrated with a symbol $(*)$. 
Table E.1. Data set of hypothetical towers

\begin{tabular}{|c|c|c|c|c|c|c|c|c|c|c|c|c|c|}
\hline Tower & Col. angle & W. P. type & Op. Type & $H / L$ & Mat. type & Gr. Topog. & Tower & Col. angle & W. P. type & Op. Type & $\mathrm{H} / \mathrm{L}$ & Mat. type & Gr. Topog. \\
\hline T. 1 & 7 & 1 & 1 & 1 & Granite & Plane $^{1}$ & T. 421 & 7 & 1 & 1 & 1 & Granite & Inclined \\
\hline T. 2 & 7 & 1 & 2 & 1 & Granite & Plane & T. 422 & 7 & 1 & 2 & 1 & Granite & Inclined \\
\hline T. 3 & 7 & 1 & 3 & 1 & Granite & Plane & T. 423 & 7 & 1 & 3 & 1 & Granite & Inclined \\
\hline T. 4 & 7 & 1 & 4 & 1 & Granite & Plane & T. 424 & 7 & 1 & 4 & 1 & Granite & Inclined \\
\hline T. 5 & 7 & 1 & 5 & 1 & Granite & Plane & T. 425 & 7 & 1 & 5 & 1 & Granite & Inclined \\
\hline T. 6 & 7 & 1 & 6 & 1 & Granite & Plane & T. 426 & 7 & 1 & 6 & 1 & Granite & Inclined \\
\hline T. 7 & 7 & 1 & 7 & 1 & Granite & Plane & T. 427 & 7 & 1 & 7 & 1 & Granite & Inclined \\
\hline T. 8 & 7 & 1 & 8 & 1 & Granite & Plane & T. 428 & 7 & 1 & 8 & 1 & Granite & Inclined \\
\hline T. 9 & 7 & 1 & 9 & 1 & Granite & Plane & T. 429 & 7 & 1 & 9 & 1 & Granite & Inclined \\
\hline T. 10 & 6 & 1 & 10 & 1 & Granite & Plane & T. 430 & 6 & 1 & 10 & 1 & Granite & Inclined \\
\hline T. 11 & 7 & 1 & 11 & 1 & Granite & Plane & T. 431 & 7 & 1 & 11 & 1 & Granite & Inclined \\
\hline T. 12 & 7 & 1 & 12 & 1 & Granite & Plane & T. 432 & 7 & 1 & 12 & 1 & Granite & Inclined \\
\hline T. 13 & 7 & 1 & 13 & 1 & Granite & Plane & T. 433 & 7 & 1 & 13 & 1 & Granite & Inclined \\
\hline T. 14 & 7 & 1 & 14 & 1 & Granite & Plane & T. 434 & 7 & 1 & 14 & 1 & Granite & Inclined \\
\hline T. 15 & 7 & 1 & 15 & 1 & Granite & Plane & T. 435 & 7 & 1 & 15 & 1 & Granite & Inclined \\
\hline T. 16 & 8 & 1 & 1 & 1.3 & Granite & Plane & T. 436 & 8 & 1 & 1 & 1.3 & Granite & Inclined \\
\hline T. 17 & 8 & 1 & 2 & 1.3 & Granite & Plane & T. 437 & 8 & 1 & 2 & 1.3 & Granite & Inclined \\
\hline T. 18 & 8 & 1 & 3 & 1.3 & Granite & Plane & T. 438 & 8 & 1 & 3 & 1.3 & Granite & Inclined \\
\hline T. 19 & 8 & 1 & 4 & 1.3 & Granite & Plane & T. 439 & 8 & 1 & 4 & 1.3 & Granite & Inclined \\
\hline T. 20 & 8 & 1 & 5 & 1.3 & Granite & Plane & T. 440 & 8 & 1 & 5 & 1.3 & Granite & Inclined \\
\hline T. 21 & 8 & 1 & 6 & 1.3 & Granite & Plane & T. 441 & 8 & 1 & 6 & 1.3 & Granite & Inclined \\
\hline T. 22 & 8 & 1 & 7 & 1.3 & Granite & Plane & T. 442 & 8 & 1 & 7 & 1.3 & Granite & Inclined \\
\hline T. 23 & 8 & 1 & 8 & 1.3 & Granite & Plane & T. 443 & 8 & 1 & 8 & 1.3 & Granite & Inclined \\
\hline T. 24 & 8 & 1 & 9 & 1.3 & Granite & Plane & T. 444 & 8 & 1 & 9 & 1.3 & Granite & Inclined \\
\hline T. 25 & 8 & 1 & 10 & 1.3 & Granite & Plane & T. 445 & 8 & 1 & 10 & 1.3 & Granite & Inclined \\
\hline T. 26 & 8 & 1 & 11 & 1.3 & Granite & Plane & T. 446 & 8 & 1 & 11 & 1.3 & Granite & Inclined \\
\hline T. 27 & 8 & 1 & 12 & 1.3 & Granite & Plane & T. 447 & 8 & 1 & 12 & 1.3 & Granite & Inclined \\
\hline T. 28 & 8 & 1 & 13 & 1.3 & Granite & Plane & T. 448 & 8 & 1 & 13 & 1.3 & Granite & Inclined \\
\hline T. 29 & 8 & 1 & 14 & 1.3 & Granite & Plane & T. 449 & 8 & 1 & 14 & 1.3 & Granite & Inclined \\
\hline T. 30 & 8 & 1 & 15 & 1.3 & Granite & Plane & T. 450 & 8 & 1 & 15 & 1.3 & Granite & Inclined \\
\hline${ }^{*}$ T. 312 & 11 & 1 & 1 & 1.6 & Granite & Plane & *T. 451 & 11 & 1 & 1 & 1.6 & Granite & Inclined \\
\hline${ }^{*} \mathrm{~T} .32$ & 11 & 1 & 2 & 1.6 & Granite & Plane & *T. 452 & 11 & 1 & 2 & 1.6 & Granite & Inclined \\
\hline
\end{tabular}


Table E.1. (cont.)

\begin{tabular}{|c|c|c|c|c|c|c|c|c|c|c|c|c|c|}
\hline *T. 33 & 11 & 1 & 3 & 1.6 & Granite & Plane & ${ }^{*} \mathrm{~T} .453$ & 11 & 1 & 3 & 1.6 & Granite & Inclined \\
\hline *T. 34 & 11 & 1 & 4 & 1.6 & Granite & Plane & *T. 454 & 11 & 1 & 4 & 1.6 & Granite & Inclined \\
\hline *T. 35 & 11 & 1 & 5 & 1.6 & Granite & Plane & *T. 455 & 11 & 1 & 5 & 1.6 & Granite & Inclined \\
\hline *T. 36 & 11 & 1 & 6 & 1.6 & Granite & Plane & *T. 456 & 11 & 1 & 6 & 1.6 & Granite & Inclined \\
\hline *T. 37 & 11 & 1 & 7 & 1.6 & Granite & Plane & *T. 457 & 11 & 1 & 7 & 1.6 & Granite & Inclined \\
\hline *T. 38 & 11 & 1 & 8 & 1.6 & Granite & Plane & *T. 458 & 11 & 1 & 8 & 1.6 & Granite & Inclined \\
\hline *T. 39 & 10 & 1 & 9 & 1.6 & Granite & Plane & *T. 459 & 10 & 1 & 9 & 1.6 & Granite & Inclined \\
\hline *T. 40 & 9 & 1 & 10 & 1.6 & Granite & Plane & *T. 460 & 9 & 1 & 10 & 1.6 & Granite & Inclined \\
\hline *T. 41 & 10 & 1 & 11 & 1.6 & Granite & Plane & *T. 461 & 10 & 1 & 11 & 1.6 & Granite & Inclined \\
\hline *T. 42 & 10 & 1 & 12 & 1.6 & Granite & Plane & *T. 462 & 10 & 1 & 12 & 1.6 & Granite & Inclined \\
\hline *T. 43 & 10 & 1 & 13 & 1.6 & Granite & Plane & ${ }^{*} \mathrm{~T} .463$ & 10 & 1 & 13 & 1.6 & Granite & Inclined \\
\hline *T. 44 & 10 & 1 & 14 & 1.6 & Granite & Plane & *T. 464 & 10 & 1 & 14 & 1.6 & Granite & Inclined \\
\hline *T. 45 & 11 & 1 & 15 & 1.6 & Granite & Plane & *T. 465 & 11 & 1 & 15 & 1.6 & Granite & Inclined \\
\hline *T. 46 & 11 & 1 & 1 & 1.8 & Granite & Plane & ${ }^{*} \mathrm{~T} .466$ & 11 & 1 & 1 & 1.8 & Granite & Inclined \\
\hline *T. 47 & 11 & 1 & 2 & 1.8 & Granite & Plane & *T. 467 & 11 & 1 & 2 & 1.8 & Granite & Inclined \\
\hline *T. 48 & 11 & 1 & 3 & 1.8 & Granite & Plane & *T. 468 & 11 & 1 & 3 & 1.8 & Granite & Inclined \\
\hline *T. 49 & 11 & 1 & 4 & 1.8 & Granite & Plane & *T. 469 & 11 & 1 & 4 & 1.8 & Granite & Inclined \\
\hline *T. 50 & 11 & 1 & 5 & 1.8 & Granite & Plane & *T. 470 & 11 & 1 & 5 & 1.8 & Granite & Inclined \\
\hline *T. 51 & 11 & 1 & 6 & 1.8 & Granite & Plane & *T. 471 & 11 & 1 & 6 & 1.8 & Granite & Inclined \\
\hline *T. 52 & 11 & 1 & 7 & 1.8 & Granite & Plane & *T. 472 & 11 & 1 & 7 & 1.8 & Granite & Inclined \\
\hline *T. 53 & 11 & 1 & 8 & 1.8 & Granite & Plane & *T. 473 & 11 & 1 & 8 & 1.8 & Granite & Inclined \\
\hline *T. 54 & 10 & 1 & 9 & 1.8 & Granite & Plane & *T. 474 & 10 & 1 & 9 & 1.8 & Granite & Inclined \\
\hline *T. 55 & 9 & 1 & 10 & 1.8 & Granite & Plane & *T. 475 & 9 & 1 & 10 & 1.8 & Granite & Inclined \\
\hline *T. 56 & 10 & 1 & 11 & 1.8 & Granite & Plane & *T. 476 & 10 & 1 & 11 & 1.8 & Granite & Inclined \\
\hline *T. 57 & 10 & 1 & 12 & 1.8 & Granite & Plane & *T. 477 & 10 & 1 & 12 & 1.8 & Granite & Inclined \\
\hline *T. 58 & 10 & 1 & 13 & 1.8 & Granite & Plane & *T. 478 & 10 & 1 & 13 & 1.8 & Granite & Inclined \\
\hline *T. 59 & 10 & 1 & 14 & 1.8 & Granite & Plane & *T. 479 & 10 & 1 & 14 & 1.8 & Granite & Inclined \\
\hline *T. 60 & 11 & 1 & 15 & 1.8 & Granite & Plane & *T. 480 & 11 & 1 & 15 & 1.8 & Granite & Inclined \\
\hline *T. 61 & 11 & 1 & 1 & 2 & Granite & Plane & *T. 481 & 11 & 1 & 1 & 2 & Granite & Inclined \\
\hline *T. 62 & 11 & 1 & 2 & 2 & Granite & Plane & *T. 482 & 11 & 1 & 2 & 2 & Granite & Inclined \\
\hline *T. 63 & 11 & 1 & 3 & 2 & Granite & Plane & *T. 483 & 11 & 1 & 3 & 2 & Granite & Inclined \\
\hline *T. 64 & 11 & 1 & 4 & 2 & Granite & Plane & ${ }^{*} \mathrm{~T} .484$ & 11 & 1 & 4 & 2 & Granite & Inclined \\
\hline *T. 65 & 11 & 1 & 5 & 2 & Granite & Plane & *T. 485 & 11 & 1 & 5 & 2 & Granite & Inclined \\
\hline
\end{tabular}


Table E.1. (cont.)

\begin{tabular}{|c|c|c|c|c|c|c|c|c|c|c|c|c|c|}
\hline *T. 66 & 11 & 1 & 6 & 2 & Granite & Plane & *T. 486 & 11 & 1 & 6 & 2 & Granite & Inclined \\
\hline *T. 67 & 11 & 1 & 7 & 2 & Granite & Plane & *T. 487 & 11 & 1 & 7 & 2 & Granite & Inclined \\
\hline *T. 68 & 11 & 1 & 8 & 2 & Granite & Plane & *T. 488 & 11 & 1 & 8 & 2 & Granite & Inclined \\
\hline *T. 69 & 10 & 1 & 9 & 2 & Granite & Plane & *T. 489 & 10 & 1 & 9 & 2 & Granite & Inclined \\
\hline *T. 70 & 8 & 1 & 10 & 2 & Granite & Plane & *T. 490 & 8 & 1 & 10 & 2 & Granite & Inclined \\
\hline *T. 71 & 9 & 1 & 11 & 2 & Granite & Plane & *T. 491 & 9 & 1 & 11 & 2 & Granite & Inclined \\
\hline *T. 72 & 10 & 1 & 12 & 2 & Granite & Plane & *T. 492 & 10 & 1 & 12 & 2 & Granite & Inclined \\
\hline *T. 73 & 10 & 1 & 13 & 2 & Granite & Plane & *T. 493 & 10 & 1 & 13 & 2 & Granite & Inclined \\
\hline *T. 74 & 10 & 1 & 14 & 2 & Granite & Plane & *T. 494 & 10 & 1 & 14 & 2 & Granite & Inclined \\
\hline *T. 75 & 9 & 1 & 15 & 2 & Granite & Plane & *T. 495 & 9 & 1 & 15 & 2 & Granite & Inclined \\
\hline *T. 76 & 11 & 1 & 1 & 2.3 & Granite & Plane & *T. 496 & 11 & 1 & 1 & 2.3 & Granite & Inclined \\
\hline *T. 77 & 11 & 1 & 2 & 2.3 & Granite & Plane & *T. 497 & 11 & 1 & 2 & 2.3 & Granite & Inclined \\
\hline *T. 78 & 11 & 1 & 3 & 2.3 & Granite & Plane & *T. 498 & 11 & 1 & 3 & 2.3 & Granite & Inclined \\
\hline *T. 79 & 11 & 1 & 4 & 2.3 & Granite & Plane & *T. 499 & 11 & 1 & 4 & 2.3 & Granite & Inclined \\
\hline *T. 80 & 11 & 1 & 5 & 2.3 & Granite & Plane & *T. 500 & 11 & 1 & 5 & 2.3 & Granite & Inclined \\
\hline *T. 81 & 11 & 1 & 6 & 2.3 & Granite & Plane & *T. 501 & 11 & 1 & 6 & 2.3 & Granite & Inclined \\
\hline *T. 82 & 11 & 1 & 7 & 2.3 & Granite & Plane & *T. 502 & 11 & 1 & 7 & 2.3 & Granite & Inclined \\
\hline${ }^{*}$ T. 83 & 11 & 1 & 8 & 2.3 & Granite & Plane & *T. 503 & 11 & 1 & 8 & 2.3 & Granite & Inclined \\
\hline${ }^{*} \mathrm{~T} .84$ & 10 & 1 & 9 & 2.3 & Granite & Plane & *T. 504 & 10 & 1 & 9 & 2.3 & Granite & Inclined \\
\hline *T. 85 & 8 & 1 & 10 & 2.3 & Granite & Plane & *T. 505 & 8 & 1 & 10 & 2.3 & Granite & Inclined \\
\hline *T. 86 & 8 & 1 & 11 & 2.3 & Granite & Plane & *T. 506 & 8 & 1 & 11 & 2.3 & Granite & Inclined \\
\hline *T. 87 & 10 & 1 & 12 & 2.3 & Granite & Plane & *T. 507 & 10 & 1 & 12 & 2.3 & Granite & Inclined \\
\hline *T. 88 & 10 & 1 & 13 & 2.3 & Granite & Plane & *T. 508 & 10 & 1 & 13 & 2.3 & Granite & Inclined \\
\hline${ }^{*}$ T. 89 & 10 & 1 & 14 & 2.3 & Granite & Plane & *T. 509 & 10 & 1 & 14 & 2.3 & Granite & Inclined \\
\hline *T. 90 & 9 & 1 & 15 & 2.3 & Granite & Plane & *T. $\mathbf{5 1 0}$ & 9 & 1 & 15 & 2.3 & Granite & Inclined \\
\hline T. 91 & 10 & 1 & 1 & 2.5 & Granite & Plane & T. 511 & 10 & 1 & 1 & 2.5 & Granite & Inclined \\
\hline T. 92 & 10 & 1 & 2 & 2.5 & Granite & Plane & T. 512 & 10 & 1 & 2 & 2.5 & Granite & Inclined \\
\hline T. 93 & 10 & 1 & 3 & 2.5 & Granite & Plane & T. 513 & 10 & 1 & 3 & 2.5 & Granite & Inclined \\
\hline T. 94 & 10 & 1 & 4 & 2.5 & Granite & Plane & T. 514 & 10 & 1 & 4 & 2.5 & Granite & Inclined \\
\hline T. 95 & 10 & 1 & 5 & 2.5 & Granite & Plane & T. 515 & 10 & 1 & 5 & 2.5 & Granite & Inclined \\
\hline T. 96 & 10 & 1 & 6 & 2.5 & Granite & Plane & T. 516 & 10 & 1 & 6 & 2.5 & Granite & Inclined \\
\hline T. 97 & 10 & 1 & 7 & 2.5 & Granite & Plane & T. 517 & 10 & 1 & 7 & 2.5 & Granite & Inclined \\
\hline T. 98 & 10 & 1 & 8 & 2.5 & Granite & Plane & T. 518 & 10 & 1 & 8 & 2.5 & Granite & Inclined \\
\hline
\end{tabular}


Table E.1. (cont.)

\begin{tabular}{|c|c|c|c|c|c|c|c|c|c|c|c|c|c|}
\hline T. 99 & 9 & 1 & 9 & 2.5 & Granite & Plane & T. 519 & 9 & 1 & 9 & 2.5 & Granite & Inclined \\
\hline T. 100 & 8 & 1 & 10 & 2.5 & Granite & Plane & T. 520 & 8 & 1 & 10 & 2.5 & Granite & Inclined \\
\hline T. 101 & 8 & 1 & 11 & 2.5 & Granite & Plane & T. 521 & 8 & 1 & 11 & 2.5 & Granite & Inclined \\
\hline T. 102 & 9 & 1 & 12 & 2.5 & Granite & Plane & T. 522 & 9 & 1 & 12 & 2.5 & Granite & Inclined \\
\hline T. 103 & 9 & 1 & 13 & 2.5 & Granite & Plane & T. 523 & 9 & 1 & 13 & 2.5 & Granite & Inclined \\
\hline T. 104 & 8 & 1 & 14 & 2.5 & Granite & Plane & T. 524 & 8 & 1 & 14 & 2.5 & Granite & Inclined \\
\hline T. 105 & 8 & 1 & 15 & 2.5 & Granite & Plane & T. 525 & 8 & 1 & 15 & 2.5 & Granite & Inclined \\
\hline T. 106 & 7 & 1 & 1 & 1 & Limestone & Plane & T. 526 & 7 & 1 & 1 & 1 & Limestone & Inclined \\
\hline T. 107 & 7 & 1 & 2 & 1 & Limestone & Plane & T. 527 & 7 & 1 & 2 & 1 & Limestone & Inclined \\
\hline T. 108 & 7 & 1 & 3 & 1 & Limestone & Plane & T. 528 & 7 & 1 & 3 & 1 & Limestone & Inclined \\
\hline T. 109 & 7 & 1 & 4 & 1 & Limestone & Plane & T. 529 & 7 & 1 & 4 & 1 & Limestone & Inclined \\
\hline T. 110 & 7 & 1 & 5 & 1 & Limestone & Plane & T. 530 & 7 & 1 & 5 & 1 & Limestone & Inclined \\
\hline T. 111 & 7 & 1 & 6 & 1 & Limestone & Plane & T. 531 & 7 & 1 & 6 & 1 & Limestone & Inclined \\
\hline T. 112 & 7 & 1 & 7 & 1 & Limestone & Plane & T. 532 & 7 & 1 & 7 & 1 & Limestone & Inclined \\
\hline T. 113 & 7 & 1 & 8 & 1 & Limestone & Plane & T. 533 & 7 & 1 & 8 & 1 & Limestone & Inclined \\
\hline T. 114 & 7 & 1 & 9 & 1 & Limestone & Plane & T. 534 & 7 & 1 & 9 & 1 & Limestone & Inclined \\
\hline T. 115 & 6 & 1 & 10 & 1 & Limestone & Plane & T. 535 & 6 & 1 & 10 & 1 & Limestone & Inclined \\
\hline T. 116 & 7 & 1 & 11 & 1 & Limestone & Plane & T. 536 & 7 & 1 & 11 & 1 & Limestone & Inclined \\
\hline T. 117 & 7 & 1 & 12 & 1 & Limestone & Plane & T. 537 & 7 & 1 & 12 & 1 & Limestone & Inclined \\
\hline Т. 118 & 7 & 1 & 13 & 1 & Limestone & Plane & T. 538 & 7 & 1 & 13 & 1 & Limestone & Inclined \\
\hline T. 119 & 7 & 1 & 14 & 1 & Limestone & Plane & T. 539 & 7 & 1 & 14 & 1 & Limestone & Inclined \\
\hline T. 120 & 7 & 1 & 15 & 1 & Limestone & Plane & T. 540 & 7 & 1 & 15 & 1 & Limestone & Inclined \\
\hline T. 121 & 8 & 1 & 1 & 1.3 & Limestone & Plane & T. 541 & 8 & 1 & 1 & 1.3 & Limestone & Inclined \\
\hline T. 122 & 8 & 1 & 2 & 1.3 & Limestone & Plane & T. 542 & 8 & 1 & 2 & 1.3 & Limestone & Inclined \\
\hline T. 123 & 8 & 1 & 3 & 1.3 & Limestone & Plane & T. 543 & 8 & 1 & 3 & 1.3 & Limestone & Inclined \\
\hline T. 124 & 8 & 1 & 4 & 1.3 & Limestone & Plane & T. 544 & 8 & 1 & 4 & 1.3 & Limestone & Inclined \\
\hline T. 125 & 8 & 1 & 5 & 1.3 & Limestone & Plane & T. 545 & 8 & 1 & 5 & 1.3 & Limestone & Inclined \\
\hline T. 126 & 8 & 1 & 6 & 1.3 & Limestone & Plane & T. 546 & 8 & 1 & 6 & 1.3 & Limestone & Inclined \\
\hline T. 127 & 8 & 1 & 7 & 1.3 & Limestone & Plane & T. 547 & 8 & 1 & 7 & 1.3 & Limestone & Inclined \\
\hline T. 128 & 8 & 1 & 8 & 1.3 & Limestone & Plane & T. 548 & 8 & 1 & 8 & 1.3 & Limestone & Inclined \\
\hline T. 129 & 8 & 1 & 9 & 1.3 & Limestone & Plane & T. 549 & 8 & 1 & 9 & 1.3 & Limestone & Inclined \\
\hline T. 130 & 8 & 1 & 10 & 1.3 & Limestone & Plane & T. 550 & 8 & 1 & 10 & 1.3 & Limestone & Inclined \\
\hline T. 131 & 8 & 1 & 11 & 1.3 & Limestone & Plane & T. 551 & 8 & 1 & 11 & 1.3 & Limestone & Inclined \\
\hline
\end{tabular}


Table E.1. (cont.)

\begin{tabular}{|c|c|c|c|c|c|c|c|c|c|c|c|c|c|}
\hline T. 132 & 8 & 1 & 12 & 1.3 & Limestone & Plane & T. 552 & 8 & 1 & 12 & 1.3 & Limestone & Inclined \\
\hline T. 133 & 8 & 1 & 13 & 1.3 & Limestone & Plane & T. 553 & 8 & 1 & 13 & 1.3 & Limestone & Inclined \\
\hline T. 134 & 8 & 1 & 14 & 1.3 & Limestone & Plane & T. 554 & 8 & 1 & 14 & 1.3 & Limestone & Inclined \\
\hline T. 135 & 8 & 1 & 15 & 1.3 & Limestone & Plane & T. 555 & 8 & 1 & 15 & 1.3 & Limestone & Inclined \\
\hline${ }^{*} \mathrm{~T} .136$ & 11 & 1 & 1 & 1.6 & Limestone & Plane & T. 556 & 11 & 1 & 1 & 1.6 & Limestone & Inclined \\
\hline *T. 137 & 11 & 1 & 2 & 1.6 & Limestone & Plane & T. 557 & 11 & 1 & 2 & 1.6 & Limestone & Inclined \\
\hline${ }^{*} \mathrm{~T} .138$ & 11 & 1 & 3 & 1.6 & Limestone & Plane & T. 558 & 11 & 1 & 3 & 1.6 & Limestone & Inclined \\
\hline${ }^{*} \mathrm{~T} .139$ & 11 & 1 & 4 & 1.6 & Limestone & Plane & T. 559 & 11 & 1 & 4 & 1.6 & Limestone & Inclined \\
\hline${ }^{*} \mathrm{~T} .140$ & 11 & 1 & 5 & 1.6 & Limestone & Plane & T. 560 & 11 & 1 & 5 & 1.6 & Limestone & Inclined \\
\hline${ }^{*} \mathrm{~T} .141$ & 11 & 1 & 6 & 1.6 & Limestone & Plane & T. 561 & 11 & 1 & 6 & 1.6 & Limestone & Inclined \\
\hline${ }^{*}$ T. 142 & 11 & 1 & 7 & 1.6 & Limestone & Plane & T. 562 & 11 & 1 & 7 & 1.6 & Limestone & Inclined \\
\hline *T. 143 & 11 & 1 & 8 & 1.6 & Limestone & Plane & T. 563 & 11 & 1 & 8 & 1.6 & Limestone & Inclined \\
\hline${ }^{*}$ T. 144 & 10 & 1 & 9 & 1.6 & Limestone & Plane & T. 564 & 10 & 1 & 9 & 1.6 & Limestone & Inclined \\
\hline${ }^{*} \mathrm{~T} .145$ & 9 & 1 & 10 & 1.6 & Limestone & Plane & T. 565 & 9 & 1 & 10 & 1.6 & Limestone & Inclined \\
\hline${ }^{*}$ T. 146 & 10 & 1 & 11 & 1.6 & Limestone & Plane & T. 566 & 10 & 1 & 11 & 1.6 & Limestone & Inclined \\
\hline *T. 147 & 10 & 1 & 12 & 1.6 & Limestone & Plane & T. 567 & 10 & 1 & 12 & 1.6 & Limestone & Inclined \\
\hline${ }^{*} \mathrm{~T} .148$ & 10 & 1 & 13 & 1.6 & Limestone & Plane & T. 568 & 10 & 1 & 13 & 1.6 & Limestone & Inclined \\
\hline${ }^{*}$ T. 149 & 10 & 1 & 14 & 1.6 & Limestone & Plane & T. 569 & 10 & 1 & 14 & 1.6 & Limestone & Inclined \\
\hline${ }^{*}$ T. 150 & 11 & 1 & 15 & 1.6 & Limestone & Plane & T. 570 & 11 & 1 & 15 & 1.6 & Limestone & Inclined \\
\hline${ }^{*} \mathrm{~T} .151$ & 11 & 1 & 1 & 1.8 & Limestone & Plane & T. 571 & 11 & 1 & 1 & 1.8 & Limestone & Inclined \\
\hline${ }^{*} \mathrm{~T} .152$ & 11 & 1 & 2 & 1.8 & Limestone & Plane & T. 572 & 11 & 1 & 2 & 1.8 & Limestone & Inclined \\
\hline *T. 153 & 11 & 1 & 3 & 1.8 & Limestone & Plane & T. 573 & 11 & 1 & 3 & 1.8 & Limestone & Inclined \\
\hline *T. 154 & 11 & 1 & 4 & 1.8 & Limestone & Plane & T. 574 & 11 & 1 & 4 & 1.8 & Limestone & Inclined \\
\hline *T. 155 & 11 & 1 & 5 & 1.8 & Limestone & Plane & T. 575 & 11 & 1 & 5 & 1.8 & Limestone & Inclined \\
\hline${ }^{*} \mathrm{~T} .156$ & 11 & 1 & 6 & 1.8 & Limestone & Plane & T. 576 & 11 & 1 & 6 & 1.8 & Limestone & Inclined \\
\hline *T. 157 & 11 & 1 & 7 & 1.8 & Limestone & Plane & T. 577 & 11 & 1 & 7 & 1.8 & Limestone & Inclined \\
\hline *T. 158 & 11 & 1 & 8 & 1.8 & Limestone & Plane & T. 578 & 11 & 1 & 8 & 1.8 & Limestone & Inclined \\
\hline *T. 159 & 10 & 1 & 9 & 1.8 & Limestone & Plane & T. 579 & 10 & 1 & 9 & 1.8 & Limestone & Inclined \\
\hline${ }^{*}$ T. 160 & 9 & 1 & 10 & 1.8 & Limestone & Plane & T. 580 & 9 & 1 & 10 & 1.8 & Limestone & Inclined \\
\hline${ }^{*}$ T. 161 & 10 & 1 & 11 & 1.8 & Limestone & Plane & T. 581 & 10 & 1 & 11 & 1.8 & Limestone & Inclined \\
\hline${ }^{*}$ T. 162 & 10 & 1 & 12 & 1.8 & Limestone & Plane & T. 582 & 10 & 1 & 12 & 1.8 & Limestone & Inclined \\
\hline${ }^{*} \mathrm{~T} .163$ & 10 & 1 & 13 & 1.8 & Limestone & Plane & T. 583 & 10 & 1 & 13 & 1.8 & Limestone & Inclined \\
\hline *T. 164 & 10 & 1 & 14 & 1.8 & Limestone & Plane & T. 584 & 10 & 1 & 14 & 1.8 & Limestone & Inclined \\
\hline
\end{tabular}

(cont. on next page) 
Table E.1. (cont.)

\begin{tabular}{|c|c|c|c|c|c|c|c|c|c|c|c|c|c|}
\hline *T. 165 & 11 & 1 & 15 & 1.8 & Limestone & Plane & T. 585 & 11 & 1 & 15 & 1.8 & Limestone & Inclined \\
\hline *T. 166 & 11 & 1 & 1 & 2 & Limestone & Plane & T. 586 & 11 & 1 & 1 & 2 & Limestone & Inclined \\
\hline *T. 167 & 11 & 1 & 2 & 2 & Limestone & Plane & T. 587 & 11 & 1 & 2 & 2 & Limestone & Inclined \\
\hline *T. 168 & 11 & 1 & 3 & 2 & Limestone & Plane & T. 588 & 11 & 1 & 3 & 2 & Limestone & Inclined \\
\hline *T. 169 & 11 & 1 & 4 & 2 & Limestone & Plane & T. 589 & 11 & 1 & 4 & 2 & Limestone & Inclined \\
\hline *T. 170 & 11 & 1 & 5 & 2 & Limestone & Plane & T. 590 & 11 & 1 & 5 & 2 & Limestone & Inclined \\
\hline *T. 171 & 11 & 1 & 6 & 2 & Limestone & Plane & T. 591 & 11 & 1 & 6 & 2 & Limestone & Inclined \\
\hline *T. 172 & 11 & 1 & 7 & 2 & Limestone & Plane & T. 592 & 11 & 1 & 7 & 2 & Limestone & Inclined \\
\hline *T. 173 & 11 & 1 & 8 & 2 & Limestone & Plane & T. 593 & 11 & 1 & 8 & 2 & Limestone & Inclined \\
\hline *T. 174 & 10 & 1 & 9 & 2 & Limestone & Plane & T. 594 & 10 & 1 & 9 & 2 & Limestone & Inclined \\
\hline *T. 175 & 8 & 1 & 10 & 2 & Limestone & Plane & T. 595 & 8 & 1 & 10 & 2 & Limestone & Inclined \\
\hline *T. 176 & 9 & 1 & 11 & 2 & Limestone & Plane & T. 596 & 9 & 1 & 11 & 2 & Limestone & Inclined \\
\hline *T. 177 & 10 & 1 & 12 & 2 & Limestone & Plane & T. 597 & 10 & 1 & 12 & 2 & Limestone & Inclined \\
\hline *T. 178 & 10 & 1 & 13 & 2 & Limestone & Plane & T. 598 & 10 & 1 & 13 & 2 & Limestone & Inclined \\
\hline *T. 179 & 10 & 1 & 14 & 2 & Limestone & Plane & T. 599 & 10 & 1 & 14 & 2 & Limestone & Inclined \\
\hline *T. 180 & 9 & 1 & 15 & 2 & Limestone & Plane & T. 600 & 9 & 1 & 15 & 2 & Limestone & Inclined \\
\hline *T. 181 & 11 & 1 & 1 & 2.3 & Limestone & Plane & T. 601 & 11 & 1 & 1 & 2.3 & Limestone & Inclined \\
\hline *T. 182 & 11 & 1 & 2 & 2.3 & Limestone & Plane & T. 602 & 11 & 1 & 2 & 2.3 & Limestone & Inclined \\
\hline *T. 183 & 11 & 1 & 3 & 2.3 & Limestone & Plane & T. 603 & 11 & 1 & 3 & 2.3 & Limestone & Inclined \\
\hline *T. 184 & 11 & 1 & 4 & 2.3 & Limestone & Plane & T. 604 & 11 & 1 & 4 & 2.3 & Limestone & Inclined \\
\hline *T. 185 & 11 & 1 & 5 & 2.3 & Limestone & Plane & T. 605 & 11 & 1 & 5 & 2.3 & Limestone & Inclined \\
\hline *T. 186 & 11 & 1 & 6 & 2.3 & Limestone & Plane & T. 606 & 11 & 1 & 6 & 2.3 & Limestone & Inclined \\
\hline *T. 187 & 11 & 1 & 7 & 2.3 & Limestone & Plane & T. 607 & 11 & 1 & 7 & 2.3 & Limestone & Inclined \\
\hline *T. 188 & 11 & 1 & 8 & 2.3 & Limestone & Plane & T. 608 & 11 & 1 & 8 & 2.3 & Limestone & Inclined \\
\hline *T. 189 & 10 & 1 & 9 & 2.3 & Limestone & Plane & T. 609 & 10 & 1 & 9 & 2.3 & Limestone & Inclined \\
\hline *T. 190 & 8 & 1 & 10 & 2.3 & Limestone & Plane & T. 610 & 8 & 1 & 10 & 2.3 & Limestone & Inclined \\
\hline *T. 191 & 8 & 1 & 11 & 2.3 & Limestone & Plane & T. 611 & 8 & 1 & 11 & 2.3 & Limestone & Inclined \\
\hline *T. 192 & 10 & 1 & 12 & 2.3 & Limestone & Plane & T. 612 & 10 & 1 & 12 & 2.3 & Limestone & Inclined \\
\hline *T. 193 & 10 & 1 & 13 & 2.3 & Limestone & Plane & T. 613 & 10 & 1 & 13 & 2.3 & Limestone & Inclined \\
\hline *T. 194 & 10 & 1 & 14 & 2.3 & Limestone & Plane & T. 614 & 10 & 1 & 14 & 2.3 & Limestone & Inclined \\
\hline *T. 195 & 9 & 1 & 15 & 2.3 & Limestone & Plane & T. 615 & 9 & 1 & 15 & 2.3 & Limestone & Inclined \\
\hline T. 196 & 10 & 1 & 1 & 2.5 & Limestone & Plane & T. 616 & 10 & 1 & 1 & 2.5 & Limestone & Inclined \\
\hline T. 197 & 10 & 1 & 2 & 2.5 & Limestone & Plane & T. 617 & 10 & 1 & 2 & 2.5 & Limestone & Inclined \\
\hline
\end{tabular}

(cont. on next page) 
Table E.1. (cont.)

\begin{tabular}{|c|c|c|c|c|c|c|c|c|c|c|c|c|c|}
\hline T. 198 & 10 & 1 & 3 & 2.5 & Limestone & Plane & T. 618 & 10 & 1 & 3 & 2.5 & Limestone & Inclined \\
\hline T. 199 & 10 & 1 & 4 & 2.5 & Limestone & Plane & T. 619 & 10 & 1 & 4 & 2.5 & Limestone & Inclined \\
\hline T. 200 & 10 & 1 & 5 & 2.5 & Limestone & Plane & T. 620 & 10 & 1 & 5 & 2.5 & Limestone & Inclined \\
\hline T. 201 & 10 & 1 & 6 & 2.5 & Limestone & Plane & T. 621 & 10 & 1 & 6 & 2.5 & Limestone & Inclined \\
\hline T. 202 & 10 & 1 & 7 & 2.5 & Limestone & Plane & T. 622 & 10 & 1 & 7 & 2.5 & Limestone & Inclined \\
\hline T. 203 & 10 & 1 & 8 & 2.5 & Limestone & Plane & T. 623 & 10 & 1 & 8 & 2.5 & Limestone & Inclined \\
\hline T. 204 & 9 & 1 & 9 & 2.5 & Limestone & Plane & T. 624 & 9 & 1 & 9 & 2.5 & Limestone & Inclined \\
\hline T. 205 & 8 & 1 & 10 & 2.5 & Limestone & Plane & T. 625 & 8 & 1 & 10 & 2.5 & Limestone & Inclined \\
\hline T. 206 & 8 & 1 & 11 & 2.5 & Limestone & Plane & T. 626 & 8 & 1 & 11 & 2.5 & Limestone & Inclined \\
\hline T. 207 & 9 & 1 & 12 & 2.5 & Limestone & Plane & T. 627 & 9 & 1 & 12 & 2.5 & Limestone & Inclined \\
\hline T. 208 & 9 & 1 & 13 & 2.5 & Limestone & Plane & T. 628 & 9 & 1 & 13 & 2.5 & Limestone & Inclined \\
\hline T. 209 & 8 & 1 & 14 & 2.5 & Limestone & Plane & T. 629 & 8 & 1 & 14 & 2.5 & Limestone & Inclined \\
\hline T. 210 & 8 & 1 & 15 & 2.5 & Limestone & Plane & T. 630 & 8 & 1 & 15 & 2.5 & Limestone & Inclined \\
\hline T. 211 & 7 & 1 & 1 & 1 & Sandstone & Plane & T. 631 & 7 & 1 & 1 & 1 & Sandstone & Inclined \\
\hline T. 212 & 7 & 1 & 2 & 1 & Sandstone & Plane & T. 632 & 7 & 1 & 2 & 1 & Sandstone & Inclined \\
\hline T. 213 & 7 & 1 & 3 & 1 & Sandstone & Plane & T. 633 & 7 & 1 & 3 & 1 & Sandstone & Inclined \\
\hline T. 214 & 7 & 1 & 4 & 1 & Sandstone & Plane & T. 634 & 7 & 1 & 4 & 1 & Sandstone & Inclined \\
\hline T. 215 & 7 & 1 & 5 & 1 & Sandstone & Plane & T. 635 & 7 & 1 & 5 & 1 & Sandstone & Inclined \\
\hline T. 216 & 7 & 1 & 6 & 1 & Sandstone & Plane & T. 636 & 7 & 1 & 6 & 1 & Sandstone & Inclined \\
\hline T. 217 & 7 & 1 & 7 & 1 & Sandstone & Plane & T. 637 & 7 & 1 & 7 & 1 & Sandstone & Inclined \\
\hline T. 218 & 7 & 1 & 8 & 1 & Sandstone & Plane & T. 638 & 7 & 1 & 8 & 1 & Sandstone & Inclined \\
\hline T. 219 & 7 & 1 & 9 & 1 & Sandstone & Plane & T. 639 & 7 & 1 & 9 & 1 & Sandstone & Inclined \\
\hline T. 220 & 6 & 1 & 10 & 1 & Sandstone & Plane & T. 640 & 6 & 1 & 10 & 1 & Sandstone & Inclined \\
\hline T. 221 & 7 & 1 & 11 & 1 & Sandstone & Plane & T. 641 & 7 & 1 & 11 & 1 & Sandstone & Inclined \\
\hline T. 222 & 7 & 1 & 12 & 1 & Sandstone & Plane & T. 642 & 7 & 1 & 12 & 1 & Sandstone & Inclined \\
\hline T. 223 & 7 & 1 & 13 & 1 & Sandstone & Plane & T. 643 & 7 & 1 & 13 & 1 & Sandstone & Inclined \\
\hline T. 224 & 7 & 1 & 14 & 1 & Sandstone & Plane & T. 644 & 7 & 1 & 14 & 1 & Sandstone & Inclined \\
\hline T. 225 & 7 & 1 & 15 & 1 & Sandstone & Plane & T. 645 & 7 & 1 & 15 & 1 & Sandstone & Inclined \\
\hline T. 226 & 8 & 1 & 1 & 1.3 & Sandstone & Plane & T. 646 & 8 & 1 & 1 & 1.3 & Sandstone & Inclined \\
\hline T. 227 & 8 & 1 & 2 & 1.3 & Sandstone & Plane & T. 647 & 8 & 1 & 2 & 1.3 & Sandstone & Inclined \\
\hline T. 228 & 8 & 1 & 3 & 1.3 & Sandstone & Plane & T. 648 & 8 & 1 & 3 & 1.3 & Sandstone & Inclined \\
\hline T. 229 & 8 & 1 & 4 & 1.3 & Sandstone & Plane & T. 649 & 8 & 1 & 4 & 1.3 & Sandstone & Inclined \\
\hline T. 230 & 8 & 1 & 5 & 1.3 & Sandstone & Plane & T. 650 & 8 & 1 & 5 & 1.3 & Sandstone & Inclined \\
\hline
\end{tabular}

(cont. on next page) 
Table E.1. (cont.)

\begin{tabular}{|c|c|c|c|c|c|c|c|c|c|c|c|c|c|}
\hline T. 231 & 8 & 1 & 6 & 1.3 & Sandstone & Plane & T. 651 & 8 & 1 & 6 & 1.3 & Sandstone & Inclined \\
\hline T. 232 & 8 & 1 & 7 & 1.3 & Sandstone & Plane & T. 652 & 8 & 1 & 7 & 1.3 & Sandstone & Inclined \\
\hline T. 233 & 8 & 1 & 8 & 1.3 & Sandstone & Plane & T. 653 & 8 & 1 & 8 & 1.3 & Sandstone & Inclined \\
\hline T. 234 & 8 & 1 & 9 & 1.3 & Sandstone & Plane & T. 654 & 8 & 1 & 9 & 1.3 & Sandstone & Inclined \\
\hline T. 235 & 8 & 1 & 10 & 1.3 & Sandstone & Plane & T. 655 & 8 & 1 & 10 & 1.3 & Sandstone & Inclined \\
\hline T. 236 & 8 & 1 & 11 & 1.3 & Sandstone & Plane & T. 656 & 8 & 1 & 11 & 1.3 & Sandstone & Inclined \\
\hline T. 237 & 8 & 1 & 12 & 1.3 & Sandstone & Plane & T. 657 & 8 & 1 & 12 & 1.3 & Sandstone & Inclined \\
\hline T. 238 & 8 & 1 & 13 & 1.3 & Sandstone & Plane & T. 658 & 8 & 1 & 13 & 1.3 & Sandstone & Inclined \\
\hline T. 239 & 8 & 1 & 14 & 1.3 & Sandstone & Plane & T. 659 & 8 & 1 & 14 & 1.3 & Sandstone & Inclined \\
\hline T. 240 & 8 & 1 & 15 & 1.3 & Sandstone & Plane & T. 660 & 8 & 1 & 15 & 1.3 & Sandstone & Inclined \\
\hline T. 241 & 11 & 1 & 1 & 1.6 & Sandstone & Plane & T. 661 & 11 & 1 & 1 & 1.6 & Sandstone & Inclined \\
\hline T. 242 & 11 & 1 & 2 & 1.6 & Sandstone & Plane & T. 662 & 11 & 1 & 2 & 1.6 & Sandstone & Inclined \\
\hline T. 243 & 11 & 1 & 3 & 1.6 & Sandstone & Plane & T. 663 & 11 & 1 & 3 & 1.6 & Sandstone & Inclined \\
\hline T. 244 & 11 & 1 & 4 & 1.6 & Sandstone & Plane & T. 664 & 11 & 1 & 4 & 1.6 & Sandstone & Inclined \\
\hline T. 245 & 11 & 1 & 5 & 1.6 & Sandstone & Plane & T. 665 & 11 & 1 & 5 & 1.6 & Sandstone & Inclined \\
\hline T. 246 & 11 & 1 & 6 & 1.6 & Sandstone & Plane & T. 666 & 11 & 1 & 6 & 1.6 & Sandstone & Inclined \\
\hline T. 247 & 11 & 1 & 7 & 1.6 & Sandstone & Plane & T. 667 & 11 & 1 & 7 & 1.6 & Sandstone & Inclined \\
\hline T. 248 & 11 & 1 & 8 & 1.6 & Sandstone & Plane & T. 668 & 11 & 1 & 8 & 1.6 & Sandstone & Inclined \\
\hline T. 249 & 10 & 1 & 9 & 1.6 & Sandstone & Plane & T. 669 & 10 & 1 & 9 & 1.6 & Sandstone & Inclined \\
\hline T. 250 & 9 & 1 & 10 & 1.6 & Sandstone & Plane & T. 670 & 9 & 1 & 10 & 1.6 & Sandstone & Inclined \\
\hline T. 251 & 10 & 1 & 11 & 1.6 & Sandstone & Plane & T. 671 & 10 & 1 & 11 & 1.6 & Sandstone & Inclined \\
\hline T. 252 & 10 & 1 & 12 & 1.6 & Sandstone & Plane & T. 672 & 10 & 1 & 12 & 1.6 & Sandstone & Inclined \\
\hline T. 253 & 10 & 1 & 13 & 1.6 & Sandstone & Plane & T. 673 & 10 & 1 & 13 & 1.6 & Sandstone & Inclined \\
\hline T. 254 & 10 & 1 & 14 & 1.6 & Sandstone & Plane & T. 674 & 10 & 1 & 14 & 1.6 & Sandstone & Inclined \\
\hline T. 255 & 11 & 1 & 15 & 1.6 & Sandstone & Plane & T. 675 & 11 & 1 & 15 & 1.6 & Sandstone & Inclined \\
\hline T. 256 & 11 & 1 & 1 & 1.8 & Sandstone & Plane & T. 676 & 11 & 1 & 1 & 1.8 & Sandstone & Inclined \\
\hline T. 257 & 11 & 1 & 2 & 1.8 & Sandstone & Plane & T. 677 & 11 & 1 & 2 & 1.8 & Sandstone & Inclined \\
\hline T. 258 & 11 & 1 & 3 & 1.8 & Sandstone & Plane & T. 678 & 11 & 1 & 3 & 1.8 & Sandstone & Inclined \\
\hline T. 259 & 11 & 1 & 4 & 1.8 & Sandstone & Plane & T. 679 & 11 & 1 & 4 & 1.8 & Sandstone & Inclined \\
\hline T. 260 & 11 & 1 & 5 & 1.8 & Sandstone & Plane & T. 680 & 11 & 1 & 5 & 1.8 & Sandstone & Inclined \\
\hline T. 261 & 11 & 1 & 6 & 1.8 & Sandstone & Plane & T. 681 & 11 & 1 & 6 & 1.8 & Sandstone & Inclined \\
\hline T. 262 & 11 & 1 & 7 & 1.8 & Sandstone & Plane & T. 682 & 11 & 1 & 7 & 1.8 & Sandstone & Inclined \\
\hline T. 263 & 11 & 1 & 8 & 1.8 & Sandstone & Plane & T. 683 & 11 & 1 & 8 & 1.8 & Sandstone & Inclined \\
\hline
\end{tabular}

(cont. on next page) 
Table E.1. (cont.)

\begin{tabular}{|c|c|c|c|c|c|c|c|c|c|c|c|c|c|}
\hline T. 264 & 10 & 1 & 9 & 1.8 & Sandstone & Plane & T. 684 & 10 & 1 & 9 & 1.8 & Sandstone & Inclined \\
\hline T. 265 & 9 & 1 & 10 & 1.8 & Sandstone & Plane & T. 685 & 9 & 1 & 10 & 1.8 & Sandstone & Inclined \\
\hline T. 266 & 10 & 1 & 11 & 1.8 & Sandstone & Plane & T. 686 & 10 & 1 & 11 & 1.8 & Sandstone & Inclined \\
\hline T. 267 & 10 & 1 & 12 & 1.8 & Sandstone & Plane & T. 687 & 10 & 1 & 12 & 1.8 & Sandstone & Inclined \\
\hline T. 268 & 10 & 1 & 13 & 1.8 & Sandstone & Plane & T. 688 & 10 & 1 & 13 & 1.8 & Sandstone & Inclined \\
\hline T. 269 & 10 & 1 & 14 & 1.8 & Sandstone & Plane & T. 689 & 10 & 1 & 14 & 1.8 & Sandstone & Inclined \\
\hline T. 270 & 11 & 1 & 15 & 1.8 & Sandstone & Plane & T. 690 & 11 & 1 & 15 & 1.8 & Sandstone & Inclined \\
\hline T. 271 & 11 & 1 & 1 & 2 & Sandstone & Plane & T. 691 & 11 & 1 & 1 & 2 & Sandstone & Inclined \\
\hline T. 272 & 11 & 1 & 2 & 2 & Sandstone & Plane & T. 692 & 11 & 1 & 2 & 2 & Sandstone & Inclined \\
\hline T. 273 & 11 & 1 & 3 & 2 & Sandstone & Plane & T. 693 & 11 & 1 & 3 & 2 & Sandstone & Inclined \\
\hline T. 274 & 11 & 1 & 4 & 2 & Sandstone & Plane & T. 694 & 11 & 1 & 4 & 2 & Sandstone & Inclined \\
\hline T. 275 & 11 & 1 & 5 & 2 & Sandstone & Plane & T. 695 & 11 & 1 & 5 & 2 & Sandstone & Inclined \\
\hline T. 276 & 11 & 1 & 6 & 2 & Sandstone & Plane & T. 696 & 11 & 1 & 6 & 2 & Sandstone & Inclined \\
\hline T. 277 & 11 & 1 & 7 & 2 & Sandstone & Plane & T. 697 & 11 & 1 & 7 & 2 & Sandstone & Inclined \\
\hline T. 278 & 11 & 1 & 8 & 2 & Sandstone & Plane & T. 698 & 11 & 1 & 8 & 2 & Sandstone & Inclined \\
\hline T. 279 & 10 & 1 & 9 & 2 & Sandstone & Plane & T. 699 & 10 & 1 & 9 & 2 & Sandstone & Inclined \\
\hline T. 280 & 8 & 1 & 10 & 2 & Sandstone & Plane & T. 700 & 8 & 1 & 10 & 2 & Sandstone & Inclined \\
\hline T. 281 & 9 & 1 & 11 & 2 & Sandstone & Plane & T. 701 & 9 & 1 & 11 & 2 & Sandstone & Inclined \\
\hline T. 282 & 10 & 1 & 12 & 2 & Sandstone & Plane & T. 702 & 10 & 1 & 12 & 2 & Sandstone & Inclined \\
\hline T. 283 & 10 & 1 & 13 & 2 & Sandstone & Plane & T. 703 & 10 & 1 & 13 & 2 & Sandstone & Inclined \\
\hline T. 284 & 10 & 1 & 14 & 2 & Sandstone & Plane & T. 704 & 10 & 1 & 14 & 2 & Sandstone & Inclined \\
\hline T. 285 & 9 & 1 & 15 & 2 & Sandstone & Plane & T. 705 & 9 & 1 & 15 & 2 & Sandstone & Inclined \\
\hline T. 286 & 11 & 1 & 1 & 2.3 & Sandstone & Plane & T. 706 & 11 & 1 & 1 & 2.3 & Sandstone & Inclined \\
\hline T. 287 & 11 & 1 & 2 & 2.3 & Sandstone & Plane & T. 707 & 11 & 1 & 2 & 2.3 & Sandstone & Inclined \\
\hline T. 288 & 11 & 1 & 3 & 2.3 & Sandstone & Plane & T. 708 & 11 & 1 & 3 & 2.3 & Sandstone & Inclined \\
\hline T. 289 & 11 & 1 & 4 & 2.3 & Sandstone & Plane & T. 709 & 11 & 1 & 4 & 2.3 & Sandstone & Inclined \\
\hline T. 290 & 11 & 1 & 5 & 2.3 & Sandstone & Plane & T. 710 & 11 & 1 & 5 & 2.3 & Sandstone & Inclined \\
\hline T. 291 & 11 & 1 & 6 & 2.3 & Sandstone & Plane & T. 711 & 11 & 1 & 6 & 2.3 & Sandstone & Inclined \\
\hline T. 292 & 11 & 1 & 7 & 2.3 & Sandstone & Plane & T. 712 & 11 & 1 & 7 & 2.3 & Sandstone & Inclined \\
\hline T. 293 & 11 & 1 & 8 & 2.3 & Sandstone & Plane & T. 713 & 11 & 1 & 8 & 2.3 & Sandstone & Inclined \\
\hline T. 294 & 10 & 1 & 9 & 2.3 & Sandstone & Plane & T. 714 & 10 & 1 & 9 & 2.3 & Sandstone & Inclined \\
\hline T. 295 & 8 & 1 & 10 & 2.3 & Sandstone & Plane & T. 715 & 8 & 1 & 10 & 2.3 & Sandstone & Inclined \\
\hline T. 296 & 8 & 1 & 11 & 2.3 & Sandstone & Plane & T. 716 & 8 & 1 & 11 & 2.3 & Sandstone & Inclined \\
\hline
\end{tabular}


Table E.1. (cont.)

\begin{tabular}{|c|c|c|c|c|c|c|c|c|c|c|c|c|c|}
\hline T. 297 & 10 & 1 & 12 & 2.3 & Sandstone & Plane & T. 717 & 10 & 1 & 12 & 2.3 & Sandstone & Inclined \\
\hline T. 298 & 10 & 1 & 13 & 2.3 & Sandstone & Plane & T. 718 & 10 & 1 & 13 & 2.3 & Sandstone & Inclined \\
\hline T. 299 & 10 & 1 & 14 & 2.3 & Sandstone & Plane & T. 719 & 10 & 1 & 14 & 2.3 & Sandstone & Inclined \\
\hline T. 300 & 9 & 1 & 15 & 2.3 & Sandstone & Plane & T. 720 & 9 & 1 & 15 & 2.3 & Sandstone & Inclined \\
\hline T. 301 & 10 & 1 & 1 & 2.5 & Sandstone & Plane & T. 721 & 10 & 1 & 1 & 2.5 & Sandstone & Inclined \\
\hline T. 302 & 10 & 1 & 2 & 2.5 & Sandstone & Plane & T. 722 & 10 & 1 & 2 & 2.5 & Sandstone & Inclined \\
\hline T. 303 & 10 & 1 & 3 & 2.5 & Sandstone & Plane & T. 723 & 10 & 1 & 3 & 2.5 & Sandstone & Inclined \\
\hline T. 304 & 10 & 1 & 4 & 2.5 & Sandstone & Plane & T. 724 & 10 & 1 & 4 & 2.5 & Sandstone & Inclined \\
\hline T. 305 & 10 & 1 & 5 & 2.5 & Sandstone & Plane & T. 725 & 10 & 1 & 5 & 2.5 & Sandstone & Inclined \\
\hline T. 306 & 10 & 1 & 6 & 2.5 & Sandstone & Plane & T. 726 & 10 & 1 & 6 & 2.5 & Sandstone & Inclined \\
\hline T. 307 & 10 & 1 & 7 & 2.5 & Sandstone & Plane & T. 727 & 10 & 1 & 7 & 2.5 & Sandstone & Inclined \\
\hline T. 308 & 10 & 1 & 8 & 2.5 & Sandstone & Plane & T. 728 & 10 & 1 & 8 & 2.5 & Sandstone & Inclined \\
\hline T. 309 & 9 & 1 & 9 & 2.5 & Sandstone & Plane & T. 729 & 9 & 1 & 9 & 2.5 & Sandstone & Inclined \\
\hline T. 310 & 8 & 1 & 10 & 2.5 & Sandstone & Plane & T. 730 & 8 & 1 & 10 & 2.5 & Sandstone & Inclined \\
\hline T. 311 & 8 & 1 & 11 & 2.5 & Sandstone & Plane & T. 731 & 8 & 1 & 11 & 2.5 & Sandstone & Inclined \\
\hline T. 312 & 9 & 1 & 12 & 2.5 & Sandstone & Plane & T. 732 & 9 & 1 & 12 & 2.5 & Sandstone & Inclined \\
\hline T. 313 & 9 & 1 & 13 & 2.5 & Sandstone & Plane & T. 733 & 9 & 1 & 13 & 2.5 & Sandstone & Inclined \\
\hline T. 314 & 8 & 1 & 14 & 2.5 & Sandstone & Plane & T. 734 & 8 & 1 & 14 & 2.5 & Sandstone & Inclined \\
\hline T. 315 & 8 & 1 & 15 & 2.5 & Sandstone & Plane & T. 735 & 8 & 1 & 15 & 2.5 & Sandstone & Inclined \\
\hline T. 316 & 6 & 1 & 1 & 1 & Brick & Plane & T. 736 & 7 & 1 & 1 & 1 & Brick & Inclined \\
\hline T. 317 & 6 & 1 & 2 & 1 & Brick & Plane & T. 737 & 7 & 1 & 2 & 1 & Brick & Inclined \\
\hline T. 318 & 6 & 1 & 3 & 1 & Brick & Plane & T. 738 & 7 & 1 & 3 & 1 & Brick & Inclined \\
\hline T. 319 & 6 & 1 & 4 & 1 & Brick & Plane & T. 739 & 7 & 1 & 4 & 1 & Brick & Inclined \\
\hline T. 320 & 6 & 1 & 5 & 1 & Brick & Plane & T. 740 & 7 & 1 & 5 & 1 & Brick & Inclined \\
\hline T. 321 & 6 & 1 & 6 & 1 & Brick & Plane & T. 741 & 7 & 1 & 6 & 1 & Brick & Inclined \\
\hline T. 322 & 6 & 1 & 7 & 1 & Brick & Plane & T. 742 & 7 & 1 & 7 & 1 & Brick & Inclined \\
\hline T. 323 & 6 & 1 & 8 & 1 & Brick & Plane & T. 743 & 7 & 1 & 8 & 1 & Brick & Inclined \\
\hline T. 324 & 6 & 1 & 9 & 1 & Brick & Plane & T. 744 & 7 & 1 & 9 & 1 & Brick & Inclined \\
\hline T. 325 & 6 & 1 & 10 & 1 & Brick & Plane & T. 745 & 7 & 1 & 10 & 1 & Brick & Inclined \\
\hline T. 326 & 6 & 1 & 11 & 1 & Brick & Plane & T. 746 & 7 & 1 & 11 & 1 & Brick & Inclined \\
\hline T. 327 & 6 & 1 & 12 & 1 & Brick & Plane & T. 747 & 7 & 1 & 12 & 1 & Brick & Inclined \\
\hline T. 328 & 6 & 1 & 13 & 1 & Brick & Plane & T. 748 & 7 & 1 & 13 & 1 & Brick & Inclined \\
\hline T. 329 & 6 & 1 & 14 & 1 & Brick & Plane & T. 749 & 7 & 1 & 14 & 1 & Brick & Inclined \\
\hline
\end{tabular}

(cont. on next page) 
Table E.1. (cont.)

\begin{tabular}{|c|c|c|c|c|c|c|c|c|c|c|c|c|c|}
\hline T. 330 & 6 & 1 & 15 & 1 & Brick & Plane & T. 750 & 7 & 1 & 15 & 1 & Brick & Inclined \\
\hline T. 331 & 7 & 1 & 1 & 1.3 & Brick & Plane & T. 751 & 8 & 1 & 1 & 1.3 & Brick & Inclined \\
\hline T. 332 & 7 & 1 & 2 & 1.3 & Brick & Plane & T. 752 & 8 & 1 & 2 & 1.3 & Brick & Inclined \\
\hline T. 333 & 7 & 1 & 3 & 1.3 & Brick & Plane & T. 753 & 8 & 1 & 3 & 1.3 & Brick & Inclined \\
\hline T. 334 & 7 & 1 & 4 & 1.3 & Brick & Plane & T. 754 & 8 & 1 & 4 & 1.3 & Brick & Inclined \\
\hline T. 335 & 7 & 1 & 5 & 1.3 & Brick & Plane & T. 755 & 8 & 1 & 5 & 1.3 & Brick & Inclined \\
\hline T. 336 & 7 & 1 & 6 & 1.3 & Brick & Plane & T. 756 & 8 & 1 & 6 & 1.3 & Brick & Inclined \\
\hline T. 337 & 7 & 1 & 7 & 1.3 & Brick & Plane & T. 757 & 8 & 1 & 7 & 1.3 & Brick & Inclined \\
\hline T. 338 & 7 & 1 & 8 & 1.3 & Brick & Plane & T. 758 & 8 & 1 & 8 & 1.3 & Brick & Inclined \\
\hline T. 339 & 7 & 1 & 9 & 1.3 & Brick & Plane & T. 759 & 8 & 1 & 9 & 1.3 & Brick & Inclined \\
\hline T. 340 & 7 & 1 & 10 & 1.3 & Brick & Plane & T. 760 & 8 & 1 & 10 & 1.3 & Brick & Inclined \\
\hline T. 341 & 7 & 1 & 11 & 1.3 & Brick & Plane & T. 761 & 8 & 1 & 11 & 1.3 & Brick & Inclined \\
\hline T. 342 & 7 & 1 & 12 & 1.3 & Brick & Plane & T. 762 & 8 & 1 & 12 & 1.3 & Brick & Inclined \\
\hline T. 343 & 7 & 1 & 13 & 1.3 & Brick & Plane & T. 763 & 8 & 1 & 13 & 1.3 & Brick & Inclined \\
\hline T. 344 & 7 & 1 & 14 & 1.3 & Brick & Plane & T. 764 & 8 & 1 & 14 & 1.3 & Brick & Inclined \\
\hline T. 345 & 7 & 1 & 15 & 1.3 & Brick & Plane & T. 765 & 8 & 1 & 15 & 1.3 & Brick & Inclined \\
\hline T. 346 & 10 & 1 & 1 & 1.6 & Brick & Plane & T. 766 & 11 & 1 & 1 & 1.6 & Brick & Inclined \\
\hline T. 347 & 10 & 1 & 2 & 1.6 & Brick & Plane & T. 767 & 11 & 1 & 2 & 1.6 & Brick & Inclined \\
\hline T. 348 & 10 & 1 & 3 & 1.6 & Brick & Plane & T. 768 & 11 & 1 & 3 & 1.6 & Brick & Inclined \\
\hline T. 349 & 10 & 1 & 4 & 1.6 & Brick & Plane & T. 769 & 11 & 1 & 4 & 1.6 & Brick & Inclined \\
\hline T. 350 & 10 & 1 & 5 & 1.6 & Brick & Plane & T. 770 & 11 & 1 & 5 & 1.6 & Brick & Inclined \\
\hline T. 351 & 10 & 1 & 6 & 1.6 & Brick & Plane & T. 771 & 11 & 1 & 6 & 1.6 & Brick & Inclined \\
\hline T. 352 & 10 & 1 & 7 & 1.6 & Brick & Plane & T. 772 & 11 & 1 & 7 & 1.6 & Brick & Inclined \\
\hline T. 353 & 10 & 1 & 8 & 1.6 & Brick & Plane & T. 773 & 11 & 1 & 8 & 1.6 & Brick & Inclined \\
\hline T. 354 & 10 & 1 & 9 & 1.6 & Brick & Plane & T. 774 & 11 & 1 & 9 & 1.6 & Brick & Inclined \\
\hline T. 355 & 8 & 1 & 10 & 1.6 & Brick & Plane & T. 775 & 9 & 1 & 10 & 1.6 & Brick & Inclined \\
\hline T. 356 & 9 & 1 & 11 & 1.6 & Brick & Plane & T. 776 & 10 & 1 & 11 & 1.6 & Brick & Inclined \\
\hline T. 357 & 9 & 1 & 12 & 1.6 & Brick & Plane & T. 777 & 10 & 1 & 12 & 1.6 & Brick & Inclined \\
\hline T. 358 & 9 & 1 & 13 & 1.6 & Brick & Plane & T. 778 & 10 & 1 & 13 & 1.6 & Brick & Inclined \\
\hline T. 359 & 9 & 1 & 14 & 1.6 & Brick & Plane & T. 779 & 10 & 1 & 14 & 1.6 & Brick & Inclined \\
\hline T. 360 & 9 & 1 & 15 & 1.6 & Brick & Plane & T. 780 & 10 & 1 & 15 & 1.6 & Brick & Inclined \\
\hline T. 361 & 10 & 1 & 1 & 1.8 & Brick & Plane & T. 781 & 11 & 1 & 1 & 1.8 & Brick & Inclined \\
\hline T. 362 & 10 & 1 & 2 & 1.8 & Brick & Plane & T. 782 & 11 & 1 & 2 & 1.8 & Brick & Inclined \\
\hline
\end{tabular}

(cont. on next page) 
Table E.1. (cont.)

\begin{tabular}{|c|c|c|c|c|c|c|c|c|c|c|c|c|c|}
\hline T. 363 & 10 & 1 & 3 & 1.8 & Brick & Plane & T. 783 & 11 & 1 & 3 & 1.8 & Brick & Inclined \\
\hline T. 364 & 10 & 1 & 4 & 1.8 & Brick & Plane & T. 784 & 11 & 1 & 4 & 1.8 & Brick & Inclined \\
\hline T. 365 & 10 & 1 & 5 & 1.8 & Brick & Plane & T. 785 & 11 & 1 & 5 & 1.8 & Brick & Inclined \\
\hline T. 366 & 10 & 1 & 6 & 1.8 & Brick & Plane & T. 786 & 11 & 1 & 6 & 1.8 & Brick & Inclined \\
\hline T. 367 & 10 & 1 & 7 & 1.8 & Brick & Plane & T. 787 & 11 & 1 & 7 & 1.8 & Brick & Inclined \\
\hline T. 368 & 10 & 1 & 8 & 1.8 & Brick & Plane & T. 788 & 11 & 1 & 8 & 1.8 & Brick & Inclined \\
\hline T. 369 & 10 & 1 & 9 & 1.8 & Brick & Plane & T. 789 & 11 & 1 & 9 & 1.8 & Brick & Inclined \\
\hline T. 370 & 8 & 1 & 10 & 1.8 & Brick & Plane & T. 790 & 9 & 1 & 10 & 1.8 & Brick & Inclined \\
\hline T. 371 & 9 & 1 & 11 & 1.8 & Brick & Plane & T. 791 & 10 & 1 & 11 & 1.8 & Brick & Inclined \\
\hline T. 372 & 9 & 1 & 12 & 1.8 & Brick & Plane & T. 792 & 10 & 1 & 12 & 1.8 & Brick & Inclined \\
\hline T. 373 & 9 & 1 & 13 & 1.8 & Brick & Plane & T. 793 & 10 & 1 & 13 & 1.8 & Brick & Inclined \\
\hline T. 374 & 9 & 1 & 14 & 1.8 & Brick & Plane & T. 794 & 10 & 1 & 14 & 1.8 & Brick & Inclined \\
\hline T. 375 & 9 & 1 & 15 & 1.8 & Brick & Plane & T. 795 & 10 & 1 & 15 & 1.8 & Brick & Inclined \\
\hline T. 376 & 10 & 1 & 1 & 2 & Brick & Plane & T. 796 & 11 & 1 & 1 & 2 & Brick & Inclined \\
\hline T. 377 & 10 & 1 & 2 & 2 & Brick & Plane & T. 797 & 11 & 1 & 2 & 2 & Brick & Inclined \\
\hline T. 378 & 10 & 1 & 3 & 2 & Brick & Plane & T. 798 & 11 & 1 & 3 & 2 & Brick & Inclined \\
\hline T. 379 & 10 & 1 & 4 & 2 & Brick & Plane & T. 799 & 11 & 1 & 4 & 2 & Brick & Inclined \\
\hline T. 380 & 10 & 1 & 5 & 2 & Brick & Plane & T. 800 & 11 & 1 & 5 & 2 & Brick & Inclined \\
\hline T. 381 & 10 & 1 & 6 & 2 & Brick & Plane & T. 801 & 11 & 1 & 6 & 2 & Brick & Inclined \\
\hline T. 382 & 10 & 1 & 7 & 2 & Brick & Plane & T. 802 & 11 & 1 & 7 & 2 & Brick & Inclined \\
\hline T. $\mathbf{3 8 3}$ & 10 & 1 & 8 & 2 & Brick & Plane & T. 803 & 11 & 1 & 8 & 2 & Brick & Inclined \\
\hline T. 384 & 10 & 1 & 9 & 2 & Brick & Plane & T. 804 & 11 & 1 & 9 & 2 & Brick & Inclined \\
\hline T. 385 & 8 & 1 & 10 & 2 & Brick & Plane & T. 805 & 9 & 1 & 10 & 2 & Brick & Inclined \\
\hline T. 386 & 9 & 1 & 11 & 2 & Brick & Plane & T. 806 & 10 & 1 & 11 & 2 & Brick & Inclined \\
\hline T. 387 & 9 & 1 & 12 & 2 & Brick & Plane & T. 807 & 10 & 1 & 12 & 2 & Brick & Inclined \\
\hline T. 388 & 9 & 1 & 13 & 2 & Brick & Plane & T. 808 & 10 & 1 & 13 & 2 & Brick & Inclined \\
\hline T. 389 & 9 & 1 & 14 & 2 & Brick & Plane & T. 809 & 10 & 1 & 14 & 2 & Brick & Inclined \\
\hline T. 390 & 9 & 1 & 15 & 2 & Brick & Plane & T. 810 & 10 & 1 & 15 & 2 & Brick & Inclined \\
\hline T. 391 & 10 & 1 & 1 & 2.3 & Brick & Plane & T. 811 & 11 & 1 & 1 & 2.3 & Brick & Inclined \\
\hline T. 392 & 10 & 1 & 2 & 2.3 & Brick & Plane & T. 812 & 11 & 1 & 2 & 2.3 & Brick & Inclined \\
\hline T. 393 & 10 & 1 & 3 & 2.3 & Brick & Plane & T. 813 & 11 & 1 & 3 & 2.3 & Brick & Inclined \\
\hline T. 394 & 10 & 1 & 4 & 2.3 & Brick & Plane & T. 814 & 11 & 1 & 4 & 2.3 & Brick & Inclined \\
\hline T. 395 & 10 & 1 & 5 & 2.3 & Brick & Plane & T. 815 & 11 & 1 & 5 & 2.3 & Brick & Inclined \\
\hline
\end{tabular}

(cont. on next page) 
Table E.1. (cont.)

\begin{tabular}{|c|c|c|c|c|c|c|c|c|c|c|c|c|c|}
\hline T. 396 & 10 & 1 & 6 & 2.3 & Brick & Plane & T. 816 & 11 & 1 & 6 & 2.3 & Brick & Inclined \\
\hline T. 397 & 10 & 1 & 7 & 2.3 & Brick & Plane & T. 817 & 11 & 1 & 7 & 2.3 & Brick & Inclined \\
\hline T. 398 & 10 & 1 & 8 & 2.3 & Brick & Plane & T. 818 & 11 & 1 & 8 & 2.3 & Brick & Inclined \\
\hline T. 399 & 10 & 1 & 9 & 2.3 & Brick & Plane & T. 819 & 11 & 1 & 9 & 2.3 & Brick & Inclined \\
\hline T. 400 & 8 & 1 & 10 & 2.3 & Brick & Plane & T. 820 & 9 & 1 & 10 & 2.3 & Brick & Inclined \\
\hline T. 401 & 9 & 1 & 11 & 2.3 & Brick & Plane & T. 821 & 10 & 1 & 11 & 2.3 & Brick & Inclined \\
\hline T. 402 & 9 & 1 & 12 & 2.3 & Brick & Plane & T. 822 & 10 & 1 & 12 & 2.3 & Brick & Inclined \\
\hline T. 403 & 9 & 1 & 13 & 2.3 & Brick & Plane & T. 823 & 10 & 1 & 13 & 2.3 & Brick & Inclined \\
\hline T. 404 & 9 & 1 & 14 & 2.3 & Brick & Plane & T. 824 & 10 & 1 & 14 & 2.3 & Brick & Inclined \\
\hline T. 405 & 9 & 1 & 15 & 2.3 & Brick & Plane & T. 825 & 10 & 1 & 15 & 2.3 & Brick & Inclined \\
\hline T. 406 & 9 & 1 & 1 & 2.5 & Brick & Plane & T. 826 & 10 & 1 & 1 & 2.5 & Brick & Inclined \\
\hline T. 407 & 9 & 1 & 2 & 2.5 & Brick & Plane & T. 827 & 10 & 1 & 2 & 2.5 & Brick & Inclined \\
\hline T. 408 & 9 & 1 & 3 & 2.5 & Brick & Plane & T. 828 & 10 & 1 & 3 & 2.5 & Brick & Inclined \\
\hline T. 409 & 9 & 1 & 4 & 2.5 & Brick & Plane & T. 829 & 10 & 1 & 4 & 2.5 & Brick & Inclined \\
\hline T. 410 & 9 & 1 & 5 & 2.5 & Brick & Plane & T. 830 & 10 & 1 & 5 & 2.5 & Brick & Inclined \\
\hline T. 411 & 9 & 1 & 6 & 2.5 & Brick & Plane & T. 831 & 10 & 1 & 6 & 2.5 & Brick & Inclined \\
\hline T. 412 & 9 & 1 & 7 & 2.5 & Brick & Plane & T. 832 & 10 & 1 & 7 & 2.5 & Brick & Inclined \\
\hline T. 413 & 9 & 1 & 8 & 2.5 & Brick & Plane & T. 833 & 10 & 1 & 8 & 2.5 & Brick & Inclined \\
\hline T. 414 & 9 & 1 & 9 & 2.5 & Brick & Plane & T. 834 & 10 & 1 & 9 & 2.5 & Brick & Inclined \\
\hline T. 415 & 7 & 1 & 10 & 2.5 & Brick & Plane & T. 835 & 8 & 1 & 10 & 2.5 & Brick & Inclined \\
\hline T. 416 & 8 & 1 & 11 & 2.5 & Brick & Plane & T. 836 & 9 & 1 & 11 & 2.5 & Brick & Inclined \\
\hline T. 417 & 9 & 1 & 12 & 2.5 & Brick & Plane & T. 837 & 10 & 1 & 12 & 2.5 & Brick & Inclined \\
\hline T. 418 & 10 & 1 & 13 & 2.5 & Brick & Plane & T. 838 & 11 & 1 & 13 & 2.5 & Brick & Inclined \\
\hline T. 419 & 8 & 1 & 14 & 2.5 & Brick & Plane & T. 839 & 9 & 1 & 14 & 2.5 & Brick & Inclined \\
\hline T. 420 & 8 & 1 & 15 & 2.5 & Brick & Plane & T. 840 & 9 & 1 & 15 & 2.5 & Brick & Inclined \\
\hline T. 841 & 9 & 2 & 1 & 1 & Granite & Plane & T. 1261 & 10 & 2 & 1 & 1 & Granite & Inclined \\
\hline T. 842 & 9 & 2 & 2 & 1 & Granite & Plane & T. 1262 & 10 & 2 & 2 & 1 & Granite & Inclined \\
\hline T. 843 & 9 & 2 & 3 & 1 & Granite & Plane & T. 1263 & 10 & 2 & 3 & 1 & Granite & Inclined \\
\hline T. 844 & 9 & 2 & 4 & 1 & Granite & Plane & T. 1264 & 10 & 2 & 4 & 1 & Granite & Inclined \\
\hline T. 845 & 9 & 2 & 5 & 1 & Granite & Plane & T. 1265 & 10 & 2 & 5 & 1 & Granite & Inclined \\
\hline T. 846 & 9 & 2 & 6 & 1 & Granite & Plane & T. 1266 & 10 & 2 & 6 & 1 & Granite & Inclined \\
\hline T. 847 & 9 & 2 & 7 & 1 & Granite & Plane & T. 1267 & 10 & 2 & 7 & 1 & Granite & Inclined \\
\hline T. 848 & 9 & 2 & 8 & 1 & Granite & Plane & T. 1268 & 10 & 2 & 8 & 1 & Granite & Inclined \\
\hline
\end{tabular}


Table E.1. (cont.)

\begin{tabular}{|c|c|c|c|c|c|c|c|c|c|c|c|c|c|}
\hline T. 849 & 9 & 2 & 9 & 1 & Granite & Plane & T. 1269 & 10 & 2 & 9 & 1 & Granite & Inclined \\
\hline T. 850 & 9 & 2 & 10 & 1 & Granite & Plane & T. 1270 & 10 & 2 & 10 & 1 & Granite & Inclined \\
\hline T. 851 & 9 & 2 & 11 & 1 & Granite & Plane & T. 1271 & 10 & 2 & 11 & 1 & Granite & Inclined \\
\hline T. 852 & 9 & 2 & 12 & 1 & Granite & Plane & T. 1272 & 10 & 2 & 12 & 1 & Granite & Inclined \\
\hline T. 853 & 9 & 2 & 13 & 1 & Granite & Plane & T. 1273 & 10 & 2 & 13 & 1 & Granite & Inclined \\
\hline T. 854 & 9 & 2 & 14 & 1 & Granite & Plane & T. 1274 & 10 & 2 & 14 & 1 & Granite & Inclined \\
\hline T. 855 & 9 & 2 & 15 & 1 & Granite & Plane & T. 1275 & 10 & 2 & 15 & 1 & Granite & Inclined \\
\hline T. 856 & 11 & 2 & 1 & 1.3 & Granite & Plane & T. 1276 & 12 & 2 & 1 & 1.3 & Granite & Inclined \\
\hline T. 857 & 11 & 2 & 2 & 1.3 & Granite & Plane & T. 1277 & 12 & 2 & 2 & 1.3 & Granite & Inclined \\
\hline T. 858 & 11 & 2 & 3 & 1.3 & Granite & Plane & T. 1278 & 12 & 2 & 3 & 1.3 & Granite & Inclined \\
\hline T. 859 & 11 & 2 & 4 & 1.3 & Granite & Plane & T. 1279 & 12 & 2 & 4 & 1.3 & Granite & Inclined \\
\hline T. 860 & 11 & 2 & 5 & 1.3 & Granite & Plane & T. 1280 & 12 & 2 & 5 & 1.3 & Granite & Inclined \\
\hline T. 861 & 11 & 2 & 6 & 1.3 & Granite & Plane & T. 1281 & 12 & 2 & 6 & 1.3 & Granite & Inclined \\
\hline T. 862 & 11 & 2 & 7 & 1.3 & Granite & Plane & T. 1282 & 12 & 2 & 7 & 1.3 & Granite & Inclined \\
\hline T. 863 & 11 & 2 & 8 & 1.3 & Granite & Plane & T. 1283 & 12 & 2 & 8 & 1.3 & Granite & Inclined \\
\hline T. 864 & 11 & 2 & 9 & 1.3 & Granite & Plane & T. 1284 & 12 & 2 & 9 & 1.3 & Granite & Inclined \\
\hline T. 865 & 10 & 2 & 10 & 1.3 & Granite & Plane & T. 1285 & 11 & 2 & 10 & 1.3 & Granite & Inclined \\
\hline T. 866 & 10 & 2 & 11 & 1.3 & Granite & Plane & T. 1286 & 11 & 2 & 11 & 1.3 & Granite & Inclined \\
\hline T. 867 & 11 & 2 & 12 & 1.3 & Granite & Plane & T. 1287 & 12 & 2 & 12 & 1.3 & Granite & Inclined \\
\hline T. 868 & 11 & 2 & 13 & 1.3 & Granite & Plane & T. 1288 & 12 & 2 & 13 & 1.3 & Granite & Inclined \\
\hline T. 869 & 11 & 2 & 14 & 1.3 & Granite & Plane & T. 1289 & 12 & 2 & 14 & 1.3 & Granite & Inclined \\
\hline T. 870 & 11 & 2 & 15 & 1.3 & Granite & Plane & T. 1290 & 12 & 2 & 15 & 1.3 & Granite & Inclined \\
\hline *T. 871 & 12 & 2 & 1 & 1.6 & Granite & Plane & *T. 1291 & 13 & 2 & 1 & 1.6 & Granite & Inclined \\
\hline *T. 872 & 12 & 2 & 2 & 1.6 & Granite & Plane & *T. 1292 & 13 & 2 & 2 & 1.6 & Granite & Inclined \\
\hline${ }^{*} \mathrm{~T} .873$ & 12 & 2 & 3 & 1.6 & Granite & Plane & *T. 1293 & 13 & 2 & 3 & 1.6 & Granite & Inclined \\
\hline *T. 874 & 12 & 2 & 4 & 1.6 & Granite & Plane & *T. 1294 & 13 & 2 & 4 & 1.6 & Granite & Inclined \\
\hline *T. 875 & 12 & 2 & 5 & 1.6 & Granite & Plane & *T. 1295 & 13 & 2 & 5 & 1.6 & Granite & Inclined \\
\hline *T. 876 & 12 & 2 & 6 & 1.6 & Granite & Plane & *T. 1296 & 13 & 2 & 6 & 1.6 & Granite & Inclined \\
\hline *T. 877 & 12 & 2 & 7 & 1.6 & Granite & Plane & *T. 1297 & 13 & 2 & 7 & 1.6 & Granite & Inclined \\
\hline *T. 878 & 12 & 2 & 8 & 1.6 & Granite & Plane & *T. 1298 & 13 & 2 & 8 & 1.6 & Granite & Inclined \\
\hline *T. 879 & 12 & 2 & 9 & 1.6 & Granite & Plane & *T. 1299 & 13 & 2 & 9 & 1.6 & Granite & Inclined \\
\hline${ }^{*} \mathrm{~T} .880$ & 11 & 2 & 10 & 1.6 & Granite & Plane & *T. 1300 & 12 & 2 & 10 & 1.6 & Granite & Inclined \\
\hline *T. 881 & 11 & 2 & 11 & 1.6 & Granite & Plane & *T. 1301 & 12 & 2 & 11 & 1.6 & Granite & Inclined \\
\hline
\end{tabular}


Table E.1. (cont.)

\begin{tabular}{|c|c|c|c|c|c|c|c|c|c|c|c|c|c|}
\hline *T. 882 & 12 & 2 & 12 & 1.6 & Granite & Plane & *T. 1302 & 13 & 2 & 12 & 1.6 & Granite & Inclined \\
\hline *T. 883 & 12 & 2 & 13 & 1.6 & Granite & Plane & ${ }^{*} \mathrm{~T} .1303$ & 13 & 2 & 13 & 1.6 & Granite & Inclined \\
\hline *T. 884 & 11 & 2 & 14 & 1.6 & Granite & Plane & *T. 1304 & 12 & 2 & 14 & 1.6 & Granite & Inclined \\
\hline *T. 885 & 11 & 2 & 15 & 1.6 & Granite & Plane & *T. 1305 & 12 & 2 & 15 & 1.6 & Granite & Inclined \\
\hline *T. 886 & 12 & 2 & 1 & 1.8 & Granite & Plane & ${ }^{*} \mathrm{~T} .1306$ & 13 & 2 & 1 & 1.8 & Granite & Inclined \\
\hline *T. 887 & 12 & 2 & 2 & 1.8 & Granite & Plane & *T. 1307 & 13 & 2 & 2 & 1.8 & Granite & Inclined \\
\hline *T. 888 & 12 & 2 & 3 & 1.8 & Granite & Plane & *T. 1308 & 13 & 2 & 3 & 1.8 & Granite & Inclined \\
\hline *T. 889 & 12 & 2 & 4 & 1.8 & Granite & Plane & *T. 1309 & 13 & 2 & 4 & 1.8 & Granite & Inclined \\
\hline *T. 890 & 12 & 2 & 5 & 1.8 & Granite & Plane & ${ }^{*} \mathrm{~T} .1310$ & 13 & 2 & 5 & 1.8 & Granite & Inclined \\
\hline *T. 891 & 12 & 2 & 6 & 1.8 & Granite & Plane & *T. 1311 & 13 & 2 & 6 & 1.8 & Granite & Inclined \\
\hline *T. 892 & 12 & 2 & 7 & 1.8 & Granite & Plane & *T. 1312 & 13 & 2 & 7 & 1.8 & Granite & Inclined \\
\hline *T. 893 & 12 & 2 & 8 & 1.8 & Granite & Plane & *T. 1313 & 13 & 2 & 8 & 1.8 & Granite & Inclined \\
\hline *T. 894 & 12 & 2 & 9 & 1.8 & Granite & Plane & *T. 1314 & 13 & 2 & 9 & 1.8 & Granite & Inclined \\
\hline *T. 895 & 11 & 2 & 10 & 1.8 & Granite & Plane & ${ }^{*} \mathrm{~T} .1315$ & 12 & 2 & 10 & 1.8 & Granite & Inclined \\
\hline *T. 896 & 11 & 2 & 11 & 1.8 & Granite & Plane & *T. 1316 & 12 & 2 & 11 & 1.8 & Granite & Inclined \\
\hline *T. 897 & 12 & 2 & 12 & 1.8 & Granite & Plane & *T. 1317 & 13 & 2 & 12 & 1.8 & Granite & Inclined \\
\hline *T. 898 & 12 & 2 & 13 & 1.8 & Granite & Plane & ${ }^{*}$ T. 1318 & 13 & 2 & 13 & 1.8 & Granite & Inclined \\
\hline *T. 899 & 11 & 2 & 14 & 1.8 & Granite & Plane & ${ }^{*} \mathrm{~T} .1319$ & 12 & 2 & 14 & 1.8 & Granite & Inclined \\
\hline *T. 900 & 11 & 2 & 15 & 1.8 & Granite & Plane & ${ }^{*} \mathrm{~T} .1320$ & 12 & 2 & 15 & 1.8 & Granite & Inclined \\
\hline *T. 901 & 11 & 2 & 1 & 2 & Granite & Plane & *T. 1321 & 12 & 2 & 1 & 2 & Granite & Inclined \\
\hline *T. 902 & 12 & 2 & 2 & 2 & Granite & Plane & *T. 1322 & 13 & 2 & 2 & 2 & Granite & Inclined \\
\hline *T. 903 & 12 & 2 & 3 & 2 & Granite & Plane & *T. 1323 & 13 & 2 & 3 & 2 & Granite & Inclined \\
\hline *T. 904 & 12 & 2 & 4 & 2 & Granite & Plane & *T. 1324 & 13 & 2 & 4 & 2 & Granite & Inclined \\
\hline *T. 905 & 12 & 2 & 5 & 2 & Granite & Plane & *T. 1325 & 13 & 2 & 5 & 2 & Granite & Inclined \\
\hline *T. 906 & 12 & 2 & 6 & 2 & Granite & Plane & *T. 1326 & 13 & 2 & 6 & 2 & Granite & Inclined \\
\hline *T. 907 & 12 & 2 & 7 & 2 & Granite & Plane & *T. 1327 & 13 & 2 & 7 & 2 & Granite & Inclined \\
\hline *T. 908 & 12 & 2 & 8 & 2 & Granite & Plane & *T. 1328 & 13 & 2 & 8 & 2 & Granite & Inclined \\
\hline *T. 909 & 11 & 2 & 9 & 2 & Granite & Plane & *T. 1329 & 12 & 2 & 9 & 2 & Granite & Inclined \\
\hline *T. 910 & 10 & 2 & 10 & 2 & Granite & Plane & *T. 1330 & 11 & 2 & 10 & 2 & Granite & Inclined \\
\hline *T. 911 & 10 & 2 & 11 & 2 & Granite & Plane & *T. 1331 & 11 & 2 & 11 & 2 & Granite & Inclined \\
\hline *T. 912 & 11 & 2 & 12 & 2 & Granite & Plane & *T. 1332 & 12 & 2 & 12 & 2 & Granite & Inclined \\
\hline *T. 913 & 11 & 2 & 13 & 2 & Granite & Plane & *T. 1333 & 12 & 2 & 13 & 2 & Granite & Inclined \\
\hline *T. 914 & 10 & 2 & 14 & 2 & Granite & Plane & *T. 1334 & 11 & 2 & 14 & 2 & Granite & Inclined \\
\hline
\end{tabular}


Table E.1. (cont.)

\begin{tabular}{|c|c|c|c|c|c|c|c|c|c|c|c|c|c|}
\hline *T. 915 & 10 & 2 & 15 & 2 & Granite & Plane & *T. 1335 & 11 & 2 & 15 & 2 & Granite & Inclined \\
\hline *T. 916 & 12 & 2 & 1 & 2.3 & Granite & Plane & *T. 1336 & 13 & 2 & 1 & 2.3 & Granite & Inclined \\
\hline *T. 917 & 12 & 2 & 2 & 2.3 & Granite & Plane & ${ }^{*} \mathrm{~T} .1337$ & 13 & 2 & 2 & 2.3 & Granite & Inclined \\
\hline *T. 918 & 12 & 2 & 3 & 2.3 & Granite & Plane & *T. 1338 & 13 & 2 & 3 & 2.3 & Granite & Inclined \\
\hline *T. 919 & 12 & 2 & 4 & 2.3 & Granite & Plane & *T. 1339 & 13 & 2 & 4 & 2.3 & Granite & Inclined \\
\hline *T. 920 & 12 & 2 & 5 & 2.3 & Granite & Plane & *T. 1340 & 13 & 2 & 5 & 2.3 & Granite & Inclined \\
\hline *T. 921 & 12 & 2 & 6 & 2.3 & Granite & Plane & *T. 1341 & 13 & 2 & 6 & 2.3 & Granite & Inclined \\
\hline *T. 922 & 12 & 2 & 7 & 2.3 & Granite & Plane & ${ }^{*} \mathrm{~T} .1342$ & 13 & 2 & 7 & 2.3 & Granite & Inclined \\
\hline *T. 923 & 12 & 2 & 8 & 2.3 & Granite & Plane & *T. 1343 & 13 & 2 & 8 & 2.3 & Granite & Inclined \\
\hline *T. 924 & 11 & 2 & 9 & 2.3 & Granite & Plane & *T. 1344 & 12 & 2 & 9 & 2.3 & Granite & Inclined \\
\hline *T. 925 & 10 & 2 & 10 & 2.3 & Granite & Plane & *T. 1345 & 11 & 2 & 10 & 2.3 & Granite & Inclined \\
\hline *T. 926 & 11 & 2 & 11 & 2.3 & Granite & Plane & ${ }^{*} \mathrm{~T} .1346$ & 12 & 2 & 11 & 2.3 & Granite & Inclined \\
\hline *T. 927 & 10 & 2 & 12 & 2.3 & Granite & Plane & *T. 1347 & 11 & 2 & 12 & 2.3 & Granite & Inclined \\
\hline *T. 928 & 10 & 2 & 13 & 2.3 & Granite & Plane & *T. 1348 & 11 & 2 & 13 & 2.3 & Granite & Inclined \\
\hline *T. 929 & 9 & 2 & 14 & 2.3 & Granite & Plane & *T. 1349 & 10 & 2 & 14 & 2.3 & Granite & Inclined \\
\hline *T. 930 & 9 & 2 & 15 & 2.3 & Granite & Plane & *T. 1350 & 10 & 2 & 15 & 2.3 & Granite & Inclined \\
\hline T. 931 & 12 & 2 & 1 & 2.5 & Granite & Plane & T. 1351 & 13 & 2 & 1 & 2.5 & Granite & Inclined \\
\hline T. 932 & 12 & 2 & 2 & 2.5 & Granite & Plane & T. 1352 & 13 & 2 & 2 & 2.5 & Granite & Inclined \\
\hline T. 933 & 12 & 2 & 3 & 2.5 & Granite & Plane & T. 1353 & 13 & 2 & 3 & 2.5 & Granite & Inclined \\
\hline T. 934 & 12 & 2 & 4 & 2.5 & Granite & Plane & T. 1354 & 13 & 2 & 4 & 2.5 & Granite & Inclined \\
\hline T. 935 & 12 & 2 & 5 & 2.5 & Granite & Plane & T. 1355 & 13 & 2 & 5 & 2.5 & Granite & Inclined \\
\hline T. 936 & 12 & 2 & 6 & 2.5 & Granite & Plane & T. 1356 & 13 & 2 & 6 & 2.5 & Granite & Inclined \\
\hline T. 937 & 12 & 2 & 7 & 2.5 & Granite & Plane & T. 1357 & 13 & 2 & 7 & 2.5 & Granite & Inclined \\
\hline T. 938 & 12 & 2 & 8 & 2.5 & Granite & Plane & Т. 1358 & 13 & 2 & 8 & 2.5 & Granite & Inclined \\
\hline T. 939 & 11 & 2 & 9 & 2.5 & Granite & Plane & T. 1359 & 12 & 2 & 9 & 2.5 & Granite & Inclined \\
\hline T. 940 & 9 & 2 & 10 & 2.5 & Granite & Plane & T. 1360 & 10 & 2 & 10 & 2.5 & Granite & Inclined \\
\hline T. 941 & 10 & 2 & 11 & 2.5 & Granite & Plane & T. 1361 & 11 & 2 & 11 & 2.5 & Granite & Inclined \\
\hline T. 942 & 9 & 2 & 12 & 2.5 & Granite & Plane & T. 1362 & 10 & 2 & 12 & 2.5 & Granite & Inclined \\
\hline T. 943 & 9 & 2 & 13 & 2.5 & Granite & Plane & T. 1363 & 10 & 2 & 13 & 2.5 & Granite & Inclined \\
\hline T. 944 & 8 & 2 & 14 & 2.5 & Granite & Plane & T. 1364 & 9 & 2 & 14 & 2.5 & Granite & Inclined \\
\hline T. 945 & 8 & 2 & 15 & 2.5 & Granite & Plane & T. 1365 & 9 & 2 & 15 & 2.5 & Granite & Inclined \\
\hline T. 946 & 9 & 2 & 1 & 1 & Limestone & Plane & T. 1366 & 10 & 2 & 1 & 1 & Limestone & Inclined \\
\hline T. 947 & 9 & 2 & 2 & 1 & Limestone & Plane & T. 1367 & 10 & 2 & 2 & 1 & Limestone & Inclined \\
\hline
\end{tabular}


Table E.1. (cont.)

\begin{tabular}{|c|c|c|c|c|c|c|c|c|c|c|c|c|c|}
\hline T. 948 & 9 & 2 & 3 & 1 & Limestone & Plane & T. 1368 & 10 & 2 & 3 & 1 & Limestone & Inclined \\
\hline T. 949 & 9 & 2 & 4 & 1 & Limestone & Plane & T. 1369 & 10 & 2 & 4 & 1 & Limestone & Inclined \\
\hline T. 950 & 9 & 2 & 5 & 1 & Limestone & Plane & T. 1370 & 10 & 2 & 5 & 1 & Limestone & Inclined \\
\hline T. 951 & 9 & 2 & 6 & 1 & Limestone & Plane & T. 1371 & 10 & 2 & 6 & 1 & Limestone & Inclined \\
\hline T. 952 & 9 & 2 & 7 & 1 & Limestone & Plane & T. 1372 & 10 & 2 & 7 & 1 & Limestone & Inclined \\
\hline T. 953 & 9 & 2 & 8 & 1 & Limestone & Plane & T. 1373 & 10 & 2 & 8 & 1 & Limestone & Inclined \\
\hline T. 954 & 9 & 2 & 9 & 1 & Limestone & Plane & T. 1374 & 10 & 2 & 9 & 1 & Limestone & Inclined \\
\hline T. 955 & 9 & 2 & 10 & 1 & Limestone & Plane & T. 1375 & 10 & 2 & 10 & 1 & Limestone & Inclined \\
\hline T. 956 & 9 & 2 & 11 & 1 & Limestone & Plane & T. 1376 & 10 & 2 & 11 & 1 & Limestone & Inclined \\
\hline T. 957 & 9 & 2 & 12 & 1 & Limestone & Plane & T. 1377 & 10 & 2 & 12 & 1 & Limestone & Inclined \\
\hline T. 958 & 9 & 2 & 13 & 1 & Limestone & Plane & T. 1378 & 10 & 2 & 13 & 1 & Limestone & Inclined \\
\hline T. 959 & 9 & 2 & 14 & 1 & Limestone & Plane & T. 1379 & 10 & 2 & 14 & 1 & Limestone & Inclined \\
\hline T. 960 & 9 & 2 & 15 & 1 & Limestone & Plane & T. 1380 & 10 & 2 & 15 & 1 & Limestone & Inclined \\
\hline T. 961 & 11 & 2 & 1 & 1.3 & Limestone & Plane & T. 1381 & 12 & 2 & 1 & 1.3 & Limestone & Inclined \\
\hline T. 962 & 11 & 2 & 2 & 1.3 & Limestone & Plane & T. 1382 & 12 & 2 & 2 & 1.3 & Limestone & Inclined \\
\hline T. 963 & 11 & 2 & 3 & 1.3 & Limestone & Plane & T. 1383 & 12 & 2 & 3 & 1.3 & Limestone & Inclined \\
\hline T. 964 & 11 & 2 & 4 & 1.3 & Limestone & Plane & T. 1384 & 12 & 2 & 4 & 1.3 & Limestone & Inclined \\
\hline T. 965 & 11 & 2 & 5 & 1.3 & Limestone & Plane & T. 1385 & 12 & 2 & 5 & 1.3 & Limestone & Inclined \\
\hline T. 966 & 11 & 2 & 6 & 1.3 & Limestone & Plane & T. 1386 & 12 & 2 & 6 & 1.3 & Limestone & Inclined \\
\hline T. 967 & 11 & 2 & 7 & 1.3 & Limestone & Plane & T. 1387 & 12 & 2 & 7 & 1.3 & Limestone & Inclined \\
\hline T. 968 & 11 & 2 & 8 & 1.3 & Limestone & Plane & T. 1388 & 12 & 2 & 8 & 1.3 & Limestone & Inclined \\
\hline T. 969 & 11 & 2 & 9 & 1.3 & Limestone & Plane & T. 1389 & 12 & 2 & 9 & 1.3 & Limestone & Inclined \\
\hline T. 970 & 10 & 2 & 10 & 1.3 & Limestone & Plane & T. 1390 & 11 & 2 & 10 & 1.3 & Limestone & Inclined \\
\hline T. 971 & 10 & 2 & 11 & 1.3 & Limestone & Plane & T. 1391 & 11 & 2 & 11 & 1.3 & Limestone & Inclined \\
\hline T. 972 & 11 & 2 & 12 & 1.3 & Limestone & Plane & T. 1392 & 12 & 2 & 12 & 1.3 & Limestone & Inclined \\
\hline T. 973 & 11 & 2 & 13 & 1.3 & Limestone & Plane & T. 1393 & 12 & 2 & 13 & 1.3 & Limestone & Inclined \\
\hline T. 974 & 11 & 2 & 14 & 1.3 & Limestone & Plane & T. 1394 & 12 & 2 & 14 & 1.3 & Limestone & Inclined \\
\hline T. 975 & 11 & 2 & 15 & 1.3 & Limestone & Plane & T. 1395 & 12 & 2 & 15 & 1.3 & Limestone & Inclined \\
\hline *T. 976 & 12 & 2 & 1 & 1.6 & Limestone & Plane & *T. 1396 & 13 & 2 & 1 & 1.6 & Limestone & Inclined \\
\hline *T. 977 & 12 & 2 & 2 & 1.6 & Limestone & Plane & *T. 1397 & 13 & 2 & 2 & 1.6 & Limestone & Inclined \\
\hline *T. 978 & 12 & 2 & 3 & 1.6 & Limestone & Plane & *T. 1398 & 13 & 2 & 3 & 1.6 & Limestone & Inclined \\
\hline *T. 979 & 12 & 2 & 4 & 1.6 & Limestone & Plane & *T. 1399 & 13 & 2 & 4 & 1.6 & Limestone & Inclined \\
\hline *T. 980 & 12 & 2 & 5 & 1.6 & Limestone & Plane & *T. 1400 & 13 & 2 & 5 & 1.6 & Limestone & Inclined \\
\hline
\end{tabular}

(cont. on next page) 
Table E.1. (cont.)

\begin{tabular}{|c|c|c|c|c|c|c|c|c|c|c|c|c|c|}
\hline *T. 981 & 12 & 2 & 6 & 1.6 & Limestone & Plane & ${ }^{*} \mathrm{~T} .1401$ & 13 & 2 & 6 & 1.6 & Limestone & Inclined \\
\hline *T. 982 & 12 & 2 & 7 & 1.6 & Limestone & Plane & ${ }^{*} \mathrm{~T} .1402$ & 13 & 2 & 7 & 1.6 & Limestone & Inclined \\
\hline *T. 983 & 12 & 2 & 8 & 1.6 & Limestone & Plane & ${ }^{*} \mathrm{~T} .1403$ & 13 & 2 & 8 & 1.6 & Limestone & Inclined \\
\hline *T. 984 & 12 & 2 & 9 & 1.6 & Limestone & Plane & *T. 1404 & 13 & 2 & 9 & 1.6 & Limestone & Inclined \\
\hline *T. 985 & 11 & 2 & 10 & 1.6 & Limestone & Plane & *T. 1405 & 12 & 2 & 10 & 1.6 & Limestone & Inclined \\
\hline *T. 986 & 11 & 2 & 11 & 1.6 & Limestone & Plane & *T. 1406 & 12 & 2 & 11 & 1.6 & Limestone & Inclined \\
\hline *T. 987 & 12 & 2 & 12 & 1.6 & Limestone & Plane & ${ }^{*} \mathrm{~T} .1407$ & 13 & 2 & 12 & 1.6 & Limestone & Inclined \\
\hline *T. 988 & 12 & 2 & 13 & 1.6 & Limestone & Plane & *T. 1408 & 13 & 2 & 13 & 1.6 & Limestone & Inclined \\
\hline *T. 989 & 11 & 2 & 14 & 1.6 & Limestone & Plane & *T. 1409 & 12 & 2 & 14 & 1.6 & Limestone & Inclined \\
\hline *T. 990 & 11 & 2 & 15 & 1.6 & Limestone & Plane & *T. 1410 & 12 & 2 & 15 & 1.6 & Limestone & Inclined \\
\hline *T. 991 & 12 & 2 & 1 & 1.8 & Limestone & Plane & *T. 1411 & 13 & 2 & 1 & 1.8 & Limestone & Inclined \\
\hline *T. 992 & 12 & 2 & 2 & 1.8 & Limestone & Plane & ${ }^{*}$ T. 1412 & 13 & 2 & 2 & 1.8 & Limestone & Inclined \\
\hline *T. 993 & 12 & 2 & 3 & 1.8 & Limestone & Plane & ${ }^{*} \mathrm{~T} .1413$ & 13 & 2 & 3 & 1.8 & Limestone & Inclined \\
\hline${ }^{*}$ T. 994 & 12 & 2 & 4 & 1.8 & Limestone & Plane & *T. 1414 & 13 & 2 & 4 & 1.8 & Limestone & Inclined \\
\hline *T. 995 & 12 & 2 & 5 & 1.8 & Limestone & Plane & *T. 1415 & 13 & 2 & 5 & 1.8 & Limestone & Inclined \\
\hline *T. 996 & 12 & 2 & 6 & 1.8 & Limestone & Plane & *T. 1416 & 13 & 2 & 6 & 1.8 & Limestone & Inclined \\
\hline *T. 997 & 12 & 2 & 7 & 1.8 & Limestone & Plane & ${ }^{*} \mathrm{~T} .1417$ & 13 & 2 & 7 & 1.8 & Limestone & Inclined \\
\hline *T. 998 & 12 & 2 & 8 & 1.8 & Limestone & Plane & ${ }^{*} \mathrm{~T} .1418$ & 13 & 2 & 8 & 1.8 & Limestone & Inclined \\
\hline *T. 999 & 12 & 2 & 9 & 1.8 & Limestone & Plane & *T. 1419 & 13 & 2 & 9 & 1.8 & Limestone & Inclined \\
\hline *T. 1000 & 11 & 2 & 10 & 1.8 & Limestone & Plane & *T. 1420 & 12 & 2 & 10 & 1.8 & Limestone & Inclined \\
\hline${ }^{*} \mathrm{~T} .1001$ & 11 & 2 & 11 & 1.8 & Limestone & Plane & *T. 1421 & 12 & 2 & 11 & 1.8 & Limestone & Inclined \\
\hline *T. 1002 & 12 & 2 & 12 & 1.8 & Limestone & Plane & *T. 1422 & 13 & 2 & 12 & 1.8 & Limestone & Inclined \\
\hline *T. 1003 & 12 & 2 & 13 & 1.8 & Limestone & Plane & *T. 1423 & 13 & 2 & 13 & 1.8 & Limestone & Inclined \\
\hline *T. 1004 & 11 & 2 & 14 & 1.8 & Limestone & Plane & *T. 1424 & 12 & 2 & 14 & 1.8 & Limestone & Inclined \\
\hline *T. 1005 & 11 & 2 & 15 & 1.8 & Limestone & Plane & *T. 1425 & 12 & 2 & 15 & 1.8 & Limestone & Inclined \\
\hline *T. 1006 & 11 & 2 & 1 & 2 & Limestone & Plane & *T. 1426 & 12 & 2 & 1 & 2 & Limestone & Inclined \\
\hline *T. 1007 & 12 & 2 & 2 & 2 & Limestone & Plane & *T. 1427 & 13 & 2 & 2 & 2 & Limestone & Inclined \\
\hline${ }^{*} \mathrm{~T} .1008$ & 12 & 2 & 3 & 2 & Limestone & Plane & *T. 1428 & 13 & 2 & 3 & 2 & Limestone & Inclined \\
\hline *T. 1009 & 12 & 2 & 4 & 2 & Limestone & Plane & *T. 1429 & 13 & 2 & 4 & 2 & Limestone & Inclined \\
\hline *T. 1010 & 12 & 2 & 5 & 2 & Limestone & Plane & *T. 1430 & 13 & 2 & 5 & 2 & Limestone & Inclined \\
\hline *T. 1011 & 12 & 2 & 6 & 2 & Limestone & Plane & ${ }^{*} \mathrm{~T} .1431$ & 13 & 2 & 6 & 2 & Limestone & Inclined \\
\hline *T. 1012 & 12 & 2 & 7 & 2 & Limestone & Plane & *T. 1432 & 13 & 2 & 7 & 2 & Limestone & Inclined \\
\hline *T. 1013 & 12 & 2 & 8 & 2 & Limestone & Plane & ${ }^{*} \mathrm{~T} .1433$ & 13 & 2 & 8 & 2 & Limestone & Inclined \\
\hline
\end{tabular}

(cont. on next page) 
Table E.1. (cont.)

\begin{tabular}{|c|c|c|c|c|c|c|c|c|c|c|c|c|c|}
\hline *T. 1014 & 11 & 2 & 9 & 2 & Limestone & Plane & *T. 1434 & 12 & 2 & 9 & 2 & Limestone & Inclined \\
\hline *T. 1015 & 10 & 2 & 10 & 2 & Limestone & Plane & *T. 1435 & 11 & 2 & 10 & 2 & Limestone & Inclined \\
\hline *T. 1016 & 10 & 2 & 11 & 2 & Limestone & Plane & *T. 1436 & 11 & 2 & 11 & 2 & Limestone & Inclined \\
\hline *T. 1017 & 11 & 2 & 12 & 2 & Limestone & Plane & *T. 1437 & 12 & 2 & 12 & 2 & Limestone & Inclined \\
\hline *T. 1018 & 11 & 2 & 13 & 2 & Limestone & Plane & ${ }^{*} \mathrm{~T} .1438$ & 12 & 2 & 13 & 2 & Limestone & Inclined \\
\hline *T. 1019 & 10 & 2 & 14 & 2 & Limestone & Plane & *T. 1439 & 11 & 2 & 14 & 2 & Limestone & Inclined \\
\hline *T. 1020 & 10 & 2 & 15 & 2 & Limestone & Plane & *T. 1440 & 11 & 2 & 15 & 2 & Limestone & Inclined \\
\hline *T. 1021 & 12 & 2 & 1 & 2.3 & Limestone & Plane & *T. 1441 & 13 & 2 & 1 & 2.3 & Limestone & Inclined \\
\hline *T. 1022 & 12 & 2 & 2 & 2.3 & Limestone & Plane & *T. 1442 & 13 & 2 & 2 & 2.3 & Limestone & Inclined \\
\hline${ }^{*}$ T. 1023 & 12 & 2 & 3 & 2.3 & Limestone & Plane & *T. 1443 & 13 & 2 & 3 & 2.3 & Limestone & Inclined \\
\hline *T. 1024 & 12 & 2 & 4 & 2.3 & Limestone & Plane & *T. 1444 & 13 & 2 & 4 & 2.3 & Limestone & Inclined \\
\hline *T. 1025 & 12 & 2 & 5 & 2.3 & Limestone & Plane & *T. 1445 & 13 & 2 & 5 & 2.3 & Limestone & Inclined \\
\hline *T. 1026 & 12 & 2 & 6 & 2.3 & Limestone & Plane & *T. 1446 & 13 & 2 & 6 & 2.3 & Limestone & Inclined \\
\hline *T. 1027 & 12 & 2 & 7 & 2.3 & Limestone & Plane & *T. 1447 & 13 & 2 & 7 & 2.3 & Limestone & Inclined \\
\hline${ }^{*}$ T. 1028 & 12 & 2 & 8 & 2.3 & Limestone & Plane & ${ }^{*} \mathrm{~T} .1448$ & 13 & 2 & 8 & 2.3 & Limestone & Inclined \\
\hline *T. 1029 & 11 & 2 & 9 & 2.3 & Limestone & Plane & *T. 1449 & 12 & 2 & 9 & 2.3 & Limestone & Inclined \\
\hline *T. 1030 & 10 & 2 & 10 & 2.3 & Limestone & Plane & *T. 1450 & 11 & 2 & 10 & 2.3 & Limestone & Inclined \\
\hline *T. 1031 & 11 & 2 & 11 & 2.3 & Limestone & Plane & *T. 1451 & 12 & 2 & 11 & 2.3 & Limestone & Inclined \\
\hline *T. 1032 & 10 & 2 & 12 & 2.3 & Limestone & Plane & *T. 1452 & 11 & 2 & 12 & 2.3 & Limestone & Inclined \\
\hline *T. 1033 & 10 & 2 & 13 & 2.3 & Limestone & Plane & *T. 1453 & 11 & 2 & 13 & 2.3 & Limestone & Inclined \\
\hline *T. 1034 & 9 & 2 & 14 & 2.3 & Limestone & Plane & ${ }^{*} \mathrm{~T} .1454$ & 10 & 2 & 14 & 2.3 & Limestone & Inclined \\
\hline *T. 1035 & 9 & 2 & 15 & 2.3 & Limestone & Plane & *T. 1455 & 10 & 2 & 15 & 2.3 & Limestone & Inclined \\
\hline T. 1036 & 12 & 2 & 1 & 2.5 & Limestone & Plane & T. 1456 & 13 & 2 & 1 & 2.5 & Limestone & Inclined \\
\hline T. 1037 & 12 & 2 & 2 & 2.5 & Limestone & Plane & T. 1457 & 13 & 2 & 2 & 2.5 & Limestone & Inclined \\
\hline T. 1038 & 12 & 2 & 3 & 2.5 & Limestone & Plane & T. 1458 & 13 & 2 & 3 & 2.5 & Limestone & Inclined \\
\hline T. 1039 & 12 & 2 & 4 & 2.5 & Limestone & Plane & T. 1459 & 13 & 2 & 4 & 2.5 & Limestone & Inclined \\
\hline T. 1040 & 12 & 2 & 5 & 2.5 & Limestone & Plane & T. 1460 & 13 & 2 & 5 & 2.5 & Limestone & Inclined \\
\hline T. 1041 & 12 & 2 & 6 & 2.5 & Limestone & Plane & T. 1461 & 13 & 2 & 6 & 2.5 & Limestone & Inclined \\
\hline T. 1042 & 12 & 2 & 7 & 2.5 & Limestone & Plane & T. 1462 & 13 & 2 & 7 & 2.5 & Limestone & Inclined \\
\hline T. 1043 & 12 & 2 & 8 & 2.5 & Limestone & Plane & T. 1463 & 13 & 2 & 8 & 2.5 & Limestone & Inclined \\
\hline T. 1044 & 11 & 2 & 9 & 2.5 & Limestone & Plane & T. 1464 & 12 & 2 & 9 & 2.5 & Limestone & Inclined \\
\hline T. 1045 & 9 & 2 & 10 & 2.5 & Limestone & Plane & T. 1465 & 10 & 2 & 10 & 2.5 & Limestone & Inclined \\
\hline T. 1046 & 10 & 2 & 11 & 2.5 & Limestone & Plane & T. 1466 & 11 & 2 & 11 & 2.5 & Limestone & Inclined \\
\hline
\end{tabular}

(cont. on next page) 
Table E.1. (cont.)

\begin{tabular}{|c|c|c|c|c|c|c|c|c|c|c|c|c|c|}
\hline T. 1047 & 9 & 2 & 12 & 2.5 & Limestone & Plane & T. 1467 & 10 & 2 & 12 & 2.5 & Limestone & Inclined \\
\hline T. 1048 & 9 & 2 & 13 & 2.5 & Limestone & Plane & T. 1468 & 10 & 2 & 13 & 2.5 & Limestone & Inclined \\
\hline T. 1049 & 8 & 2 & 14 & 2.5 & Limestone & Plane & T. 1469 & 9 & 2 & 14 & 2.5 & Limestone & Inclined \\
\hline T. 1050 & 8 & 2 & 15 & 2.5 & Limestone & Plane & T. 1470 & 9 & 2 & 15 & 2.5 & Limestone & Inclined \\
\hline T. 1051 & 9 & 2 & 1 & 1 & Sandstone & Plane & T. 1471 & 10 & 2 & 1 & 1 & Sandstone & Inclined \\
\hline T. 1052 & 9 & 2 & 2 & 1 & Sandstone & Plane & T. 1472 & 10 & 2 & 2 & 1 & Sandstone & Inclined \\
\hline T. 1053 & 9 & 2 & 3 & 1 & Sandstone & Plane & T. 1473 & 10 & 2 & 3 & 1 & Sandstone & Inclined \\
\hline T. 1054 & 9 & 2 & 4 & 1 & Sandstone & Plane & T. 1474 & 10 & 2 & 4 & 1 & Sandstone & Inclined \\
\hline T. 1055 & 9 & 2 & 5 & 1 & Sandstone & Plane & T. 1475 & 10 & 2 & 5 & 1 & Sandstone & Inclined \\
\hline T. 1056 & 9 & 2 & 6 & 1 & Sandstone & Plane & T. 1476 & 10 & 2 & 6 & 1 & Sandstone & Inclined \\
\hline T. 1057 & 9 & 2 & 7 & 1 & Sandstone & Plane & T. 1477 & 10 & 2 & 7 & 1 & Sandstone & Inclined \\
\hline T. 1058 & 9 & 2 & 8 & 1 & Sandstone & Plane & T. 1478 & 10 & 2 & 8 & 1 & Sandstone & Inclined \\
\hline T. 1059 & 9 & 2 & 9 & 1 & Sandstone & Plane & T. 1479 & 10 & 2 & 9 & 1 & Sandstone & Inclined \\
\hline T. 1060 & 9 & 2 & 10 & 1 & Sandstone & Plane & T. 1480 & 10 & 2 & 10 & 1 & Sandstone & Inclined \\
\hline T. 1061 & 9 & 2 & 11 & 1 & Sandstone & Plane & T. 1481 & 10 & 2 & 11 & 1 & Sandstone & Inclined \\
\hline T. 1062 & 9 & 2 & 12 & 1 & Sandstone & Plane & T. 1482 & 10 & 2 & 12 & 1 & Sandstone & Inclined \\
\hline T. 1063 & 9 & 2 & 13 & 1 & Sandstone & Plane & T. 1483 & 10 & 2 & 13 & 1 & Sandstone & Inclined \\
\hline T. 1064 & 9 & 2 & 14 & 1 & Sandstone & Plane & T. 1484 & 10 & 2 & 14 & 1 & Sandstone & Inclined \\
\hline T. 1065 & 9 & 2 & 15 & 1 & Sandstone & Plane & T. 1485 & 10 & 2 & 15 & 1 & Sandstone & Inclined \\
\hline T. 1066 & 11 & 2 & 1 & 1.3 & Sandstone & Plane & T. 1486 & 12 & 2 & 1 & 1.3 & Sandstone & Inclined \\
\hline T. 1067 & 11 & 2 & 2 & 1.3 & Sandstone & Plane & T. 1487 & 12 & 2 & 2 & 1.3 & Sandstone & Inclined \\
\hline T. 1068 & 11 & 2 & 3 & 1.3 & Sandstone & Plane & T. 1488 & 12 & 2 & 3 & 1.3 & Sandstone & Inclined \\
\hline T. 1069 & 11 & 2 & 4 & 1.3 & Sandstone & Plane & T. 1489 & 12 & 2 & 4 & 1.3 & Sandstone & Inclined \\
\hline T. 1070 & 11 & 2 & 5 & 1.3 & Sandstone & Plane & T. 1490 & 12 & 2 & 5 & 1.3 & Sandstone & Inclined \\
\hline T. 1071 & 11 & 2 & 6 & 1.3 & Sandstone & Plane & T. 1491 & 12 & 2 & 6 & 1.3 & Sandstone & Inclined \\
\hline T. 1072 & 11 & 2 & 7 & 1.3 & Sandstone & Plane & T. 1492 & 12 & 2 & 7 & 1.3 & Sandstone & Inclined \\
\hline T. 1073 & 11 & 2 & 8 & 1.3 & Sandstone & Plane & T. 1493 & 12 & 2 & 8 & 1.3 & Sandstone & Inclined \\
\hline T. 1074 & 11 & 2 & 9 & 1.3 & Sandstone & Plane & T. 1494 & 12 & 2 & 9 & 1.3 & Sandstone & Inclined \\
\hline T. 1075 & 10 & 2 & 10 & 1.3 & Sandstone & Plane & T. 1495 & 11 & 2 & 10 & 1.3 & Sandstone & Inclined \\
\hline T. 1076 & 10 & 2 & 11 & 1.3 & Sandstone & Plane & T. 1496 & 11 & 2 & 11 & 1.3 & Sandstone & Inclined \\
\hline T. 1077 & 11 & 2 & 12 & 1.3 & Sandstone & Plane & T. 1497 & 12 & 2 & 12 & 1.3 & Sandstone & Inclined \\
\hline T. 1078 & 11 & 2 & 13 & 1.3 & Sandstone & Plane & T. 1498 & 12 & 2 & 13 & 1.3 & Sandstone & Inclined \\
\hline T. 1079 & 11 & 2 & 14 & 1.3 & Sandstone & Plane & T. 1499 & 12 & 2 & 14 & 1.3 & Sandstone & Inclined \\
\hline
\end{tabular}

(cont. on next page) 
Table E.1. (cont.)

\begin{tabular}{|c|c|c|c|c|c|c|c|c|c|c|c|c|c|}
\hline T. 1080 & 11 & 2 & 15 & 1.3 & Sandstone & Plane & T. 1500 & 12 & 2 & 15 & 1.3 & Sandstone & Inclined \\
\hline T. 1081 & 12 & 2 & 1 & 1.6 & Sandstone & Plane & T. 1501 & 13 & 2 & 1 & 1.6 & Sandstone & Inclined \\
\hline T. 1082 & 12 & 2 & 2 & 1.6 & Sandstone & Plane & T. 1502 & 13 & 2 & 2 & 1.6 & Sandstone & Inclined \\
\hline T. 1083 & 12 & 2 & 3 & 1.6 & Sandstone & Plane & T. 1503 & 13 & 2 & 3 & 1.6 & Sandstone & Inclined \\
\hline T. 1084 & 12 & 2 & 4 & 1.6 & Sandstone & Plane & T. 1504 & 13 & 2 & 4 & 1.6 & Sandstone & Inclined \\
\hline T. 1085 & 12 & 2 & 5 & 1.6 & Sandstone & Plane & T. 1505 & 13 & 2 & 5 & 1.6 & Sandstone & Inclined \\
\hline T. 1086 & 12 & 2 & 6 & 1.6 & Sandstone & Plane & T. 1506 & 13 & 2 & 6 & 1.6 & Sandstone & Inclined \\
\hline T. 1087 & 12 & 2 & 7 & 1.6 & Sandstone & Plane & T. 1507 & 13 & 2 & 7 & 1.6 & Sandstone & Inclined \\
\hline T. 1088 & 12 & 2 & 8 & 1.6 & Sandstone & Plane & T. 1508 & 13 & 2 & 8 & 1.6 & Sandstone & Inclined \\
\hline T. 1089 & 12 & 2 & 9 & 1.6 & Sandstone & Plane & T. 1509 & 13 & 2 & 9 & 1.6 & Sandstone & Inclined \\
\hline T. 1090 & 11 & 2 & 10 & 1.6 & Sandstone & Plane & T. 1510 & 12 & 2 & 10 & 1.6 & Sandstone & Inclined \\
\hline T. 1091 & 11 & 2 & 11 & 1.6 & Sandstone & Plane & T. 1511 & 12 & 2 & 11 & 1.6 & Sandstone & Inclined \\
\hline T. 1092 & 12 & 2 & 12 & 1.6 & Sandstone & Plane & T. 1512 & 13 & 2 & 12 & 1.6 & Sandstone & Inclined \\
\hline T. 1093 & 12 & 2 & 13 & 1.6 & Sandstone & Plane & T. 1513 & 13 & 2 & 13 & 1.6 & Sandstone & Inclined \\
\hline T. 1094 & 11 & 2 & 14 & 1.6 & Sandstone & Plane & T. 1514 & 12 & 2 & 14 & 1.6 & Sandstone & Inclined \\
\hline T. 1095 & 11 & 2 & 15 & 1.6 & Sandstone & Plane & T. 1515 & 12 & 2 & 15 & 1.6 & Sandstone & Inclined \\
\hline T. 1096 & 12 & 2 & 1 & 1.8 & Sandstone & Plane & T. 1516 & 13 & 2 & 1 & 1.8 & Sandstone & Inclined \\
\hline T. 1097 & 12 & 2 & 2 & 1.8 & Sandstone & Plane & T. 1517 & 13 & 2 & 2 & 1.8 & Sandstone & Inclined \\
\hline T. 1098 & 12 & 2 & 3 & 1.8 & Sandstone & Plane & T. 1518 & 13 & 2 & 3 & 1.8 & Sandstone & Inclined \\
\hline T. 1099 & 12 & 2 & 4 & 1.8 & Sandstone & Plane & T. 1519 & 13 & 2 & 4 & 1.8 & Sandstone & Inclined \\
\hline T. 1100 & 12 & 2 & 5 & 1.8 & Sandstone & Plane & T. 1520 & 13 & 2 & 5 & 1.8 & Sandstone & Inclined \\
\hline T. 1101 & 12 & 2 & 6 & 1.8 & Sandstone & Plane & T. 1521 & 13 & 2 & 6 & 1.8 & Sandstone & Inclined \\
\hline T. 1102 & 12 & 2 & 7 & 1.8 & Sandstone & Plane & T. 1522 & 13 & 2 & 7 & 1.8 & Sandstone & Inclined \\
\hline T. 1103 & 12 & 2 & 8 & 1.8 & Sandstone & Plane & T. 1523 & 13 & 2 & 8 & 1.8 & Sandstone & Inclined \\
\hline T. 1104 & 12 & 2 & 9 & 1.8 & Sandstone & Plane & T. 1524 & 13 & 2 & 9 & 1.8 & Sandstone & Inclined \\
\hline T. 1105 & 11 & 2 & 10 & 1.8 & Sandstone & Plane & T. 1525 & 12 & 2 & 10 & 1.8 & Sandstone & Inclined \\
\hline T. 1106 & 11 & 2 & 11 & 1.8 & Sandstone & Plane & T. 1526 & 12 & 2 & 11 & 1.8 & Sandstone & Inclined \\
\hline T. 1107 & 12 & 2 & 12 & 1.8 & Sandstone & Plane & T. 1527 & 13 & 2 & 12 & 1.8 & Sandstone & Inclined \\
\hline T. 1108 & 12 & 2 & 13 & 1.8 & Sandstone & Plane & T. 1528 & 13 & 2 & 13 & 1.8 & Sandstone & Inclined \\
\hline T. 1109 & 11 & 2 & 14 & 1.8 & Sandstone & Plane & T. 1529 & 12 & 2 & 14 & 1.8 & Sandstone & Inclined \\
\hline T. 1110 & 11 & 2 & 15 & 1.8 & Sandstone & Plane & T. 1530 & 12 & 2 & 15 & 1.8 & Sandstone & Inclined \\
\hline T. 1111 & 11 & 2 & 1 & 2 & Sandstone & Plane & T. 1531 & 12 & 2 & 1 & 2 & Sandstone & Inclined \\
\hline T. 1112 & 12 & 2 & 2 & 2 & Sandstone & Plane & T. 1532 & 13 & 2 & 2 & 2 & Sandstone & Inclined \\
\hline
\end{tabular}

(cont. on next page) 
Table E.1. (cont.)

\begin{tabular}{|c|c|c|c|c|c|c|c|c|c|c|c|c|c|}
\hline T. 1113 & 12 & 2 & 3 & 2 & Sandstone & Plane & T. 1533 & 13 & 2 & 3 & 2 & Sandstone & Inclined \\
\hline T. 1114 & 12 & 2 & 4 & 2 & Sandstone & Plane & T. 1534 & 13 & 2 & 4 & 2 & Sandstone & Inclined \\
\hline T. 1115 & 12 & 2 & 5 & 2 & Sandstone & Plane & T. 1535 & 13 & 2 & 5 & 2 & Sandstone & Inclined \\
\hline T. 1116 & 12 & 2 & 6 & 2 & Sandstone & Plane & T. 1536 & 13 & 2 & 6 & 2 & Sandstone & Inclined \\
\hline T. 1117 & 12 & 2 & 7 & 2 & Sandstone & Plane & T. 1537 & 13 & 2 & 7 & 2 & Sandstone & Inclined \\
\hline T. 1118 & 12 & 2 & 8 & 2 & Sandstone & Plane & T. 1538 & 13 & 2 & 8 & 2 & Sandstone & Inclined \\
\hline T. 1119 & 11 & 2 & 9 & 2 & Sandstone & Plane & T. 1539 & 12 & 2 & 9 & 2 & Sandstone & Inclined \\
\hline T. 1120 & 10 & 2 & 10 & 2 & Sandstone & Plane & T. 1540 & 11 & 2 & 10 & 2 & Sandstone & Inclined \\
\hline T. 1121 & 10 & 2 & 11 & 2 & Sandstone & Plane & T. 1541 & 11 & 2 & 11 & 2 & Sandstone & Inclined \\
\hline T. 1122 & 11 & 2 & 12 & 2 & Sandstone & Plane & T. 1542 & 12 & 2 & 12 & 2 & Sandstone & Inclined \\
\hline T. 1123 & 11 & 2 & 13 & 2 & Sandstone & Plane & T. 1543 & 12 & 2 & 13 & 2 & Sandstone & Inclined \\
\hline T. 1124 & 10 & 2 & 14 & 2 & Sandstone & Plane & T. 1544 & 11 & 2 & 14 & 2 & Sandstone & Inclined \\
\hline T. 1125 & 10 & 2 & 15 & 2 & Sandstone & Plane & T. 1545 & 11 & 2 & 15 & 2 & Sandstone & Inclined \\
\hline T. 1126 & 12 & 2 & 1 & 2.3 & Sandstone & Plane & T. 1546 & 13 & 2 & 1 & 2.3 & Sandstone & Inclined \\
\hline T. 1127 & 12 & 2 & 2 & 2.3 & Sandstone & Plane & T. 1547 & 13 & 2 & 2 & 2.3 & Sandstone & Inclined \\
\hline T. 1128 & 12 & 2 & 3 & 2.3 & Sandstone & Plane & T. 1548 & 13 & 2 & 3 & 2.3 & Sandstone & Inclined \\
\hline T. 1129 & 12 & 2 & 4 & 2.3 & Sandstone & Plane & T. 1549 & 13 & 2 & 4 & 2.3 & Sandstone & Inclined \\
\hline T. 1130 & 12 & 2 & 5 & 2.3 & Sandstone & Plane & T. 1550 & 13 & 2 & 5 & 2.3 & Sandstone & Inclined \\
\hline T. 1131 & 12 & 2 & 6 & 2.3 & Sandstone & Plane & T. 1551 & 13 & 2 & 6 & 2.3 & Sandstone & Inclined \\
\hline T. 1132 & 12 & 2 & 7 & 2.3 & Sandstone & Plane & T. 1552 & 13 & 2 & 7 & 2.3 & Sandstone & Inclined \\
\hline T. 1133 & 12 & 2 & 8 & 2.3 & Sandstone & Plane & T. 1553 & 13 & 2 & 8 & 2.3 & Sandstone & Inclined \\
\hline T. 1134 & 11 & 2 & 9 & 2.3 & Sandstone & Plane & T. 1554 & 12 & 2 & 9 & 2.3 & Sandstone & Inclined \\
\hline T. 1135 & 10 & 2 & 10 & 2.3 & Sandstone & Plane & T. 1555 & 11 & 2 & 10 & 2.3 & Sandstone & Inclined \\
\hline T. 1136 & 11 & 2 & 11 & 2.3 & Sandstone & Plane & T. 1556 & 12 & 2 & 11 & 2.3 & Sandstone & Inclined \\
\hline T. 1137 & 10 & 2 & 12 & 2.3 & Sandstone & Plane & T. 1557 & 11 & 2 & 12 & 2.3 & Sandstone & Inclined \\
\hline T. 1138 & 10 & 2 & 13 & 2.3 & Sandstone & Plane & T. 1558 & 11 & 2 & 13 & 2.3 & Sandstone & Inclined \\
\hline T. 1139 & 9 & 2 & 14 & 2.3 & Sandstone & Plane & T. 1559 & 10 & 2 & 14 & 2.3 & Sandstone & Inclined \\
\hline T. 1140 & 9 & 2 & 15 & 2.3 & Sandstone & Plane & T. 1560 & 10 & 2 & 15 & 2.3 & Sandstone & Inclined \\
\hline T. 1141 & 12 & 2 & 1 & 2.5 & Sandstone & Plane & T. 1561 & 13 & 2 & 1 & 2.5 & Sandstone & Inclined \\
\hline T. 1142 & 12 & 2 & 2 & 2.5 & Sandstone & Plane & T. 1562 & 13 & 2 & 2 & 2.5 & Sandstone & Inclined \\
\hline T. 1143 & 12 & 2 & 3 & 2.5 & Sandstone & Plane & T. 1563 & 13 & 2 & 3 & 2.5 & Sandstone & Inclined \\
\hline T. 1144 & 12 & 2 & 4 & 2.5 & Sandstone & Plane & T. 1564 & 13 & 2 & 4 & 2.5 & Sandstone & Inclined \\
\hline T. 1145 & 12 & 2 & 5 & 2.5 & Sandstone & Plane & T. 1565 & 13 & 2 & 5 & 2.5 & Sandstone & Inclined \\
\hline
\end{tabular}

(cont. on next page) 
Table E.1. (cont.)

\begin{tabular}{|c|c|c|c|c|c|c|c|c|c|c|c|c|c|}
\hline T. 1146 & 12 & 2 & 6 & 2.5 & Sandstone & Plane & T. 1566 & 13 & 2 & 6 & 2.5 & Sandstone & Inclined \\
\hline T. 1147 & 12 & 2 & 7 & 2.5 & Sandstone & Plane & T. 1567 & 13 & 2 & 7 & 2.5 & Sandstone & Inclined \\
\hline T. 1148 & 12 & 2 & 8 & 2.5 & Sandstone & Plane & T. 1568 & 13 & 2 & 8 & 2.5 & Sandstone & Inclined \\
\hline T. 1149 & 11 & 2 & 9 & 2.5 & Sandstone & Plane & T. 1569 & 12 & 2 & 9 & 2.5 & Sandstone & Inclined \\
\hline T. 1150 & 9 & 2 & 10 & 2.5 & Sandstone & Plane & T. 1570 & 10 & 2 & 10 & 2.5 & Sandstone & Inclined \\
\hline T. 1151 & 10 & 2 & 11 & 2.5 & Sandstone & Plane & T. 1571 & 11 & 2 & 11 & 2.5 & Sandstone & Inclined \\
\hline T. 1152 & 9 & 2 & 12 & 2.5 & Sandstone & Plane & T. 1572 & 10 & 2 & 12 & 2.5 & Sandstone & Inclined \\
\hline T. 1153 & 9 & 2 & 13 & 2.5 & Sandstone & Plane & T. 1573 & 10 & 2 & 13 & 2.5 & Sandstone & Inclined \\
\hline T. 1154 & 8 & 2 & 14 & 2.5 & Sandstone & Plane & T. 1574 & 9 & 2 & 14 & 2.5 & Sandstone & Inclined \\
\hline T. 1155 & 8 & 2 & 15 & 2.5 & Sandstone & Plane & T. 1575 & 9 & 2 & 15 & 2.5 & Sandstone & Inclined \\
\hline T. 1156 & 8 & 2 & 1 & 1 & Brick & Plane & T. 1576 & 9 & 2 & 1 & 1 & Brick & Inclined \\
\hline T. 1157 & 8 & 2 & 2 & 1 & Brick & Plane & T. 1577 & 9 & 2 & 2 & 1 & Brick & Inclined \\
\hline T. 1158 & 8 & 2 & 3 & 1 & Brick & Plane & T. 1578 & 9 & 2 & 3 & 1 & Brick & Inclined \\
\hline T. 1159 & 8 & 2 & 4 & 1 & Brick & Plane & T. 1579 & 9 & 2 & 4 & 1 & Brick & Inclined \\
\hline T. 1160 & 8 & 2 & 5 & 1 & Brick & Plane & T. 1580 & 9 & 2 & 5 & 1 & Brick & Inclined \\
\hline T. 1161 & 8 & 2 & 6 & 1 & Brick & Plane & T. 1581 & 9 & 2 & 6 & 1 & Brick & Inclined \\
\hline T. 1162 & 8 & 2 & 7 & 1 & Brick & Plane & T. 1582 & 9 & 2 & 7 & 1 & Brick & Inclined \\
\hline T. 1163 & 8 & 2 & 8 & 1 & Brick & Plane & T. 1583 & 9 & 2 & 8 & 1 & Brick & Inclined \\
\hline T. 1164 & 8 & 2 & 9 & 1 & Brick & Plane & T. 1584 & 9 & 2 & 9 & 1 & Brick & Inclined \\
\hline T. 1165 & 8 & 2 & 10 & 1 & Brick & Plane & T. 1585 & 9 & 2 & 10 & 1 & Brick & Inclined \\
\hline T. 1166 & 8 & 2 & 11 & 1 & Brick & Plane & T. 1586 & 9 & 2 & 11 & 1 & Brick & Inclined \\
\hline T. 1167 & 8 & 2 & 12 & 1 & Brick & Plane & T. 1587 & 9 & 2 & 12 & 1 & Brick & Inclined \\
\hline T. 1168 & 8 & 2 & 13 & 1 & Brick & Plane & T. 1588 & 9 & 2 & 13 & 1 & Brick & Inclined \\
\hline T. 1169 & 8 & 2 & 14 & 1 & Brick & Plane & T. 1589 & 9 & 2 & 14 & 1 & Brick & Inclined \\
\hline T. 1170 & 8 & 2 & 15 & 1 & Brick & Plane & T. 1590 & 9 & 2 & 15 & 1 & Brick & Inclined \\
\hline T. 1171 & 10 & 2 & 1 & 1.3 & Brick & Plane & T. 1591 & 11 & 2 & 1 & 1.3 & Brick & Inclined \\
\hline T. 1172 & 10 & 2 & 2 & 1.3 & Brick & Plane & T. 1592 & 11 & 2 & 2 & 1.3 & Brick & Inclined \\
\hline T. 1173 & 10 & 2 & 3 & 1.3 & Brick & Plane & T. 1593 & 11 & 2 & 3 & 1.3 & Brick & Inclined \\
\hline T. 1174 & 10 & 2 & 4 & 1.3 & Brick & Plane & T. 1594 & 11 & 2 & 4 & 1.3 & Brick & Inclined \\
\hline T. 1175 & 10 & 2 & 5 & 1.3 & Brick & Plane & T. 1595 & 11 & 2 & 5 & 1.3 & Brick & Inclined \\
\hline T. 1176 & 10 & 2 & 6 & 1.3 & Brick & Plane & T. 1596 & 11 & 2 & 6 & 1.3 & Brick & Inclined \\
\hline T. 1177 & 10 & 2 & 7 & 1.3 & Brick & Plane & T. 1597 & 11 & 2 & 7 & 1.3 & Brick & Inclined \\
\hline T. 1178 & 10 & 2 & 8 & 1.3 & Brick & Plane & T. 1598 & 11 & 2 & 8 & 1.3 & Brick & Inclined \\
\hline
\end{tabular}

(cont. on next page) 
Table E.1. (cont.)

\begin{tabular}{|c|c|c|c|c|c|c|c|c|c|c|c|c|c|}
\hline T. 1179 & 10 & 2 & 9 & 1.3 & Brick & Plane & T. 1599 & 11 & 2 & 9 & 1.3 & Brick & Inclined \\
\hline T. 1180 & 9 & 2 & 10 & 1.3 & Brick & Plane & T. 1600 & 10 & 2 & 10 & 1.3 & Brick & Inclined \\
\hline T. 1181 & 9 & 2 & 11 & 1.3 & Brick & Plane & T. 1601 & 10 & 2 & 11 & 1.3 & Brick & Inclined \\
\hline T. 1182 & 10 & 2 & 12 & 1.3 & Brick & Plane & T. 1602 & 11 & 2 & 12 & 1.3 & Brick & Inclined \\
\hline T. 1183 & 10 & 2 & 13 & 1.3 & Brick & Plane & T. 1603 & 11 & 2 & 13 & 1.3 & Brick & Inclined \\
\hline T. 1184 & 10 & 2 & 14 & 1.3 & Brick & Plane & T. 1604 & 11 & 2 & 14 & 1.3 & Brick & Inclined \\
\hline T. 1185 & 10 & 2 & 15 & 1.3 & Brick & Plane & T. 1605 & 11 & 2 & 15 & 1.3 & Brick & Inclined \\
\hline T. 1186 & 11 & 2 & 1 & 1.6 & Brick & Plane & T. 1606 & 12 & 2 & 1 & 1.6 & Brick & Inclined \\
\hline T. 1187 & 11 & 2 & 2 & 1.6 & Brick & Plane & T. 1607 & 12 & 2 & 2 & 1.6 & Brick & Inclined \\
\hline T. 1188 & 11 & 2 & 3 & 1.6 & Brick & Plane & T. 1608 & 12 & 2 & 3 & 1.6 & Brick & Inclined \\
\hline T. 1189 & 11 & 2 & 4 & 1.6 & Brick & Plane & T. 1609 & 12 & 2 & 4 & 1.6 & Brick & Inclined \\
\hline T. 1190 & 11 & 2 & 5 & 1.6 & Brick & Plane & T. 1610 & 12 & 2 & 5 & 1.6 & Brick & Inclined \\
\hline T. 1191 & 11 & 2 & 6 & 1.6 & Brick & Plane & T. 1611 & 12 & 2 & 6 & 1.6 & Brick & Inclined \\
\hline T. 1192 & 11 & 2 & 7 & 1.6 & Brick & Plane & T. 1612 & 12 & 2 & 7 & 1.6 & Brick & Inclined \\
\hline T. 1193 & 11 & 2 & 8 & 1.6 & Brick & Plane & T. 1613 & 12 & 2 & 8 & 1.6 & Brick & Inclined \\
\hline T. 1194 & 11 & 2 & 9 & 1.6 & Brick & Plane & T. 1614 & 12 & 2 & 9 & 1.6 & Brick & Inclined \\
\hline T. 1195 & 10 & 2 & 10 & 1.6 & Brick & Plane & T. 1615 & 11 & 2 & 10 & 1.6 & Brick & Inclined \\
\hline T. 1196 & 10 & 2 & 11 & 1.6 & Brick & Plane & T. 1616 & 11 & 2 & 11 & 1.6 & Brick & Inclined \\
\hline T. 1197 & 11 & 2 & 12 & 1.6 & Brick & Plane & T. 1617 & 12 & 2 & 12 & 1.6 & Brick & Inclined \\
\hline T. 1198 & 11 & 2 & 13 & 1.6 & Brick & Plane & T. 1618 & 12 & 2 & 13 & 1.6 & Brick & Inclined \\
\hline T. 1199 & 10 & 2 & 14 & 1.6 & Brick & Plane & T. 1619 & 11 & 2 & 14 & 1.6 & Brick & Inclined \\
\hline T. 1200 & 10 & 2 & 15 & 1.6 & Brick & Plane & T. 1620 & 11 & 2 & 15 & 1.6 & Brick & Inclined \\
\hline T. 1201 & 11 & 2 & 1 & 1.8 & Brick & Plane & T. 1621 & 12 & 2 & 1 & 1.8 & Brick & Inclined \\
\hline T. 1202 & 11 & 2 & 2 & 1.8 & Brick & Plane & T. 1622 & 12 & 2 & 2 & 1.8 & Brick & Inclined \\
\hline T. 1203 & 11 & 2 & 3 & 1.8 & Brick & Plane & T. 1623 & 12 & 2 & 3 & 1.8 & Brick & Inclined \\
\hline T. 1204 & 11 & 2 & 4 & 1.8 & Brick & Plane & T. 1624 & 12 & 2 & 4 & 1.8 & Brick & Inclined \\
\hline T. 1205 & 11 & 2 & 5 & 1.8 & Brick & Plane & T. 1625 & 12 & 2 & 5 & 1.8 & Brick & Inclined \\
\hline T. 1206 & 11 & 2 & 6 & 1.8 & Brick & Plane & T. 1626 & 12 & 2 & 6 & 1.8 & Brick & Inclined \\
\hline T. 1207 & 11 & 2 & 7 & 1.8 & Brick & Plane & T. 1627 & 12 & 2 & 7 & 1.8 & Brick & Inclined \\
\hline T. 1208 & 11 & 2 & 8 & 1.8 & Brick & Plane & T. 1628 & 12 & 2 & 8 & 1.8 & Brick & Inclined \\
\hline T. 1209 & 11 & 2 & 9 & 1.8 & Brick & Plane & T. 1629 & 12 & 2 & 9 & 1.8 & Brick & Inclined \\
\hline T. 1210 & 10 & 2 & 10 & 1.8 & Brick & Plane & T. 1630 & 11 & 2 & 10 & 1.8 & Brick & Inclined \\
\hline T. 1211 & 10 & 2 & 11 & 1.8 & Brick & Plane & T. 1631 & 11 & 2 & 11 & 1.8 & Brick & Inclined \\
\hline
\end{tabular}

(cont. on next page) 
Table E.1. (cont.)

\begin{tabular}{|c|c|c|c|c|c|c|c|c|c|c|c|c|c|}
\hline T. 1212 & 11 & 2 & 12 & 1.8 & Brick & Plane & T. 1632 & 12 & 2 & 12 & 1.8 & Brick & Inclined \\
\hline T. 1213 & 11 & 2 & 13 & 1.8 & Brick & Plane & T. 1633 & 12 & 2 & 13 & 1.8 & Brick & Inclined \\
\hline T. 1214 & 10 & 2 & 14 & 1.8 & Brick & Plane & T. 1634 & 11 & 2 & 14 & 1.8 & Brick & Inclined \\
\hline T. 1215 & 10 & 2 & 15 & 1.8 & Brick & Plane & T. 1635 & 11 & 2 & 15 & 1.8 & Brick & Inclined \\
\hline T. 1216 & 10 & 2 & 1 & 2 & Brick & Plane & T. 1636 & 11 & 2 & 1 & 2 & Brick & Inclined \\
\hline T. 1217 & 11 & 2 & 2 & 2 & Brick & Plane & T. 1637 & 12 & 2 & 2 & 2 & Brick & Inclined \\
\hline T. 1218 & 11 & 2 & 3 & 2 & Brick & Plane & T. 1638 & 12 & 2 & 3 & 2 & Brick & Inclined \\
\hline T. 1219 & 11 & 2 & 4 & 2 & Brick & Plane & T. 1639 & 12 & 2 & 4 & 2 & Brick & Inclined \\
\hline T. 1220 & 11 & 2 & 5 & 2 & Brick & Plane & T. 1640 & 12 & 2 & 5 & 2 & Brick & Inclined \\
\hline T. 1221 & 11 & 2 & 6 & 2 & Brick & Plane & T. 1641 & 12 & 2 & 6 & 2 & Brick & Inclined \\
\hline T. 1222 & 11 & 2 & 7 & 2 & Brick & Plane & T. 1642 & 12 & 2 & 7 & 2 & Brick & Inclined \\
\hline T. 1223 & 11 & 2 & 8 & 2 & Brick & Plane & T. 1643 & 12 & 2 & 8 & 2 & Brick & Inclined \\
\hline T. 1224 & 10 & 2 & 9 & 2 & Brick & Plane & T. 1644 & 11 & 2 & 9 & 2 & Brick & Inclined \\
\hline T. 1225 & 9 & 2 & 10 & 2 & Brick & Plane & T. 1645 & 10 & 2 & 10 & 2 & Brick & Inclined \\
\hline T. 1226 & 9 & 2 & 11 & 2 & Brick & Plane & T. 1646 & 10 & 2 & 11 & 2 & Brick & Inclined \\
\hline T. 1227 & 10 & 2 & 12 & 2 & Brick & Plane & T. 1647 & 11 & 2 & 12 & 2 & Brick & Inclined \\
\hline T. 1228 & 10 & 2 & 13 & 2 & Brick & Plane & T. 1648 & 11 & 2 & 13 & 2 & Brick & Inclined \\
\hline T. 1229 & 9 & 2 & 14 & 2 & Brick & Plane & T. 1649 & 10 & 2 & 14 & 2 & Brick & Inclined \\
\hline T. 1230 & 9 & 2 & 15 & 2 & Brick & Plane & T. 1650 & 10 & 2 & 15 & 2 & Brick & Inclined \\
\hline T. 1231 & 11 & 2 & 1 & 2.3 & Brick & Plane & T. 1651 & 12 & 2 & 1 & 2.3 & Brick & Inclined \\
\hline T. 1232 & 11 & 2 & 2 & 2.3 & Brick & Plane & T. 1652 & 12 & 2 & 2 & 2.3 & Brick & Inclined \\
\hline T. 1233 & 11 & 2 & 3 & 2.3 & Brick & Plane & T. 1653 & 12 & 2 & 3 & 2.3 & Brick & Inclined \\
\hline T. 1234 & 11 & 2 & 4 & 2.3 & Brick & Plane & T. 1654 & 12 & 2 & 4 & 2.3 & Brick & Inclined \\
\hline T. 1235 & 11 & 2 & 5 & 2.3 & Brick & Plane & T. 1655 & 12 & 2 & 5 & 2.3 & Brick & Inclined \\
\hline T. 1236 & 11 & 2 & 6 & 2.3 & Brick & Plane & T. 1656 & 12 & 2 & 6 & 2.3 & Brick & Inclined \\
\hline T. 1237 & 11 & 2 & 7 & 2.3 & Brick & Plane & T. 1657 & 12 & 2 & 7 & 2.3 & Brick & Inclined \\
\hline T. 1238 & 11 & 2 & 8 & 2.3 & Brick & Plane & T. 1658 & 12 & 2 & 8 & 2.3 & Brick & Inclined \\
\hline T. 1239 & 10 & 2 & 9 & 2.3 & Brick & Plane & T. 1659 & 11 & 2 & 9 & 2.3 & Brick & Inclined \\
\hline T. 1240 & 9 & 2 & 10 & 2.3 & Brick & Plane & T. 1660 & 10 & 2 & 10 & 2.3 & Brick & Inclined \\
\hline T. 1241 & 10 & 2 & 11 & 2.3 & Brick & Plane & T. 1661 & 11 & 2 & 11 & 2.3 & Brick & Inclined \\
\hline T. 1242 & 9 & 2 & 12 & 2.3 & Brick & Plane & T. 1662 & 10 & 2 & 12 & 2.3 & Brick & Inclined \\
\hline T. 1243 & 9 & 2 & 13 & 2.3 & Brick & Plane & T. 1663 & 10 & 2 & 13 & 2.3 & Brick & Inclined \\
\hline T. 1244 & 8 & 2 & 14 & 2.3 & Brick & Plane & T. 1664 & 9 & 2 & 14 & 2.3 & Brick & Inclined \\
\hline
\end{tabular}

(cont. on next page) 
Table E.1. (cont.)

\begin{tabular}{|c|c|c|c|c|c|c|c|c|c|c|c|c|c|}
\hline T. 1245 & 8 & 2 & 15 & 2.3 & Brick & Plane & T. 1665 & 9 & 2 & 15 & 2.3 & Brick & Inclined \\
\hline T. 1246 & 11 & 2 & 1 & 2.5 & Brick & Plane & T. 1666 & 12 & 2 & 1 & 2.5 & Brick & Inclined \\
\hline T. 1247 & 11 & 2 & 2 & 2.5 & Brick & Plane & T. 1667 & 12 & 2 & 2 & 2.5 & Brick & Inclined \\
\hline T. 1248 & 11 & 2 & 3 & 2.5 & Brick & Plane & T. 1668 & 12 & 2 & 3 & 2.5 & Brick & Inclined \\
\hline T. 1249 & 11 & 2 & 4 & 2.5 & Brick & Plane & T. 1669 & 12 & 2 & 4 & 2.5 & Brick & Inclined \\
\hline T. 1250 & 11 & 2 & 5 & 2.5 & Brick & Plane & T. 1670 & 12 & 2 & 5 & 2.5 & Brick & Inclined \\
\hline T. 1251 & 11 & 2 & 6 & 2.5 & Brick & Plane & T. 1671 & 12 & 2 & 6 & 2.5 & Brick & Inclined \\
\hline T. 1252 & 11 & 2 & 7 & 2.5 & Brick & Plane & T. 1672 & 12 & 2 & 7 & 2.5 & Brick & Inclined \\
\hline T. 1253 & 11 & 2 & 8 & 2.5 & Brick & Plane & T. 1673 & 12 & 2 & 8 & 2.5 & Brick & Inclined \\
\hline T. 1254 & 10 & 2 & 9 & 2.5 & Brick & Plane & T. 1674 & 11 & 2 & 9 & 2.5 & Brick & Inclined \\
\hline T. 1255 & 8 & 2 & 10 & 2.5 & Brick & Plane & T. 1675 & 9 & 2 & 10 & 2.5 & Brick & Inclined \\
\hline T. 1256 & 9 & 2 & 11 & 2.5 & Brick & Plane & T. 1676 & 10 & 2 & 11 & 2.5 & Brick & Inclined \\
\hline T. 1257 & 8 & 2 & 12 & 2.5 & Brick & Plane & T. 1677 & 9 & 2 & 12 & 2.5 & Brick & Inclined \\
\hline T. 1258 & 8 & 2 & 13 & 2.5 & Brick & Plane & T. 1678 & 9 & 2 & 13 & 2.5 & Brick & Inclined \\
\hline T. 1259 & 7 & 2 & 14 & 2.5 & Brick & Plane & T. 1679 & 8 & 2 & 14 & 2.5 & Brick & Inclined \\
\hline T. 1260 & 7 & 2 & 15 & 2.5 & Brick & Plane & T. 1680 & 8 & 2 & 15 & 2.5 & Brick & Inclined \\
\hline T. 1681 & 11 & 3 & 1 & 1 & Granite & Plane & T. 2101 & 12 & 3 & 1 & 1 & Granite & Inclined \\
\hline T. 1682 & 11 & 3 & 2 & 1 & Granite & Plane & T. 2102 & 12 & 3 & 2 & 1 & Granite & Inclined \\
\hline T. 1683 & 11 & 3 & 3 & 1 & Granite & Plane & T. 2103 & 12 & 3 & 3 & 1 & Granite & Inclined \\
\hline T. 1684 & 11 & 3 & 4 & 1 & Granite & Plane & T. 2104 & 12 & 3 & 4 & 1 & Granite & Inclined \\
\hline T. 1685 & 11 & 3 & 5 & 1 & Granite & Plane & T. 2105 & 12 & 3 & 5 & 1 & Granite & Inclined \\
\hline T. 1686 & 11 & 3 & 6 & 1 & Granite & Plane & T. 2106 & 12 & 3 & 6 & 1 & Granite & Inclined \\
\hline T. 1687 & 11 & 3 & 7 & 1 & Granite & Plane & T. 2107 & 12 & 3 & 7 & 1 & Granite & Inclined \\
\hline T. 1688 & 11 & 3 & 8 & 1 & Granite & Plane & T. 2108 & 12 & 3 & 8 & 1 & Granite & Inclined \\
\hline T. 1689 & 11 & 3 & 9 & 1 & Granite & Plane & T. 2109 & 12 & 3 & 9 & 1 & Granite & Inclined \\
\hline T. 1690 & 10 & 3 & 10 & 1 & Granite & Plane & T. 2110 & 11 & 3 & 10 & 1 & Granite & Inclined \\
\hline T. 1691 & 10 & 3 & 11 & 1 & Granite & Plane & T. 2111 & 11 & 3 & 11 & 1 & Granite & Inclined \\
\hline T. 1692 & 11 & 3 & 12 & 1 & Granite & Plane & T. 2112 & 12 & 3 & 12 & 1 & Granite & Inclined \\
\hline T. 1693 & 11 & 3 & 13 & 1 & Granite & Plane & T. 2113 & 12 & 3 & 13 & 1 & Granite & Inclined \\
\hline T. 1694 & 10 & 3 & 14 & 1 & Granite & Plane & T. 2114 & 11 & 3 & 14 & 1 & Granite & Inclined \\
\hline T. 1695 & 10 & 3 & 15 & 1 & Granite & Plane & T. 2115 & 11 & 3 & 15 & 1 & Granite & Inclined \\
\hline T. 1696 & 13 & 3 & 1 & 1.3 & Granite & Plane & T. 2116 & 14 & 3 & 1 & 1.3 & Granite & Inclined \\
\hline T. 1697 & 13 & 3 & 2 & 1.3 & Granite & Plane & T. 2117 & 14 & 3 & 2 & 1.3 & Granite & Inclined \\
\hline
\end{tabular}

(cont. on next page) 
Table E.1. (cont.)

\begin{tabular}{|c|c|c|c|c|c|c|c|c|c|c|c|c|c|}
\hline T. 1698 & 13 & 3 & 3 & 1.3 & Granite & Plane & T. 2118 & 14 & 3 & 3 & 1.3 & Granite & Inclined \\
\hline T. 1699 & 13 & 3 & 4 & 1.3 & Granite & Plane & T. 2119 & 14 & 3 & 4 & 1.3 & Granite & Inclined \\
\hline T. 1700 & 13 & 3 & 5 & 1.3 & Granite & Plane & T. 2120 & 14 & 3 & 5 & 1.3 & Granite & Inclined \\
\hline T. 1701 & 13 & 3 & 6 & 1.3 & Granite & Plane & T. 2121 & 14 & 3 & 6 & 1.3 & Granite & Inclined \\
\hline T. 1702 & 13 & 3 & 7 & 1.3 & Granite & Plane & T. 2122 & 14 & 3 & 7 & 1.3 & Granite & Inclined \\
\hline T. 1703 & 13 & 3 & 8 & 1.3 & Granite & Plane & T. 2123 & 14 & 3 & 8 & 1.3 & Granite & Inclined \\
\hline T. 1704 & 13 & 3 & 9 & 1.3 & Granite & Plane & T. 2124 & 14 & 3 & 9 & 1.3 & Granite & Inclined \\
\hline T. 1705 & 12 & 3 & 10 & 1.3 & Granite & Plane & T. 2125 & 13 & 3 & 10 & 1.3 & Granite & Inclined \\
\hline T. 1706 & 12 & 3 & 11 & 1.3 & Granite & Plane & T. 2126 & 13 & 3 & 11 & 1.3 & Granite & Inclined \\
\hline T. 1707 & 13 & 3 & 12 & 1.3 & Granite & Plane & T. 2127 & 14 & 3 & 12 & 1.3 & Granite & Inclined \\
\hline T. 1708 & 13 & 3 & 13 & 1.3 & Granite & Plane & T. 2128 & 14 & 3 & 13 & 1.3 & Granite & Inclined \\
\hline T. 1709 & 12 & 3 & 14 & 1.3 & Granite & Plane & T. 2129 & 13 & 3 & 14 & 1.3 & Granite & Inclined \\
\hline T. 1710 & 12 & 3 & 15 & 1.3 & Granite & Plane & T. 2130 & 13 & 3 & 15 & 1.3 & Granite & Inclined \\
\hline *T. 1711 & 14 & 3 & 1 & 1.6 & Granite & Plane & *T. 2131 & 15 & 3 & 1 & 1.6 & Granite & Inclined \\
\hline${ }^{*} \mathrm{~T} .1712$ & 14 & 3 & 2 & 1.6 & Granite & Plane & ${ }^{*} \mathrm{~T} .2132$ & 15 & 3 & 2 & 1.6 & Granite & Inclined \\
\hline *T. 1713 & 14 & 3 & 3 & 1.6 & Granite & Plane & *T. 2133 & 15 & 3 & 3 & 1.6 & Granite & Inclined \\
\hline *T. 1714 & 14 & 3 & 4 & 1.6 & Granite & Plane & *T. 2134 & 15 & 3 & 4 & 1.6 & Granite & Inclined \\
\hline *T. 1715 & 14 & 3 & 5 & 1.6 & Granite & Plane & *T. 2135 & 15 & 3 & 5 & 1.6 & Granite & Inclined \\
\hline *T. 1716 & 14 & 3 & 6 & 1.6 & Granite & Plane & *T. 2136 & 15 & 3 & 6 & 1.6 & Granite & Inclined \\
\hline *T. 1717 & 14 & 3 & 7 & 1.6 & Granite & Plane & *T. 2137 & 15 & 3 & 7 & 1.6 & Granite & Inclined \\
\hline *T. 1718 & 14 & 3 & 8 & 1.6 & Granite & Plane & ${ }^{*} \mathrm{~T} .2138$ & 15 & 3 & 8 & 1.6 & Granite & Inclined \\
\hline *T. 1719 & 14 & 3 & 9 & 1.6 & Granite & Plane & *T. 2139 & 15 & 3 & 9 & 1.6 & Granite & Inclined \\
\hline *T. 1720 & 12 & 3 & 10 & 1.6 & Granite & Plane & *T. 2140 & 13 & 3 & 10 & 1.6 & Granite & Inclined \\
\hline *T. 1721 & 12 & 3 & 11 & 1.6 & Granite & Plane & *T. 2141 & 13 & 3 & 11 & 1.6 & Granite & Inclined \\
\hline *T. 1722 & 14 & 3 & 12 & 1.6 & Granite & Plane & *T. 2142 & 15 & 3 & 12 & 1.6 & Granite & Inclined \\
\hline *T. 1723 & 14 & 3 & 13 & 1.6 & Granite & Plane & *T. 2143 & 15 & 3 & 13 & 1.6 & Granite & Inclined \\
\hline *T. 1724 & 12 & 3 & 14 & 1.6 & Granite & Plane & *T. 2144 & 13 & 3 & 14 & 1.6 & Granite & Inclined \\
\hline *T. 1725 & 12 & 3 & 15 & 1.6 & Granite & Plane & *T. 2145 & 13 & 3 & 15 & 1.6 & Granite & Inclined \\
\hline *T. 1726 & 14 & 3 & 1 & 1.8 & Granite & Plane & *T. 2146 & 15 & 3 & 1 & 1.8 & Granite & Inclined \\
\hline *T. 1727 & 14 & 3 & 2 & 1.8 & Granite & Plane & *T. 2147 & 15 & 3 & 2 & 1.8 & Granite & Inclined \\
\hline *T. 1728 & 14 & 3 & 3 & 1.8 & Granite & Plane & *T. 2148 & 15 & 3 & 3 & 1.8 & Granite & Inclined \\
\hline *T. 1729 & 14 & 3 & 4 & 1.8 & Granite & Plane & *T. 2149 & 15 & 3 & 4 & 1.8 & Granite & Inclined \\
\hline${ }^{*} \mathrm{~T} .1730$ & 14 & 3 & 5 & 1.8 & Granite & Plane & *T. 2150 & 15 & 3 & 5 & 1.8 & Granite & Inclined \\
\hline
\end{tabular}

(cont. on next page) 
Table E.1. (cont.)

\begin{tabular}{|c|c|c|c|c|c|c|c|c|c|c|c|c|c|}
\hline *T. 1731 & 14 & 3 & 6 & 1.8 & Granite & Plane & *T. 2151 & 15 & 3 & 6 & 1.8 & Granite & Inclined \\
\hline *T. 1732 & 14 & 3 & 7 & 1.8 & Granite & Plane & *T. 2152 & 15 & 3 & 7 & 1.8 & Granite & Inclined \\
\hline *T. 1733 & 14 & 3 & 8 & 1.8 & Granite & Plane & *T. 2153 & 15 & 3 & 8 & 1.8 & Granite & Inclined \\
\hline *T. 1734 & 14 & 3 & 9 & 1.8 & Granite & Plane & *T. 2154 & 15 & 3 & 9 & 1.8 & Granite & Inclined \\
\hline *T. 1735 & 12 & 3 & 10 & 1.8 & Granite & Plane & *T. 2155 & 13 & 3 & 10 & 1.8 & Granite & Inclined \\
\hline *T. 1736 & 12 & 3 & 11 & 1.8 & Granite & Plane & *T. 2156 & 13 & 3 & 11 & 1.8 & Granite & Inclined \\
\hline *T. 1737 & 14 & 3 & 12 & 1.8 & Granite & Plane & *T. 2157 & 15 & 3 & 12 & 1.8 & Granite & Inclined \\
\hline *T. 1738 & 14 & 3 & 13 & 1.8 & Granite & Plane & *T. 2158 & 15 & 3 & 13 & 1.8 & Granite & Inclined \\
\hline *T. 1739 & 12 & 3 & 14 & 1.8 & Granite & Plane & *T. 2159 & 13 & 3 & 14 & 1.8 & Granite & Inclined \\
\hline${ }^{* \mathrm{~T}} .1740$ & 12 & 3 & 15 & 1.8 & Granite & Plane & *T. 2160 & 13 & 3 & 15 & 1.8 & Granite & Inclined \\
\hline *T. 1741 & 13,5 & 3 & 1 & 2 & Granite & Plane & *T. 2161 & 15 & 3 & 1 & 2 & Granite & Inclined \\
\hline *T. 1742 & 13,5 & 3 & 2 & 2 & Granite & Plane & ${ }^{*} \mathrm{~T} .2162$ & 15 & 3 & 2 & 2 & Granite & Inclined \\
\hline *T. 1743 & 13,5 & 3 & 3 & 2 & Granite & Plane & *T. 2163 & 15 & 3 & 3 & 2 & Granite & Inclined \\
\hline *T. 1744 & 13,5 & 3 & 4 & 2 & Granite & Plane & *T. 2164 & 15 & 3 & 4 & 2 & Granite & Inclined \\
\hline *T. 1745 & 13,5 & 3 & 5 & 2 & Granite & Plane & *T. 2165 & 15 & 3 & 5 & 2 & Granite & Inclined \\
\hline *T. 1746 & 13,5 & 3 & 6 & 2 & Granite & Plane & *T. 2166 & 15 & 3 & 6 & 2 & Granite & Inclined \\
\hline${ }^{*} \mathrm{~T} .1747$ & 13,5 & 3 & 7 & 2 & Granite & Plane & *T. 2167 & 15 & 3 & 7 & 2 & Granite & Inclined \\
\hline *T. 1748 & 13,5 & 3 & 8 & 2 & Granite & Plane & *T. 2168 & 15 & 3 & 8 & 2 & Granite & Inclined \\
\hline *T. 1749 & 13 & 3 & 9 & 2 & Granite & Plane & *T. 2169 & 14 & 3 & 9 & 2 & Granite & Inclined \\
\hline *T. 1750 & 12 & 3 & 10 & 2 & Granite & Plane & ${ }^{*} \mathrm{~T} .2170$ & 13 & 3 & 10 & 2 & Granite & Inclined \\
\hline *T. 1751 & 12 & 3 & 11 & 2 & Granite & Plane & *T. 2171 & 13 & 3 & 11 & 2 & Granite & Inclined \\
\hline *T. 1752 & 13,5 & 3 & 12 & 2 & Granite & Plane & *T. 2172 & 15 & 3 & 12 & 2 & Granite & Inclined \\
\hline *T. 1753 & 13,5 & 3 & 13 & 2 & Granite & Plane & *T. 2173 & 15 & 3 & 13 & 2 & Granite & Inclined \\
\hline *T. 1754 & 12 & 3 & 14 & 2 & Granite & Plane & *T. 2174 & 13 & 3 & 14 & 2 & Granite & Inclined \\
\hline *T. 1755 & 12 & 3 & 15 & 2 & Granite & Plane & *T. 2175 & 13 & 3 & 15 & 2 & Granite & Inclined \\
\hline *T. 1756 & 13,5 & 3 & 1 & 2.3 & Granite & Plane & *T. 2176 & 15 & 3 & 1 & 2.3 & Granite & Inclined \\
\hline *T. 1757 & 13,5 & 3 & 2 & 2.3 & Granite & Plane & *T. 2177 & 15 & 3 & 2 & 2.3 & Granite & Inclined \\
\hline *T. 1758 & 13,5 & 3 & 3 & 2.3 & Granite & Plane & *T. 2178 & 15 & 3 & 3 & 2.3 & Granite & Inclined \\
\hline *T. 1759 & 13,5 & 3 & 4 & 2.3 & Granite & Plane & *T. 2179 & 15 & 3 & 4 & 2.3 & Granite & Inclined \\
\hline *T. 1760 & 13,5 & 3 & 5 & 2.3 & Granite & Plane & *T. 2180 & 15 & 3 & 5 & 2.3 & Granite & Inclined \\
\hline *T. 1761 & 13,5 & 3 & 6 & 2.3 & Granite & Plane & ${ }^{*}$ T. 2181 & 15 & 3 & 6 & 2.3 & Granite & Inclined \\
\hline *T. 1762 & 13,5 & 3 & 7 & 2.3 & Granite & Plane & *T. 2182 & 15 & 3 & 7 & 2.3 & Granite & Inclined \\
\hline *T. 1763 & 13,5 & 3 & 8 & 2.3 & Granite & Plane & ${ }^{*} \mathrm{~T} .2183$ & 15 & 3 & 8 & 2.3 & Granite & Inclined \\
\hline
\end{tabular}


Table E.1. (cont.)

\begin{tabular}{|c|c|c|c|c|c|c|c|c|c|c|c|c|c|}
\hline *T. 1764 & 13,5 & 3 & 9 & 2.3 & Granite & Plane & ${ }^{*} \mathrm{~T} .2184$ & 15 & 3 & 9 & 2.3 & Granite & Inclined \\
\hline *T. 1765 & 12 & 3 & 10 & 2.3 & Granite & Plane & *T. 2185 & 13 & 3 & 10 & 2.3 & Granite & Inclined \\
\hline *T. 1766 & 12 & 3 & 11 & 2.3 & Granite & Plane & ${ }^{*} \mathrm{~T} .2186$ & 13 & 3 & 11 & 2.3 & Granite & Inclined \\
\hline *T. 1767 & 13,5 & 3 & 12 & 2.3 & Granite & Plane & *T. 2187 & 15 & 3 & 12 & 2.3 & Granite & Inclined \\
\hline${ }^{*}$ T. 1768 & 13,5 & 3 & 13 & 2.3 & Granite & Plane & ${ }^{*} \mathrm{~T} .2188$ & 15 & 3 & 13 & 2.3 & Granite & Inclined \\
\hline *T. 1769 & 12 & 3 & 14 & 2.3 & Granite & Plane & *T. 2189 & 13 & 3 & 14 & 2.3 & Granite & Inclined \\
\hline *T. 1770 & 12 & 3 & 15 & 2.3 & Granite & Plane & *T. 2190 & 13 & 3 & 15 & 2.3 & Granite & Inclined \\
\hline T. 1771 & 13 & 3 & 1 & 2.5 & Granite & Plane & T. 2191 & 14 & 3 & 1 & 2.5 & Granite & Inclined \\
\hline T. 1772 & 13 & 3 & 2 & 2.5 & Granite & Plane & T. 2192 & 14 & 3 & 2 & 2.5 & Granite & Inclined \\
\hline T. 1773 & 13 & 3 & 3 & 2.5 & Granite & Plane & T. 2193 & 14 & 3 & 3 & 2.5 & Granite & Inclined \\
\hline T. 1774 & 13 & 3 & 4 & 2.5 & Granite & Plane & T. 2194 & 14 & 3 & 4 & 2.5 & Granite & Inclined \\
\hline T. 1775 & 13 & 3 & 5 & 2.5 & Granite & Plane & T. 2195 & 14 & 3 & 5 & 2.5 & Granite & Inclined \\
\hline T. 1776 & 13 & 3 & 6 & 2.5 & Granite & Plane & T. 2196 & 14 & 3 & 6 & 2.5 & Granite & Inclined \\
\hline T. 1777 & 13 & 3 & 7 & 2.5 & Granite & Plane & T. 2197 & 14 & 3 & 7 & 2.5 & Granite & Inclined \\
\hline T. 1778 & 13 & 3 & 8 & 2.5 & Granite & Plane & T. 2198 & 14 & 3 & 8 & 2.5 & Granite & Inclined \\
\hline T. 1779 & 13 & 3 & 9 & 2.5 & Granite & Plane & T. 2199 & 14 & 3 & 9 & 2.5 & Granite & Inclined \\
\hline T. 1780 & 11 & 3 & 10 & 2.5 & Granite & Plane & T. 2200 & 12 & 3 & 10 & 2.5 & Granite & Inclined \\
\hline T. 1781 & 11 & 3 & 11 & 2.5 & Granite & Plane & T. 2201 & 12 & 3 & 11 & 2.5 & Granite & Inclined \\
\hline T. 1782 & 13 & 3 & 12 & 2.5 & Granite & Plane & T. 2202 & 14 & 3 & 12 & 2.5 & Granite & Inclined \\
\hline T. 1783 & 13 & 3 & 13 & 2.5 & Granite & Plane & T. 2203 & 14 & 3 & 13 & 2.5 & Granite & Inclined \\
\hline T. 1784 & 11 & 3 & 14 & 2.5 & Granite & Plane & T. 2204 & 12 & 3 & 14 & 2.5 & Granite & Inclined \\
\hline T. 1785 & 11 & 3 & 15 & 2.5 & Granite & Plane & T. 2205 & 12 & 3 & 15 & 2.5 & Granite & Inclined \\
\hline T. 1786 & 11 & 3 & 1 & 1 & Limestone & Plane & T. 2206 & 12 & 3 & 1 & 1 & Limestone & Inclined \\
\hline T. 1787 & 11 & 3 & 2 & 1 & Limestone & Plane & T. 2207 & 12 & 3 & 2 & 1 & Limestone & Inclined \\
\hline T. 1788 & 11 & 3 & 3 & 1 & Limestone & Plane & T. 2208 & 12 & 3 & 3 & 1 & Limestone & Inclined \\
\hline T. 1789 & 11 & 3 & 4 & 1 & Limestone & Plane & T. 2209 & 12 & 3 & 4 & 1 & Limestone & Inclined \\
\hline T. 1790 & 11 & 3 & 5 & 1 & Limestone & Plane & T. 2210 & 12 & 3 & 5 & 1 & Limestone & Inclined \\
\hline T. 1791 & 11 & 3 & 6 & 1 & Limestone & Plane & T. 2211 & 12 & 3 & 6 & 1 & Limestone & Inclined \\
\hline T. 1792 & 11 & 3 & 7 & 1 & Limestone & Plane & T. 2212 & 12 & 3 & 7 & 1 & Limestone & Inclined \\
\hline T. 1793 & 11 & 3 & 8 & 1 & Limestone & Plane & T. 2213 & 12 & 3 & 8 & 1 & Limestone & Inclined \\
\hline T. 1794 & 11 & 3 & 9 & 1 & Limestone & Plane & T. 2214 & 12 & 3 & 9 & 1 & Limestone & Inclined \\
\hline T. 1795 & 10 & 3 & 10 & 1 & Limestone & Plane & T. 2215 & 11 & 3 & 10 & 1 & Limestone & Inclined \\
\hline T. 1796 & 10 & 3 & 11 & 1 & Limestone & Plane & T. 2216 & 11 & 3 & 11 & 1 & Limestone & Inclined \\
\hline
\end{tabular}

(cont. on next page) 
Table E.1. (cont.)

\begin{tabular}{|c|c|c|c|c|c|c|c|c|c|c|c|c|c|}
\hline T. 1797 & 11 & 3 & 12 & 1 & Limestone & Plane & T. 2217 & 12 & 3 & 12 & 1 & Limestone & Inclined \\
\hline T. 1798 & 11 & 3 & 13 & 1 & Limestone & Plane & T. 2218 & 12 & 3 & 13 & 1 & Limestone & Inclined \\
\hline T. 1799 & 10 & 3 & 14 & 1 & Limestone & Plane & T. 2219 & 11 & 3 & 14 & 1 & Limestone & Inclined \\
\hline T. 1800 & 10 & 3 & 15 & 1 & Limestone & Plane & T. 2220 & 11 & 3 & 15 & 1 & Limestone & Inclined \\
\hline T. 1801 & 13 & 3 & 1 & 1.3 & Limestone & Plane & T. 2221 & 14 & 3 & 1 & 1.3 & Limestone & Inclined \\
\hline T. 1802 & 13 & 3 & 2 & 1.3 & Limestone & Plane & T. 2222 & 14 & 3 & 2 & 1.3 & Limestone & Inclined \\
\hline T. 1803 & 13 & 3 & 3 & 1.3 & Limestone & Plane & T. 2223 & 14 & 3 & 3 & 1.3 & Limestone & Inclined \\
\hline T. 1804 & 13 & 3 & 4 & 1.3 & Limestone & Plane & T. 2224 & 14 & 3 & 4 & 1.3 & Limestone & Inclined \\
\hline T. 1805 & 13 & 3 & 5 & 1.3 & Limestone & Plane & T. 2225 & 14 & 3 & 5 & 1.3 & Limestone & Inclined \\
\hline T. 1806 & 13 & 3 & 6 & 1.3 & Limestone & Plane & T. 2226 & 14 & 3 & 6 & 1.3 & Limestone & Inclined \\
\hline T. 1807 & 13 & 3 & 7 & 1.3 & Limestone & Plane & T. 2227 & 14 & 3 & 7 & 1.3 & Limestone & Inclined \\
\hline T. 1808 & 13 & 3 & 8 & 1.3 & Limestone & Plane & T. 2228 & 14 & 3 & 8 & 1.3 & Limestone & Inclined \\
\hline T. 1809 & 13 & 3 & 9 & 1.3 & Limestone & Plane & T. 2229 & 14 & 3 & 9 & 1.3 & Limestone & Inclined \\
\hline T. 1810 & 12 & 3 & 10 & 1.3 & Limestone & Plane & T. 2230 & 13 & 3 & 10 & 1.3 & Limestone & Inclined \\
\hline T. 1811 & 12 & 3 & 11 & 1.3 & Limestone & Plane & T. 2231 & 13 & 3 & 11 & 1.3 & Limestone & Inclined \\
\hline T. 1812 & 13 & 3 & 12 & 1.3 & Limestone & Plane & T. 2232 & 14 & 3 & 12 & 1.3 & Limestone & Inclined \\
\hline T. 1813 & 13 & 3 & 13 & 1.3 & Limestone & Plane & T. 2233 & 14 & 3 & 13 & 1.3 & Limestone & Inclined \\
\hline T. 1814 & 12 & 3 & 14 & 1.3 & Limestone & Plane & T. 2234 & 13 & 3 & 14 & 1.3 & Limestone & Inclined \\
\hline T. 1815 & 12 & 3 & 15 & 1.3 & Limestone & Plane & T. 2235 & 13 & 3 & 15 & 1.3 & Limestone & Inclined \\
\hline *T. 1816 & 14 & 3 & 1 & 1.6 & Limestone & Plane & ${ }^{*} \mathrm{~T} .2236$ & 15 & 3 & 1 & 1.6 & Limestone & Inclined \\
\hline *T. 1817 & 14 & 3 & 2 & 1.6 & Limestone & Plane & *T. 2237 & 15 & 3 & 2 & 1.6 & Limestone & Inclined \\
\hline *T. 1818 & 14 & 3 & 3 & 1.6 & Limestone & Plane & ${ }^{*} \mathrm{~T} .2238$ & 15 & 3 & 3 & 1.6 & Limestone & Inclined \\
\hline *T. 1819 & 14 & 3 & 4 & 1.6 & Limestone & Plane & *T. 2239 & 15 & 3 & 4 & 1.6 & Limestone & Inclined \\
\hline *T. 1820 & 14 & 3 & 5 & 1.6 & Limestone & Plane & *T. 2240 & 15 & 3 & 5 & 1.6 & Limestone & Inclined \\
\hline *T. 1821 & 14 & 3 & 6 & 1.6 & Limestone & Plane & *T. 2241 & 15 & 3 & 6 & 1.6 & Limestone & Inclined \\
\hline *T. 1822 & 14 & 3 & 7 & 1.6 & Limestone & Plane & *T. 2242 & 15 & 3 & 7 & 1.6 & Limestone & Inclined \\
\hline *T. 1823 & 14 & 3 & 8 & 1.6 & Limestone & Plane & ${ }^{*} \mathrm{~T} .2243$ & 15 & 3 & 8 & 1.6 & Limestone & Inclined \\
\hline *T. 1824 & 14 & 3 & 9 & 1.6 & Limestone & Plane & *T. 2244 & 15 & 3 & 9 & 1.6 & Limestone & Inclined \\
\hline *T. 1825 & 12 & 3 & 10 & 1.6 & Limestone & Plane & *T. 2245 & 13 & 3 & 10 & 1.6 & Limestone & Inclined \\
\hline *T. 1826 & 12 & 3 & 11 & 1.6 & Limestone & Plane & *T. 2246 & 13 & 3 & 11 & 1.6 & Limestone & Inclined \\
\hline *T. 1827 & 14 & 3 & 12 & 1.6 & Limestone & Plane & *T. 2247 & 15 & 3 & 12 & 1.6 & Limestone & Inclined \\
\hline *T. 1828 & 14 & 3 & 13 & 1.6 & Limestone & Plane & *T. 2248 & 15 & 3 & 13 & 1.6 & Limestone & Inclined \\
\hline *T. 1829 & 12 & 3 & 14 & 1.6 & Limestone & Plane & *T. 2249 & 13 & 3 & 14 & 1.6 & Limestone & Inclined \\
\hline
\end{tabular}

(cont. on next page) 
Table E.1. (cont.)

\begin{tabular}{|c|c|c|c|c|c|c|c|c|c|c|c|c|c|}
\hline *T. 1830 & 12 & 3 & 15 & 1.6 & Limestone & Plane & *T. 2250 & 13 & 3 & 15 & 1.6 & Limestone & Inclined \\
\hline *T. 1831 & 14 & 3 & 1 & 1.8 & Limestone & Plane & *T. 2251 & 15 & 3 & 1 & 1.8 & Limestone & Inclined \\
\hline *T. 1832 & 14 & 3 & 2 & 1.8 & Limestone & Plane & *T. 2252 & 15 & 3 & 2 & 1.8 & Limestone & Inclined \\
\hline *T. 1833 & 14 & 3 & 3 & 1.8 & Limestone & Plane & ${ }^{*} \mathrm{~T} .2253$ & 15 & 3 & 3 & 1.8 & Limestone & Inclined \\
\hline *T. 1834 & 14 & 3 & 4 & 1.8 & Limestone & Plane & ${ }^{*} \mathrm{~T} .2254$ & 15 & 3 & 4 & 1.8 & Limestone & Inclined \\
\hline *T. 1835 & 14 & 3 & 5 & 1.8 & Limestone & Plane & ${ }^{*}$ T. 2255 & 15 & 3 & 5 & 1.8 & Limestone & Inclined \\
\hline *T. 1836 & 14 & 3 & 6 & 1.8 & Limestone & Plane & *T. 2256 & 15 & 3 & 6 & 1.8 & Limestone & Inclined \\
\hline *T. 1837 & 14 & 3 & 7 & 1.8 & Limestone & Plane & *T. 2257 & 15 & 3 & 7 & 1.8 & Limestone & Inclined \\
\hline *T. 1838 & 14 & 3 & 8 & 1.8 & Limestone & Plane & *T. 2258 & 15 & 3 & 8 & 1.8 & Limestone & Inclined \\
\hline${ }^{*}$ T. 1839 & 14 & 3 & 9 & 1.8 & Limestone & Plane & *T. 2259 & 15 & 3 & 9 & 1.8 & Limestone & Inclined \\
\hline *T. 1840 & 12 & 3 & 10 & 1.8 & Limestone & Plane & ${ }^{*} \mathrm{~T} .2260$ & 13 & 3 & 10 & 1.8 & Limestone & Inclined \\
\hline *T. 1841 & 12 & 3 & 11 & 1.8 & Limestone & Plane & *T. 2261 & 13 & 3 & 11 & 1.8 & Limestone & Inclined \\
\hline *T. 1842 & 14 & 3 & 12 & 1.8 & Limestone & Plane & *T. 2262 & 15 & 3 & 12 & 1.8 & Limestone & Inclined \\
\hline *T. 1843 & 14 & 3 & 13 & 1.8 & Limestone & Plane & *T. 2263 & 15 & 3 & 13 & 1.8 & Limestone & Inclined \\
\hline${ }^{*} \mathrm{~T} .1844$ & 12 & 3 & 14 & 1.8 & Limestone & Plane & ${ }^{*} \mathrm{~T} .2264$ & 13 & 3 & 14 & 1.8 & Limestone & Inclined \\
\hline *T. 1845 & 12 & 3 & 15 & 1.8 & Limestone & Plane & *T. 2265 & 13 & 3 & 15 & 1.8 & Limestone & Inclined \\
\hline *T. 1846 & 13,5 & 3 & 1 & 2 & Limestone & Plane & *T. 2266 & 15 & 3 & 1 & 2 & Limestone & Inclined \\
\hline *T. 1847 & 13,5 & 3 & 2 & 2 & Limestone & Plane & *T. 2267 & 15 & 3 & 2 & 2 & Limestone & Inclined \\
\hline *T. 1848 & 13,5 & 3 & 3 & 2 & Limestone & Plane & *T. 2268 & 15 & 3 & 3 & 2 & Limestone & Inclined \\
\hline *T. 1849 & 13,5 & 3 & 4 & 2 & Limestone & Plane & *T. 2269 & 15 & 3 & 4 & 2 & Limestone & Inclined \\
\hline *T. 1850 & 13,5 & 3 & 5 & 2 & Limestone & Plane & ${ }^{*} \mathrm{~T} .2270$ & 15 & 3 & 5 & 2 & Limestone & Inclined \\
\hline *T. 1851 & 13,5 & 3 & 6 & 2 & Limestone & Plane & *T. 2271 & 15 & 3 & 6 & 2 & Limestone & Inclined \\
\hline *T. 1852 & 13,5 & 3 & 7 & 2 & Limestone & Plane & *T. 2272 & 15 & 3 & 7 & 2 & Limestone & Inclined \\
\hline *T. 1853 & 13,5 & 3 & 8 & 2 & Limestone & Plane & *T. 2273 & 15 & 3 & 8 & 2 & Limestone & Inclined \\
\hline *T. 1854 & 13 & 3 & 9 & 2 & Limestone & Plane & *T. 2274 & 14 & 3 & 9 & 2 & Limestone & Inclined \\
\hline *T. 1855 & 12 & 3 & 10 & 2 & Limestone & Plane & *T. 2275 & 13 & 3 & 10 & 2 & Limestone & Inclined \\
\hline *T. 1856 & 12 & 3 & 11 & 2 & Limestone & Plane & *T. 2276 & 13 & 3 & 11 & 2 & Limestone & Inclined \\
\hline *T. 1857 & 13,5 & 3 & 12 & 2 & Limestone & Plane & *T. 2277 & 15 & 3 & 12 & 2 & Limestone & Inclined \\
\hline *T. 1858 & 13,5 & 3 & 13 & 2 & Limestone & Plane & *T. 2278 & 15 & 3 & 13 & 2 & Limestone & Inclined \\
\hline *T. 1859 & 12 & 3 & 14 & 2 & Limestone & Plane & *T. 2279 & 13 & 3 & 14 & 2 & Limestone & Inclined \\
\hline *T. 1860 & 12 & 3 & 15 & 2 & Limestone & Plane & *T. 2280 & 13 & 3 & 15 & 2 & Limestone & Inclined \\
\hline *T. 1861 & 13,5 & 3 & 1 & 2.3 & Limestone & Plane & *T. 2281 & 15 & 3 & 1 & 2.3 & Limestone & Inclined \\
\hline *T. 1862 & 13,5 & 3 & 2 & 2.3 & Limestone & Plane & *T. 2282 & 15 & 3 & 2 & 2.3 & Limestone & Inclined \\
\hline
\end{tabular}

(cont. on next page) 
Table E.1. (cont.)

\begin{tabular}{|c|c|c|c|c|c|c|c|c|c|c|c|c|c|}
\hline *T. 1863 & 13,5 & 3 & 3 & 2.3 & Limestone & Plane & *T. 2283 & 15 & 3 & 3 & 2.3 & Limestone & Inclined \\
\hline *T. 1864 & 13,5 & 3 & 4 & 2.3 & Limestone & Plane & *T. 2284 & 15 & 3 & 4 & 2.3 & Limestone & Inclined \\
\hline *T. 1865 & 13,5 & 3 & 5 & 2.3 & Limestone & Plane & *T. 2285 & 15 & 3 & 5 & 2.3 & Limestone & Inclined \\
\hline *T. 1866 & 13,5 & 3 & 6 & 2.3 & Limestone & Plane & *T. 2286 & 15 & 3 & 6 & 2.3 & Limestone & Inclined \\
\hline *T. 1867 & 13,5 & 3 & 7 & 2.3 & Limestone & Plane & *T. 2287 & 15 & 3 & 7 & 2.3 & Limestone & Inclined \\
\hline *T. 1868 & 13,5 & 3 & 8 & 2.3 & Limestone & Plane & *T. 2288 & 15 & 3 & 8 & 2.3 & Limestone & Inclined \\
\hline *T. 1869 & 13,5 & 3 & 9 & 2.3 & Limestone & Plane & *T. 2289 & 15 & 3 & 9 & 2.3 & Limestone & Inclined \\
\hline *T. 1870 & 12 & 3 & 10 & 2.3 & Limestone & Plane & *T. 2290 & 13 & 3 & 10 & 2.3 & Limestone & Inclined \\
\hline *T. 1871 & 12 & 3 & 11 & 2.3 & Limestone & Plane & *T. 2291 & 13 & 3 & 11 & 2.3 & Limestone & Inclined \\
\hline${ }^{*} \mathrm{~T} .1872$ & 13,5 & 3 & 12 & 2.3 & Limestone & Plane & *T. 2292 & 15 & 3 & 12 & 2.3 & Limestone & Inclined \\
\hline *T. 1873 & 13,5 & 3 & 13 & 2.3 & Limestone & Plane & *T. 2293 & 15 & 3 & 13 & 2.3 & Limestone & Inclined \\
\hline${ }^{*}$ T. 1874 & 12 & 3 & 14 & 2.3 & Limestone & Plane & *T. 2294 & 13 & 3 & 14 & 2.3 & Limestone & Inclined \\
\hline *T. 1875 & 12 & 3 & 15 & 2.3 & Limestone & Plane & *T. 2295 & 13 & 3 & 15 & 2.3 & Limestone & Inclined \\
\hline T. 1876 & 13 & 3 & 1 & 2.5 & Limestone & Plane & T. 2296 & 14 & 3 & 1 & 2.5 & Limestone & Inclined \\
\hline T. 1877 & 13 & 3 & 2 & 2.5 & Limestone & Plane & T. 2297 & 14 & 3 & 2 & 2.5 & Limestone & Inclined \\
\hline T. 1878 & 13 & 3 & 3 & 2.5 & Limestone & Plane & T. 2298 & 14 & 3 & 3 & 2.5 & Limestone & Inclined \\
\hline T. 1879 & 13 & 3 & 4 & 2.5 & Limestone & Plane & T. 2299 & 14 & 3 & 4 & 2.5 & Limestone & Inclined \\
\hline T. 1880 & 13 & 3 & 5 & 2.5 & Limestone & Plane & T. 2300 & 14 & 3 & 5 & 2.5 & Limestone & Inclined \\
\hline T. 1881 & 13 & 3 & 6 & 2.5 & Limestone & Plane & T. 2301 & 14 & 3 & 6 & 2.5 & Limestone & Inclined \\
\hline T. 1882 & 13 & 3 & 7 & 2.5 & Limestone & Plane & T. 2302 & 14 & 3 & 7 & 2.5 & Limestone & Inclined \\
\hline T. 1883 & 13 & 3 & 8 & 2.5 & Limestone & Plane & T. 2303 & 14 & 3 & 8 & 2.5 & Limestone & Inclined \\
\hline T. 1884 & 13 & 3 & 9 & 2.5 & Limestone & Plane & T. 2304 & 14 & 3 & 9 & 2.5 & Limestone & Inclined \\
\hline T. 1885 & 11 & 3 & 10 & 2.5 & Limestone & Plane & T. 2305 & 12 & 3 & 10 & 2.5 & Limestone & Inclined \\
\hline T. 1886 & 11 & 3 & 11 & 2.5 & Limestone & Plane & T. 2306 & 12 & 3 & 11 & 2.5 & Limestone & Inclined \\
\hline T. 1887 & 13 & 3 & 12 & 2.5 & Limestone & Plane & T. 2307 & 14 & 3 & 12 & 2.5 & Limestone & Inclined \\
\hline T. 1888 & 13 & 3 & 13 & 2.5 & Limestone & Plane & T. 2308 & 14 & 3 & 13 & 2.5 & Limestone & Inclined \\
\hline T. 1889 & 11 & 3 & 14 & 2.5 & Limestone & Plane & T. 2309 & 12 & 3 & 14 & 2.5 & Limestone & Inclined \\
\hline T. 1890 & 11 & 3 & 15 & 2.5 & Limestone & Plane & T. 2310 & 12 & 3 & 15 & 2.5 & Limestone & Inclined \\
\hline T. 1891 & 11 & 3 & 1 & 1 & Sandstone & Plane & T. 2311 & 12 & 3 & 1 & 1 & Sandstone & Inclined \\
\hline T. 1892 & 11 & 3 & 2 & 1 & Sandstone & Plane & T. 2312 & 12 & 3 & 2 & 1 & Sandstone & Inclined \\
\hline T. 1893 & 11 & 3 & 3 & 1 & Sandstone & Plane & T. 2313 & 12 & 3 & 3 & 1 & Sandstone & Inclined \\
\hline T. 1894 & 11 & 3 & 4 & 1 & Sandstone & Plane & T. 2314 & 12 & 3 & 4 & 1 & Sandstone & Inclined \\
\hline T. 1895 & 11 & 3 & 5 & 1 & Sandstone & Plane & T. 2315 & 12 & 3 & 5 & 1 & Sandstone & Inclined \\
\hline
\end{tabular}

(cont. on next page) 
Table E.1. (cont.)

\begin{tabular}{|c|c|c|c|c|c|c|c|c|c|c|c|c|c|}
\hline T. 1896 & 11 & 3 & 6 & 1 & Sandstone & Plane & T. 2316 & 12 & 3 & 6 & 1 & Sandstone & Inclined \\
\hline T. 1897 & 11 & 3 & 7 & 1 & Sandstone & Plane & T. 2317 & 12 & 3 & 7 & 1 & Sandstone & Inclined \\
\hline T. 1898 & 11 & 3 & 8 & 1 & Sandstone & Plane & T. 2318 & 12 & 3 & 8 & 1 & Sandstone & Inclined \\
\hline T. 1899 & 11 & 3 & 9 & 1 & Sandstone & Plane & T. 2319 & 12 & 3 & 9 & 1 & Sandstone & Inclined \\
\hline T. 1900 & 10 & 3 & 10 & 1 & Sandstone & Plane & T. 2320 & 11 & 3 & 10 & 1 & Sandstone & Inclined \\
\hline T. 1901 & 10 & 3 & 11 & 1 & Sandstone & Plane & T. 2321 & 11 & 3 & 11 & 1 & Sandstone & Inclined \\
\hline T. 1902 & 11 & 3 & 12 & 1 & Sandstone & Plane & T. 2322 & 12 & 3 & 12 & 1 & Sandstone & Inclined \\
\hline T. 1903 & 11 & 3 & 13 & 1 & Sandstone & Plane & T. 2323 & 12 & 3 & 13 & 1 & Sandstone & Inclined \\
\hline T. 1904 & 10 & 3 & 14 & 1 & Sandstone & Plane & T. 2324 & 11 & 3 & 14 & 1 & Sandstone & Inclined \\
\hline T. 1905 & 10 & 3 & 15 & 1 & Sandstone & Plane & T. 2325 & 11 & 3 & 15 & 1 & Sandstone & Inclined \\
\hline T. 1906 & 13 & 3 & 1 & 1.3 & Sandstone & Plane & T. 2326 & 14 & 3 & 1 & 1.3 & Sandstone & Inclined \\
\hline T. 1907 & 13 & 3 & 2 & 1.3 & Sandstone & Plane & T. 2327 & 14 & 3 & 2 & 1.3 & Sandstone & Inclined \\
\hline T. 1908 & 13 & 3 & 3 & 1.3 & Sandstone & Plane & T. 2328 & 14 & 3 & 3 & 1.3 & Sandstone & Inclined \\
\hline T. 1909 & 13 & 3 & 4 & 1.3 & Sandstone & Plane & T. 2329 & 14 & 3 & 4 & 1.3 & Sandstone & Inclined \\
\hline T. 1910 & 13 & 3 & 5 & 1.3 & Sandstone & Plane & T. 2330 & 14 & 3 & 5 & 1.3 & Sandstone & Inclined \\
\hline T. 1911 & 13 & 3 & 6 & 1.3 & Sandstone & Plane & T. 2331 & 14 & 3 & 6 & 1.3 & Sandstone & Inclined \\
\hline T. 1912 & 13 & 3 & 7 & 1.3 & Sandstone & Plane & T. 2332 & 14 & 3 & 7 & 1.3 & Sandstone & Inclined \\
\hline T. 1913 & 13 & 3 & 8 & 1.3 & Sandstone & Plane & T. 2333 & 14 & 3 & 8 & 1.3 & Sandstone & Inclined \\
\hline T. 1914 & 13 & 3 & 9 & 1.3 & Sandstone & Plane & T. 2334 & 14 & 3 & 9 & 1.3 & Sandstone & Inclined \\
\hline T. 1915 & 12 & 3 & 10 & 1.3 & Sandstone & Plane & T. 2335 & 13 & 3 & 10 & 1.3 & Sandstone & Inclined \\
\hline T. 1916 & 12 & 3 & 11 & 1.3 & Sandstone & Plane & T. 2336 & 13 & 3 & 11 & 1.3 & Sandstone & Inclined \\
\hline T. 1917 & 13 & 3 & 12 & 1.3 & Sandstone & Plane & T. 2337 & 14 & 3 & 12 & 1.3 & Sandstone & Inclined \\
\hline T. 1918 & 13 & 3 & 13 & 1.3 & Sandstone & Plane & T. 2338 & 14 & 3 & 13 & 1.3 & Sandstone & Inclined \\
\hline T. 1919 & 12 & 3 & 14 & 1.3 & Sandstone & Plane & T. 2339 & 13 & 3 & 14 & 1.3 & Sandstone & Inclined \\
\hline T. 1920 & 12 & 3 & 15 & 1.3 & Sandstone & Plane & T. 2340 & 13 & 3 & 15 & 1.3 & Sandstone & Inclined \\
\hline T. 1921 & 14 & 3 & 1 & 1.6 & Sandstone & Plane & T. 2341 & 15 & 3 & 1 & 1.6 & Sandstone & Inclined \\
\hline T. 1922 & 14 & 3 & 2 & 1.6 & Sandstone & Plane & T. 2342 & 15 & 3 & 2 & 1.6 & Sandstone & Inclined \\
\hline T. 1923 & 14 & 3 & 3 & 1.6 & Sandstone & Plane & T. 2343 & 15 & 3 & 3 & 1.6 & Sandstone & Inclined \\
\hline T. 1924 & 14 & 3 & 4 & 1.6 & Sandstone & Plane & T. 2344 & 15 & 3 & 4 & 1.6 & Sandstone & Inclined \\
\hline T. 1925 & 14 & 3 & 5 & 1.6 & Sandstone & Plane & T. 2345 & 15 & 3 & 5 & 1.6 & Sandstone & Inclined \\
\hline T. 1926 & 14 & 3 & 6 & 1.6 & Sandstone & Plane & T. 2346 & 15 & 3 & 6 & 1.6 & Sandstone & Inclined \\
\hline T. 1927 & 14 & 3 & 7 & 1.6 & Sandstone & Plane & T. 2347 & 15 & 3 & 7 & 1.6 & Sandstone & Inclined \\
\hline T. 1928 & 14 & 3 & 8 & 1.6 & Sandstone & Plane & T. 2348 & 15 & 3 & 8 & 1.6 & Sandstone & Inclined \\
\hline
\end{tabular}

(cont. on next page) 
Table E.1. (cont.)

\begin{tabular}{|c|c|c|c|c|c|c|c|c|c|c|c|c|c|}
\hline T. 1929 & 14 & 3 & 9 & 1.6 & Sandstone & Plane & T. 2349 & 15 & 3 & 9 & 1.6 & Sandstone & Inclined \\
\hline T. 1930 & 12 & 3 & 10 & 1.6 & Sandstone & Plane & T. 2350 & 13 & 3 & 10 & 1.6 & Sandstone & Inclined \\
\hline T. 1931 & 12 & 3 & 11 & 1.6 & Sandstone & Plane & T. 2351 & 13 & 3 & 11 & 1.6 & Sandstone & Inclined \\
\hline T. 1932 & 14 & 3 & 12 & 1.6 & Sandstone & Plane & T. 2352 & 15 & 3 & 12 & 1.6 & Sandstone & Inclined \\
\hline T. 1933 & 14 & 3 & 13 & 1.6 & Sandstone & Plane & T. 2353 & 15 & 3 & 13 & 1.6 & Sandstone & Inclined \\
\hline T. 1934 & 12 & 3 & 14 & 1.6 & Sandstone & Plane & T. 2354 & 13 & 3 & 14 & 1.6 & Sandstone & Inclined \\
\hline T. 1935 & 12 & 3 & 15 & 1.6 & Sandstone & Plane & T. 2355 & 13 & 3 & 15 & 1.6 & Sandstone & Inclined \\
\hline T. 1936 & 14 & 3 & 1 & 1.8 & Sandstone & Plane & T. 2356 & 15 & 3 & 1 & 1.8 & Sandstone & Inclined \\
\hline T. 1937 & 14 & 3 & 2 & 1.8 & Sandstone & Plane & T. 2357 & 15 & 3 & 2 & 1.8 & Sandstone & Inclined \\
\hline T. 1938 & 14 & 3 & 3 & 1.8 & Sandstone & Plane & T. 2358 & 15 & 3 & 3 & 1.8 & Sandstone & Inclined \\
\hline T. 1939 & 14 & 3 & 4 & 1.8 & Sandstone & Plane & T. 2359 & 15 & 3 & 4 & 1.8 & Sandstone & Inclined \\
\hline T. 1940 & 14 & 3 & 5 & 1.8 & Sandstone & Plane & T. 2360 & 15 & 3 & 5 & 1.8 & Sandstone & Inclined \\
\hline T. 1941 & 14 & 3 & 6 & 1.8 & Sandstone & Plane & T. 2361 & 15 & 3 & 6 & 1.8 & Sandstone & Inclined \\
\hline T. 1942 & 14 & 3 & 7 & 1.8 & Sandstone & Plane & T. 2362 & 15 & 3 & 7 & 1.8 & Sandstone & Inclined \\
\hline T. 1943 & 14 & 3 & 8 & 1.8 & Sandstone & Plane & T. 2363 & 15 & 3 & 8 & 1.8 & Sandstone & Inclined \\
\hline T. 1944 & 14 & 3 & 9 & 1.8 & Sandstone & Plane & T. 2364 & 15 & 3 & 9 & 1.8 & Sandstone & Inclined \\
\hline T. 1945 & 12 & 3 & 10 & 1.8 & Sandstone & Plane & T. 2365 & 13 & 3 & 10 & 1.8 & Sandstone & Inclined \\
\hline T. 1946 & 12 & 3 & 11 & 1.8 & Sandstone & Plane & T. 2366 & 13 & 3 & 11 & 1.8 & Sandstone & Inclined \\
\hline T. 1947 & 14 & 3 & 12 & 1.8 & Sandstone & Plane & T. 2367 & 15 & 3 & 12 & 1.8 & Sandstone & Inclined \\
\hline T. 1948 & 14 & 3 & 13 & 1.8 & Sandstone & Plane & T. 2368 & 15 & 3 & 13 & 1.8 & Sandstone & Inclined \\
\hline T. 1949 & 12 & 3 & 14 & 1.8 & Sandstone & Plane & T. 2369 & 13 & 3 & 14 & 1.8 & Sandstone & Inclined \\
\hline T. 1950 & 12 & 3 & 15 & 1.8 & Sandstone & Plane & T. 2370 & 13 & 3 & 15 & 1.8 & Sandstone & Inclined \\
\hline T. 1951 & 13,5 & 3 & 1 & 2 & Sandstone & Plane & T. 2371 & 15 & 3 & 1 & 2 & Sandstone & Inclined \\
\hline T. 1952 & 13,5 & 3 & 2 & 2 & Sandstone & Plane & T. 2372 & 15 & 3 & 2 & 2 & Sandstone & Inclined \\
\hline T. 1953 & 13,5 & 3 & 3 & 2 & Sandstone & Plane & T. 2373 & 15 & 3 & 3 & 2 & Sandstone & Inclined \\
\hline T. 1954 & 13,5 & 3 & 4 & 2 & Sandstone & Plane & T. 2374 & 15 & 3 & 4 & 2 & Sandstone & Inclined \\
\hline T. 1955 & 13,5 & 3 & 5 & 2 & Sandstone & Plane & T. 2375 & 15 & 3 & 5 & 2 & Sandstone & Inclined \\
\hline T. 1956 & 13,5 & 3 & 6 & 2 & Sandstone & Plane & T. 2376 & 15 & 3 & 6 & 2 & Sandstone & Inclined \\
\hline T. 1957 & 13,5 & 3 & 7 & 2 & Sandstone & Plane & T. 2377 & 15 & 3 & 7 & 2 & Sandstone & Inclined \\
\hline T. 1958 & 13,5 & 3 & 8 & 2 & Sandstone & Plane & T. 2378 & 15 & 3 & 8 & 2 & Sandstone & Inclined \\
\hline T. 1959 & 13 & 3 & 9 & 2 & Sandstone & Plane & T. 2379 & 14 & 3 & 9 & 2 & Sandstone & Inclined \\
\hline T. 1960 & 12 & 3 & 10 & 2 & Sandstone & Plane & T. 2380 & 13 & 3 & 10 & 2 & Sandstone & Inclined \\
\hline T. 1961 & 12 & 3 & 11 & 2 & Sandstone & Plane & T. 2381 & 13 & 3 & 11 & 2 & Sandstone & Inclined \\
\hline
\end{tabular}

(cont. on next page) 
Table E.1. (cont.)

\begin{tabular}{|c|c|c|c|c|c|c|c|c|c|c|c|c|c|}
\hline T. 1962 & 13,5 & 3 & 12 & 2 & Sandstone & Plane & T. 2382 & 15 & 3 & 12 & 2 & Sandstone & Inclined \\
\hline T. 1963 & 13,5 & 3 & 13 & 2 & Sandstone & Plane & T. 2383 & 15 & 3 & 13 & 2 & Sandstone & Inclined \\
\hline T. 1964 & 12 & 3 & 14 & 2 & Sandstone & Plane & T. 2384 & 13 & 3 & 14 & 2 & Sandstone & Inclined \\
\hline T. 1965 & 12 & 3 & 15 & 2 & Sandstone & Plane & T. 2385 & 13 & 3 & 15 & 2 & Sandstone & Inclined \\
\hline T. 1966 & 13,5 & 3 & 1 & 2.3 & Sandstone & Plane & T. 2386 & 15 & 3 & 1 & 2.3 & Sandstone & Inclined \\
\hline T. 1967 & 13,5 & 3 & 2 & 2.3 & Sandstone & Plane & T. 2387 & 15 & 3 & 2 & 2.3 & Sandstone & Inclined \\
\hline T. 1968 & 13,5 & 3 & 3 & 2.3 & Sandstone & Plane & T. 2388 & 15 & 3 & 3 & 2.3 & Sandstone & Inclined \\
\hline T. 1969 & 13,5 & 3 & 4 & 2.3 & Sandstone & Plane & T. 2389 & 15 & 3 & 4 & 2.3 & Sandstone & Inclined \\
\hline T. 1970 & 13,5 & 3 & 5 & 2.3 & Sandstone & Plane & T. 2390 & 15 & 3 & 5 & 2.3 & Sandstone & Inclined \\
\hline T. 1971 & 13,5 & 3 & 6 & 2.3 & Sandstone & Plane & T. 2391 & 15 & 3 & 6 & 2.3 & Sandstone & Inclined \\
\hline T. 1972 & 13,5 & 3 & 7 & 2.3 & Sandstone & Plane & T. 2392 & 15 & 3 & 7 & 2.3 & Sandstone & Inclined \\
\hline T. 1973 & 13,5 & 3 & 8 & 2.3 & Sandstone & Plane & T. 2393 & 15 & 3 & 8 & 2.3 & Sandstone & Inclined \\
\hline T. 1974 & 13,5 & 3 & 9 & 2.3 & Sandstone & Plane & T. 2394 & 15 & 3 & 9 & 2.3 & Sandstone & Inclined \\
\hline T. 1975 & 12 & 3 & 10 & 2.3 & Sandstone & Plane & T. 2395 & 13 & 3 & 10 & 2.3 & Sandstone & Inclined \\
\hline T. 1976 & 12 & 3 & 11 & 2.3 & Sandstone & Plane & T. 2396 & 13 & 3 & 11 & 2.3 & Sandstone & Inclined \\
\hline T. 1977 & 13,5 & 3 & 12 & 2.3 & Sandstone & Plane & T. 2397 & 15 & 3 & 12 & 2.3 & Sandstone & Inclined \\
\hline T. 1978 & 13,5 & 3 & 13 & 2.3 & Sandstone & Plane & T. 2398 & 15 & 3 & 13 & 2.3 & Sandstone & Inclined \\
\hline T. 1979 & 12 & 3 & 14 & 2.3 & Sandstone & Plane & T. 2399 & 13 & 3 & 14 & 2.3 & Sandstone & Inclined \\
\hline T. 1980 & 12 & 3 & 15 & 2.3 & Sandstone & Plane & T. 2400 & 13 & 3 & 15 & 2.3 & Sandstone & Inclined \\
\hline T. 1981 & 13 & 3 & 1 & 2.5 & Sandstone & Plane & T. 2401 & 14 & 3 & 1 & 2.5 & Sandstone & Inclined \\
\hline T. 1982 & 13 & 3 & 2 & 2.5 & Sandstone & Plane & T. 2402 & 14 & 3 & 2 & 2.5 & Sandstone & Inclined \\
\hline T. 1983 & 13 & 3 & 3 & 2.5 & Sandstone & Plane & T. 2403 & 14 & 3 & 3 & 2.5 & Sandstone & Inclined \\
\hline T. 1984 & 13 & 3 & 4 & 2.5 & Sandstone & Plane & T. 2404 & 14 & 3 & 4 & 2.5 & Sandstone & Inclined \\
\hline T. 1985 & 13 & 3 & 5 & 2.5 & Sandstone & Plane & T. 2405 & 14 & 3 & 5 & 2.5 & Sandstone & Inclined \\
\hline T. 1986 & 13 & 3 & 6 & 2.5 & Sandstone & Plane & T. 2406 & 14 & 3 & 6 & 2.5 & Sandstone & Inclined \\
\hline T. 1987 & 13 & 3 & 7 & 2.5 & Sandstone & Plane & T. 2407 & 14 & 3 & 7 & 2.5 & Sandstone & Inclined \\
\hline T. 1988 & 13 & 3 & 8 & 2.5 & Sandstone & Plane & T. 2408 & 14 & 3 & 8 & 2.5 & Sandstone & Inclined \\
\hline T. 1989 & 13 & 3 & 9 & 2.5 & Sandstone & Plane & T. 2409 & 14 & 3 & 9 & 2.5 & Sandstone & Inclined \\
\hline T. 1990 & 11 & 3 & 10 & 2.5 & Sandstone & Plane & T. 2410 & 12 & 3 & 10 & 2.5 & Sandstone & Inclined \\
\hline T. 1991 & 11 & 3 & 11 & 2.5 & Sandstone & Plane & T. 2411 & 12 & 3 & 11 & 2.5 & Sandstone & Inclined \\
\hline T. 1992 & 13 & 3 & 12 & 2.5 & Sandstone & Plane & T. 2412 & 14 & 3 & 12 & 2.5 & Sandstone & Inclined \\
\hline T. 1993 & 13 & 3 & 13 & 2.5 & Sandstone & Plane & T. 2413 & 14 & 3 & 13 & 2.5 & Sandstone & Inclined \\
\hline T. 1994 & 11 & 3 & 14 & 2.5 & Sandstone & Plane & T. 2414 & 12 & 3 & 14 & 2.5 & Sandstone & Inclined \\
\hline
\end{tabular}

(cont. on next page) 
Table E.1. (cont.)

\begin{tabular}{|c|c|c|c|c|c|c|c|c|c|c|c|c|c|}
\hline T. 1995 & 11 & 3 & 15 & 2.5 & Sandstone & Plane & T. 2415 & 12 & 3 & 15 & 2.5 & Sandstone & Inclined \\
\hline T. 1996 & 10 & 3 & 1 & 1 & Brick & Plane & T. 2416 & 11 & 3 & 1 & 1 & Brick & Inclined \\
\hline T. 1997 & 10 & 3 & 2 & 1 & Brick & Plane & T. 2417 & 11 & 3 & 2 & 1 & Brick & Inclined \\
\hline T. 1998 & 10 & 3 & 3 & 1 & Brick & Plane & T. 2418 & 11 & 3 & 3 & 1 & Brick & Inclined \\
\hline T. 1999 & 10 & 3 & 4 & 1 & Brick & Plane & T. 2419 & 11 & 3 & 4 & 1 & Brick & Inclined \\
\hline T. 2000 & 10 & 3 & 5 & 1 & Brick & Plane & T. 2420 & 11 & 3 & 5 & 1 & Brick & Inclined \\
\hline T. 2001 & 10 & 3 & 6 & 1 & Brick & Plane & T. 2421 & 11 & 3 & 6 & 1 & Brick & Inclined \\
\hline T. 2002 & 10 & 3 & 7 & 1 & Brick & Plane & T. 2422 & 11 & 3 & 7 & 1 & Brick & Inclined \\
\hline T. 2003 & 10 & 3 & 8 & 1 & Brick & Plane & T. 2423 & 11 & 3 & 8 & 1 & Brick & Inclined \\
\hline T. 2004 & 10 & 3 & 9 & 1 & Brick & Plane & T. 2424 & 11 & 3 & 9 & 1 & Brick & Inclined \\
\hline T. 2005 & 10 & 3 & 10 & 1 & Brick & Plane & T. 2425 & 11 & 3 & 10 & 1 & Brick & Inclined \\
\hline T. 2006 & 9 & 3 & 11 & 1 & Brick & Plane & T. 2426 & 10 & 3 & 11 & 1 & Brick & Inclined \\
\hline T. 2007 & 9 & 3 & 12 & 1 & Brick & Plane & T. 2427 & 10 & 3 & 12 & 1 & Brick & Inclined \\
\hline T. 2008 & 10 & 3 & 13 & 1 & Brick & Plane & T. 2428 & 11 & 3 & 13 & 1 & Brick & Inclined \\
\hline T. 2009 & 10 & 3 & 14 & 1 & Brick & Plane & T. 2429 & 11 & 3 & 14 & 1 & Brick & Inclined \\
\hline T. 2010 & 9 & 3 & 15 & 1 & Brick & Plane & T. 2430 & 10 & 3 & 15 & 1 & Brick & Inclined \\
\hline T. 2011 & 9 & 3 & 1 & 1.3 & Brick & Plane & T. 2431 & 10 & 3 & 1 & 1.3 & Brick & Inclined \\
\hline T. 2012 & 12 & 3 & 2 & 1.3 & Brick & Plane & T. 2432 & 13 & 3 & 2 & 1.3 & Brick & Inclined \\
\hline T. 2013 & 12 & 3 & 3 & 1.3 & Brick & Plane & T. 2433 & 13 & 3 & 3 & 1.3 & Brick & Inclined \\
\hline T. 2014 & 12 & 3 & 4 & 1.3 & Brick & Plane & T. 2434 & 13 & 3 & 4 & 1.3 & Brick & Inclined \\
\hline T. 2015 & 12 & 3 & 5 & 1.3 & Brick & Plane & T. 2435 & 13 & 3 & 5 & 1.3 & Brick & Inclined \\
\hline T. 2016 & 12 & 3 & 6 & 1.3 & Brick & Plane & T. 2436 & 13 & 3 & 6 & 1.3 & Brick & Inclined \\
\hline T. 2017 & 12 & 3 & 7 & 1.3 & Brick & Plane & T. 2437 & 13 & 3 & 7 & 1.3 & Brick & Inclined \\
\hline T. 2018 & 12 & 3 & 8 & 1.3 & Brick & Plane & T. 2438 & 13 & 3 & 8 & 1.3 & Brick & Inclined \\
\hline T. 2019 & 12 & 3 & 9 & 1.3 & Brick & Plane & T. 2439 & 13 & 3 & 9 & 1.3 & Brick & Inclined \\
\hline T. 2020 & 12 & 3 & 10 & 1.3 & Brick & Plane & T. 2440 & 13 & 3 & 10 & 1.3 & Brick & Inclined \\
\hline T. 2021 & 11 & 3 & 11 & 1.3 & Brick & Plane & T. 2441 & 12 & 3 & 11 & 1.3 & Brick & Inclined \\
\hline T. 2022 & 11 & 3 & 12 & 1.3 & Brick & Plane & T. 2442 & 12 & 3 & 12 & 1.3 & Brick & Inclined \\
\hline T. 2023 & 12 & 3 & 13 & 1.3 & Brick & Plane & T. 2443 & 13 & 3 & 13 & 1.3 & Brick & Inclined \\
\hline T. 2024 & 12 & 3 & 14 & 1.3 & Brick & Plane & T. 2444 & 13 & 3 & 14 & 1.3 & Brick & Inclined \\
\hline T. 2025 & 11 & 3 & 15 & 1.3 & Brick & Plane & T. 2445 & 12 & 3 & 15 & 1.3 & Brick & Inclined \\
\hline T. 2026 & 11 & 3 & 1 & 1.6 & Brick & Plane & T. 2446 & 12 & 3 & 1 & 1.6 & Brick & Inclined \\
\hline T. 2027 & 13 & 3 & 2 & 1.6 & Brick & Plane & T. 2447 & 14 & 3 & 2 & 1.6 & Brick & Inclined \\
\hline
\end{tabular}

(cont. on next page) 
Table E.1. (cont.)

\begin{tabular}{|c|c|c|c|c|c|c|c|c|c|c|c|c|c|}
\hline T. 2028 & 13 & 3 & 3 & 1.6 & Brick & Plane & T. 2448 & 14 & 3 & 3 & 1.6 & Brick & Inclined \\
\hline T. 2029 & 13 & 3 & 4 & 1.6 & Brick & Plane & T. 2449 & 14 & 3 & 4 & 1.6 & Brick & Inclined \\
\hline T. 2030 & 13 & 3 & 5 & 1.6 & Brick & Plane & T. 2450 & 14 & 3 & 5 & 1.6 & Brick & Inclined \\
\hline T. 2031 & 13 & 3 & 6 & 1.6 & Brick & Plane & T. 2451 & 14 & 3 & 6 & 1.6 & Brick & Inclined \\
\hline T. 2032 & 13 & 3 & 7 & 1.6 & Brick & Plane & T. 2452 & 14 & 3 & 7 & 1.6 & Brick & Inclined \\
\hline Т. 2033 & 13 & 3 & 8 & 1.6 & Brick & Plane & T. 2453 & 14 & 3 & 8 & 1.6 & Brick & Inclined \\
\hline T. 2034 & 13 & 3 & 9 & 1.6 & Brick & Plane & T. 2454 & 14 & 3 & 9 & 1.6 & Brick & Inclined \\
\hline T. 2035 & 13 & 3 & 10 & 1.6 & Brick & Plane & T. 2455 & 14 & 3 & 10 & 1.6 & Brick & Inclined \\
\hline T. 2036 & 11 & 3 & 11 & 1.6 & Brick & Plane & T. 2456 & 12 & 3 & 11 & 1.6 & Brick & Inclined \\
\hline T. 2037 & 11 & 3 & 12 & 1.6 & Brick & Plane & T. 2457 & 12 & 3 & 12 & 1.6 & Brick & Inclined \\
\hline T. 2038 & 13 & 3 & 13 & 1.6 & Brick & Plane & T. 2458 & 14 & 3 & 13 & 1.6 & Brick & Inclined \\
\hline T. 2039 & 13 & 3 & 14 & 1.6 & Brick & Plane & T. 2459 & 14 & 3 & 14 & 1.6 & Brick & Inclined \\
\hline T. 2040 & 11 & 3 & 15 & 1.6 & Brick & Plane & T. 2460 & 12 & 3 & 15 & 1.6 & Brick & Inclined \\
\hline T. 2041 & 11 & 3 & 1 & 1.8 & Brick & Plane & T. 2461 & 12 & 3 & 1 & 1.8 & Brick & Inclined \\
\hline T. 2042 & 13 & 3 & 2 & 1.8 & Brick & Plane & T. 2462 & 14 & 3 & 2 & 1.8 & Brick & Inclined \\
\hline T. 2043 & 13 & 3 & 3 & 1.8 & Brick & Plane & T. 2463 & 14 & 3 & 3 & 1.8 & Brick & Inclined \\
\hline T. 2044 & 13 & 3 & 4 & 1.8 & Brick & Plane & T. 2464 & 14 & 3 & 4 & 1.8 & Brick & Inclined \\
\hline T. 2045 & 13 & 3 & 5 & 1.8 & Brick & Plane & T. 2465 & 14 & 3 & 5 & 1.8 & Brick & Inclined \\
\hline T. 2046 & 13 & 3 & 6 & 1.8 & Brick & Plane & T. 2466 & 14 & 3 & 6 & 1.8 & Brick & Inclined \\
\hline T. 2047 & 13 & 3 & 7 & 1.8 & Brick & Plane & T. 2467 & 14 & 3 & 7 & 1.8 & Brick & Inclined \\
\hline T. 2048 & 13 & 3 & 8 & 1.8 & Brick & Plane & T. 2468 & 14 & 3 & 8 & 1.8 & Brick & Inclined \\
\hline T. 2049 & 13 & 3 & 9 & 1.8 & Brick & Plane & T. 2469 & 14 & 3 & 9 & 1.8 & Brick & Inclined \\
\hline T. 2050 & 13 & 3 & 10 & 1.8 & Brick & Plane & T. 2470 & 14 & 3 & 10 & 1.8 & Brick & Inclined \\
\hline T. 2051 & 11 & 3 & 11 & 1.8 & Brick & Plane & T. 2471 & 12 & 3 & 11 & 1.8 & Brick & Inclined \\
\hline T. 2052 & 11 & 3 & 12 & 1.8 & Brick & Plane & T. 2472 & 12 & 3 & 12 & 1.8 & Brick & Inclined \\
\hline T. 2053 & 13 & 3 & 13 & 1.8 & Brick & Plane & T. 2473 & 14 & 3 & 13 & 1.8 & Brick & Inclined \\
\hline T. 2054 & 13 & 3 & 14 & 1.8 & Brick & Plane & T. 2474 & 14 & 3 & 14 & 1.8 & Brick & Inclined \\
\hline T. 2055 & 11 & 3 & 15 & 1.8 & Brick & Plane & T. 2475 & 12 & 3 & 15 & 1.8 & Brick & Inclined \\
\hline T. 2056 & 11 & 3 & 1 & 2 & Brick & Plane & T. 2476 & 12 & 3 & 1 & 2 & Brick & Inclined \\
\hline T. 2057 & 12,5 & 3 & 2 & 2 & Brick & Plane & T. 2477 & 14 & 3 & 2 & 2 & Brick & Inclined \\
\hline T. 2058 & 12,5 & 3 & 3 & 2 & Brick & Plane & T. 2478 & 14 & 3 & 3 & 2 & Brick & Inclined \\
\hline T. 2059 & 12,5 & 3 & 4 & 2 & Brick & Plane & T. 2479 & 14 & 3 & 4 & 2 & Brick & Inclined \\
\hline T. 2060 & 12,5 & 3 & 5 & 2 & Brick & Plane & T. 2480 & 14 & 3 & 5 & 2 & Brick & Inclined \\
\hline
\end{tabular}


Table E.1. (cont.)

\begin{tabular}{|c|c|c|c|c|c|c|c|c|c|c|c|c|c|}
\hline T. 2061 & 12,5 & 3 & 6 & 2 & Brick & Plane & T. 2481 & 14 & 3 & 6 & 2 & Brick & Inclined \\
\hline T. 2062 & 12,5 & 3 & 7 & 2 & Brick & Plane & T. 2482 & 14 & 3 & 7 & 2 & Brick & Inclined \\
\hline T. 2063 & 12,5 & 3 & 8 & 2 & Brick & Plane & T. 2483 & 14 & 3 & 8 & 2 & Brick & Inclined \\
\hline T. 2064 & 12,5 & 3 & 9 & 2 & Brick & Plane & T. 2484 & 14 & 3 & 9 & 2 & Brick & Inclined \\
\hline T. 2065 & 12 & 3 & 10 & 2 & Brick & Plane & T. 2485 & 13 & 3 & 10 & 2 & Brick & Inclined \\
\hline T. 2066 & 11 & 3 & 11 & 2 & Brick & Plane & T. 2486 & 12 & 3 & 11 & 2 & Brick & Inclined \\
\hline T. 2067 & 11 & 3 & 12 & 2 & Brick & Plane & T. 2487 & 12 & 3 & 12 & 2 & Brick & Inclined \\
\hline T. 2068 & 12,5 & 3 & 13 & 2 & Brick & Plane & T. 2488 & 14 & 3 & 13 & 2 & Brick & Inclined \\
\hline T. 2069 & 12,5 & 3 & 14 & 2 & Brick & Plane & T. 2489 & 14 & 3 & 14 & 2 & Brick & Inclined \\
\hline T. 2070 & 11 & 3 & 15 & 2 & Brick & Plane & T. 2490 & 12 & 3 & 15 & 2 & Brick & Inclined \\
\hline T. 2071 & 11 & 3 & 1 & 2.3 & Brick & Plane & T. 2491 & 12 & 3 & 1 & 2.3 & Brick & Inclined \\
\hline T. 2072 & 12,5 & 3 & 2 & 2.3 & Brick & Plane & T. 2492 & 14 & 3 & 2 & 2.3 & Brick & Inclined \\
\hline T. 2073 & 12,5 & 3 & 3 & 2.3 & Brick & Plane & T. 2493 & 14 & 3 & 3 & 2.3 & Brick & Inclined \\
\hline T. 2074 & 12,5 & 3 & 4 & 2.3 & Brick & Plane & T. 2494 & 14 & 3 & 4 & 2.3 & Brick & Inclined \\
\hline T. 2075 & 12,5 & 3 & 5 & 2.3 & Brick & Plane & T. 2495 & 14 & 3 & 5 & 2.3 & Brick & Inclined \\
\hline T. 2076 & 12,5 & 3 & 6 & 2.3 & Brick & Plane & T. 2496 & 14 & 3 & 6 & 2.3 & Brick & Inclined \\
\hline T. 2077 & 12,5 & 3 & 7 & 2.3 & Brick & Plane & T. 2497 & 14 & 3 & 7 & 2.3 & Brick & Inclined \\
\hline T. 2078 & 12,5 & 3 & 8 & 2.3 & Brick & Plane & T. 2498 & 14 & 3 & 8 & 2.3 & Brick & Inclined \\
\hline T. 2079 & 12,5 & 3 & 9 & 2.3 & Brick & Plane & T. 2499 & 14 & 3 & 9 & 2.3 & Brick & Inclined \\
\hline T. 2080 & 12,5 & 3 & 10 & 2.3 & Brick & Plane & T. 2500 & 14 & 3 & 10 & 2.3 & Brick & Inclined \\
\hline T. 2081 & 11 & 3 & 11 & 2.3 & Brick & Plane & T. 2501 & 12 & 3 & 11 & 2.3 & Brick & Inclined \\
\hline T. 2082 & 11 & 3 & 12 & 2.3 & Brick & Plane & T. 2502 & 12 & 3 & 12 & 2.3 & Brick & Inclined \\
\hline T. 2083 & 12,5 & 3 & 13 & 2.3 & Brick & Plane & T. 2503 & 14 & 3 & 13 & 2.3 & Brick & Inclined \\
\hline T. 2084 & 12,5 & 3 & 14 & 2.3 & Brick & Plane & T. 2504 & 14 & 3 & 14 & 2.3 & Brick & Inclined \\
\hline T. 2085 & 11 & 3 & 15 & 2.3 & Brick & Plane & T. 2505 & 12 & 3 & 15 & 2.3 & Brick & Inclined \\
\hline T. 2086 & 11 & 3 & 1 & 2.5 & Brick & Plane & T. 2506 & 12 & 3 & 1 & 2.5 & Brick & Inclined \\
\hline T. 2087 & 12 & 3 & 2 & 2.5 & Brick & Plane & T. 2507 & 13 & 3 & 2 & 2.5 & Brick & Inclined \\
\hline T. 2088 & 12 & 3 & 3 & 2.5 & Brick & Plane & T. 2508 & 13 & 3 & 3 & 2.5 & Brick & Inclined \\
\hline T. 2089 & 12 & 3 & 4 & 2.5 & Brick & Plane & T. 2509 & 13 & 3 & 4 & 2.5 & Brick & Inclined \\
\hline T. 2090 & 12 & 3 & 5 & 2.5 & Brick & Plane & T. 2510 & 13 & 3 & 5 & 2.5 & Brick & Inclined \\
\hline T. 2091 & 12 & 3 & 6 & 2.5 & Brick & Plane & T. 2511 & 13 & 3 & 6 & 2.5 & Brick & Inclined \\
\hline T. 2092 & 12 & 3 & 7 & 2.5 & Brick & Plane & T. 2512 & 13 & 3 & 7 & 2.5 & Brick & Inclined \\
\hline T. 2093 & 12 & 3 & 8 & 2.5 & Brick & Plane & T. 2513 & 13 & 3 & 8 & 2.5 & Brick & Inclined \\
\hline
\end{tabular}

(cont. on next page) 
Table E.1. (cont.)

\begin{tabular}{|c|c|c|c|c|c|c|c|c|c|c|c|c|c|}
\hline T. 2094 & 12 & 3 & 9 & 2.5 & Brick & Plane & T. 2514 & 13 & 3 & 9 & 2.5 & Brick & Inclined \\
\hline T. 2095 & 12 & 3 & 10 & 2.5 & Brick & Plane & T. 2515 & 13 & 3 & 10 & 2.5 & Brick & Inclined \\
\hline T. 2096 & 10 & 3 & 11 & 2.5 & Brick & Plane & T. 2516 & 11 & 3 & 11 & 2.5 & Brick & Inclined \\
\hline T. 2097 & 10 & 3 & 12 & 2.5 & Brick & Plane & T. 2517 & 11 & 3 & 12 & 2.5 & Brick & Inclined \\
\hline T. 2098 & 12 & 3 & 13 & 2.5 & Brick & Plane & T. 2518 & 13 & 3 & 13 & 2.5 & Brick & Inclined \\
\hline T. 2099 & 12 & 3 & 14 & 2.5 & Brick & Plane & T. 2519 & 13 & 3 & 14 & 2.5 & Brick & Inclined \\
\hline T. 2100 & 10 & 3 & 15 & 2.5 & Brick & Plane & T. 2520 & 11 & 3 & 15 & 2.5 & Brick & Inclined \\
\hline T. 2521 & 14 & 4 & 1 & 1 & Granite & Plane & T. 2941 & 15 & 4 & 1 & 1 & Granite & Inclined \\
\hline T. 2522 & 14 & 4 & 2 & 1 & Granite & Plane & T. 2942 & 15 & 4 & 2 & 1 & Granite & Inclined \\
\hline T. 2523 & 14 & 4 & 3 & 1 & Granite & Plane & T. 2943 & 15 & 4 & 3 & 1 & Granite & Inclined \\
\hline T. 2524 & 14 & 4 & 4 & 1 & Granite & Plane & T. 2944 & 15 & 4 & 4 & 1 & Granite & Inclined \\
\hline T. 2525 & 14 & 4 & 5 & 1 & Granite & Plane & T. 2945 & 15 & 4 & 5 & 1 & Granite & Inclined \\
\hline T. 2526 & 14 & 4 & 6 & 1 & Granite & Plane & T. 2946 & 15 & 4 & 6 & 1 & Granite & Inclined \\
\hline T. 2527 & 14 & 4 & 7 & 1 & Granite & Plane & T. 2947 & 15 & 4 & 7 & 1 & Granite & Inclined \\
\hline T. 2528 & 14 & 4 & 8 & 1 & Granite & Plane & T. 2948 & 15 & 4 & 8 & 1 & Granite & Inclined \\
\hline T. 2529 & 14 & 4 & 9 & 1 & Granite & Plane & T. 2949 & 15 & 4 & 9 & 1 & Granite & Inclined \\
\hline T. 2530 & 12 & 4 & 10 & 1 & Granite & Plane & T. 2950 & 13 & 4 & 10 & 1 & Granite & Inclined \\
\hline T. 2531 & 13 & 4 & 11 & 1 & Granite & Plane & T. 2951 & 14 & 4 & 11 & 1 & Granite & Inclined \\
\hline T. 2532 & 14 & 4 & 12 & 1 & Granite & Plane & T. 2952 & 15 & 4 & 12 & 1 & Granite & Inclined \\
\hline T. 2533 & 14 & 4 & 13 & 1 & Granite & Plane & T. 2953 & 15 & 4 & 13 & 1 & Granite & Inclined \\
\hline T. 2534 & 13 & 4 & 14 & 1 & Granite & Plane & T. 2954 & 14 & 4 & 14 & 1 & Granite & Inclined \\
\hline T. 2535 & 13 & 4 & 15 & 1 & Granite & Plane & T. 2955 & 14 & 4 & 15 & 1 & Granite & Inclined \\
\hline T. 2536 & 16 & 4 & 1 & 1.3 & Granite & Plane & T. 2956 & 17 & 4 & 1 & 1.3 & Granite & Inclined \\
\hline T. 2537 & 16 & 4 & 2 & 1.3 & Granite & Plane & T. 2957 & 17 & 4 & 2 & 1.3 & Granite & Inclined \\
\hline T. 2538 & 16 & 4 & 3 & 1.3 & Granite & Plane & T. 2958 & 17 & 4 & 3 & 1.3 & Granite & Inclined \\
\hline T. 2539 & 16 & 4 & 4 & 1.3 & Granite & Plane & T. 2959 & 17 & 4 & 4 & 1.3 & Granite & Inclined \\
\hline T. 2540 & 16 & 4 & 5 & 1.3 & Granite & Plane & T. 2960 & 17 & 4 & 5 & 1.3 & Granite & Inclined \\
\hline T. 2541 & 16 & 4 & 6 & 1.3 & Granite & Plane & T. 2961 & 17 & 4 & 6 & 1.3 & Granite & Inclined \\
\hline T. 2542 & 16 & 4 & 7 & 1.3 & Granite & Plane & T. 2962 & 17 & 4 & 7 & 1.3 & Granite & Inclined \\
\hline T. 2543 & 16 & 4 & 8 & 1.3 & Granite & Plane & T. 2963 & 17 & 4 & 8 & 1.3 & Granite & Inclined \\
\hline T. 2544 & 16 & 4 & 9 & 1.3 & Granite & Plane & T. 2964 & 17 & 4 & 9 & 1.3 & Granite & Inclined \\
\hline T. 2545 & 13 & 4 & 10 & 1.3 & Granite & Plane & T. 2965 & 14 & 4 & 10 & 1.3 & Granite & Inclined \\
\hline T. 2546 & 15 & 4 & 11 & 1.3 & Granite & Plane & T. 2966 & 16 & 4 & 11 & 1.3 & Granite & Inclined \\
\hline
\end{tabular}

(cont. on next page) 
Table E.1. (cont.)

\begin{tabular}{|c|c|c|c|c|c|c|c|c|c|c|c|c|c|}
\hline T. 2547 & 16 & 4 & 12 & 1.3 & Granite & Plane & T. 2967 & 17 & 4 & 12 & 1.3 & Granite & Inclined \\
\hline T. 2548 & 16 & 4 & 13 & 1.3 & Granite & Plane & T. 2968 & 17 & 4 & 13 & 1.3 & Granite & Inclined \\
\hline T. 2549 & 15 & 4 & 14 & 1.3 & Granite & Plane & T. 2969 & 16 & 4 & 14 & 1.3 & Granite & Inclined \\
\hline T. 2550 & 15 & 4 & 15 & 1.3 & Granite & Plane & T. 2970 & 16 & 4 & 15 & 1.3 & Granite & Inclined \\
\hline *T. 2551 & 17 & 4 & 1 & 1.6 & Granite & Plane & *T. 2971 & 18 & 4 & 1 & 1.6 & Granite & Inclined \\
\hline *T. 2552 & 17 & 4 & 2 & 1.6 & Granite & Plane & *T. 2972 & 18 & 4 & 2 & 1.6 & Granite & Inclined \\
\hline *T. 2553 & 17 & 4 & 3 & 1.6 & Granite & Plane & *T. 2973 & 18 & 4 & 3 & 1.6 & Granite & Inclined \\
\hline *T. 2554 & 17 & 4 & 4 & 1.6 & Granite & Plane & *T. 2974 & 18 & 4 & 4 & 1.6 & Granite & Inclined \\
\hline *T. 2555 & 17 & 4 & 5 & 1.6 & Granite & Plane & *T. 2975 & 18 & 4 & 5 & 1.6 & Granite & Inclined \\
\hline *Т. 2556 & 17 & 4 & 6 & 1.6 & Granite & Plane & *T. 2976 & 18 & 4 & 6 & 1.6 & Granite & Inclined \\
\hline *T. 2557 & 17 & 4 & 7 & 1.6 & Granite & Plane & *T. 2977 & 18 & 4 & 7 & 1.6 & Granite & Inclined \\
\hline *T. 2558 & 17 & 4 & 8 & 1.6 & Granite & Plane & *T. 2978 & 18 & 4 & 8 & 1.6 & Granite & Inclined \\
\hline *T. 2559 & 17 & 4 & 9 & 1.6 & Granite & Plane & *T. 2979 & 18 & 4 & 9 & 1.6 & Granite & Inclined \\
\hline *T. 2560 & 15 & 4 & 10 & 1.6 & Granite & Plane & *T. 2980 & 16 & 4 & 10 & 1.6 & Granite & Inclined \\
\hline *T. 2561 & 17 & 4 & 11 & 1.6 & Granite & Plane & *T. 2981 & 18 & 4 & 11 & 1.6 & Granite & Inclined \\
\hline *T. 2562 & 17 & 4 & 12 & 1.6 & Granite & Plane & *T. 2982 & 18 & 4 & 12 & 1.6 & Granite & Inclined \\
\hline *T. 2563 & 17 & 4 & 13 & 1.6 & Granite & Plane & *T. 2983 & 18 & 4 & 13 & 1.6 & Granite & Inclined \\
\hline *T. 2564 & 17 & 4 & 14 & 1.6 & Granite & Plane & *T. 2984 & 18 & 4 & 14 & 1.6 & Granite & Inclined \\
\hline *T. 2565 & 17 & 4 & 15 & 1.6 & Granite & Plane & *T. 2985 & 18 & 4 & 15 & 1.6 & Granite & Inclined \\
\hline *T. 2566 & 17 & 4 & 1 & 1.8 & Granite & Plane & *T. 2986 & 18 & 4 & 1 & 1.8 & Granite & Inclined \\
\hline *T. 2567 & 17 & 4 & 2 & 1.8 & Granite & Plane & *T. 2987 & 18 & 4 & 2 & 1.8 & Granite & Inclined \\
\hline *T. 2568 & 17 & 4 & 3 & 1.8 & Granite & Plane & *T. 2988 & 18 & 4 & 3 & 1.8 & Granite & Inclined \\
\hline *T. 2569 & 17 & 4 & 4 & 1.8 & Granite & Plane & *T. 2989 & 18 & 4 & 4 & 1.8 & Granite & Inclined \\
\hline *T. 2570 & 17 & 4 & 5 & 1.8 & Granite & Plane & *T. 2990 & 18 & 4 & 5 & 1.8 & Granite & Inclined \\
\hline *T. 2571 & 17 & 4 & 6 & 1.8 & Granite & Plane & *T. 2991 & 18 & 4 & 6 & 1.8 & Granite & Inclined \\
\hline *T. 2572 & 17 & 4 & 7 & 1.8 & Granite & Plane & *T. 2992 & 18 & 4 & 7 & 1.8 & Granite & Inclined \\
\hline *T. 2573 & 17 & 4 & 8 & 1.8 & Granite & Plane & *T. 2993 & 18 & 4 & 8 & 1.8 & Granite & Inclined \\
\hline *T. 2574 & 17 & 4 & 9 & 1.8 & Granite & Plane & *T. 2994 & 18 & 4 & 9 & 1.8 & Granite & Inclined \\
\hline *T. 2575 & 15 & 4 & 10 & 1.8 & Granite & Plane & *T. 2995 & 16 & 4 & 10 & 1.8 & Granite & Inclined \\
\hline *T. 2576 & 17 & 4 & 11 & 1.8 & Granite & Plane & *T. 2996 & 18 & 4 & 11 & 1.8 & Granite & Inclined \\
\hline *T. 2577 & 17 & 4 & 12 & 1.8 & Granite & Plane & *T. 2997 & 18 & 4 & 12 & 1.8 & Granite & Inclined \\
\hline *T. 2578 & 17 & 4 & 13 & 1.8 & Granite & Plane & *T. 2998 & 18 & 4 & 13 & 1.8 & Granite & Inclined \\
\hline *T. 2579 & 17 & 4 & 14 & 1.8 & Granite & Plane & *T. 2999 & 18 & 4 & 14 & 1.8 & Granite & Inclined \\
\hline
\end{tabular}

(cont. on next page) 
Table E.1. (cont.)

\begin{tabular}{|c|c|c|c|c|c|c|c|c|c|c|c|c|c|}
\hline *T. 2580 & 17 & 4 & 15 & 1.8 & Granite & Plane & *T. 3000 & 18 & 4 & 15 & 1.8 & Granite & Inclined \\
\hline *T. 2581 & 17 & 4 & 1 & 2 & Granite & Plane & *T. 3001 & 18 & 4 & 1 & 2 & Granite & Inclined \\
\hline *T. 2582 & 17 & 4 & 2 & 2 & Granite & Plane & *T. 3002 & 18 & 4 & 2 & 2 & Granite & Inclined \\
\hline *T. 2583 & 17 & 4 & 3 & 2 & Granite & Plane & *T. 3003 & 18 & 4 & 3 & 2 & Granite & Inclined \\
\hline *T. 2584 & 17 & 4 & 4 & 2 & Granite & Plane & *T. 3004 & 18 & 4 & 4 & 2 & Granite & Inclined \\
\hline *T. 2585 & 17 & 4 & 5 & 2 & Granite & Plane & *T. 3005 & 18 & 4 & 5 & 2 & Granite & Inclined \\
\hline *T. 2586 & 17 & 4 & 6 & 2 & Granite & Plane & *T. 3006 & 18 & 4 & 6 & 2 & Granite & Inclined \\
\hline *T. 2587 & 17 & 4 & 7 & 2 & Granite & Plane & *T. 3007 & 18 & 4 & 7 & 2 & Granite & Inclined \\
\hline *T. 2588 & 17 & 4 & 8 & 2 & Granite & Plane & *T. 3008 & 18 & 4 & 8 & 2 & Granite & Inclined \\
\hline *T. 2589 & 17 & 4 & 9 & 2 & Granite & Plane & *T. 3009 & 18 & 4 & 9 & 2 & Granite & Inclined \\
\hline *T. 2590 & 14 & 4 & 10 & 2 & Granite & Plane & *T. 3010 & 15 & 4 & 10 & 2 & Granite & Inclined \\
\hline *T. 2591 & 16 & 4 & 11 & 2 & Granite & Plane & *T. 3011 & 17 & 4 & 11 & 2 & Granite & Inclined \\
\hline *T. 2592 & 17 & 4 & 12 & 2 & Granite & Plane & *T. 3012 & 18 & 4 & 12 & 2 & Granite & Inclined \\
\hline *T. 2593 & 17 & 4 & 13 & 2 & Granite & Plane & *T. 3013 & 18 & 4 & 13 & 2 & Granite & Inclined \\
\hline *T. 2594 & 16 & 4 & 14 & 2 & Granite & Plane & *T. 3014 & 17 & 4 & 14 & 2 & Granite & Inclined \\
\hline *T. 2595 & 16 & 4 & 15 & 2 & Granite & Plane & *T. 3015 & 17 & 4 & 15 & 2 & Granite & Inclined \\
\hline *T. 2596 & 16 & 4 & 1 & 2.3 & Granite & Plane & *Т. 3016 & 17 & 4 & 1 & 2.3 & Granite & Inclined \\
\hline *T. 2597 & 16 & 4 & 2 & 2.3 & Granite & Plane & *T. 3017 & 17 & 4 & 2 & 2.3 & Granite & Inclined \\
\hline *T. 2598 & 16 & 4 & 3 & 2.3 & Granite & Plane & *T. 3018 & 17 & 4 & 3 & 2.3 & Granite & Inclined \\
\hline *T. 2599 & 16 & 4 & 4 & 2.3 & Granite & Plane & *T. 3019 & 17 & 4 & 4 & 2.3 & Granite & Inclined \\
\hline *T. 2600 & 16 & 4 & 5 & 2.3 & Granite & Plane & *T. 3020 & 17 & 4 & 5 & 2.3 & Granite & Inclined \\
\hline *T. 2601 & 16 & 4 & 6 & 2.3 & Granite & Plane & *T. 3021 & 17 & 4 & 6 & 2.3 & Granite & Inclined \\
\hline *T. 2602 & 16 & 4 & 7 & 2.3 & Granite & Plane & *T. 3022 & 17 & 4 & 7 & 2.3 & Granite & Inclined \\
\hline *T. 2603 & 16 & 4 & 8 & 2.3 & Granite & Plane & *T. 3023 & 17 & 4 & 8 & 2.3 & Granite & Inclined \\
\hline *T. 2604 & 16 & 4 & 9 & 2.3 & Granite & Plane & *T. 3024 & 17 & 4 & 9 & 2.3 & Granite & Inclined \\
\hline *T. 2605 & 13 & 4 & 10 & 2.3 & Granite & Plane & *T. 3025 & 14 & 4 & 10 & 2.3 & Granite & Inclined \\
\hline *T. 2606 & 16 & 4 & 11 & 2.3 & Granite & Plane & *T. 3026 & 17 & 4 & 11 & 2.3 & Granite & Inclined \\
\hline *T. 2607 & 16 & 4 & 12 & 2.3 & Granite & Plane & *T. 3027 & 17 & 4 & 12 & 2.3 & Granite & Inclined \\
\hline *T. 2608 & 16 & 4 & 13 & 2.3 & Granite & Plane & *T. 3028 & 17 & 4 & 13 & 2.3 & Granite & Inclined \\
\hline *T. 2609 & 15 & 4 & 14 & 2.3 & Granite & Plane & *T. 3029 & 16 & 4 & 14 & 2.3 & Granite & Inclined \\
\hline *T. 2610 & 15 & 4 & 15 & 2.3 & Granite & Plane & *T. 3030 & 16 & 4 & 15 & 2.3 & Granite & Inclined \\
\hline T. 2611 & 15 & 4 & 1 & 2.5 & Granite & Plane & T. 3031 & 16 & 4 & 1 & 2.5 & Granite & Inclined \\
\hline T. 2612 & 15 & 4 & 2 & 2.5 & Granite & Plane & T. 3032 & 16 & 4 & 2 & 2.5 & Granite & Inclined \\
\hline
\end{tabular}

(cont. on next page) 
Table E.1. (cont.)

\begin{tabular}{|c|c|c|c|c|c|c|c|c|c|c|c|c|c|}
\hline T. 2613 & 15 & 4 & 3 & 2.5 & Granite & Plane & T. 3033 & 16 & 4 & 3 & 2.5 & Granite & Inclined \\
\hline T. 2614 & 15 & 4 & 4 & 2.5 & Granite & Plane & T. 3034 & 16 & 4 & 4 & 2.5 & Granite & Inclined \\
\hline T. 2615 & 15 & 4 & 5 & 2.5 & Granite & Plane & T. 3035 & 16 & 4 & 5 & 2.5 & Granite & Inclined \\
\hline T. 2616 & 15 & 4 & 6 & 2.5 & Granite & Plane & T. 3036 & 16 & 4 & 6 & 2.5 & Granite & Inclined \\
\hline T. 2617 & 15 & 4 & 7 & 2.5 & Granite & Plane & T. 3037 & 16 & 4 & 7 & 2.5 & Granite & Inclined \\
\hline T. 2618 & 15 & 4 & 8 & 2.5 & Granite & Plane & T. 3038 & 16 & 4 & 8 & 2.5 & Granite & Inclined \\
\hline T. 2619 & 15 & 4 & 9 & 2.5 & Granite & Plane & T. 3039 & 16 & 4 & 9 & 2.5 & Granite & Inclined \\
\hline T. 2620 & 12 & 4 & 10 & 2.5 & Granite & Plane & T. 3040 & 13 & 4 & 10 & 2.5 & Granite & Inclined \\
\hline T. 2621 & 13 & 4 & 11 & 2.5 & Granite & Plane & T. 3041 & 14 & 4 & 11 & 2.5 & Granite & Inclined \\
\hline T. 2622 & 15 & 4 & 12 & 2.5 & Granite & Plane & T. 3042 & 16 & 4 & 12 & 2.5 & Granite & Inclined \\
\hline T. 2623 & 15 & 4 & 13 & 2.5 & Granite & Plane & T. 3043 & 16 & 4 & 13 & 2.5 & Granite & Inclined \\
\hline T. 2624 & 13 & 4 & 14 & 2.5 & Granite & Plane & T. 3044 & 14 & 4 & 14 & 2.5 & Granite & Inclined \\
\hline T. 2625 & 13 & 4 & 15 & 2.5 & Granite & Plane & T. 3045 & 14 & 4 & 15 & 2.5 & Granite & Inclined \\
\hline T. 2626 & 14 & 4 & 1 & 1 & Limestone & Plane & T. 3046 & 15 & 4 & 1 & 1 & Limestone & Inclined \\
\hline T. 2627 & 14 & 4 & 2 & 1 & Limestone & Plane & T. 3047 & 15 & 4 & 2 & 1 & Limestone & Inclined \\
\hline T. 2628 & 14 & 4 & 3 & 1 & Limestone & Plane & T. 3048 & 15 & 4 & 3 & 1 & Limestone & Inclined \\
\hline T. 2629 & 14 & 4 & 4 & 1 & Limestone & Plane & T. 3049 & 15 & 4 & 4 & 1 & Limestone & Inclined \\
\hline T. 2630 & 14 & 4 & 5 & 1 & Limestone & Plane & T. 3050 & 15 & 4 & 5 & 1 & Limestone & Inclined \\
\hline T. 2631 & 14 & 4 & 6 & 1 & Limestone & Plane & T. 3051 & 15 & 4 & 6 & 1 & Limestone & Inclined \\
\hline T. 2632 & 14 & 4 & 7 & 1 & Limestone & Plane & T. 3052 & 15 & 4 & 7 & 1 & Limestone & Inclined \\
\hline T. 2633 & 14 & 4 & 8 & 1 & Limestone & Plane & T. 3053 & 15 & 4 & 8 & 1 & Limestone & Inclined \\
\hline T. 2634 & 14 & 4 & 9 & 1 & Limestone & Plane & T. 3054 & 15 & 4 & 9 & 1 & Limestone & Inclined \\
\hline T. 2635 & 12 & 4 & 10 & 1 & Limestone & Plane & T. 3055 & 13 & 4 & 10 & 1 & Limestone & Inclined \\
\hline T. 2636 & 13 & 4 & 11 & 1 & Limestone & Plane & T. 3056 & 14 & 4 & 11 & 1 & Limestone & Inclined \\
\hline T. 2637 & 14 & 4 & 12 & 1 & Limestone & Plane & T. 3057 & 15 & 4 & 12 & 1 & Limestone & Inclined \\
\hline T. 2638 & 14 & 4 & 13 & 1 & Limestone & Plane & T. 3058 & 15 & 4 & 13 & 1 & Limestone & Inclined \\
\hline T. 2639 & 13 & 4 & 14 & 1 & Limestone & Plane & T. 3059 & 14 & 4 & 14 & 1 & Limestone & Inclined \\
\hline T. 2640 & 13 & 4 & 15 & 1 & Limestone & Plane & T. 3060 & 14 & 4 & 15 & 1 & Limestone & Inclined \\
\hline T. 2641 & 16 & 4 & 1 & 1.3 & Limestone & Plane & T. 3061 & 17 & 4 & 1 & 1.3 & Limestone & Inclined \\
\hline T. 2642 & 16 & 4 & 2 & 1.3 & Limestone & Plane & T. 3062 & 17 & 4 & 2 & 1.3 & Limestone & Inclined \\
\hline T. 2643 & 16 & 4 & 3 & 1.3 & Limestone & Plane & T. 3063 & 17 & 4 & 3 & 1.3 & Limestone & Inclined \\
\hline T. 2644 & 16 & 4 & 4 & 1.3 & Limestone & Plane & T. 3064 & 17 & 4 & 4 & 1.3 & Limestone & Inclined \\
\hline T. 2645 & 16 & 4 & 5 & 1.3 & Limestone & Plane & T. 3065 & 17 & 4 & 5 & 1.3 & Limestone & Inclined \\
\hline
\end{tabular}


Table E.1. (cont.)

\begin{tabular}{|c|c|c|c|c|c|c|c|c|c|c|c|c|c|}
\hline T. 2646 & 16 & 4 & 6 & 1.3 & Limestone & Plane & T. 3066 & 17 & 4 & 6 & 1.3 & Limestone & Inclined \\
\hline T. 2647 & 16 & 4 & 7 & 1.3 & Limestone & Plane & T. 3067 & 17 & 4 & 7 & 1.3 & Limestone & Inclined \\
\hline T. 2648 & 16 & 4 & 8 & 1.3 & Limestone & Plane & T. 3068 & 17 & 4 & 8 & 1.3 & Limestone & Inclined \\
\hline T. 2649 & 16 & 4 & 9 & 1.3 & Limestone & Plane & T. 3069 & 17 & 4 & 9 & 1.3 & Limestone & Inclined \\
\hline T. 2650 & 13 & 4 & 10 & 1.3 & Limestone & Plane & T. 3070 & 14 & 4 & 10 & 1.3 & Limestone & Inclined \\
\hline T. 2651 & 15 & 4 & 11 & 1.3 & Limestone & Plane & T. 3071 & 16 & 4 & 11 & 1.3 & Limestone & Inclined \\
\hline T. 2652 & 16 & 4 & 12 & 1.3 & Limestone & Plane & T. 3072 & 17 & 4 & 12 & 1.3 & Limestone & Inclined \\
\hline T. 2653 & 16 & 4 & 13 & 1.3 & Limestone & Plane & T. 3073 & 17 & 4 & 13 & 1.3 & Limestone & Inclined \\
\hline T. 2654 & 15 & 4 & 14 & 1.3 & Limestone & Plane & T. 3074 & 16 & 4 & 14 & 1.3 & Limestone & Inclined \\
\hline T. 2655 & 15 & 4 & 15 & 1.3 & Limestone & Plane & T. 3075 & 16 & 4 & 15 & 1.3 & Limestone & Inclined \\
\hline *T. 2656 & 17 & 4 & 1 & 1.6 & Limestone & Plane & *T. 3076 & 18 & 4 & 1 & 1.6 & Limestone & Inclined \\
\hline *T. 2657 & 17 & 4 & 2 & 1.6 & Limestone & Plane & *T. 3077 & 18 & 4 & 2 & 1.6 & Limestone & Inclined \\
\hline *T. 2658 & 17 & 4 & 3 & 1.6 & Limestone & Plane & ${ }^{*} \mathrm{~T} .3078$ & 18 & 4 & 3 & 1.6 & Limestone & Inclined \\
\hline *T. 2659 & 17 & 4 & 4 & 1.6 & Limestone & Plane & *T. 3079 & 18 & 4 & 4 & 1.6 & Limestone & Inclined \\
\hline *T. 2660 & 17 & 4 & 5 & 1.6 & Limestone & Plane & *T. 3080 & 18 & 4 & 5 & 1.6 & Limestone & Inclined \\
\hline${ }^{*}$ T. 2661 & 17 & 4 & 6 & 1.6 & Limestone & Plane & *T. 3081 & 18 & 4 & 6 & 1.6 & Limestone & Inclined \\
\hline *T. 2662 & 17 & 4 & 7 & 1.6 & Limestone & Plane & ${ }^{*} \mathrm{~T} .3082$ & 18 & 4 & 7 & 1.6 & Limestone & Inclined \\
\hline *T. 2663 & 17 & 4 & 8 & 1.6 & Limestone & Plane & ${ }^{*} \mathrm{~T} .3083$ & 18 & 4 & 8 & 1.6 & Limestone & Inclined \\
\hline *T. 2664 & 17 & 4 & 9 & 1.6 & Limestone & Plane & ${ }^{*} \mathrm{~T} .3084$ & 18 & 4 & 9 & 1.6 & Limestone & Inclined \\
\hline *T. 2665 & 15 & 4 & 10 & 1.6 & Limestone & Plane & *T. 3085 & 16 & 4 & 10 & 1.6 & Limestone & Inclined \\
\hline${ }^{*}$ T. 2666 & 17 & 4 & 11 & 1.6 & Limestone & Plane & *T. 3086 & 18 & 4 & 11 & 1.6 & Limestone & Inclined \\
\hline *T. 2667 & 17 & 4 & 12 & 1.6 & Limestone & Plane & *T. 3087 & 18 & 4 & 12 & 1.6 & Limestone & Inclined \\
\hline *T. 2668 & 17 & 4 & 13 & 1.6 & Limestone & Plane & ${ }^{*} \mathrm{~T} .3088$ & 18 & 4 & 13 & 1.6 & Limestone & Inclined \\
\hline *T. 2669 & 17 & 4 & 14 & 1.6 & Limestone & Plane & *T. 3089 & 18 & 4 & 14 & 1.6 & Limestone & Inclined \\
\hline *T. 2670 & 17 & 4 & 15 & 1.6 & Limestone & Plane & *T. 3090 & 18 & 4 & 15 & 1.6 & Limestone & Inclined \\
\hline *T. 2671 & 17 & 4 & 1 & 1.8 & Limestone & Plane & *T. 3091 & 18 & 4 & 1 & 1.8 & Limestone & Inclined \\
\hline *T. 2672 & 17 & 4 & 2 & 1.8 & Limestone & Plane & *T. 3092 & 18 & 4 & 2 & 1.8 & Limestone & Inclined \\
\hline *T. 2673 & 17 & 4 & 3 & 1.8 & Limestone & Plane & *T. 3093 & 18 & 4 & 3 & 1.8 & Limestone & Inclined \\
\hline *T. 2674 & 17 & 4 & 4 & 1.8 & Limestone & Plane & *T. 3094 & 18 & 4 & 4 & 1.8 & Limestone & Inclined \\
\hline *T. 2675 & 17 & 4 & 5 & 1.8 & Limestone & Plane & *T. 3095 & 18 & 4 & 5 & 1.8 & Limestone & Inclined \\
\hline *T. 2676 & 17 & 4 & 6 & 1.8 & Limestone & Plane & ${ }^{*}$ T. 3096 & 18 & 4 & 6 & 1.8 & Limestone & Inclined \\
\hline *T. 2677 & 17 & 4 & 7 & 1.8 & Limestone & Plane & *T. 3097 & 18 & 4 & 7 & 1.8 & Limestone & Inclined \\
\hline *T. 2678 & 17 & 4 & 8 & 1.8 & Limestone & Plane & *T. 3098 & 18 & 4 & 8 & 1.8 & Limestone & Inclined \\
\hline
\end{tabular}


Table E.1. (cont.)

\begin{tabular}{|c|c|c|c|c|c|c|c|c|c|c|c|c|c|}
\hline *T. 2679 & 17 & 4 & 9 & 1.8 & Limestone & Plane & *T. 3099 & 18 & 4 & 9 & 1.8 & Limestone & Inclined \\
\hline *T. 2680 & 15 & 4 & 10 & 1.8 & Limestone & Plane & *T. 3100 & 16 & 4 & 10 & 1.8 & Limestone & Inclined \\
\hline *T. 2681 & 17 & 4 & 11 & 1.8 & Limestone & Plane & *T. 3101 & 18 & 4 & 11 & 1.8 & Limestone & Inclined \\
\hline *T. 2682 & 17 & 4 & 12 & 1.8 & Limestone & Plane & ${ }^{*} \mathrm{~T} .3102$ & 18 & 4 & 12 & 1.8 & Limestone & Inclined \\
\hline *T. 2683 & 17 & 4 & 13 & 1.8 & Limestone & Plane & *T. 3103 & 18 & 4 & 13 & 1.8 & Limestone & Inclined \\
\hline${ }^{*} \mathrm{~T} .2684$ & 17 & 4 & 14 & 1.8 & Limestone & Plane & *T. 3104 & 18 & 4 & 14 & 1.8 & Limestone & Inclined \\
\hline *T. 2685 & 17 & 4 & 15 & 1.8 & Limestone & Plane & *T. 3105 & 18 & 4 & 15 & 1.8 & Limestone & Inclined \\
\hline *T. 2686 & 17 & 4 & 1 & 2 & Limestone & Plane & *T. 3106 & 18 & 4 & 1 & 2 & Limestone & Inclined \\
\hline *T. 2687 & 17 & 4 & 2 & 2 & Limestone & Plane & *T. 3107 & 18 & 4 & 2 & 2 & Limestone & Inclined \\
\hline${ }^{*}$ T. 2688 & 17 & 4 & 3 & 2 & Limestone & Plane & ${ }^{*} \mathrm{~T} . \mathbf{3 1 0 8}$ & 18 & 4 & 3 & 2 & Limestone & Inclined \\
\hline *T. 2689 & 17 & 4 & 4 & 2 & Limestone & Plane & *T. 3109 & 18 & 4 & 4 & 2 & Limestone & Inclined \\
\hline *T. 2690 & 17 & 4 & 5 & 2 & Limestone & Plane & *T. 3110 & 18 & 4 & 5 & 2 & Limestone & Inclined \\
\hline *T. 2691 & 17 & 4 & 6 & 2 & Limestone & Plane & ${ }^{*} \mathrm{~T} .3111$ & 18 & 4 & 6 & 2 & Limestone & Inclined \\
\hline *T. 2692 & 17 & 4 & 7 & 2 & Limestone & Plane & *T. 3112 & 18 & 4 & 7 & 2 & Limestone & Inclined \\
\hline${ }^{*}$ T. 2693 & 17 & 4 & 8 & 2 & Limestone & Plane & ${ }^{*} \mathrm{~T} .3113$ & 18 & 4 & 8 & 2 & Limestone & Inclined \\
\hline *T. 2694 & 17 & 4 & 9 & 2 & Limestone & Plane & *T. 3114 & 18 & 4 & 9 & 2 & Limestone & Inclined \\
\hline *T. 2695 & 14 & 4 & 10 & 2 & Limestone & Plane & *T. 3115 & 15 & 4 & 10 & 2 & Limestone & Inclined \\
\hline *T. 2696 & 16 & 4 & 11 & 2 & Limestone & Plane & *T. 3116 & 17 & 4 & 11 & 2 & Limestone & Inclined \\
\hline *T. 2697 & 17 & 4 & 12 & 2 & Limestone & Plane & *T. 3117 & 18 & 4 & 12 & 2 & Limestone & Inclined \\
\hline *T. 2698 & 17 & 4 & 13 & 2 & Limestone & Plane & *T. 3118 & 18 & 4 & 13 & 2 & Limestone & Inclined \\
\hline *T. 2699 & 16 & 4 & 14 & 2 & Limestone & Plane & ${ }^{*} \mathrm{~T} .3119$ & 17 & 4 & 14 & 2 & Limestone & Inclined \\
\hline *T. 2700 & 16 & 4 & 15 & 2 & Limestone & Plane & *T. 3120 & 17 & 4 & 15 & 2 & Limestone & Inclined \\
\hline *T. 2701 & 16 & 4 & 1 & 2.3 & Limestone & Plane & *T. 3121 & 17 & 4 & 1 & 2.3 & Limestone & Inclined \\
\hline *T. 2702 & 16 & 4 & 2 & 2.3 & Limestone & Plane & *T. 3122 & 17 & 4 & 2 & 2.3 & Limestone & Inclined \\
\hline *T. 2703 & 16 & 4 & 3 & 2.3 & Limestone & Plane & *T. 3123 & 17 & 4 & 3 & 2.3 & Limestone & Inclined \\
\hline *T. 2704 & 16 & 4 & 4 & 2.3 & Limestone & Plane & *T. 3124 & 17 & 4 & 4 & 2.3 & Limestone & Inclined \\
\hline *T. 2705 & 16 & 4 & 5 & 2.3 & Limestone & Plane & *T. 3125 & 17 & 4 & 5 & 2.3 & Limestone & Inclined \\
\hline *T. 2706 & 16 & 4 & 6 & 2.3 & Limestone & Plane & *T. 3126 & 17 & 4 & 6 & 2.3 & Limestone & Inclined \\
\hline *T. 2707 & 16 & 4 & 7 & 2.3 & Limestone & Plane & *T. 3127 & 17 & 4 & 7 & 2.3 & Limestone & Inclined \\
\hline *T. 2708 & 16 & 4 & 8 & 2.3 & Limestone & Plane & *T. 3128 & 17 & 4 & 8 & 2.3 & Limestone & Inclined \\
\hline *T. 2709 & 16 & 4 & 9 & 2.3 & Limestone & Plane & *T. 3129 & 17 & 4 & 9 & 2.3 & Limestone & Inclined \\
\hline *T. 2710 & 13 & 4 & 10 & 2.3 & Limestone & Plane & ${ }^{*}$ T. 3130 & 14 & 4 & 10 & 2.3 & Limestone & Inclined \\
\hline *T. 2711 & 16 & 4 & 11 & 2.3 & Limestone & Plane & *T. 3131 & 17 & 4 & 11 & 2.3 & Limestone & Inclined \\
\hline
\end{tabular}

(cont. on next page) 
Table E.1. (cont.)

\begin{tabular}{|c|c|c|c|c|c|c|c|c|c|c|c|c|c|}
\hline *T. 2712 & 16 & 4 & 12 & 2.3 & Limestone & Plane & ${ }^{*} \mathrm{~T} .3132$ & 17 & 4 & 12 & 2.3 & Limestone & Inclined \\
\hline *T. 2713 & 16 & 4 & 13 & 2.3 & Limestone & Plane & ${ }^{*} \mathrm{~T} .3133$ & 17 & 4 & 13 & 2.3 & Limestone & Inclined \\
\hline *T. 2714 & 15 & 4 & 14 & 2.3 & Limestone & Plane & *T. 3134 & 16 & 4 & 14 & 2.3 & Limestone & Inclined \\
\hline *T. 2715 & 15 & 4 & 15 & 2.3 & Limestone & Plane & *T. 3135 & 16 & 4 & 15 & 2.3 & Limestone & Inclined \\
\hline T. 2716 & 15 & 4 & 1 & 2.5 & Limestone & Plane & T. 3136 & 16 & 4 & 1 & 2.5 & Limestone & Inclined \\
\hline T. 2717 & 15 & 4 & 2 & 2.5 & Limestone & Plane & T. 3137 & 16 & 4 & 2 & 2.5 & Limestone & Inclined \\
\hline T. 2718 & 15 & 4 & 3 & 2.5 & Limestone & Plane & T. 3138 & 16 & 4 & 3 & 2.5 & Limestone & Inclined \\
\hline T. 2719 & 15 & 4 & 4 & 2.5 & Limestone & Plane & T. 3139 & 16 & 4 & 4 & 2.5 & Limestone & Inclined \\
\hline T. 2720 & 15 & 4 & 5 & 2.5 & Limestone & Plane & T. 3140 & 16 & 4 & 5 & 2.5 & Limestone & Inclined \\
\hline T. 2721 & 15 & 4 & 6 & 2.5 & Limestone & Plane & T. 3141 & 16 & 4 & 6 & 2.5 & Limestone & Inclined \\
\hline T. 2722 & 15 & 4 & 7 & 2.5 & Limestone & Plane & T. 3142 & 16 & 4 & 7 & 2.5 & Limestone & Inclined \\
\hline T. 2723 & 15 & 4 & 8 & 2.5 & Limestone & Plane & T. 3143 & 16 & 4 & 8 & 2.5 & Limestone & Inclined \\
\hline T. 2724 & 15 & 4 & 9 & 2.5 & Limestone & Plane & T. 3144 & 16 & 4 & 9 & 2.5 & Limestone & Inclined \\
\hline T. 2725 & 12 & 4 & 10 & 2.5 & Limestone & Plane & T. 3145 & 13 & 4 & 10 & 2.5 & Limestone & Inclined \\
\hline T. 2726 & 13 & 4 & 11 & 2.5 & Limestone & Plane & T. 3146 & 14 & 4 & 11 & 2.5 & Limestone & Inclined \\
\hline T. 2727 & 15 & 4 & 12 & 2.5 & Limestone & Plane & T. 3147 & 16 & 4 & 12 & 2.5 & Limestone & Inclined \\
\hline T. 2728 & 15 & 4 & 13 & 2.5 & Limestone & Plane & T. 3148 & 16 & 4 & 13 & 2.5 & Limestone & Inclined \\
\hline T. 2729 & 13 & 4 & 14 & 2.5 & Limestone & Plane & T. 3149 & 14 & 4 & 14 & 2.5 & Limestone & Inclined \\
\hline T. 2730 & 13 & 4 & 15 & 2.5 & Limestone & Plane & T. 3150 & 14 & 4 & 15 & 2.5 & Limestone & Inclined \\
\hline T. 2731 & 14 & 4 & 1 & 1 & Sandstone & Plane & T. 3151 & 15 & 4 & 1 & 1 & Sandstone & Inclined \\
\hline T. 2732 & 14 & 4 & 2 & 1 & Sandstone & Plane & T. 3152 & 15 & 4 & 2 & 1 & Sandstone & Inclined \\
\hline T. 2733 & 14 & 4 & 3 & 1 & Sandstone & Plane & T. 3153 & 15 & 4 & 3 & 1 & Sandstone & Inclined \\
\hline T. 2734 & 14 & 4 & 4 & 1 & Sandstone & Plane & T. 3154 & 15 & 4 & 4 & 1 & Sandstone & Inclined \\
\hline T. 2735 & 14 & 4 & 5 & 1 & Sandstone & Plane & T. 3155 & 15 & 4 & 5 & 1 & Sandstone & Inclined \\
\hline T. 2736 & 14 & 4 & 6 & 1 & Sandstone & Plane & T. 3156 & 15 & 4 & 6 & 1 & Sandstone & Inclined \\
\hline T. 2737 & 14 & 4 & 7 & 1 & Sandstone & Plane & T. 3157 & 15 & 4 & 7 & 1 & Sandstone & Inclined \\
\hline T. 2738 & 14 & 4 & 8 & 1 & Sandstone & Plane & T. 3158 & 15 & 4 & 8 & 1 & Sandstone & Inclined \\
\hline T. 2739 & 14 & 4 & 9 & 1 & Sandstone & Plane & T. 3159 & 15 & 4 & 9 & 1 & Sandstone & Inclined \\
\hline T. 2740 & 12 & 4 & 10 & 1 & Sandstone & Plane & T. 3160 & 13 & 4 & 10 & 1 & Sandstone & Inclined \\
\hline T. 2741 & 13 & 4 & 11 & 1 & Sandstone & Plane & T. 3161 & 14 & 4 & 11 & 1 & Sandstone & Inclined \\
\hline T. 2742 & 14 & 4 & 12 & 1 & Sandstone & Plane & T. 3162 & 15 & 4 & 12 & 1 & Sandstone & Inclined \\
\hline T. 2743 & 14 & 4 & 13 & 1 & Sandstone & Plane & T. 3163 & 15 & 4 & 13 & 1 & Sandstone & Inclined \\
\hline T. 2744 & 13 & 4 & 14 & 1 & Sandstone & Plane & T. 3164 & 14 & 4 & 14 & 1 & Sandstone & Inclined \\
\hline
\end{tabular}

(cont. on next page) 
Table E.1. (cont.)

\begin{tabular}{|c|c|c|c|c|c|c|c|c|c|c|c|c|c|}
\hline T. 2745 & 13 & 4 & 15 & 1 & Sandstone & Plane & T. 3165 & 14 & 4 & 15 & 1 & Sandstone & Inclined \\
\hline T. 2746 & 16 & 4 & 1 & 1.3 & Sandstone & Plane & T. 3166 & 17 & 4 & 1 & 1.3 & Sandstone & Inclined \\
\hline T. 2747 & 16 & 4 & 2 & 1.3 & Sandstone & Plane & T. 3167 & 17 & 4 & 2 & 1.3 & Sandstone & Inclined \\
\hline T. 2748 & 16 & 4 & 3 & 1.3 & Sandstone & Plane & T. 3168 & 17 & 4 & 3 & 1.3 & Sandstone & Inclined \\
\hline T. 2749 & 16 & 4 & 4 & 1.3 & Sandstone & Plane & T. 3169 & 17 & 4 & 4 & 1.3 & Sandstone & Inclined \\
\hline T. 2750 & 16 & 4 & 5 & 1.3 & Sandstone & Plane & T. 3170 & 17 & 4 & 5 & 1.3 & Sandstone & Inclined \\
\hline T. 2751 & 16 & 4 & 6 & 1.3 & Sandstone & Plane & T. 3171 & 17 & 4 & 6 & 1.3 & Sandstone & Inclined \\
\hline T. 2752 & 16 & 4 & 7 & 1.3 & Sandstone & Plane & T. 3172 & 17 & 4 & 7 & 1.3 & Sandstone & Inclined \\
\hline T. 2753 & 16 & 4 & 8 & 1.3 & Sandstone & Plane & T. 3173 & 17 & 4 & 8 & 1.3 & Sandstone & Inclined \\
\hline T. 2754 & 16 & 4 & 9 & 1.3 & Sandstone & Plane & T. 3174 & 17 & 4 & 9 & 1.3 & Sandstone & Inclined \\
\hline T. 2755 & 13 & 4 & 10 & 1.3 & Sandstone & Plane & T. 3175 & 14 & 4 & 10 & 1.3 & Sandstone & Inclined \\
\hline T. 2756 & 15 & 4 & 11 & 1.3 & Sandstone & Plane & T. 3176 & 16 & 4 & 11 & 1.3 & Sandstone & Inclined \\
\hline T. 2757 & 16 & 4 & 12 & 1.3 & Sandstone & Plane & T. 3177 & 17 & 4 & 12 & 1.3 & Sandstone & Inclined \\
\hline T. 2758 & 16 & 4 & 13 & 1.3 & Sandstone & Plane & T. 3178 & 17 & 4 & 13 & 1.3 & Sandstone & Inclined \\
\hline T. 2759 & 15 & 4 & 14 & 1.3 & Sandstone & Plane & T. 3179 & 16 & 4 & 14 & 1.3 & Sandstone & Inclined \\
\hline T. 2760 & 15 & 4 & 15 & 1.3 & Sandstone & Plane & T. 3180 & 16 & 4 & 15 & 1.3 & Sandstone & Inclined \\
\hline T. 2761 & 17 & 4 & 1 & 1.6 & Sandstone & Plane & T. 3181 & 18 & 4 & 1 & 1.6 & Sandstone & Inclined \\
\hline T. 2762 & 17 & 4 & 2 & 1.6 & Sandstone & Plane & T. 3182 & 18 & 4 & 2 & 1.6 & Sandstone & Inclined \\
\hline T. 2763 & 17 & 4 & 3 & 1.6 & Sandstone & Plane & T. 3183 & 18 & 4 & 3 & 1.6 & Sandstone & Inclined \\
\hline T. 2764 & 17 & 4 & 4 & 1.6 & Sandstone & Plane & T. 3184 & 18 & 4 & 4 & 1.6 & Sandstone & Inclined \\
\hline T. 2765 & 17 & 4 & 5 & 1.6 & Sandstone & Plane & T. 3185 & 18 & 4 & 5 & 1.6 & Sandstone & Inclined \\
\hline T. 2766 & 17 & 4 & 6 & 1.6 & Sandstone & Plane & T. 3186 & 18 & 4 & 6 & 1.6 & Sandstone & Inclined \\
\hline T. 2767 & 17 & 4 & 7 & 1.6 & Sandstone & Plane & T. 3187 & 18 & 4 & 7 & 1.6 & Sandstone & Inclined \\
\hline T. 2768 & 17 & 4 & 8 & 1.6 & Sandstone & Plane & T. 3188 & 18 & 4 & 8 & 1.6 & Sandstone & Inclined \\
\hline T. 2769 & 17 & 4 & 9 & 1.6 & Sandstone & Plane & T. 3189 & 18 & 4 & 9 & 1.6 & Sandstone & Inclined \\
\hline T. 2770 & 15 & 4 & 10 & 1.6 & Sandstone & Plane & T. 3190 & 16 & 4 & 10 & 1.6 & Sandstone & Inclined \\
\hline T. 2771 & 17 & 4 & 11 & 1.6 & Sandstone & Plane & T. 3191 & 18 & 4 & 11 & 1.6 & Sandstone & Inclined \\
\hline T. 2772 & 17 & 4 & 12 & 1.6 & Sandstone & Plane & T. 3192 & 18 & 4 & 12 & 1.6 & Sandstone & Inclined \\
\hline T. 2773 & 17 & 4 & 13 & 1.6 & Sandstone & Plane & T. 3193 & 18 & 4 & 13 & 1.6 & Sandstone & Inclined \\
\hline T. 2774 & 17 & 4 & 14 & 1.6 & Sandstone & Plane & T. 3194 & 18 & 4 & 14 & 1.6 & Sandstone & Inclined \\
\hline T. 2775 & 17 & 4 & 15 & 1.6 & Sandstone & Plane & T. 3195 & 18 & 4 & 15 & 1.6 & Sandstone & Inclined \\
\hline T. 2776 & 17 & 4 & 1 & 1.8 & Sandstone & Plane & T. 3196 & 18 & 4 & 1 & 1.8 & Sandstone & Inclined \\
\hline T. 2777 & 17 & 4 & 2 & 1.8 & Sandstone & Plane & T. 3197 & 18 & 4 & 2 & 1.8 & Sandstone & Inclined \\
\hline
\end{tabular}

(cont. on next page) 
Table E.1. (cont.)

\begin{tabular}{|c|c|c|c|c|c|c|c|c|c|c|c|c|c|}
\hline T. 2778 & 17 & 4 & 3 & 1.8 & Sandstone & Plane & T. 3198 & 18 & 4 & 3 & 1.8 & Sandstone & Inclined \\
\hline T. 2779 & 17 & 4 & 4 & 1.8 & Sandstone & Plane & T. 3199 & 18 & 4 & 4 & 1.8 & Sandstone & Inclined \\
\hline T. 2780 & 17 & 4 & 5 & 1.8 & Sandstone & Plane & T. 3200 & 18 & 4 & 5 & 1.8 & Sandstone & Inclined \\
\hline T. 2781 & 17 & 4 & 6 & 1.8 & Sandstone & Plane & T. 3201 & 18 & 4 & 6 & 1.8 & Sandstone & Inclined \\
\hline T. 2782 & 17 & 4 & 7 & 1.8 & Sandstone & Plane & T. 3202 & 18 & 4 & 7 & 1.8 & Sandstone & Inclined \\
\hline T. 2783 & 17 & 4 & 8 & 1.8 & Sandstone & Plane & T. 3203 & 18 & 4 & 8 & 1.8 & Sandstone & Inclined \\
\hline T. 2784 & 17 & 4 & 9 & 1.8 & Sandstone & Plane & T. 3204 & 18 & 4 & 9 & 1.8 & Sandstone & Inclined \\
\hline T. 2785 & 15 & 4 & 10 & 1.8 & Sandstone & Plane & T. 3205 & 16 & 4 & 10 & 1.8 & Sandstone & Inclined \\
\hline T. 2786 & 17 & 4 & 11 & 1.8 & Sandstone & Plane & T. 3206 & 18 & 4 & 11 & 1.8 & Sandstone & Inclined \\
\hline T. 2787 & 17 & 4 & 12 & 1.8 & Sandstone & Plane & T. 3207 & 18 & 4 & 12 & 1.8 & Sandstone & Inclined \\
\hline T. 2788 & 17 & 4 & 13 & 1.8 & Sandstone & Plane & T. 3208 & 18 & 4 & 13 & 1.8 & Sandstone & Inclined \\
\hline T. 2789 & 17 & 4 & 14 & 1.8 & Sandstone & Plane & T. 3209 & 18 & 4 & 14 & 1.8 & Sandstone & Inclined \\
\hline T. 2790 & 17 & 4 & 15 & 1.8 & Sandstone & Plane & T. 3210 & 18 & 4 & 15 & 1.8 & Sandstone & Inclined \\
\hline T. 2791 & 17 & 4 & 1 & 2 & Sandstone & Plane & T. 3211 & 18 & 4 & 1 & 2 & Sandstone & Inclined \\
\hline T. 2792 & 17 & 4 & 2 & 2 & Sandstone & Plane & T. 3212 & 18 & 4 & 2 & 2 & Sandstone & Inclined \\
\hline T. 2793 & 17 & 4 & 3 & 2 & Sandstone & Plane & T. 3213 & 18 & 4 & 3 & 2 & Sandstone & Inclined \\
\hline T. 2794 & 17 & 4 & 4 & 2 & Sandstone & Plane & T. 3214 & 18 & 4 & 4 & 2 & Sandstone & Inclined \\
\hline T. 2795 & 17 & 4 & 5 & 2 & Sandstone & Plane & T. 3215 & 18 & 4 & 5 & 2 & Sandstone & Inclined \\
\hline T. 2796 & 17 & 4 & 6 & 2 & Sandstone & Plane & T. 3216 & 18 & 4 & 6 & 2 & Sandstone & Inclined \\
\hline T. 2797 & 17 & 4 & 7 & 2 & Sandstone & Plane & T. 3217 & 18 & 4 & 7 & 2 & Sandstone & Inclined \\
\hline T. 2798 & 17 & 4 & 8 & 2 & Sandstone & Plane & T. 3218 & 18 & 4 & 8 & 2 & Sandstone & Inclined \\
\hline T. 2799 & 17 & 4 & 9 & 2 & Sandstone & Plane & T. 3219 & 18 & 4 & 9 & 2 & Sandstone & Inclined \\
\hline T. 2800 & 14 & 4 & 10 & 2 & Sandstone & Plane & T. 3220 & 15 & 4 & 10 & 2 & Sandstone & Inclined \\
\hline T. 2801 & 16 & 4 & 11 & 2 & Sandstone & Plane & T. 3221 & 17 & 4 & 11 & 2 & Sandstone & Inclined \\
\hline T. 2802 & 17 & 4 & 12 & 2 & Sandstone & Plane & T. 3222 & 18 & 4 & 12 & 2 & Sandstone & Inclined \\
\hline T. 2803 & 17 & 4 & 13 & 2 & Sandstone & Plane & T. 3223 & 18 & 4 & 13 & 2 & Sandstone & Inclined \\
\hline T. 2804 & 16 & 4 & 14 & 2 & Sandstone & Plane & T. 3224 & 17 & 4 & 14 & 2 & Sandstone & Inclined \\
\hline T. 2805 & 16 & 4 & 15 & 2 & Sandstone & Plane & T. 3225 & 17 & 4 & 15 & 2 & Sandstone & Inclined \\
\hline T. 2806 & 16 & 4 & 1 & 2.3 & Sandstone & Plane & T. 3226 & 17 & 4 & 1 & 2.3 & Sandstone & Inclined \\
\hline T. 2807 & 16 & 4 & 2 & 2.3 & Sandstone & Plane & T. 3227 & 17 & 4 & 2 & 2.3 & Sandstone & Inclined \\
\hline T. 2808 & 16 & 4 & 3 & 2.3 & Sandstone & Plane & T. 3228 & 17 & 4 & 3 & 2.3 & Sandstone & Inclined \\
\hline T. 2809 & 16 & 4 & 4 & 2.3 & Sandstone & Plane & T. 3229 & 17 & 4 & 4 & 2.3 & Sandstone & Inclined \\
\hline T. 2810 & 16 & 4 & 5 & 2.3 & Sandstone & Plane & T. 3230 & 17 & 4 & 5 & 2.3 & Sandstone & Inclined \\
\hline
\end{tabular}

(cont. on next page) 
Table E.1. (cont.)

\begin{tabular}{|c|c|c|c|c|c|c|c|c|c|c|c|c|c|}
\hline T. 2811 & 16 & 4 & 6 & 2.3 & Sandstone & Plane & T. 3231 & 17 & 4 & 6 & 2.3 & Sandstone & Inclined \\
\hline T. 2812 & 16 & 4 & 7 & 2.3 & Sandstone & Plane & T. 3232 & 17 & 4 & 7 & 2.3 & Sandstone & Inclined \\
\hline T. 2813 & 16 & 4 & 8 & 2.3 & Sandstone & Plane & T. 3233 & 17 & 4 & 8 & 2.3 & Sandstone & Inclined \\
\hline T. 2814 & 16 & 4 & 9 & 2.3 & Sandstone & Plane & T. 3234 & 17 & 4 & 9 & 2.3 & Sandstone & Inclined \\
\hline T. 2815 & 13 & 4 & 10 & 2.3 & Sandstone & Plane & T. 3235 & 14 & 4 & 10 & 2.3 & Sandstone & Inclined \\
\hline T. 2816 & 16 & 4 & 11 & 2.3 & Sandstone & Plane & T. 3236 & 17 & 4 & 11 & 2.3 & Sandstone & Inclined \\
\hline T. 2817 & 16 & 4 & 12 & 2.3 & Sandstone & Plane & T. 3237 & 17 & 4 & 12 & 2.3 & Sandstone & Inclined \\
\hline T. 2818 & 16 & 4 & 13 & 2.3 & Sandstone & Plane & T. 3238 & 17 & 4 & 13 & 2.3 & Sandstone & Inclined \\
\hline T. 2819 & 15 & 4 & 14 & 2.3 & Sandstone & Plane & T. 3239 & 16 & 4 & 14 & 2.3 & Sandstone & Inclined \\
\hline T. 2820 & 15 & 4 & 15 & 2.3 & Sandstone & Plane & T. 3240 & 16 & 4 & 15 & 2.3 & Sandstone & Inclined \\
\hline T. 2821 & 15 & 4 & 1 & 2.5 & Sandstone & Plane & T. 3241 & 16 & 4 & 1 & 2.5 & Sandstone & Inclined \\
\hline T. 2822 & 15 & 4 & 2 & 2.5 & Sandstone & Plane & T. 3242 & 16 & 4 & 2 & 2.5 & Sandstone & Inclined \\
\hline T. 2823 & 15 & 4 & 3 & 2.5 & Sandstone & Plane & T. 3243 & 16 & 4 & 3 & 2.5 & Sandstone & Inclined \\
\hline T. 2824 & 15 & 4 & 4 & 2.5 & Sandstone & Plane & T. 3244 & 16 & 4 & 4 & 2.5 & Sandstone & Inclined \\
\hline T. 2825 & 15 & 4 & 5 & 2.5 & Sandstone & Plane & T. 3245 & 16 & 4 & 5 & 2.5 & Sandstone & Inclined \\
\hline T. 2826 & 15 & 4 & 6 & 2.5 & Sandstone & Plane & T. 3246 & 16 & 4 & 6 & 2.5 & Sandstone & Inclined \\
\hline T. 2827 & 15 & 4 & 7 & 2.5 & Sandstone & Plane & T. 3247 & 16 & 4 & 7 & 2.5 & Sandstone & Inclined \\
\hline T. 2828 & 15 & 4 & 8 & 2.5 & Sandstone & Plane & T. 3248 & 16 & 4 & 8 & 2.5 & Sandstone & Inclined \\
\hline T. 2829 & 15 & 4 & 9 & 2.5 & Sandstone & Plane & T. 3249 & 16 & 4 & 9 & 2.5 & Sandstone & Inclined \\
\hline T. 2830 & 12 & 4 & 10 & 2.5 & Sandstone & Plane & T. 3250 & 13 & 4 & 10 & 2.5 & Sandstone & Inclined \\
\hline T. 2831 & 13 & 4 & 11 & 2.5 & Sandstone & Plane & T. 3251 & 14 & 4 & 11 & 2.5 & Sandstone & Inclined \\
\hline T. 2832 & 15 & 4 & 12 & 2.5 & Sandstone & Plane & T. 3252 & 16 & 4 & 12 & 2.5 & Sandstone & Inclined \\
\hline T. 2833 & 15 & 4 & 13 & 2.5 & Sandstone & Plane & T. 3253 & 16 & 4 & 13 & 2.5 & Sandstone & Inclined \\
\hline T. 2834 & 13 & 4 & 14 & 2.5 & Sandstone & Plane & T. 3254 & 14 & 4 & 14 & 2.5 & Sandstone & Inclined \\
\hline T. 2835 & 13 & 4 & 15 & 2.5 & Sandstone & Plane & T. 3255 & 14 & 4 & 15 & 2.5 & Sandstone & Inclined \\
\hline T. 2836 & 13 & 4 & 1 & 1 & Brick & Plane & T. 3256 & 14 & 4 & 1 & 1 & Brick & Inclined \\
\hline T. 2837 & 13 & 4 & 2 & 1 & Brick & Plane & T. 3257 & 14 & 4 & 2 & 1 & Brick & Inclined \\
\hline T. 2838 & 13 & 4 & 3 & 1 & Brick & Plane & T. 3258 & 14 & 4 & 3 & 1 & Brick & Inclined \\
\hline T. 2839 & 13 & 4 & 4 & 1 & Brick & Plane & T. 3259 & 14 & 4 & 4 & 1 & Brick & Inclined \\
\hline T. 2840 & 13 & 4 & 5 & 1 & Brick & Plane & T. 3260 & 14 & 4 & 5 & 1 & Brick & Inclined \\
\hline T. 2841 & 13 & 4 & 6 & 1 & Brick & Plane & T. 3261 & 14 & 4 & 6 & 1 & Brick & Inclined \\
\hline T. 2842 & 13 & 4 & 7 & 1 & Brick & Plane & T. 3262 & 14 & 4 & 7 & 1 & Brick & Inclined \\
\hline T. 2843 & 13 & 4 & 8 & 1 & Brick & Plane & T. 3263 & 14 & 4 & 8 & 1 & Brick & Inclined \\
\hline
\end{tabular}

(cont. on next page) 
Table E.1. (cont.)

\begin{tabular}{|c|c|c|c|c|c|c|c|c|c|c|c|c|c|}
\hline T. 2844 & 13 & 4 & 9 & 1 & Brick & Plane & T. 3264 & 14 & 4 & 9 & 1 & Brick & Inclined \\
\hline T. 2845 & 11 & 4 & 10 & 1 & Brick & Plane & T. 3265 & 12 & 4 & 10 & 1 & Brick & Inclined \\
\hline T. 2846 & 12 & 4 & 11 & 1 & Brick & Plane & T. 3266 & 13 & 4 & 11 & 1 & Brick & Inclined \\
\hline T. 2847 & 13 & 4 & 12 & 1 & Brick & Plane & T. 3267 & 14 & 4 & 12 & 1 & Brick & Inclined \\
\hline T. 2848 & 13 & 4 & 13 & 1 & Brick & Plane & T. 3268 & 14 & 4 & 13 & 1 & Brick & Inclined \\
\hline T. 2849 & 12 & 4 & 14 & 1 & Brick & Plane & T. 3269 & 13 & 4 & 14 & 1 & Brick & Inclined \\
\hline T. 2850 & 12 & 4 & 15 & 1 & Brick & Plane & T. 3270 & 13 & 4 & 15 & 1 & Brick & Inclined \\
\hline T. 2851 & 15 & 4 & 1 & 1.3 & Brick & Plane & T. 3271 & 16 & 4 & 1 & 1.3 & Brick & Inclined \\
\hline T. 2852 & 15 & 4 & 2 & 1.3 & Brick & Plane & T. 3272 & 16 & 4 & 2 & 1.3 & Brick & Inclined \\
\hline T. 2853 & 15 & 4 & 3 & 1.3 & Brick & Plane & T. 3273 & 16 & 4 & 3 & 1.3 & Brick & Inclined \\
\hline T. 2854 & 15 & 4 & 4 & 1.3 & Brick & Plane & T. 3274 & 16 & 4 & 4 & 1.3 & Brick & Inclined \\
\hline T. 2855 & 15 & 4 & 5 & 1.3 & Brick & Plane & T. 3275 & 16 & 4 & 5 & 1.3 & Brick & Inclined \\
\hline T. 2856 & 15 & 4 & 6 & 1.3 & Brick & Plane & T. 3276 & 16 & 4 & 6 & 1.3 & Brick & Inclined \\
\hline T. 2857 & 15 & 4 & 7 & 1.3 & Brick & Plane & T. 3277 & 16 & 4 & 7 & 1.3 & Brick & Inclined \\
\hline T. 2858 & 15 & 4 & 8 & 1.3 & Brick & Plane & T. 3278 & 16 & 4 & 8 & 1.3 & Brick & Inclined \\
\hline T. 2859 & 15 & 4 & 9 & 1.3 & Brick & Plane & T. 3279 & 16 & 4 & 9 & 1.3 & Brick & Inclined \\
\hline T. 2860 & 12 & 4 & 10 & 1.3 & Brick & Plane & T. 3280 & 13 & 4 & 10 & 1.3 & Brick & Inclined \\
\hline T. 2861 & 14 & 4 & 11 & 1.3 & Brick & Plane & T. 3281 & 15 & 4 & 11 & 1.3 & Brick & Inclined \\
\hline T. 2862 & 15 & 4 & 12 & 1.3 & Brick & Plane & T. 3282 & 16 & 4 & 12 & 1.3 & Brick & Inclined \\
\hline T. 2863 & 15 & 4 & 13 & 1.3 & Brick & Plane & T. 3283 & 16 & 4 & 13 & 1.3 & Brick & Inclined \\
\hline T. 2864 & 14 & 4 & 14 & 1.3 & Brick & Plane & T. 3284 & 15 & 4 & 14 & 1.3 & Brick & Inclined \\
\hline T. 2865 & 14 & 4 & 15 & 1.3 & Brick & Plane & T. 3285 & 15 & 4 & 15 & 1.3 & Brick & Inclined \\
\hline T. 2866 & 16 & 4 & 1 & 1.6 & Brick & Plane & T. 3286 & 17 & 4 & 1 & 1.6 & Brick & Inclined \\
\hline T. 2867 & 16 & 4 & 2 & 1.6 & Brick & Plane & T. 3287 & 17 & 4 & 2 & 1.6 & Brick & Inclined \\
\hline T. 2868 & 16 & 4 & 3 & 1.6 & Brick & Plane & T. 3288 & 17 & 4 & 3 & 1.6 & Brick & Inclined \\
\hline T. 2869 & 16 & 4 & 4 & 1.6 & Brick & Plane & T. 3289 & 17 & 4 & 4 & 1.6 & Brick & Inclined \\
\hline T. 2870 & 16 & 4 & 5 & 1.6 & Brick & Plane & T. 3290 & 17 & 4 & 5 & 1.6 & Brick & Inclined \\
\hline T. 2871 & 16 & 4 & 6 & 1.6 & Brick & Plane & T. 3291 & 17 & 4 & 6 & 1.6 & Brick & Inclined \\
\hline T. 2872 & 16 & 4 & 7 & 1.6 & Brick & Plane & T. 3292 & 17 & 4 & 7 & 1.6 & Brick & Inclined \\
\hline T. 2873 & 16 & 4 & 8 & 1.6 & Brick & Plane & T. 3293 & 17 & 4 & 8 & 1.6 & Brick & Inclined \\
\hline T. 2874 & 16 & 4 & 9 & 1.6 & Brick & Plane & T. 3294 & 17 & 4 & 9 & 1.6 & Brick & Inclined \\
\hline T. 2875 & 14 & 4 & 10 & 1.6 & Brick & Plane & T. 3295 & 15 & 4 & 10 & 1.6 & Brick & Inclined \\
\hline T. 2876 & 16 & 4 & 11 & 1.6 & Brick & Plane & T. 3296 & 17 & 4 & 11 & 1.6 & Brick & Inclined \\
\hline
\end{tabular}

(cont. on next page) 
Table E.1. (cont.)

\begin{tabular}{|c|c|c|c|c|c|c|c|c|c|c|c|c|c|}
\hline T. 2877 & 16 & 4 & 12 & 1.6 & Brick & Plane & T. 3297 & 17 & 4 & 12 & 1.6 & Brick & Inclined \\
\hline T. 2878 & 16 & 4 & 13 & 1.6 & Brick & Plane & T. 3298 & 17 & 4 & 13 & 1.6 & Brick & Inclined \\
\hline T. 2879 & 16 & 4 & 14 & 1.6 & Brick & Plane & T. 3299 & 17 & 4 & 14 & 1.6 & Brick & Inclined \\
\hline T. 2880 & 16 & 4 & 15 & 1.6 & Brick & Plane & T. 3300 & 17 & 4 & 15 & 1.6 & Brick & Inclined \\
\hline T. 2881 & 16 & 4 & 1 & 1.8 & Brick & Plane & T. 3301 & 17 & 4 & 1 & 1.8 & Brick & Inclined \\
\hline T. 2882 & 16 & 4 & 2 & 1.8 & Brick & Plane & T. 3302 & 17 & 4 & 2 & 1.8 & Brick & Inclined \\
\hline T. 2883 & 16 & 4 & 3 & 1.8 & Brick & Plane & T. 3303 & 17 & 4 & 3 & 1.8 & Brick & Inclined \\
\hline T. 2884 & 16 & 4 & 4 & 1.8 & Brick & Plane & T. 3304 & 17 & 4 & 4 & 1.8 & Brick & Inclined \\
\hline T. 2885 & 16 & 4 & 5 & 1.8 & Brick & Plane & T. 3305 & 17 & 4 & 5 & 1.8 & Brick & Inclined \\
\hline T. 2886 & 16 & 4 & 6 & 1.8 & Brick & Plane & T. 3306 & 17 & 4 & 6 & 1.8 & Brick & Inclined \\
\hline T. 2887 & 16 & 4 & 7 & 1.8 & Brick & Plane & T. 3307 & 17 & 4 & 7 & 1.8 & Brick & Inclined \\
\hline T. 2888 & 16 & 4 & 8 & 1.8 & Brick & Plane & T. 3308 & 17 & 4 & 8 & 1.8 & Brick & Inclined \\
\hline T. 2889 & 16 & 4 & 9 & 1.8 & Brick & Plane & T. 3309 & 17 & 4 & 9 & 1.8 & Brick & Inclined \\
\hline T. 2890 & 14 & 4 & 10 & 1.8 & Brick & Plane & T. 3310 & 15 & 4 & 10 & 1.8 & Brick & Inclined \\
\hline T. 2891 & 16 & 4 & 11 & 1.8 & Brick & Plane & T. 3311 & 17 & 4 & 11 & 1.8 & Brick & Inclined \\
\hline T. 2892 & 16 & 4 & 12 & 1.8 & Brick & Plane & T. 3312 & 17 & 4 & 12 & 1.8 & Brick & Inclined \\
\hline T. 2893 & 16 & 4 & 13 & 1.8 & Brick & Plane & T. 3313 & 17 & 4 & 13 & 1.8 & Brick & Inclined \\
\hline T. 2894 & 16 & 4 & 14 & 1.8 & Brick & Plane & T. 3314 & 17 & 4 & 14 & 1.8 & Brick & Inclined \\
\hline T. 2895 & 16 & 4 & 15 & 1.8 & Brick & Plane & T. 3315 & 17 & 4 & 15 & 1.8 & Brick & Inclined \\
\hline T. 2896 & 16 & 4 & 1 & 2 & Brick & Plane & T. 3316 & 17 & 4 & 1 & 2 & Brick & Inclined \\
\hline T. 2897 & 16 & 4 & 2 & 2 & Brick & Plane & T. 3317 & 17 & 4 & 2 & 2 & Brick & Inclined \\
\hline T. 2898 & 16 & 4 & 3 & 2 & Brick & Plane & T. 3318 & 17 & 4 & 3 & 2 & Brick & Inclined \\
\hline T. 2899 & 16 & 4 & 4 & 2 & Brick & Plane & T. 3319 & 17 & 4 & 4 & 2 & Brick & Inclined \\
\hline T. 2900 & 16 & 4 & 5 & 2 & Brick & Plane & T. 3320 & 17 & 4 & 5 & 2 & Brick & Inclined \\
\hline T. 2901 & 16 & 4 & 6 & 2 & Brick & Plane & T. 3321 & 17 & 4 & 6 & 2 & Brick & Inclined \\
\hline T. 2902 & 16 & 4 & 7 & 2 & Brick & Plane & T. 3322 & 17 & 4 & 7 & 2 & Brick & Inclined \\
\hline T. 2903 & 16 & 4 & 8 & 2 & Brick & Plane & T. 3323 & 17 & 4 & 8 & 2 & Brick & Inclined \\
\hline T. 2904 & 16 & 4 & 9 & 2 & Brick & Plane & T. 3324 & 17 & 4 & 9 & 2 & Brick & Inclined \\
\hline T. 2905 & 13 & 4 & 10 & 2 & Brick & Plane & T. 3325 & 14 & 4 & 10 & 2 & Brick & Inclined \\
\hline T. 2906 & 15 & 4 & 11 & 2 & Brick & Plane & T. 3326 & 16 & 4 & 11 & 2 & Brick & Inclined \\
\hline T. 2907 & 16 & 4 & 12 & 2 & Brick & Plane & T. 3327 & 17 & 4 & 12 & 2 & Brick & Inclined \\
\hline T. 2908 & 16 & 4 & 13 & 2 & Brick & Plane & T. 3328 & 17 & 4 & 13 & 2 & Brick & Inclined \\
\hline T. 2909 & 15 & 4 & 14 & 2 & Brick & Plane & T. 3329 & 16 & 4 & 14 & 2 & Brick & Inclined \\
\hline
\end{tabular}

(cont. on next page) 
Table E.1. (cont.)

\begin{tabular}{|c|c|c|c|c|c|c|c|c|c|c|c|c|c|}
\hline T. 2910 & 15 & 4 & 15 & 2 & Brick & Plane & T. 3330 & 16 & 4 & 15 & 2 & Brick & Inclined \\
\hline T. 2911 & 15 & 4 & 1 & 2.3 & Brick & Plane & T. 3331 & 16 & 4 & 1 & 2.3 & Brick & Inclined \\
\hline T. 2912 & 15 & 4 & 2 & 2.3 & Brick & Plane & T. 3332 & 16 & 4 & 2 & 2.3 & Brick & Inclined \\
\hline T. 2913 & 15 & 4 & 3 & 2.3 & Brick & Plane & T. 3333 & 16 & 4 & 3 & 2.3 & Brick & Inclined \\
\hline T. 2914 & 15 & 4 & 4 & 2.3 & Brick & Plane & T. 3334 & 16 & 4 & 4 & 2.3 & Brick & Inclined \\
\hline T. 2915 & 15 & 4 & 5 & 2.3 & Brick & Plane & T. 3335 & 16 & 4 & 5 & 2.3 & Brick & Inclined \\
\hline T. 2916 & 15 & 4 & 6 & 2.3 & Brick & Plane & T. 3336 & 16 & 4 & 6 & 2.3 & Brick & Inclined \\
\hline T. 2917 & 15 & 4 & 7 & 2.3 & Brick & Plane & T. 3337 & 16 & 4 & 7 & 2.3 & Brick & Inclined \\
\hline T. 2918 & 15 & 4 & 8 & 2.3 & Brick & Plane & T. 3338 & 16 & 4 & 8 & 2.3 & Brick & Inclined \\
\hline T. 2919 & 15 & 4 & 9 & 2.3 & Brick & Plane & T. 3339 & 16 & 4 & 9 & 2.3 & Brick & Inclined \\
\hline T. 2920 & 12 & 4 & 10 & 2.3 & Brick & Plane & T. 3340 & 13 & 4 & 10 & 2.3 & Brick & Inclined \\
\hline T. 2921 & 15 & 4 & 11 & 2.3 & Brick & Plane & T. 3341 & 16 & 4 & 11 & 2.3 & Brick & Inclined \\
\hline T. 2922 & 15 & 4 & 12 & 2.3 & Brick & Plane & T. 3342 & 16 & 4 & 12 & 2.3 & Brick & Inclined \\
\hline T. 2923 & 15 & 4 & 13 & 2.3 & Brick & Plane & T. 3343 & 16 & 4 & 13 & 2.3 & Brick & Inclined \\
\hline T. 2924 & 14 & 4 & 14 & 2.3 & Brick & Plane & T. 3344 & 15 & 4 & 14 & 2.3 & Brick & Inclined \\
\hline T. 2925 & 14 & 4 & 15 & 2.3 & Brick & Plane & T. 3345 & 15 & 4 & 15 & 2.3 & Brick & Inclined \\
\hline T. 2926 & 14 & 4 & 1 & 2.5 & Brick & Plane & T. 3346 & 15 & 4 & 1 & 2.5 & Brick & Inclined \\
\hline Т. 2927 & 14 & 4 & 2 & 2.5 & Brick & Plane & T. 3347 & 15 & 4 & 2 & 2.5 & Brick & Inclined \\
\hline T. 2928 & 14 & 4 & 3 & 2.5 & Brick & Plane & T. 3348 & 15 & 4 & 3 & 2.5 & Brick & Inclined \\
\hline T. 2929 & 14 & 4 & 4 & 2.5 & Brick & Plane & T. 3349 & 15 & 4 & 4 & 2.5 & Brick & Inclined \\
\hline T. 2930 & 14 & 4 & 5 & 2.5 & Brick & Plane & T. 3350 & 15 & 4 & 5 & 2.5 & Brick & Inclined \\
\hline T. 2931 & 14 & 4 & 6 & 2.5 & Brick & Plane & T. 3351 & 15 & 4 & 6 & 2.5 & Brick & Inclined \\
\hline T. 2932 & 14 & 4 & 7 & 2.5 & Brick & Plane & T. 3352 & 15 & 4 & 7 & 2.5 & Brick & Inclined \\
\hline T. 2933 & 14 & 4 & 8 & 2.5 & Brick & Plane & T. 3353 & 15 & 4 & 8 & 2.5 & Brick & Inclined \\
\hline T. 2934 & 14 & 4 & 9 & 2.5 & Brick & Plane & T. 3354 & 15 & 4 & 9 & 2.5 & Brick & Inclined \\
\hline T. 2935 & 11 & 4 & 10 & 2.5 & Brick & Plane & T. 3355 & 12 & 4 & 10 & 2.5 & Brick & Inclined \\
\hline T. 2936 & 12 & 4 & 11 & 2.5 & Brick & Plane & T. 3356 & 13 & 4 & 11 & 2.5 & Brick & Inclined \\
\hline T. 2937 & 14 & 4 & 12 & 2.5 & Brick & Plane & T. 3357 & 15 & 4 & 12 & 2.5 & Brick & Inclined \\
\hline T. 2938 & 14 & 4 & 13 & 2.5 & Brick & Plane & T. 3358 & 15 & 4 & 13 & 2.5 & Brick & Inclined \\
\hline T. 2939 & 12 & 4 & 14 & 2.5 & Brick & Plane & T. 3359 & 13 & 4 & 14 & 2.5 & Brick & Inclined \\
\hline T. 2940 & 12 & 4 & 15 & 2.5 & Brick & Plane & T. 3360 & 13 & 4 & 15 & 2.5 & Brick & Inclined \\
\hline T. 3361 & 12 & 5 & 1 & 1 & Granite & Plane & T. 3781 & 13 & 5 & 1 & 1 & Granite & Inclined \\
\hline T. 3362 & 12 & 5 & 2 & 1 & Granite & Plane & T. 3782 & 13 & 5 & 2 & 1 & Granite & Inclined \\
\hline
\end{tabular}


Table E.1. (cont.)

\begin{tabular}{|c|c|c|c|c|c|c|c|c|c|c|c|c|c|}
\hline T. 3363 & 12 & 5 & 3 & 1 & Granite & Plane & T. 3783 & 13 & 5 & 3 & 1 & Granite & Inclined \\
\hline T. 3364 & 12 & 5 & 4 & 1 & Granite & Plane & T. 3784 & 13 & 5 & 4 & 1 & Granite & Inclined \\
\hline T. 3365 & 12 & 5 & 5 & 1 & Granite & Plane & T. 3785 & 13 & 5 & 5 & 1 & Granite & Inclined \\
\hline T. 3366 & 11 & 5 & 6 & 1 & Granite & Plane & T. 3786 & 12 & 5 & 6 & 1 & Granite & Inclined \\
\hline T. 3367 & 12 & 5 & 7 & 1 & Granite & Plane & T. 3787 & 13 & 5 & 7 & 1 & Granite & Inclined \\
\hline T. 3368 & 12 & 5 & 8 & 1 & Granite & Plane & T. 3788 & 13 & 5 & 8 & 1 & Granite & Inclined \\
\hline T. 3369 & 11 & 5 & 9 & 1 & Granite & Plane & T. 3789 & 12 & 5 & 9 & 1 & Granite & Inclined \\
\hline T. 3370 & 10 & 5 & 10 & 1 & Granite & Plane & T. 3790 & 11 & 5 & 10 & 1 & Granite & Inclined \\
\hline T. 3371 & 10 & 5 & 11 & 1 & Granite & Plane & T. 3791 & 11 & 5 & 11 & 1 & Granite & Inclined \\
\hline T. 3372 & 12 & 5 & 12 & 1 & Granite & Plane & T. 3792 & 13 & 5 & 12 & 1 & Granite & Inclined \\
\hline T. 3373 & 12 & 5 & 13 & 1 & Granite & Plane & T. 3793 & 13 & 5 & 13 & 1 & Granite & Inclined \\
\hline T. 3374 & 10 & 5 & 14 & 1 & Granite & Plane & T. 3794 & 11 & 5 & 14 & 1 & Granite & Inclined \\
\hline T. 3375 & 10 & 5 & 15 & 1 & Granite & Plane & T. 3795 & 11 & 5 & 15 & 1 & Granite & Inclined \\
\hline T. 3376 & 13 & 5 & 1 & 1.3 & Granite & Plane & T. 3796 & 14 & 5 & 1 & 1.3 & Granite & Inclined \\
\hline T. 3377 & 13 & 5 & 2 & 1.3 & Granite & Plane & T. 3797 & 14 & 5 & 2 & 1.3 & Granite & Inclined \\
\hline T. 3378 & 13 & 5 & 3 & 1.3 & Granite & Plane & T. 3798 & 14 & 5 & 3 & 1.3 & Granite & Inclined \\
\hline T. 3379 & 13 & 5 & 4 & 1.3 & Granite & Plane & T. 3799 & 14 & 5 & 4 & 1.3 & Granite & Inclined \\
\hline T. 3380 & 13 & 5 & 5 & 1.3 & Granite & Plane & T. 3800 & 14 & 5 & 5 & 1.3 & Granite & Inclined \\
\hline T. 3381 & 12 & 5 & 6 & 1.3 & Granite & Plane & T. 3801 & 13 & 5 & 6 & 1.3 & Granite & Inclined \\
\hline T. 3382 & 13 & 5 & 7 & 1.3 & Granite & Plane & T. 3802 & 14 & 5 & 7 & 1.3 & Granite & Inclined \\
\hline T. 3383 & 13 & 5 & 8 & 1.3 & Granite & Plane & T. 3803 & 14 & 5 & 8 & 1.3 & Granite & Inclined \\
\hline T. 3384 & 12 & 5 & 9 & 1.3 & Granite & Plane & T. 3804 & 13 & 5 & 9 & 1.3 & Granite & Inclined \\
\hline T. 3385 & 11 & 5 & 10 & 1.3 & Granite & Plane & T. 3805 & 12 & 5 & 10 & 1.3 & Granite & Inclined \\
\hline T. 3386 & 11 & 5 & 11 & 1.3 & Granite & Plane & T. 3806 & 12 & 5 & 11 & 1.3 & Granite & Inclined \\
\hline T. 3387 & 13 & 5 & 12 & 1.3 & Granite & Plane & T. 3807 & 14 & 5 & 12 & 1.3 & Granite & Inclined \\
\hline T. 3388 & 13 & 5 & 13 & 1.3 & Granite & Plane & T. 3808 & 14 & 5 & 13 & 1.3 & Granite & Inclined \\
\hline T. 3389 & 11 & 5 & 14 & 1.3 & Granite & Plane & T. 3809 & 12 & 5 & 14 & 1.3 & Granite & Inclined \\
\hline T. 3390 & 11 & 5 & 15 & 1.3 & Granite & Plane & T. 3810 & 12 & 5 & 15 & 1.3 & Granite & Inclined \\
\hline *T. 3391 & 15 & 5 & 1 & 1.6 & Granite & Plane & *T. 3811 & 16 & 5 & 1 & 1.6 & Granite & Inclined \\
\hline *T. 3392 & 15 & 5 & 2 & 1.6 & Granite & Plane & *T. 3812 & 16 & 5 & 2 & 1.6 & Granite & Inclined \\
\hline *T. 3393 & 15 & 5 & 3 & 1.6 & Granite & Plane & *T. 3813 & 16 & 5 & 3 & 1.6 & Granite & Inclined \\
\hline *T. 3394 & 15 & 5 & 4 & 1.6 & Granite & Plane & ${ }^{*} \mathrm{~T} .3814$ & 16 & 5 & 4 & 1.6 & Granite & Inclined \\
\hline *T. 3395 & 15 & 5 & 5 & 1.6 & Granite & Plane & *T. 3815 & 16 & 5 & 5 & 1.6 & Granite & Inclined \\
\hline
\end{tabular}

(cont. on next page) 
Table E.1. (cont.)

\begin{tabular}{|c|c|c|c|c|c|c|c|c|c|c|c|c|c|}
\hline *T. 3396 & 14 & 5 & 6 & 1.6 & Granite & Plane & *T. 3816 & 15 & 5 & 6 & 1.6 & Granite & Inclined \\
\hline *T. 3397 & 15 & 5 & 7 & 1.6 & Granite & Plane & *T. 3817 & 16 & 5 & 7 & 1.6 & Granite & Inclined \\
\hline *T. 3398 & 15 & 5 & 8 & 1.6 & Granite & Plane & *T. 3818 & 16 & 5 & 8 & 1.6 & Granite & Inclined \\
\hline *T. 3399 & 14 & 5 & 9 & 1.6 & Granite & Plane & *T. 3819 & 15 & 5 & 9 & 1.6 & Granite & Inclined \\
\hline *T. 3400 & 12 & 5 & 10 & 1.6 & Granite & Plane & *T. 3820 & 13 & 5 & 10 & 1.6 & Granite & Inclined \\
\hline *T. 3401 & 13 & 5 & 11 & 1.6 & Granite & Plane & *T. 3821 & 14 & 5 & 11 & 1.6 & Granite & Inclined \\
\hline *T. 3402 & 15 & 5 & 12 & 1.6 & Granite & Plane & *T. 3822 & 16 & 5 & 12 & 1.6 & Granite & Inclined \\
\hline *T. 3403 & 15 & 5 & 13 & 1.6 & Granite & Plane & *T. 3823 & 16 & 5 & 13 & 1.6 & Granite & Inclined \\
\hline *T. 3404 & 13 & 5 & 14 & 1.6 & Granite & Plane & ${ }^{*} \mathrm{~T} .3824$ & 14 & 5 & 14 & 1.6 & Granite & Inclined \\
\hline${ }^{*}$ T. 3405 & 13 & 5 & 15 & 1.6 & Granite & Plane & *T. 3825 & 14 & 5 & 15 & 1.6 & Granite & Inclined \\
\hline${ }^{*}$ T. 3406 & 15 & 5 & 1 & 1.8 & Granite & Plane & ${ }^{*}$ T. 3826 & 16 & 5 & 1 & 1.8 & Granite & Inclined \\
\hline${ }^{*}$ T. 3407 & 15 & 5 & 2 & 1.8 & Granite & Plane & ${ }^{*}$ T. 3827 & 16 & 5 & 2 & 1.8 & Granite & Inclined \\
\hline *T. 3408 & 15 & 5 & 3 & 1.8 & Granite & Plane & *T. 3828 & 16 & 5 & 3 & 1.8 & Granite & Inclined \\
\hline *T. 3409 & 15 & 5 & 4 & 1.8 & Granite & Plane & *T. 3829 & 16 & 5 & 4 & 1.8 & Granite & Inclined \\
\hline *T. 3410 & 15 & 5 & 5 & 1.8 & Granite & Plane & *T. 3830 & 16 & 5 & 5 & 1.8 & Granite & Inclined \\
\hline *T. 3411 & 14 & 5 & 6 & 1.8 & Granite & Plane & *T. 3831 & 15 & 5 & 6 & 1.8 & Granite & Inclined \\
\hline${ }^{*} \mathrm{~T} .3412$ & 15 & 5 & 7 & 1.8 & Granite & Plane & ${ }^{*} \mathrm{~T} .3832$ & 16 & 5 & 7 & 1.8 & Granite & Inclined \\
\hline *T. 3413 & 15 & 5 & 8 & 1.8 & Granite & Plane & *T. 3833 & 16 & 5 & 8 & 1.8 & Granite & Inclined \\
\hline *T. 3414 & 14 & 5 & 9 & 1.8 & Granite & Plane & *T. 3834 & 15 & 5 & 9 & 1.8 & Granite & Inclined \\
\hline *T. 3415 & 12 & 5 & 10 & 1.8 & Granite & Plane & *T. 3835 & 13 & 5 & 10 & 1.8 & Granite & Inclined \\
\hline *T. 3416 & 13 & 5 & 11 & 1.8 & Granite & Plane & *T. 3836 & 14 & 5 & 11 & 1.8 & Granite & Inclined \\
\hline *T. 3417 & 15 & 5 & 12 & 1.8 & Granite & Plane & *T. 3837 & 16 & 5 & 12 & 1.8 & Granite & Inclined \\
\hline *T. 3418 & 15 & 5 & 13 & 1.8 & Granite & Plane & *T. 3838 & 16 & 5 & 13 & 1.8 & Granite & Inclined \\
\hline *T. 3419 & 13 & 5 & 14 & 1.8 & Granite & Plane & *T. 3839 & 14 & 5 & 14 & 1.8 & Granite & Inclined \\
\hline *T. 3420 & 13 & 5 & 15 & 1.8 & Granite & Plane & *T. 3840 & 14 & 5 & 15 & 1.8 & Granite & Inclined \\
\hline *T. 3421 & 14 & 5 & 1 & 2 & Granite & Plane & *T. 3841 & 15 & 5 & 1 & 2 & Granite & Inclined \\
\hline *T. 3422 & 14 & 5 & 2 & 2 & Granite & Plane & *T. 3842 & 15 & 5 & 2 & 2 & Granite & Inclined \\
\hline *T. 3423 & 14 & 5 & 3 & 2 & Granite & Plane & *T. 3843 & 15 & 5 & 3 & 2 & Granite & Inclined \\
\hline *T. 3424 & 14 & 5 & 4 & 2 & Granite & Plane & *T. 3844 & 15 & 5 & 4 & 2 & Granite & Inclined \\
\hline *T. 3425 & 14 & 5 & 5 & 2 & Granite & Plane & *T. 3845 & 15 & 5 & 5 & 2 & Granite & Inclined \\
\hline *T. 3426 & 13 & 5 & 6 & 2 & Granite & Plane & *T. 3846 & 14 & 5 & 6 & 2 & Granite & Inclined \\
\hline *T. 3427 & 14 & 5 & 7 & 2 & Granite & Plane & *T. 3847 & 15 & 5 & 7 & 2 & Granite & Inclined \\
\hline *T. 3428 & 14 & 5 & 8 & 2 & Granite & Plane & *T. 3848 & 15 & 5 & 8 & 2 & Granite & Inclined \\
\hline
\end{tabular}


Table E.1. (cont.)

\begin{tabular}{|c|c|c|c|c|c|c|c|c|c|c|c|c|c|}
\hline *T. 3429 & 13 & 5 & 9 & 2 & Granite & Plane & *T. 3849 & 14 & 5 & 9 & 2 & Granite & Inclined \\
\hline *T. 3430 & 12 & 5 & 10 & 2 & Granite & Plane & *T. 3850 & 13 & 5 & 10 & 2 & Granite & Inclined \\
\hline *T. 3431 & 13 & 5 & 11 & 2 & Granite & Plane & *T. 3851 & 14 & 5 & 11 & 2 & Granite & Inclined \\
\hline *T. 3432 & 14 & 5 & 12 & 2 & Granite & Plane & *T. 3852 & 15 & 5 & 12 & 2 & Granite & Inclined \\
\hline *T. 3433 & 14 & 5 & 13 & 2 & Granite & Plane & *T. 3853 & 15 & 5 & 13 & 2 & Granite & Inclined \\
\hline *T. 3434 & 13 & 5 & 14 & 2 & Granite & Plane & *T. 3854 & 14 & 5 & 14 & 2 & Granite & Inclined \\
\hline *T. 3435 & 13 & 5 & 15 & 2 & Granite & Plane & *T. 3855 & 14 & 5 & 15 & 2 & Granite & Inclined \\
\hline *T. 3436 & 14 & 5 & 1 & 2.3 & Granite & Plane & *T. 3856 & 15 & 5 & 1 & 2.3 & Granite & Inclined \\
\hline *T. 3437 & 14 & 5 & 2 & 2.3 & Granite & Plane & *T. 3857 & 15 & 5 & 2 & 2.3 & Granite & Inclined \\
\hline *T. 3438 & 14 & 5 & 3 & 2.3 & Granite & Plane & *T. 3858 & 15 & 5 & 3 & 2.3 & Granite & Inclined \\
\hline *T. 3439 & 14 & 5 & 4 & 2.3 & Granite & Plane & *T. 3859 & 15 & 5 & 4 & 2.3 & Granite & Inclined \\
\hline *T. 3440 & 14 & 5 & 5 & 2.3 & Granite & Plane & ${ }^{*}$ T. 3860 & 15 & 5 & 5 & 2.3 & Granite & Inclined \\
\hline *T. 3441 & 13 & 5 & 6 & 2.3 & Granite & Plane & *T. 3861 & 14 & 5 & 6 & 2.3 & Granite & Inclined \\
\hline *T. 3442 & 14 & 5 & 7 & 2.3 & Granite & Plane & *T. 3862 & 15 & 5 & 7 & 2.3 & Granite & Inclined \\
\hline *T. 3443 & 14 & 5 & 8 & 2.3 & Granite & Plane & ${ }^{*} \mathrm{~T} .3863$ & 15 & 5 & 8 & 2.3 & Granite & Inclined \\
\hline *T. 3444 & 13 & 5 & 9 & 2.3 & Granite & Plane & ${ }^{*} \mathrm{~T} .3864$ & 14 & 5 & 9 & 2.3 & Granite & Inclined \\
\hline *T. 3445 & 12 & 5 & 10 & 2.3 & Granite & Plane & *T. 3865 & 13 & 5 & 10 & 2.3 & Granite & Inclined \\
\hline *T. 3446 & 12 & 5 & 11 & 2.3 & Granite & Plane & *T. 3866 & 13 & 5 & 11 & 2.3 & Granite & Inclined \\
\hline *T. 3447 & 14 & 5 & 12 & 2.3 & Granite & Plane & *T. 3867 & 15 & 5 & 12 & 2.3 & Granite & Inclined \\
\hline *T. 3448 & 14 & 5 & 13 & 2.3 & Granite & Plane & ${ }^{*} \mathrm{~T} .3868$ & 15 & 5 & 13 & 2.3 & Granite & Inclined \\
\hline *T. 3449 & 12 & 5 & 14 & 2.3 & Granite & Plane & ${ }^{*} \mathrm{~T} .3869$ & 13 & 5 & 14 & 2.3 & Granite & Inclined \\
\hline *T. 3450 & 12 & 5 & 15 & 2.3 & Granite & Plane & *T. 3870 & 13 & 5 & 15 & 2.3 & Granite & Inclined \\
\hline T. 3451 & 13 & 5 & 1 & 2.5 & Granite & Plane & T. 3871 & 14 & 5 & 1 & 2.5 & Granite & Inclined \\
\hline T. 3452 & 13 & 5 & 2 & 2.5 & Granite & Plane & T. 3872 & 14 & 5 & 2 & 2.5 & Granite & Inclined \\
\hline T. 3453 & 13 & 5 & 3 & 2.5 & Granite & Plane & T. 3873 & 14 & 5 & 3 & 2.5 & Granite & Inclined \\
\hline T. 3454 & 13 & 5 & 4 & 2.5 & Granite & Plane & T. 3874 & 14 & 5 & 4 & 2.5 & Granite & Inclined \\
\hline T. 3455 & 13 & 5 & 5 & 2.5 & Granite & Plane & T. 3875 & 14 & 5 & 5 & 2.5 & Granite & Inclined \\
\hline T. 3456 & 12 & 5 & 6 & 2.5 & Granite & Plane & T. 3876 & 13 & 5 & 6 & 2.5 & Granite & Inclined \\
\hline T. 3457 & 13 & 5 & 7 & 2.5 & Granite & Plane & T. 3877 & 14 & 5 & 7 & 2.5 & Granite & Inclined \\
\hline T. 3458 & 13 & 5 & 8 & 2.5 & Granite & Plane & T. 3878 & 14 & 5 & 8 & 2.5 & Granite & Inclined \\
\hline T. 3459 & 12 & 5 & 9 & 2.5 & Granite & Plane & T. 3879 & 13 & 5 & 9 & 2.5 & Granite & Inclined \\
\hline T. 3460 & 11 & 5 & 10 & 2.5 & Granite & Plane & T. 3880 & 12 & 5 & 10 & 2.5 & Granite & Inclined \\
\hline T. 3461 & 12 & 5 & 11 & 2.5 & Granite & Plane & T. 3881 & 13 & 5 & 11 & 2.5 & Granite & Inclined \\
\hline
\end{tabular}


Table E.1. (cont.)

\begin{tabular}{|c|c|c|c|c|c|c|c|c|c|c|c|c|c|}
\hline T. 3462 & 13 & 5 & 12 & 2.5 & Granite & Plane & T. 3882 & 14 & 5 & 12 & 2.5 & Granite & Inclined \\
\hline T. 3463 & 13 & 5 & 13 & 2.5 & Granite & Plane & T. 3883 & 14 & 5 & 13 & 2.5 & Granite & Inclined \\
\hline T. 3464 & 12 & 5 & 14 & 2.5 & Granite & Plane & T. 3884 & 13 & 5 & 14 & 2.5 & Granite & Inclined \\
\hline T. 3465 & 12 & 5 & 15 & 2.5 & Granite & Plane & T. 3885 & 13 & 5 & 15 & 2.5 & Granite & Inclined \\
\hline T. 3466 & 12 & 5 & 1 & 1 & Limestone & Plane & T. 3886 & 13 & 5 & 1 & 1 & Limestone & Inclined \\
\hline T. 3467 & 12 & 5 & 2 & 1 & Limestone & Plane & T. 3887 & 13 & 5 & 2 & 1 & Limestone & Inclined \\
\hline T. 3468 & 12 & 5 & 3 & 1 & Limestone & Plane & T. 3888 & 13 & 5 & 3 & 1 & Limestone & Inclined \\
\hline T. 3469 & 12 & 5 & 4 & 1 & Limestone & Plane & T. 3889 & 13 & 5 & 4 & 1 & Limestone & Inclined \\
\hline T. 3470 & 12 & 5 & 5 & 1 & Limestone & Plane & T. 3890 & 13 & 5 & 5 & 1 & Limestone & Inclined \\
\hline T. 3471 & 11 & 5 & 6 & 1 & Limestone & Plane & T. 3891 & 12 & 5 & 6 & 1 & Limestone & Inclined \\
\hline T. 3472 & 12 & 5 & 7 & 1 & Limestone & Plane & T. 3892 & 13 & 5 & 7 & 1 & Limestone & Inclined \\
\hline T. 3473 & 12 & 5 & 8 & 1 & Limestone & Plane & T. 3893 & 13 & 5 & 8 & 1 & Limestone & Inclined \\
\hline T. 3474 & 11 & 5 & 9 & 1 & Limestone & Plane & T. 3894 & 12 & 5 & 9 & 1 & Limestone & Inclined \\
\hline T. 3475 & 10 & 5 & 10 & 1 & Limestone & Plane & T. 3895 & 11 & 5 & 10 & 1 & Limestone & Inclined \\
\hline T. 3476 & 10 & 5 & 11 & 1 & Limestone & Plane & T. 3896 & 11 & 5 & 11 & 1 & Limestone & Inclined \\
\hline T. 3477 & 12 & 5 & 12 & 1 & Limestone & Plane & T. 3897 & 13 & 5 & 12 & 1 & Limestone & Inclined \\
\hline T. 3478 & 12 & 5 & 13 & 1 & Limestone & Plane & T. 3898 & 13 & 5 & 13 & 1 & Limestone & Inclined \\
\hline T. 3479 & 10 & 5 & 14 & 1 & Limestone & Plane & T. 3899 & 11 & 5 & 14 & 1 & Limestone & Inclined \\
\hline T. 3480 & 10 & 5 & 15 & 1 & Limestone & Plane & T. 3900 & 11 & 5 & 15 & 1 & Limestone & Inclined \\
\hline T. 3481 & 13 & 5 & 1 & 1.3 & Limestone & Plane & T. 3901 & 14 & 5 & 1 & 1.3 & Limestone & Inclined \\
\hline T. 3482 & 13 & 5 & 2 & 1.3 & Limestone & Plane & T. 3902 & 14 & 5 & 2 & 1.3 & Limestone & Inclined \\
\hline T. 3483 & 13 & 5 & 3 & 1.3 & Limestone & Plane & T. 3903 & 14 & 5 & 3 & 1.3 & Limestone & Inclined \\
\hline T. 3484 & 13 & 5 & 4 & 1.3 & Limestone & Plane & T. 3904 & 14 & 5 & 4 & 1.3 & Limestone & Inclined \\
\hline T. 3485 & 13 & 5 & 5 & 1.3 & Limestone & Plane & T. 3905 & 14 & 5 & 5 & 1.3 & Limestone & Inclined \\
\hline T. 3486 & 12 & 5 & 6 & 1.3 & Limestone & Plane & T. 3906 & 13 & 5 & 6 & 1.3 & Limestone & Inclined \\
\hline T. 3487 & 13 & 5 & 7 & 1.3 & Limestone & Plane & T. 3907 & 14 & 5 & 7 & 1.3 & Limestone & Inclined \\
\hline T. 3488 & 13 & 5 & 8 & 1.3 & Limestone & Plane & T. 3908 & 14 & 5 & 8 & 1.3 & Limestone & Inclined \\
\hline T. 3489 & 12 & 5 & 9 & 1.3 & Limestone & Plane & T. 3909 & 13 & 5 & 9 & 1.3 & Limestone & Inclined \\
\hline T. 3490 & 11 & 5 & 10 & 1.3 & Limestone & Plane & T. 3910 & 12 & 5 & 10 & 1.3 & Limestone & Inclined \\
\hline T. 3491 & 11 & 5 & 11 & 1.3 & Limestone & Plane & T. 3911 & 12 & 5 & 11 & 1.3 & Limestone & Inclined \\
\hline T. 3492 & 13 & 5 & 12 & 1.3 & Limestone & Plane & T. 3912 & 14 & 5 & 12 & 1.3 & Limestone & Inclined \\
\hline T. 3493 & 13 & 5 & 13 & 1.3 & Limestone & Plane & T. 3913 & 14 & 5 & 13 & 1.3 & Limestone & Inclined \\
\hline T. 3494 & 11 & 5 & 14 & 1.3 & Limestone & Plane & T. 3914 & 12 & 5 & 14 & 1.3 & Limestone & Inclined \\
\hline
\end{tabular}

(cont. on next page) 
Table E.1. (cont.)

\begin{tabular}{|c|c|c|c|c|c|c|c|c|c|c|c|c|c|}
\hline T. 3495 & 11 & 5 & 15 & 1.3 & Limestone & Plane & T. 3915 & 12 & 5 & 15 & 1.3 & Limestone & Inclined \\
\hline *T. 3496 & 15 & 5 & 1 & 1.6 & Limestone & Plane & *T. 3916 & 16 & 5 & 1 & 1.6 & Limestone & Inclined \\
\hline *T. 3497 & 15 & 5 & 2 & 1.6 & Limestone & Plane & *T. 3917 & 16 & 5 & 2 & 1.6 & Limestone & Inclined \\
\hline *T. 3498 & 15 & 5 & 3 & 1.6 & Limestone & Plane & *T. 3918 & 16 & 5 & 3 & 1.6 & Limestone & Inclined \\
\hline *T. 3499 & 15 & 5 & 4 & 1.6 & Limestone & Plane & *T. 3919 & 16 & 5 & 4 & 1.6 & Limestone & Inclined \\
\hline *T. 3500 & 15 & 5 & 5 & 1.6 & Limestone & Plane & *T. 3920 & 16 & 5 & 5 & 1.6 & Limestone & Inclined \\
\hline *T. 3501 & 14 & 5 & 6 & 1.6 & Limestone & Plane & *T. 3921 & 15 & 5 & 6 & 1.6 & Limestone & Inclined \\
\hline *T. 3502 & 15 & 5 & 7 & 1.6 & Limestone & Plane & *T. 3922 & 16 & 5 & 7 & 1.6 & Limestone & Inclined \\
\hline *T. 3503 & 15 & 5 & 8 & 1.6 & Limestone & Plane & *T. 3923 & 16 & 5 & 8 & 1.6 & Limestone & Inclined \\
\hline *T. 3504 & 14 & 5 & 9 & 1.6 & Limestone & Plane & *T. 3924 & 15 & 5 & 9 & 1.6 & Limestone & Inclined \\
\hline *T. 3505 & 12 & 5 & 10 & 1.6 & Limestone & Plane & *T. 3925 & 13 & 5 & 10 & 1.6 & Limestone & Inclined \\
\hline *T. 3506 & 13 & 5 & 11 & 1.6 & Limestone & Plane & *T. 3926 & 14 & 5 & 11 & 1.6 & Limestone & Inclined \\
\hline *T. 3507 & 15 & 5 & 12 & 1.6 & Limestone & Plane & *T. 3927 & 16 & 5 & 12 & 1.6 & Limestone & Inclined \\
\hline *T. 3508 & 15 & 5 & 13 & 1.6 & Limestone & Plane & *T. 3928 & 16 & 5 & 13 & 1.6 & Limestone & Inclined \\
\hline *T. 3509 & 13 & 5 & 14 & 1.6 & Limestone & Plane & *T. 3929 & 14 & 5 & 14 & 1.6 & Limestone & Inclined \\
\hline *T. 3510 & 13 & 5 & 15 & 1.6 & Limestone & Plane & ${ }^{*} \mathrm{~T} .3930$ & 14 & 5 & 15 & 1.6 & Limestone & Inclined \\
\hline *T. 3511 & 15 & 5 & 1 & 1.8 & Limestone & Plane & *T. 3931 & 16 & 5 & 1 & 1.8 & Limestone & Inclined \\
\hline *T. 3512 & 15 & 5 & 2 & 1.8 & Limestone & Plane & *T. 3932 & 16 & 5 & 2 & 1.8 & Limestone & Inclined \\
\hline *T. 3513 & 15 & 5 & 3 & 1.8 & Limestone & Plane & *T. 3933 & 16 & 5 & 3 & 1.8 & Limestone & Inclined \\
\hline *T. 3514 & 15 & 5 & 4 & 1.8 & Limestone & Plane & ${ }^{*} \mathrm{~T} .3934$ & 16 & 5 & 4 & 1.8 & Limestone & Inclined \\
\hline *T. 3515 & 15 & 5 & 5 & 1.8 & Limestone & Plane & ${ }^{*} \mathrm{~T} .3935$ & 16 & 5 & 5 & 1.8 & Limestone & Inclined \\
\hline *T. 3516 & 14 & 5 & 6 & 1.8 & Limestone & Plane & *T. 3936 & 15 & 5 & 6 & 1.8 & Limestone & Inclined \\
\hline *T. 3517 & 15 & 5 & 7 & 1.8 & Limestone & Plane & *T. 3937 & 16 & 5 & 7 & 1.8 & Limestone & Inclined \\
\hline *T. 3518 & 15 & 5 & 8 & 1.8 & Limestone & Plane & *T. 3938 & 16 & 5 & 8 & 1.8 & Limestone & Inclined \\
\hline *T. 3519 & 14 & 5 & 9 & 1.8 & Limestone & Plane & ${ }^{*} \mathrm{~T} .3939$ & 15 & 5 & 9 & 1.8 & Limestone & Inclined \\
\hline *T. 3520 & 12 & 5 & 10 & 1.8 & Limestone & Plane & ${ }^{*} \mathrm{~T} .3940$ & 13 & 5 & 10 & 1.8 & Limestone & Inclined \\
\hline *T. 3521 & 13 & 5 & 11 & 1.8 & Limestone & Plane & *T. 3941 & 14 & 5 & 11 & 1.8 & Limestone & Inclined \\
\hline *T. 3522 & 15 & 5 & 12 & 1.8 & Limestone & Plane & *T. 3942 & 16 & 5 & 12 & 1.8 & Limestone & Inclined \\
\hline *T. 3523 & 15 & 5 & 13 & 1.8 & Limestone & Plane & *T. 3943 & 16 & 5 & 13 & 1.8 & Limestone & Inclined \\
\hline${ }^{*} \mathrm{~T} .3524$ & 13 & 5 & 14 & 1.8 & Limestone & Plane & ${ }^{*} \mathrm{~T} .3944$ & 14 & 5 & 14 & 1.8 & Limestone & Inclined \\
\hline *T. 3525 & 13 & 5 & 15 & 1.8 & Limestone & Plane & *T. 3945 & 14 & 5 & 15 & 1.8 & Limestone & Inclined \\
\hline *T. 3526 & 14 & 5 & 1 & 2 & Limestone & Plane & *T. 3946 & 15 & 5 & 1 & 2 & Limestone & Inclined \\
\hline *T. 3527 & 14 & 5 & 2 & 2 & Limestone & Plane & *T. 3947 & 15 & 5 & 2 & 2 & Limestone & Inclined \\
\hline
\end{tabular}


Table E.1. (cont.)

\begin{tabular}{|c|c|c|c|c|c|c|c|c|c|c|c|c|c|}
\hline *T. 3528 & 14 & 5 & 3 & 2 & Limestone & Plane & *T. 3948 & 15 & 5 & 3 & 2 & Limestone & Inclined \\
\hline *T. 3529 & 14 & 5 & 4 & 2 & Limestone & Plane & *T. 3949 & 15 & 5 & 4 & 2 & Limestone & Inclined \\
\hline *T. 3530 & 14 & 5 & 5 & 2 & Limestone & Plane & *T. 3950 & 15 & 5 & 5 & 2 & Limestone & Inclined \\
\hline *T. 3531 & 13 & 5 & 6 & 2 & Limestone & Plane & *T. 3951 & 14 & 5 & 6 & 2 & Limestone & Inclined \\
\hline *T. 3532 & 14 & 5 & 7 & 2 & Limestone & Plane & *T. 3952 & 15 & 5 & 7 & 2 & Limestone & Inclined \\
\hline *T. 3533 & 14 & 5 & 8 & 2 & Limestone & Plane & *T. 3953 & 15 & 5 & 8 & 2 & Limestone & Inclined \\
\hline *T. 3534 & 13 & 5 & 9 & 2 & Limestone & Plane & *T. 3954 & 14 & 5 & 9 & 2 & Limestone & Inclined \\
\hline *T. 3535 & 12 & 5 & 10 & 2 & Limestone & Plane & *T. 3955 & 13 & 5 & 10 & 2 & Limestone & Inclined \\
\hline *T. 3536 & 13 & 5 & 11 & 2 & Limestone & Plane & *T. 3956 & 14 & 5 & 11 & 2 & Limestone & Inclined \\
\hline *T. 3537 & 14 & 5 & 12 & 2 & Limestone & Plane & *T. 3957 & 15 & 5 & 12 & 2 & Limestone & Inclined \\
\hline *T. 3538 & 14 & 5 & 13 & 2 & Limestone & Plane & *T. 3958 & 15 & 5 & 13 & 2 & Limestone & Inclined \\
\hline *T. 3539 & 13 & 5 & 14 & 2 & Limestone & Plane & *T. 3959 & 14 & 5 & 14 & 2 & Limestone & Inclined \\
\hline *T. 3540 & 13 & 5 & 15 & 2 & Limestone & Plane & *T. 3960 & 14 & 5 & 15 & 2 & Limestone & Inclined \\
\hline *T. 3541 & 14 & 5 & 1 & 2.3 & Limestone & Plane & *T. 3961 & 15 & 5 & 1 & 2.3 & Limestone & Inclined \\
\hline${ }^{*} \mathrm{~T} .3542$ & 14 & 5 & 2 & 2.3 & Limestone & Plane & ${ }^{*} \mathrm{~T} .3962$ & 15 & 5 & 2 & 2.3 & Limestone & Inclined \\
\hline *T. 3543 & 14 & 5 & 3 & 2.3 & Limestone & Plane & *T. 3963 & 15 & 5 & 3 & 2.3 & Limestone & Inclined \\
\hline *T. 3544 & 14 & 5 & 4 & 2.3 & Limestone & Plane & *T. 3964 & 15 & 5 & 4 & 2.3 & Limestone & Inclined \\
\hline *T. 3545 & 14 & 5 & 5 & 2.3 & Limestone & Plane & *T. 3965 & 15 & 5 & 5 & 2.3 & Limestone & Inclined \\
\hline *T. 3546 & 13 & 5 & 6 & 2.3 & Limestone & Plane & *T. 3966 & 14 & 5 & 6 & 2.3 & Limestone & Inclined \\
\hline *T. 3547 & 14 & 5 & 7 & 2.3 & Limestone & Plane & *T. 3967 & 15 & 5 & 7 & 2.3 & Limestone & Inclined \\
\hline *T. 3548 & 14 & 5 & 8 & 2.3 & Limestone & Plane & ${ }^{*} \mathrm{~T} .3968$ & 15 & 5 & 8 & 2.3 & Limestone & Inclined \\
\hline *T. 3549 & 13 & 5 & 9 & 2.3 & Limestone & Plane & *T. 3969 & 14 & 5 & 9 & 2.3 & Limestone & Inclined \\
\hline *T. 3550 & 12 & 5 & 10 & 2.3 & Limestone & Plane & *T. 3970 & 13 & 5 & 10 & 2.3 & Limestone & Inclined \\
\hline *T. 3551 & 12 & 5 & 11 & 2.3 & Limestone & Plane & *T. 3971 & 13 & 5 & 11 & 2.3 & Limestone & Inclined \\
\hline *T. 3552 & 14 & 5 & 12 & 2.3 & Limestone & Plane & *T. 3972 & 15 & 5 & 12 & 2.3 & Limestone & Inclined \\
\hline *T. 3553 & 14 & 5 & 13 & 2.3 & Limestone & Plane & *T. 3973 & 15 & 5 & 13 & 2.3 & Limestone & Inclined \\
\hline *T. 3554 & 12 & 5 & 14 & 2.3 & Limestone & Plane & *T. 3974 & 13 & 5 & 14 & 2.3 & Limestone & Inclined \\
\hline *T. 3555 & 12 & 5 & 15 & 2.3 & Limestone & Plane & *T. 3975 & 13 & 5 & 15 & 2.3 & Limestone & Inclined \\
\hline T. 3556 & 13 & 5 & 1 & 2.5 & Limestone & Plane & T. 3976 & 14 & 5 & 1 & 2.5 & Limestone & Inclined \\
\hline T. 3557 & 13 & 5 & 2 & 2.5 & Limestone & Plane & T. 3977 & 14 & 5 & 2 & 2.5 & Limestone & Inclined \\
\hline T. 3558 & 13 & 5 & 3 & 2.5 & Limestone & Plane & T. 3978 & 14 & 5 & 3 & 2.5 & Limestone & Inclined \\
\hline T. 3559 & 13 & 5 & 4 & 2.5 & Limestone & Plane & T. 3979 & 14 & 5 & 4 & 2.5 & Limestone & Inclined \\
\hline T. 3560 & 13 & 5 & 5 & 2.5 & Limestone & Plane & T. 3980 & 14 & 5 & 5 & 2.5 & Limestone & Inclined \\
\hline
\end{tabular}

(cont. on next page) 
Table E.1. (cont.)

\begin{tabular}{|c|c|c|c|c|c|c|c|c|c|c|c|c|c|}
\hline T. 3561 & 12 & 5 & 6 & 2.5 & Limestone & Plane & T. 3981 & 13 & 5 & 6 & 2.5 & Limestone & Inclined \\
\hline T. 3562 & 13 & 5 & 7 & 2.5 & Limestone & Plane & T. 3982 & 14 & 5 & 7 & 2.5 & Limestone & Inclined \\
\hline T. 3563 & 13 & 5 & 8 & 2.5 & Limestone & Plane & T. 3983 & 14 & 5 & 8 & 2.5 & Limestone & Inclined \\
\hline T. 3564 & 12 & 5 & 9 & 2.5 & Limestone & Plane & T. 3984 & 13 & 5 & 9 & 2.5 & Limestone & Inclined \\
\hline T. 3565 & 11 & 5 & 10 & 2.5 & Limestone & Plane & T. 3985 & 12 & 5 & 10 & 2.5 & Limestone & Inclined \\
\hline T. 3566 & 12 & 5 & 11 & 2.5 & Limestone & Plane & T. 3986 & 13 & 5 & 11 & 2.5 & Limestone & Inclined \\
\hline T. 3567 & 13 & 5 & 12 & 2.5 & Limestone & Plane & T. 3987 & 14 & 5 & 12 & 2.5 & Limestone & Inclined \\
\hline T. 3568 & 13 & 5 & 13 & 2.5 & Limestone & Plane & T. 3988 & 14 & 5 & 13 & 2.5 & Limestone & Inclined \\
\hline T. 3569 & 12 & 5 & 14 & 2.5 & Limestone & Plane & T. 3989 & 13 & 5 & 14 & 2.5 & Limestone & Inclined \\
\hline T. 3570 & 12 & 5 & 15 & 2.5 & Limestone & Plane & T. 3990 & 13 & 5 & 15 & 2.5 & Limestone & Inclined \\
\hline T. 3571 & 12 & 5 & 1 & 1 & Sandstone & Plane & T. 3991 & 13 & 5 & 1 & 1 & Sandstone & Inclined \\
\hline T. 3572 & 12 & 5 & 2 & 1 & Sandstone & Plane & T. 3992 & 13 & 5 & 2 & 1 & Sandstone & Inclined \\
\hline T. 3573 & 12 & 5 & 3 & 1 & Sandstone & Plane & T. 3993 & 13 & 5 & 3 & 1 & Sandstone & Inclined \\
\hline T. 3574 & 12 & 5 & 4 & 1 & Sandstone & Plane & T. 3994 & 13 & 5 & 4 & 1 & Sandstone & Inclined \\
\hline T. 3575 & 12 & 5 & 5 & 1 & Sandstone & Plane & T. 3995 & 13 & 5 & 5 & 1 & Sandstone & Inclined \\
\hline T. 3576 & 11 & 5 & 6 & 1 & Sandstone & Plane & T. 3996 & 12 & 5 & 6 & 1 & Sandstone & Inclined \\
\hline T. 3577 & 12 & 5 & 7 & 1 & Sandstone & Plane & T. 3997 & 13 & 5 & 7 & 1 & Sandstone & Inclined \\
\hline T. 3578 & 12 & 5 & 8 & 1 & Sandstone & Plane & T. 3998 & 13 & 5 & 8 & 1 & Sandstone & Inclined \\
\hline T. 3579 & 11 & 5 & 9 & 1 & Sandstone & Plane & T. 3999 & 12 & 5 & 9 & 1 & Sandstone & Inclined \\
\hline T. 3580 & 10 & 5 & 10 & 1 & Sandstone & Plane & T. 4000 & 11 & 5 & 10 & 1 & Sandstone & Inclined \\
\hline T. 3581 & 10 & 5 & 11 & 1 & Sandstone & Plane & T. 4001 & 11 & 5 & 11 & 1 & Sandstone & Inclined \\
\hline T. 3582 & 12 & 5 & 12 & 1 & Sandstone & Plane & T. 4002 & 13 & 5 & 12 & 1 & Sandstone & Inclined \\
\hline T. 3583 & 12 & 5 & 13 & 1 & Sandstone & Plane & T. 4003 & 13 & 5 & 13 & 1 & Sandstone & Inclined \\
\hline T. 3584 & 10 & 5 & 14 & 1 & Sandstone & Plane & T. 4004 & 11 & 5 & 14 & 1 & Sandstone & Inclined \\
\hline T. 3585 & 10 & 5 & 15 & 1 & Sandstone & Plane & T. 4005 & 11 & 5 & 15 & 1 & Sandstone & Inclined \\
\hline T. 3586 & 13 & 5 & 1 & 1.3 & Sandstone & Plane & T. 4006 & 14 & 5 & 1 & 1.3 & Sandstone & Inclined \\
\hline T. 3587 & 13 & 5 & 2 & 1.3 & Sandstone & Plane & T. 4007 & 14 & 5 & 2 & 1.3 & Sandstone & Inclined \\
\hline T. 3588 & 13 & 5 & 3 & 1.3 & Sandstone & Plane & T. 4008 & 14 & 5 & 3 & 1.3 & Sandstone & Inclined \\
\hline T. 3589 & 13 & 5 & 4 & 1.3 & Sandstone & Plane & T. 4009 & 14 & 5 & 4 & 1.3 & Sandstone & Inclined \\
\hline T. 3590 & 13 & 5 & 5 & 1.3 & Sandstone & Plane & T. 4010 & 14 & 5 & 5 & 1.3 & Sandstone & Inclined \\
\hline T. 3591 & 12 & 5 & 6 & 1.3 & Sandstone & Plane & T. 4011 & 13 & 5 & 6 & 1.3 & Sandstone & Inclined \\
\hline T. 3592 & 13 & 5 & 7 & 1.3 & Sandstone & Plane & T. 4012 & 14 & 5 & 7 & 1.3 & Sandstone & Inclined \\
\hline T. 3593 & 13 & 5 & 8 & 1.3 & Sandstone & Plane & T. 4013 & 14 & 5 & 8 & 1.3 & Sandstone & Inclined \\
\hline
\end{tabular}

(cont. on next page) 
Table E.1. (cont.)

\begin{tabular}{|c|c|c|c|c|c|c|c|c|c|c|c|c|c|}
\hline T. 3594 & 12 & 5 & 9 & 1.3 & Sandstone & Plane & T. 4014 & 13 & 5 & 9 & 1.3 & Sandstone & Inclined \\
\hline T. 3595 & 11 & 5 & 10 & 1.3 & Sandstone & Plane & T. 4015 & 12 & 5 & 10 & 1.3 & Sandstone & Inclined \\
\hline T. 3596 & 11 & 5 & 11 & 1.3 & Sandstone & Plane & T. 4016 & 12 & 5 & 11 & 1.3 & Sandstone & Inclined \\
\hline T. 3597 & 13 & 5 & 12 & 1.3 & Sandstone & Plane & T. 4017 & 14 & 5 & 12 & 1.3 & Sandstone & Inclined \\
\hline T. 3598 & 13 & 5 & 13 & 1.3 & Sandstone & Plane & T. 4018 & 14 & 5 & 13 & 1.3 & Sandstone & Inclined \\
\hline T. 3599 & 11 & 5 & 14 & 1.3 & Sandstone & Plane & T. 4019 & 12 & 5 & 14 & 1.3 & Sandstone & Inclined \\
\hline T. 3600 & 11 & 5 & 15 & 1.3 & Sandstone & Plane & T. 4020 & 12 & 5 & 15 & 1.3 & Sandstone & Inclined \\
\hline T. 3601 & 15 & 5 & 1 & 1.6 & Sandstone & Plane & T. 4021 & 16 & 5 & 1 & 1.6 & Sandstone & Inclined \\
\hline T. 3602 & 15 & 5 & 2 & 1.6 & Sandstone & Plane & T. 4022 & 16 & 5 & 2 & 1.6 & Sandstone & Inclined \\
\hline T. 3603 & 15 & 5 & 3 & 1.6 & Sandstone & Plane & T. 4023 & 16 & 5 & 3 & 1.6 & Sandstone & Inclined \\
\hline T. 3604 & 15 & 5 & 4 & 1.6 & Sandstone & Plane & T. 4024 & 16 & 5 & 4 & 1.6 & Sandstone & Inclined \\
\hline T. 3605 & 15 & 5 & 5 & 1.6 & Sandstone & Plane & T. 4025 & 16 & 5 & 5 & 1.6 & Sandstone & Inclined \\
\hline T. 3606 & 14 & 5 & 6 & 1.6 & Sandstone & Plane & T. 4026 & 15 & 5 & 6 & 1.6 & Sandstone & Inclined \\
\hline T. 3607 & 15 & 5 & 7 & 1.6 & Sandstone & Plane & T. 4027 & 16 & 5 & 7 & 1.6 & Sandstone & Inclined \\
\hline T. 3608 & 15 & 5 & 8 & 1.6 & Sandstone & Plane & T. 4028 & 16 & 5 & 8 & 1.6 & Sandstone & Inclined \\
\hline T. 3609 & 14 & 5 & 9 & 1.6 & Sandstone & Plane & T. 4029 & 15 & 5 & 9 & 1.6 & Sandstone & Inclined \\
\hline T. 3610 & 12 & 5 & 10 & 1.6 & Sandstone & Plane & T. 4030 & 13 & 5 & 10 & 1.6 & Sandstone & Inclined \\
\hline T. 3611 & 13 & 5 & 11 & 1.6 & Sandstone & Plane & T. 4031 & 14 & 5 & 11 & 1.6 & Sandstone & Inclined \\
\hline T. 3612 & 15 & 5 & 12 & 1.6 & Sandstone & Plane & T. 4032 & 16 & 5 & 12 & 1.6 & Sandstone & Inclined \\
\hline T. 3613 & 15 & 5 & 13 & 1.6 & Sandstone & Plane & T. 4033 & 16 & 5 & 13 & 1.6 & Sandstone & Inclined \\
\hline T. 3614 & 13 & 5 & 14 & 1.6 & Sandstone & Plane & T. 4034 & 14 & 5 & 14 & 1.6 & Sandstone & Inclined \\
\hline T. 3615 & 13 & 5 & 15 & 1.6 & Sandstone & Plane & T. 4035 & 14 & 5 & 15 & 1.6 & Sandstone & Inclined \\
\hline T. 3616 & 15 & 5 & 1 & 1.8 & Sandstone & Plane & T. 4036 & 16 & 5 & 1 & 1.8 & Sandstone & Inclined \\
\hline T. 3617 & 15 & 5 & 2 & 1.8 & Sandstone & Plane & T. 4037 & 16 & 5 & 2 & 1.8 & Sandstone & Inclined \\
\hline T. 3618 & 15 & 5 & 3 & 1.8 & Sandstone & Plane & T. 4038 & 16 & 5 & 3 & 1.8 & Sandstone & Inclined \\
\hline T. 3619 & 15 & 5 & 4 & 1.8 & Sandstone & Plane & T. 4039 & 16 & 5 & 4 & 1.8 & Sandstone & Inclined \\
\hline T. 3620 & 15 & 5 & 5 & 1.8 & Sandstone & Plane & T. 4040 & 16 & 5 & 5 & 1.8 & Sandstone & Inclined \\
\hline T. 3621 & 14 & 5 & 6 & 1.8 & Sandstone & Plane & T. 4041 & 15 & 5 & 6 & 1.8 & Sandstone & Inclined \\
\hline T. 3622 & 15 & 5 & 7 & 1.8 & Sandstone & Plane & T. 4042 & 16 & 5 & 7 & 1.8 & Sandstone & Inclined \\
\hline T. 3623 & 15 & 5 & 8 & 1.8 & Sandstone & Plane & T. 4043 & 16 & 5 & 8 & 1.8 & Sandstone & Inclined \\
\hline T. 3624 & 14 & 5 & 9 & 1.8 & Sandstone & Plane & T. 4044 & 15 & 5 & 9 & 1.8 & Sandstone & Inclined \\
\hline T. 3625 & 12 & 5 & 10 & 1.8 & Sandstone & Plane & T. 4045 & 13 & 5 & 10 & 1.8 & Sandstone & Inclined \\
\hline T. 3626 & 13 & 5 & 11 & 1.8 & Sandstone & Plane & T. 4046 & 14 & 5 & 11 & 1.8 & Sandstone & Inclined \\
\hline
\end{tabular}

(cont. on next page) 
Table E.1. (cont.)

\begin{tabular}{|c|c|c|c|c|c|c|c|c|c|c|c|c|c|}
\hline T. 3627 & 15 & 5 & 12 & 1.8 & Sandstone & Plane & T. 4047 & 16 & 5 & 12 & 1.8 & Sandstone & Inclined \\
\hline T. 3628 & 15 & 5 & 13 & 1.8 & Sandstone & Plane & T. 4048 & 16 & 5 & 13 & 1.8 & Sandstone & Inclined \\
\hline T. 3629 & 13 & 5 & 14 & 1.8 & Sandstone & Plane & T. 4049 & 14 & 5 & 14 & 1.8 & Sandstone & Inclined \\
\hline T. 3630 & 13 & 5 & 15 & 1.8 & Sandstone & Plane & T. 4050 & 14 & 5 & 15 & 1.8 & Sandstone & Inclined \\
\hline T. 3631 & 14 & 5 & 1 & 2 & Sandstone & Plane & T. 4051 & 15 & 5 & 1 & 2 & Sandstone & Inclined \\
\hline T. 3632 & 14 & 5 & 2 & 2 & Sandstone & Plane & T. 4052 & 15 & 5 & 2 & 2 & Sandstone & Inclined \\
\hline T. 3633 & 14 & 5 & 3 & 2 & Sandstone & Plane & T. 4053 & 15 & 5 & 3 & 2 & Sandstone & Inclined \\
\hline T. 3634 & 14 & 5 & 4 & 2 & Sandstone & Plane & T. 4054 & 15 & 5 & 4 & 2 & Sandstone & Inclined \\
\hline T. 3635 & 14 & 5 & 5 & 2 & Sandstone & Plane & T. 4055 & 15 & 5 & 5 & 2 & Sandstone & Inclined \\
\hline T. 3636 & 13 & 5 & 6 & 2 & Sandstone & Plane & T. 4056 & 14 & 5 & 6 & 2 & Sandstone & Inclined \\
\hline T. 3637 & 14 & 5 & 7 & 2 & Sandstone & Plane & T. 4057 & 15 & 5 & 7 & 2 & Sandstone & Inclined \\
\hline T. 3638 & 14 & 5 & 8 & 2 & Sandstone & Plane & T. 4058 & 15 & 5 & 8 & 2 & Sandstone & Inclined \\
\hline T. 3639 & 13 & 5 & 9 & 2 & Sandstone & Plane & T. 4059 & 14 & 5 & 9 & 2 & Sandstone & Inclined \\
\hline T. 3640 & 12 & 5 & 10 & 2 & Sandstone & Plane & T. 4060 & 13 & 5 & 10 & 2 & Sandstone & Inclined \\
\hline T. 3641 & 13 & 5 & 11 & 2 & Sandstone & Plane & T. 4061 & 14 & 5 & 11 & 2 & Sandstone & Inclined \\
\hline T. 3642 & 14 & 5 & 12 & 2 & Sandstone & Plane & T. 4062 & 15 & 5 & 12 & 2 & Sandstone & Inclined \\
\hline T. 3643 & 14 & 5 & 13 & 2 & Sandstone & Plane & T. 4063 & 15 & 5 & 13 & 2 & Sandstone & Inclined \\
\hline T. 3644 & 13 & 5 & 14 & 2 & Sandstone & Plane & T. 4064 & 14 & 5 & 14 & 2 & Sandstone & Inclined \\
\hline T. 3645 & 13 & 5 & 15 & 2 & Sandstone & Plane & T. 4065 & 14 & 5 & 15 & 2 & Sandstone & Inclined \\
\hline T. 3646 & 14 & 5 & 1 & 2.3 & Sandstone & Plane & T. 4066 & 15 & 5 & 1 & 2.3 & Sandstone & Inclined \\
\hline T. 3647 & 14 & 5 & 2 & 2.3 & Sandstone & Plane & T. 4067 & 15 & 5 & 2 & 2.3 & Sandstone & Inclined \\
\hline T. 3648 & 14 & 5 & 3 & 2.3 & Sandstone & Plane & T. 4068 & 15 & 5 & 3 & 2.3 & Sandstone & Inclined \\
\hline T. 3649 & 14 & 5 & 4 & 2.3 & Sandstone & Plane & T. 4069 & 15 & 5 & 4 & 2.3 & Sandstone & Inclined \\
\hline T. 3650 & 14 & 5 & 5 & 2.3 & Sandstone & Plane & T. 4070 & 15 & 5 & 5 & 2.3 & Sandstone & Inclined \\
\hline T. 3651 & 13 & 5 & 6 & 2.3 & Sandstone & Plane & T. 4071 & 14 & 5 & 6 & 2.3 & Sandstone & Inclined \\
\hline T. 3652 & 14 & 5 & 7 & 2.3 & Sandstone & Plane & T. 4072 & 15 & 5 & 7 & 2.3 & Sandstone & Inclined \\
\hline T. 3653 & 14 & 5 & 8 & 2.3 & Sandstone & Plane & T. 4073 & 15 & 5 & 8 & 2.3 & Sandstone & Inclined \\
\hline T. 3654 & 13 & 5 & 9 & 2.3 & Sandstone & Plane & T. 4074 & 14 & 5 & 9 & 2.3 & Sandstone & Inclined \\
\hline T. 3655 & 12 & 5 & 10 & 2.3 & Sandstone & Plane & T. 4075 & 13 & 5 & 10 & 2.3 & Sandstone & Inclined \\
\hline T. 3656 & 12 & 5 & 11 & 2.3 & Sandstone & Plane & T. 4076 & 13 & 5 & 11 & 2.3 & Sandstone & Inclined \\
\hline T. 3657 & 14 & 5 & 12 & 2.3 & Sandstone & Plane & T. 4077 & 15 & 5 & 12 & 2.3 & Sandstone & Inclined \\
\hline T. 3658 & 14 & 5 & 13 & 2.3 & Sandstone & Plane & T. 4078 & 15 & 5 & 13 & 2.3 & Sandstone & Inclined \\
\hline T. 3659 & 12 & 5 & 14 & 2.3 & Sandstone & Plane & T. 4079 & 13 & 5 & 14 & 2.3 & Sandstone & Inclined \\
\hline
\end{tabular}

(cont. on next page) 
Table E.1. (cont.)

\begin{tabular}{|c|c|c|c|c|c|c|c|c|c|c|c|c|c|}
\hline T. 3660 & 12 & 5 & 15 & 2.3 & Sandstone & Plane & T. 4080 & 13 & 5 & 15 & 2.3 & Sandstone & Inclined \\
\hline T. 3661 & 13 & 5 & 1 & 2.5 & Sandstone & Plane & T. 4081 & 14 & 5 & 1 & 2.5 & Sandstone & Inclined \\
\hline T. 3662 & 13 & 5 & 2 & 2.5 & Sandstone & Plane & T. 4082 & 14 & 5 & 2 & 2.5 & Sandstone & Inclined \\
\hline T. 3663 & 13 & 5 & 3 & 2.5 & Sandstone & Plane & T. 4083 & 14 & 5 & 3 & 2.5 & Sandstone & Inclined \\
\hline T. 3664 & 13 & 5 & 4 & 2.5 & Sandstone & Plane & T. 4084 & 14 & 5 & 4 & 2.5 & Sandstone & Inclined \\
\hline T. 3665 & 13 & 5 & 5 & 2.5 & Sandstone & Plane & T. 4085 & 14 & 5 & 5 & 2.5 & Sandstone & Inclined \\
\hline T. 3666 & 12 & 5 & 6 & 2.5 & Sandstone & Plane & T. 4086 & 13 & 5 & 6 & 2.5 & Sandstone & Inclined \\
\hline T. 3667 & 13 & 5 & 7 & 2.5 & Sandstone & Plane & T. 4087 & 14 & 5 & 7 & 2.5 & Sandstone & Inclined \\
\hline T. 3668 & 13 & 5 & 8 & 2.5 & Sandstone & Plane & T. 4088 & 14 & 5 & 8 & 2.5 & Sandstone & Inclined \\
\hline T. 3669 & 12 & 5 & 9 & 2.5 & Sandstone & Plane & T. 4089 & 13 & 5 & 9 & 2.5 & Sandstone & Inclined \\
\hline T. 3670 & 11 & 5 & 10 & 2.5 & Sandstone & Plane & T. 4090 & 12 & 5 & 10 & 2.5 & Sandstone & Inclined \\
\hline T. 3671 & 12 & 5 & 11 & 2.5 & Sandstone & Plane & T. 4091 & 13 & 5 & 11 & 2.5 & Sandstone & Inclined \\
\hline T. 3672 & 13 & 5 & 12 & 2.5 & Sandstone & Plane & T. 4092 & 14 & 5 & 12 & 2.5 & Sandstone & Inclined \\
\hline T. 3673 & 13 & 5 & 13 & 2.5 & Sandstone & Plane & T. 4093 & 14 & 5 & 13 & 2.5 & Sandstone & Inclined \\
\hline T. 3674 & 12 & 5 & 14 & 2.5 & Sandstone & Plane & T. 4094 & 13 & 5 & 14 & 2.5 & Sandstone & Inclined \\
\hline T. 3675 & 12 & 5 & 15 & 2.5 & Sandstone & Plane & T. 4095 & 13 & 5 & 15 & 2.5 & Sandstone & Inclined \\
\hline T. 3676 & 11 & 5 & 1 & 1 & Brick & Plane & T. 4096 & 12 & 5 & 1 & 1 & Brick & Inclined \\
\hline T. 3677 & 11 & 5 & 2 & 1 & Brick & Plane & T. 4097 & 12 & 5 & 2 & 1 & Brick & Inclined \\
\hline T. 3678 & 11 & 5 & 3 & 1 & Brick & Plane & T. 4098 & 12 & 5 & 3 & 1 & Brick & Inclined \\
\hline T. 3679 & 11 & 5 & 4 & 1 & Brick & Plane & T. 4099 & 12 & 5 & 4 & 1 & Brick & Inclined \\
\hline T. 3680 & 11 & 5 & 5 & 1 & Brick & Plane & T. 4100 & 12 & 5 & 5 & 1 & Brick & Inclined \\
\hline T. 3681 & 10 & 5 & 6 & 1 & Brick & Plane & T. 4101 & 11 & 5 & 6 & 1 & Brick & Inclined \\
\hline T. 3682 & 11 & 5 & 7 & 1 & Brick & Plane & T. 4102 & 12 & 5 & 7 & 1 & Brick & Inclined \\
\hline T. 3683 & 11 & 5 & 8 & 1 & Brick & Plane & T. 4103 & 12 & 5 & 8 & 1 & Brick & Inclined \\
\hline T. 3684 & 10 & 5 & 9 & 1 & Brick & Plane & T. 4104 & 11 & 5 & 9 & 1 & Brick & Inclined \\
\hline T. 3685 & 9 & 5 & 10 & 1 & Brick & Plane & T. 4105 & 10 & 5 & 10 & 1 & Brick & Inclined \\
\hline T. 3686 & 9 & 5 & 11 & 1 & Brick & Plane & T. 4106 & 10 & 5 & 11 & 1 & Brick & Inclined \\
\hline T. 3687 & 11 & 5 & 12 & 1 & Brick & Plane & T. 4107 & 12 & 5 & 12 & 1 & Brick & Inclined \\
\hline T. 3688 & 11 & 5 & 13 & 1 & Brick & Plane & T. 4108 & 12 & 5 & 13 & 1 & Brick & Inclined \\
\hline T. 3689 & 9 & 5 & 14 & 1 & Brick & Plane & T. 4109 & 10 & 5 & 14 & 1 & Brick & Inclined \\
\hline T. 3690 & 9 & 5 & 15 & 1 & Brick & Plane & T. 4110 & 10 & 5 & 15 & 1 & Brick & Inclined \\
\hline T. 3691 & 12 & 5 & 1 & 1.3 & Brick & Plane & T. 4111 & 13 & 5 & 1 & 1.3 & Brick & Inclined \\
\hline T. 3692 & 12 & 5 & 2 & 1.3 & Brick & Plane & T. 4112 & 13 & 5 & 2 & 1.3 & Brick & Inclined \\
\hline
\end{tabular}

(cont. on next page) 
Table E.1. (cont.)

\begin{tabular}{|c|c|c|c|c|c|c|c|c|c|c|c|c|c|}
\hline T. 3693 & 12 & 5 & 3 & 1.3 & Brick & Plane & T. 4113 & 13 & 5 & 3 & 1.3 & Brick & Inclined \\
\hline T. 3694 & 12 & 5 & 4 & 1.3 & Brick & Plane & T. 4114 & 13 & 5 & 4 & 1.3 & Brick & Inclined \\
\hline T. 3695 & 12 & 5 & 5 & 1.3 & Brick & Plane & T. 4115 & 13 & 5 & 5 & 1.3 & Brick & Inclined \\
\hline T. 3696 & 11 & 5 & 6 & 1.3 & Brick & Plane & T. 4116 & 12 & 5 & 6 & 1.3 & Brick & Inclined \\
\hline T. 3697 & 12 & 5 & 7 & 1.3 & Brick & Plane & T. 4117 & 13 & 5 & 7 & 1.3 & Brick & Inclined \\
\hline T. 3698 & 12 & 5 & 8 & 1.3 & Brick & Plane & T. 4118 & 13 & 5 & 8 & 1.3 & Brick & Inclined \\
\hline T. 3699 & 11 & 5 & 9 & 1.3 & Brick & Plane & T. 4119 & 12 & 5 & 9 & 1.3 & Brick & Inclined \\
\hline T. 3700 & 10 & 5 & 10 & 1.3 & Brick & Plane & T. 4120 & 11 & 5 & 10 & 1.3 & Brick & Inclined \\
\hline Т. 3701 & 10 & 5 & 11 & 1.3 & Brick & Plane & T. 4121 & 11 & 5 & 11 & 1.3 & Brick & Inclined \\
\hline T. 3702 & 12 & 5 & 12 & 1.3 & Brick & Plane & T. 4122 & 13 & 5 & 12 & 1.3 & Brick & Inclined \\
\hline T. 3703 & 12 & 5 & 13 & 1.3 & Brick & Plane & T. 4123 & 13 & 5 & 13 & 1.3 & Brick & Inclined \\
\hline T. 3704 & 10 & 5 & 14 & 1.3 & Brick & Plane & T. 4124 & 11 & 5 & 14 & 1.3 & Brick & Inclined \\
\hline T. 3705 & 10 & 5 & 15 & 1.3 & Brick & Plane & T. 4125 & 11 & 5 & 15 & 1.3 & Brick & Inclined \\
\hline T. 3706 & 14 & 5 & 1 & 1.6 & Brick & Plane & T. 4126 & 15 & 5 & 1 & 1.6 & Brick & Inclined \\
\hline T. 3707 & 14 & 5 & 2 & 1.6 & Brick & Plane & T. 4127 & 15 & 5 & 2 & 1.6 & Brick & Inclined \\
\hline T. 3708 & 14 & 5 & 3 & 1.6 & Brick & Plane & T. 4128 & 15 & 5 & 3 & 1.6 & Brick & Inclined \\
\hline T. 3709 & 14 & 5 & 4 & 1.6 & Brick & Plane & T. 4129 & 15 & 5 & 4 & 1.6 & Brick & Inclined \\
\hline T. 3710 & 14 & 5 & 5 & 1.6 & Brick & Plane & T. 4130 & 15 & 5 & 5 & 1.6 & Brick & Inclined \\
\hline T. 3711 & 13 & 5 & 6 & 1.6 & Brick & Plane & T. 4131 & 14 & 5 & 6 & 1.6 & Brick & Inclined \\
\hline T. 3712 & 14 & 5 & 7 & 1.6 & Brick & Plane & T. 4132 & 15 & 5 & 7 & 1.6 & Brick & Inclined \\
\hline T. 3713 & 14 & 5 & 8 & 1.6 & Brick & Plane & T. 4133 & 15 & 5 & 8 & 1.6 & Brick & Inclined \\
\hline T. 3714 & 13 & 5 & 9 & 1.6 & Brick & Plane & T. 4134 & 14 & 5 & 9 & 1.6 & Brick & Inclined \\
\hline T. 3715 & 11 & 5 & 10 & 1.6 & Brick & Plane & T. 4135 & 12 & 5 & 10 & 1.6 & Brick & Inclined \\
\hline T. 3716 & 12 & 5 & 11 & 1.6 & Brick & Plane & T. 4136 & 13 & 5 & 11 & 1.6 & Brick & Inclined \\
\hline T. 3717 & 14 & 5 & 12 & 1.6 & Brick & Plane & T. 4137 & 15 & 5 & 12 & 1.6 & Brick & Inclined \\
\hline T. 3718 & 14 & 5 & 13 & 1.6 & Brick & Plane & T. 4138 & 15 & 5 & 13 & 1.6 & Brick & Inclined \\
\hline T. 3719 & 12 & 5 & 14 & 1.6 & Brick & Plane & T. 4139 & 13 & 5 & 14 & 1.6 & Brick & Inclined \\
\hline T. 3720 & 12 & 5 & 15 & 1.6 & Brick & Plane & T. 4140 & 13 & 5 & 15 & 1.6 & Brick & Inclined \\
\hline T. 3721 & 14 & 5 & 1 & 1.8 & Brick & Plane & T. 4141 & 15 & 5 & 1 & 1.8 & Brick & Inclined \\
\hline T. 3722 & 14 & 5 & 2 & 1.8 & Brick & Plane & T. 4142 & 15 & 5 & 2 & 1.8 & Brick & Inclined \\
\hline T. 3723 & 14 & 5 & 3 & 1.8 & Brick & Plane & T. 4143 & 15 & 5 & 3 & 1.8 & Brick & Inclined \\
\hline T. 3724 & 14 & 5 & 4 & 1.8 & Brick & Plane & T. 4144 & 15 & 5 & 4 & 1.8 & Brick & Inclined \\
\hline T. 3725 & 14 & 5 & 5 & 1.8 & Brick & Plane & T. 4145 & 15 & 5 & 5 & 1.8 & Brick & Inclined \\
\hline
\end{tabular}

(cont. on next page) 
Table E.1. (cont.)

\begin{tabular}{|c|c|c|c|c|c|c|c|c|c|c|c|c|c|}
\hline T. 3726 & 13 & 5 & 6 & 1.8 & Brick & Plane & T. 4146 & 14 & 5 & 6 & 1.8 & Brick & Inclined \\
\hline T. 3727 & 14 & 5 & 7 & 1.8 & Brick & Plane & T. 4147 & 15 & 5 & 7 & 1.8 & Brick & Inclined \\
\hline T. 3728 & 14 & 5 & 8 & 1.8 & Brick & Plane & T. 4148 & 15 & 5 & 8 & 1.8 & Brick & Inclined \\
\hline T. 3729 & 13 & 5 & 9 & 1.8 & Brick & Plane & T. 4149 & 14 & 5 & 9 & 1.8 & Brick & Inclined \\
\hline T. 3730 & 11 & 5 & 10 & 1.8 & Brick & Plane & T. 4150 & 12 & 5 & 10 & 1.8 & Brick & Inclined \\
\hline T. 3731 & 12 & 5 & 11 & 1.8 & Brick & Plane & T. 4151 & 13 & 5 & 11 & 1.8 & Brick & Inclined \\
\hline T. 3732 & 14 & 5 & 12 & 1.8 & Brick & Plane & T. 4152 & 15 & 5 & 12 & 1.8 & Brick & Inclined \\
\hline T. 3733 & 14 & 5 & 13 & 1.8 & Brick & Plane & T. 4153 & 15 & 5 & 13 & 1.8 & Brick & Inclined \\
\hline T. 3734 & 12 & 5 & 14 & 1.8 & Brick & Plane & T. 4154 & 13 & 5 & 14 & 1.8 & Brick & Inclined \\
\hline T. 3735 & 12 & 5 & 15 & 1.8 & Brick & Plane & T. 4155 & 13 & 5 & 15 & 1.8 & Brick & Inclined \\
\hline T. 3736 & 13 & 5 & 1 & 2 & Brick & Plane & T. 4156 & 14 & 5 & 1 & 2 & Brick & Inclined \\
\hline T. 3737 & 13 & 5 & 2 & 2 & Brick & Plane & T. 4157 & 14 & 5 & 2 & 2 & Brick & Inclined \\
\hline T. 3738 & 13 & 5 & 3 & 2 & Brick & Plane & T. 4158 & 14 & 5 & 3 & 2 & Brick & Inclined \\
\hline T. 3739 & 13 & 5 & 4 & 2 & Brick & Plane & T. 4159 & 14 & 5 & 4 & 2 & Brick & Inclined \\
\hline T. 3740 & 13 & 5 & 5 & 2 & Brick & Plane & T. 4160 & 14 & 5 & 5 & 2 & Brick & Inclined \\
\hline T. 3741 & 12 & 5 & 6 & 2 & Brick & Plane & T. 4161 & 13 & 5 & 6 & 2 & Brick & Inclined \\
\hline T. 3742 & 13 & 5 & 7 & 2 & Brick & Plane & T. 4162 & 14 & 5 & 7 & 2 & Brick & Inclined \\
\hline T. 3743 & 13 & 5 & 8 & 2 & Brick & Plane & T. 4163 & 14 & 5 & 8 & 2 & Brick & Inclined \\
\hline T. 3744 & 12 & 5 & 9 & 2 & Brick & Plane & T. 4164 & 13 & 5 & 9 & 2 & Brick & Inclined \\
\hline T. 3745 & 11 & 5 & 10 & 2 & Brick & Plane & T. 4165 & 12 & 5 & 10 & 2 & Brick & Inclined \\
\hline T. 3746 & 12 & 5 & 11 & 2 & Brick & Plane & T. 4166 & 13 & 5 & 11 & 2 & Brick & Inclined \\
\hline T. 3747 & 13 & 5 & 12 & 2 & Brick & Plane & T. 4167 & 14 & 5 & 12 & 2 & Brick & Inclined \\
\hline T. 3748 & 13 & 5 & 13 & 2 & Brick & Plane & T. 4168 & 14 & 5 & 13 & 2 & Brick & Inclined \\
\hline T. 3749 & 12 & 5 & 14 & 2 & Brick & Plane & T. 4169 & 13 & 5 & 14 & 2 & Brick & Inclined \\
\hline T. 3750 & 12 & 5 & 15 & 2 & Brick & Plane & T. 4170 & 13 & 5 & 15 & 2 & Brick & Inclined \\
\hline T. 3751 & 13 & 5 & 1 & 2.3 & Brick & Plane & T. 4171 & 14 & 5 & 1 & 2.3 & Brick & Inclined \\
\hline T. 3752 & 13 & 5 & 2 & 2.3 & Brick & Plane & T. 4172 & 14 & 5 & 2 & 2.3 & Brick & Inclined \\
\hline T. 3753 & 13 & 5 & 3 & 2.3 & Brick & Plane & T. 4173 & 14 & 5 & 3 & 2.3 & Brick & Inclined \\
\hline T. 3754 & 13 & 5 & 4 & 2.3 & Brick & Plane & T. 4174 & 14 & 5 & 4 & 2.3 & Brick & Inclined \\
\hline T. 3755 & 13 & 5 & 5 & 2.3 & Brick & Plane & T. 4175 & 14 & 5 & 5 & 2.3 & Brick & Inclined \\
\hline T. 3756 & 12 & 5 & 6 & 2.3 & Brick & Plane & T. 4176 & 13 & 5 & 6 & 2.3 & Brick & Inclined \\
\hline T. 3757 & 13 & 5 & 7 & 2.3 & Brick & Plane & T. 4177 & 14 & 5 & 7 & 2.3 & Brick & Inclined \\
\hline T. 3758 & 13 & 5 & 8 & 2.3 & Brick & Plane & T. 4178 & 14 & 5 & 8 & 2.3 & Brick & Inclined \\
\hline
\end{tabular}

(cont. on next page) 
Table E.1. (cont.)

\begin{tabular}{|c|c|c|c|c|c|c|c|c|c|c|c|c|c|}
\hline T. 3759 & 12 & 5 & 9 & 2.3 & Brick & Plane & T. 4179 & 13 & 5 & 9 & 2.3 & Brick & Inclined \\
\hline T. 3760 & 11 & 5 & 10 & 2.3 & Brick & Plane & T. 4180 & 12 & 5 & 10 & 2.3 & Brick & Inclined \\
\hline T. 3761 & 11 & 5 & 11 & 2.3 & Brick & Plane & T. 4181 & 12 & 5 & 11 & 2.3 & Brick & Inclined \\
\hline T. 3762 & 13 & 5 & 12 & 2.3 & Brick & Plane & T. 4182 & 14 & 5 & 12 & 2.3 & Brick & Inclined \\
\hline T. 3763 & 13 & 5 & 13 & 2.3 & Brick & Plane & T. 4183 & 14 & 5 & 13 & 2.3 & Brick & Inclined \\
\hline T. 3764 & 11 & 5 & 14 & 2.3 & Brick & Plane & T. 4184 & 12 & 5 & 14 & 2.3 & Brick & Inclined \\
\hline T. 3765 & 11 & 5 & 15 & 2.3 & Brick & Plane & T. 4185 & 12 & 5 & 15 & 2.3 & Brick & Inclined \\
\hline T. 3766 & 12 & 5 & 1 & 2.5 & Brick & Plane & T. 4186 & 13 & 5 & 1 & 2.5 & Brick & Inclined \\
\hline T. 3767 & 12 & 5 & 2 & 2.5 & Brick & Plane & T. 4187 & 13 & 5 & 2 & 2.5 & Brick & Inclined \\
\hline T. 3768 & 12 & 5 & 3 & 2.5 & Brick & Plane & T. 4188 & 13 & 5 & 3 & 2.5 & Brick & Inclined \\
\hline T. 3769 & 12 & 5 & 4 & 2.5 & Brick & Plane & T. 4189 & 13 & 5 & 4 & 2.5 & Brick & Inclined \\
\hline T. 3770 & 12 & 5 & 5 & 2.5 & Brick & Plane & T. 4190 & 13 & 5 & 5 & 2.5 & Brick & Inclined \\
\hline T. 3771 & 11 & 5 & 6 & 2.5 & Brick & Plane & T. 4191 & 12 & 5 & 6 & 2.5 & Brick & Inclined \\
\hline T. 3772 & 12 & 5 & 7 & 2.5 & Brick & Plane & T. 4192 & 13 & 5 & 7 & 2.5 & Brick & Inclined \\
\hline T. 3773 & 12 & 5 & 8 & 2.5 & Brick & Plane & T. 4193 & 13 & 5 & 8 & 2.5 & Brick & Inclined \\
\hline T. 3774 & 11 & 5 & 9 & 2.5 & Brick & Plane & T. 4194 & 12 & 5 & 9 & 2.5 & Brick & Inclined \\
\hline T. 3775 & 10 & 5 & 10 & 2.5 & Brick & Plane & T. 4195 & 11 & 5 & 10 & 2.5 & Brick & Inclined \\
\hline T. 3776 & 11 & 5 & 11 & 2.5 & Brick & Plane & T. 4196 & 12 & 5 & 11 & 2.5 & Brick & Inclined \\
\hline T. 3777 & 12 & 5 & 12 & 2.5 & Brick & Plane & T. 4197 & 13 & 5 & 12 & 2.5 & Brick & Inclined \\
\hline T. 3778 & 12 & 5 & 13 & 2.5 & Brick & Plane & T. 4198 & 13 & 5 & 13 & 2.5 & Brick & Inclined \\
\hline T. 3779 & 11 & 5 & 14 & 2.5 & Brick & Plane & T. 4199 & 12 & 5 & 14 & 2.5 & Brick & Inclined \\
\hline T. 3780 & 11 & 5 & 15 & 2.5 & Brick & Plane & T. 4200 & 12 & 5 & 15 & 2.5 & Brick & Inclined \\
\hline T. 4201 & 17 & 6 & 1 & 1 & Granite & Plane & T. 4621 & 18 & 6 & 1 & 1 & Granite & Inclined \\
\hline T. 4202 & 17 & 6 & 2 & 1 & Granite & Plane & T. 4622 & 18 & 6 & 2 & 1 & Granite & Inclined \\
\hline T. 4203 & 17 & 6 & 3 & 1 & Granite & Plane & T. 4623 & 18 & 6 & 3 & 1 & Granite & Inclined \\
\hline T. 4204 & 17 & 6 & 4 & 1 & Granite & Plane & T. 4624 & 18 & 6 & 4 & 1 & Granite & Inclined \\
\hline T. 4205 & 17 & 6 & 5 & 1 & Granite & Plane & T. 4625 & 18 & 6 & 5 & 1 & Granite & Inclined \\
\hline T. 4206 & 17 & 6 & 6 & 1 & Granite & Plane & T. 4626 & 18 & 6 & 6 & 1 & Granite & Inclined \\
\hline T. 4207 & 17 & 6 & 7 & 1 & Granite & Plane & T. 4627 & 18 & 6 & 7 & 1 & Granite & Inclined \\
\hline T. 4208 & 17 & 6 & 8 & 1 & Granite & Plane & T. 4628 & 18 & 6 & 8 & 1 & Granite & Inclined \\
\hline T. 4209 & 17 & 6 & 9 & 1 & Granite & Plane & T. 4629 & 18 & 6 & 9 & 1 & Granite & Inclined \\
\hline T. 4210 & 15 & 6 & 10 & 1 & Granite & Plane & T. 4630 & 16 & 6 & 10 & 1 & Granite & Inclined \\
\hline T. 4211 & 16 & 6 & 11 & 1 & Granite & Plane & T. 4631 & 17 & 6 & 11 & 1 & Granite & Inclined \\
\hline
\end{tabular}

(cont. on next page) 
Table E.1. (cont.)

\begin{tabular}{|c|c|c|c|c|c|c|c|c|c|c|c|c|c|}
\hline T. 4212 & 17 & 6 & 12 & 1 & Granite & Plane & T. 4632 & 18 & 6 & 12 & 1 & Granite & Inclined \\
\hline T. 4213 & 17 & 6 & 13 & 1 & Granite & Plane & T. 4633 & 18 & 6 & 13 & 1 & Granite & Inclined \\
\hline T. 4214 & 16 & 6 & 14 & 1 & Granite & Plane & T. 4634 & 17 & 6 & 14 & 1 & Granite & Inclined \\
\hline T. 4215 & 16 & 6 & 15 & 1 & Granite & Plane & T. 4635 & 17 & 6 & 15 & 1 & Granite & Inclined \\
\hline T. 4216 & 19 & 6 & 1 & 1.3 & Granite & Plane & T. 4636 & 20 & 6 & 1 & 1.3 & Granite & Inclined \\
\hline T. 4217 & 19 & 6 & 2 & 1.3 & Granite & Plane & T. 4637 & 20 & 6 & 2 & 1.3 & Granite & Inclined \\
\hline T. 4218 & 19 & 6 & 3 & 1.3 & Granite & Plane & T. 4638 & 20 & 6 & 3 & 1.3 & Granite & Inclined \\
\hline T. 4219 & 19 & 6 & 4 & 1.3 & Granite & Plane & T. 4639 & 20 & 6 & 4 & 1.3 & Granite & Inclined \\
\hline T. 4220 & 19 & 6 & 5 & 1.3 & Granite & Plane & T. 4640 & 20 & 6 & 5 & 1.3 & Granite & Inclined \\
\hline T. 4221 & 19 & 6 & 6 & 1.3 & Granite & Plane & T. 4641 & 20 & 6 & 6 & 1.3 & Granite & Inclined \\
\hline T. 4222 & 19 & 6 & 7 & 1.3 & Granite & Plane & T. 4642 & 20 & 6 & 7 & 1.3 & Granite & Inclined \\
\hline T. 4223 & 19 & 6 & 8 & 1.3 & Granite & Plane & T. 4643 & 20 & 6 & 8 & 1.3 & Granite & Inclined \\
\hline T. 4224 & 19 & 6 & 9 & 1.3 & Granite & Plane & T. 4644 & 20 & 6 & 9 & 1.3 & Granite & Inclined \\
\hline T. 4225 & 18 & 6 & 10 & 1.3 & Granite & Plane & T. 4645 & 19 & 6 & 10 & 1.3 & Granite & Inclined \\
\hline T. 4226 & 18 & 6 & 11 & 1.3 & Granite & Plane & T. 4646 & 19 & 6 & 11 & 1.3 & Granite & Inclined \\
\hline T. 4227 & 19 & 6 & 12 & 1.3 & Granite & Plane & T. 4647 & 20 & 6 & 12 & 1.3 & Granite & Inclined \\
\hline T. 4228 & 19 & 6 & 13 & 1.3 & Granite & Plane & T. 4648 & 20 & 6 & 13 & 1.3 & Granite & Inclined \\
\hline T. 4229 & 18 & 6 & 14 & 1.3 & Granite & Plane & T. 4649 & 19 & 6 & 14 & 1.3 & Granite & Inclined \\
\hline T. 4230 & 18 & 6 & 15 & 1.3 & Granite & Plane & T. 4650 & 19 & 6 & 15 & 1.3 & Granite & Inclined \\
\hline *T. 4231 & 19 & 6 & 1 & 1.6 & Granite & Plane & *T. 4651 & 20 & 6 & 1 & 1.6 & Granite & Inclined \\
\hline *T. 4232 & 19 & 6 & 2 & 1.6 & Granite & Plane & *T. 4652 & 20 & 6 & 2 & 1.6 & Granite & Inclined \\
\hline *T. 4233 & 19 & 6 & 3 & 1.6 & Granite & Plane & *T. 4653 & 20 & 6 & 3 & 1.6 & Granite & Inclined \\
\hline *T. 4234 & 19 & 6 & 4 & 1.6 & Granite & Plane & *T. 4654 & 20 & 6 & 4 & 1.6 & Granite & Inclined \\
\hline *T. 4235 & 19 & 6 & 5 & 1.6 & Granite & Plane & *T. 4655 & 20 & 6 & 5 & 1.6 & Granite & Inclined \\
\hline *T. 4236 & 19 & 6 & 6 & 1.6 & Granite & Plane & *T. 4656 & 20 & 6 & 6 & 1.6 & Granite & Inclined \\
\hline *T. 4237 & 19 & 6 & 7 & 1.6 & Granite & Plane & *T. 4657 & 20 & 6 & 7 & 1.6 & Granite & Inclined \\
\hline *T. 4238 & 19 & 6 & 8 & 1.6 & Granite & Plane & *T. 4658 & 20 & 6 & 8 & 1.6 & Granite & Inclined \\
\hline *T. 4239 & 19 & 6 & 9 & 1.6 & Granite & Plane & *T. 4659 & 20 & 6 & 9 & 1.6 & Granite & Inclined \\
\hline${ }^{*}$ T. 4240 & 18 & 6 & 10 & 1.6 & Granite & Plane & *T. 4660 & 19 & 6 & 10 & 1.6 & Granite & Inclined \\
\hline *T. 4241 & 18 & 6 & 11 & 1.6 & Granite & Plane & *T. 4661 & 19 & 6 & 11 & 1.6 & Granite & Inclined \\
\hline *T. 4242 & 19 & 6 & 12 & 1.6 & Granite & Plane & *T. 4662 & 20 & 6 & 12 & 1.6 & Granite & Inclined \\
\hline *T. 4243 & 19 & 6 & 13 & 1.6 & Granite & Plane & *T. 4663 & 20 & 6 & 13 & 1.6 & Granite & Inclined \\
\hline *T. 4244 & 19 & 6 & 14 & 1.6 & Granite & Plane & *T. 4664 & 20 & 6 & 14 & 1.6 & Granite & Inclined \\
\hline
\end{tabular}

(cont. on next page) 
Table E.1. (cont.

\begin{tabular}{|c|c|c|c|c|c|c|c|c|c|c|c|c|c|}
\hline *T. 4245 & 19 & 6 & 15 & 1.6 & Granite & Plane & *T. 4665 & 20 & 6 & 15 & 1.6 & Granite & Inclined \\
\hline *T. 4246 & 19 & 6 & 1 & 1.8 & Granite & Plane & *T. 4666 & 20 & 6 & 1 & 1.8 & Granite & Inclined \\
\hline *T. 4247 & 19 & 6 & 2 & 1.8 & Granite & Plane & *T. 4667 & 20 & 6 & 2 & 1.8 & Granite & Inclined \\
\hline *T. 4248 & 19 & 6 & 3 & 1.8 & Granite & Plane & *T. 4668 & 20 & 6 & 3 & 1.8 & Granite & Inclined \\
\hline *T. 4249 & 19 & 6 & 4 & 1.8 & Granite & Plane & *T. 4669 & 20 & 6 & 4 & 1.8 & Granite & Inclined \\
\hline *T. 4250 & 19 & 6 & 5 & 1.8 & Granite & Plane & *T. 4670 & 20 & 6 & 5 & 1.8 & Granite & Inclined \\
\hline *T. 4251 & 19 & 6 & 6 & 1.8 & Granite & Plane & *T. 4671 & 20 & 6 & 6 & 1.8 & Granite & Inclined \\
\hline *T. 4252 & 19 & 6 & 7 & 1.8 & Granite & Plane & *T. 4672 & 20 & 6 & 7 & 1.8 & Granite & Inclined \\
\hline *T. 4253 & 19 & 6 & 8 & 1.8 & Granite & Plane & *T. 4673 & 20 & 6 & 8 & 1.8 & Granite & Inclined \\
\hline *T. 4254 & 19 & 6 & 9 & 1.8 & Granite & Plane & *T. 4674 & 20 & 6 & 9 & 1.8 & Granite & Inclined \\
\hline *T. 4255 & 18 & 6 & 10 & 1.8 & Granite & Plane & *T. 4675 & 19 & 6 & 10 & 1.8 & Granite & Inclined \\
\hline *T. 4256 & 19 & 6 & 11 & 1.8 & Granite & Plane & *T. 4676 & 20 & 6 & 11 & 1.8 & Granite & Inclined \\
\hline *T. 4257 & 19 & 6 & 12 & 1.8 & Granite & Plane & *T. 4677 & 20 & 6 & 12 & 1.8 & Granite & Inclined \\
\hline *T. 4258 & 19 & 6 & 13 & 1.8 & Granite & Plane & *T. 4678 & 20 & 6 & 13 & 1.8 & Granite & Inclined \\
\hline *T. 4259 & 18 & 6 & 14 & 1.8 & Granite & Plane & *T. 4679 & 19 & 6 & 14 & 1.8 & Granite & Inclined \\
\hline *T. 4260 & 18 & 6 & 15 & 1.8 & Granite & Plane & *T. 4680 & 19 & 6 & 15 & 1.8 & Granite & Inclined \\
\hline${ }^{*}$ T. 4261 & 18 & 6 & 1 & 2 & Granite & Plane & *T. 4681 & 19 & 6 & 1 & 2 & Granite & Inclined \\
\hline${ }^{*} \mathrm{~T} .4262$ & 18 & 6 & 2 & 2 & Granite & Plane & *T. 4682 & 19 & 6 & 2 & 2 & Granite & Inclined \\
\hline *T. 4263 & 18 & 6 & 3 & 2 & Granite & Plane & *T. 4683 & 19 & 6 & 3 & 2 & Granite & Inclined \\
\hline *T. 4264 & 18 & 6 & 4 & 2 & Granite & Plane & *T. 4684 & 19 & 6 & 4 & 2 & Granite & Inclined \\
\hline *T. 4265 & 18 & 6 & 5 & 2 & Granite & Plane & *T. 4685 & 19 & 6 & 5 & 2 & Granite & Inclined \\
\hline *T. 4266 & 18 & 6 & 6 & 2 & Granite & Plane & *T. 4686 & 19 & 6 & 6 & 2 & Granite & Inclined \\
\hline *T. 4267 & 18 & 6 & 7 & 2 & Granite & Plane & *T. 4687 & 19 & 6 & 7 & 2 & Granite & Inclined \\
\hline *T. 4268 & 18 & 6 & 8 & 2 & Granite & Plane & *T. 4688 & 19 & 6 & 8 & 2 & Granite & Inclined \\
\hline *T. 4269 & 18 & 6 & 9 & 2 & Granite & Plane & *T. 4689 & 19 & 6 & 9 & 2 & Granite & Inclined \\
\hline *T. 4270 & 17 & 6 & 10 & 2 & Granite & Plane & *T. 4690 & 18 & 6 & 10 & 2 & Granite & Inclined \\
\hline *T. 4271 & 18 & 6 & 11 & 2 & Granite & Plane & *T. 4691 & 19 & 6 & 11 & 2 & Granite & Inclined \\
\hline *T. 4272 & 18 & 6 & 12 & 2 & Granite & Plane & *T. 4692 & 19 & 6 & 12 & 2 & Granite & Inclined \\
\hline *T. 4273 & 18 & 6 & 13 & 2 & Granite & Plane & *T. 4693 & 19 & 6 & 13 & 2 & Granite & Inclined \\
\hline *T. 4274 & 18 & 6 & 14 & 2 & Granite & Plane & *T. 4694 & 19 & 6 & 14 & 2 & Granite & Inclined \\
\hline *T. 4275 & 18 & 6 & 15 & 2 & Granite & Plane & *T. 4695 & 19 & 6 & 15 & 2 & Granite & Inclined \\
\hline *T. 4276 & 16 & 6 & 1 & 2.3 & Granite & Plane & *T. 4696 & 17 & 6 & 1 & 2.3 & Granite & Inclined \\
\hline *T. 4277 & 16 & 6 & 2 & 2.3 & Granite & Plane & *T. 4697 & 17 & 6 & 2 & 2.3 & Granite & Inclined \\
\hline
\end{tabular}


Table E.1. (cont.)

\begin{tabular}{|c|c|c|c|c|c|c|c|c|c|c|c|c|c|}
\hline *T. 4278 & 16 & 6 & 3 & 2.3 & Granite & Plane & ${ }^{*} \mathrm{~T} .4698$ & 17 & 6 & 3 & 2.3 & Granite & Inclined \\
\hline *T. 4279 & 16 & 6 & 4 & 2.3 & Granite & Plane & ${ }^{*} \mathrm{~T} .4699$ & 17 & 6 & 4 & 2.3 & Granite & Inclined \\
\hline *T. 4280 & 16 & 6 & 5 & 2.3 & Granite & Plane & ${ }^{*} \mathrm{~T} .4700$ & 17 & 6 & 5 & 2.3 & Granite & Inclined \\
\hline${ }^{*} \mathrm{~T} .4281$ & 16 & 6 & 6 & 2.3 & Granite & Plane & *T. 4701 & 17 & 6 & 6 & 2.3 & Granite & Inclined \\
\hline *T. 4282 & 16 & 6 & 7 & 2.3 & Granite & Plane & *T. 4702 & 17 & 6 & 7 & 2.3 & Granite & Inclined \\
\hline *T. 4283 & 16 & 6 & 8 & 2.3 & Granite & Plane & *T. 4703 & 17 & 6 & 8 & 2.3 & Granite & Inclined \\
\hline *T. 4284 & 16 & 6 & 9 & 2.3 & Granite & Plane & *T. 4704 & 17 & 6 & 9 & 2.3 & Granite & Inclined \\
\hline *T. 4285 & 16 & 6 & 10 & 2.3 & Granite & Plane & *T. 4705 & 17 & 6 & 10 & 2.3 & Granite & Inclined \\
\hline${ }^{*}$ T. 4286 & 16 & 6 & 11 & 2.3 & Granite & Plane & *T. 4706 & 17 & 6 & 11 & 2.3 & Granite & Inclined \\
\hline *T. 4287 & 16 & 6 & 12 & 2.3 & Granite & Plane & *T. 4707 & 17 & 6 & 12 & 2.3 & Granite & Inclined \\
\hline *T. 4288 & 16 & 6 & 13 & 2.3 & Granite & Plane & *T. 4708 & 17 & 6 & 13 & 2.3 & Granite & Inclined \\
\hline${ }^{*}$ T. 4289 & 16 & 6 & 14 & 2.3 & Granite & Plane & *T. 4709 & 17 & 6 & 14 & 2.3 & Granite & Inclined \\
\hline *T. 4290 & 16 & 6 & 15 & 2.3 & Granite & Plane & ${ }^{*} \mathrm{~T} .4710$ & 17 & 6 & 15 & 2.3 & Granite & Inclined \\
\hline T. 4291 & 15 & 6 & 1 & 2.5 & Granite & Plane & T. 4711 & 16 & 6 & 1 & 2.5 & Granite & Inclined \\
\hline T. 4292 & 15 & 6 & 2 & 2.5 & Granite & Plane & T. 4712 & 16 & 6 & 2 & 2.5 & Granite & Inclined \\
\hline T. 4293 & 15 & 6 & 3 & 2.5 & Granite & Plane & T. 4713 & 16 & 6 & 3 & 2.5 & Granite & Inclined \\
\hline T. 4294 & 15 & 6 & 4 & 2.5 & Granite & Plane & T. 4714 & 16 & 6 & 4 & 2.5 & Granite & Inclined \\
\hline T. 4295 & 15 & 6 & 5 & 2.5 & Granite & Plane & T. 4715 & 16 & 6 & 5 & 2.5 & Granite & Inclined \\
\hline T. 4296 & 15 & 6 & 6 & 2.5 & Granite & Plane & T. 4716 & 16 & 6 & 6 & 2.5 & Granite & Inclined \\
\hline T. 4297 & 15 & 6 & 7 & 2.5 & Granite & Plane & T. 4717 & 16 & 6 & 7 & 2.5 & Granite & Inclined \\
\hline T. 4298 & 15 & 6 & 8 & 2.5 & Granite & Plane & T. 4718 & 16 & 6 & 8 & 2.5 & Granite & Inclined \\
\hline T. 4299 & 15 & 6 & 9 & 2.5 & Granite & Plane & T. 4719 & 16 & 6 & 9 & 2.5 & Granite & Inclined \\
\hline T. 4300 & 15 & 6 & 10 & 2.5 & Granite & Plane & T. 4720 & 16 & 6 & 10 & 2.5 & Granite & Inclined \\
\hline T. 4301 & 15 & 6 & 11 & 2.5 & Granite & Plane & T. 4721 & 16 & 6 & 11 & 2.5 & Granite & Inclined \\
\hline T. 4302 & 15 & 6 & 12 & 2.5 & Granite & Plane & T. 4722 & 16 & 6 & 12 & 2.5 & Granite & Inclined \\
\hline T. 4303 & 15 & 6 & 13 & 2.5 & Granite & Plane & T. 4723 & 16 & 6 & 13 & 2.5 & Granite & Inclined \\
\hline T. 4304 & 15 & 6 & 14 & 2.5 & Granite & Plane & T. 4724 & 16 & 6 & 14 & 2.5 & Granite & Inclined \\
\hline T. 4305 & 15 & 6 & 15 & 2.5 & Granite & Plane & T. 4725 & 16 & 6 & 15 & 2.5 & Granite & Inclined \\
\hline T. 4306 & 17 & 6 & 1 & 1 & Limestone & Plane & T. 4726 & 18 & 6 & 1 & 1 & Limestone & Inclined \\
\hline T. 4307 & 17 & 6 & 2 & 1 & Limestone & Plane & T. 4727 & 18 & 6 & 2 & 1 & Limestone & Inclined \\
\hline T. 4308 & 17 & 6 & 3 & 1 & Limestone & Plane & T. 4728 & 18 & 6 & 3 & 1 & Limestone & Inclined \\
\hline T. 4309 & 17 & 6 & 4 & 1 & Limestone & Plane & T. 4729 & 18 & 6 & 4 & 1 & Limestone & Inclined \\
\hline T. 4310 & 17 & 6 & 5 & 1 & Limestone & Plane & T. 4730 & 18 & 6 & 5 & 1 & Limestone & Inclined \\
\hline
\end{tabular}


Table E.1. (cont.

\begin{tabular}{|c|c|c|c|c|c|c|c|c|c|c|c|c|c|}
\hline T. 4311 & 17 & 6 & 6 & 1 & Limestone & Plane & T. 4731 & 18 & 6 & 6 & 1 & Limestone & Inclined \\
\hline T. 4312 & 17 & 6 & 7 & 1 & Limestone & Plane & T. 4732 & 18 & 6 & 7 & 1 & Limestone & Inclined \\
\hline T. 4313 & 17 & 6 & 8 & 1 & Limestone & Plane & T. 4733 & 18 & 6 & 8 & 1 & Limestone & Inclined \\
\hline T. 4314 & 17 & 6 & 9 & 1 & Limestone & Plane & T. 4734 & 18 & 6 & 9 & 1 & Limestone & Inclined \\
\hline T. 4315 & 15 & 6 & 10 & 1 & Limestone & Plane & T. 4735 & 16 & 6 & 10 & 1 & Limestone & Inclined \\
\hline T. 4316 & 16 & 6 & 11 & 1 & Limestone & Plane & T. 4736 & 17 & 6 & 11 & 1 & Limestone & Inclined \\
\hline T. 4317 & 17 & 6 & 12 & 1 & Limestone & Plane & T. 4737 & 18 & 6 & 12 & 1 & Limestone & Inclined \\
\hline T. 4318 & 17 & 6 & 13 & 1 & Limestone & Plane & T. 4738 & 18 & 6 & 13 & 1 & Limestone & Inclined \\
\hline T. 4319 & 16 & 6 & 14 & 1 & Limestone & Plane & T. 4739 & 17 & 6 & 14 & 1 & Limestone & Inclined \\
\hline T. 4320 & 16 & 6 & 15 & 1 & Limestone & Plane & T. 4740 & 17 & 6 & 15 & 1 & Limestone & Inclined \\
\hline T. 4321 & 19 & 6 & 1 & 1.3 & Limestone & Plane & T. 4741 & 20 & 6 & 1 & 1.3 & Limestone & Inclined \\
\hline T. 4322 & 19 & 6 & 2 & 1.3 & Limestone & Plane & T. 4742 & 20 & 6 & 2 & 1.3 & Limestone & Inclined \\
\hline T. 4323 & 19 & 6 & 3 & 1.3 & Limestone & Plane & T. 4743 & 20 & 6 & 3 & 1.3 & Limestone & Inclined \\
\hline T. 4324 & 19 & 6 & 4 & 1.3 & Limestone & Plane & T. 4744 & 20 & 6 & 4 & 1.3 & Limestone & Inclined \\
\hline T. 4325 & 19 & 6 & 5 & 1.3 & Limestone & Plane & T. 4745 & 20 & 6 & 5 & 1.3 & Limestone & Inclined \\
\hline T. 4326 & 19 & 6 & 6 & 1.3 & Limestone & Plane & T. 4746 & 20 & 6 & 6 & 1.3 & Limestone & Inclined \\
\hline T. 4327 & 19 & 6 & 7 & 1.3 & Limestone & Plane & T. 4747 & 20 & 6 & 7 & 1.3 & Limestone & Inclined \\
\hline T. 4328 & 19 & 6 & 8 & 1.3 & Limestone & Plane & T. 4748 & 20 & 6 & 8 & 1.3 & Limestone & Inclined \\
\hline T. 4329 & 19 & 6 & 9 & 1.3 & Limestone & Plane & T. 4749 & 20 & 6 & 9 & 1.3 & Limestone & Inclined \\
\hline T. 4330 & 18 & 6 & 10 & 1.3 & Limestone & Plane & T. 4750 & 19 & 6 & 10 & 1.3 & Limestone & Inclined \\
\hline T. 4331 & 18 & 6 & 11 & 1.3 & Limestone & Plane & T. 4751 & 19 & 6 & 11 & 1.3 & Limestone & Inclined \\
\hline T. 4332 & 19 & 6 & 12 & 1.3 & Limestone & Plane & T. 4752 & 20 & 6 & 12 & 1.3 & Limestone & Inclined \\
\hline T. 4333 & 19 & 6 & 13 & 1.3 & Limestone & Plane & T. 4753 & 20 & 6 & 13 & 1.3 & Limestone & Inclined \\
\hline T. 4334 & 18 & 6 & 14 & 1.3 & Limestone & Plane & T. 4754 & 19 & 6 & 14 & 1.3 & Limestone & Inclined \\
\hline T. 4335 & 18 & 6 & 15 & 1.3 & Limestone & Plane & T. 4755 & 19 & 6 & 15 & 1.3 & Limestone & Inclined \\
\hline *T. 4336 & 19 & 6 & 1 & 1.6 & Limestone & Plane & *T. 4756 & 20 & 6 & 1 & 1.6 & Limestone & Inclined \\
\hline *T. 4337 & 19 & 6 & 2 & 1.6 & Limestone & Plane & *T. 4757 & 20 & 6 & 2 & 1.6 & Limestone & Inclined \\
\hline *T. 4338 & 19 & 6 & 3 & 1.6 & Limestone & Plane & *T. 4758 & 20 & 6 & 3 & 1.6 & Limestone & Inclined \\
\hline *T. 4339 & 19 & 6 & 4 & 1.6 & Limestone & Plane & *T. 4759 & 20 & 6 & 4 & 1.6 & Limestone & Inclined \\
\hline *T. 4340 & 19 & 6 & 5 & 1.6 & Limestone & Plane & *T. 4760 & 20 & 6 & 5 & 1.6 & Limestone & Inclined \\
\hline *T. 4341 & 19 & 6 & 6 & 1.6 & Limestone & Plane & *T. 4761 & 20 & 6 & 6 & 1.6 & Limestone & Inclined \\
\hline *T. 4342 & 19 & 6 & 7 & 1.6 & Limestone & Plane & *T. 4762 & 20 & 6 & 7 & 1.6 & Limestone & Inclined \\
\hline *T. 4343 & 19 & 6 & 8 & 1.6 & Limestone & Plane & *T. 4763 & 20 & 6 & 8 & 1.6 & Limestone & Inclined \\
\hline
\end{tabular}

(cont. on next page) 
Table E.1. (cont.)

\begin{tabular}{|c|c|c|c|c|c|c|c|c|c|c|c|c|c|}
\hline *T. 4344 & 19 & 6 & 9 & 1.6 & Limestone & Plane & ${ }^{*} \mathrm{~T} .4764$ & 20 & 6 & 9 & 1.6 & Limestone & Inclined \\
\hline *T. 4345 & 18 & 6 & 10 & 1.6 & Limestone & Plane & *T. 4765 & 19 & 6 & 10 & 1.6 & Limestone & Inclined \\
\hline *T. 4346 & 18 & 6 & 11 & 1.6 & Limestone & Plane & ${ }^{*} \mathrm{~T} .4766$ & 19 & 6 & 11 & 1.6 & Limestone & Inclined \\
\hline *T. 4347 & 19 & 6 & 12 & 1.6 & Limestone & Plane & ${ }^{*} \mathrm{~T} .4767$ & 20 & 6 & 12 & 1.6 & Limestone & Inclined \\
\hline *T. 4348 & 19 & 6 & 13 & 1.6 & Limestone & Plane & *T. 4768 & 20 & 6 & 13 & 1.6 & Limestone & Inclined \\
\hline *T. 4349 & 19 & 6 & 14 & 1.6 & Limestone & Plane & *T. 4769 & 20 & 6 & 14 & 1.6 & Limestone & Inclined \\
\hline${ }^{*} \mathrm{~T} .4350$ & 19 & 6 & 15 & 1.6 & Limestone & Plane & *T. 4770 & 20 & 6 & 15 & 1.6 & Limestone & Inclined \\
\hline *T. 4351 & 19 & 6 & 1 & 1.8 & Limestone & Plane & ${ }^{*} \mathrm{~T} .4771$ & 20 & 6 & 1 & 1.8 & Limestone & Inclined \\
\hline *T. 4352 & 19 & 6 & 2 & 1.8 & Limestone & Plane & *T. 4772 & 20 & 6 & 2 & 1.8 & Limestone & Inclined \\
\hline *T. 4353 & 19 & 6 & 3 & 1.8 & Limestone & Plane & *T. 4773 & 20 & 6 & 3 & 1.8 & Limestone & Inclined \\
\hline *T. 4354 & 19 & 6 & 4 & 1.8 & Limestone & Plane & *T. 4774 & 20 & 6 & 4 & 1.8 & Limestone & Inclined \\
\hline *T. 4355 & 19 & 6 & 5 & 1.8 & Limestone & Plane & *T. 4775 & 20 & 6 & 5 & 1.8 & Limestone & Inclined \\
\hline *T. 4356 & 19 & 6 & 6 & 1.8 & Limestone & Plane & ${ }^{*} \mathrm{~T} .4776$ & 20 & 6 & 6 & 1.8 & Limestone & Inclined \\
\hline *T. 4357 & 19 & 6 & 7 & 1.8 & Limestone & Plane & *T. 4777 & 20 & 6 & 7 & 1.8 & Limestone & Inclined \\
\hline *T. 4358 & 19 & 6 & 8 & 1.8 & Limestone & Plane & ${ }^{*} \mathrm{~T} .4778$ & 20 & 6 & 8 & 1.8 & Limestone & Inclined \\
\hline *T. 4359 & 19 & 6 & 9 & 1.8 & Limestone & Plane & *T. 4779 & 20 & 6 & 9 & 1.8 & Limestone & Inclined \\
\hline${ }^{*}$ T. 4360 & 18 & 6 & 10 & 1.8 & Limestone & Plane & ${ }^{*} \mathrm{~T} .4780$ & 19 & 6 & 10 & 1.8 & Limestone & Inclined \\
\hline *T. 4361 & 19 & 6 & 11 & 1.8 & Limestone & Plane & ${ }^{*} \mathrm{~T} .4781$ & 20 & 6 & 11 & 1.8 & Limestone & Inclined \\
\hline *T. 4362 & 19 & 6 & 12 & 1.8 & Limestone & Plane & *T. 4782 & 20 & 6 & 12 & 1.8 & Limestone & Inclined \\
\hline${ }^{*} \mathrm{~T} .4363$ & 19 & 6 & 13 & 1.8 & Limestone & Plane & ${ }^{*} \mathrm{~T} .4783$ & 20 & 6 & 13 & 1.8 & Limestone & Inclined \\
\hline *T. 4364 & 18 & 6 & 14 & 1.8 & Limestone & Plane & ${ }^{*} \mathrm{~T} .4784$ & 19 & 6 & 14 & 1.8 & Limestone & Inclined \\
\hline${ }^{*} \mathrm{~T} .4365$ & 18 & 6 & 15 & 1.8 & Limestone & Plane & *T. 4785 & 19 & 6 & 15 & 1.8 & Limestone & Inclined \\
\hline *T. 4366 & 18 & 6 & 1 & 2 & Limestone & Plane & *T. 4786 & 19 & 6 & 1 & 2 & Limestone & Inclined \\
\hline *T. 4367 & 18 & 6 & 2 & 2 & Limestone & Plane & *T. 4787 & 19 & 6 & 2 & 2 & Limestone & Inclined \\
\hline *T. 4368 & 18 & 6 & 3 & 2 & Limestone & Plane & ${ }^{*} \mathrm{~T} .4788$ & 19 & 6 & 3 & 2 & Limestone & Inclined \\
\hline${ }^{*} \mathrm{~T} .4369$ & 18 & 6 & 4 & 2 & Limestone & Plane & ${ }^{*} \mathrm{~T} .4789$ & 19 & 6 & 4 & 2 & Limestone & Inclined \\
\hline *T. 4370 & 18 & 6 & 5 & 2 & Limestone & Plane & ${ }^{*} \mathrm{~T} .4790$ & 19 & 6 & 5 & 2 & Limestone & Inclined \\
\hline *T. 4371 & 18 & 6 & 6 & 2 & Limestone & Plane & ${ }^{*} \mathrm{~T} .4791$ & 19 & 6 & 6 & 2 & Limestone & Inclined \\
\hline *T. 4372 & 18 & 6 & 7 & 2 & Limestone & Plane & *T. 4792 & 19 & 6 & 7 & 2 & Limestone & Inclined \\
\hline *T. 4373 & 18 & 6 & 8 & 2 & Limestone & Plane & ${ }^{*} \mathrm{~T} .4793$ & 19 & 6 & 8 & 2 & Limestone & Inclined \\
\hline *T. 4374 & 18 & 6 & 9 & 2 & Limestone & Plane & *T. 4794 & 19 & 6 & 9 & 2 & Limestone & Inclined \\
\hline *T. 4375 & 17 & 6 & 10 & 2 & Limestone & Plane & *T. 4795 & 18 & 6 & 10 & 2 & Limestone & Inclined \\
\hline *T. 4376 & 18 & 6 & 11 & 2 & Limestone & Plane & *T. 4796 & 19 & 6 & 11 & 2 & Limestone & Inclined \\
\hline
\end{tabular}


Table E.1. (cont.)

\begin{tabular}{|c|c|c|c|c|c|c|c|c|c|c|c|c|c|}
\hline *T. 4377 & 18 & 6 & 12 & 2 & Limestone & Plane & *T. 4797 & 19 & 6 & 12 & 2 & Limestone & Inclined \\
\hline *T. 4378 & 18 & 6 & 13 & 2 & Limestone & Plane & *T. 4798 & 19 & 6 & 13 & 2 & Limestone & Inclined \\
\hline *T. 4379 & 18 & 6 & 14 & 2 & Limestone & Plane & *T. 4799 & 19 & 6 & 14 & 2 & Limestone & Inclined \\
\hline *T. 4380 & 18 & 6 & 15 & 2 & Limestone & Plane & ${ }^{*} \mathrm{~T} .4800$ & 19 & 6 & 15 & 2 & Limestone & Inclined \\
\hline *T. 4381 & 16 & 6 & 1 & 2.3 & Limestone & Plane & *T. 4801 & 17 & 6 & 1 & 2.3 & Limestone & Inclined \\
\hline${ }^{*} \mathrm{~T} .4382$ & 16 & 6 & 2 & 2.3 & Limestone & Plane & ${ }^{*}$ T. 4802 & 17 & 6 & 2 & 2.3 & Limestone & Inclined \\
\hline *T. 4383 & 16 & 6 & 3 & 2.3 & Limestone & Plane & *T. 4803 & 17 & 6 & 3 & 2.3 & Limestone & Inclined \\
\hline *T. 4384 & 16 & 6 & 4 & 2.3 & Limestone & Plane & *T. 4804 & 17 & 6 & 4 & 2.3 & Limestone & Inclined \\
\hline *T. 4385 & 16 & 6 & 5 & 2.3 & Limestone & Plane & *T. 4805 & 17 & 6 & 5 & 2.3 & Limestone & Inclined \\
\hline${ }^{*} \mathrm{~T} .4386$ & 16 & 6 & 6 & 2.3 & Limestone & Plane & ${ }^{*} \mathrm{~T} .4806$ & 17 & 6 & 6 & 2.3 & Limestone & Inclined \\
\hline *T. 4387 & 16 & 6 & 7 & 2.3 & Limestone & Plane & *T. 4807 & 17 & 6 & 7 & 2.3 & Limestone & Inclined \\
\hline *T. 4388 & 16 & 6 & 8 & 2.3 & Limestone & Plane & *T. 4808 & 17 & 6 & 8 & 2.3 & Limestone & Inclined \\
\hline *T. 4389 & 16 & 6 & 9 & 2.3 & Limestone & Plane & *T. 4809 & 17 & 6 & 9 & 2.3 & Limestone & Inclined \\
\hline *T. 4390 & 16 & 6 & 10 & 2.3 & Limestone & Plane & *T. 4810 & 17 & 6 & 10 & 2.3 & Limestone & Inclined \\
\hline${ }^{*} \mathrm{~T} .4391$ & 16 & 6 & 11 & 2.3 & Limestone & Plane & ${ }^{*} \mathrm{~T} .4811$ & 17 & 6 & 11 & 2.3 & Limestone & Inclined \\
\hline *T. 4392 & 16 & 6 & 12 & 2.3 & Limestone & Plane & *T. 4812 & 17 & 6 & 12 & 2.3 & Limestone & Inclined \\
\hline *T. 4393 & 16 & 6 & 13 & 2.3 & Limestone & Plane & *T. 4813 & 17 & 6 & 13 & 2.3 & Limestone & Inclined \\
\hline *T. 4394 & 16 & 6 & 14 & 2.3 & Limestone & Plane & ${ }^{*} \mathrm{~T} .4814$ & 17 & 6 & 14 & 2.3 & Limestone & Inclined \\
\hline *T. 4395 & 16 & 6 & 15 & 2.3 & Limestone & Plane & *T. 4815 & 17 & 6 & 15 & 2.3 & Limestone & Inclined \\
\hline T. 4396 & 15 & 6 & 1 & 2.5 & Limestone & Plane & T. 4816 & 16 & 6 & 1 & 2.5 & Limestone & Inclined \\
\hline T. 4397 & 15 & 6 & 2 & 2.5 & Limestone & Plane & T. 4817 & 16 & 6 & 2 & 2.5 & Limestone & Inclined \\
\hline T. 4398 & 15 & 6 & 3 & 2.5 & Limestone & Plane & T. 4818 & 16 & 6 & 3 & 2.5 & Limestone & Inclined \\
\hline T. 4399 & 15 & 6 & 4 & 2.5 & Limestone & Plane & T. 4819 & 16 & 6 & 4 & 2.5 & Limestone & Inclined \\
\hline T. 4400 & 15 & 6 & 5 & 2.5 & Limestone & Plane & T. 4820 & 16 & 6 & 5 & 2.5 & Limestone & Inclined \\
\hline T. 4401 & 15 & 6 & 6 & 2.5 & Limestone & Plane & T. 4821 & 16 & 6 & 6 & 2.5 & Limestone & Inclined \\
\hline T. 4402 & 15 & 6 & 7 & 2.5 & Limestone & Plane & T. 4822 & 16 & 6 & 7 & 2.5 & Limestone & Inclined \\
\hline T. 4403 & 15 & 6 & 8 & 2.5 & Limestone & Plane & T. 4823 & 16 & 6 & 8 & 2.5 & Limestone & Inclined \\
\hline T. 4404 & 15 & 6 & 9 & 2.5 & Limestone & Plane & T. 4824 & 16 & 6 & 9 & 2.5 & Limestone & Inclined \\
\hline T. 4405 & 15 & 6 & 10 & 2.5 & Limestone & Plane & T. 4825 & 16 & 6 & 10 & 2.5 & Limestone & Inclined \\
\hline T. 4406 & 15 & 6 & 11 & 2.5 & Limestone & Plane & T. 4826 & 16 & 6 & 11 & 2.5 & Limestone & Inclined \\
\hline T. 4407 & 15 & 6 & 12 & 2.5 & Limestone & Plane & T. 4827 & 16 & 6 & 12 & 2.5 & Limestone & Inclined \\
\hline T. 4408 & 15 & 6 & 13 & 2.5 & Limestone & Plane & T. 4828 & 16 & 6 & 13 & 2.5 & Limestone & Inclined \\
\hline T. 4409 & 15 & 6 & 14 & 2.5 & Limestone & Plane & T. 4829 & 16 & 6 & 14 & 2.5 & Limestone & Inclined \\
\hline
\end{tabular}

(cont. on next page) 
Table E.1. (cont.)

\begin{tabular}{|c|c|c|c|c|c|c|c|c|c|c|c|c|c|}
\hline T. 4410 & 15 & 6 & 15 & 2.5 & Limestone & Plane & T. 4830 & 16 & 6 & 15 & 2.5 & Limestone & Inclined \\
\hline T. 4411 & 17 & 6 & 1 & 1 & Sandstone & Plane & T. 4831 & 18 & 6 & 1 & 1 & Sandstone & Inclined \\
\hline T. 4412 & 17 & 6 & 2 & 1 & Sandstone & Plane & T. 4832 & 18 & 6 & 2 & 1 & Sandstone & Inclined \\
\hline T. 4413 & 17 & 6 & 3 & 1 & Sandstone & Plane & T. 4833 & 18 & 6 & 3 & 1 & Sandstone & Inclined \\
\hline T. 4414 & 17 & 6 & 4 & 1 & Sandstone & Plane & T. 4834 & 18 & 6 & 4 & 1 & Sandstone & Inclined \\
\hline T. 4415 & 17 & 6 & 5 & 1 & Sandstone & Plane & T. 4835 & 18 & 6 & 5 & 1 & Sandstone & Inclined \\
\hline T. 4416 & 17 & 6 & 6 & 1 & Sandstone & Plane & T. 4836 & 18 & 6 & 6 & 1 & Sandstone & Inclined \\
\hline T. 4417 & 17 & 6 & 7 & 1 & Sandstone & Plane & T. 4837 & 18 & 6 & 7 & 1 & Sandstone & Inclined \\
\hline T. 4418 & 17 & 6 & 8 & 1 & Sandstone & Plane & T. 4838 & 18 & 6 & 8 & 1 & Sandstone & Inclined \\
\hline T. 4419 & 17 & 6 & 9 & 1 & Sandstone & Plane & T. 4839 & 18 & 6 & 9 & 1 & Sandstone & Inclined \\
\hline T. 4420 & 15 & 6 & 10 & 1 & Sandstone & Plane & T. 4840 & 16 & 6 & 10 & 1 & Sandstone & Inclined \\
\hline T. 4421 & 16 & 6 & 11 & 1 & Sandstone & Plane & T. 4841 & 17 & 6 & 11 & 1 & Sandstone & Inclined \\
\hline T. 4422 & 17 & 6 & 12 & 1 & Sandstone & Plane & T. 4842 & 18 & 6 & 12 & 1 & Sandstone & Inclined \\
\hline T. 4423 & 17 & 6 & 13 & 1 & Sandstone & Plane & T. 4843 & 18 & 6 & 13 & 1 & Sandstone & Inclined \\
\hline T. 4424 & 16 & 6 & 14 & 1 & Sandstone & Plane & T. 4844 & 17 & 6 & 14 & 1 & Sandstone & Inclined \\
\hline T. 4425 & 16 & 6 & 15 & 1 & Sandstone & Plane & T. 4845 & 17 & 6 & 15 & 1 & Sandstone & Inclined \\
\hline T. 4426 & 19 & 6 & 1 & 1.3 & Sandstone & Plane & T. 4846 & 20 & 6 & 1 & 1.3 & Sandstone & Inclined \\
\hline T. 4427 & 19 & 6 & 2 & 1.3 & Sandstone & Plane & T. 4847 & 20 & 6 & 2 & 1.3 & Sandstone & Inclined \\
\hline T. 4428 & 19 & 6 & 3 & 1.3 & Sandstone & Plane & T. 4848 & 20 & 6 & 3 & 1.3 & Sandstone & Inclined \\
\hline T. 4429 & 19 & 6 & 4 & 1.3 & Sandstone & Plane & T. 4849 & 20 & 6 & 4 & 1.3 & Sandstone & Inclined \\
\hline T. 4430 & 19 & 6 & 5 & 1.3 & Sandstone & Plane & T. 4850 & 20 & 6 & 5 & 1.3 & Sandstone & Inclined \\
\hline T. 4431 & 19 & 6 & 6 & 1.3 & Sandstone & Plane & T. 4851 & 20 & 6 & 6 & 1.3 & Sandstone & Inclined \\
\hline T. 4432 & 19 & 6 & 7 & 1.3 & Sandstone & Plane & T. 4852 & 20 & 6 & 7 & 1.3 & Sandstone & Inclined \\
\hline T. 4433 & 19 & 6 & 8 & 1.3 & Sandstone & Plane & T. 4853 & 20 & 6 & 8 & 1.3 & Sandstone & Inclined \\
\hline T. 4434 & 19 & 6 & 9 & 1.3 & Sandstone & Plane & T. 4854 & 20 & 6 & 9 & 1.3 & Sandstone & Inclined \\
\hline T. 4435 & 18 & 6 & 10 & 1.3 & Sandstone & Plane & T. 4855 & 19 & 6 & 10 & 1.3 & Sandstone & Inclined \\
\hline T. 4436 & 18 & 6 & 11 & 1.3 & Sandstone & Plane & T. 4856 & 19 & 6 & 11 & 1.3 & Sandstone & Inclined \\
\hline T. 4437 & 19 & 6 & 12 & 1.3 & Sandstone & Plane & T. 4857 & 20 & 6 & 12 & 1.3 & Sandstone & Inclined \\
\hline T. 4438 & 19 & 6 & 13 & 1.3 & Sandstone & Plane & T. 4858 & 20 & 6 & 13 & 1.3 & Sandstone & Inclined \\
\hline T. 4439 & 18 & 6 & 14 & 1.3 & Sandstone & Plane & T. 4859 & 19 & 6 & 14 & 1.3 & Sandstone & Inclined \\
\hline T. 4440 & 18 & 6 & 15 & 1.3 & Sandstone & Plane & T. 4860 & 19 & 6 & 15 & 1.3 & Sandstone & Inclined \\
\hline T. 4441 & 19 & 6 & 1 & 1.6 & Sandstone & Plane & T. 4861 & 20 & 6 & 1 & 1.6 & Sandstone & Inclined \\
\hline T. 4442 & 19 & 6 & 2 & 1.6 & Sandstone & Plane & T. 4862 & 20 & 6 & 2 & 1.6 & Sandstone & Inclined \\
\hline
\end{tabular}

(cont. on next page) 
Table E.1. (cont.)

\begin{tabular}{|c|c|c|c|c|c|c|c|c|c|c|c|c|c|}
\hline T. 4443 & 19 & 6 & 3 & 1.6 & Sandstone & Plane & T. 4863 & 20 & 6 & 3 & 1.6 & Sandstone & Inclined \\
\hline T. 4444 & 19 & 6 & 4 & 1.6 & Sandstone & Plane & T. 4864 & 20 & 6 & 4 & 1.6 & Sandstone & Inclined \\
\hline T. 4445 & 19 & 6 & 5 & 1.6 & Sandstone & Plane & T. 4865 & 20 & 6 & 5 & 1.6 & Sandstone & Inclined \\
\hline T. 4446 & 19 & 6 & 6 & 1.6 & Sandstone & Plane & T. 4866 & 20 & 6 & 6 & 1.6 & Sandstone & Inclined \\
\hline T. 4447 & 19 & 6 & 7 & 1.6 & Sandstone & Plane & T. 4867 & 20 & 6 & 7 & 1.6 & Sandstone & Inclined \\
\hline T. 4448 & 19 & 6 & 8 & 1.6 & Sandstone & Plane & T. 4868 & 20 & 6 & 8 & 1.6 & Sandstone & Inclined \\
\hline T. 4449 & 19 & 6 & 9 & 1.6 & Sandstone & Plane & T. 4869 & 20 & 6 & 9 & 1.6 & Sandstone & Inclined \\
\hline T. 4450 & 18 & 6 & 10 & 1.6 & Sandstone & Plane & T. 4870 & 19 & 6 & 10 & 1.6 & Sandstone & Inclined \\
\hline T. 4451 & 18 & 6 & 11 & 1.6 & Sandstone & Plane & T. 4871 & 19 & 6 & 11 & 1.6 & Sandstone & Inclined \\
\hline T. 4452 & 19 & 6 & 12 & 1.6 & Sandstone & Plane & T. 4872 & 20 & 6 & 12 & 1.6 & Sandstone & Inclined \\
\hline T. 4453 & 19 & 6 & 13 & 1.6 & Sandstone & Plane & T. 4873 & 20 & 6 & 13 & 1.6 & Sandstone & Inclined \\
\hline T. 4454 & 19 & 6 & 14 & 1.6 & Sandstone & Plane & T. 4874 & 20 & 6 & 14 & 1.6 & Sandstone & Inclined \\
\hline T. 4455 & 19 & 6 & 15 & 1.6 & Sandstone & Plane & T. 4875 & 20 & 6 & 15 & 1.6 & Sandstone & Inclined \\
\hline T. 4456 & 19 & 6 & 1 & 1.8 & Sandstone & Plane & T. 4876 & 20 & 6 & 1 & 1.8 & Sandstone & Inclined \\
\hline T. 4457 & 19 & 6 & 2 & 1.8 & Sandstone & Plane & T. 4877 & 20 & 6 & 2 & 1.8 & Sandstone & Inclined \\
\hline T. 4458 & 19 & 6 & 3 & 1.8 & Sandstone & Plane & T. 4878 & 20 & 6 & 3 & 1.8 & Sandstone & Inclined \\
\hline T. 4459 & 19 & 6 & 4 & 1.8 & Sandstone & Plane & T. 4879 & 20 & 6 & 4 & 1.8 & Sandstone & Inclined \\
\hline T. 4460 & 19 & 6 & 5 & 1.8 & Sandstone & Plane & T. 4880 & 20 & 6 & 5 & 1.8 & Sandstone & Inclined \\
\hline T. 4461 & 19 & 6 & 6 & 1.8 & Sandstone & Plane & T. 4881 & 20 & 6 & 6 & 1.8 & Sandstone & Inclined \\
\hline T. 4462 & 19 & 6 & 7 & 1.8 & Sandstone & Plane & T. 4882 & 20 & 6 & 7 & 1.8 & Sandstone & Inclined \\
\hline T. 4463 & 19 & 6 & 8 & 1.8 & Sandstone & Plane & T. 4883 & 20 & 6 & 8 & 1.8 & Sandstone & Inclined \\
\hline T. 4464 & 19 & 6 & 9 & 1.8 & Sandstone & Plane & T. 4884 & 20 & 6 & 9 & 1.8 & Sandstone & Inclined \\
\hline T. 4465 & 18 & 6 & 10 & 1.8 & Sandstone & Plane & T. 4885 & 19 & 6 & 10 & 1.8 & Sandstone & Inclined \\
\hline T. 4466 & 19 & 6 & 11 & 1.8 & Sandstone & Plane & T. 4886 & 20 & 6 & 11 & 1.8 & Sandstone & Inclined \\
\hline T. 4467 & 19 & 6 & 12 & 1.8 & Sandstone & Plane & T. 4887 & 20 & 6 & 12 & 1.8 & Sandstone & Inclined \\
\hline T. 4468 & 19 & 6 & 13 & 1.8 & Sandstone & Plane & T. 4888 & 20 & 6 & 13 & 1.8 & Sandstone & Inclined \\
\hline T. 4469 & 18 & 6 & 14 & 1.8 & Sandstone & Plane & T. 4889 & 19 & 6 & 14 & 1.8 & Sandstone & Inclined \\
\hline T. 4470 & 18 & 6 & 15 & 1.8 & Sandstone & Plane & T. 4890 & 19 & 6 & 15 & 1.8 & Sandstone & Inclined \\
\hline T. 4471 & 18 & 6 & 1 & 2 & Sandstone & Plane & T. 4891 & 19 & 6 & 1 & 2 & Sandstone & Inclined \\
\hline T. 4472 & 18 & 6 & 2 & 2 & Sandstone & Plane & T. 4892 & 19 & 6 & 2 & 2 & Sandstone & Inclined \\
\hline T. 4473 & 18 & 6 & 3 & 2 & Sandstone & Plane & T. 4893 & 19 & 6 & 3 & 2 & Sandstone & Inclined \\
\hline T. 4474 & 18 & 6 & 4 & 2 & Sandstone & Plane & T. 4894 & 19 & 6 & 4 & 2 & Sandstone & Inclined \\
\hline T. 4475 & 18 & 6 & 5 & 2 & Sandstone & Plane & T. 4895 & 19 & 6 & 5 & 2 & Sandstone & Inclined \\
\hline
\end{tabular}

(cont. on next page) 
Table E.1. (cont.)

\begin{tabular}{|c|c|c|c|c|c|c|c|c|c|c|c|c|c|}
\hline T. 4476 & 18 & 6 & 6 & 2 & Sandstone & Plane & T. 4896 & 19 & 6 & 6 & 2 & Sandstone & Inclined \\
\hline T. 4477 & 18 & 6 & 7 & 2 & Sandstone & Plane & T. 4897 & 19 & 6 & 7 & 2 & Sandstone & Inclined \\
\hline T. 4478 & 18 & 6 & 8 & 2 & Sandstone & Plane & T. 4898 & 19 & 6 & 8 & 2 & Sandstone & Inclined \\
\hline T. 4479 & 18 & 6 & 9 & 2 & Sandstone & Plane & T. 4899 & 19 & 6 & 9 & 2 & Sandstone & Inclined \\
\hline T. 4480 & 17 & 6 & 10 & 2 & Sandstone & Plane & T. 4900 & 18 & 6 & 10 & 2 & Sandstone & Inclined \\
\hline T. 4481 & 18 & 6 & 11 & 2 & Sandstone & Plane & T. 4901 & 19 & 6 & 11 & 2 & Sandstone & Inclined \\
\hline T. 4482 & 18 & 6 & 12 & 2 & Sandstone & Plane & T. 4902 & 19 & 6 & 12 & 2 & Sandstone & Inclined \\
\hline T. 4483 & 18 & 6 & 13 & 2 & Sandstone & Plane & T. 4903 & 19 & 6 & 13 & 2 & Sandstone & Inclined \\
\hline T. 4484 & 18 & 6 & 14 & 2 & Sandstone & Plane & T. 4904 & 19 & 6 & 14 & 2 & Sandstone & Inclined \\
\hline T. 4485 & 18 & 6 & 15 & 2 & Sandstone & Plane & T. 4905 & 19 & 6 & 15 & 2 & Sandstone & Inclined \\
\hline T. 4486 & 16 & 6 & 1 & 2.3 & Sandstone & Plane & T. 4906 & 17 & 6 & 1 & 2.3 & Sandstone & Inclined \\
\hline T. 4487 & 16 & 6 & 2 & 2.3 & Sandstone & Plane & T. 4907 & 17 & 6 & 2 & 2.3 & Sandstone & Inclined \\
\hline T. 4488 & 16 & 6 & 3 & 2.3 & Sandstone & Plane & T. 4908 & 17 & 6 & 3 & 2.3 & Sandstone & Inclined \\
\hline T. 4489 & 16 & 6 & 4 & 2.3 & Sandstone & Plane & T. 4909 & 17 & 6 & 4 & 2.3 & Sandstone & Inclined \\
\hline T. 4490 & 16 & 6 & 5 & 2.3 & Sandstone & Plane & T. 4910 & 17 & 6 & 5 & 2.3 & Sandstone & Inclined \\
\hline T. 4491 & 16 & 6 & 6 & 2.3 & Sandstone & Plane & T. 4911 & 17 & 6 & 6 & 2.3 & Sandstone & Inclined \\
\hline T. 4492 & 16 & 6 & 7 & 2.3 & Sandstone & Plane & T. 4912 & 17 & 6 & 7 & 2.3 & Sandstone & Inclined \\
\hline T. 4493 & 16 & 6 & 8 & 2.3 & Sandstone & Plane & T. 4913 & 17 & 6 & 8 & 2.3 & Sandstone & Inclined \\
\hline T. 4494 & 16 & 6 & 9 & 2.3 & Sandstone & Plane & T. 4914 & 17 & 6 & 9 & 2.3 & Sandstone & Inclined \\
\hline T. 4495 & 16 & 6 & 10 & 2.3 & Sandstone & Plane & T. 4915 & 17 & 6 & 10 & 2.3 & Sandstone & Inclined \\
\hline T. 4496 & 16 & 6 & 11 & 2.3 & Sandstone & Plane & T. 4916 & 17 & 6 & 11 & 2.3 & Sandstone & Inclined \\
\hline T. 4497 & 16 & 6 & 12 & 2.3 & Sandstone & Plane & T. 4917 & 17 & 6 & 12 & 2.3 & Sandstone & Inclined \\
\hline T. 4498 & 16 & 6 & 13 & 2.3 & Sandstone & Plane & T. 4918 & 17 & 6 & 13 & 2.3 & Sandstone & Inclined \\
\hline T. 4499 & 16 & 6 & 14 & 2.3 & Sandstone & Plane & T. 4919 & 17 & 6 & 14 & 2.3 & Sandstone & Inclined \\
\hline T. 4500 & 16 & 6 & 15 & 2.3 & Sandstone & Plane & T. 4920 & 17 & 6 & 15 & 2.3 & Sandstone & Inclined \\
\hline T. 4501 & 15 & 6 & 1 & 2.5 & Sandstone & Plane & T. 4921 & 16 & 6 & 1 & 2.5 & Sandstone & Inclined \\
\hline T. 4502 & 15 & 6 & 2 & 2.5 & Sandstone & Plane & T. 4922 & 16 & 6 & 2 & 2.5 & Sandstone & Inclined \\
\hline T. 4503 & 15 & 6 & 3 & 2.5 & Sandstone & Plane & T. 4923 & 16 & 6 & 3 & 2.5 & Sandstone & Inclined \\
\hline T. 4504 & 15 & 6 & 4 & 2.5 & Sandstone & Plane & T. 4924 & 16 & 6 & 4 & 2.5 & Sandstone & Inclined \\
\hline T. 4505 & 15 & 6 & 5 & 2.5 & Sandstone & Plane & T. 4925 & 16 & 6 & 5 & 2.5 & Sandstone & Inclined \\
\hline T. 4506 & 15 & 6 & 6 & 2.5 & Sandstone & Plane & T. 4926 & 16 & 6 & 6 & 2.5 & Sandstone & Inclined \\
\hline T. 4507 & 15 & 6 & 7 & 2.5 & Sandstone & Plane & T. 4927 & 16 & 6 & 7 & 2.5 & Sandstone & Inclined \\
\hline T. 4508 & 15 & 6 & 8 & 2.5 & Sandstone & Plane & T. 4928 & 16 & 6 & 8 & 2.5 & Sandstone & Inclined \\
\hline
\end{tabular}

(cont. on next page) 
Table E.1. (cont.

\begin{tabular}{|c|c|c|c|c|c|c|c|c|c|c|c|c|c|}
\hline T. 4509 & 15 & 6 & 9 & 2.5 & Sandstone & Plane & T. 4929 & 16 & 6 & 9 & 2.5 & Sandstone & Inclined \\
\hline T. 4510 & 15 & 6 & 10 & 2.5 & Sandstone & Plane & T. 4930 & 16 & 6 & 10 & 2.5 & Sandstone & Inclined \\
\hline T. 4511 & 15 & 6 & 11 & 2.5 & Sandstone & Plane & T. 4931 & 16 & 6 & 11 & 2.5 & Sandstone & Inclined \\
\hline T. 4512 & 15 & 6 & 12 & 2.5 & Sandstone & Plane & T. 4932 & 16 & 6 & 12 & 2.5 & Sandstone & Inclined \\
\hline T. 4513 & 15 & 6 & 13 & 2.5 & Sandstone & Plane & T. 4933 & 16 & 6 & 13 & 2.5 & Sandstone & Inclined \\
\hline T. 4514 & 15 & 6 & 14 & 2.5 & Sandstone & Plane & T. 4934 & 16 & 6 & 14 & 2.5 & Sandstone & Inclined \\
\hline T. 4515 & 15 & 6 & 15 & 2.5 & Sandstone & Plane & T. 4935 & 16 & 6 & 15 & 2.5 & Sandstone & Inclined \\
\hline T. 4516 & 16 & 6 & 1 & 1 & Brick & Plane & T. 4936 & 17 & 6 & 1 & 1 & Brick & Inclined \\
\hline T. 4517 & 16 & 6 & 2 & 1 & Brick & Plane & T. 4937 & 17 & 6 & 2 & 1 & Brick & Inclined \\
\hline T. 4518 & 16 & 6 & 3 & 1 & Brick & Plane & T. 4938 & 17 & 6 & 3 & 1 & Brick & Inclined \\
\hline T. 4519 & 16 & 6 & 4 & 1 & Brick & Plane & T. 4939 & 17 & 6 & 4 & 1 & Brick & Inclined \\
\hline T. 4520 & 16 & 6 & 5 & 1 & Brick & Plane & T. 4940 & 17 & 6 & 5 & 1 & Brick & Inclined \\
\hline T. 4521 & 16 & 6 & 6 & 1 & Brick & Plane & T. 4941 & 17 & 6 & 6 & 1 & Brick & Inclined \\
\hline T. 4522 & 16 & 6 & 7 & 1 & Brick & Plane & T. 4942 & 17 & 6 & 7 & 1 & Brick & Inclined \\
\hline T. 4523 & 16 & 6 & 8 & 1 & Brick & Plane & T. 4943 & 17 & 6 & 8 & 1 & Brick & Inclined \\
\hline T. 4524 & 16 & 6 & 9 & 1 & Brick & Plane & T. 4944 & 17 & 6 & 9 & 1 & Brick & Inclined \\
\hline T. 4525 & 14 & 6 & 10 & 1 & Brick & Plane & T. 4945 & 15 & 6 & 10 & 1 & Brick & Inclined \\
\hline T. 4526 & 15 & 6 & 11 & 1 & Brick & Plane & T. 4946 & 16 & 6 & 11 & 1 & Brick & Inclined \\
\hline T. 4527 & 16 & 6 & 12 & 1 & Brick & Plane & T. 4947 & 17 & 6 & 12 & 1 & Brick & Inclined \\
\hline T. 4528 & 16 & 6 & 13 & 1 & Brick & Plane & T. 4948 & 17 & 6 & 13 & 1 & Brick & Inclined \\
\hline T. 4529 & 15 & 6 & 14 & 1 & Brick & Plane & T. 4949 & 16 & 6 & 14 & 1 & Brick & Inclined \\
\hline T. 4530 & 15 & 6 & 15 & 1 & Brick & Plane & T. 4950 & 16 & 6 & 15 & 1 & Brick & Inclined \\
\hline T. 4531 & 18 & 6 & 1 & 1.3 & Brick & Plane & T. 4951 & 19 & 6 & 1 & 1.3 & Brick & Inclined \\
\hline T. 4532 & 18 & 6 & 2 & 1.3 & Brick & Plane & T. 4952 & 19 & 6 & 2 & 1.3 & Brick & Inclined \\
\hline T. 4533 & 18 & 6 & 3 & 1.3 & Brick & Plane & T. 4953 & 19 & 6 & 3 & 1.3 & Brick & Inclined \\
\hline T. 4534 & 18 & 6 & 4 & 1.3 & Brick & Plane & T. 4954 & 19 & 6 & 4 & 1.3 & Brick & Inclined \\
\hline T. 4535 & 18 & 6 & 5 & 1.3 & Brick & Plane & T. 4955 & 19 & 6 & 5 & 1.3 & Brick & Inclined \\
\hline T. 4536 & 18 & 6 & 6 & 1.3 & Brick & Plane & T. 4956 & 19 & 6 & 6 & 1.3 & Brick & Inclined \\
\hline T. 4537 & 18 & 6 & 7 & 1.3 & Brick & Plane & T. 4957 & 19 & 6 & 7 & 1.3 & Brick & Inclined \\
\hline T. 4538 & 18 & 6 & 8 & 1.3 & Brick & Plane & T. 4958 & 19 & 6 & 8 & 1.3 & Brick & Inclined \\
\hline T. 4539 & 18 & 6 & 9 & 1.3 & Brick & Plane & T. 4959 & 19 & 6 & 9 & 1.3 & Brick & Inclined \\
\hline T. 4540 & 17 & 6 & 10 & 1.3 & Brick & Plane & T. 4960 & 18 & 6 & 10 & 1.3 & Brick & Inclined \\
\hline T. 4541 & 17 & 6 & 11 & 1.3 & Brick & Plane & T. 4961 & 18 & 6 & 11 & 1.3 & Brick & Inclined \\
\hline
\end{tabular}

(cont. on next page) 
Table E.1. (cont.)

\begin{tabular}{|c|c|c|c|c|c|c|c|c|c|c|c|c|c|}
\hline T. 4542 & 18 & 6 & 12 & 1.3 & Brick & Plane & T. 4962 & 19 & 6 & 12 & 1.3 & Brick & Inclined \\
\hline T. 4543 & 18 & 6 & 13 & 1.3 & Brick & Plane & T. 4963 & 19 & 6 & 13 & 1.3 & Brick & Inclined \\
\hline T. 4544 & 17 & 6 & 14 & 1.3 & Brick & Plane & T. 4964 & 18 & 6 & 14 & 1.3 & Brick & Inclined \\
\hline T. 4545 & 17 & 6 & 15 & 1.3 & Brick & Plane & T. 4965 & 18 & 6 & 15 & 1.3 & Brick & Inclined \\
\hline T. 4546 & 18 & 6 & 1 & 1.6 & Brick & Plane & T. 4966 & 19 & 6 & 1 & 1.6 & Brick & Inclined \\
\hline T. 4547 & 18 & 6 & 2 & 1.6 & Brick & Plane & T. 4967 & 19 & 6 & 2 & 1.6 & Brick & Inclined \\
\hline T. 4548 & 18 & 6 & 3 & 1.6 & Brick & Plane & T. 4968 & 19 & 6 & 3 & 1.6 & Brick & Inclined \\
\hline T. 4549 & 18 & 6 & 4 & 1.6 & Brick & Plane & T. 4969 & 19 & 6 & 4 & 1.6 & Brick & Inclined \\
\hline T. 4550 & 18 & 6 & 5 & 1.6 & Brick & Plane & T. 4970 & 19 & 6 & 5 & 1.6 & Brick & Inclined \\
\hline T. 4551 & 18 & 6 & 6 & 1.6 & Brick & Plane & T. 4971 & 19 & 6 & 6 & 1.6 & Brick & Inclined \\
\hline T. 4552 & 18 & 6 & 7 & 1.6 & Brick & Plane & T. 4972 & 19 & 6 & 7 & 1.6 & Brick & Inclined \\
\hline T. 4553 & 18 & 6 & 8 & 1.6 & Brick & Plane & T. 4973 & 19 & 6 & 8 & 1.6 & Brick & Inclined \\
\hline T. 4554 & 18 & 6 & 9 & 1.6 & Brick & Plane & T. 4974 & 19 & 6 & 9 & 1.6 & Brick & Inclined \\
\hline T. 4555 & 17 & 6 & 10 & 1.6 & Brick & Plane & T. 4975 & 18 & 6 & 10 & 1.6 & Brick & Inclined \\
\hline T. 4556 & 17 & 6 & 11 & 1.6 & Brick & Plane & T. 4976 & 18 & 6 & 11 & 1.6 & Brick & Inclined \\
\hline T. 4557 & 18 & 6 & 12 & 1.6 & Brick & Plane & T. 4977 & 19 & 6 & 12 & 1.6 & Brick & Inclined \\
\hline T. 4558 & 18 & 6 & 13 & 1.6 & Brick & Plane & T. 4978 & 19 & 6 & 13 & 1.6 & Brick & Inclined \\
\hline T. 4559 & 18 & 6 & 14 & 1.6 & Brick & Plane & T. 4979 & 19 & 6 & 14 & 1.6 & Brick & Inclined \\
\hline T. 4560 & 18 & 6 & 15 & 1.6 & Brick & Plane & T. 4980 & 19 & 6 & 15 & 1.6 & Brick & Inclined \\
\hline T. 4561 & 18 & 6 & 1 & 1.8 & Brick & Plane & T. 4981 & 19 & 6 & 1 & 1.8 & Brick & Inclined \\
\hline T. 4562 & 18 & 6 & 2 & 1.8 & Brick & Plane & T. 4982 & 19 & 6 & 2 & 1.8 & Brick & Inclined \\
\hline T. 4563 & 18 & 6 & 3 & 1.8 & Brick & Plane & T. 4983 & 19 & 6 & 3 & 1.8 & Brick & Inclined \\
\hline T. 4564 & 18 & 6 & 4 & 1.8 & Brick & Plane & T. 4984 & 19 & 6 & 4 & 1.8 & Brick & Inclined \\
\hline T. 4565 & 18 & 6 & 5 & 1.8 & Brick & Plane & T. 4985 & 19 & 6 & 5 & 1.8 & Brick & Inclined \\
\hline T. 4566 & 18 & 6 & 6 & 1.8 & Brick & Plane & T. 4986 & 19 & 6 & 6 & 1.8 & Brick & Inclined \\
\hline T. 4567 & 18 & 6 & 7 & 1.8 & Brick & Plane & T. 4987 & 19 & 6 & 7 & 1.8 & Brick & Inclined \\
\hline T. 4568 & 18 & 6 & 8 & 1.8 & Brick & Plane & T. 4988 & 19 & 6 & 8 & 1.8 & Brick & Inclined \\
\hline T. 4569 & 18 & 6 & 9 & 1.8 & Brick & Plane & T. 4989 & 19 & 6 & 9 & 1.8 & Brick & Inclined \\
\hline T. 4570 & 17 & 6 & 10 & 1.8 & Brick & Plane & T. 4990 & 18 & 6 & 10 & 1.8 & Brick & Inclined \\
\hline T. 4571 & 18 & 6 & 11 & 1.8 & Brick & Plane & T. 4991 & 19 & 6 & 11 & 1.8 & Brick & Inclined \\
\hline T. 4572 & 18 & 6 & 12 & 1.8 & Brick & Plane & T. 4992 & 19 & 6 & 12 & 1.8 & Brick & Inclined \\
\hline T. 4573 & 18 & 6 & 13 & 1.8 & Brick & Plane & T. 4993 & 19 & 6 & 13 & 1.8 & Brick & Inclined \\
\hline T. 4574 & 17 & 6 & 14 & 1.8 & Brick & Plane & T. 4994 & 18 & 6 & 14 & 1.8 & Brick & Inclined \\
\hline
\end{tabular}

(cont. on next page) 
Table E.1. (cont.)

\begin{tabular}{|c|c|c|c|c|c|c|c|c|c|c|c|c|c|}
\hline T. 4575 & 17 & 6 & 15 & 1.8 & Brick & Plane & T. 4995 & 18 & 6 & 15 & 1.8 & Brick & Inclined \\
\hline T. 4576 & 17 & 6 & 1 & 2 & Brick & Plane & T. 4996 & 18 & 6 & 1 & 2 & Brick & Inclined \\
\hline T. 4577 & 17 & 6 & 2 & 2 & Brick & Plane & T. 4997 & 18 & 6 & 2 & 2 & Brick & Inclined \\
\hline T. 4578 & 17 & 6 & 3 & 2 & Brick & Plane & T. 4998 & 18 & 6 & 3 & 2 & Brick & Inclined \\
\hline T. 4579 & 17 & 6 & 4 & 2 & Brick & Plane & T. 4999 & 18 & 6 & 4 & 2 & Brick & Inclined \\
\hline T. 4580 & 17 & 6 & 5 & 2 & Brick & Plane & T. 5000 & 18 & 6 & 5 & 2 & Brick & Inclined \\
\hline T. 4581 & 17 & 6 & 6 & 2 & Brick & Plane & T. 5001 & 18 & 6 & 6 & 2 & Brick & Inclined \\
\hline T. 4582 & 17 & 6 & 7 & 2 & Brick & Plane & T. 5002 & 18 & 6 & 7 & 2 & Brick & Inclined \\
\hline T. 4583 & 17 & 6 & 8 & 2 & Brick & Plane & T. 5003 & 18 & 6 & 8 & 2 & Brick & Inclined \\
\hline T. 4584 & 17 & 6 & 9 & 2 & Brick & Plane & T. 5004 & 18 & 6 & 9 & 2 & Brick & Inclined \\
\hline T. 4585 & 16 & 6 & 10 & 2 & Brick & Plane & T. 5005 & 17 & 6 & 10 & 2 & Brick & Inclined \\
\hline T. 4586 & 17 & 6 & 11 & 2 & Brick & Plane & T. 5006 & 18 & 6 & 11 & 2 & Brick & Inclined \\
\hline T. 4587 & 17 & 6 & 12 & 2 & Brick & Plane & T. 5007 & 18 & 6 & 12 & 2 & Brick & Inclined \\
\hline T. 4588 & 17 & 6 & 13 & 2 & Brick & Plane & T. 5008 & 18 & 6 & 13 & 2 & Brick & Inclined \\
\hline T. 4589 & 17 & 6 & 14 & 2 & Brick & Plane & T. 5009 & 18 & 6 & 14 & 2 & Brick & Inclined \\
\hline T. 4590 & 17 & 6 & 15 & 2 & Brick & Plane & T. 5010 & 18 & 6 & 15 & 2 & Brick & Inclined \\
\hline T. 4591 & 15 & 6 & 1 & 2.3 & Brick & Plane & T. 5011 & 16 & 6 & 1 & 2.3 & Brick & Inclined \\
\hline T. 4592 & 15 & 6 & 2 & 2.3 & Brick & Plane & T. 5012 & 16 & 6 & 2 & 2.3 & Brick & Inclined \\
\hline T. 4593 & 15 & 6 & 3 & 2.3 & Brick & Plane & T. 5013 & 16 & 6 & 3 & 2.3 & Brick & Inclined \\
\hline T. 4594 & 15 & 6 & 4 & 2.3 & Brick & Plane & T. 5014 & 16 & 6 & 4 & 2.3 & Brick & Inclined \\
\hline T. 4595 & 15 & 6 & 5 & 2.3 & Brick & Plane & T. 5015 & 16 & 6 & 5 & 2.3 & Brick & Inclined \\
\hline T. 4596 & 15 & 6 & 6 & 2.3 & Brick & Plane & T. 5016 & 16 & 6 & 6 & 2.3 & Brick & Inclined \\
\hline T. 4597 & 15 & 6 & 7 & 2.3 & Brick & Plane & T. 5017 & 16 & 6 & 7 & 2.3 & Brick & Inclined \\
\hline T. 4598 & 15 & 6 & 8 & 2.3 & Brick & Plane & T. 5018 & 16 & 6 & 8 & 2.3 & Brick & Inclined \\
\hline T. 4599 & 15 & 6 & 9 & 2.3 & Brick & Plane & T. 5019 & 16 & 6 & 9 & 2.3 & Brick & Inclined \\
\hline T. 4600 & 15 & 6 & 10 & 2.3 & Brick & Plane & T. 5020 & 16 & 6 & 10 & 2.3 & Brick & Inclined \\
\hline T. 4601 & 15 & 6 & 11 & 2.3 & Brick & Plane & T. 5021 & 16 & 6 & 11 & 2.3 & Brick & Inclined \\
\hline T. 4602 & 15 & 6 & 12 & 2.3 & Brick & Plane & T. 5022 & 16 & 6 & 12 & 2.3 & Brick & Inclined \\
\hline T. 4603 & 15 & 6 & 13 & 2.3 & Brick & Plane & T. 5023 & 16 & 6 & 13 & 2.3 & Brick & Inclined \\
\hline T. 4604 & 15 & 6 & 14 & 2.3 & Brick & Plane & T. 5024 & 16 & 6 & 14 & 2.3 & Brick & Inclined \\
\hline T. 4605 & 15 & 6 & 15 & 2.3 & Brick & Plane & T. 5025 & 16 & 6 & 15 & 2.3 & Brick & Inclined \\
\hline T. 4606 & 14 & 6 & 1 & 2.5 & Brick & Plane & T. 5026 & 15 & 6 & 1 & 2.5 & Brick & Inclined \\
\hline T. 4607 & 14 & 6 & 2 & 2.5 & Brick & Plane & T. 5027 & 15 & 6 & 2 & 2.5 & Brick & Inclined \\
\hline
\end{tabular}

(cont. on next page) 
Table E.1. (cont.)

\begin{tabular}{|c|c|c|c|c|c|c|c|c|c|c|c|c|c|}
\hline T. 4608 & 14 & 6 & 3 & 2.5 & Brick & Plane & T. 5028 & 15 & 6 & 3 & 2.5 & Brick & Inclined \\
\hline T. 4609 & 14 & 6 & 4 & 2.5 & Brick & Plane & T. 5029 & 15 & 6 & 4 & 2.5 & Brick & Inclined \\
\hline T. 4610 & 14 & 6 & 5 & 2.5 & Brick & Plane & T. 5030 & 15 & 6 & 5 & 2.5 & Brick & Inclined \\
\hline T. 4611 & 14 & 6 & 6 & 2.5 & Brick & Plane & T. 5031 & 15 & 6 & 6 & 2.5 & Brick & Inclined \\
\hline T. 4612 & 14 & 6 & 7 & 2.5 & Brick & Plane & T. 5032 & 15 & 6 & 7 & 2.5 & Brick & Inclined \\
\hline T. 4613 & 14 & 6 & 8 & 2.5 & Brick & Plane & T. 5033 & 15 & 6 & 8 & 2.5 & Brick & Inclined \\
\hline T. 4614 & 14 & 6 & 9 & 2.5 & Brick & Plane & T. 5034 & 15 & 6 & 9 & 2.5 & Brick & Inclined \\
\hline T. 4615 & 14 & 6 & 10 & 2.5 & Brick & Plane & T. 5035 & 15 & 6 & 10 & 2.5 & Brick & Inclined \\
\hline T. 4616 & 14 & 6 & 11 & 2.5 & Brick & Plane & T. 5036 & 15 & 6 & 11 & 2.5 & Brick & Inclined \\
\hline T. 4617 & 14 & 6 & 12 & 2.5 & Brick & Plane & T. 5037 & 15 & 6 & 12 & 2.5 & Brick & Inclined \\
\hline T. 4618 & 14 & 6 & 13 & 2.5 & Brick & Plane & T. 5038 & 15 & 6 & 13 & 2.5 & Brick & Inclined \\
\hline T. 4619 & 14 & 6 & 14 & 2.5 & Brick & Plane & T. 5039 & 15 & 6 & 14 & 2.5 & Brick & Inclined \\
\hline T. 4620 & 14 & 6 & 15 & 2.5 & Brick & Plane & T. 5040 & 15 & 6 & 15 & 2.5 & Brick & Inclined \\
\hline
\end{tabular}




\section{VITA}

\section{PERSONAL INFORMATION}

Surname, Name: GENÇER, Funda

Date and Place of Birth: 11.12.1986 - Muğla (Turkey)

E-mail: fundauygungencer@gmail.com

\section{EDUCATION}

Ph.D., İzmir Institute of Technology, Graduate School of Engineering and Sciences, Department of Architectural Restoration (2013-2019)

Thesis: "Structural Vulnerability of Ancient Dry Masonry Towers Under Lateral Loading"

M.Sc., İzmir Institute of Technology, Graduate School of Engineering and Sciences, Department of Architectural Restoration (2010-2013)

Thesis: "Photogrammetric Evaluation Options for Ancient Structures in Hypokremnos, Pagos, Paradiso And Nysa"

Erasmus Exchange Student, Faculty of Architecture and Civil Engineering, Bielefeld University of Applied Sciences, Germany (2011, Fall Semester)

Project: Virtualizing the Architectural Model of the Town Gumbinnen (Eastprussia)

B.Arch., Dokuz Eylül University, Department of Architecture (Graduate ranking third in the department) (2005-2009)

\section{ACADEMIC EXPERIENCES}

Research Assistant, İzmir Institute of Technology, Department of Architectural Restoration (2010-2017)

Research Assistant, Manisa Celal Bayar University, Faculty of Fine Arts, Design and Architecture, Department of Architecture (since 2017) 